ODAIR BARBOSA DE MORAES

MÉTODO DE ANÁLISE DE DADOS PARA AVALIAÇÃO DE ÁREAS URBANAS RECUPERADAS - UMA ABORDAGEM UTILIZANDO A LÓGICA FUZZY 

ODAIR BARBOSA DE MORAES

MÉTODO DE ANÁLISE DE DADOS PARA AVALIAÇÃO DE ÁREAS URBANAS RECUPERADAS - UMA ABORDAGEM UTILIZANDO A LÓGICA FUZZY

Tese apresentada à Escola

Politécnica da Universidade de São

Paulo para obtenção do título de

Doutor em Engenharia 

ODAIR BARBOSA DE MORAES

\section{MÉTODO DE ANÁLISE DE DADOS PARA AVALIAÇÃO DE ÁREAS URBANAS RECUPERADAS - UMA ABORDAGEM UTILIZANDO A LÓGICA FUZZY}

Tese apresentada à Escola Politécnica da Universidade de São Paulo para obtenção do título de Doutor em Engenharia

Área de concentração: Engenharia de Construção Civil e Urbana

Orientador: Prof. Dr. Alex Kenya Abiko 
Este exemplar foi revisado e alterado em relação à versão original, sob responsabilidade única do autor e com a anuência de seu orientador.

São Paulo, de outubro de 2008.

Assinatura do autor

Assinatura do orientador

FICHA CATALOGRÁFICA

Moraes, Odair Barbosa de

Método de análise de dados para avaliação de áreas urbanas recuperadas : Uma abordagem utilizando a lógica fuzzy / O.B. de Moraes. -- ed.rev. -- São Paulo, 2008.

$302 \mathrm{p}$.

Tese (Doutorado) - Escola Politécnica da Universidade de São Paulo. Departamento de Engenharia de Construção Civil.

1.Favelas 2.Urbanização 3.Qualidade de vida urbana (Aspectos ambientais) 4.Fuzzy 5.Avaliação pós-ocupação I.Universidade de de São Paulo. Escola Politécnica. Departamento de Engenharia de Construção Civil II.t. 


\section{DEDICATÓRIA}

À minha família e meus amigos companheiros José Rivair e Ecivaldo Matos. 



\section{AGRADECIMENTOS}

Ao orientador, Professor Dr. Alex Kenya Abiko, pela orientação, apoio e incentivo durante a realização deste trabalho e principalmente pela confiança depositada.

Ao Professor Dr. Marcos Jorge Almeida Santana, pelo apoio e incentivo na nova empreitada.

Ao Professor Dr. Cheng Liang Yee, pelas orientações prestadas para realização deste trabalho. À Professora Dr. Sheila Walbe Ornstein (FAU/USP) pelas leituras e discussões do trabalho.

Aos colegas do Grupo de Lógica Fuzzy do Instituto de Matemática e Estatística da USP, especialmente aos professores: Dr. Pedro A. Tonelli, Dr. Laécio C. Barros e Dr. Júlio C. R. Pereira, cujas discussões e observações durante os seminários foram essenciais para o desenvolvimento deste trabalho.

À Fundação de Amparo a Pesquisa do Estado de São Paulo (FAPESP) pela bolsa concedida para realização desta pesquisa.

Ao amigo Rivair pelo apoio cotidiano e à amiga Sílvia pela realização da pesquisa de campo. Aos amigos e colegas do PCC/USP, Luciana Peixoto, Gerusa Aguiar, Patrícia Aulicino, Fernanda Marchiori, Antônio Acácio, Yoakim Petrola, Juarez Hoppe, Renata Spinelli, Natália Macêdo, Renato Nascimento, Marcelo Medeiros, Elisabeth Nascimento, Marcus Vinicius, Fernanda Araújo, Juan Temoche e Jamil Salim pela convivência diária.

À equipe da Incubadora Tecnológica de Cooperativas Populares (ITCP/UNEB), Suely, Zuzélia, Maurício, Olmo e Elaine que propiciaram uma vivência e preparação para esta jornada.

Aos meus primeiros orientadores: Fernando Medeiros, Edmilson Pontes e Dilze Codá pela introdução à pesquisa. À Flávia, minha amiga e professora de inglês, pelos cafés e pelas aulas. Ao arquiteto Flávio e ao engenheiro Paulo Ramos, técnicos da Conder, pelas informações fornecidas. Aos especialistas que responderam a pesquisa e aos moradores que se dispuseram a responder as entrevistas. Às secretárias Fátima Regina, Fátima Alcione e Denise, assim como ao pessoal da informática, especialmente a Patrícia pela atenção e paciência.

Enfim, aos amigos do dia-a-dia que, de alguma forma, contribuíram para a concretização desse trabalho. 



\section{RESUMO}

As grandes cidades brasileiras apresentam, atualmente, um quadro de desigualdades e segregação fruto de décadas de conflitos pela ocupação do solo urbano, principalmente por meio das invasões. O acesso à terra urbana tornou-se uma barreira social que exclui, dos bens e serviços básicos da urbanização, grande parcela da população das cidades. Diversas ações, ou intervenções, têm sido implementadas no ambiente urbano no sentido de contornar os problemas causados por este tipo de ocupação, desde a remoção das favelas até as urbanizações atuais. Do passado, ficaram as críticas às remoções e ao padrão de conjuntos habitacionais de periferias, construídos pelo Banco Nacional da Habitação (BNH). Das ações atuais, destacando-se as urbanizações de favelas, pouco se sabe sobre o seu desempenho. Acrescenta-se à preocupação de avaliar estas ações, a necessidade de agregar, neste processo, a opinião dos moradores sobre o habitat recuperado. A Avaliação Pós-Ocupação (APO) e os sistemas indicadores têm sido utilizados como importantes ferramentas para o provimento de informações sobre o ambiente construído em diferentes escalas. Embora estes métodos reconheçam a importância da opinião dos usuários no processo de avaliação, eles ainda encontram dificuldades ao tratar os conceitos subjetivos de qualidade. Se por um lado, as incertezas presentes neste tipo de informação têm imposto limitações às análises tradicionais, por outro, o surgimento de novas teorias e modelos que buscam incorporar as variadas formas de incerteza às análises propiciam a criação de novos campos de pesquisa: a Lógica Fuzzy é um destes novos campos de pesquisa. Assim, o objetivo deste trabalho é estabelecer um método de análise de dados para a obtenção de indicadores de qualidade ambiental urbana em áreas recuperadas, levando em conta a opinião dos moradores, utilizando ferramentas de Lógica Fuzzy. Para isto, buscou-se aliar as técnicas utilizadas para Avaliação Pós-Ocupação (APO) e sistemas indicadores com a Lógica Fuzzy para desenvolver ferramentas de análise, representando formalmente as informações vagas ou mal definidas presentes neste tipo de avaliação. O método obtido é divido em seis etapas: (i) definição de variáveis/indicadores; (ii) coleta de dados; (iii) identificação de pontos positivos e negativos; (iv) obtenção de indicadores quantitativos e qualitativos; (v) análise de resultados e; (vi) relatório de qualidade ambiental. Os resultados obtidos foram satisfatórios, onde se conseguiu agregar mais informação às análises realizadas. Os estudos desenvolvidos para a pesquisa piloto e para a validação do método em áreas do Programa Ribeira Azul revelaram grandes chances de sucesso das intervenções, mas também, problemas ainda não resolvidos que merecem atenção em projetos futuros. Por fim, recomenda-se a continuidade de pesquisas para o desenvolvimento de ferramentas baseadas na Lógica Fuzzy, visto o grande número de possibilidades de aplicações que se mostraram no decorrer desta pesquisa. 



\section{ABSTRACT \\ METHOD OF DATA ANALYSIS FOR ENVIRONMENTAL QUALITY EVALUATION ON UPGRADED URBAN AREAS - A FUZZY LOGIC APPROACH}

Large cities in Brazil currently present a picture of inequality and segregation resulting from decades of conflict over the occupation of urban land. Access to land has become a social barrier which excludes a large part of the urban population from basic urban goods and services. A number of initiatives - including slum clearance and upgrading - have been undertaken over the years in an effort to ameliorate the problems arising from informal occupation in urban environments. From past actions, criticism has been developed towards slum clearance and towards the pattern of periphery housing schemes built by the Housing National Bank (BNH). Little is known about the performance outcome of the current actions, including slum upgrading. Post-Occupancy Evaluation (POE) and indicator systems have been used as important tools for the provision of information on the built environment in different scales. Although these methods recognize the importance of the views of users in the evaluation process, they fail to adequately reflect the prevailing subjective concepts of quality. If on the one hand, the uncertainties in this type of information have imposed limitations on the traditional analysis, on the other hand, the emergence of new theories and models that seek to incorporate analysis of uncertainty creates new knowledge fields: Fuzzy Logic is one of these new fields. This thesis aims to establish a method of data analysis for environmental quality evaluation of upgraded urban areas, taking into account the views of dwellers using Fuzzy Logic. POE and indicator systems were combined with Fuzzy Logic to develop analysis tools that formally represent vague and ill-defined information presented in this kind of evaluation. The method obtained is composed of six stages: (i) definition of variables/indicators, (ii) data collection, (iii) identification of strengths and weaknesses, (iv) obtaining quantitative and qualitative indicators, (v) analysis of results and (vi) environmental quality report. Results were satisfactory and it was possible to add more information into analyses. Studies carried out in a pilot research and validation researches of this method in areas of the Ribeira Azul Program showed great chances of success of interventions, but they also showed unresolved problems that deserve attention in future projects. Finally, additional researches are recommended in continuation of this research for the development of tools based on fuzzy logic, since a large number of possibilities of applications were disclosed in the course of this research. 



\section{LISTA DE FIGURAS}

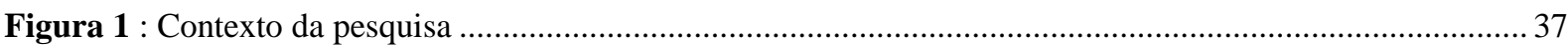

Figura 2 : Qualidade de vida como auto-implicação de três grandes dimensões ou áreas lógicas ...................... 40

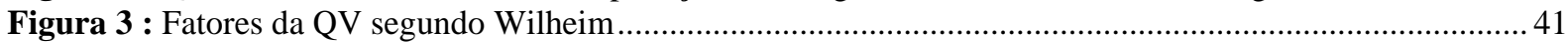

Figura 4 : Tramonto em Veneza, à esquerda representação do pintor Claude Monet, à direita fotografia

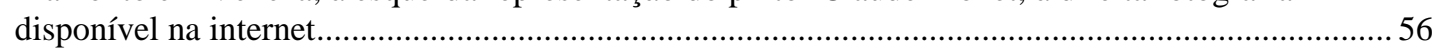

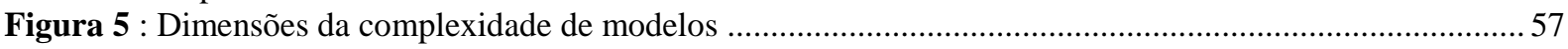

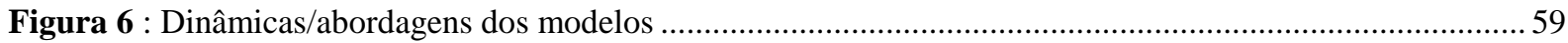

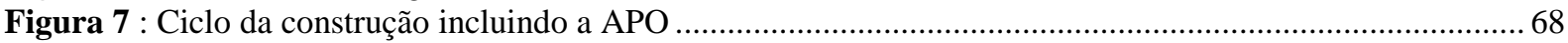

Figura 8 : Fluxograma de desenvolvimento metodológico da APO .......................................................70

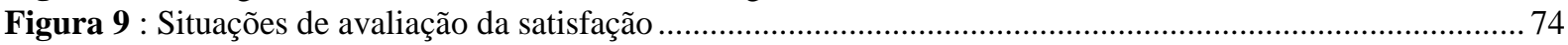

Figura 10 : Trecho de questionário típico com avaliação do usuário utilizado em escolas ...............................76

Figura 11 : Trecho de questionário típico com avaliação do usuário utilizado em edifício de escritórios ...........77

Figura 12 : Domínios e áreas temáticas da QV segundo Santos e Martins (2002) ....................................... 85

Figura 13 : Exemplo de objeto fuzzy, à esquerda e representação simplificada à direita ..............................102

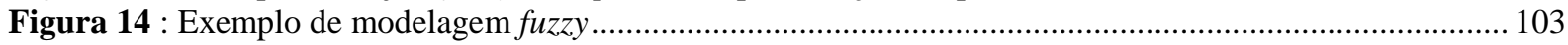

Figura 15 : Exemplos de modelagem do número fuzzy "aproximadamente 5" ......................................... 114

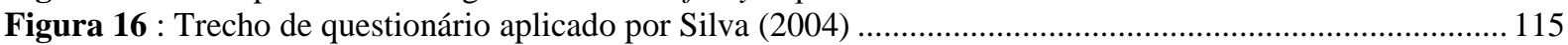

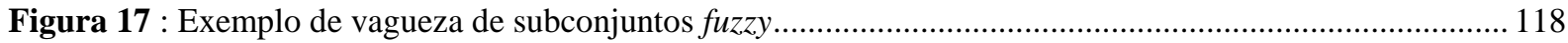

Figura 18 : Exemplos de não-especificidade de subconjuntos fuzzy ................................................... 122

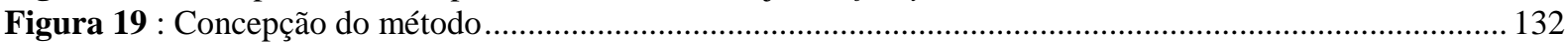

Figura 20 : Definição do agrupamento espacial dos indicadores ............................................................ 133

Figura 21 : Concepção para obtenção de indicadores utilizando inferência fuzzy ........................................ 137

Figura 22 : Modelo de inferência baseado nas relações fuzzy ............................................................... 137

Figura 23 : Modelo de inferência baseado nas relações fuzzy para avaliação da Moradia .............................. 138

Figura 24 : Esquema de classificação pelo reconhecimento de padrão ......................................................... 138

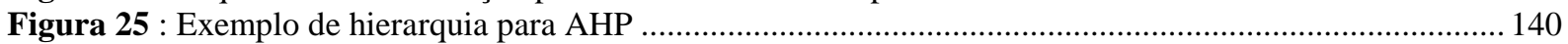

Figura 26 : Localização da área do Programa Ribeira Azul ................................................................... 144

Figura 27 : Palafitas - moradia precária típica da área do Programa Ribeira Azul....................................... 145

Figura 28 : Vista da área do Programa Ribeira Azul ................................................................................... 145

Figura 29 : Capa de material de divulgação do projeto Novos Alagados ...................................................... 147

Figura 30 : Áreas de atuação do Programa Ribeira Azul ...................................................................... 149

Figura 31 : Área de Novos Alagados, antes e depois da intervenção ......................................................... 154

Figura 32 : Autoconstrução à esquerda e embrião da Conder com ampliação à direita - - Pesquisa Piloto..... 155

Figura 33 : Autoconstrução com tijolos cerâmicos furados - Pesquisa Piloto ................................................. 159

Figura 34 : Contêiner utilizado para a coleta de lixo - Pesquisa Piloto ...................................................... 161

Figura 35 : Contrastes entre ruas: pista de borda à esquerda e rua sem pavimento à direita - Pesquisa Piloto.. 163

Figura 36 : Hierarquia para o Indicador de Salubridade ambiental .............................................................. 195

Figura 37 : Hierarquia para o Indicador de Moradia ........................................................................ 196

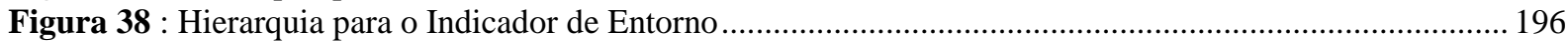

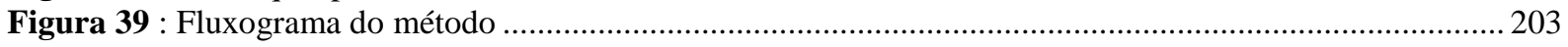

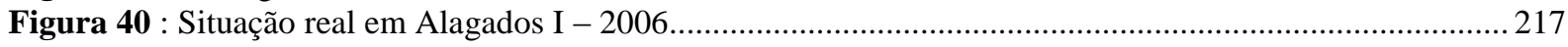

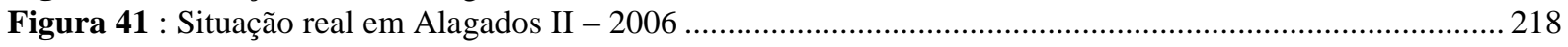

Figura 42 : Resultado da amostragem dos domicílios em Alagados I ....................................................221

Figura 43 : Resultado da amostragem de domicílios em Alagados II ........................................................222

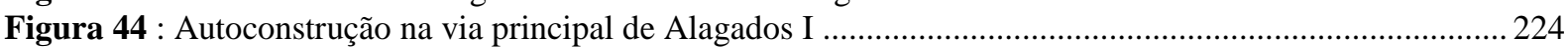

Figura 45 : Autoconstrução na via principal de Alagados II .......................................................................224

Figura 46 : Contêineres utilizados para coleta de lixo em Alagados I......................................................230

Figura 47 : Ponto de lixo em Alagados II........................................................................................... 230

Figura 48 : Proteção construída pela própria população contra alagamentos em Alagados II ..........................2231

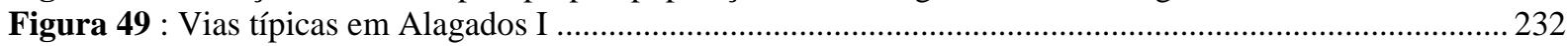

Figura 50 : Situação precária de trechos de via em Alagados II.............................................................233

Figura 51 : Distribuição espacial das avaliações do serviço de varrição pelo morador - Alagados I ................241 



\section{LISTA DE GRÁFICOS}

Gráfico 1 : Crescimento da população urbana/rural no Brasil - 1950-2000 ................................................... 48

Gráfico 2 : Percentuais de população urbana e rural no Brasil - 1950-2000 …….........................................49

Gráfico 3 : Modelagem crisp da definição de Quente ........................................................................... 104

Gráfico 4 : Modelagem fuzzy da definição de Quente ........................................................................... 104

Gráfico 5 : Exemplo de representação crisp para os subconjuntos de idades................................................ 107

Gráfico 6 : Exemplo de representação de subconjuntos fuzzy para idades .................................................. 107

Gráfico 7 : Representação dos Conjuntos Fuzzy de Satisfação do Usuário ................................................... 116

Gráfico 8 : Distribuição do número de pessoas por domicílio - Pesquisa Piloto ........................................... 156

Gráfico 9 : Tempo de residência no local - Pesquisa Piloto.......................................................................... 157

Gráfico 10 : Freqüências relativas e U-Incerteza para uma escala com cinco classes - Pesquisa Piloto ........... 170

Gráfico 11 : Freqüências relativas e U-Incerteza para uma escala com três classes - Pesquisa Piloto .............. 170

Gráfico 12 : Moradia: médias e desvios-padrão - Pesquisa Piloto ............................................................. 173

Gráfico 13 : Moradia: freqüências relativas e U-Incerteza - Pesquisa Piloto.............................................. 173

Gráfico 14 : Salubridade ambiental: médias e desvios-padrão - Pesquisa Piloto.......................................... 175

Gráfico 15 : Salubridade ambiental: Freqüências relativas e U-Incerteza - Pesquisa Piloto.......................... 175

Gráfico 16 : Entorno: médias e desvios-padrão - Pesquisa Piloto ............................................................. 176

Gráfico 17 : Entorno: Frequiências e U-Incerteza - Pesquisa Piloto.............................................................. 177

Gráfico 18 : Percentual da população x população.......................................................................................20 208

Gráfico 19 : Tamanhos das amostras para diferentes erros de estimação e coeficientes de confiança .............. 219 



\section{LISTA DE QUADROS}

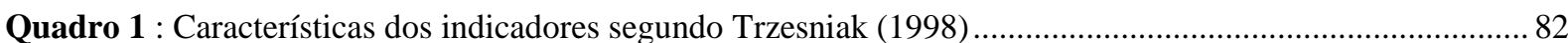

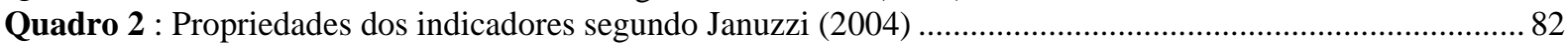

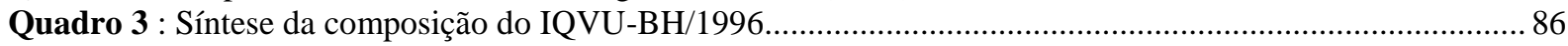

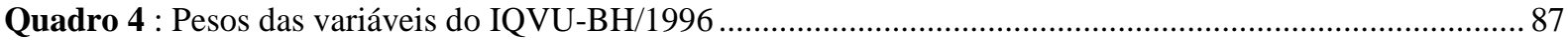

Quadro 5 : Indicadores de Qualidade de Vida de Itajaí......................................................................... 88

Quadro 6 : Classificação da Qualidade de Vida de Itajaí ........................................................................... 88

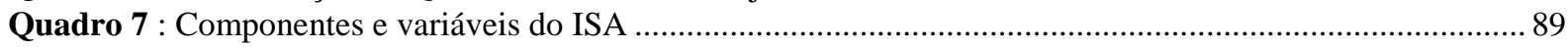

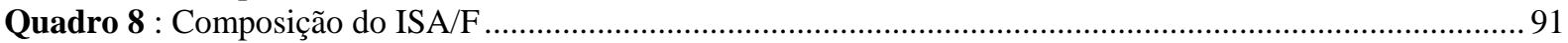

Quadro 9 : Classificação da Salubridade de acordo com o ISA/F.......................................................... 91

Quadro 10 : Condições, componentes, variáveis e Indicadores de composição do ISA/OE .............................992

Quadro 11 : Ponderação dos componentes do ISA/OE ..........................................................................93

Quadro 12 : Situação de salubridade por faixas de pontuação do ISA/OE ..................................................93

Quadro 13 : Temas de indicadores da Comissão de Desenvolvimento Sustentável da ONU ...........................94

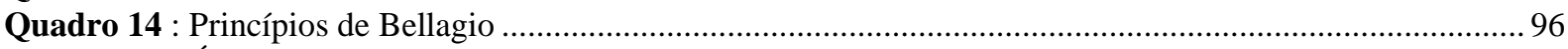

Quadro 15 : Áreas e categorias de análise do Informe de Indicadores de Sustentabilidade - CF+S .................97

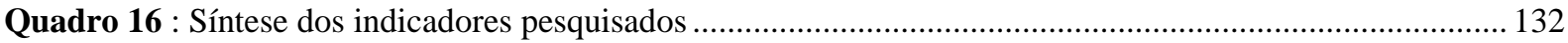

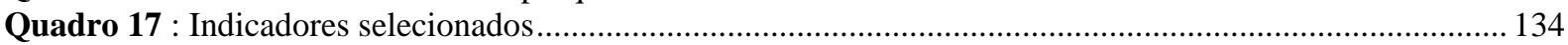

Quadro 18 : Escala de importâncias utilizada no AHP ............................................................................ 140

Quadro 19 : Abordagem fuzzy: resultados finais - Pesquisa Piloto ........................................................... 179

Quadro 20 : Exemplo de matriz de comparação utilizada no AHP ............................................................ 196

Quadro 21 : Composição do Indicador de Salubridade ambiental ............................................................... 198

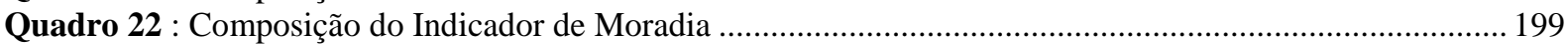

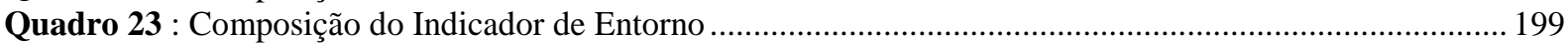

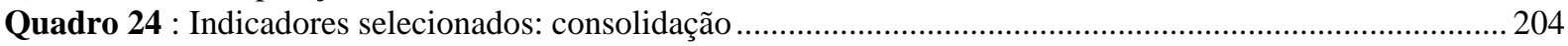

Quadro 25 : Composição do Indicador de Moradia: consolidação ...........................................................2 211

Quadro 26 : Composição do Indicador de Entorno ......................................................................................2 211

Quadro 27 : Composição do Indicador de Salubridade Ambiental ............................................................ 212 



\section{LISTA DE TABELAS}

Tabela 1 : Apuração de freqüência para satisfação do usuário ...................................................................... 116

Tabela 2 : Exemplo de relação fuzzy: presa/predador ......................................................................... 125

Tabela 3 : Dados sobre as áreas pesquisadas utilizando os setores censitários............................................ 150

Tabela 4 : Percentual de domicílios particulares permanentes (DPP) por condição da ocupação - 2000 $\ldots \ldots \ldots \ldots . . .150$

Tabela 5 : Percentual de DPP por número de habitantes - 2000 ............................................................... 150

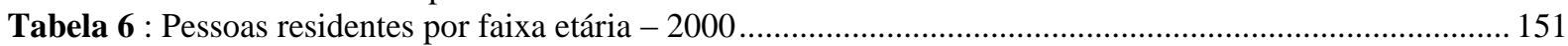

Tabela 7 : Percentual de responsáveis por domicílios segundo graus de escolaridade -2000 ........................ 151

Tabela 8 : Percentual de pessoas residentes não-alfabetizadas, com 5 anos ou mais, segundo faixas de idade 2000 .

Tabela 9 : Percentual de responsáveis dos domicílios por classe de renda - 2000 ...................................... 151

Tabela 10 : Percentual de DPP por tipologia do esgotamento sanitário - 2000 ........................................... 152

Tabela 11 : Percentual de DPP por situação da coleta de lixo - 2000....................................................... 152

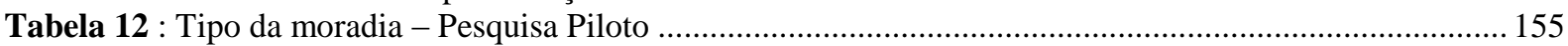

Tabela 13 : Quantas pessoas moram na casa - Pesquisa Piloto ............................................................... 155

Tabela 14 : Renda média da família - Pesquisa Piloto ...................................................................... 156

Tabela 15 : Grau de escolaridade máxima - Pesquisa Piloto ..................................................................... 156

Tabela 16 : Tipologia espacial - Pesquisa Piloto ........................................................................................ 157

Tabela 17 : Número de quartos, utilização de outros cômodos para dormir e avaliação do morador - Pesquisa

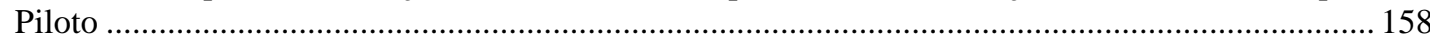

Tabela 18 : Instalações hidrossanitárias e avaliação do morador - Pesquisa Piloto ....................................... 158

Tabela 19 : Instalações elétricas e avaliação do morador - Pesquisa Piloto................................................... 158

Tabela 20 : Cobertura: material, problemas no telhado quando chove e avaliação do morador - Pesquisa Piloto

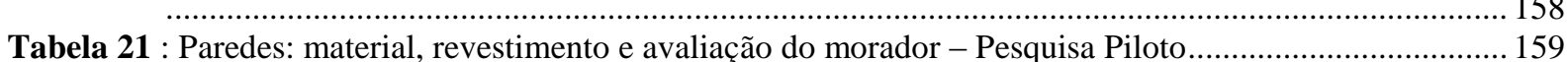

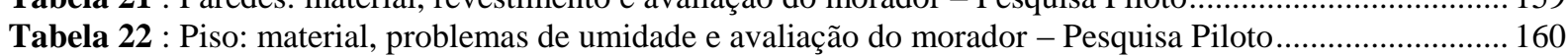

Tabela 23 : Iluminação e ventilação e avaliação do morador - Pesquisa Piloto.............................................. 160

Tabela 24 : Abastecimento, regularização, origem da água e avaliação do abastecimento de água - Pesquisa

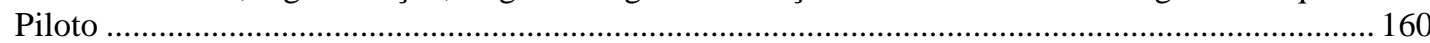

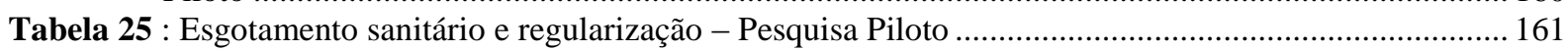

Tabela 26 : Coleta de lixo e varrição e avaliação dos serviços - Pesquisa Piloto .......................................... 161

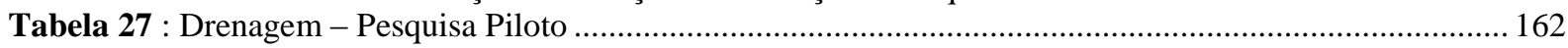

Tabela 28 : Avaliação do morador quanto ao funcionamento de bocas de lobo e sarjetas e segurança contra

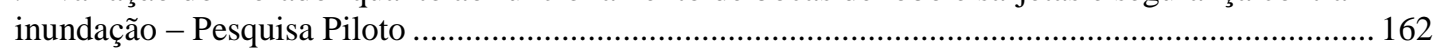

Tabela 29 : Vias de circulação e condições do pavimento e avaliação do morador - Pesquisa Piloto ............... 162

Tabela 30 : Energia elétrica, iluminação pública e avaliação do morador - Pesquisa Piloto ............................ 163

Tabela 31 : Espaços públicos de lazer e avaliação do morador - Pesquisa Piloto......................................... 163

Tabela 32 : Telefone público e avaliação do morador - Pesquisa Piloto......................................................... 164

Tabela 33 : Regularização fundiária e avaliação do morador - Pesquisa Piloto.............................................. 164

Tabela 34 : Serviços comunitários e avaliação do morador - Pesquisa Piloto ............................................... 164

Tabela 35 : Lazer fora da área e avaliação do morador - Pesquisa Piloto ................................................... 164

Tabela 36 : Associativismo e avaliação do morador - Pesquisa Piloto ............................................................ 165

Tabela 37 : Transporte e avaliação do morador quanto ao ponto de ônibus - Pesquisa Piloto........................... 165

Tabela 38 : Avaliação da casa - Pesquisa Piloto ................................................................................. 165

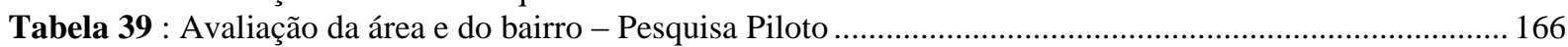

Tabela 40 : Dados de moradia: freqüência relativa e distribuição de possibilidade - escala com cinco classes -

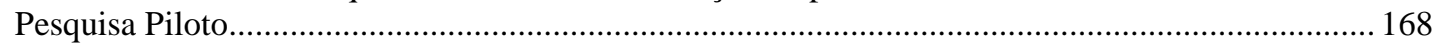

Tabela 41 : Dados de moradia: freqüência relativa e distribuição de possibilidade - escala com três classes Pesquisa Piloto............................................................................................................... 169

Tabela 42 : Moradia: freqüências relativas e medidas de incerteza com escalas de cinco e três classes - Pesquisa

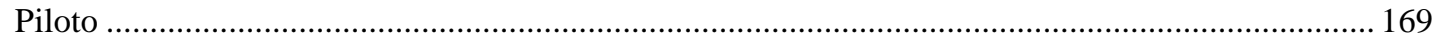

Tabela 43 : Moradia: Graus de possibilidade, incerteza, avaliação média e desvio padrão - Pesquisa Piloto ... 172

Tabela 44 : Moradia: síntese dos pontos positivos e negativos - Pesquisa Piloto..... 
Tabela 45 : Salubridade ambiental: Graus de possibilidade, incerteza, avaliação média e desvio padrão -

Pesquisa Piloto....

Tabela 46 : Salubridade ambiental: síntese dos pontos positivos e negativos - Pesquisa Piloto .........................176

Tabela 47 : Entorno: Graus de possibilidade, incerteza, avaliação média e desvio padrão - Pesquisa Piloto .... 176

Tabela 48 : Entorno: síntese dos pontos positivos e negativos - Pesquisa Piloto ...........................................177

Tabela 49 : Abordagem fuzzy por categorias de moradia - Pesquisa Piloto ...............................................178

Tabela 50 : Agrupamento da variável instalações de água por avaliação final da casa - Pesquisa Piloto ......... 181

Tabela 51 : Moradia: exemplo avaliações finais para o modelo de equações relacionais fuzzy.........................181

Tabela 52 : Moradia: matriz de avaliações parciais para equações relacionais fuzzy - Pesquisa Piloto ............. 183

Tabela 53 : Moradia: matrizes de avaliação final - menor distância ao ideal (MDI) e menor soma das

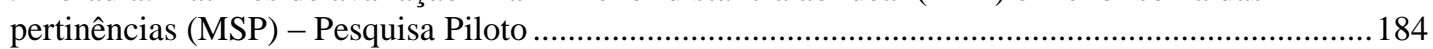

Tabela 54 : Moradia: matrizes de relação com MDI e MSP e composição max-min - Pesquisa Piloto ..............184

Tabela 55 : Moradia: percentual de acertos por construção da avaliação final e regra de composição - Pesquisa

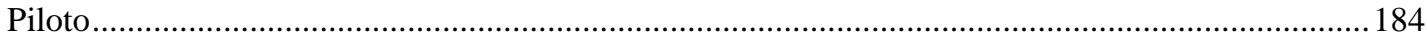

Tabela 56 : Salubridade ambiental: matriz de avaliações parciais transposta - Pesquisa Piloto........................... 185

Tabela 57 : Salubridade ambiental: matrizes de avaliação final - Pesquisa Piloto ......................................... 186

Tabela 58 : Salubridade ambiental: matriz de relação com MDI e MSP e composição max-min - Pesquisa Piloto

Tabela 59 : Salubridade : percentual de acertos por construção da avaliação final e regra de composição -

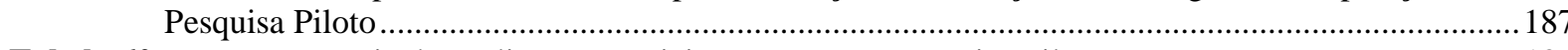

Tabela 60 : Entorno: matriz de avaliações parciais transposta - Pesquisa Piloto ......................................... 187

Tabela 61 : Entorno: matrizes de avaliação final - Pesquisa Piloto............................................................ 187

Tabela 62 : Entorno: matriz de relação com MDI e MSP e composição max-min - Pesquisa Piloto .................188

Tabela 63 : Entorno: percentual de acertos por construção da avaliação final e regra de composição - Pesquisa Piloto.

Tabela 64 : Dados para o cálculo dos indicadores finais qualitativos - Pesquisa Piloto..... 189

Tabela 65 : Indicadores qualitativos da intervenção obtidos utilizando equações relacionais fuzzy - Pesquisa Piloto.

Tabela 66 : Moradia: Padrões de respostas - Pesquisa Piloto................................................................... 191

Tabela 67 : Moradia: percentual de acertos com reconhecimento de padrão - Pesquisa Piloto .........................191

Tabela 68 : Salubridade: Padrões de respostas - Pesquisa Piloto .................................................................... 192

Tabela 69 : Salubridade: percentual de acertos com reconhecimento de padrão - Pesquisa Piloto................... 192

Tabela 70 : Entorno: Padrões de respostas - Pesquisa Piloto ..................................................................193

Tabela 71 : Salubridade: percentual de acertos com reconhecimento de padrão - Pesquisa Piloto................... 193

Tabela 72 : Padrões globais de respostas - Pesquisa Piloto...................................................................... 193

Tabela 73 : Indicadores qualitativos da intervenção obtidos utilizando o reconhecimento de padrão fuzzy -

Pesquisa Piloto.

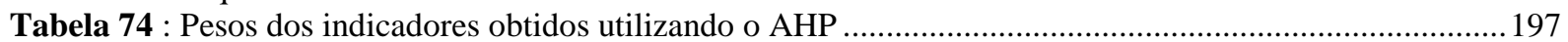

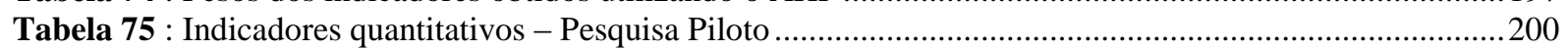

Tabela 76 : População e tamanho da amostra nas áreas de estudo................................................................220

Tabela 77 : Caracterização dos domicílios pesquisados - Alagados I e II..................................................2223

Tabela 78 : Composição e adequação dos domicílios - Alagados I e II ......................................................225

Tabela 79 : Ambientes: avaliação do morador - Alagados I e II ................................................................225

Tabela 80 : Instalações de água, esgoto e elétricas - Alagados I e II ..........................................................2226

Tabela 81 : Instalações: avaliação do morador - Alagados I e II............................................................226

Tabela 82 : Materiais e acabamento do telhado, paredes e piso - Alagados I e II ........................................227

Tabela 83 : Problemas do telhado, paredes e piso - Alagados I e II .............................................................2227

Tabela 84 : Telhado, paredes e piso: avaliação do morador - Alagados I e II.............................................222

Tabela 85 : Janelas ou aberturas - Alagados I e II..............................................................................228

Tabela 86 : Ventilação: avaliação do morador - Alagados I e II .............................................................228

Tabela 87 : Saneamento básico - Alagados I e II .....................................................................................2229

Tabela 88 : Saneamento básico: avaliação do morador - Alagados I e II......................................................2229

Tabela 89 : Segurança contra inundação: avaliação do morador - Alagados I e II ......................................2230

Tabela 90 : Infra-estrutura e outros serviços - Alagados I e II ...................................................................2232

Tabela 91 : Infra-estrutura e outros serviços: avaliação do morador - Alagados I e II....................................2233

Tabela 92 : Telefone público - Alagados I e II..........................................................................................234

Tabela 93 : Telefone público: avaliação do morador - Alagados I e II .......................................................234

Tabela 94 : Segurança no terreno: Alagados I e II .....................................................................................2234

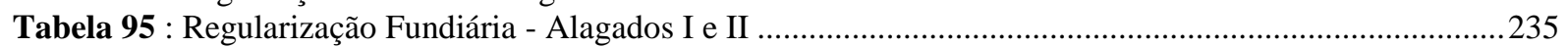

Tabela 96 : Segurança de posse: avaliação do morador - Alagados I e II ....................................................2235 
Tabela 97 : Entorno e serviços comunitários - Alagados I e II

Tabela 98 : Entorno e serviços comunitários: avaliação do morador - Alagados I e II.....

Tabela 99 : Avaliação geral da casa e comparação do antes e depois: avaliação do morador - Alagados I e II 236

Tabela 100 : Avaliação geral da área e comparação do antes e depois: avaliação do morador - Alagados I e II

Tabela 101 : Avaliação geral dos serviços e do bairro: avaliação do morador - Alagados I e II

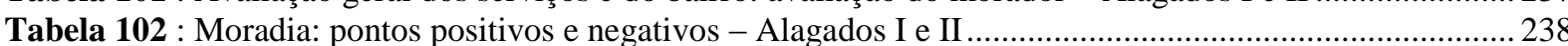

Tabela 103 : Moradia: pontos positivos e negativos por categorias de moradia - Alagados I e II....................2239

Tabela 104 : Salubridade ambiental: pontos positivos e negativos - Alagados I e II..................................240

Tabela 105 : Moradia: pontos positivos e negativos por categorias de moradia - Alagados I e II..................2242

Tabela 106 : Entorno: pontos positivos e negativos - Alagados I e II........................................................2. 243

Tabela 107 : Entorno: pontos positivos e negativos - Alagados I e II.....................................................243

Tabela 108 : Moradia: matrizes de avaliações parciais transpostas - Alagados I e II .................................. 244

Tabela 109 : Moradia: matrizes de avaliação final - Alagados I e II ........................................................244

Tabela 110 : Moradia: matrizes de relação com MDI e MSP - Alagados I e II................................................2. 245

Tabela 111 : Moradia: percentual de acertos por construção da avaliação final - Alagados I e II ...................2246

Tabela 112 : Salubridade ambiental: matrizes de avaliações parciais transpostas - Alagados I e II ................246

Tabela 113 : Salubridade ambiental: matrizes de avaliações final - Alagados I e II..................................2247

Tabela 114 : Salubridade ambiental: matrizes de relação com MDI e MSP- Alagados I e II ..........................2 248

Tabela 115 : Salubridade ambiental: percentual de acertos por construção da avaliação final - Alagados I e II 248

Tabela 116 : Entorno: matrizes de avaliações parciais transpostas - Alagados I e II ................................... 249

Tabela 117 : Entorno: matrizes de avaliação final com MDI e MSP-Alagados I e II ................................2249

Tabela 118 : Entorno: matrizes de relação com MDI e MSP- Alagados I e II................................................250

Tabela 119 : Entorno: percentual de acertos por construção da avaliação final - Alagados I e II.....................250

Tabela 120 : Dados para o cálculo dos indicadores finais qualitativos - Alagados I e II ..............................251

Tabela 121 : Indicadores qualitativos obtidos utilizando equações relacionais fuzzy - Alagados I e II ............252

Tabela 122 : Moradia: Padrões de satisfação fuzzy - Alagados I e II .............................................................253

Tabela 123 : Moradia: percentual de acertos com o reconhecimento de padrão - Alagados I e II...................253

Tabela 124 : Salubridade ambiental - padrões de satisfação - Alagados I e II ..........................................2254

Tabela 125 : Salubridade ambiental: percentual de acertos com o reconhecimento de padrão - Alagados I e II

Tabela 126 : Entorno: padrões de satisfação - Alagados I e II ............................................................... 255

Tabela 127 : Entorno: percentual de acertos com o reconhecimento de padrão - Alagados I e II ....................255

Tabela 128 : Padrão de satisfação geral - Alagados I e II .......................................................................... 256

Tabela 129 : Indicadores qualitativos obtidos utilizando reconhecimento de padrão fuzzy - Alagados I e II .... 256

Tabela 130 : Indicadores quantitativos - Alagados I e II .................................................................... 257 



\section{SUMÁRIO}

1 INTRODUÇÃ

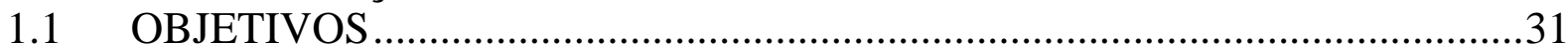

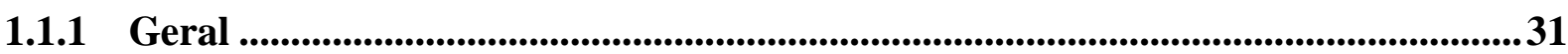

1.1.2 Específicos ..............................................................................................................................32

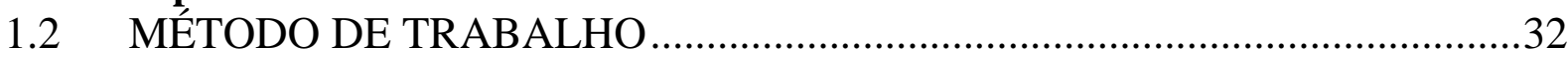

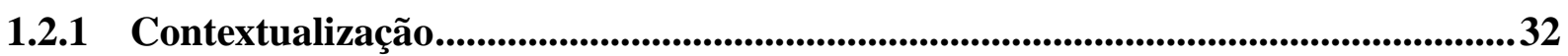

1.2.2 Definição do método de análise .........................................................................................33

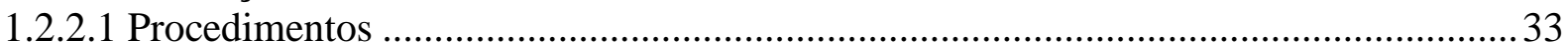

1.2.2.2 Construção de ferramentas de análise .............................................................................. 33

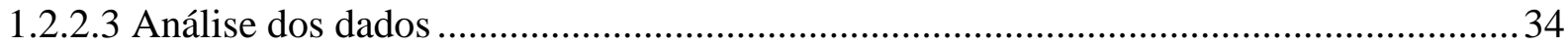

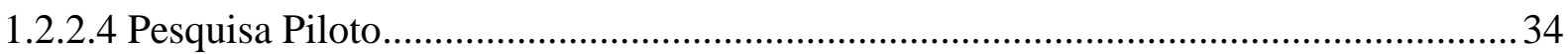

1.2.3 Validação do método .......................................................................................................34

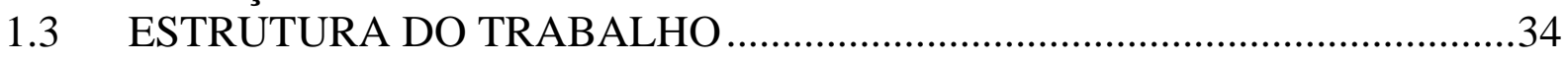

2 CONTEXTUALIZAÇÃO DA PESQUISA ......................................... 37

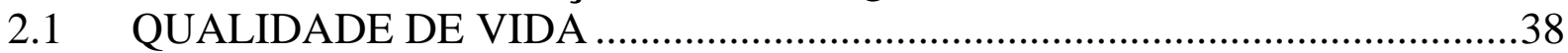

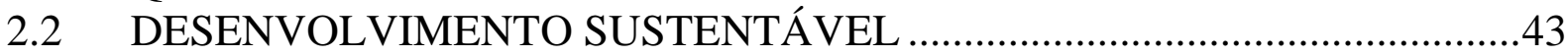

2.3 ASSENTAMENTOS URBANOS PRECÁRIOS E A SUA RECUPERAÇÃO48

3 MODELAGEM E MENSURAÇÃO DE DADOS ..............................55

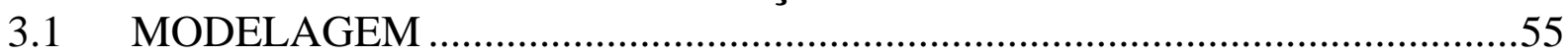

3.2 ABORDAGENS DETERMINÍSTICA, ESTOCÁSTICA E FUZZY …….........57

3.3 DADOS, VARIÁVEIS E ESCALAS DE MENSURAÇÃO ............................59

3.4 TESTES ESTATÍSTICOS PARAMÉTRICOS X NÃO-PARAMÉTRICOS ...63

3.5 TÉCNICAS ESTATÍSTICAS MULTIVARIADAS .........................................64

4 AVALIAÇÃO PÓS-OCUPAÇÃO E SISTEMAS DE INDICADORES APLICADOS AO AMBIENTE URBANO .......................................6 67

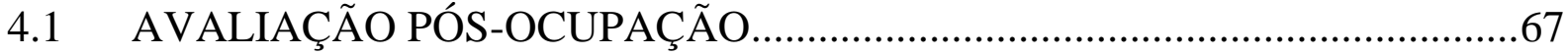

4.1.1 Avaliação técnica ....................................................................................................70

4.1.2 Avaliação da satisfação do morador/usuário ................................................................71

4.1.2.1 Medidas de satisfação utilizando formulários ..........................................................75

4.2 SISTEMAS DE INDICADORES APLICADOS AO AMBIENTE URBANO 78

4.2.1 Definições......................................................................................................79

4.2.2 Classificação dos indicadores ...............................................................................................8

4.2.3 Características dos indicadores......................................................................................8

4.2.4 Indicadores de qualidade de vida....................................................................................83

4.2.4.1 Sistema de informação da Qualidade de Vida na cidade do Porto ................................83

4.2.4.2 Índice de Qualidade de Vida Urbana da cidade de Belo Horizonte - IQVU-BH .........85

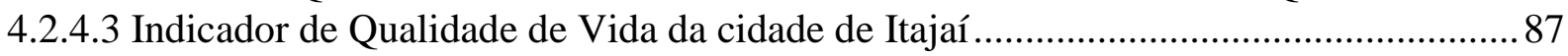

4.2.5 Indicadores de salubridade ambiental.....................................................................89

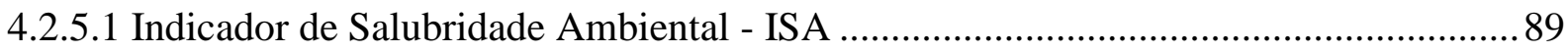


4.2.5.2 Indicadores de Salubridade Ambiental para Favelas Urbanizadas - ISA/F ............... 90

4.2.5.3 Indicadores de Salubridade Ambiental para Áreas de Ocupação Espontânea - ISA/OE

4.2.6 Indicadores de sustentabilidade................................................................................ 93

4.3 CONSIDERAÇÕES SOBRE OS MÉTODOS DE AVALIAÇÃO ..................98

5 LÓGICA FUZZY: CONCEITOS E DEFINIÇÕES PARA ESTE TRABALHO .............................................................................................101

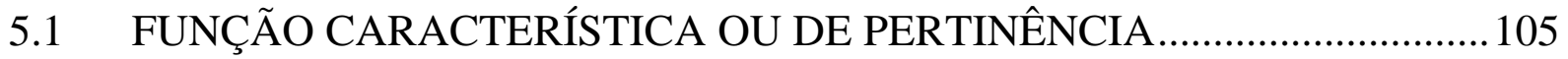

$5.2 \quad$ CORTES $-\alpha$ OU $\alpha$-CORTES .................................................................. 108

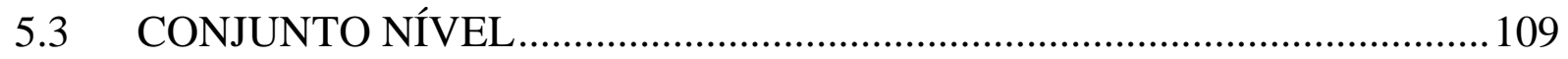

5.4 SUPORTE DE UM SUBCONJUNTO FUZZY …....................................... 109

5.5 ALTURA DE UM SUBCONJUNTO FUZZY ........................................... 109

5.6 SUBCONJUNTO FUZZY NORMAL ......................................................... 110

5.7 OPERAÇÕES BÁSICAS EM SUBCONJUNTOS FUZZY …......................110

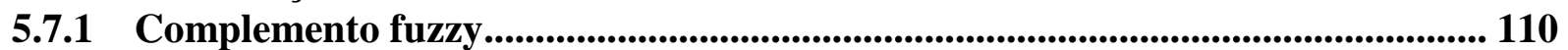

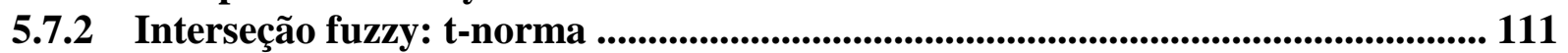

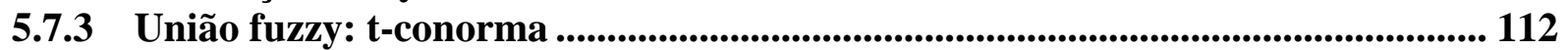

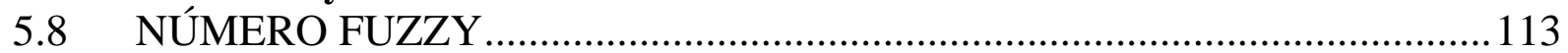

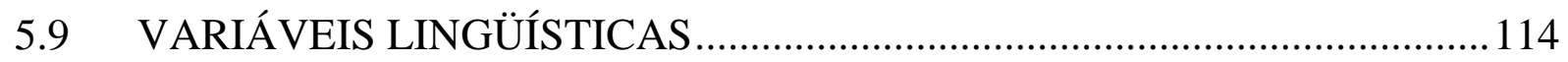

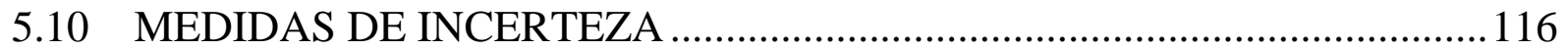

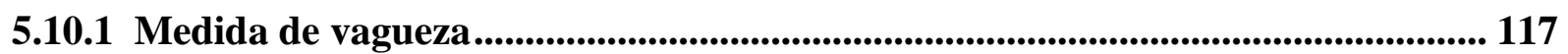

5.10.1.1 Cálculo da vagueza de um subconjunto pela comparação com seu complemento. 119

5.10.1.2 Cálculo da vagueza de um subconjunto pela comparação com o crisp aproximador

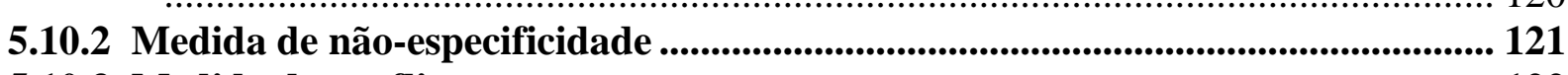

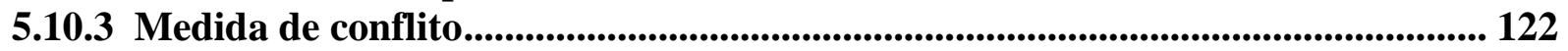

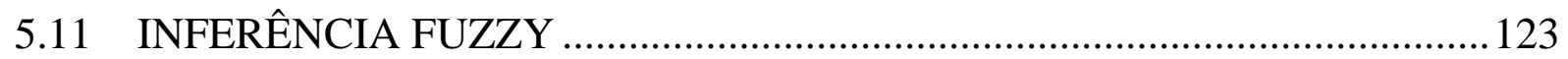

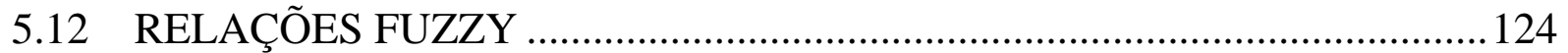

5.12.1 Relações fuzzy binárias....................................................................................... 125

5.12.2 Composições de relações fuzzy................................................................................ 126

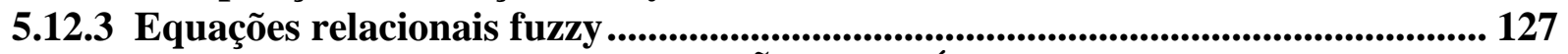

5.13 RECONHECIMENTO DE PADRÃO E ANÁLISE DE AGRUPAMENTO . 128

5.13.1 Agrupamento fuzzy baseado em relações de equivalência.................................... 129

5.13.2 Reconhecimento de padrão utilizando o método da lista fuzzy de pertinência.. 130

6 MÉTODO PROPOSTO: CONCEPÇÃO INICIAL ............................131

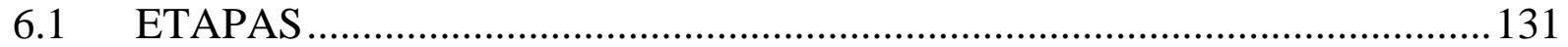

6.1.1 Definição de variáveis/indicadores .......................................................................... 131

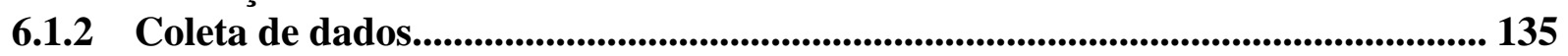

6.1.3 Análise de dados de avaliação do morador .......................................................... 135

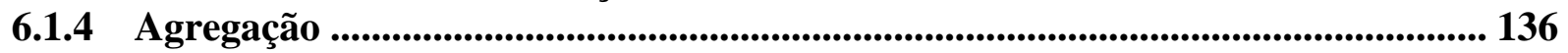

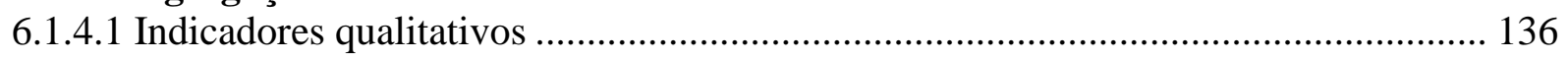

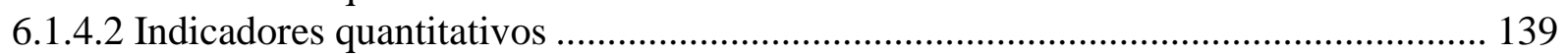

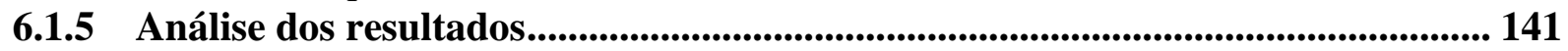

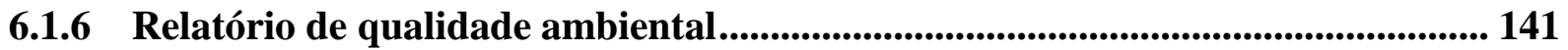


7 DESCRIÇÃO DA ÁREA DE ESTUDO: ÁREA DO PROGRAMA

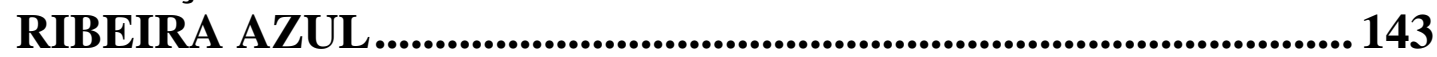

7.1 HISTÓRICO DE INTERVENÇÕES E CARACTERIZAÇÃO DA ÁREA ...146

7.2 CONSIDERAÇÕES SOBRE AS ÁREAS DE ESTUDO.................................152

8 PESQUISA PILOTO - NOVOS ALAGADOS 1A. ETAPA ............ 153

8.1 DESCRIÇÃO DOS DADOS COLETADOS ............................................154

8.1.1 Caracterização dos domicílios pesquisados................................................................155

8.1.2 Moradia ..........................................................................................................................157

8.1.3 Salubridade ambiental ......................................................................................................160

8.1.4 Entorno e serviços comunitários ...................................................................................164

8.1.5 Avaliação final ............................................................................................................165

8.1.6 Considerações sobre Novos Alagados - 1a. Etapa com base nos dados descritos

8.2 QUESTÕES PRELIMINARES À ANÁLISE DE DADOS

8.2.1 Definição do método de fuzzificação .............................................................................167

8.2.2 Definição do método de defuzzificação.......................................................................167

8.2.3 Definição do número de classes da escala de avaliação do morador .....................168

8.3 ANÁLISE DE DADOS DE AVALIAÇÃO DO MORADOR ………..............171

8.3.1 Moradia ...........................................................................................................172

8.3.2 Salubridade ambiental ..................................................................................174

8.3.3 Entorno ...............................................................................................176

8.3.4 Desdobramentos ..............................................................................................177

8.3.5 Considerações finais sobre a utilização de medidas de incerteza............................180

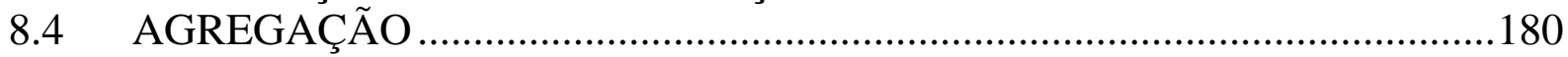

8.4.1 Indicadores qualitativos ....................................................................................................180

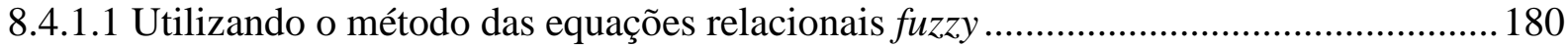

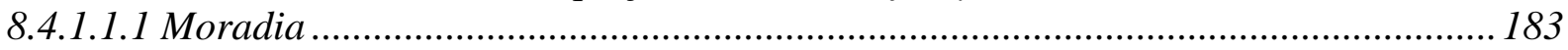

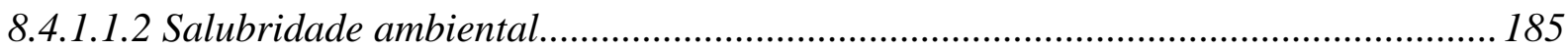

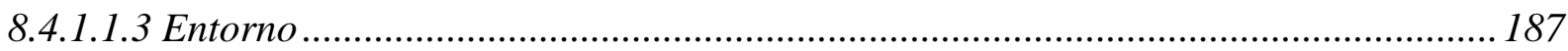

8.4.1.1.4 Indicadores segundo o modelo das equações relacionais fuzzy ............................. 188

8.4.1.2 Reconhecimento de padrão fuzzy - Método da lista fuzzy de pertinência .................... 190

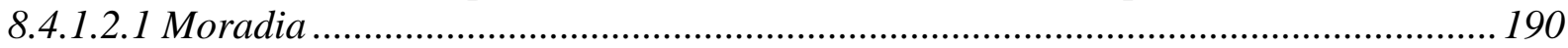

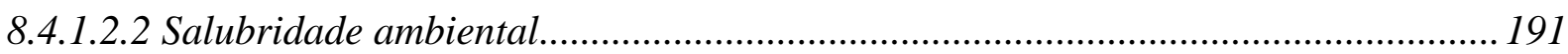

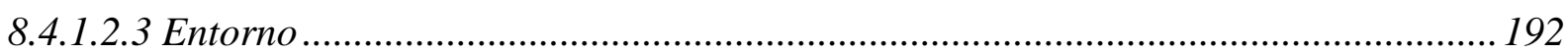

8.4.1.2.4 Indicadores finais utilizando o método de reconhecimento de padrão.....................193

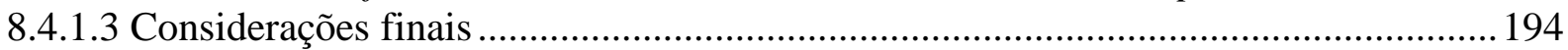

8.4.2 Indicadores quantitativos ...........................................................................................195

8.4.2.1 Definição dos pesos relativos dos indicadores .......................................................195

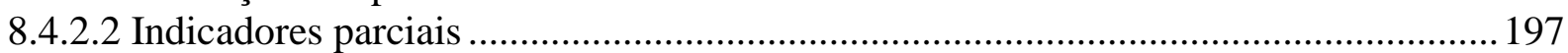

8.4.2.3 Cálculo do indicador quantitativo final ................................................................... 199

8.4.3 Considerações finais ...................................................................................................200

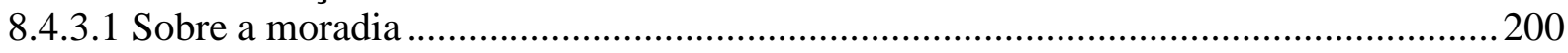

8.4.3.2 Sobre a salubridade ambiental e o entorno ……………………………………........201

9 MÉTODO PROPOSTO: CONSOLIDAÇÕES................................... 203

9.1 DEFINIÇÃO DE VARIÁVEIS/INDICADORES …........................................203

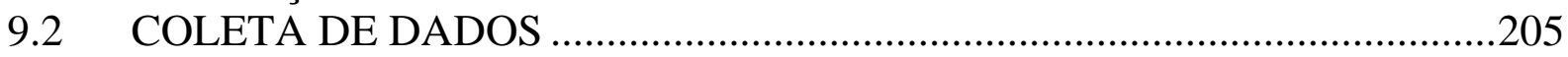




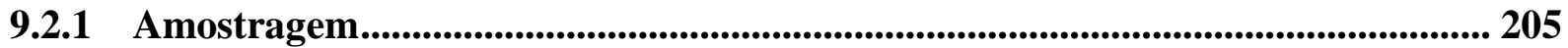

9.2.1.1 Definição dos parâmetros para seleção da amostra .................................................. 207

9.3 IDENTIFICAÇÃO DOS PONTOS POSITIVOS E NEGATIVOS ...............209

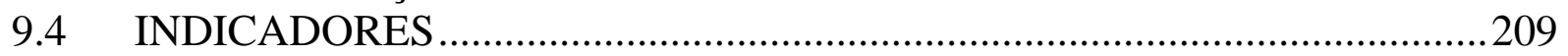

9.4.1 Indicadores qualitativos ........................................................................................................ 209

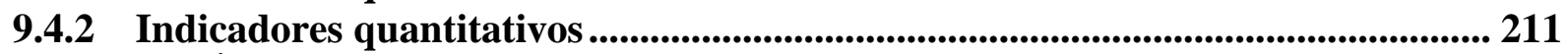

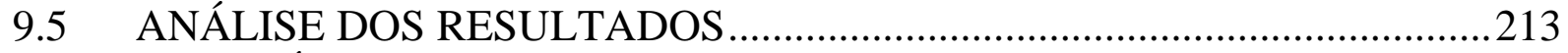

9.6 RELATÓRIO DE QUALIDADE AMBIENTAL..........................................213

10 VALIDAÇÃO DO MÉTODO: ALAGADOS I E II .......................... 215

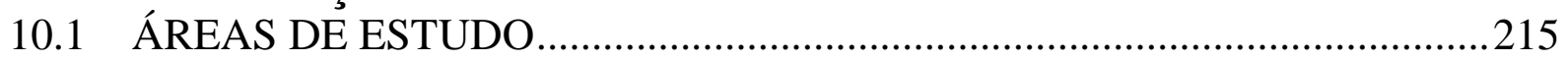

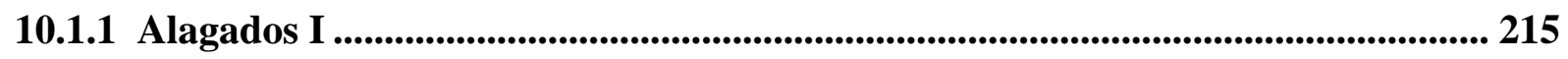

10.1.2 Alagados II............................................................................................................................... 217

10.1.3 Amostragem........................................................................................................................... 219

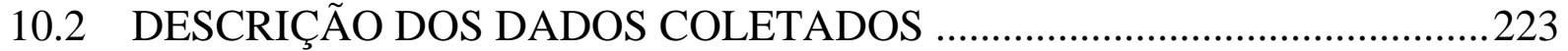

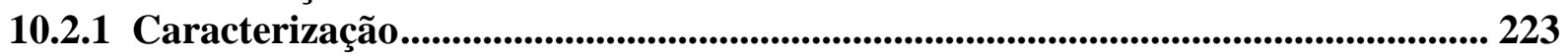

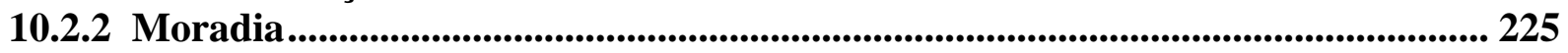

10.2.2.1 Composição e adequação .......................................................................... 225

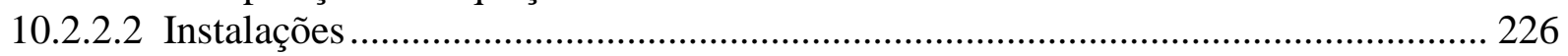

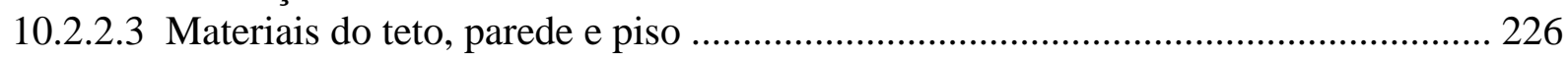

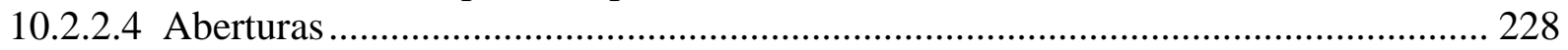

10.2.3 Salubridade ambiental................................................................................ 228

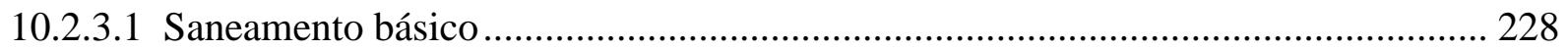

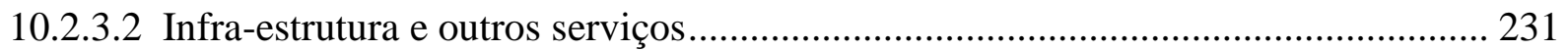

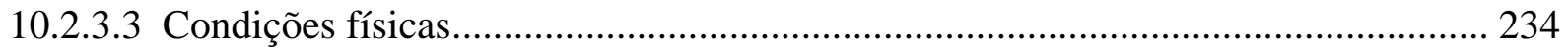

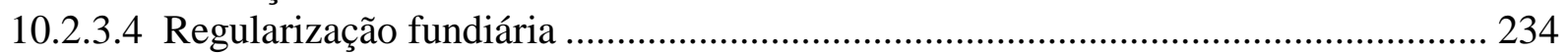

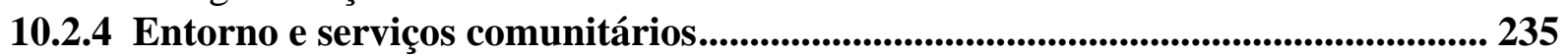

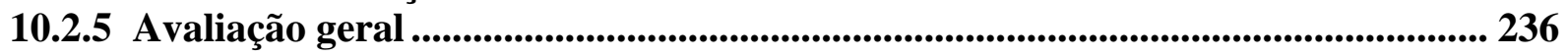

10.2.6 Considerações sobre Alagados I e II com base nos dados descritos ..................... 237

10.3 IDENTIFICAÇÃO DOS PONTOS POSITIVOS E NEGATIVOS ................237

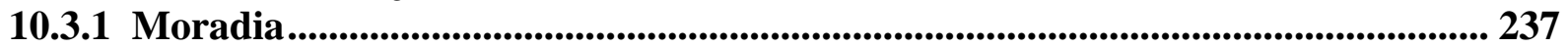

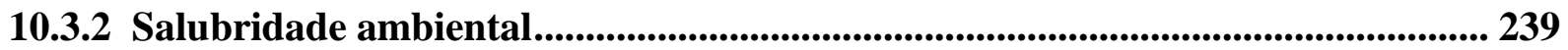

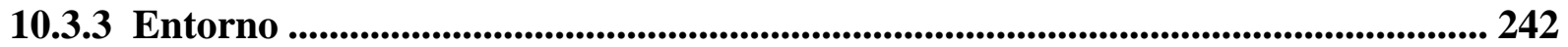

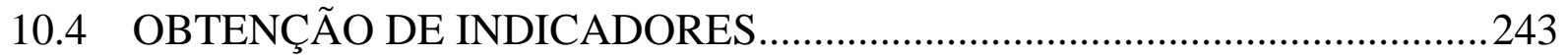

10.4.1 Indicadores qualitativos ....................................................................................... 243

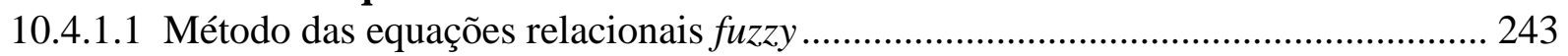

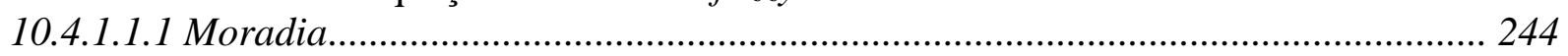

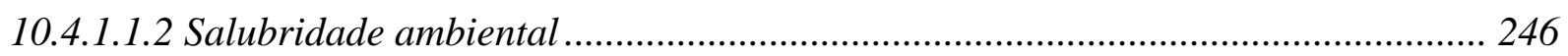

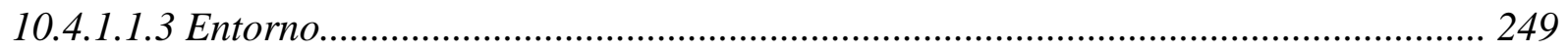

10.4.1.1.4 Indicadores segundo o modelo das equações relacionais fuzzy ........................... 250

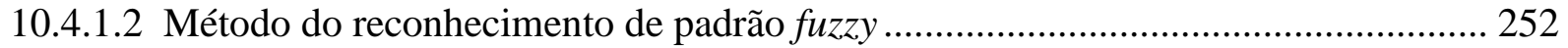

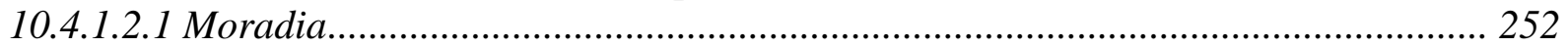

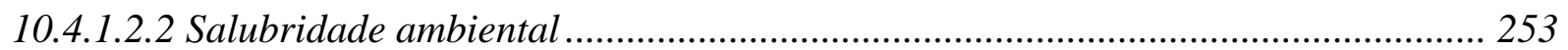

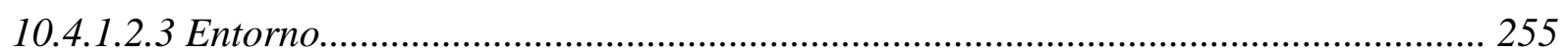

10.4.1.2.4 Indicadores segundo o modelo de reconhecimento de padrão............................... 255

10.4.2 Indicadores quantitativos ................................................................................. 257

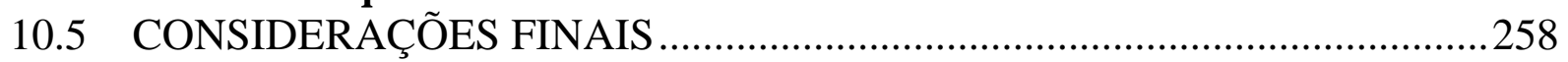

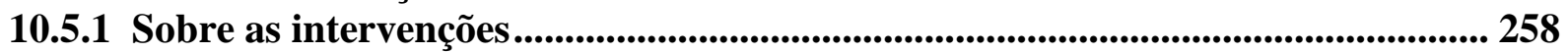

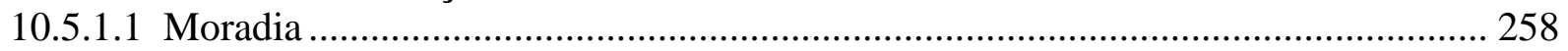




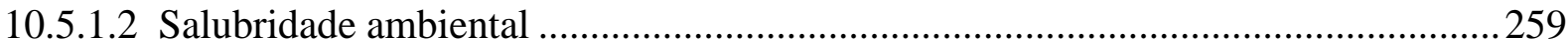

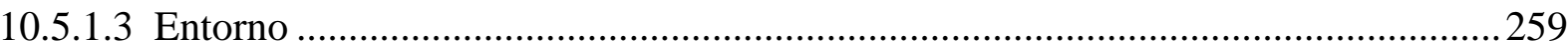

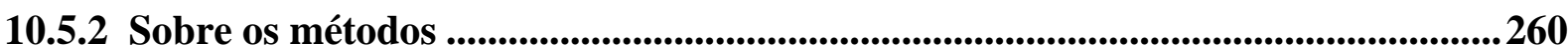

11 CONCLUSÕES E RECOMENDAÇÕES..............................................261

11.1 MEIO AMBIENTE URBANO: AVALIAÇÕES E INCERTEZAS ................261

11.2 MÉTODOS PROPOSTOS: PRINCIPAIS CONCLUSÕES ……………….....263

11.2.1 A agregação de informações pelos métodos propostos utilizando a Lógica Fuzzy

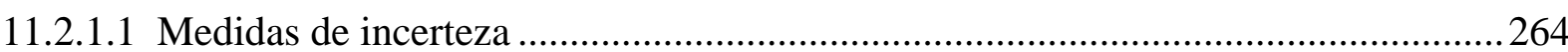

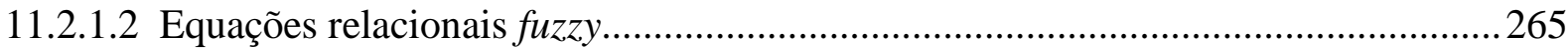

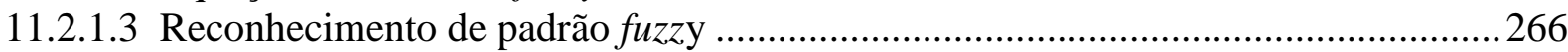

11.2.2 A utilização do AHP para definição de pesos em indicadores quantitativos ......266

11.3 AS AÇÕES DO PROGRAMA RIBEIRA AZUL: PRINCIPAIS CONCLUSÕES BASEADAS NA PESQUISA PILOTO E NOS ESTUDOS

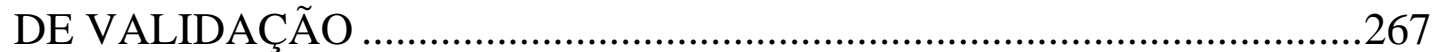

11.4 RECOMENDAÇÕES PARA FUTUROS TRABALHOS ............................268

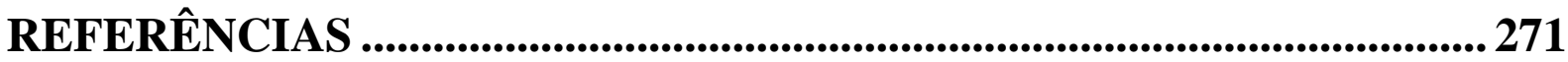

APÊNDICE A: FORMULÁRIO DE CAMPO - PESQUISA PILOTO.... 281 APÊNDICE B: CÓDIGOS DA VARIÁVEIS UTILIZADAS........................ 287 APÊNDICE C: QUESTIONÁRIO DE CONSULTA AOS

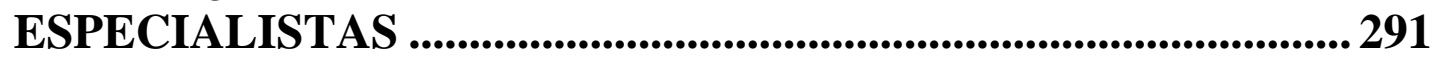

APÊNDICE D: FORMULÁRIO DE CAMPO - VALIDAÇÃO................. 297 



\section{INTRODUÇÃO}

As grandes cidades brasileiras apresentam um quadro de desigualdades, onde o acesso à terra urbana tornou-se uma barreira social que exclui, dos bens e serviços básicos da urbanização, grande parcela da população das cidades. Essa população acaba ocupando e construindo seu próprio espaço urbano por meio das invasões, favelas e loteamentos clandestinos.

Por outro lado, o Estado busca contornar esta situação, utilizando-se de diversas ações, ou intervenções, no ambiente urbano desde a remoção das favelas e construção de novas moradias até as urbanizações atuais. Do passado, ficaram as críticas às remoções e ao padrão de conjuntos habitacionais de periferias, construídos pelo Banco Nacional da Habitação $(\mathrm{BNH})$ e na atualidade, das diferentes modalidades de ações, destacando-se as urbanizações de favelas, pouco se sabe sobre o seu desempenho.

Nas ações atuais, há uma preocupação clara de incorporar questões relativas a qualidade de vida e a sustentabilidade, conceitos cada vez mais presentes no cotidiano de todos. Logo, há também a necessidade de avaliação destas ações onde, além de uma avaliação técnica, tornase necessário considerar a opinião dos moradores sobre o seu habitat, de forma a incorporar as questões subjetivas e de qualidade avaliada pelos moradores sobre o ambiente que o cerca.

Além disso, a avaliação do ambiente urbano tem consistido numa importante ferramenta para definição de políticas públicas e projetos relacionados a ele, buscando uma melhoria no espaço urbano que propicie ganhos na qualidade de vida de seus moradores, muito embora, poucos sejam os métodos que considerem a opinião desses moradores no processo de avaliação.

Diversos pesquisadores têm reconhecido a importância dessa informação justificada principalmente pelo fato de ser o morador/usuário o principal experimentador do habitat avaliado, cuja avaliação, apesar de impregnada de subjetividades, é capaz de identificar aspectos apenas detectáveis com a vivência e ainda mais, refletindo o grau de identificação do morador com o seu ambiente, um indicador da manutenção das condições ambientais.

Dentre os métodos de avaliação do ambiente urbano que têm sido objeto de estudo de diversos pesquisadores destacamos os sistemas indicadores e a Avaliação Pós-Ocupação (APO). Os sistemas indicadores, com uma tendência mais quantitativa, possuem um leque 
vasto de aplicações como: verificar tendências, avaliar políticas públicas e obter rankings. As estatísticas públicas formam sua principal base e são, por tradição, um instrumento para tomada de decisão e planejamento em médias ou grandes escalas espaciais. Contudo, destacase na atualidade, uma tendência de formulação de indicadores em escalas menores, como os indicadores de sustentabilidade para edifícios e empreendimentos. Já a APO caracteriza-se mais por ser uma ferramenta de avaliação para planejamento e projetos. Suas bases teóricas são oriundas da área denominada Psicologia Ambiental e possuem fortes influências dos procedimentos das áreas de Ciências Sociais. Este método possui grande foco nas relações ambiente-comportamento como base de informações para o aprimoramento de projetos. Além disso, apresenta uma grande flexibilidade de métodos, sendo que em princípio não há restrição de escalas, podendo ser aplicada desde espaços internos, residenciais e edifícios de escritórios até a escala urbana de bairros ou cidades. Em ambos os métodos, a importância da opinião do morador/usuário é reconhecida, porém na APO esta informação é fundamental. Mesmo assim o ferramental disponível para análise de dados utilizados pela APO ainda apresenta limitações ao tratar conceitos subjetivos de qualidade.

O instrumento mais freqüente para coleta da opinião do morador/usuário é o questionário/formulário. Ele é utilizado para obter índices e satisfação ou rejeição no caso dos sistemas indicadores, enquanto na APO é uma das ferramentas utilizadas para identificar pontos positivos e negativos dos projetos, como meio de retroalimentação do processo de projeto. As escalas utilizadas neste tipo de instrumento geralmente são escalas ordinais, portanto qualitativas, as quais, durante o processo de análise de dados são atribuídos códigos numéricos, e equivocadamente são tratadas como tal, ou seja, como escalas quantitativas. Contudo, existem diferenças entre escalas qualitativas e quantitativas, tais como distância entre pontos e validade de operações matemáticas, que restringem as possibilidades de análise de dados e que quando não reconhecidas podem agregar incertezas às conclusões obtidas.

A incerteza, por outro lado, tem ocupado um lugar de destaque desde o Século XX, a ponto do pensador Edgard Morin (2002) afirmar que uma das maiores conquistas deste período ter sido o reconhecimento das incertezas.

De fato, questões relacionadas as incertezas podem ser vistas em diversas áreas, desde questões surgidas em relação à questão ambiental, das condições de sobrevivência do homem na Terra, às questões relacionadas aos modelos matemáticos, como a Estatística e a Lógica Fuzzy. 
A Lógica Fuzzy surge como uma alternativa, uma extensão da Lógica Clássica, para trabalhar as questões vagas, incertas ou mal definidas, presentes no raciocínio humano. Ela difere do tratamento dado pela Estatística, pois enquanto a incerteza nos modelos estatísticos está relacionada à casualidade dos eventos, a incerteza nos modelos fuzzy está relacionada à imprecisão ou vagueza dos conceitos (CORNELISSEN et al., 2001).

A Lógica Fuzzy foi proposta inicialmente para resolver problemas de automação e controle, porém, houve uma expansão do conhecimento nesta área e atualmente, encontramos diversas aplicações em diferentes áreas tais como geoprocessamento, medicina e apoio à tomada de decisão (CHENG, 2001). O termo Lógica Fuzzy tem sido utilizado em dois sentidos: num sentido restrito, quando se refere aos processos de inferência tal qual a Lógica Clássica ou num sentido amplo, quando se refere a um conjunto de teorias e métodos baseados na Teoria dos Conjuntos Fuzzy (DVORAK et al., 2003).

No contexto apresentado, este trabalho tem como objetivo o estabelecimento de um método de análise de dados para obtenção de indicadores de qualidade ambiental urbana em áreas recuperadas, que considere também a opinião dos moradores, utilizando ferramentas de Lógica Fuzzy. Para isto, buscamos aliar algumas técnicas utilizadas em APO - com ênfase em pesquisas de opinião utilizando formulários - e sistemas indicadores com a Lógica Fuzzy para desenvolver ferramentas que melhor representem e manipulem as informações referentes à avaliação do ambiente urbano.

\subsection{OBJETIVOS}

\subsubsection{Geral}

Estabelecer um método de análise de dados para avaliação da qualidade ambiental em áreas urbanas recuperadas que leve em conta a opinião dos moradores, utilizando ferramentas de Lógica Fuzzy. 


\subsubsection{Específicos}

- contextualizar os conceitos relacionados aos sistemas indicadores de qualidade ambiental urbana, aos métodos de avaliação do ambiente urbano e aos métodos de análise de dados qualitativos;

- definir um método para avaliação da qualidade ambiental em áreas urbanas recuperadas;

- estabelecer um método de análise de dados de avaliação da qualidade ambiental urbana utilizando a Lógica Fuzzy;

- realizar estudo de caso em áreas urbanas recuperadas em Salvador para a validação do método proposto.

\subsection{MÉTODO DE TRABALHO}

O caminho seguido para a realização deste trabalho pode ser dividido em três etapas:

- contextualização da pesquisa;

- definição do método de análise: procedimentos, construção de ferramentas e pesquisa piloto e;

- validação do método.

\subsubsection{Contextualização}

A contextualização da pesquisa se deu com base em levantamento bibliográfico sobre a problemática ambiental urbana, os assentamentos urbanos deteriorados, as experiências de recuperação destes assentamentos, os métodos de avaliação da sua qualidade, Lógica Fuzzy e ferramentas de análise de dados quantitativos e qualitativos.

Ênfase especial foi dada aos métodos de análise de variáveis qualitativas que, de acordo com alguns autores pesquisados, é uma das principais preocupações na construção de indicadores 
de qualidade de vida e/ou ambiental urbana, de forma a equilibrar as informações objetivas com as subjetivas, de opinião dos moradores.

\subsubsection{Definição do método de análise}

\subsubsection{Procedimentos}

A partir da revisão bibliográfica, foi possível definir um conjunto de procedimentos para a obtenção de indicadores de qualidade ambiental urbana para áreas urbanas recuperadas, baseado nos diversos indicadores já propostos e aplicados.

O sistema de indicadores dos dados qualitativos foi adequado à Lógica Fuzzy, para sua conversão em subconjuntos fuzzy, e também para agregação das variáveis num indicador qualitativo único, que deverá ser comparado ao indicador quantitativo.

Para a coleta de dados utilizamos pesquisa documental para análise de projetos, pesquisas exploratórias e formulários para levantamento de campo sobre a infra-estrutura e os serviços, assim como para coleta de dados sobre avaliação da satisfação do morador/usuário.

A análise de dados para composição de um relatório de qualidade ambiental foi feita utilizando-se as ferramentas desenvolvidas, que descrevemos a seguir.

\subsubsection{Construção de ferramentas de análise}

A construção de ferramentas de análise mais adequadas ao tratamento, tanto de variáveis quantitativas quanto qualitativas para modelagem da linguagem humana, foi feita utilizandose a Lógica Fuzzy. Neste sentido, foram formulados e implementados algoritmos para o tratamento e análise destes dados que podem ser agrupadas da seguinte forma:

- ferramentas de conversão dos dados;

- ferramentas de análise da qualidade das informações;

- ferramentas de agregação dos dados. 


\subsubsection{Análise dos dados}

A análise dos dados foi feita, sempre que possível, de forma comparativa. Os métodos clássicos e os indicadores já desenvolvidos foram utilizados como referencial para verificar a adequação do método proposto.

\subsubsection{Pesquisa Piloto}

Após o desenvolvimento destas ferramentas foi realizada uma pesquisa piloto, com o objetivo de aferir a adequação dos formulários, bem como das ferramentas desenvolvidas. Esta pesquisa foi realizada em uma das áreas do Programa Ribeira Azul, em Salvador (Bahia), onde as obras já tinham sido concluídas há mais de sete anos.

\subsubsection{Validação do método}

A validação do método se deu com base em estudos de caso, cujo objetivo foi comprovar a sua replicabilidade. Os estudos de caso foram desenvolvidos em Salvador, nas outras duas áreas onde as ações de recuperação de áreas urbanas deterioradas foram realizadas e concluídas pelo Programa Ribeira Azul.

Nesta etapa formulários definitivos foram aplicados e os dados coletados foram analisados com as ferramentas desenvolvidas. Os resultados forneceram informações importantes sobre a intervenção, bem como, indicadores de qualidade ambiental baseados tanto na opinião da população beneficiada, quanto nos aspectos de quantidade dos bens e serviços realizados.

\subsection{ESTRUTURA DO TRABALHO}

No Capítulo 2 apresentamos um breve contexto da pesquisa, cujo objetivo é tecer algumas considerações sobre os conceitos envolvidos neste trabalho, notadamente os conceitos de 
qualidade de vida e de desenvolvimento sustentável e um resumo das ações na área da habitação de baixa renda no Brasil na busca por estes paradigmas.

No Capítulo 3 são levantadas algumas questões relacionadas à modelagem e à mensuração de dados como base para as questões discutidas nos problemas de avaliação do ambiente urbano, que são descritas no Capítulo 4.

No Capítulo 5 é feita uma revisão orientada sobre os conceitos, definições e técnicas utilizadas em Lógica Fuzzy de forma a subsidiar a definição do método de análise proposto que é feita no Capítulo 6, de forma preliminar, com base nas necessidades já levantadas.

No Capítulo 7 apresentamos uma descrição da área de estudo, com algumas informações sobre as áreas de intervenção que foram pesquisadas.

O resultados da pesquisa piloto são descritos no Capítulo 8 , onde foram testadas as ferramentas propostas e feitas as devidas considerações para o aperfeiçoamento do método; o qual é apresentado de forma consolidada no Capítulo 9.

Por fim, a validação do método é apresentada no Capítulo 10, com a sua replicação em duas outras áreas do Programa Ribeira Azul, seguido das considerações finais e conclusões que são apresentadas no Capítulo 11. 


\section{CONTEXTUALIZAÇÃO DA PESQUISA}

O pano de fundo desta pesquisa é constituído pelos assentamentos urbanos deteriorados em países em desenvolvimento e os paradigmas que têm justificado as ações nestes assentamentos, notadamente os paradigmas que envolvem os conceitos de qualidade de vida e de desenvolvimento sustentável (Figura 1). A revisão, a seguir, não pretende ser exaustiva, nem poderia ser, em função da vasta produção bibliográfica na área e da complexidade atual que os temas sugerem, contudo, pretende ser suficiente para apresentar o contexto desta pesquisa.

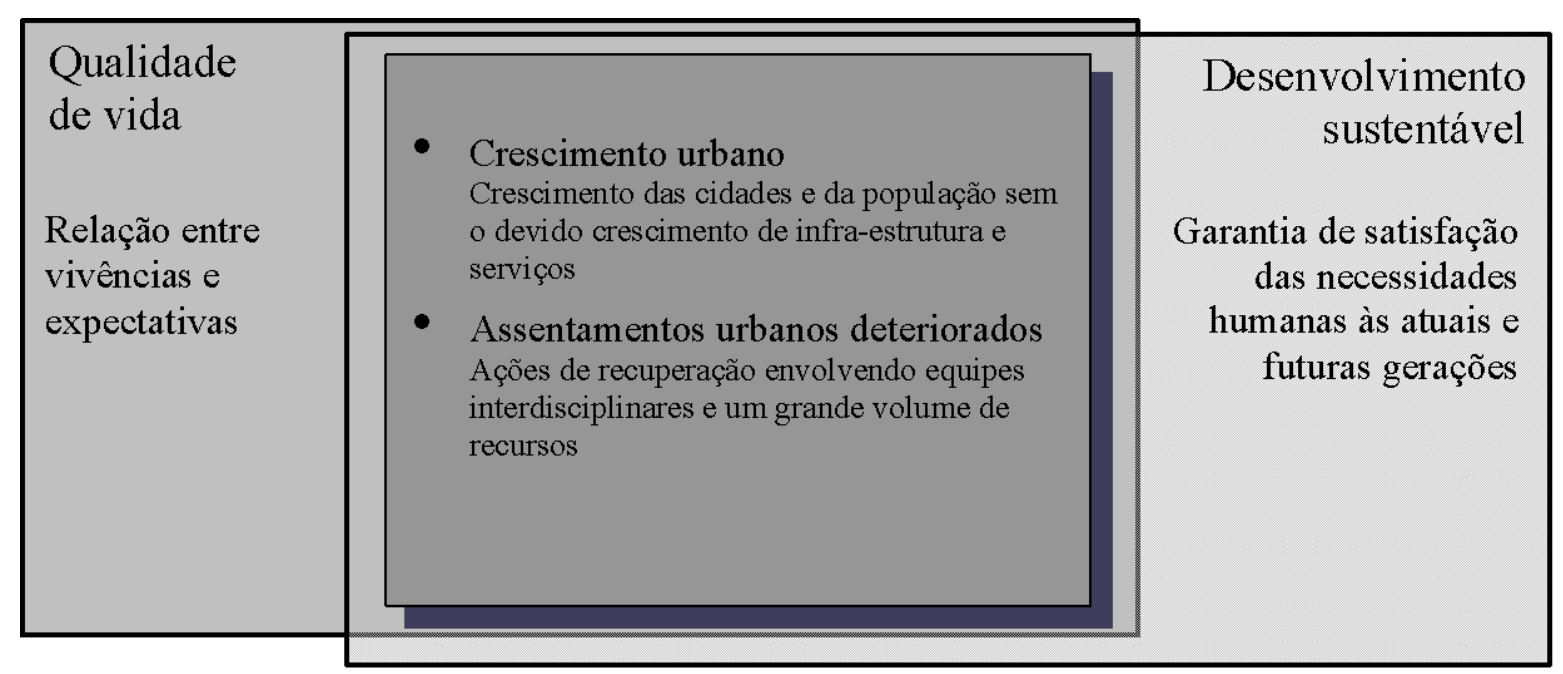

Figura 1: Contexto da pesquisa

Tomando-se os conceitos de qualidade de vida e desenvolvimento sustentável apresentados na Figura 1 podemos admitir as suas complementaridades. Enquanto a qualidade de vida pode ser definida como o grau de atendimento das expectativas dos indivíduos relacionadas às suas vivências e necessidades (GÓMEZ, 2001), o desenvolvimento sustentável é definido como aquele desenvolvimento que visa garantir as necessidades das gerações atuais sem comprometer a capacidade das futuras gerações atenderem as suas (WORLD COMMISSION ON ENVIRONMENT AND DEVELOPMENT, 1987), ou seja, ambos estão focados no atendimento de necessidades/expectativas humanas.

Por outro lado, há um processo de urbanização mundial que produz situações cada vez mais conflitantes. Mesmo que a urbanização seja, em geral, associada ao desenvolvimento, este processo de urbanização não tem se refletido em melhor qualidade de vida para todos. Há 
uma necessidade urgente nas cidades de países em desenvolvimento de acomodar o rápido crescimento populacional, prover infra-estrutura básica, responder aos problemas de rápida deterioração física dos ambientes e, acima de tudo, melhorar as condições habitacionais, especialmente para os pobres (SALAT, 2006; UNCHS, 2002). Porém, o atendimento a estas necessidades tem sido aquém e desproporcional às demandas (BECHTEL, 1997). Cada vez mais surgem assentamentos urbanos deteriorados e degradados que figuram como um dos maiores desafios a serem enfrentados para a promoção do desenvolvimento sustentável e de uma melhor qualidade de vida.

No Brasil, o processo de urbanização das grandes cidades está mais relacionado ao crescimento urbano que ao próprio desenvolvimento. Como afirma Veiga (2005) ao tentar diferenciar crescimento econômico de desenvolvimento, enquanto interessa ao crescimento as questões relacionadas à quantidade, ao desenvolvimento interessa as questões de qualidade. Assim, no Brasil nós podemos afirmar que há em maior intensidade um crescimento urbano que um desenvolvimento urbano.

Com as discussões sobre sustentabilidade, no Brasil como em outros países em desenvolvimento, dado as condições precárias de grande parte das habitações, as questões de habitabilidade têm sido bastante discutidas, onde se considera que nestes países, o caminho da sustentabilidade passa, inevitavelmente, pela melhoria destas condições (RUEDA, 1997).

Nesta breve introdução notamos que qualidade de vida, desenvolvimento sustentável e as questões relativas aos assentamentos urbanos deteriorados estão relacionados de forma a compor um cenário de discussões muito amplo e bastante explorado por pesquisadores de diversas áreas. Dada a vasta literatura sobre estes temas faremos, a seguir, uma breve revisão focada nos estudos relacionados ao ambiente urbano para subsidiar a nossa discussão, mais adiante, sobre as necessidades de levar em consideração a opinião dos moradores no processo de avaliação do ambiente urbano.

\subsection{QUALIDADE DE VIDA}

Historicamente, o conceito de qualidade de vida (QV) começou a ser utilizado na década de 1960, porém, de forma mais enfática a partir da década seguinte. Este conceito surge como uma reação aos critérios economicistas e de quantidade que prevaleciam nos chamados informes sociais e estudos de nível de vida. A corrente economicista analisava o crescimento 
econômico das sociedades com base na evolução do respectivo Produto Interno Bruto (PIB), cuja medida corresponde ao montante de bens e serviços gerados, sendo, assim, um indicador da riqueza produzida e distribuída. Ela traduz de forma global o crescimento econômico, mas não contempla diversos aspectos fundamentais que permitem analisar o desenvolvimento de uma sociedade (RUEDA, 1997; SANTOS; MARTINS, 2002).

Para Rueda (1997) a maioria dos autores concebe a QV como uma construção complexa e multifatorial sobre a qual podem desenvolver-se algumas formas de medidas objetivas baseadas numa série de indicadores, mas onde a vivência do sujeito possui um peso específico importante.

Wilheim (2003), por exemplo, define QV como a sensação de bem-estar do indivíduo. Esta sensação depende de fatores objetivos e externos, assim como de fatores subjetivos e internos. Já para o próprio Rueda (1997), a QV como conceito é de definição imprecisa, o termo pertence a um universo ideológico e não tem sentido se não está relacionado com um sistema de valores. Gómez (2001), por sua vez, acredita que a definição da QV pode ser aproximada por uma supradefinição, que define a QV como um grau ótimo da satisfação das necessidades humanas, e por subdefinições de cada um de seus componentes e de cada um dos subcomponentes, que podem ser buscadas em estágios intermediários utilizando-se sistemas de indicadores e pela construção de um processo de articulação múltipla entre os mesmos.

Ainda segundo Gómez (2001), o significado da QV poderia ser enunciado como: quanto maior a interseção e a reciprocidade entre os aspectos objetivos e subjetivos, e a maior interseção e reciprocidade entre as dimensões dos componentes da vida humana, maior será o grau de otimização da QV.

Para Rueda (1997) analisar a QV exige conhecer como vivem os sujeitos, suas condições objetivas de existência e que expectativas de transformação destas condições desejam, e avaliar o grau de satisfação que se consegue.

Neste sentido, alguns autores identificam a QV em dimensões: física, social e emocional, por exemplo, outros propõem a construção da QV a partir de aspectos dicotômicos: materiais/imateriais, individuais/coletivos e objetivos/subjetivos (SANTOS; MARTINS, 2002), ou ainda como auto-implicação de dimensões, como Gómez (2001), que propõe a auto-implicação de três grandes dimensões ou áreas lógicas representadas sob uma forma triangular: a escala territorial sobre a qual se determina a qualidade ambiental, o bem estar 
sobre o qual se determina o nível de vida, e as interações sociais que determinam a identidade cultural (Figura 2).

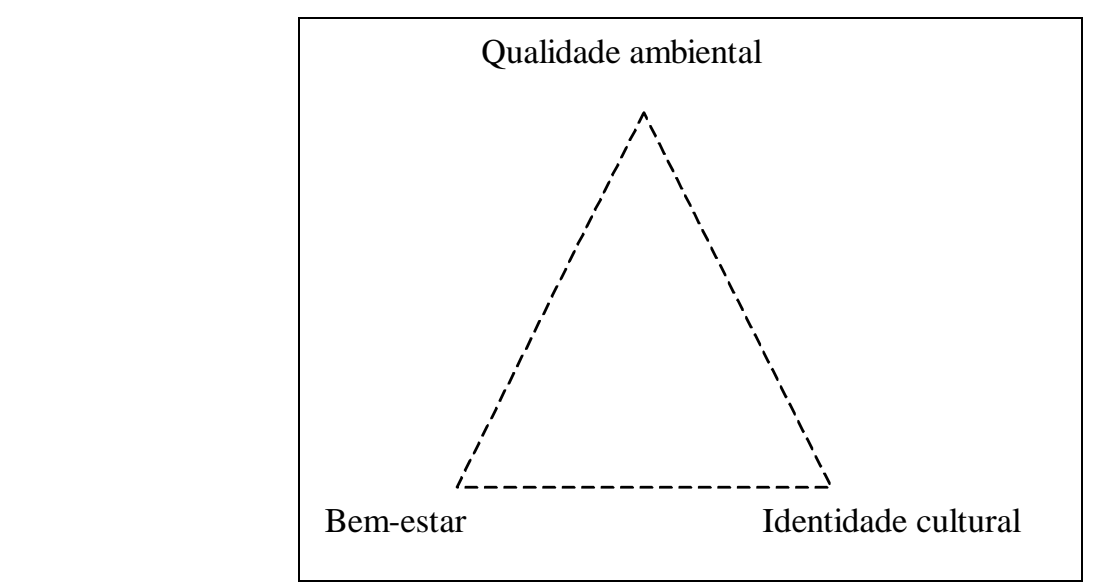

Figura 2: Qualidade de vida como auto-implicação de três grandes dimensões ou áreas lógicas Fonte: Gómez (2001, Não paginado)

Gómez (2001) defende que utilizando-se esse conceito de qualidade de vida incorpora-se a sustentabilidade ambiental e pode-se recuperar o sentido das necessidades culturais de identidade (apropriação, participação, sociabilidade).

Wilheim (2003), por sua vez, avalia a QV a partir de fatores distintos em dois setores: fatores mínimos e determinantes e os fatores de demanda. No setor dos fatores mínimos e determinantes estão as condições básicas de QV e a partir de cujo atendimento se estabelece a região de oportunidades do individuo. Estas condições básicas são: alimentação, saúde mental, segurança básica, renda de subsistência e instrução. Já no setor de demandas, assumese que estas sejam crescentes em função da afluência econômica, assim como em conseqüência da comunicação de massa a serviço de um padrão econômico que estimula o consumo (Figura 3).

Para Santos e Martins (2002) o conceito de qualidade de vida engloba diversos aspectos, que se interligam, e que vão desde as questões mais materiais, ligadas à satisfação das necessidades humanas básicas, até às questões imateriais (exemplos: a segurança e a participação cívica), desde aspectos objetivos até aspectos subjetivos, estes últimos relacionados com a percepção individual da qualidade de vida e do bem estar dos indivíduos, desde aspectos de índole mais individual até aspectos de índole mais coletiva. Estes três âmbitos de análise (materiais/imateriais, individuais/coletivos e objetivos/subjetivos) não são mutuamente exclusivos, pelo contrário, interligam-se de forma intensa. 


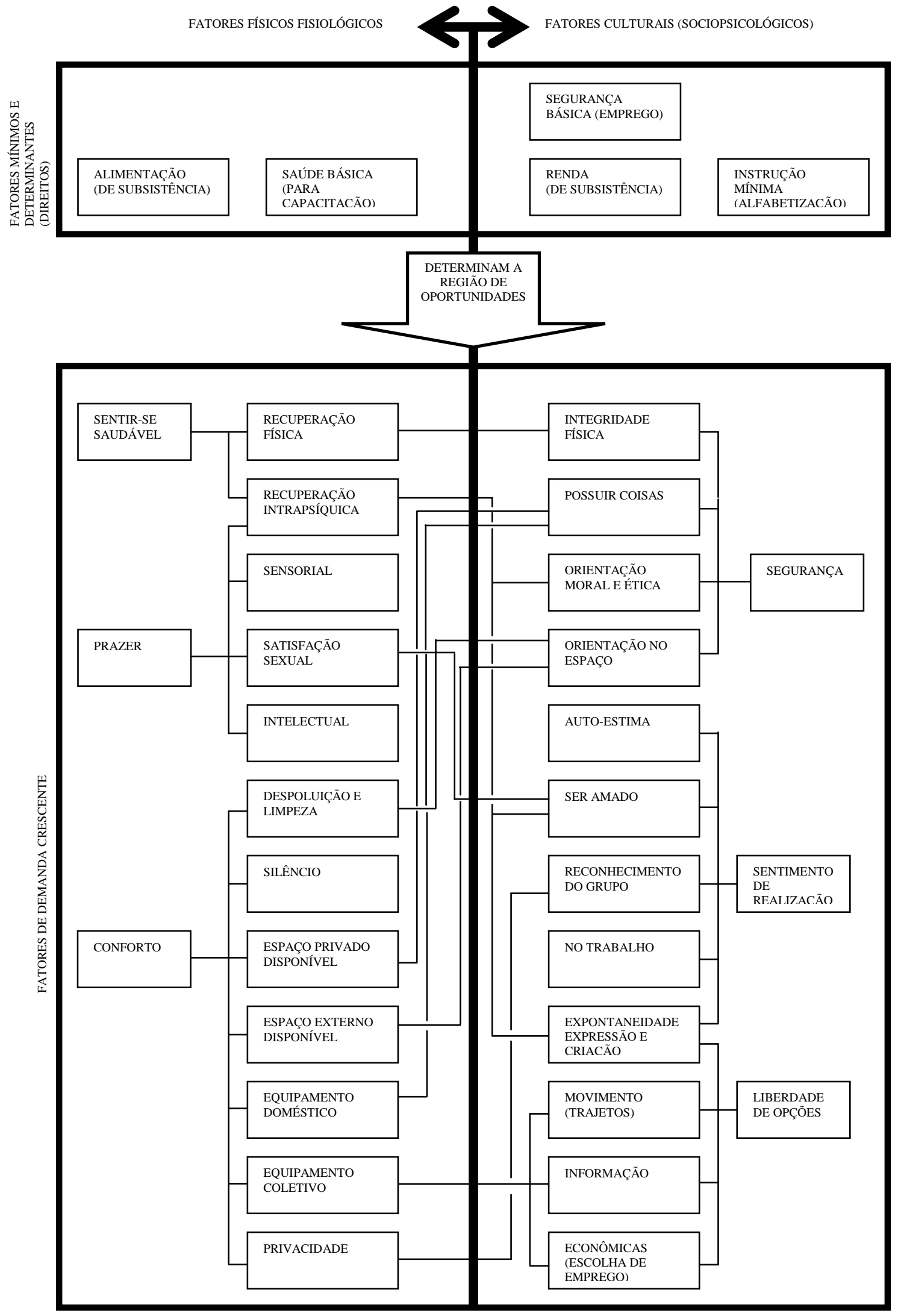

Figura 3: Fatores da QV segundo Wilheim Fonte: Wilheim (2003), p. 134 
Santos e Martins (2002) ressaltam também a importância de algumas questões consideradas por eles fundamentais na avaliação da QV que são a temporalidade (contexto social, político e cultural) e o espaço (acessibilidade e facilidade de utilização, mais ligados à questão do nível de satisfação da população utilizadora).

É importante ressaltar que os estudos sobre a QV têm sido focados em sua maioria em torno da realidade urbana. Gómez (2001) chega a afirmar que fenômeno urbano e qualidade de vida se superpõem e se retroalimentam ao ponto em que cada um deles é inexplicável sem a presença do outro.

Essa preocupação com a QV urbana pode ser entendida, pois ao mesmo tempo em que os centros urbanos ganham indiscutível protagonismo econômico e político, afirmando-se como espaços territoriais mais propícios à criação de riqueza, de emprego e a inovação, eles também são dotados de um conjunto significativo de aspectos negativos associados à sociedade atual, tais como a degradação ambiental e a exclusão social.

É importante ressaltar que na avaliação da QV nenhum dos aspectos pode ser considerado periférico ou menos importante. Contudo, muitas vezes não se pode, ou se deseja, avaliá-la na sua totalidade. Como exemplo, numa avaliação de programas de políticas para habitação, cujo objetivo geral também é a melhoria da qualidade de vida, torna-se mais conveniente avaliar aspectos parciais da QV, como a qualidade ambiental (QA) e o bem-estar promovido. É importante deixar claro que não estamos, neste caso, avaliando a QV, mas alguns de seus aspectos, considerados atingíveis pelo referido programa e que impactam sobre a ela.

Dada a complexidade e abrangência do conceito de QV focaremos esta tese em uma aproximação a este conceito, mais relacionada ao espaço físico, o conceito de qualidade ambiental, ou mais precisamente, qualidade ambiental urbana (QAU).

Uma definição proposta por Borja (1997) define a QAU como a qualidade referente às condições ambientais do meio urbano (natural e cultural), sendo resultante da ação do homem e repercutindo na sua qualidade de vida. A autora afirma ainda que a QAU é percebida de forma diferenciada por indivíduos e grupos de indivíduos em função de aspectos sócioculturais. Assim, cada grupo social tem demandas específicas em relação ao meio ambiente urbano, respaldadas em concepções de vida, desejos e necessidades culturalmente construídos. Esta definição é também compartilhada por Alva apud Borja (1997) que afirma que qualidade ambiental é percebida e qualificada em primeiro lugar numa dimensão pessoal, 
baseada em preferências individuais e familiares, que é forçada a se compor com valores sociais pelo comportamento coletivo e pela organização da comunidade.

As definições de QAU, acima citadas, possuem uma grande similaridade com as definições de QV apresentadas anteriormente e pode ser recuperada por meio das relações determinadas pela auto-implicação da Qualidade ambiental - Bem-estar da Figura 2. Ressaltamos que esta definição, se por um lado, se mostra bastante ampla e dependente do contexto, logo, com maior dificuldade de avaliação, por outro, nos permite avaliar as diversas dimensões da QAU, podendo-se incorporar as questões material/imaterial, objetivo/subjetivo e individual/coletivo discutidas por Santos e Martins (2002) para a QV.

Ressalta-se ainda, que nesta definição de QAU, além da idéia de qualidade de vida, está presente a noção de desenvolvimento sustentável, como atendimento das necessidades humanas, entendidas aqui como necessidades básicas e culturalmente construídas.

$\mathrm{O}$ atendimento destas necessidades nos leva a discussão dos modelos de desenvolvimento propostos. Neste sentido, as sociedades atuais encontram-se diante de um verdadeiro dilema onde, a partir de um modelo já estabelecido de desenvolvimento, que tem como principal meio, e talvez fim, o consumo, torna-se cada vez mais evidente a necessidade de mudança de paradigma, com base na constatação de que existem limites para o consumo e que o modo e a velocidade como temos utilizado os recursos naturais podem por em risco a própria existência do homem na Terra. Esta discussão tem sido o foco dos debates sobre desenvolvimento sustentável que discutiremos a seguir.

\subsection{DESENVOLVIMENTO SUSTENTÁVEL}

Até o início dos anos 1960, não se sentiu muito a necessidade de distinguir desenvolvimento de crescimento econômico, pois as poucas nações desenvolvidas eram as que haviam se tornado ricas pela industrialização. De outro lado, os países que haviam permanecido subdesenvolvidos eram os pobres, nos quais o processo de industrialização era incipiente ou nem havia começado (VEIGA, 2005).

A essa idéia de desenvolvimento como crescimento econômico e industrialização, adicione-se as idéias, a seguir, descritas por Bateson (1987), como dominantes em nossa sociedade desde a Revolução Industrial: 
- O homem contra o ambiente.

- O homem contra outros homens.

- O que importa é o indivíduo (ou a empresa individual).

- Podemos ter um controle unilateral sobre o ambiente e temos que nos esforçar para consegui-lo.

- O determinismo econômico é algo de sentido comum.

- A tecnologia e a especialização se encarregarão de consertar o resto.

O reflexo dessas idéias tem sido uma crise sócio-ambiental atual a qual estão relacionados diversos impactos negativos como a extinção de recursos naturais, a poluição do ambiente natural e conseqüente deterioração da qualidade de vida, a pobreza, a miséria, a má distribuição de renda, a devastação dos recursos naturais, entre outros, que ocorrem tanto em países desenvolvidos, como em desenvolvimento.

Esta crise sócio-ambiental fez surgir uma discussão acerca dos limites do crescimento e a conservação dos recursos necessários ao seu desenvolvimento, bem como acerca da construção de um novo modelo de desenvolvimento que equilibrasse estes dois elementos sem por em risco nenhum deles, muito menos, a própria existência do homem.

De acordo com Veiga (2005) existem três correntes de discussão sobre o que vem a ser desenvolvimento:

- desenvolvimento como crescimento econômico, que é considerada uma visão simplista, porém dominou a idéia de desenvolvimento por um longo período;

- desenvolvimento como ilusão, crença, mito, ou manipulação ideológica, que parte de uma visão mais antropológica e de uma discussão o papel do mito nas sociedades contemporâneas e;

- o chamado caminho do meio, que segundo o autor seria a alternativa mais difícil de explicar, e que de forma simplificada entende o desenvolvimento como crescimento econômico aliado a um projeto social subjacente.

As duas primeiras opções parecem ser descartadas atualmente: a primeira mostrou-se insuficiente e a segunda nos coloca diante da não necessidade de discussão do tema, mas sim de discutir o papel dos mitos na sociedade. A terceira opção busca associar o desenvolvimento ao crescimento econômico com desenvolvimento social e melhoria da qualidade de vida. Esta 
proposta se assemelha, em certo grau, ao que se convencionou chamar desenvolvimento sustentável. O desenvolvimento sustentável tornou-se um dos paradigmas mais discutidos desde o final do século XX.

A construção desse novo modelo vem sendo moldada desde o início da década de 1970, quando Ignacy Sachs, em 1973, sugeriu o termo ecodesenvolvimento, como termo de compromisso que tentava conciliar o aumento da produção com a preservação dos ecossistemas necessários para manter as condições de habitabilidade na Terra. $\mathrm{O}$ termo não se manteve por razões e interesses diversos, dando lugar, anos mais tarde, ao chamado desenvolvimento sustentável (BELLEN, 2005; NAREDO, 1997).

Embora esta discussão seja recente, Naredo (1997) identifica no século XVIII, com os fisiocratas, o possível embrião para as discussões atuais.Segundo o autor, naquela época já se discutia a questão de aumentar as riquezas renováveis sem desprezar os bens de capital.

Retomando a história recente, diversos momentos foram importantes para a construção desse modelo, o qual se convencionou chamar de desenvolvimento sustentável. Segundo Bellen (2005) alguns pontos importantes nesta discussão foram: o relatório sobre os limites do crescimento de 1972, seguido do surgimento do conceito, já mencionado, de ecodesenvolvimento em 1973, a Declaração de Cocoyok em 1974, a publicação do Relatório Nosso Futuro Comum de 1987 (ou Relatório Brutland como também é conhecido), culminando com a Conferência da Organização das Nações Unidas sobre Meio Ambiente e Desenvolvimento em 1992, a Rio 92 e a mais recente Conferência Rio+10, em Johannesburgo.

Enquanto definição, o desenvolvimento sustentável é impreciso e ambíguo, sendo sua definição mais conhecida a proposta no Relatório Nosso Futuro Comum, da Organização das Nações Unidas. Neste relatório o desenvolvimento sustentável é entendido como "aquele que permite satisfazer nossas necessidades atuais sem comprometer a capacidade de satisfazer as necessidades das gerações futuras" (WORLD COMMISSION ON ENVIRONMENT AND DEVELOPMENT, 1987, p. 43, tradução do autor).

Esta definição tem recebido diversas críticas, tanto por ser pouco operativa, quanto pela sua ambigüidade (NAREDO, 1997; VEIGA, 2005). Veiga (2005) admite que essa ambigüidade do termo pode ser entendida como uma opção deliberada de uma estratégia de institucionalização da problemática ambiental no âmbito das organizações internacionais e dos governos nacionais. Naredo (1997), apesar das críticas, vê justamente nessa ambigüidade 
o responsável pelo êxito do uso do termo, alertando, porém para a possibilidade desta mesma ambigüidade minar o êxito político que o termo conseguiu inicialmente.

Com relação ao fato de ser uma definição pouco operativa, isso não tem impedido que ações sejam levadas a cabo. Como afirma Acselrad (2001), a noção de sustentabilidade está submetida à lógica das práticas, articula-se aos efeitos sociais desejados, a funções práticas que o discurso pretende tornar realidade objetiva. Neste sentido, a sustentabilidade ganhou bastante espaço no campo prático, onde diversas ações têm sido promovidas na tentativa de se alcançar este novo modelo, inclusive as ações de recuperação de assentamentos urbanos.

Mesmo com todas as incertezas acerca do que seria esse novo modelo, acredita-se que ele seja multidimensional e não esteja apenas relacionado ao crescimento econômico, mas sim, à liberdade de escolha e principalmente ao contexto em que poderá ser implementado (GRIGOLETTI; SATTLER, 2003; SACHS, 2007). De fato, como exemplificam Grigoletti e Sattler (2003) dependendo do contexto social que se propõe a seguir o novo paradigma, algumas das dimensões terão maior prioridade sobre outras. Para países desenvolvidos, questões sociais, em geral, estão bem resolvidas e não são obstáculos à adoção de paradigmas ambientais, por exemplo. Já em países subdesenvolvidos ou em desenvolvimento, a dimensão social não poderá ser secundária.

O desafio de definir um modelo de desenvolvimento que compatibilize crescimento econômico, conservação dos recursos naturais e um projeto de sociedade produziu uma série de definições que passamos a discutir.

Como já afirmado, a definição comumente aceita é aquela apresentada no Relatório Brutland, porém outras organizações e pesquisadores também buscaram dar sua contribuição nesta área. A definição dada pelo Conselho Internacional de Iniciativas Ambientais Locais (ICLEI), entende o desenvolvimento sustentável como aquele que oferece serviços ambientais, sociais e econômicos básicos a todos os membros de uma comunidade, sem pôr em perigo a viabilidade dos entornos naturais, construídos e sociais de que depende o oferecimento destes serviços (ICLEI, 1995). Nesta definição a preocupação com o entorno construído já se torna evidente, de forma a entendê-lo como parte integrante do meio ambiente como um todo.

Já na definição de ecodesenvolvimento de Sachs (2007) todo esforço de planejamento do desenvolvimento precisa levar em conta, simultaneamente, as seguintes dimensões do conceito de sustentabilidade: social, econômica, ecológica, espacial e cultural. O autor ressalta 
que a sustentabilidade social vem em primeiro lugar e ainda, sobrepõe-se a própria finalidade do desenvolvimento.

Buscando diferenciar este novo modelo, Veiga (2005), afirma que enquanto o crescimento é uma mudança quantitativa, o desenvolvimento é uma mudança qualitativa. Este enfoque qualitativo também é visto na abordagem da Organization for Economic Co-operation and Development (OECD) onde é ressaltado que enquanto muitas análises econômicas têm tentado associar o desenvolvimento com o crescimento da produção ou consumo real per capita, e enfocam as condições de durabilidade do crescimento econômico, tais como preservação da estabilidade financeira e um baixo e estável ambiente inflacionário, interessa ao desenvolvimento sustentável o enfoque da qualidade do crescimento econômico, tanto quanto a quantidade (OECD, 1999).

No ambiente urbano, este novo modelo tem influenciado e justificado diversas ações, notadamente em assentamentos deteriorados e degradados, fazendo com que o objetivo da sustentabilidade seja confundido em muitos casos com o de habitabilidade, ou seja, com a pretensão de manter a qualidade de vida nestes sistemas (RUEDA, 1997). Isto pode ser explicado pelas diferentes necessidades locais como já mencionado, porém cabe aqui destacar que o conceito de sustentabilidade é mais amplo, pois é multidimensional e abrange outros aspectos como sociais, econômicos e ambientais.

Desta forma, entendemos que a melhoria das condições de habitabilidade do ambiente urbano torna-se imprescindível na busca do desenvolvimento, com crescimento econômico, preservação ambiental e um projeto social associado, ou seja, mais sustentável.

Por fim, o desenvolvimento sustentável é considerado aqui, como um modelo a ser buscado, um processo em construção, e que esteja de acordo com as necessidades e expectativas de cada sociedade no sentido de garantir o seu atendimento em todas as dimensões, sem por em perigo os recursos naturais necessários para este atendimento, atual e futuro. É neste sentido que buscamos entender as necessidades e expectativas por meio da opinião dos moradores em ações de recuperação do ambiente urbano, considerando este entendimento como um passo importante para otimizar os resultados de intervenções futuras, alcançando assim uma maior identificação entre o morador e o seu espaço e por fim facilitando a sua manutenção, como contribuição para a sustentabilidade do ambiente urbano. 
A seguir, passamos para uma breve discussão da questão habitacional no Brasil, relacionada aos assentamentos urbanos deteriorados e algumas ações que têm sido empreendidas para o seu melhoramento.

\subsection{ASSENTAMENTOS URBANOS PRECÁRIOS E A SUA RECUPERAÇÃO}

O processo de urbanização é uma realidade constatada mundialmente. No Brasil, este processo deu-se praticamente no século $\mathrm{XX}$ sob a influência de diversos fatores, como a regulamentação do trabalho urbano, incentivo à industrialização e construção de infraestrutura industrial, entre outras medidas, que reforçaram o movimento migratório campocidade (MARICATO, 2003).

No Gráfico 1 podemos ver que a partir de meados dos anos 1960 a população urbana no Brasil, que já seguia uma trajetória ascendente ao contrário da população rural, supera esta última.

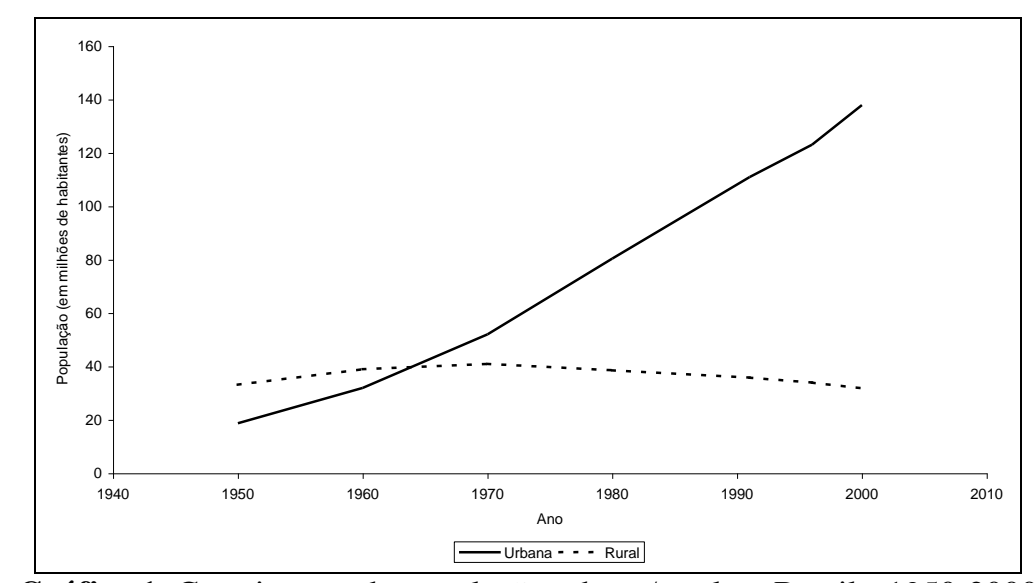

Gráfico 1: Crescimento da população urbana/rural no Brasil - 1950-2000 Fonte: Elaborado a partir de dados do IBGE disponíveis em http://www.ibge.gov.br

Em termos percentuais, a proporção urbano/rural que era de aproximadamente $36 \%$ - $64 \%$ em 1950 praticamente se inverte em 1980 com $68 \%$ - 32\%, chegando a atingir no último censo cerca de $80 \%$ da população brasileira vivendo em áreas urbanas (Gráfico 2). 


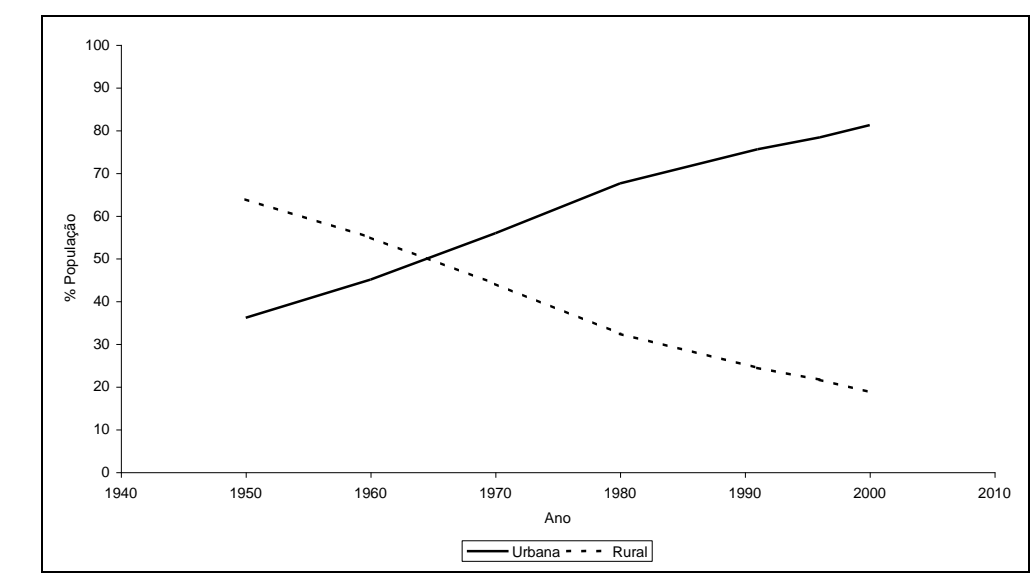

Gráfico 2: Percentuais de população urbana e rural no Brasil - 1950-2000

Fonte: Elaborado a partir de dados do IBGE disponíveis em http://www.ibge.gov.br

Muito embora a associação entre urbanização e desenvolvimento seja freqüente, no Brasil, bem como em outros países em desenvolvimento, o resultado desse processo tem sido cidades onde o acesso a terra e aos bens e serviços urbanos se dá de forma desigual. Abramo (2003) coloca a questão do acesso à terra urbana como uma verdadeira barreira social nas grandes cidades latino-americanas e destaca que na maioria delas, o acesso à terra se dá por meio da informalidade fundiária e/ou urbanística obedecendo à três grandes lógicas da ação social: a lógica de Estado, a de mercado e a da necessidade.

De fato, como já citado, nas cidades de países em desenvolvimento, há uma necessidade urgente de acomodar o rápido crescimento, prover infra-estrutura essencial, lidar com a deterioração física do meio ambiente, e melhorar as oportunidades de abrigo, especialmente para os pobres (UNCHS, 2002).

A idéia de urbanização associada ao desenvolvimento e melhores condições de vida gerou um gigantesco movimento de construção urbana, necessário para acomodar a grande quantidade de pessoas que se dirigiam às cidades. Assim, as cidades que no início pareciam ser a salvação, onde o futuro já havia chegado, onde havia emprego pleno, assistência social providenciada pelo Estado, lazer e novas oportunidades para os filhos, no final do século XX, têm sua imagem associada à violência, poluição das águas e do ar, criança desamparada, tráfego caótico, enchentes (MARICATO, 2003).

Historicamente, o Estado, de alguma forma, tentou prover habitação e serviços para parte dessa população. Taschner (1997) identificou sete grandes períodos na política habitacional brasileira, que vão desde 1831 durante a sociedade escravocrata, onde a solução habitacional para a classe trabalhadora escrava era a senzala; até o período do Governo Fernando Henrique 
Cardoso, na tentativa de montar uma nova política de habitação popular, baseada em um novo sistema de captação de recursos, o Sistema Financeiro Imobiliário (SFI), passando pelo período de criação e atuação do BNH, de 1965 a 1985, período também marcado pelo regime militar no Brasil. Este período merece destaque pela construção em massa de habitações em conjuntos habitacionais, encerrando-se em 1986 com a falência e extinção do BNH.

Além da construção de novas moradias, o BNH também promoveu uma série de remoções e transferências das populações de favelas e outros assentamentos precários bem como, posteriormente, algumas obras de urbanizações de favelas.

Há uma série de críticas à atuação do $\mathrm{BNH}$, o qual caracterizou-se ao longo de sua duração pelo afastamento e não atendimento às populações previstas, como também pela baixa qualidade dos bens oferecidos (ROLNIK, 1997; TASCHNER, 1997).

Cabe salientar também que houve uma grande produção de habitação no período que antecedeu a criação do BNH, por meio de diversos institutos e agências, como os institutos de aposentadorias e pensões (IAP's). Esta produção foi pesquisada em profundidade por Bonduki (1998).

Já uma análise representativa da produção informal, do tipo favela, pode ser vista em Valladares (2005), que reúne a sua experiência sobre as favelas, partindo dos anos 1930, com o processo de favelização no Rio de Janeiro até os dias atuais com os programas de urbanização de favelas.

Apesar dos esforços, a tentativa do Estado de prover habitação e serviços não tem sido suficiente para acompanhar a demanda por estes bens, não conseguindo evitar o movimento de invasões e construções informais, principalmente nas grandes cidades brasileiras (ESPIRITO SANTO, 2000; GORDILHO-SOUZA， 1990; SANTANA， 1987; VALLADARES, 2005).

Segundo Maricato (2003), a falta de alternativas habitacionais é evidentemente o motor que faz o pano de fundo dessa dinâmica de ocupação ilegal e predatória de terra urbana. Com relação às ocupações em áreas de proteção ambiental, a autora ressalta que embora a ocupação pela população pobre e o progressivo aterramento de mangues nas cidades litorâneas brasileiras seja praticamente uma regra, não é somente a população pobre a responsável pela degradação ambiental. As classes de renda mais altas, bem como o poder público, muitas vezes foram os responsáveis por ocupações nestas áreas. 
Maricato (2003) afirma ainda que é notável a tolerância que o Estado brasileiro têm manifestado em relação às ocupações ilegais em terra urbana. Aparentemente constata-se que é admitido o direito à ocupação, mas não o direito à cidade. $\mathrm{O}$ resultado desse processo são cidades desiguais a ponto de Taschner (2003) afirmar que uma marca da nossa sociedade é a desigualdade, e esta característica reflete-se tanto no diferencial entre regiões, quanto entre cidades, como também dentro do espaço intra-urbano, onde a segregação é uma presença constante.

Para se ter uma idéia da ocupação informal do tipo favela, Maricato (2000) reuniu dados do LABHAB/FAUUSP estimados para algumas cidades brasileiras: Rio de Janeiro, 20\%; São Paulo, 22\%; Belo Horizonte, 20\%; Goiânia 13,3\%; Salvador, 30\%; Recife, 46\%; Fortaleza, $31 \%$.

Em estudo realizado por Gordilho-Souza (1999), especificamente sobre Salvador, foi revelada uma realidade alarmante. Salvador possuía em 1991 cerca de $60 \%$ da população morando numa cidade informal, composta de invasões, loteamentos clandestinos e outros modos informais de parcelamento e uso do solo. Cabe, no entanto salientar, que o significado de informalidade aqui não é sinônimo de precariedade. Embora, os assentamentos precários em geral sejam informais, a informalidade não se restringe a esta forma de ocupação. De fato, grande parcela da população nas cidades brasileira reside informalmente, quer seja pela ilegalidade da posse da terra ou pela falta de regularização, quer seja pelo não atendimento aos requisitos urbanísticos, que também caracteriza uma situação de informalidade.

Já outro estudo promovido pelo Ministério das Cidades em alguns municípios selecionados, estimou-se em cerca de $14 \%$ da população destes municípios, a população residente em assentamentos precários, equivalente a mais de 12 milhões de habitantes residindo sem as devidas condições de moradia e saneamento (SECRETARIA NACIONAL DE HABITAÇÃO DO MINISTÉRIO DAS CIDADES; CENTRO DE ESTUDOS DA METRÓPOLE, [2007?]).

Estes dados apenas confirmam o quadro apresentado no relatório da UNCHS (2002) ou nas afirmações de BECHTEL (1997) e SALAT (2006) sobre a forma de crescimento das cidades em países em desenvolvimento e geração de demandas em descompasso com o atendimento das mesmas.

Porém esta forma de crescimento não apresenta somente aspectos negativos. Aldrich e Sandhu (1995) vêem nessa forma de ocupação (autoconstrução informal) uma possível contribuição para a economia formal, e talvez mundial, pelo fato de que a construção de novas 
moradias nesta modalidade não requer grandes quantidades de capital, sendo assim uma forma de provisão habitacional ambientalmente insustentável, porém, com aspectos econômicos bem instigantes.

O estudioso Turner (1968) já levantava a discussão ao comparar conjuntos habitacionais e assentamentos informais, mostraram-se problemas - favelas, mocambos, alagados etc. que ele considerava soluções e mostraram-se soluções - conjuntos de habitações de baixo custo que o autor chamava problemas. De fato, os conjuntos habitacionais de periferia mostraram ser insuficientes para solucionar o problema habitacional, porém, as ocupações informais também não conseguem suprir estas carências, principalmente quando consideramos a moradia além da unidade habitacional.

Para a população, no entanto, a informalidade, ou ilegalidade da ocupação, apresenta algumas vantagens, dentre as quais a de tornar a moradia mais barata, pela exclusão do preço do terreno, seguida de outras características como a possibilidade de um crescimento vertical, e conseqüente aluguel de cômodos, isenção de impostos, taxas e licenças que oneram o custo da habitação em outras áreas.

Com seus prós e contras a autoconstrução acabou sendo incorporada aos programas governamentais e atualmente pode ser vista em alguns programas de mutirão (BONDUKI, 1997) e em projetos de urbanização de favelas (MORAES et al., 2002).

Atualmente, as formas de ação governamental no ambiente urbano são as mais variadas (KEIVANI; WERNA, 2001), desde a construção de moradias em regime de mutirão às urbanizações, ou requalificações, do espaço urbano, cada vez mais atreladas a projetos em outras áreas como geração de emprego e renda e educação ambiental. Estas ações têm demandado uma grande mobilização de recursos, tanto financeiros como humanos. O que também tem gerado uma preocupação quanto aos resultados obtidos. As avaliações críticas, que vinham sendo desenvolvidas, quase que exclusivamente, pelas universidades e institutos de pesquisas, cada vez mais têm sido realizadas, também, pelos próprios órgãos executores ou financiadores.

Dentre os estudos de avaliação recentes, podemos citar o trabalho do Instituto Brasileiro de Administração Municipal (IBAM) (IBAM, 2002), que dentre as diversas considerações e conclusões apresentadas destacamos: 
- na implementação dos diversos programas tem sido exigida uma interdisciplinaridade que tem modificado a estruturação dos órgãos promotores, de um modelo vertical (centralizado) para um modelo horizontal (descentralizado);

- em função dessa descentralização, tem ocorrido uma maior articulação entre os diversos setores envolvidos;

- tem-se buscado padrões alternativos, mais adequados à cidade informal e;

- tem-se buscado também incorporar questões subjetivas, como a elevação da autoestima, enquanto fator que facilita a permanência da população nos assentamentos recuperados, evitando assim a expulsão branca e a conseqüente formação de novos assentamentos informais.

Atualmente, encontra-se em desenvolvimento o Programa de Aceleração do Crescimento (PAC) do Governo Federal, que possui três eixos de infra-estrutura: logística, energética e social e urbana. No eixo de infra-estrutura social e urbana destaca-se o PAC - Urbanização de Favelas. Os seu alvo são as 12 Regiões Metropolitanas, as capitais e os municípios com mais de 150 mil habitantes. Nestas áreas foram selecionadas 192 propostas que beneficiam 157 municípios. As diretrizes gerais para seleção dos projetos foram: (i) projetos de grande porte com impacto na articulação e integração do território; (ii) recuperação ambiental; (iii) eliminação de gargalos da infra-estrutura logística (ocupações em áreas de aeroportos, portos e ferrovias); (iv) prevenção/mitigação do impacto de grandes instalações de infra-estrutura nacional e; (v) complementação de obras já iniciadas.. (SECRETARIA NACIONAL DE HABITAÇÃO DO MINISTÉRIO DAS CIDADES, [2007?]).

Para Abiko (2003) a recuperação dos assentamentos degradados representa um desafio para os técnicos e para suas instituições, quer sejam elas as prefeituras, órgãos governamentais, empresas estatais ou organizações não-governamentais. $\mathrm{O}$ autor afirma ainda que já existem no país inúmeras experiências procurando recuperar estes assentamentos, porém conhece-se pouco a respeito do desempenho de tais intervenções. Logo, faz-se necessário uma avaliação que leve em consideração os diferentes aspectos que ações deste tipo despertam, avaliando-se os impactos tanto quantitativos quanto qualitativos. 


\section{MODELAGEM E MENSURAÇÃO DE DADOS}

Neste capítulo trataremos de algumas questões relativas ao processo de modelagem da realidade que estão relacionadas à proposta de utilização da Lógica Fuzzy para a análise de dados de opinião dos moradores.

As questões tratadas a seguir, como as diferentes abordagens, as formas de registro e de medidas, fazem parte de uma literatura básica em disciplinas de modelagem e análise de dados, que muitas vezes não são discutidas. Isto pode levar o pesquisador a uma repetição e adaptação de modelos sem as devidas considerações, conduzindo-o também a conclusões equivocadas. Antes de tratarmos da questão das escalas de mensuração, cujo entendimento das aplicações e limitações torna-se fundamental para a justificativa deste projeto, faremos um resumo de algumas características dos modelos e das diferentes abordagens que podem ser dadas a um determinado fenômeno.

\subsection{MODELAGEM}

Para Goldbarg e Luna (2000), a noção intuitiva de modelo se apóia no desejo do homem de entender o mundo que o cerca, nas imposições de sobrevivência e na necessidade de conquistar o domínio de seu meio ambiente. Para estes autores, o fenômeno de modelagem faz parte da busca de uma visão bem estruturada da realidade. Eles afirmam que há uma diferença existente entre o modelo, enquanto representação substitutiva da realidade e o processo de modelagem, que vai além da idéia de simples representação, introduzindo uma idéia de simulação da realidade. Destacamos que um modelo não é uma substituição da realidade, mas sim um veículo para uma visão bem estruturada desta realidade. Logo, todo modelo possui suas simplificações e, portanto limitações relacionadas a sua capacidade de representação do fenômeno.

São exemplos comuns de modelos as fotografias, as pinturas, as maquetes, os mapas, as plantas, os gráficos e as equações matemáticas. Há uma variedade ilimitada de representações da realidade, veja por exemplo as duas representações de uma mesma realidade, feitas por um 
pintor e um fotógrafo (Figura 4). Embora sejam diferentes, ambas são verdadeiras e se prestam as suas finalidades.
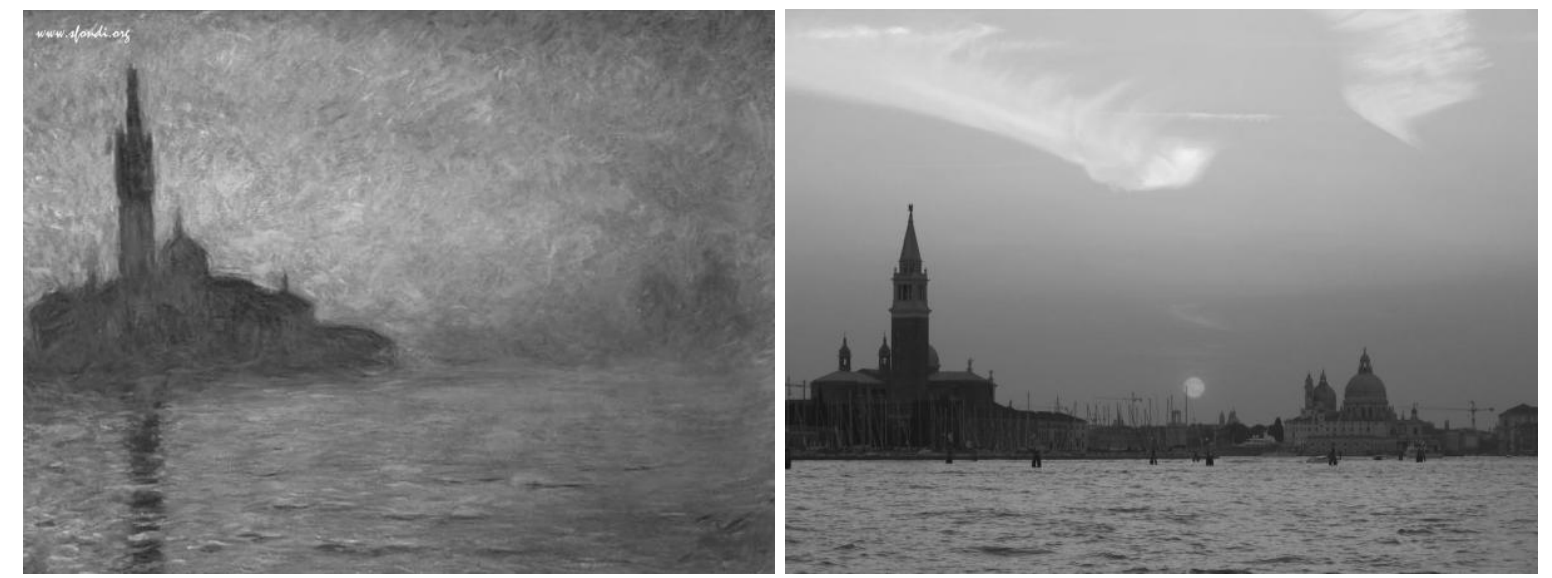

Figura 4: Tramonto em Veneza, à esquerda representação do pintor Claude Monet, à direita fotografia disponível na internet

Podemos então, definir modelos como representações da realidade que preservam, para determinadas situações e enfoques, uma equivalência adequada (GOLDBARG; LUNA, 2000).

Em relação a modelagem matemáticas, Goldbarg e Luna (2000) descrevem como características desejáveis dos modelos o poder de representatividade, relacionado a equivalência entre modelo e realidade e a sua capacidade de simplificação, ou factibilidade operacional, bem como as habilidade necessárias que são o foco holístico, o tratamento eclético das dimensões da análise e a tradução adequada. O modelo em seu processo de tradução contextual deve ser capaz de identificar os elementos fundamentais da questão e transportá-los para uma representação capaz de ser manipulada por artifícios ou métodos de solução. Esta tradução está relacionada com a capacidade de simplificação o que nos leva a discutir o conceito de complexidade.

$\mathrm{Na}$ análise da complexidade de modelos, os autores propõem três dimensões: meio ambiente, domínio e dinâmica (Figura 5) e, definem que um modelo é simples quando é pouco influenciado pelas variações em seu meio ambiente (meio ambiente); é estruturalmente estável, homogêneo e possui poucas variáveis (domínio) e; possui comportamento facilmente previsível (dinâmica). 


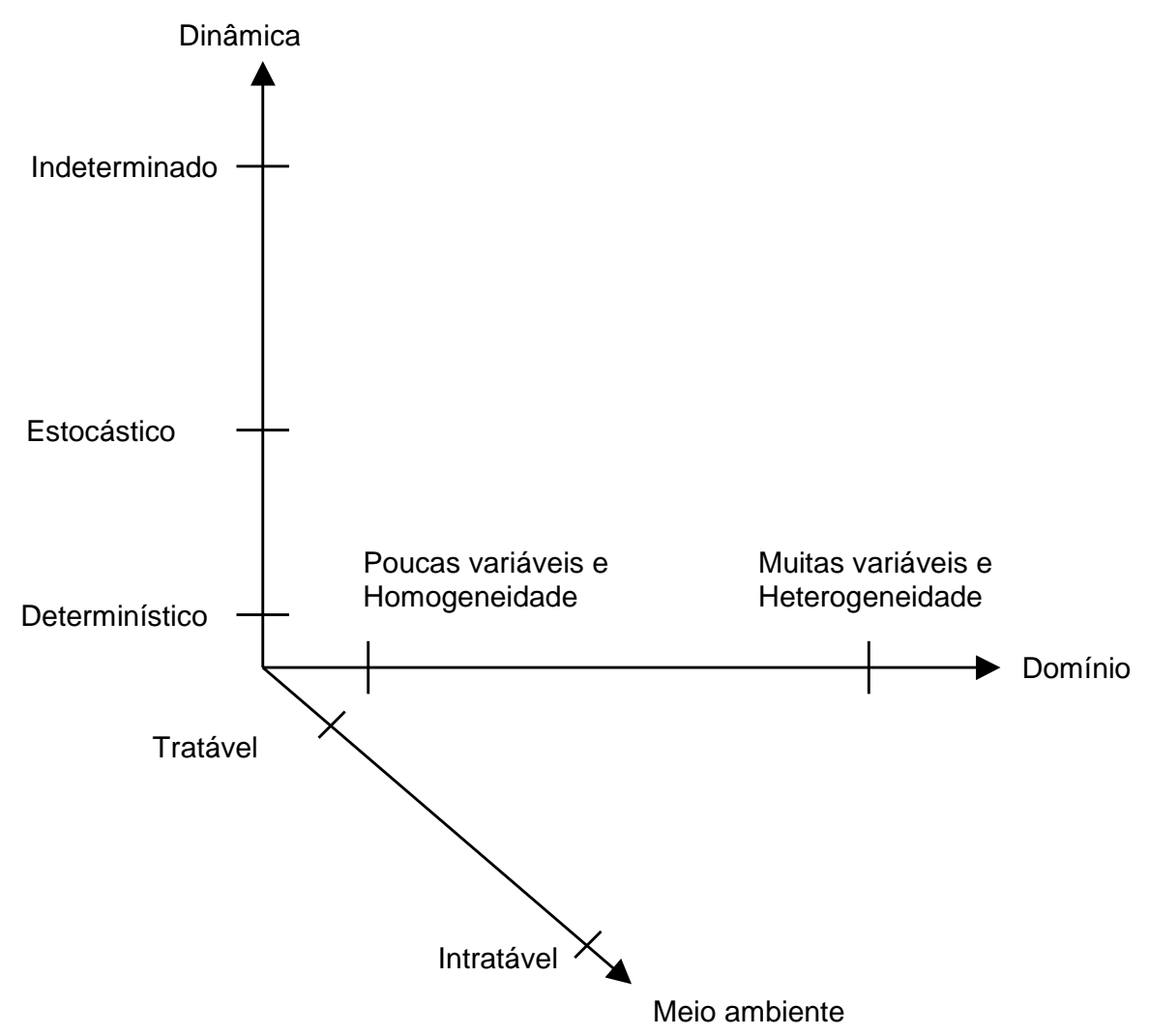

Figura 5: Dimensões da complexidade de modelos Fonte: adaptado de Goldbarg e Luna (2000)

Note que há classificações em cada dimensão e que a complexidade do modelo aumenta com o distanciamento da origem dos eixos. Devido a sua relevância para esta pesquisa, discutiremos a seguir as categorias de dinâmica dos modelos, definidas na Figura 5 como determinística, estocástica e indeterminada, as quais chamaremos de abordagens e adicionaremos uma nova categoria, a abordagem fuzzy, que como veremos, busca modelar conceitos que são vagos, incertos ou mal definidos, presentes na linguagem humana.

\subsection{ABORDAGENS DETERMINÍSTICA, ESTOCÁSTICA E FUZZY}

Conforme já afirmamos, de acordo com a dinâmica do modelo, inicialmente duas abordagens são propostas e comumente conhecidas: a determinística e a estocástica.

Segundo Trzesniak (1998), podemos diferenciar estas abordagens considerando a forma como as relações entre causa e efeitos são modeladas. Pertencem à categoria das determinísticas aquelas em que causa e efeito estão ligados diretamente: a presença (ou uma variação) da 
primeira necessariamente implica o surgimento (ou uma alteração) no último, freqüentemente obedecendo a uma lei matemática conhecida. Já no caso das estocásticas, a vinculação entre causa e efeito torna-se indireta, a presença (ou uma variação) da primeira reflete-se não no efeito, mas na probabilidade de ele surgir (ou se modificar).

Podemos afirmar que a suposição de relação de casualidade é o que diferencia a abordagem determinística da abordagem estocástica, ou seja, enquanto na abordagem determinística trata os fenômenos de forma certa, onde as conclusões são admitidas como inevitáveis e bem definidas, admite-se na abordagem estocástica que existem incertezas nestas afirmações, sob a forma da casualidade, ou eventualidade.

Trzesniak (1998) exemplifica esta diferença utilizando as relações entre o fumo e certos tipos de câncer: tal relação existe, mas não é determinística, no sentido de que não está assegurado nem que todos os fumantes irão contrair a moléstia, nem que um não-fumante não a contrairá. Fumar não traz a doença como conseqüência necessária, mas seguramente aumenta a probabilidade de que ela apareça. Além disso, quanto maior a quantidade de fumo consumido, mais a probabilidade crescerá, podendo até, como no caso determinístico, existir uma lei matemática aplicável. Ela, porém, não estará relacionando a causa ao efeito, mas à probabilidade de ele ocorrer.

A incerteza introduzida pela abordagem estocástica está relacionada à probabilidade de ocorrência de um determinado evento. Contudo, existem outros tipos de incerteza que não são considerados nesta abordagem. De fato, incertezas relacionadas a vagueza ou imprecisão de conceitos são modelados utilizando-se o que convencionou-se chamar de Lógica Fuzzy.

A Lógica Fuzzy surge com a finalidade de processar as informações subjetivas, de natureza vaga e incerta, que encontramos na linguagem natural dos seres humanos. Ela foi proposta em 1965 pelo Prof. Lotfi A. Zadeh, da Universidade da Califórnia, em Berkeley (ZADEH, 1965) e desde então tem sido utilizada em diversas áreas, mas principalmente nas áreas de automação e controle.

Adiantamos aqui a motivação para a não tradução do termo fuzzy. Visto que ele tem sido traduzido como nebuloso ou difuso, e que estes adjetivos não conseguem esgotar o seu real significado, restringindo-o, preferimos manter o adjetivo em sua língua original.

Já a expressão "Lógica Fuzzy", tem sido utilizada em dois sentidos: num sentido restrito quando se refere a um processo de inferência, ou seja, tal qual a Lógica Booleana, e num sentido amplo quando se refere a um conjunto de métodos baseados na Teoria dos Conjuntos 
Fuzzy, englobando também Lógica Fuzzy no sentido restrito (DVORAK et al., 2003). É no sentido amplo que buscaremos abordar os problemas de avaliação com dados qualitativos.

Enquanto a abordagem estocástica trata da incerteza como aleatoriedade, avaliando se um evento ocorrerá, a Lógica Fuzzy trata a incerteza não avaliando se um evento ocorrerá, mas sim o quanto ele ocorre ou ocorrerá (CORNELISSEN et al., 2001).

É importante salientar que estas abordagens não são excludentes, pelo contrário, podem ser complementares, visto que tratam diferentes facetas do fenômeno em análise (Figura 6).

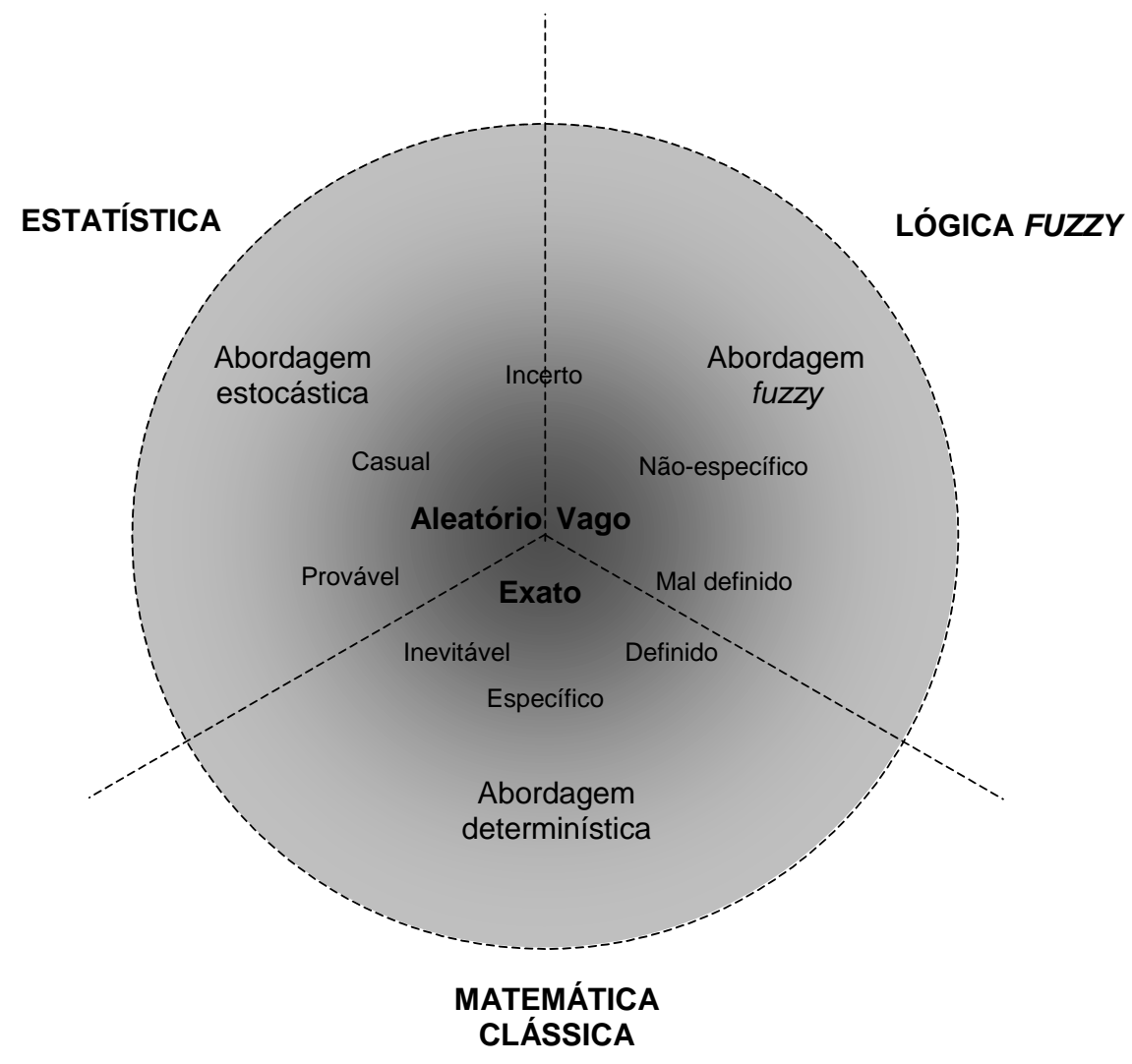

Figura 6: Dinâmicas/abordagens dos modelos Fonte:adaptado de Cheng (2001)

\subsection{DADOS, VARIÁVEIS E ESCALAS DE MENSURAÇÃO}

Dados, variáveis e escalas são conceitos com que o pesquisador tem que lidar freqüentemente e que por vezes são confundidos. Este trinômio forma a base de apoio da maioria das pesquisas em qualquer área do conhecimento

Dado, segundo o dicionário Houaiss on-line, é aquilo que se conhece e a partir do que se inicia a solução de um problema, a formulação de um juízo, o desenvolvimento de um 
raciocínio; resultado de investigação, cálculo ou pesquisa; aspecto característico que resulta da natureza, estado ou condição de alguma coisa; informação relativa a um indivíduo, capaz de identificá-lo; elemento inicial de qualquer ato de conhecimento (uma impressão sensível, um axioma, um princípio lógico etc.), apresentado de forma direta e imediata à consciência, e que servirá de base ou pressuposto no processo cognitivo. Ou seja, é a observação captada sobre o fenômeno em análise que serve como ponto de partida de uma pesquisa, o registro.

Geralmente os dados podem ser classificados em dois tipos: não-métricos (qualitativos) e métricos (quantitativos). Os dados não-métricos são atributos, características, ou propriedades categóricas que identificam ou descrevem um objeto. Eles descrevem diferenças no grupo ou classe por meio da indicação da presença ou ausência de uma determinada característica ou propriedade. Por exemplo, sexo (masculino/feminino), religião (católico/protestante/outros), escolaridade (fundamental/segundo grau/superior) e satisfação (satisfeito/insatisfeito). Já os dados métricos são obtidos quando os objetos podem ser identificados como diferentes em uma quantidade ou grau. Essas medidas refletem distância ou quantidade relativa, como exemplo temperatura, massa e volume (HAIR et al., 1995).

Daí decorre a definição e classificação de um outro conceito, o de variável. Segundo Pereira (2001), as variáveis são o agrupamento das medidas repetidas de um dado objeto de estudo, realizadas em diferentes unidades de observação.

A classificação feita para os dados pode ser estendida para as variáveis, ou seja, métricas e não-métricas. A noção de medida nos remete a outro conceito importante no processo de pesquisa, o conceito de escala de mensuração. Uma escala é uma forma particular de atribuição de números ou símbolos para medir alguma coisa. Em geral as escalas são divididas em quatro níveis de mensuração, do mais baixo ao mais alto nível de precisão de medida em: nominal, ordinal, intervalar e de razão. As escalas nominal e ordinal são classificadas por Hair et al. (1995) como não-métricas (qualitativas) e a intervalar e de razão como métricas (quantitativas).

Escalas nominais, também conhecidas como escalas categóricas, fornecem o número de ocorrências em cada classe ou categoria da variável estudada. Portanto, os números ou símbolos atribuídos aos objetos são apenas códigos e não têm significado quantitativo, apenas indicam a presença ou a ausência do atributo ou característica sob investigação. Exemplos: sexo do indivíduo (masculino/feminino), religião (católico/protestante/outro), ou partido político. 
Já nas escalas ordinais as variáveis podem ser ordenadas ou ranqueadas em relação à quantidade do atributo possuído. Cada subclasse pode ser comparada com outra em termos de um relação "maior que" ou "menor que". Números utilizados em escalas ordinais são nãoquantitativos, porque eles indicam somente posições relativas em uma série ordenada. São exemplos de dados ordinais: grau de escolaridade (fundamental/segundo grau/superior), satisfação (insatisfeito/pouco satisfeito/muito satisfeito) e conforto (desconfortável/confortável).

As escalas ordinais estão num nível superior de mensuração em relação às escalas nominais, pois, enquanto na escala nominal não existe qualquer relação de ordem, na escala ordinal as medidas podem ser comparadas em termos de maior ou menor que. Cabe destacar, no entanto que, embora as subclasses de uma escala ordinal sejam ordenadas, a distância entre eles não pode ser determinada. Ao trabalhar com dados nominais ou ordinais, o analista pode atribuir números a cada categoria, porém deve-se atentar para o fato de que estes números representam apenas códigos e não implicam quantidades de um atributo ou característica (HAIR et al., 1995; SIEGEL, 1977).

Já as escalas métricas, fornecem o nível mais alto de precisão na medição, permitindo quase todas as operações matemáticas. São subdivididas em intervalar e de razão. Estas escalas têm unidades constantes de medida, de modo que diferenças entre quaisquer dois pontos adjacentes em uma parte da escala são iguais. A única diferença entre as escalas de intervalos e de razão é que a escala de intervalos tem um ponto "zero" arbitrário, enquanto as escalas de razão têm um ponto "zero" absoluto. As escalas de razão representam a mais sofisticada forma de precisão da medida e todas as operações matemáticas são permitidas com medidas nesta escala. Como exemplo das escalas de intervalos podemos citar a escala de temperatura em graus Celsius ou Fahrenheit e das escalas de razão temos a medida de massa e a escala de temperatura de Kelvin.

Observe que nas medidas de massa, o zero possui o mesmo significado, ausência de massa, qualquer que seja a escala utilizada. Além disso, há uma razão constante entre as escalas. Já nas escalas de temperatura, enquanto o zero de temperatura nas escalas Celsius ou Fahrenheit são pontos arbitrários, não significando a mesma temperatura em cada uma delas, somente a escala Kelvin é considerada como absoluta.

É importante destacar que a escolha do tipo de variável utilizada dependerá da natureza do objeto e dos recursos de que o pesquisador dispõe para mensuração. De acordo com Pereira 
(2001), a criação de uma escala envolve o estabelecimento de premissas de relação entre atributos de um objeto e uma representação simbólica desses atributos. A escala atribui rótulos numéricos aos atributos e é arbitrada, definida, pelo pesquisador. Disto resulta que a fidedignidade da representação que os números fazem dos atributos é um juízo primário do investigador, o qual se apóia no seu conhecimento do objeto. As relações que os números utilizados têm no campo da aritmética serão, ou não, aplicáveis às relações existentes entre os atributos segundo as premissas de relação que o pesquisador estabeleça. Uma eventual inadequação nessa relação, portanto, não remete a qualquer inconsistência dos atributos ou dos números que os representam, mas sim a um conhecimento inadequado do objeto por parte do pesquisador.

Tomemos como exemplo a seguinte escala qualitativa de avaliação com três classes/categorias: "Ruim", "Regular" e "Bom". A escala apresentada é do tipo ordinal pois podemos supor que "Bom" é "maior" que "Regular" e "Regular" é "maior" que "Ruim" (isto é, Ruim $<$ Regular $<$ Bom), mas não é possível quantificar a diferença entre estas classes. Contudo, se atribuirmos "1", “2" e "3" a estas classes respectivamente e supormos que estes números significam quantidades, não somente códigos, então é possível dizer que a diferença entre as classes consecutivas é "1" (escala intervalar) ou que "Bom" é três vezes "Ruim" (escala de razão). Porém, estas suposições podem nos levar a conclusões do tipo: se "Ruim" é igual a "1" e "Bom" é igual a "3", então três "Ruins" é igual a um "Bom". Esta conclusão é absurda e contribui para corroborar com alguns pesquisadores que categoricamente afirmam que dados qualitativos tratados como quantitativos produzem resultados errados (SIEGEL, 1977).

Entender os diferentes tipos de escalas de medidas é importante visto que o pesquisador tem que identificar a escala de medida de cada variável empregada, de modo que dados nãométricos, ou métricos, não sejam usados incorretamente e também porque a escala de medida é um elemento crítico na determinação de quais técnicas são adequadas (HAIR et al., 1995).

As seções seguintes resumem os métodos comumente utilizados para análise de dados, baseados em abordagens estocásticas, e suas limitações. 


\subsection{TESTES ESTATÍSTICOS PARAMÉTRICOS X NÃO-PARAMÉTRICOS}

Consideramos os testes estatísticos paramétricos e não-paramétricos como métodos mais tradicionais e mais utilizados nas análises estatísticas. Segundo Siegel (1977) uma prova estatística paramétrica é uma prova cujo modelo especifica certas condições sobre os parâmetros da população da qual se extraiu a amostra para pesquisa, em geral, não comprovadas, e que são supostas válidas. As provas paramétricas também exigem que os valores analisados resultem de mensurações efetuadas pelo menos ao nível de uma escala de intervalos. São testes aplicáveis a escalas quantitativas e, por conseguinte, mais utilizados nas áreas de ciências naturais e engenharias. São exemplos de testes paramétricos, os testes de hipóteses sobre médias.

Já uma prova estatística não-paramétrica é uma prova cujo modelo não especifica condições sobre os parâmetros da população da qual se extraiu a amostra. Há certas suposições básicas associadas à maioria das provas não-paramétricas, mas essas suposições são em número menor, e mais fracas, do que as associadas às provas paramétricas. Além disso, as provas não paramétricas não exigem mensurações tão fortes quanto as provas paramétricas, podendo ser aplicadas em dados em escalas nominais ou ordinais. Dada a natureza dos dados, estes testes, são mais utilizados na área de ciências sociais. São exemplos de testes não-paramétricos os testes do chi-quadrado e da mediana.

Embora as suposições para os testes não-paramétricos sejam em número menor, e mais fracas, elas existem e podem inviabilizar uma análise, como exemplo, alguns testes de dependência exigem valores mínimos nas células da tabela de contingência, que nem sempre são possíveis.

Resumindo, testes paramétricos são adequados para dados quantitativos e os não-paramétricos para dados qualitativos. Contudo, testes não-paramétricos podem ser aplicados a dados quantitativos, pois estes podem ser categorizados, ao contrário dos dados qualitativos que não podem ser considerados como numéricos. Mesmo com estas limitações, claras e bem definidas, Reis e Lay (1994) afirmam que a conversão de dados qualitativos em quantitativos tem sido uma prática comum em estudos na área de ambiente-comportamento, na qual se insere a Avaliação Pós-Ocupação (APO).

Salientamos que embora, os testes não-paramétricos, já tenham sido indicados por Ornstein, Bruna e Taschner (1994) e Reis e Lay (1994), poucos são vistos nos estudos de APO no Brasil, seja pelo não atendimento das condições impostas, ou ainda pelo desconhecimento dos 
mesmos. Lay e Reis (2005), uma década depois, expandem a revisão da literatura sobre os procedimentos e métodos de coleta e análise de dados para pesquisas no ambiente construído. Os autores incluem nesta revisão, além dos testes não-paramétricos já conhecidos, a análise de dados utilizando sistema de informação geográfica (SIG) e a análise sintática. Para maiores detalhes sobre os testes paramétricos e não-paramétricos há uma ampla literatura da qual podemos citar autores básicos de Estatística como Barbetta (1999), Costa Neto (2002) e Siegel (1977).

Como já afirmado, estes testes fazem parte de uma estatística clássica, mais tradicional, que analisa distribuições de uma ou duas variáveis. Há ainda um outro ramo da estatística que se preocupa com a análise simultânea de dados, tanto quantitativos quanto qualitativos, conhecido como estatística ou análise multivariada que buscaremos resumir a seguir.

\subsection{TÉCNICAS ESTATÍSTICAS MULTIVARIADAS}

A estatística multivariada comporta um conjunto de técnicas que buscam trabalhar um número razoável de variáveis simultaneamente. As técnicas multivariadas podem ser classificadas em técnicas de dependência e de interdependência. São exemplos de técnicas de dependência, a regressão múltipla, a análise discriminante múltipla e a análise de correlação canônica. Neste grupo uma variável, ou conjunto de variáveis, é identificada como variável dependente a ser predita ou explicada por outras variáveis conhecidas como independentes. Já as técnicas de interdependência são aquelas nas quais nenhuma variável, ou grupo de variáveis, é definida como independente ou dependente. Neste grupo estão as técnicas de agrupamento, análise fatorial e escalonamento multidimensional (HAIR et al., 1995; JOHNSON; WICHERN, 2002).

Algumas técnicas são consideradas exploratórias, como a análise de agrupamento e de componentes principais, e as exigências são menores em relação à escala de mensuração e a forma de distribuição dos dados. Outras, como a análise discriminante múltipla, possuem exigências sobre as forma de distribuição dos dados, que em muitos casos também inviabilizam a análise.

As técnicas de agrupamento, ou clustering, utilizadas tanto em dados quantitativos quanto qualitativos, buscam determinar grupos homogêneos de comportamento dos dados, já na 
análise discriminante, o objetivo é definir equações que permitam a alocação ou não de um dado elemento em grupos pré-estabelecidos.

Existem diversas outras técnicas que fazem parte da estatística multivariada, de onde podemos citar a regressão múltipla, análise de caminho e modelagem de equações estruturais utilizada por Galster (1987), Amérigo e Aragonés (1990), Bonaiuto et al. (1999) e Amole (2008), o escalonamento multidimensional utilizado por Monteiro (1994), a análise de componentes principais utilizada por Fleury-Bahi, Félonneau e Marchand (2008), a análise de regressão logística utilizada por Hur e Morrow-Jones (2008), todos preocupados com os múltiplos fatores que podem influenciar a satisfação residencial ou com o ambiente de uma forma geral. Embora estas técnicas possuam uma vasta literatura, elas também têm sido pouco exploradas em estudos de APO no Brasil, donde não se pode ainda concluir sobre a sua adequação ou limitação aos dados. 


\section{AVALIAÇÃO PÓS-OCUPAÇÃO E SISTEMAS DE INDICADORES APLICADOS AO AMBIENTE URBANO}

Como o objetivo principal deste trabalho é obter um método de análise de dados para a avaliação da qualidade ambiental de assentamentos urbanos recuperados, centraremos a nossa revisão em dois tipos de estudos: Avaliação Pós-Ocupação (APO), pelos métodos de coleta de dados e pela sua habilidade em trabalhar as questões subjetivas das avaliações, e os sistemas de indicadores aplicados ao ambiente urbano pela sua habilidade em trabalhar as questões objetivas e quantitativas. Assim, buscamos aproveitar os aspectos de qualidade desenvolvidos pela APO com os aspectos quantitativos evidenciados nos estudos sobre indicadores. Alertamos que esta revisão não é uma revisão exaustiva sobre métodos de avaliação, mas sim um levantamento de alguns aspectos destes métodos que carecem de aperfeiçoamento.

\subsection{AVALIAÇÃO PÓS-OCUPAÇÃO}

A Avaliação Pós-Ocupação (APO) é uma área de conhecimento que combina avaliação técnica e o ponto de vista do usuário, pretendendo se configurar como uma avaliação global do meio a ser estudado. As variáveis a serem consideradas podem ser complementadas, reduzidas e/ou alteradas, em função da tipologia edificada, das características e dos objetivos da pesquisa (ORNSTEIN; ROMÉRO, 1992). Ela é projetada para sistematicamente avaliar o desempenho das construções depois que foram construídas e ocupadas por algum tempo. Esta abordagem difere de outras avaliações de desempenho dos edifícios, pois é focada nos requerimentos dos ocupantes das construções, incluindo saúde, segurança, funcionalidade e eficiência, conforto psicológico, qualidade estética e satisfação (PREISER, 2002).

Além de uma avaliação técnica, a APO baseia-se na idéia de que perguntar aos usuários sobre suas necessidades pode prover importantes informações no processo de projeto. As lições aprendidas de estudos de APO podem ainda prover indicadores úteis para os processos de planejamento, programação e projeto. Ressalta-se a sua importância uma vez que identifica os fatores negativos e positivos dos projetos. No caso dos fatores positivos estes devem ser cadastrados e recomendados em futuros projetos semelhantes; já no caso dos negativos 
definem-se recomendações para que sejam minimizados e possibilitem a correção dos problemas detectados e utilizando também os resultados destas avaliações para realimentar o ciclo do processo de produção e uso de ambientes de futuros projetos (Figura 7) (FEDERAL FACILITIES COUNCIL (FFC), 2002; ORNSTEIN; ROMÉRO, 1992; PREISER, 2002; RABINOWITZ, 1984).

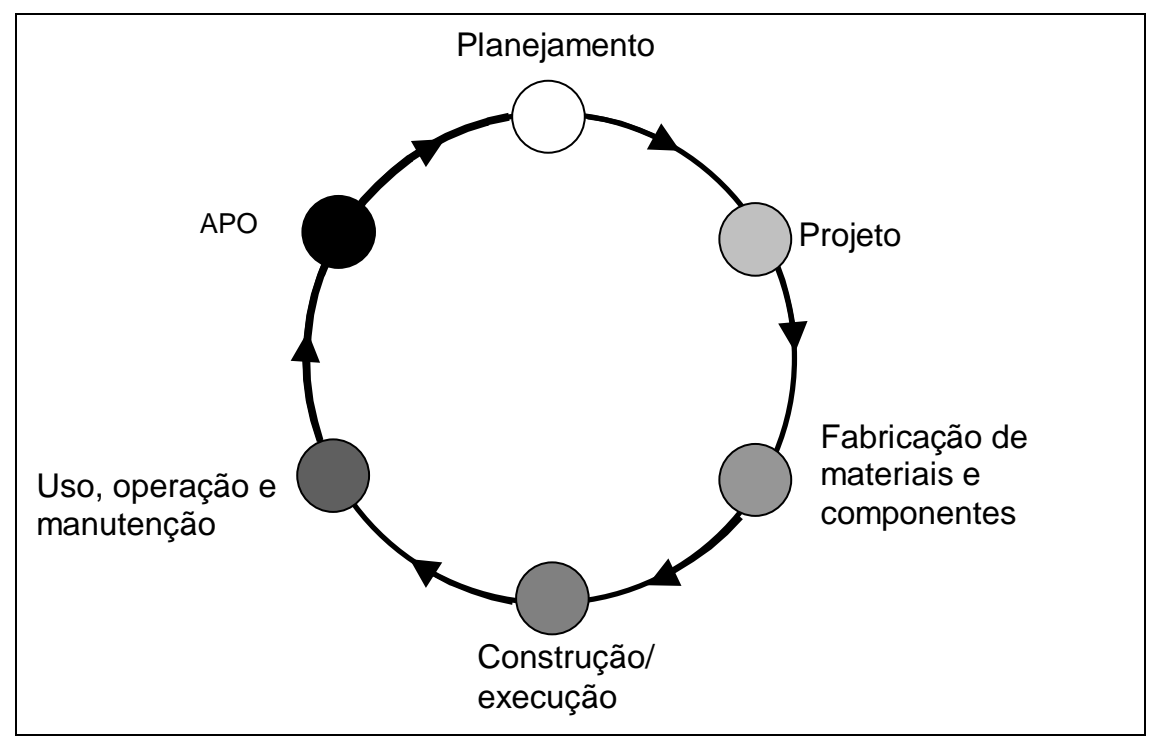

Figura 7: Ciclo da construção incluindo a APO

Fonte: Adaptado de Roméro e Ornstein (2003)

A APO apresenta uma grande flexibilidade de métodos e a possibilidade de avaliar espaços em diferentes escalas. Por isso, a APO tem se firmado como uma das principais ferramentas, onde se pode avaliar desde a unidade habitacional aos espaços urbanos em geral, incluindo construções com as mais variadas funções como escolas, hospitais, shopping centers, etc. (ROMÉRO (coord.), 1999). A flexibilidade de métodos da APO vão desde levantamento de medidas quantitativas, áreas, iluminação, temperaturas até as medidas comportamentais, utilizando entrevistas, questionários e/ou grupos focais (ORNSTEIN; ROMÉRO, 1992).

Desta flexibilidade resultam também os mais diferentes tipos de estudos. Destaca-se na área habitacional o estudo coordenado por Roméro (1999) intitulado: "Procedimentos Metodológicos para Aplicação da Avaliação Pós-Ocupação em Conjuntos Habitacionais: do Desenho Urbano à Unidade Habitacional”. Já em favelas urbanizadas temos Silva (2003) com o estudo "Urbanização de favela em áreas de proteção de mananciais: o caso da Comunidade Sete de Setembro".

Podemos ainda citar diversos outros trabalhos com objetivos diferenciados, que têm utilizado estas ferramentas, por exemplo: Basso (1998), que avalia as características de habitabilidade 
de protótipos habitacionais em uma vila tecnológica; Oliveira e Heineck (1998) que buscam identificar, utilizando estudo de caso, os principais fatores que influenciam a satisfação dos usuários de ambientes construídos em empreendimentos habitacionais; Jobim e Formoso (1998), que realizaram pesquisa semelhante, com o objetivo de propor um método de avaliação da satisfação dos clientes pós-ocupação, abordando as principais funções das empresas relacionadas ao atendimento dos clientes; Oliveira Neto e Amorim (1999) que utilizam a APO em conjunto com a Teoria das Facetas para elaborar um método de pesquisa de mercado para a construção civil e Lay e Reis (2002), que tratam de identificar os elementos de projeto que afetam o desempenho de conjuntos habitacionais e o nível de satisfação dos usuários.

De acordo com Ornstein e Roméro (1992), basicamente existem três níveis de APO:

- APO indicativa ou de curto prazo: proporciona, por meio de rápidas visitas exploratórias do ambiente em questão e entrevistas selecionadas com usuários-chave, indicação dos principais aspectos positivos e negativos do objeto de estudo;

- APO investigativa ou de médio prazo: trata-se do nível anterior acrescido da explicitação de critérios referenciais de desempenho e;

- APO diagnóstica ou de longo prazo: define detalhadamente critérios de desempenho, utiliza técnicas sofisticadas de medidas, correlacionando aquelas físicas com as respostas dos usuários, tendo-se em mente a estrutura organizacional da entidade. Para tanto, exige recursos bem maiores do que os níveis anteriores.

Destacamos porém, que esta classificação não é única. Bechtel (1997) por exemplo, define cinco tipos de APO: acadêmica, científica, colaborativa, institucional e empresarial.

Os níveis definidos por Ornstein e Roméro (1992) podem ainda ser desdobrados em subníveis e muito embora exista essa diversidade há um fluxo de informações nos estudos de APO que pode ser resumido no organograma básico da Figura 8. É importante destacar que a avaliação da satisfação do morador/usuário não exclui a avaliação técnica e vice-versa. Enquanto a avaliação técnica enfoca os aspectos objetivos e quantitativos da qualidade de um ponto de vista externo e com pouca vivência do ambiente, a avaliação do morador enfoca os aspectos qualitativos e subjetivos da qualidade de um ponto de vista interno e com uma vivência maior do ambiente. 


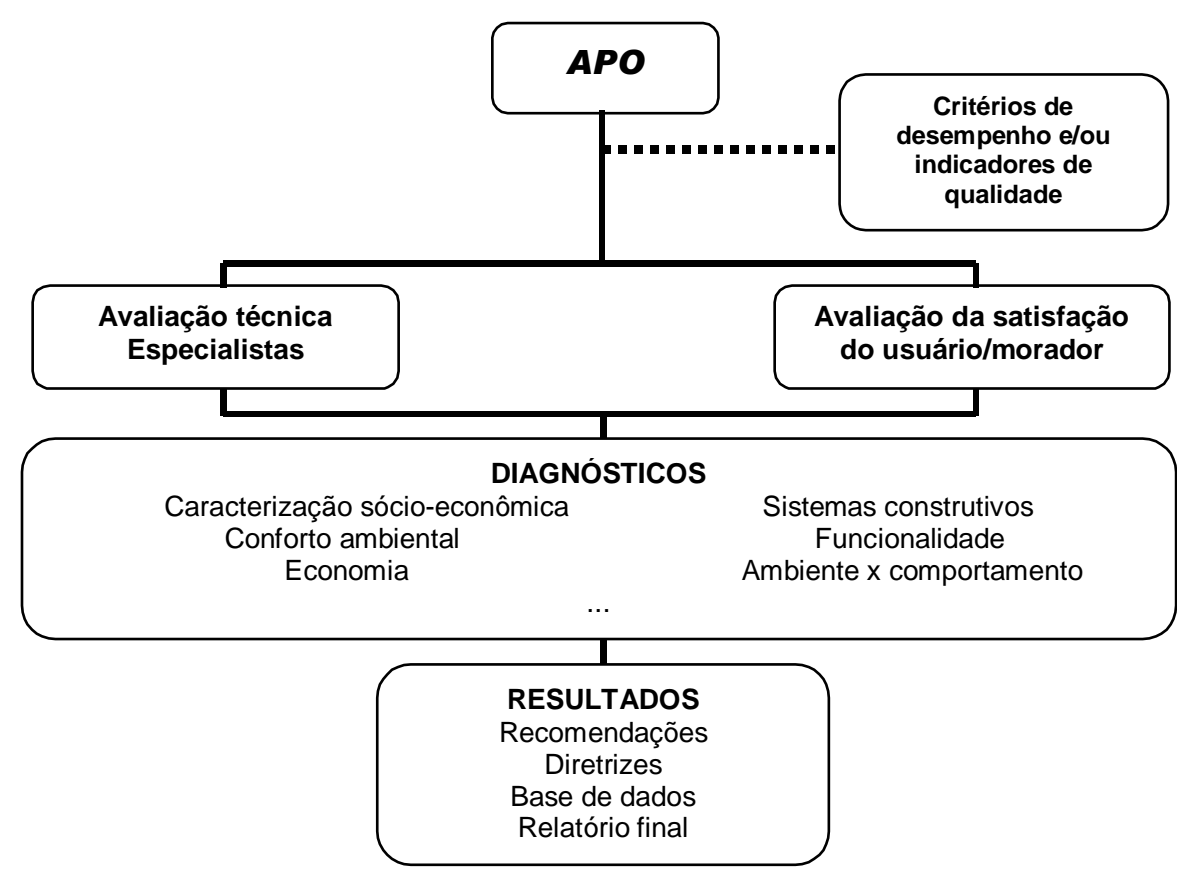

Figura 8: Fluxograma de desenvolvimento metodológico da APO Fonte: Adaptado de Roméro e Ornstein (2003)

Esta idéia presente na APO sobre a subjetividade do conceito de qualidade e de satisfação do usuário é reforçada também pela abordagem de Galster (1987) sobre a satisfação residencial. Ele defende a idéia de que o significado de satisfação não pode ser dissociado do fato de que as pessoas baseiam sua opinião em parâmetros de comparação entre seu ambiente atual e suas aspirações, influenciando, nessa opinião, características como classe social e faixa etária.

Como já afirmado, a incorporação no processo de avaliação da opinião do morador torna-se cada vez mais imprescindível e demanda um processo de modelagem para a sua análise. A seguir abordaremos os dois tipos de avaliação utilizados na APO, técnica e de satisfação. Visto o grande desenvolvimento dos métodos de avaliação técnica, enfatizaremos os métodos de avaliação da satisfação do morador coletados em pesquisas de opinião.

\subsubsection{Avaliação técnica}

Para a avaliação técnica podem ser realizadas avaliações construtivas, funcionais e econômicas. Roméro e Ornstein (2003) citam os seguintes procedimentos que podem ser utilizados:

- Entrevistas com técnicos responsáveis pelo projeto 
- Leitura de projetos, especificações técnicas e planilhas de custos

- Seleção amostral para aplicação de roteiro/checklist técnico

- Medições in loco: conforto técnico, iluminação e acústica (ruído)

- Cálculos e simulações sobre conforto ambiental e consumo energético

- Levantamento de mobiliário e equipamentos diversos

- Cálculo dos índices de obstrução em unidades domiciliares

- Reuniões com técnicos para discussão dos resultados

Diversos métodos e técnicas de avaliação técnica, com suas vantagens e desvantagens, podem ser vistos também em Ornstein e Roméro (1992), Ornstein, Bruna e Roméro (1995) e Bechtel e Churchman ([ca. 2002]). Estes métodos visam obter medidas de desempenho físico do espaço/construção em análise. O resultado deste tipo de análise é uma avaliação objetiva cujos procedimentos são baseados em normas e critérios objetivos, e em geral quantitativos. Possui como grande vantagem a obtenção de uma leitura isenta de questões subjetivas que podem confirmar ou não os pontos levantados na avaliação de satisfação. Por outro lado, a pouca experimentação do espaço em análise pelo avaliador técnico possibilita que questões cotidianas não sejam identificadas, daí a importância da avaliação do morador.

A profundidade e precisão da avaliação técnica dependerão do nível de APO que se pretende realizar. Por exemplo, em avaliações indicativas, ou de curto prazo, visitas exploratórias, do tipo Walkthrough, podem fornecer uma indicação dos principais aspectos positivos e negativos do objeto em estudo, enquanto avaliações investigativas ou diagnósticas podem demandar medidas de desempenho mais detalhadas como levantamento de projetos, medidas de conforto térmico e iluminação, entre outras. Como já afirmado, este conjunto de variáveis pode ser reduzido ou ampliado em função dos objetivos da pesquisa.

\subsubsection{Avaliação da satisfação do morador/usuário}

A obtenção de uma medida de satisfação não é uma atividade trivial. Por se tratar de uma medida subjetiva, depende de um referencial teórico que demanda uma série de definições para a formulação de um procedimento ou técnica de avaliação. A seguir faremos um resumo 
de alguns conceitos, bem como de questões relacionadas à tomada e análise deste tipo de medida.

A avaliação, de uma forma geral, pode ser definida como a atribuição de valor a um determinado objeto, e mesmo no caso de uma avaliação técnica, também está fortemente relacionada ao juízo do avaliador. Neste sentido a avaliação do morador/usuário está relacionada a dois outros conceitos: percepção e satisfação.

A percepção, mais precisamente percepção ambiental, é definida por Gifford (1996) é a coleta inicial de informação, que se dá basicamente pelos sentidos. Porém, Gifford (1996) afirma que o termo percepção ambiental tem sido utilizado num sentido mais amplo, incluindo aspectos de como o indivíduo avalia o ambiente, ou seja, ampliando a percepção para o processo de cognição. Reis e Lay (2006) também realizaram uma revisão da literatura na qual buscam distinguir o termo percepção do termo cognição, admitindo no entanto que, por uma questão de adequação ou familiaridade de linguagem, é utilizado o termo relativo à percepção em lugar de cognição. Neste trabalho, utilizamos a definição de percepção no sentindo amplo, dado por Gifford (1996).

Com relação ao termo satisfação, Amole (2008) afirma que não existe consenso em relação a que tipo de modelo de avaliação é a satisfação. Amole (2008) destaca que enquanto alguns autores concebem a satisfação como uma avaliação puramente cognitiva, outros têm mantido que a satisfação é sentimento. Entendemos a satisfação mais próxima aos conceitos apresentados para qualidade de vida, ou seja, está relacionada tanto a percepção do indivíduo quanto às suas vivências e aspirações.

Segundo Dantas (2001) a satisfação é algo que está ligado à qualidade do produto que se oferece e/ou do serviço que se presta e só quem percebe esta qualidade é quem consome o produto ou serviço. $\mathrm{O}$ autor ressalta ainda que a qualidade do ponto de vista técnico não possui validade se ela não é percebida pelo usuário/consumidor e que para satisfazer necessidades, anseios e expectativas de clientes, a primeira condição é que se conheçam essas necessidades, anseios e expectativas.

Adotamos aqui o termo avaliação de satisfação, por três motivos:

- primeiro para designar o processo de atribuição de valores a um determinado objeto;

- segundo para diferenciar da avaliação técnica e; 
- terceiro para reforçar a idéia de que esta avaliação está carregada de subjetividades, baseadas nas expectativas e vivências do morador/avaliador, logo não pode ser modelada de forma precisa, nem única, matematicamente.

Reforçando a importância da avaliação da satisfação residencial, Margarido (1989) apud Ornstein e Roméro (1992) afirma que o grande experimentador é o usuário que, no dia-a-dia, testa todos os aspectos da construção e que embora ele não possua formação específica, seus depoimentos são da maior importância.

Galster (1987) afirma que dois tratamentos conceituais contrastantes têm emergido como suporte para os trabalhos na área de avaliação da satisfação residencial. Uma abordagem "direcional", onde as pessoas têm certos objetivos e atividades associadas direcionadas ao alcance destes objetivos. A medida que um dado ambiente residencial é percebido como facilitador destas ações objetivo-direcionado é vista como uma medida de sua satisfação ambiental. Nesta abordagem a pesquisa tem que investigar objetivos, atividades associadas, e fatores ambientais. Um exemplo dessa abordagem é a utilização da teoria das facetas para avaliação dos espaços. A outra abordagem é conhecida como "diferencial entre ambiente existente e aspirações”. Neste caso as pessoas percebem os atributos de seu ambiente físico e os avaliam baseados em certos padrões de comparação, especialmente o padrão definido pelo que as pessoas acreditam que elas podem aspirar. A medida de semelhança entre ambiente existente percebido e o aspirado nos dá a medida de satisfação. As implicações desta abordagem são que características objetivas do ambiente (contextuais) e características individuais (composicionais) que presumivelmente influenciam as percepções e as avaliações têm que ser identificadas.

Esta segunda abordagem converge para as definições de qualidade de vida expostas anteriormente, onde a medida de qualidade de vida também é vista como a interseção (semelhança) entre a situação aspirada (necessidades e expectativas) e a situação existente (RUEDA, 1997).

Ainda segundo Galster (1981), as necessidades e as aspirações percebidas por um dado indivíduo são um complexo de características individuais (classe social, estágio de vida, etc) e normas culturais impostas ao indivíduo. Se a situação existente está em congruência com a situação definida pelas necessidades e aspirações, a satisfação deve ser manifestada. Se não, duas alternativas são possíveis, o indivíduo pode tentar reconciliar esta incongruência, redefinindo necessidades e reduzindo aspirações, e/ou alterando a avaliação da situação atual, 
em conseqüência produzindo um "pouco" de satisfação. Nesta situação é possível que uma pessoa alienada expresse satisfação com situações incongruentes.

De outra forma o indivíduo não consegue se adaptar a situação habitacional existente e neste caso, a insatisfação deve ser manifestada. Estas pessoas, com o tempo, seriam tentadas a reduzir sua insatisfação, seja revisando necessidades em outro estágio de vida, alterando condições na atual moradia via reformas, ou mudando-se para outra situação residencial mais congruente com suas aspirações (Figura 9).

A avaliação da satisfação, sempre estará relacionada a um determinado contexto e referencial teórico. Porém, as técnicas de coleta de dados são bem semelhantes, decorrentes das técnicas utilizadas em Ciências do comportamento. Em nosso caso, admitimos a abordagem sobre a medida de semelhança entre o ambiente existente e o aspirado.

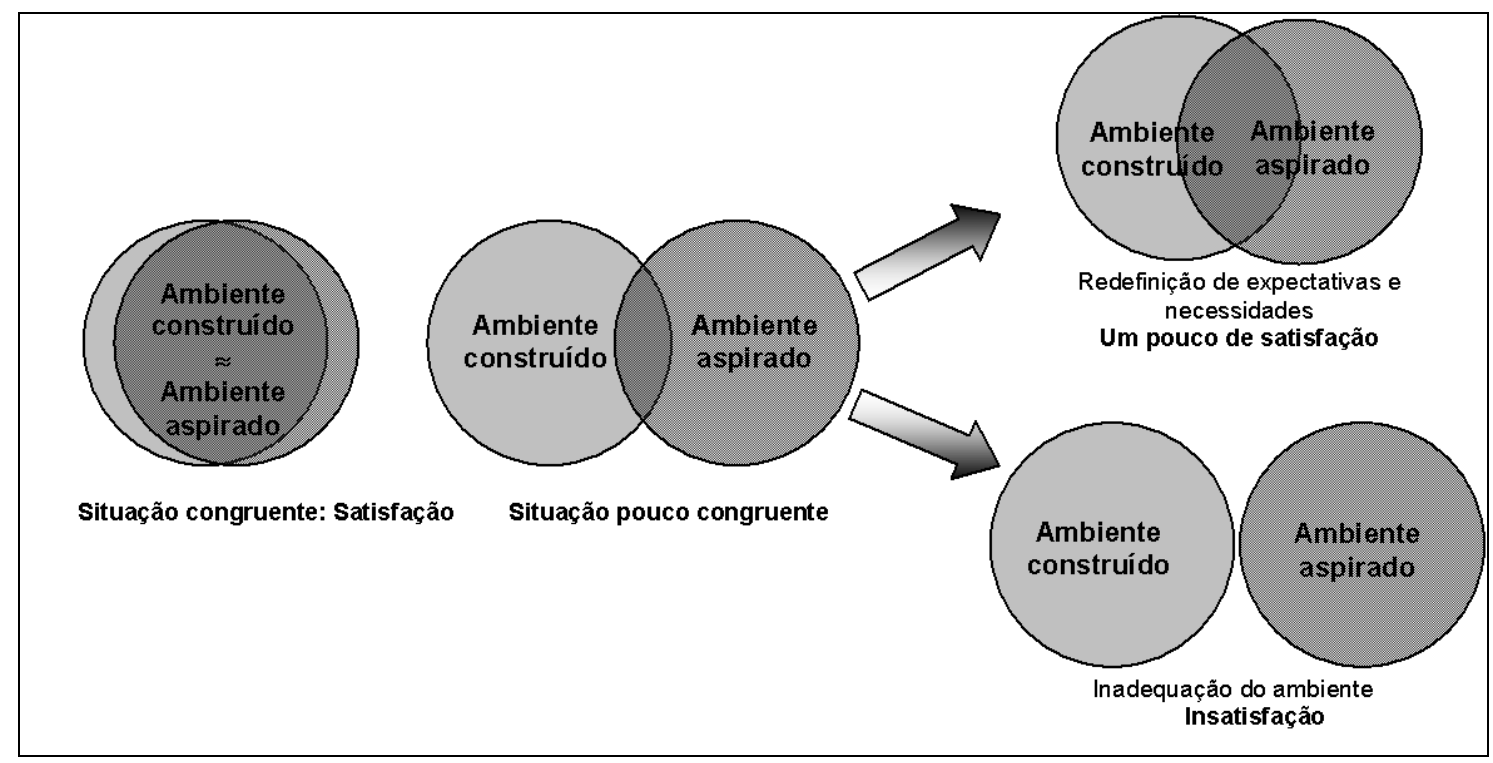

Figura 9: Situações de avaliação da satisfação

Ornstein, Bruna e Roméro (1995), Reis e Lay (1994) e Monteiro (1994) descrevem uma série de métodos e técnicas para a tomada de medidas comportamentais tais como: contatos com usuários, discussões em grupo por meio de análises verbais e visuais, observações de comportamento do usuário, entrevistas, questionários e mapas comportamentais.

Em nosso trabalho focaremos na obtenção de medidas utilizando o que Marconi e Lakatos (1999) denominam observação direta extensiva. Marconi e Lakatos (1999) afirmam que a observação direta extensiva pode ser realizada por meio de questionário, de formulário e de medidas de opinião e atitudes. As autoras destacam que o questionário é enviado ao 
respondente, pelo correio ou portador e que depois de preenchido é devolvido ao pesquisador do mesmo modo, enquanto o formulário é aplicado por meio de entrevistas. Neste caso, o formulário pode conter, além de perguntas ao entrevistado, questões que devem ser respondidas pelo próprio pesquisador.

Embora exista na literatura a possibilidade de aplicação do questionário por meio de pesquisador, é o chamado questionário face-a-face (face to face questionnaire) (CHANG; CHANG, 2005), na maioria dos casos, são considerados questionários as observações coletadas de forma direta, sem a presença do pesquisador, neste caso, a fonte das respostas é chamada respondente, enquanto que quando as questões são feitas por meio de um pesquisador, temos o que pode ser chamada de uma entrevista e a fonte das respostas é chamada de entrevistado. Uma outra característica marcante da entrevista é que ela, em geral, é feita utilizando-se questões abertas (Walizer; Wienir , 1978; Bell et al., [ca.1996]; Marconi; Lakatos, 1999).

Esta classificação obviamente não é suficiente para agrupar as diferentes formas que têm sido desenvolvidas, por exemplo, o questionário face-a-face. Segundo Marconi e Lakatos (1999), neste caso, teríamos um formulário - nem entrevista, nem questionário. Como esta discussão extrapola o objetivo deste trabalho e também não é essencial para o seu desenvolvimento, adotaremos o termo formulário para designar a aplicação do instrumento de coleta de dados composto por questões a serem respondidas pelo morador e por questões a serem respondidas pelo pesquisador e o morador, denominaremos simplesmente de entrevistado, conforme Marconi e Lakatos (1999).

A opção pelo formulário se deu em função da necessidade de obter um alto índice de retorno das respostas em campo e também pela possibilidade de quantificação das respostas para obter indicadores.

\subsubsection{Medidas de satisfação utilizando formulários}

Uma das vantagens da aplicação de formulários é que podemos desenvolver uma avaliação técnica simultaneamente à avaliação de satisfação. Ainda segundo os autores acima citados, os formulários, assim como os questionários, são mais fáceis de aplicar e interpretar, uma vez que possibilitam a quantificação por meio da utilização de escalas de valores. De fato, há uma 
facilidade de aplicação e de interpretação devido à padronização das respostas. Porém, quanto à quantificação, deve ser feita com base em suposições de escalas qualitativas e não quantitativas como freqüentemente é feito.

Os modelos de questões utilizados tanto em formulários quanto em questionários predominantes seguem o padrão de questões de múltipla escolha. As questões de múltipla escolha são perguntas fechadas mas que apresentam uma série de possíveis respostas, abrangendo várias facetas do mesmo assunto. Estas perguntas podem ser ainda de resposta única ou de resposta múltipla, devendo o pesquisador explicitar em cada caso (Marconi; Lakatos, 1999).

As questões de avaliação do morador em formato de múltipla escolha em geral seguem dois modelos: (i) respostas em escalas de conceitos, por exemplo, de Péssimo até Ótimo (Figura 10) e respostas em escalas de notas, por exemplo, de 0 até 5 (Figura 11). Em ambos os casos as questões são de resposta única.

AVALIAÇÃO DE SUA ÁREA DE TRABALHO OU ESTUDO

Funcionários: Respondam às questões somente sobre o setor em que você trabalha.

Alunos: Respondam às questões sobre o local em que você se encontra.

Funcionários: Respondam às questões somente sobre a sua sala no seu departamento.

3) Como você avalia sua sala de trabalho ou estudo quanto ao tamanho?

$\square$ Ótima

Boa

Razoável

$\square$ Precária

Péssima

4) Como você avalia sua sala de trabalho ou estudo quanto à quantidade de móveis?

Ótima

Boa

Razoável

Precária

Péssima

Figura 10: Trecho de questionário típico com avaliação do usuário utilizado em escolas Fonte: Ornstein e Roméro (1992) 


\begin{tabular}{l}
$\begin{array}{l}\text { POR FAVOR PREENCHA O SEGUINTE: } \\
\text { Andar: }\end{array}$ Departamento: \\
\hline
\end{tabular}

Por favor avalie o seu nível de conforto em sua sala de trabalho principal na seguinte escala, onde 1 é pobre ou desconfortável e 5 é bom ou confortável, e 2, 3 e 4 são intermediários, com 3 sendo neutro. Sua tarefa é circular o número em cada escala que melhor representa sua experiência de trabalho neste edifício.

1. Conforto devido a temperatura:

$\begin{array}{lllll}1 & 2 & 3 & 4 & 5 \\ \text { Geralmente Ruim } & & & & \text { Geralmente Bom }\end{array}$

Figura 11: Trecho de questionário típico com avaliação do usuário utilizado em edifício de escritórios Fonte: Traduzido de FFC (2002)

Embora nestes modelos seus códigos pareçam diferentes, ambos, de conceitos e de notas, contêm escalas ordinais, visto que estamos lidando com escalas qualitativas de satisfação. Como afirmado anteriormente, números nestas escalas são somente códigos ou posições relativas, não representam quantidades como os números em escalas quantitativas. Contudo, alguns pesquisadores realizam testes estatísticos paramétricos em dados em escalas qualitativas codificadas com números, afirmando que os erros não são significantes utilizando estes procedimentos (LABOVITZ, 1970).

Um exemplo da inconsistência desse tipo de conversão foi apresentado no Capítulo 3, quando atribuímos 1, 2 e 3 aos conceitos Ruim, Regular e Bom respectivamente e realizamos algumas operações. Reforçando esta corrente, Reis e Lay (1994) ressaltam que o uso de escalas ordinais para coleta de dados e sua posterior transformação numa escala intervalar (numérica) sem os devidos cuidados e suposições merece atenção, visto que essa conversão não é tão trivial. Os autores criticam o uso da estatística paramétrica para o tratamento destes dados, recomendado os testes não-paramétricos para análise. Outros argumentos contrários a essa conversão de escalas também podem ser vistos em Siegel (1977).

Embora Galster e Hesser (1981) e Galster (1987) tenham utilizado técnicas de regressão multivariada para determinar as relações entre o ambiente e a satisfação residencial, alertamos que essa técnica é concebida para o tratamento de dados em escalas quantitativas e ainda que, estes estudos se apóiem nos trabalhos de Labovitz (1970), onde é mostrado que o uso de medidas ordinais em modelos de regressão em grandes amostras não produzem viéses nos resultados, devido à violação de tal suposição, uma análise exaustiva deve ser realizada em cada caso para avaliar os possíveis impactos nos resultados. 
É notável a predominância de escalas qualitativas em estudos de APO, o que se justifica tanto pelo fato de que estas escalas não apresentam incertezas relacionadas à imprecisão das classes e também pela comunicação entre o entrevistador e o entrevistado que é facilitada neste tipo de escala. Porém, as limitações de análise que este tipo de escala impõe têm que ser avaliadas. Por outro lado, a utilização de conceitos associados a números como na Figura 11 pode se distanciar a realidade. Há uma clara necessidade de desenvolver técnicas mais adequadas de análise de dados e menos restritivas em relação às escalas de mensuração, que nos forneçam resultados mais confiáveis. É neste caminho que buscamos, utilizando a Lógica Fuzzy, nos aproximar cada vez mais do mundo real.

\subsection{SISTEMAS DE INDICADORES APLICADOS AO AMBIENTE URBANO}

A literatura sobre indicadores é bastante vasta, desde os indicadores de desempenho até os de sustentabilidade. Recentemente, com as discussões sobre meio ambiente e sustentabilidade, estes estudo tiveram uma verdadeira explosão. Para termos uma idéia do desenvolvimento nesta área, em 1995, Wills e Brigs (1995) realizaram um levantamento sobre indicadores de saúde ambiental com 26 projetos de indicadores internacionais, nacionais, regionais e locais no mundo, que resultou num total de mais de 1.400 indicadores que, em sua maioria estavam no estágio de propostas: do total de 1.411 indicadores identificados, 960 estavam sendo propostos, enquanto apenas 451 estavam em uso.

Da experiência brasileira na construção de indicadores, Borja (1997) realizou uma vasta revisão na qual cita as propostas de Comune, Cahpino e Rizzieri (1982), publicado pelo Instituto de Pesquisas Econômicas da USP, onde os autores propõem um sistema de indicadores de qualidade de vida urbana que envolve aspectos sociais, econômicos e ambientais; de Rodrigues (1991) do Instituto Brasileiro de Economia da Fundação Getúlio Vargas, que numa linha distinta da anterior, propõe um índice que agrupa aspectos relevantes da qualidade de vida (Índice de Desenvolvimento Social - IDS); de Garcias (1991) e de Ajzenberg et al. (1986), dentre outros, também preocupados com as questões metodológicas de obtenção e tratamento dos dados.

Centraremos nossa revisão em outros exemplos como os indicadores de qualidade de vida de Santos e Martins (2002), Nahas et al. (1996) e Guedes e Araújo (2004), de salubridade de Piza e Gregori (1999), Almeida (1999) e Dias, Borja e Moraes (2004) e no desenvolvimento 
crescente de indicadores de sustentabilidade, onde destacamos no Brasil os trabalhos Bellen (2005) e de Malheiros, Philippi Jr e Coutinho (2008), estes últimos fazem parte do programa Sistema de Informações Ambientais para o Desenvolvimento Sustentável (SIADES) da Faculdade de Saúde Pública da Universidade de São Paulo, que vem consolidando suas atividades, as quais inclui a realização periódica do Workshop Internacional de Pesquisas em Indicadores de Sustentabilidade (WIPIS).

Apesar do grande número de trabalho sobre indicadores, o seu processo de construção não é uma tarefa simples. Para Depont et al. (2002), na construção de um indicador ou sistema de indicadores é necessário que a sua escolha seja coerente com os propósitos da avaliação, portanto, é necessário ter clareza sobre: (i) o que avaliar, como avaliar, por quanto tempo avaliar e por que avaliar; (ii) de que elementos consta a avaliação; (iii) de que maneira serão expostos, integrados e aplicados os resultados da avaliação para o melhoramento do perfil dos sistemas analisados. Acrescentam-se a estas questões, outras relacionadas às características que um indicador deve apresentar e a própria definição de indicador que trataremos a seguir.

\subsubsection{Definições}

Os indicadores podem ser definidos como um meio de prover os formuladores de políticas com informação, representando o produto final de uma longa cadeia de informação (WILLS; BRIGGS, 1995). Sob a forma de indicadores sociais, tiveram um grande desenvolvimento a partir dos anos 1960 com as discussões sobre avaliação da qualidade de vida em contraposição as avaliações predominantes baseadas em medidas econômicas como o PIB (JANUZZI, 2004; SANTOS; MARTINS, 2002).

Para Costa (2003), indicadores são instrumentos que reduzem grande quantidade de informação a um número apropriado de parâmetros para análise e tomada de decisão. Traduzem conceitos abstratos e difíceis de serem mensurados em entidades operacionais e mensuráveis, fornecendo uma informação sintética sobre determinado fenômeno. Sua utilização permite revelar condições e ao mesmo tempo tendências, apontando aspectos deficientes ou aqueles que necessitam de intervenção.

De forma semelhante Januzzi (2004) define um indicador social como uma medida em geral quantitativa dotada de significado social substantivo, usada para substituir, quantificar ou 
operacionalizar um conceito social abstrato, de interesse teórico ou programático. É um recurso metodológico, empiricamente referido, que informa algo sobre um aspecto da realidade social ou sobre mudanças que estão se processando na mesma.

Bellen (2005) afirma que as definições mais comuns de indicadores e a terminologia associada a esta área são particularmente confusas e que se faz necessário alcançar maior clareza e consenso nesta área. Logo, vale relembrar a sua função básica que está na origem da palavra que significa descobrir, apontar, anunciar, estimar.

Entendemos como indicador uma variável, portanto uma aproximação ou uma representação abstrata de uma determinada característica, relacionada a um fenômeno de interesse, com a capacidade de revelar o seu estado em um dado contexto. Desta forma, a definição de indicador herda as propriedades já discutidas no Capítulo 3 das variáveis.

É comum ver nas definições de indicadores a exigência de serem mensuráveis. Dado o grande número de indicadores baseados em medidas quantitativas presentes na literatura, cabe destacar que a necessidade de mensuração não implica na utilização de dados em escalas quantitativas e ainda mais, a necessidade de ser quantificável também não implica nesta restrição. Segundo Bateson (1978) quantidades são produtos de mensurações, ou seja, com base na revisão no Capítulo 3, tanto dados qualitativos quanto quantitativos fornecem quantidades, a diferença entre eles, existe apenas na escala de medida utilizada. Enquanto, na escala qualitativa, as quantidades são resultantes da contagem de determinadas classes, na escala quantitativa estas quantidades podem resultar de operações matemáticas mais complexas, como a média. Ou seja, é importante não confundir quantificação de uma medida, com utilização de medidas quantitativas. A quantificação e a medida são permitidas a qualquer tipo de dado, seja ele qualitativo ou quantitativo. Enfim, tanto dados quantitativos quanto qualitativos se prestam para a obtenção de indicadores.

\subsubsection{Classificação dos indicadores}

Há uma certa variedade de classificação dos indicadores. Existem aqueles indicadores sintéticos, ou índices, e aqueles que constituem os sistemas indicadores. A principal diferença entre eles é que enquanto o índice busca dar uma visão geral por meio de um único valor, os sistemas indicadores apresentam uma informação mais detalhada, por meio de um conjunto de indicadores parciais (JANUZZI, 2004). 
Eles também podem ser classificados de acordo com os objetivos, geralmente se enquadrando em indicadores para: avaliação de condições e tendências; comparação entre lugares e situações (rankings); avaliação de condições e tendências em relação às metas e aos objetivos; prover informações de advertência e; antecipar futuras condições e tendências (BELLEN, 2005).

Januzzi (2004) traz uma série de classificações para os indicadores: simples/composto, descritivo/normativo, quantitativo/qualitativo, objetivo/subjetivo, insumo/fluxo/produto, esforço/resultados, performance/estoque, eficiência/eficácia/efetividade social e absoluto/relativo.

Para este trabalho uma classificação de interesse é aquela que diferencia o indicador qualitativo do quantitativo. Para Januzzi (2004) indicadores quantitativos e qualitativos são equivalentes a objetivos e subjetivos respectivamente. Ele define que, os indicadores objetivos se referem a ocorrências concretas ou entes empíricos da realidade social, construídos a partir das estatísticas públicas disponíveis (exemplos: percentual de domicílios com acesso à rede de água e taxa de desemprego). Já os indicadores subjetivos, correspondem a medidas construídas a partir da avaliação dos indivíduos ou especialistas com relação a diferentes aspectos da realidade, levantadas em pesquisas de opinião pública ou grupos de discussão (exemplos: índice de confiança nas instituições e notas avaliativas sobre a performance dos governantes).

Contudo, vale salientar que indicadores objetivos também podem ser utilizados como qualitativos. Por exemplo, tomemos o percentual de domicílios com acesso à rede de água. Se por um lado este indicador é uma ocorrência concreta, baseada em estatísticas públicas, por outro lado, também é possível utilizá-lo, em conjunto com outros indicadores, para avaliar a qualitativamente o ambiente. Embora, seja um indicador objetivo, ele também é capaz de representar um aspecto qualitativo sem, no entanto ser subjetivo. Logo a idéia de equivalência entre objetivo-quantitativo, e subjetivo-qualitativo, não pode ser considerada sempre verdadeira. De fato, de acordo com Salat (2006), um indicador qualitativo não é necessariamente um indicador subjetivo. 


\subsubsection{Características dos indicadores}

É importante também definir quais são as características desejáveis de um indicador. Trzesniak (1998), define para os indicadores cinco características a priori, relevância, gradação de intensidade, univocidade, padronização e rastreabilidade e, mais três desejáveis, cobertura, portabilidade e invariância da escala, que são descritas no Quadro 1.

Quadro 1: Características dos indicadores segundo Trzesniak (1998)

\begin{tabular}{|c|c|c|}
\hline & Características & Significado \\
\hline \multirow{4}{*}{$\frac{1}{2}$} & Relevância (ou seletividade) & $\begin{array}{l}\text { O indicador deve retratar um aspecto importante, essencial, crítico do } \\
\text { processo/sistema. }\end{array}$ \\
\hline & Gradação de intensidade & $\begin{array}{l}\text { O indicador deve variar suficientemente no espaço dos processos/sistema de } \\
\text { interesse. }\end{array}$ \\
\hline & Univocidade & $\begin{array}{l}\text { O indicador deve retratar com total clareza um aspecto único e bem definido do } \\
\text { processo/sistema. }\end{array}$ \\
\hline & Rastreabilidade & $\begin{array}{l}\text { Os dados em que a obtenção do indicador é baseada, os cálculos efetuados e os } \\
\text { nomes dos responsáveis pela apuração devem ser registrados e preservados. }\end{array}$ \\
\hline \multirow{2}{*}{ 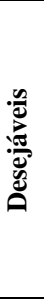 } & Cobertura (ou abrangência ou amplitude) & $\begin{array}{l}\text { A amplitude aumenta quando a nova aplicação corresponde a processos/sistemas de } \\
\text { natureza diferente, porém dentro da mesma (sub) área do conhecimento na qual o } \\
\text { indicador é usualmente empregado. }\end{array}$ \\
\hline & Portabilidade (ou transferabilidade ) & $\begin{array}{l}\text { A portabilidade, mais forte, significa que o uso do indicador pode ser estendido com } \\
\text { sucesso para o estudo de sistemas/processos de outras (sub)áreas do conhecimento } \\
\text { contíguas a alguma em que ele funciona adequadamente. }\end{array}$ \\
\hline
\end{tabular}

As características apresentadas são importantes para avaliação da adequação de um determinado indicador-candidato. Elas também podem ser utilizadas num processo de tomada de decisão sobre quais indicadores utilizar.

Januzzi (2004), também propõe algumas propriedades para os indicadores sociais. O autor destaca 10 propriedades que os indicadores devem possuir (Quadro 2).

Quadro 2: Propriedades dos indicadores segundo Januzzi (2004)

\begin{tabular}{|c|c|}
\hline Propriedade & Significado \\
\hline Relevância social & A pertinência de sua produção e uso \\
\hline Validade & $\begin{array}{l}\text { Grau de proximidade entre o conceito e a medida, isto é, sua capacidade de refletir, de fato, o } \\
\text { conceito abstrato a que o indicador se propõe a "substituir" ou operacionalizar" }\end{array}$ \\
\hline Confiabilidade & $\begin{array}{l}\text { Está relacionada à qualidade do levantamento dos dados usados no seu cômputo. Este levantamento } \\
\text { deve ser feito de forma padronizada, seguindo um protocolo. }\end{array}$ \\
\hline Cobertura & Procurar empregar indicadores de boa cobertura espacial ou populacional \\
\hline Sensibilidade & $\begin{array}{l}\text { Diz respeito a sua capacidade em refletir mudanças significativas se as condições que afetam a } \\
\text { dimensão social referida se alteram }\end{array}$ \\
\hline Especificidade & $\begin{array}{l}\text { Propriedade de refletir alterações estritamente ligadas às mudanças relacionadas à dimensão social } \\
\text { de interesse }\end{array}$ \\
\hline Inteligibilidade & Diz respeito à transparência da metodologia de construção do indicador \\
\hline Comunicabilidade & Compreensível aos demais \\
\hline Periodicidade & Necessidade de ser atualizado com certa regularidade para poder acompanhar as mudanças sociais \\
\hline Factibilidade de obtenção & Capacidade de ser obtido a custos módicos \\
\hline Desagregabilidade & $\begin{array}{l}\text { Devem se referir aos grupos sociais de interesse, isto é, espaços geográficos reduzidos, ou grupos } \\
\text { sociodemográficos específicos }\end{array}$ \\
\hline Historicidade & $\begin{array}{l}\text { É a propriedade de se dispor de séries extensas e comparáveis do mesmo, de modo a poder cotejar o } \\
\text { valor presente com situações do passado, inferir tendências e avaliar efeitos de eventuais políticas } \\
\text { sociais implementadas }\end{array}$ \\
\hline
\end{tabular}


Algumas propriedades citadas por Januzzi (2004) correspondem aquelas já citadas por Trzesniak (1998) outras podem ser consideradas desejáveis. Note que, quanto maior o número de características, ou propriedades, que um indicador deva atender maior o grau de complexidade no processo de escolha destes indicadores.

Embora existam outros critérios para eleger indicadores, como os de Depont et al. (2002) e outros específicos para determinados tipos de indicadores como os de sustentabilidade, consideramos que as propriedades descritas por Trzesniak (1998) são suficientes para uma primeira análise. Assim, partiremos para uma descrição de alguns exemplos de indicadores presentes da literatura. A escolha destes exemplos foi feita pela disponibilidade de material já publicado, bem como pelas diferenças de formulação dos sistemas, como diferentes formas de agregação dos valores.

\subsubsection{Indicadores de qualidade de vida}

\subsubsection{Sistema de informação da Qualidade de Vida na cidade do Porto}

O objetivo central do sistema de informação da qualidade de vida na cidade do Porto é promover o acompanhamento sistemático de um conjunto de dinâmicas em domínios que, de um modo mais direto ou indireto, influenciam as condições de vida num centro urbano e conseqüentemente, servir para fundamentar, de forma mais eficaz, políticas e medidas de intervenção destinadas a favorecer a melhoria sustentada da qualidade de vida urbana (SANTOS; MARTINS, 2002).

Este sistema foi selecionado por buscar uma abordagem que combine aspectos quantitativos com aspectos qualitativos baseados em pesquisas de opinião. Ele foi desenvolvido pela Câmara Municipal do Porto, sob a coordenação do Gabinete de Estudos e Planejamento, e com a colaboração do CEMPRE (Centro de Estudos Macroeconômicos e Previsão da Faculdade de Economia do Porto), e pretende melhorar o conhecimento sobre a situação atual da cidade em matéria da qualidade de vida que é oferecida aos seus habitantes e, ainda, àqueles não residentes, mas que dela são utilizadores.

Segundo os autores este modelo resulta da reflexão efetuada a partir da revisão bibliográfica, considerando não apenas as abordagens mais tradicionais em termos da definição e da 
avaliação da qualidade de vida, mas também as perspectivas emergentes que procuram redefinir o próprio conceito e adaptá-lo às transformações da sociedade moderna, bem como da análise de experiências anteriores e de projetos atualmente em curso em outros países, com objetivos operacionais idênticos.

Os domínios utilizados no modelo são subdivididos em áreas temáticas que por sua vez são compostas por indicadores de natureza quantitativa. Os quatro domínios são condições ambientais, condições materiais coletivas, condições econômicas e sociedade (Figura 12) e estão descritos a seguir:

- Condições ambientais: relacionado com o ambiente em geral, que remete aos aspectos naturais e físicos da cidade (ar, água, verde, resíduos, etc).

- Condições materiais coletivas: relativo aos equipamentos e infra-estruturas relacionados com as condições coletivas de vida na cidade nas áreas da cultura, desporto, ensino, saúde, assistência social, transportes, comércio e serviços. Tratamse, assim, de indicadores relacionados com as condições existentes na cidade, comuns para todos, e que condicionam, naquelas áreas, a vivência da cidade.

- Condições econômicas: pretende analisar a cidade enquanto núcleo de atividade econômica e as questões daí decorrentes ligadas às condições individuais de vida na cidade: rendimento e consumo, mercado de trabalho, habitação, dinâmica econômica.

- Sociedade: que integra os indicadores ligados à dimensão social da cidade e ao relacionamento entre as pessoas, ou seja, questões relacionadas com as escolhas individuais e com a participação dos cidadãos.

O sistema deverá ser alimentado também por fontes externas de informação, que serão companhias de serviços e entidades públicas e privadas, cuja colaboração é considerada essencial no desenvolvimento deste sistema de informação. A implementação deste projeto depende essencialmente da criação de uma rede eficaz de parcerias, que permita a obtenção da informação necessária em tempo útil (SANTOS; MARTINS, 2002).

Ainda segundo os autores, a análise dos indicadores deverá ser complementada com a realização de sondagens de opinião sobre a qualidade de vida na cidade do Porto. Pretende-se, desta forma, conjugar a informação de caráter mais objetivo (indicadores quantitativos selecionados) com a percepção mais subjetiva da qualidade de vida, obtendo-se assim um quadro global que permita um sistema integrado de monitoração e informação sobre a 
qualidade de vida na cidade do Porto. Os autores não mencionam a existência de um indicador final ou um sistema de ponderação dos indicadores. Contudo, a publicação recente de artigos com alguns resultados de pesquisa de opinião dos moradores (SANTOS; MARTINS, 2007), indicam que há um processo em construção com uma abordagem tanto quantitativa quanto qualitativa.

\section{Domínios e áreas temáticas}

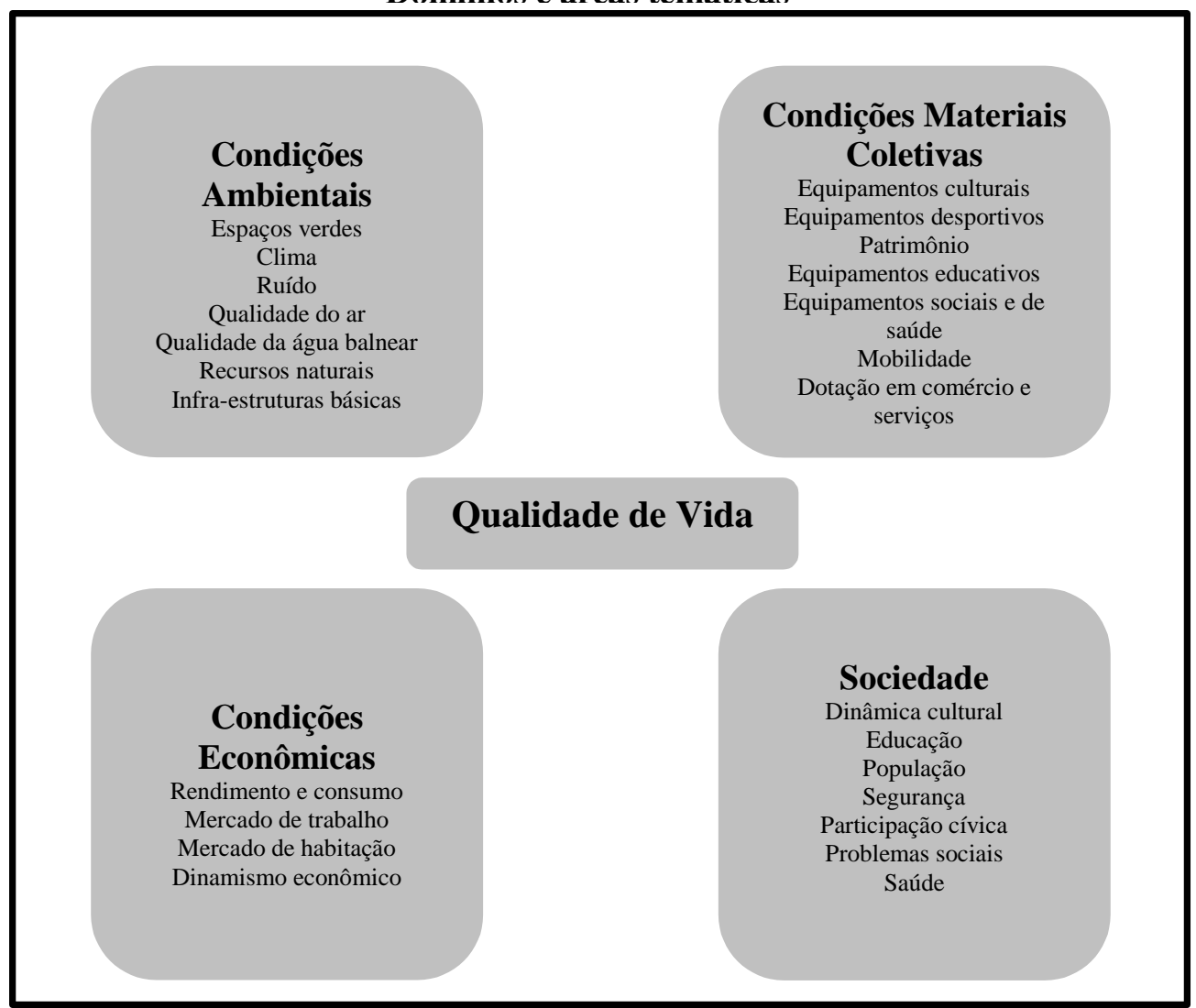

Figura 12: Domínios e áreas temáticas da QV segundo Santos e Martins (2002) Fonte: Santos e Martins (2002) p. 15.

\subsubsection{2 Índice de Qualidade de Vida Urbana da cidade de Belo Horizonte - IQVU-BH}

O IQVU-BH é um sistema de avaliação da QV bastante conhecido e divulgado no Brasil. Ele é um índice que busca expressar o acesso da população a serviços e recursos urbanos, sendo calculado a partir de indicadores georreferenciados em 81 unidades espaciais da cidade, denominadas Unidades de Planejamento (UP). Este índice foi elaborado para instrumentalizar uma distribuição mais equânime dos recursos públicos municipais (NAHAS et al., 1996).

A construção desse índice contou com a participação de representantes da Prefeitura de Belo Horizonte. Os temas abordados foram escolhidos por um grupo de gestores setoriais e 
regionais utilizando-se consultas múltiplas até que se formassem posições majoritárias sobre os temas. A partir da seleção dos temas na estrutura do índice, os gestores setoriais foram novamente chamados à participar de reuniões específicas, para definir os desdobramentos de cada tema e formular proposições de possíveis indicadores "ideais". Posteriormente, o mesmo grupo definiu os pesos com que cada tema entraria no cálculo do índice ao final.

O IQVU-BH/1996 abrange 11 variáveis: Abastecimento, Assistência Social, Cultura, Educação, Esportes, Habitação, Infra-estrutura, Meio Ambiente, Saúde, Serviços Urbanos e Segurança Urbana. Estas desdobram-se em 29 componentes e estes, em 75 (setenta e cinco) indicadores (Quadro 3).

Quadro 3: Síntese da composição do IQVU-BH/1996

\begin{tabular}{|c|c|c|}
\hline Variável & Componentes & Indicadores \\
\hline \multirow[t]{2}{*}{ Abastecimento } & Equipamentos & Área por habitante de hiper e supermercados, mercearias, restaurantes e similares \\
\hline & Cesta Básica & Economia de compra possível \\
\hline Assistência Social & Equipamentos & Número de entidades de Assistência Social \\
\hline \multirow[t]{5}{*}{ Cultura } & Meios de Comunicação & Tiragem por habitante de jornais locais \\
\hline & Patrimônio Cultural & Número de bens tombados e de grupos culturais \\
\hline & \multirow[t]{2}{*}{ Equipamentos Culturais } & $\mathrm{N}^{\circ}$. de equipamentos e freqüência de público \\
\hline & & Área/hab de livrarias e papelarias \\
\hline & Programações artístico-culturais & Número e freqüência às atividades culturais oferecidas \\
\hline \multirow[t]{2}{*}{ Educação } & Pré-Escolar & Taxa de matrícula e alunos/turma \\
\hline & $1^{\mathrm{a}}$. a $4^{\mathrm{a}}$. séries $/ 5^{\mathrm{a}}$. a $8^{\mathrm{a}}$. séries $/ 2^{\circ}$. grau & Taxa de matrícula, no. de alunos por turma e índice de aproveitamento \\
\hline \multirow[t]{2}{*}{ Esportes } & Equipamentos Esportivos & Área por habitante: quadras, piscinas, campos, clubes e congêneres \\
\hline & Promoções Esportivas & Número de eventos esportivos e freqüência de público \\
\hline \multirow[t]{3}{*}{ Habitação } & Disponibilidade & Área construída por habitante, sujeita a IPTU \\
\hline & Habitação & Padrão de acabamento das moradias \\
\hline & Conforto habitacional & Número de pessoas por dormitório \\
\hline \multirow{9}{*}{$\begin{array}{l}\text { Infra-Estrutura } \\
\text { Urbana }\end{array}$} & Limpeza Urbana & "Nota" p/ coleta, varrição e capina \\
\hline & \multirow[t]{2}{*}{ Saneamento } & Taxa e frequiência de fornecimento de água tratada. \\
\hline & & Disponibilidade de rede de esgoto \\
\hline & \multirow[t]{2}{*}{ Energia Elétrica } & Taxa de fornecimento domiciliar \\
\hline & & Iluminação pública \\
\hline & \multirow[t]{2}{*}{ Telefonia } & Taxa de ruas com rede telefônica \\
\hline & & Qualidade das ligações \\
\hline & \multirow[t]{2}{*}{ Transporte coletivo } & Possibilidade de acesso de transporte (pavimentação) \\
\hline & & Número e conforto dos veículos \\
\hline \multirow[t]{3}{*}{ Meio Ambiente } & Conforto Acústico & No. de perturbações ruidosas \\
\hline & Qualidade do ar & Autuações veículos transporte coletivo \\
\hline & Área Verde & Área/hab com cobertura vegetal \\
\hline \multirow[t]{3}{*}{ Saúde } & Atenção à Saúde & $\begin{array}{l}\text { Número por habitante de: leitos hospitalares, postos de saúde, outros equipamentos } \\
\text { de Assistência Médica e equipamentos odontológicos }\end{array}$ \\
\hline & \multirow[t]{2}{*}{ Vigilância à Saúde } & Taxa de sobrevivência até um ano \\
\hline & & Taxa de nascidos c/ peso normal \\
\hline \multirow[t]{3}{*}{ Serviços Urbanos } & Serviços pessoais & $\mathrm{N}^{\mathrm{o}}$. de agências bancárias, pontos de táxi e postos de gasolina \\
\hline & \multirow[t]{2}{*}{ Serviços de Comunicação } & $\mathrm{N}^{\circ}$. de agências de correio, bancas de revistas e telefones públicos \\
\hline & & Funcionamento telefones públicos \\
\hline \multirow[t]{6}{*}{ Segurança Urbana } & \multirow[t]{2}{*}{ Atendimento Policial } & Número de equipamentos, efetivo policial e viaturas \\
\hline & & Tempo de espera para atendimento policial \\
\hline & Segurança Pessoal & $\begin{array}{l}\text { Ausência de: homicídios, tentativas de homicídios, violações de domicílio, } \\
\text { estupros, roubos, porte ilegal de armas, atentados ao pudor e lesões corporais. }\end{array}$ \\
\hline & Segurança Patrimonial & Ausência de roubo e furto de veículos e a moradias e estabelecimentos. \\
\hline & Segurança no Trânsito & $\begin{array}{l}\text { Ausência de acidentes com ou sem vítimas, ocasionados por direção perigosa de } \\
\text { veículos, abalroamentos, colisões, choques, atropelamentos e capotamentos. }\end{array}$ \\
\hline & Segurança Habitacional & Grau de pré-disposição ao risco geológico \\
\hline
\end{tabular}


A agregação destas variáveis é feita por meio de média aritmética ponderada para construção de um índice global. Nahas et al. (1996) descrevem o cálculo do IQVU-BH, de forma simplificada, em três etapas: primeiro, os indicadores são agregados em componentes e estes em variáveis, por meiode médias aritméticas simples, produzindo-se um Índice de Oferta Local por variável, para cada UP; estes Índices de Oferta Local são corrigidos por uma medida de acessibilidade cujo valor depende da variável. A medida de acessibilidade visa tornar o cálculo mais preciso, considerando o fato de que a população de uma UP acessa serviços também em outras UP, aumentando a sua oferta e diminuindo a oferta da outra UP. Tal correção pela medida de acessibilidade produz os Índices Setoriais; os Índices Setoriais são agregados utilizando-se média aritmética ponderada (Quadro 4), num índice único, o IQVU de cada UP.

A classificação final das UP's é dada por faixas que são apresentadas em mapas temáticos.

Quadro 4: Pesos das variáveis do IQVU-BH/1996
\begin{tabular}{|l|c|}
\hline \multicolumn{1}{|c|}{ Variáveis } & Pesos \\
\hline Habitação & 17,66 \\
\hline Infra-estrutura Urbana & 15,75 \\
\hline Saúde & 13,72 \\
\hline Educação & 12,65 \\
\hline Serviços Urbanos & 10,43 \\
\hline Segurança Urbana & 7,95 \\
\hline Abastecimento & 7,64 \\
\hline Meio Ambiente & 6,19 \\
\hline Cultura & 3,17 \\
\hline Esportes & 3,05 \\
\hline Assistência Social & 1,79 \\
\hline
\end{tabular}

\subsubsection{Indicador de Qualidade de Vida da cidade de Itajaí}

Este indicador visa compreender melhor a situação da qualidade de vida no bairro Praia Brava, na cidade de Itajaí, Santa Catarina. O trabalho reporta-se a formulação de indicadores sociais adequados ao local de análise, utilizando um conjunto de variáveis relacionadas à qualidade de vida no bairro, como educação, saneamento, habitação e saúde (GUEDES; ARAÚJO, 2004).

Os dados utilizados para a caracterização da qualidade de vida do bairro são oriundos do Sistema de informação da atenção básica e gerados a partir do trabalho das equipes do Programa de saúde da família e Agentes comunitários de saúde, obtidos por meio de visitas 
domiciliares. Outros dados, referentes ao saneamento básico, foram obtidos junto a empresa responsável pelas ações de saneamento do município.

Os indicadores foram agrupados segundo o Quadro 5 e o sistema utiliza critérios de classificação em intervalos, que recebem três denominações: Bom, Satisfatório e Ruim. A cada denominação é atribuída uma nota: 10, 5 e 1 respectivamente. Essas notas determinam o intervalo de variação do indicador final, visto que o sistema não utiliza pesos diferenciados para cada indicador, apenas uma somatória.

É importante notar que neste sistema é possível qualificar cada subindicador de acordo com os intervalos mencionados, o que facilita o entendimento. Embora, não esteja claro quais critérios foram utilizados nesta construção.

Quadro 5: Indicadores de Qualidade de Vida de Itajaí

\begin{tabular}{|c|c|c|c|c|c|}
\hline \multicolumn{3}{|c|}{ Indicadores } & Bom & Satisfatório & Ruim \\
\hline \multirow[t]{2}{*}{ Educação } & \multirow[t]{2}{*}{ Alfabetização } & 7 a 14 anos na escola & $>95 \%$ & $95-75 \%$ & $<75 \%$ \\
\hline & & $>15$ anos alfabetizado & $>95 \%$ & $95-75 \%$ & $<75 \%$ \\
\hline \multirow{9}{*}{ Saneamento } & \multirow[t]{3}{*}{ Abastecimento de água } & Rede pública & $>95 \%$ & $95-75 \%$ & $<75 \%$ \\
\hline & & Poço ou nascente & $<5 \%$ & $5-10 \%$ & $>10 \%$ \\
\hline & & Outros & $0 \%$ & $0-1 \%$ & $>1 \%$ \\
\hline & \multirow[t]{3}{*}{ Esgoto } & Sistema de esgoto & $<5 \%$ & $5-10 \%$ & $>10 \%$ \\
\hline & & Fossa & $>95 \%$ & $95-75 \%$ & $<75 \%$ \\
\hline & & Céu aberto & $0 \%$ & $0-1 \%$ & $>1 \%$ \\
\hline & \multirow[t]{3}{*}{ Resíduo sólido } & Coleta pública & $>95 \%$ & $95-75 \%$ & $<75 \%$ \\
\hline & & Queimado & $<5 \%$ & $5-10 \%$ & $>10 \%$ \\
\hline & & Céu aberto & $0 \%$ & $0-1 \%$ & $>1 \%$ \\
\hline \multirow[t]{4}{*}{ Habitação } & \multirow[t]{4}{*}{ Tipo de moradia } & Alvenaria & $>75 \%$ & $75-50 \%$ & $<50 \%$ \\
\hline & & Madeira & $<25 \%$ & $25-50 \%$ & $>50 \%$ \\
\hline & & Material aproveitado & $0 \%$ & $0-1 \%$ & $>1 \%$ \\
\hline & & Outros & $0 \%$ & $0-1 \%$ & $>1 \%$ \\
\hline \multirow[t]{2}{*}{ Saúde } & \multirow[t]{2}{*}{ Assistência } & Assistência PSF & $>95 \%$ & $95-75 \%$ & $<75 \%$ \\
\hline & & Plano de Saúde & $>25 \%$ & $25-10 \%$ & $<10 \%$ \\
\hline
\end{tabular}

Fonte: Guedes e Araújo (2004)

Neste sistema a QV é avaliada utilizando-se a somatória de pontos obtidos em cada variável e classificada de acordo com a sua pontuação nas classes do Quadro 6.

Quadro 6: Classificação da Qualidade de Vida de Itajaí

\begin{tabular}{|c|c|}
\hline Pontuação & Classificação \\
\hline $128-170$ & Qualidade de vida alta \\
\hline $85-127$ & Qualidade de vida boa \\
\hline $51-84$ & Qualidade de vida satisfatória \\
\hline $17-50$ & Qualidade de vida ruim \\
\hline
\end{tabular}

Assim como no caso dos critérios de construção dos intervalos, não há uma justificativa clara para a definição destas classes. Além do que é importante manter uma padronização da classificação, ou seja, "alta", "boa”, "satisfatória"e "ruim” não apresentam uma mesma linha 
de avaliação, uma escala mais adequada, talvez fosse "Ruim", "Regular", "Boa" e "Ótima", assim mantemos o sentido da gradação da escala.

\subsubsection{Indicadores de salubridade ambiental}

\subsubsection{Indicador de Salubridade Ambiental - ISA}

O ISA proposto pelo Conselho de Saneamento do Estado de São Paulo (Conesan) tem o objetivo de subsidiar a elaboração de políticas públicas do Governo do Estado de São Paulo na área de saneamento básico, é um indicador, calculado para todos os municípios do Estado de São Paulo por meio de média ponderada de uma série de indicadores relacionados direta ou indiretamente com a salubridade ambiental (PIZA; GREGORI, 1999).

O ISA é composto por indicadores selecionados da área de saneamento ambiental, sócioeconômico, da saúde pública e de recursos hídricos. Foram escolhidas variáveis disponíveis e de fácil tabulação no sentido de facilitar a elaboração do relatório. Estas variáveis formam seis grupos de indicadores (Quadro 7).

Quadro 7: Componentes e variáveis do ISA

\begin{tabular}{|c|c|c|}
\hline Componente & Variável & Finalidade \\
\hline \multirow[t]{3}{*}{$\begin{array}{l}\text { Abastecimento de Água } \\
\text { (Peso: } 30 \% \text { ) }\end{array}$} & Cobertura & $\begin{array}{l}\text { Quantificar os Domicílios atendidos por sistemas de abastecimento de água } \\
\text { com controle sanitário. }\end{array}$ \\
\hline & $\begin{array}{l}\text { Qualidade da Água } \\
\text { Fornecida }\end{array}$ & Monitorar a qualidade da água fornecida \\
\hline & $\begin{array}{l}\text { Saturação dos Sistemas } \\
\text { Produtores }\end{array}$ & $\begin{array}{l}\text { Comparar oferta e demanda para programação de novos sistemas produtores } \\
\text { e/ou programação de redução de perdas. }\end{array}$ \\
\hline \multirow{2}{*}{$\begin{array}{l}\text { Esgoto Sanitário (Peso: } \\
20 \% \text { ) }\end{array}$} & Cobertura em Coleta & Quantificar os domicílios atendidos por coleta de esgotos. \\
\hline & Saturação do Tratamento & $\begin{array}{l}\text { Comparar oferta e demanda das instalações existentes e programar novas } \\
\text { instalações ou ampliações }\end{array}$ \\
\hline \multirow{3}{*}{$\begin{array}{l}\text { Resíduos Sólidos (Peso: } \\
20 \% \text { ) }\end{array}$} & Coleta de Lixo & Quantificar os domicílios atendidos \\
\hline & $\begin{array}{l}\text { Tratamento e Disposição } \\
\text { Final }\end{array}$ & Qualificar a situação da disposição final dos resíduos \\
\hline & $\begin{array}{l}\text { Saturação da Disposição } \\
\text { Final }\end{array}$ & Indicar a necessidade de novas instalações \\
\hline $\begin{array}{l}\text { Indicador Regional } \\
\text { (Peso: } 10 \% \text { ) }\end{array}$ & $\begin{array}{l}\text { a definir pelos comitês de } \\
\text { bacia }\end{array}$ & $\begin{array}{l}\text { Durante as reuniões, dos comitês de bacia, tem sido identificadas algumas } \\
\text { necessidades e particularidades locais que colocam em risco a saúde das } \\
\text { populações ou a Qualidade do Ambiente e que demandam ações do Sistema } \\
\text { Estadual de Saneamento. }\end{array}$ \\
\hline \multirow{3}{*}{$\begin{array}{l}\text { Indicador Sócio- } \\
\text { Econômico (Peso: 10\%) }\end{array}$} & Saúde & Indicar a possibilidade de serviços de saneamento inadequados \\
\hline & Renda & $\begin{array}{l}\text { Indicar a capacidade de pagamento da população pelos serviços e a } \\
\text { capacidade de investimento pelo município }\end{array}$ \\
\hline & Educação & $\begin{array}{l}\text { Indicar a linguagem de comunicação nas campanhas de Educação Sanitária e } \\
\text { Ambiental }\end{array}$ \\
\hline
\end{tabular}

Fonte: Piza e Gregori (1999) 
Para o cálculo da pontuação de cada variável, foram estabelecidos determinados critérios no tratamento dos dados coletados, como: faixas de população, de atendimento, de tempo de saturação, de concentração e distribuição de dados; interpolação de valores, bem como pesos de ponderação.

Os indicadores de renda e de educação são indicadores auxiliares para orientar as campanhas institucionais do Governo junto à população quanto à receptividade, compreensão e retorno.

Embora este sistema tenha alcançado uma grande repercussão, servindo de base e estimulando a criação de sistemas semelhantes, não foi possível obter resultados de sua aplicação.

\subsubsection{Indicadores de Salubridade Ambiental para Favelas Urbanizadas - ISA/F}

Como afirmamos, o ISA serviu de base estímulo para o estabelecimento de sistemas semelhantes do qual faz parte o ISA/F.

O ISA/F foi elaborado a partir da necessidade de verificar, periodicamente, as condições de salubridade ambiental de favelas urbanizadas. Segundo Almeida (1999), desenvolveu-se um método simples, direto e relativamente pouco trabalhoso de ser aplicado. O método proposto pode ser utilizado também para: analisar a situação de salubridade ambiental de uma favela antes e depois de sua urbanização; verificar se os trabalhos de urbanização executados estão atendendo as expectativas iniciais e; monitorar a manutenção dos serviços executados.

$\mathrm{O}$ ISA/F tem como função principal construir uma hierarquia de favelas quando empregado de forma comparativa. A utilização conjunta desses indicadores constitui-se um instrumento para subsidiar o processo de tomada de decisões relacionado ao planejamento de políticas públicas, as quais se encontram voltadas para a gestão urbana e, por conseguinte, para a melhoria da qualidade de vida dos moradores em áreas urbanas, da preservação do meio ambiente e dos recursos hídricos.

O ISA/F possui 14 indicadores que são descritos no Quadro 8. Segundo o autor, estes indicadores possuem sensibilidade suficiente para permitir que qualquer favela urbanizada possa ser avaliada pelo método proposto e, pelos resultados obtidos em cada área, serem comparados eqüitativamente. 
Os indicadores selecionados têm por objetivo mensurar, de forma individualizada, os elementos que interferem na funcionalidade das ações existentes na favela. Sua representação é realizada utilizando-se uma pontuação com variação de 0 (zero) a 100 (cem).

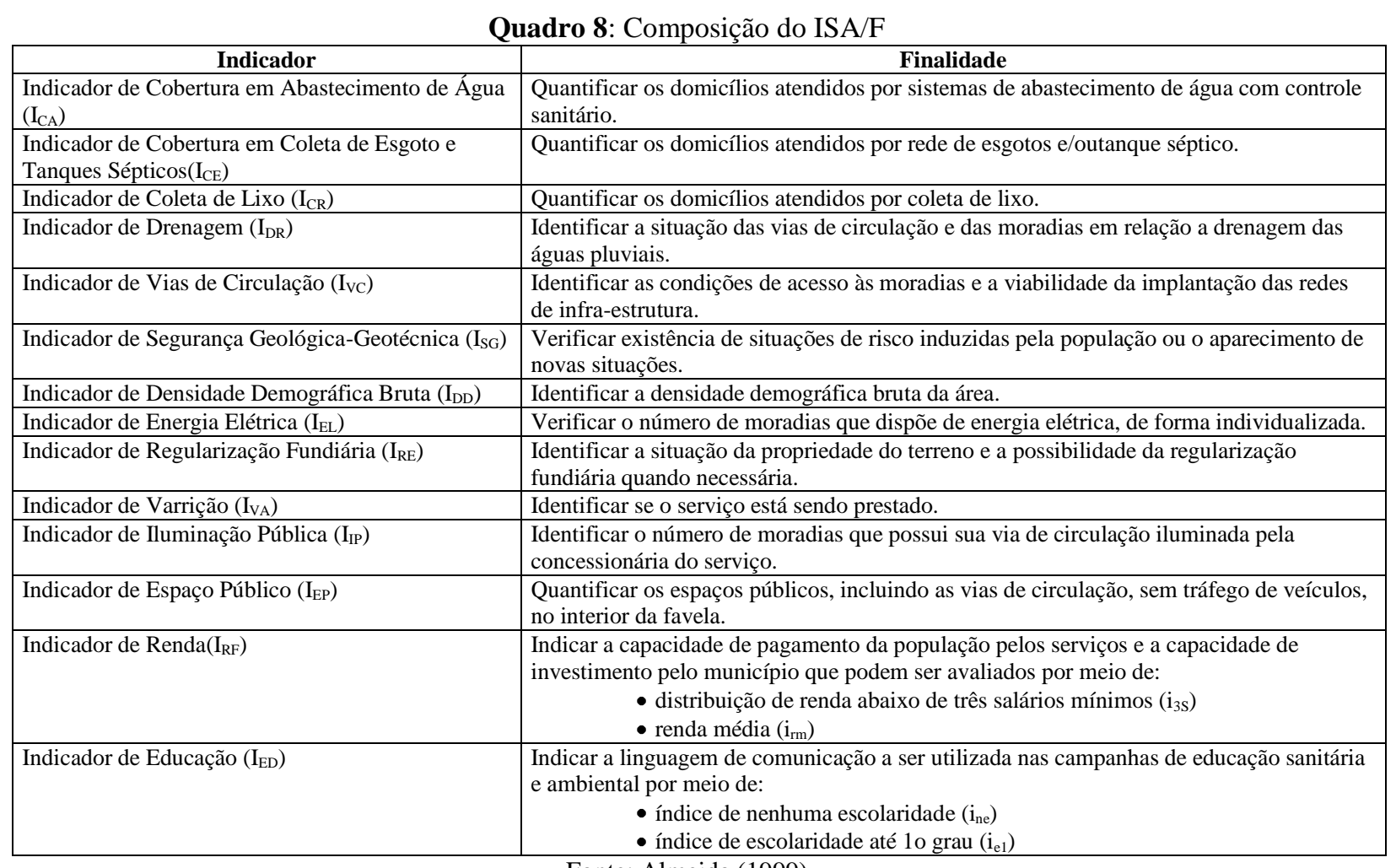

Fonte: Almeida (1999)

Após o cálculo da pontuação de todos os indicadores propostos, os resultados obtidos são agregados pelo ISA/F e calculada a nota média final correspondente. Neste cálculo, todos os indicadores têm o mesmo peso. A nota final é classificada de acordo com o Quadro 9.

Quadro 9: Classificação da Salubridade de acordo com o ISA/F

\begin{tabular}{|l|c|}
\hline \multicolumn{1}{|c|}{ Situação } & Indicador \\
\hline Salubridade positiva & $\mathrm{I}>85$ \\
\hline Salubridade moderada & $70 \leq \mathrm{I} \leq 85$ \\
\hline Salubridade insatisfatória & $\mathrm{I}<70$ \\
\hline
\end{tabular}

Fonte: Almeida (1999)

4.2.5.3 Indicadores de Salubridade Ambiental para Áreas de Ocupação Espontânea ISA/OE

Também baseado no ISA e no ISA/F, O ISA/OE é um indicador para áreas de ocupação espontânea dividido em dois fatores. Os fatores materiais que contemplam quatros componentes do saneamento ambiental: abastecimento de água, esgotamento sanitário, resíduos sólidos e drenagem urbana, acrescidas as condições de moradia do domicílio e os 
fatores sociais que constituem-se nos componentes socioeconômico-culturais e de saúde ambiental (DIAS; BORJA; MORAES, 2004).

Este fatores (ou condições) são formados por componentes, que por sua vez são formados por variáveis, que possuem um indicador associado (Quadro 10).

Quadro 10: Condições, componentes, variáveis e Indicadores de composição do ISA/OE

\begin{tabular}{|c|c|c|c|}
\hline Condição & Componente & Variável & Indicador \\
\hline \multirow{17}{*}{ Material } & \multirow{4}{*}{$\begin{array}{l}\text { Abasteciment } \\
\text { o de Água } \\
\left(\mathrm{I}_{\mathrm{AA}}\right)\end{array}$} & Origem da água no domicílio & Domicílios atendidos com rede pública (\%) \\
\hline & & $\begin{array}{l}\text { Freqüuencia do abastecimento no } \\
\text { domicílio }\end{array}$ & Domicílios que nunca ou raramente faltam água (\%) \\
\hline & & $\begin{array}{l}\text { Quantidade de água utilizada no } \\
\text { domicílio }\end{array}$ & Consumo médio per capita de água (L/hab.dia) \\
\hline & & Qualidade da água da rede & $\begin{array}{l}\text { Amostras de água sem coliformes termotolerantes (fecais) da rede de } \\
\text { distribuição }(\%)\end{array}$ \\
\hline & \multirow{2}{*}{$\begin{array}{l}\text { Esgotamento } \\
\text { Sanitário }\left(\mathrm{I}_{\mathrm{ES}}\right)\end{array}$} & $\begin{array}{l}\text { Destino dos dejetos sanitários do } \\
\text { domicílio }\end{array}$ & Domicílios com destinação adequada dos dejetos sanitários (\%) \\
\hline & & $\begin{array}{l}\text { Destino das águas servidas do } \\
\text { domicílio }\end{array}$ & Domicílios com destinação adequada das águas servidas (\%) \\
\hline & \multirow{2}{*}{$\begin{array}{l}\text { Resíduos } \\
\text { Sólidos }\left(\mathrm{I}_{\mathrm{RS}}\right)\end{array}$} & $\begin{array}{l}\text { Regularidade da coleta de resíduos } \\
\text { sólidos domiciliares }\end{array}$ & Domicílios com coleta regular de resíduos sólidos (\%) \\
\hline & & $\begin{array}{l}\text { Existência de coleta de resíduos } \\
\text { sólidos domiciliares }\end{array}$ & $\begin{array}{l}\text { Domicílios com resíduos sólidos coletados sob responsabilidade da } \\
\text { LIMPURB }(\%)\end{array}$ \\
\hline & \multirow{2}{*}{$\begin{array}{l}\text { Drenagem } \\
\text { Urbana }\left(\mathrm{I}_{\mathrm{DU}}\right)\end{array}$} & $\begin{array}{l}\text { Ocorrência de inundações ou } \\
\text { alagamentos no domicílio }\end{array}$ & Domicílios sem ocorrência de inundações ou alagamentos (\%) \\
\hline & & $\begin{array}{l}\text { Pavimentação da rua onde se situa o } \\
\text { domicílio }\end{array}$ & Domicílios cujas ruas possuem pavimentação (\%) \\
\hline & \multirow{7}{*}{$\begin{array}{l}\text { Condições da } \\
\text { Moradia }\left(\mathrm{I}_{\mathrm{CM}}\right)\end{array}$} & $\begin{array}{l}\text { Material usado nas paredes do } \\
\text { domicílio }\end{array}$ & Domicílios com parede com reboco $(\%)$ \\
\hline & & Material usado no piso do domicílio & Domicílios com piso adequado $(\%)$ \\
\hline & & $\begin{array}{l}\text { Material usado na cobertura do } \\
\text { domicílio }\end{array}$ & Domicílios com cobertura adequada $(\%)$ \\
\hline & & Existência de sanitário no domicílio & Domicílios que possuem sanitário (\%) \\
\hline & & Como a água chega no domicílio & Domicílios com canalização interna completa (\%) \\
\hline & & $\begin{array}{l}\text { Acondicionamento da água no } \\
\text { domicílio }\end{array}$ & Domicílios que guardam água em reservatório com tampa (\%) \\
\hline & & Qualidade da água no domicílio & Amostras sem coliformes termotolerantes (fecais) na água de beber (\%) \\
\hline \multirow{12}{*}{ Social } & \multirow{10}{*}{$\begin{array}{l}\text { Socioeconômi } \\
\text { co e Cultural } \\
\left(\mathrm{I}_{\mathrm{SE}}\right)\end{array}$} & Situação de propriedade do domicílio & Domicílios próprios pagos ou financiados $(\%)$ \\
\hline & & Renda mensal familiar & Renda média mensal familiar (salário mínimo) \\
\hline & & $\begin{array}{l}\text { Aglomeração (número de pessoas por } \\
\text { cômodo) }\end{array}$ & Número médio de habitantes por cômodo (um) \\
\hline & & $\begin{array}{l}\text { Acondionamento de resíduos sólidos } \\
\text { no domicílio }\end{array}$ & $\begin{array}{l}\text { Domicílios com acondicionamento adequado de resíduos sólidos no } \\
\text { domicílio }(\%)\end{array}$ \\
\hline & & Uso da cozinha no domicílio & Domicílios cuja cozinha é utilizada apenas para preparar alimentos (\%) \\
\hline & & Animais no domicílio & Domicílios que não possuem animais (\%) \\
\hline & & Existência de lavatório no domicílio & Domicílios que possuem lavatório (\%) \\
\hline & & $\begin{array}{l}\text { Escolaridade do cabeça da família no } \\
\text { domicílio }\end{array}$ & Domicílios cujo cabeça da família possui pelo menos 10 . Grau completo (\%) \\
\hline & & Tempo de residência no domicílio & $\begin{array}{l}\text { Domicílios cujos moradores residam a } 5 \text { ou mais anos - medido pelo cabeça } \\
\text { da família }(\%)\end{array}$ \\
\hline & & Tratamento da água no domicílio & Domicílios que dão tratamento doméstico a água (\%) \\
\hline & \multirow{2}{*}{$\begin{array}{l}\text { Saúde } \\
\text { Ambiental } \\
\left(\mathrm{I}_{\mathrm{SA}}\right)\end{array}$} & Resíduos próximos ao domicílio & Domicílios sem resíduos nas suas proximidades - distância =10m (\%) \\
\hline & & Presença de vetores no domicílio & Domicílios que não apresentaram aumento de vetores (\%) \\
\hline
\end{tabular}

Fonte: Dias, Borja e Moraes (2004)

Os indicadores são ponderados de acordo com o Quadro 11 e o resultado final é classificado de acordo com os níveis de salubridade do Quadro 12. 
Assim como nos indicadores apresentados anteriormente não há uma clara explicação sobre os critérios que definiram estas classes de salubridade.

Quadro 11: Ponderação dos componentes do ISA/OE

\begin{tabular}{|c|c|}
\hline Componente & Ponderação \\
\hline $\mathrm{I}_{\mathrm{AA}}-$ Componente abastecimento de água & 0,20 \\
\hline $\mathrm{I}_{\mathrm{ES}}-$ Componente esgotamento sanitário & 0,20 \\
\hline $\mathrm{I}_{\mathrm{RS}}-$ Componente resíduos sólidos & 0,15 \\
\hline $\mathrm{I}_{\mathrm{DU}}-$ Componente drenagem urbana & 0,10 \\
\hline $\mathrm{I}_{\mathrm{CM}}-$ Componente condições de moradia & 0,15 \\
\hline $\mathrm{I}_{\mathrm{SE}}-$ Componente socioeconômico e cultural & 0,10 \\
\hline $\mathrm{I}_{\mathrm{SA}}-$ Componente saúde ambiental & 0,10 \\
\hline$\Sigma$ & 1,00 \\
\hline
\end{tabular}

Fonte: Dias, Borja e Moraes (2004)

Quadro 12: Situação de salubridade por faixas de pontuação do ISA/OE

\begin{tabular}{|l|c|}
\hline \multicolumn{1}{|c|}{ Situação de salubridade } & Pontuação \\
\hline Insalubre & $0-25$ \\
\hline Baixa salubridade & $26-50$ \\
\hline Média salubridade & $51-75$ \\
\hline Salubre & $76-100$ \\
\hline
\end{tabular}

Fonte: Dias, Borja e Moraes (2004)

\subsubsection{Indicadores de sustentabilidade}

De acordo com a Comissão de Desenvolvimento Sustentável das Nações Unidas (Comission on Sustainable Development (CSD)), durante a Eco-92, com a adoção da Agenda 21, foi estabelecido o compromisso para a criação de indicadores de desenvolvimento sustentável para prover a tomada de decisão em todos os níveis (UNITED NATIONS (UN), 2007).

Ainda segundo a CSD, os indicadores desempenham diversas funções. Eles podem tanto levar a decisões melhores e ações mais efetivas pela simplificação, clareamento e transformação agregada de informação disponível para elaboradores de políticas, quanto podem ajudar a incorporar o conhecimento físico e social na tomada de decisão. Além disso, eles podem ajudar a medir e calibrar o progresso para os objetivos do desenvolvimento sustentável.

Para o atendimento ao que foi estabelecido na ECO-92, em 1995 a CSD publicou um guia de diretrizes e metodologias para o desenvolvimento destes indicadores. Nesta publicação foram listados 134 indicadores que foram testados no período de 1996 a 1999 em 22 países voluntários em forma de piloto. Como resultado deste piloto, em 2001 uma nova publicação foi divulgada com a revisão dos indicadores os quais foram reduzidos para 58, encaixados em um quadro político-orientado de temas e subtemas (Quadro 13). Em 2005, devido ao grande 
desenvolvimento na área foi iniciado um novo processo de revisão destes indicadores. Nesta nova revisão constam 50 indicadores-base que fazem parte de um conjunto maior de 96 indicadores de desenvolvimento sustentável. Estes 50 indicadores-base podem ser calculados para a maioria dos países e representam aspectos únicos do desenvolvimento sustentável, enquanto que os demais são relevantes apenas para um pequeno grupo de países e fornecem somente informações complementares (UN, 2007).

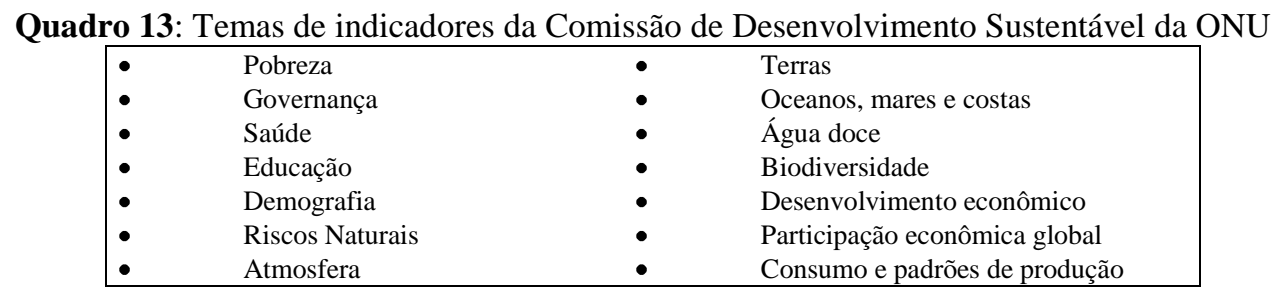

Os indicadores de desenvolvimento sustentável, propostos pela CSD, tentam medir o desenvolvimento sustentável em sua totalidade, levando em conta a sua natureza multidimensional e integrada.

No processo de seleção e adaptação destes indicadores para as diferentes realidades locais a CSD recomenda que sejam levados em consideração critérios, onde cada indicador deva ser:

- principalmente de âmbito nacional;

- relevante para avaliar os progressos do desenvolvimento sustentável;

- em número limitado, mas que se mantenham em aberto e adaptável às necessidades futuras;

- amplo na cobertura da Agenda 21 e de todos os aspectos do desenvolvimento sustentável;

- compreensível, claro e inequívoco;

- conceitualmente eficiente;

- representante de um consenso internacional, na medida do possível;

- dentro das capacidades dos governos nacionais para o desenvolvimento; e

- dependente do custo efetivo dos dados de conhecida qualidade.

É importante lembrar que os objetivos da sustentabilidade estão relacionados a uma realidade local, logo, na elaboração de seus indicadores deve-se permitir que fatores relevantes 
localmente sejam levados em consideração. Isto pode nos levar a diferentes abordagens para a elaboração e inter-relação entre os indicadores propostos pela CSD. Além dessa diversidade, existem também diferentes abordagens na elaboração destes indicadores tais como:

- Abordagem pela relação Força Motriz-Estado-Resposta: é uma variação da abordagem Pressão-Estado-Resposta da OECD. Nesta abordagem, cada indicador é classificado como força motriz, estado ou resposta. Indicadores de força motriz descrevem processos ou atividades que tem um impacto positivo ou negativo no desenvolvimento sustentável. Indicadores de estado descrevem a situação atual, enquanto indicadores de resposta refletem ações da sociedade objetivando o desenvolvimento sustentável. Embora esta abordagem continue a ser usada, a CSD interrompeu-a, principalmente pela ambigüidade apresentada na classificação dos indicadores em força motriz, estado ou resposta.

- Abordagem baseada em questões ou temas: são freqüentemente mais utilizadas especialmente em conjuntos de indicadores nacionais. Nesta abordagem, os indicadores são agrupados em várias diferentes questões relacionadas ao desenvolvimento sustentável. A principal razão para a proeminência de abordagens temáticas é sua habilidade para ligar indicadores a processos e objetivos políticos, provendo uma mensagem clara e direta para os tomadores de decisão sobre quais as questões prioritárias.

- Abordagem de capital: tenta calcular o progresso nacional como uma função da soma das interações entre diferentes tipos de capital, incluindo não somente o capital financeiro e capital de bens produzidos, mas também os capitais naturais, humanos, sociais e institucionais.

- Abordagem de contabilidade: nesta abordagem todos os indicadores são extraídos de uma única base de dados permitindo agregação setorial e usando classificações e definições consistentes. Um sistema integrado de contas nacionais é necessário para o desenvolvimento desta abordagem, que pode não levar em conta todos os aspectos da sustentabilidade.

- Indicadores agregados: um grande esforço tem sido feito para desenvolver indicadores agregados de desenvolvimento sustentável. A maioria deles são fundamentalmente usados para aumentar a consciência e obter maior atenção na mídia. Exemplos destes indicadores incluem a Pegada Ecológica (Ecological Footprint), o Índice de 
Sustentabilidade Ambiental (Environmental Sustainability Index (ESI)) e o Índice de Desempenho Ambiental (Environmental Performance Index (EPI))

Assim como o conceito de desenvolvimento sustentável, o consenso sobre determinados indicadores ainda não foi atingido. Bellen (2005) faz uma análise comparativa de três ferramentas: o Ecological Footprint, o Dashboard of Sustainability e o Barometer of Sustainability e entre outras conclusões afirma que o problema efetivo de mensurar a sustentabilidade está relacionado à utilização de uma ferramenta que capture toda a complexidade do desenvolvimento, sem reduzir a significância de cada um dos escopos utilizados no sistema. O autor ressalta ainda, o desafio de superar as limitações implícitas na utilização de metodologias predominantemente quantitativas, visto que o conceito de desenvolvimento sustentável está relacionado a diferentes dimensões, que não estão necessariamente associadas a grandezas físicas.

Segundo Bellen (2005) nos últimos anos, diferentes sistemas vêm procurando trabalhar com a dimensão humana de uma forma qualitativa e esta abordagem quase sempre revela aspectos que são imperceptíveis numa análise quantitativa. O grande desafio quanto à utilização da abordagem qualitativa é o de conseguir formular ferramentas que não sacrifiquem as vantagens da utilização de sistemas de indicadores quantitativos, como, por exemplo, a comparabilidade no espaço e no tempo.

Um outro estudo a ser considerado foi desenvolvido pela OECD, sobre o desenvolvimento de indicadores. Este estudo toma como referência os Princípios de Bellagio para definição de indicadores de sustentabilidade (Quadro 14).

Quadro 14: Princípios de Bellagio

\begin{tabular}{|llll|}
\hline $1-$ & Guia de visão e metas & $6-$ & Abertura/transparência \\
$2-$ & Perspectiva holística & $7-$ & Comunicação efetiva \\
$3-$ & Elementos essenciais & $8-$ & Ampla participação \\
$4-$ & Escopo adequado & $9-$ & Avaliação constante \\
$5-$ & Foco prático & $10-$ & Capacidade institucional \\
\hline
\end{tabular}

Fonte: Hass, Brunvoll e Hoie (2002)

Além destes princípios, o estudo recomenda como critérios de seleção, a relevância política e utilidade para os usuários, a consistência analítica e a mensurabilidade dos indicadores. Por fim, entre as conclusões do trabalho, os autores relatam a dificuldade de definir desenvolvimento sustentável e o impacto na construção de indicadores, bem como a necessidade de contextualização dos indicadores propostos (HASS; BRUNVOLL; HOIE, 2002).

Há também um estudo realizado pela biblioteca Ciudades para un Futuro más Sostenible $(C F+S)$, resultado do estudo das iniciativas de sustentabilidade local dos municípios 
espanhóis que assinaram a Carta de Aalborg. Este estudo buscou fazer uma análise sobre o próprio processo desenvolvido por cada município e os indicadores utilizados para seu controle. A Carta de Aalborg foi aprovada em maio de 1994 pelas autoridades locais participantes na Conferencia europea sobre ciudades sostenibles celebrada em Aalborg, Dinamarca (AJA, 2004).

O estudo constatou que dos 117 municípios espanhóis pesquisados, apenas 49 (42\%) possuíam indicadores, em 9 (8\%) estavam pendentes de aprovação, em 18 (15\%) estavam em desenvolvimento e nos 41 (35\%) restantes não existiam indicadores.

Dos casos estudados, apenas em 30 casos foi possível obter todos os indicadores. Na maioria deles o número de indicadores está entre 25 e 50 indicadores (60\%), seguido de municípios com número de indicadores entre 50 e 100 (20\%), com menos de 25 (13\%) e maior que 100 $(7 \%)$.

Outro fato relevante mostrado pelo estudo está relacionado ao tipo de indicador de sustentabilidade presente nos municípios: em $100 \%$ dos casos estão presentes indicadores ambientais, em 92\% indicadores urbanísticos, em 80\% indicadores sociais, em 70\% econômicos e em $20 \%$ outros tipos. Percebe-se, desta forma a grande preocupação das variáveis ambientais, urbanas e sociais, atuais, em contraposição às variáveis econômicas, consideradas determinantes no século passado.

A seguir são apresentadas as áreas e as categorias de indicadores identificados neste estudo por área (Quadro 15). É importante ressaltar que os indicadores básicos são compostos, na maioria das vezes, por outros indicadores.

Quadro 15: Áreas e categorias de análise do Informe de Indicadores de Sustentabilidade - CF+S

\begin{tabular}{|c|c|c|c|}
\hline Área & Categorias & Área & Categorias \\
\hline Meio ambiente & $\begin{array}{l}\text { Agricultura } \\
\text { Água } \\
\text { Atmosfera } \\
\text { Energia } \\
\text { Gestão ambiental } \\
\text { Recursos } \\
\text { Resíduos } \\
\text { Ruído }\end{array}$ & Social & $\begin{array}{l}\text { Qualidade de vida } \\
\text { Educação ambiental } \\
\text { População } \\
\text { Identidade } \\
\text { Inclusão social } \\
\text { Participação } \\
\text { Segurança e saúde }\end{array}$ \\
\hline Economia & $\begin{array}{l}\text { Acessibilidade econômica } \\
\text { Produção } \\
\text { Setor privado } \\
\text { Serviço público } \\
\text { Trabalho }\end{array}$ & Urbanismo & $\begin{array}{l}\text { Dotações } \\
\text { Gestão e planejamento } \\
\text { Solo } \\
\text { Transporte }\end{array}$ \\
\hline
\end{tabular}




\subsection{CONSIDERAÇÕES SOBRE OS MÉTODOS DE AVALIAÇÃO}

A APO têm se firmado como uma ferramenta importante na análise de projetos. Dada a sua flexibilidade, é possível avaliar ambientes em diferentes escalas. Apresenta como pontos positivos, além desta flexibilidade de escalas, a idéia de aliar avaliação técnica e avaliação do morador. Por outro lado, embora haja uma variedade de métodos para a coleta das informações de avaliação do morador, ainda podem permanecer dúvidas quanto a capacidade de representação da realidade dos métodos de análise, logo, quanto a sua capacidade de produzir resultados satisfatórios.

Já os sistemas indicadores são utilizados em geral para a avaliação em grandes escalas, nações, estados ou municípios. Possuem um enfoque quantitativo muito forte e torna-se cada vez clara a necessidade de agregar informações qualitativas aos sistemas de indicadores. Outro ponto a destacar está relacionada a portabilidade dos indicadores básicos: percebemos em nossa análise que na maioria dos sistemas analisados os indicadores são os mesmos, porém compondo a análise de fenômenos diferentes. Por exemplo, é fácil notar a presença do indicador de abastecimento de água tanto nos indicadores de qualidade de vida quanto de salubridade ambiental ou de desenvolvimento sustentável De fato, esta portabilidade é um indicador da relevância da variável analisada, bem como da complementaridade que estes fenômenos apresentam. Porém, quanto maior a portabilidade dos indicadores selecionados maior deve ser o cuidado na contextualização e interpretação dos resultados.

Por fim, identificamos como pontos carentes de aperfeiçoamento nestes métodos:

- Na análise de dados de avaliação do morador provenientes da APO há a necessidade de desenvolvimento de ferramentas mais adequadas, ou seja, com maior capacidade de representação da realidade.

- Essa necessidade também torna-se evidente quando se busca agregar indicadores qualitativos aos sistemas propostos.

- Há uma necessidade de estabelecer critérios adequados de agregação no processo de construção de indicadores sintéticos.

- Há uma necessidade de formulação de critérios claros e bem definidos de parâmetros de comparação dos resultados, visto que essa definição tem sido feita de forma pouco explícita. 
Diante disso, concluímos que a APO tem um grande potencial para contribuir na construção de indicadores qualitativos baseados na avaliação dos moradores, visto a sua vasta produção na área de avaliação de satisfação mesmo com as dificuldades de manipulação deste tipo de dado. Assim, este estudo se propõe a aperfeiçoar as ferramentas de análise de dados qualitativos utilizando a Lógica Fuzzy para, além de obter informações mais consistentes, habilitá-los para o uso como indicadores de qualidade do ambiente urbano. Por outro lado, os sistemas de indicadores apresentam uma grande habilidade de analisar e sintetizar informações objetivas, podendo assim serem utilizados para a análise dos dados quantitativos. No capítulo seguinte, buscaremos realizar uma revisão da Lógica Fuzzy focada nas necessidades já levantadas, que são: analisar de forma mais consistentes dados qualitativos e desenvolver ferramentas que possibilitem a agregação, ou obtenção de indicadores sintéticos com base nestes dados e em dados de natureza quantitativa. 


\section{LÓGICA FUZZY: CONCEITOS E DEFINIÇÕES PARA ESTE TRABALHO}

Como já afirmado, a Lógica Fuzzy surge com a finalidade de processar as informações subjetivas, de natureza vaga e incerta, que encontramos na linguagem natural dos seres humanos (ZADEH, 1965).

A motivação inicial para a proposição da Lógica Fuzzy surge com a aceitação de que são muito freqüentes as classes de objetos encontrados no mundo real que não apresentam critérios precisos de pertinências como exemplo, a classe de pessoas altas, a classe de pessoas bonitas, a classe de pessoas jovens, a classe de velocidades altas, a classe de temperaturas confortáveis entre outros exemplos, carregados de subjetividade que fazem parte da linguagem cotidiana (ZADEH, 1965).

A subjetividade intrínseca de variáveis, apesar de ser utilizada em nosso cotidiano, transmitida e perfeitamente compreendida lingüisticamente entre interlocutores, tem invariavelmente permanecido fora do tratamento matemático tradicional (BARROS; BASSANEZI, 2006).

Barros e Bassanezi (2006) reforçam ainda que os questionamentos a respeito de incertezas têm sido preocupações de filósofos e de pesquisadores ao longo dos tempos. A busca da verdade, do que é e do que existe, é uma questão debatida desde a Grécia Antiga. Porém, Klir e Yuan (1995) afirmam que entre as várias mudanças paradigmáticas em ciência e matemática neste século, uma delas está relacionada ao conceito de incerteza. Em ciência esta mudança tem se manifestado pela transição gradual da visão tradicional, a qual insiste que a incerteza é indesejável e deve ser evitada de alguma forma, para uma visão alternativa, a qual é tolerante com a incerteza e insiste que a ciência não pode evitá-la, admitindo que ela tem sua utilidade.

Ainda segundo Klir e Yuan (1995), essa transição teve inicio no final do século XIX, quando os físicos passaram a trabalhar os processos no nível molecular. Embora as leis da mecânica newtoniana fossem precisas e relevantes, o estudo desses processos envolvia um número de variáveis e uma complexidade tal que novas teorias tiveram que ser desenvolvidas, as quais foram feitas utilizando-se bases estatísticas. Como vimos, a incerteza modelada de forma estocástica é de característica randômica. 
Num outro sentido, a Lógica Fuzzy busca modelar as incertezas relacionadas a vagueza, imprecisão e subjetividade dos conceitos da linguagem humana. Essa capacidade dos subconjuntos fuzzy de expressar transições graduais da pertinência a não pertinência e viceversa tem uma extensa utilidade. Ela provê não somente de uma significante e poderosa representação da medida de incerteza, mas também de uma significante representação de conceitos vagos expressados na linguagem natural.

Podemos exemplificar a utilidade desse tipo de modelagem com o seguinte problema: é possível afirmar qual o volume do astro cuja imagem é apresentada na Figura 13 a esquerda?

Mesmo que sejam feitas simplificações sobre a sua superfície, ainda assim permanecem questões relativas ao seu verdadeiro diâmetro. Numa abordagem simplificada, utilizado uma representação mais nítida, obtemos a representação da Figura 13 a direita. Nesta aproximação, já é possível obter, utilizando a fórmula para o cálculo do volume de uma esfera, o volume do astro representado pela Figura 13. Contudo, qual o grau de certeza que temos deste valor?

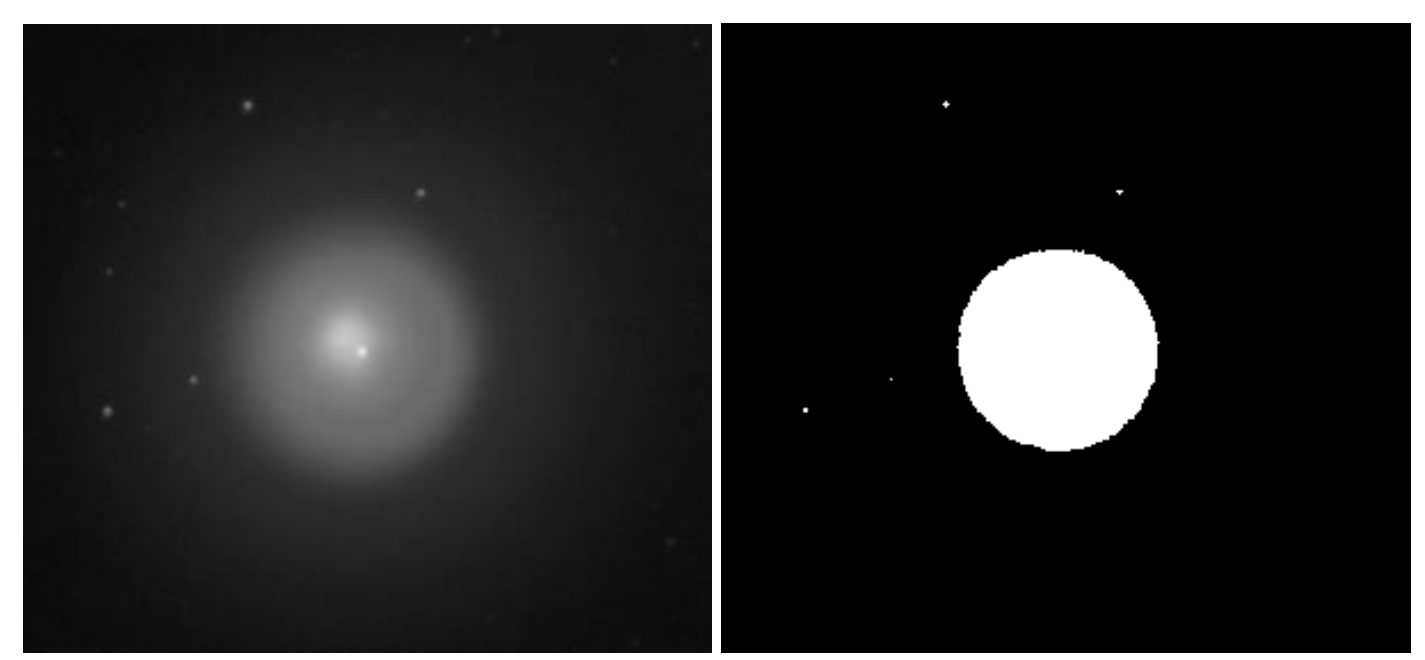

Figura 13: Exemplo de objeto fuzzy, à esquerda e representação simplificada à direita

$\mathrm{Na}$ abordagem fuzzy, podemos utilizar o seguinte recurso (Figura 14): arbitrando uma origem, podemos definir quais pontos temos certeza que pertencem ao astro (entre x2 e x3) e atribuímos a ele um grau de verdade, ou de certeza, ou ainda de pertinência igual a "1". Aos pontos que temos certeza que não pertencem (menores que x1 e maiores x4) atribuímos o grau de verdade " 0 ". Já aos pontos situados entre os que pertencem e não pertencem podem ser modelados como pertencentes em um determinado grau obtido por uma função, neste caso linear. Assim podemos obter diferentes volumes deste objeto, com diferentes graus de certeza. Por exemplo, se tomarmos o diâmetro formado pelos pontos entre x2 e x3, teremos um grau de certeza "1" no resultado obtido. Isso não quer dizer que temos certeza que este é o volume, 
mas que este volume pertence com certeza ao objeto. De outra forma, se tomarmos o diâmetro entre $\mathrm{x} 1$ e $\mathrm{x} 4$, teríamos grau de certeza " 0 ", ou seja, temos certeza de que o volume obtido com esta medida com certeza não pertence ao objeto. Neste processo introduzimos um dos conceitos mais importantes da Lógica $F u z z y$, o conceito de função de pertinência, ou função característica de um conjunto.

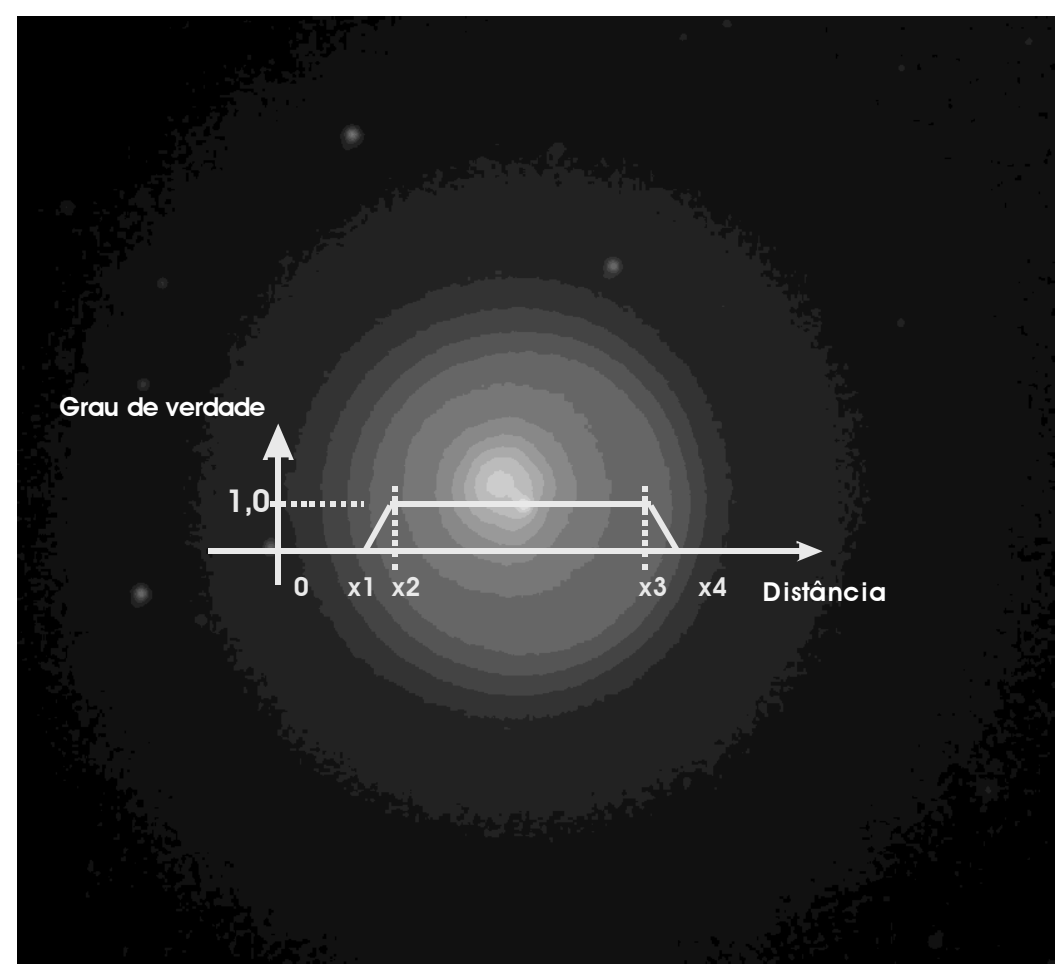

Figura 14: Exemplo de modelagem fuzzy

Outro exemplo pode ser dado com a modelagem da proposição: "a água está quente". Podemos modelar esta proposição em função da temperatura da água em graus Celsius. Pela metodologia clássica, utilizando conjuntos crisp, podemos definir "Quente" em relação a temperatura da água, como sendo o intervalo entre 50 e $90^{\circ} \mathrm{C}$. Ou seja, "Quente” é um subconjunto das temperaturas que pode ser definido como $\mathrm{Q} \subseteq T$, onde $\mathrm{Q}=\{\mathrm{x} \mid \mathrm{x} \in[50,90]\}$. Neste caso específico, podemos ver que uma temperatura de $50^{\circ} \mathrm{C}$ é considerada quente e um valor imediatamente inferior de $49,9^{\circ} \mathrm{C}$ já é considerado não-quente, ou fria. Também podemos representar o conjunto de temperatura "Quente" por sua função característica (Gráfico 3). 


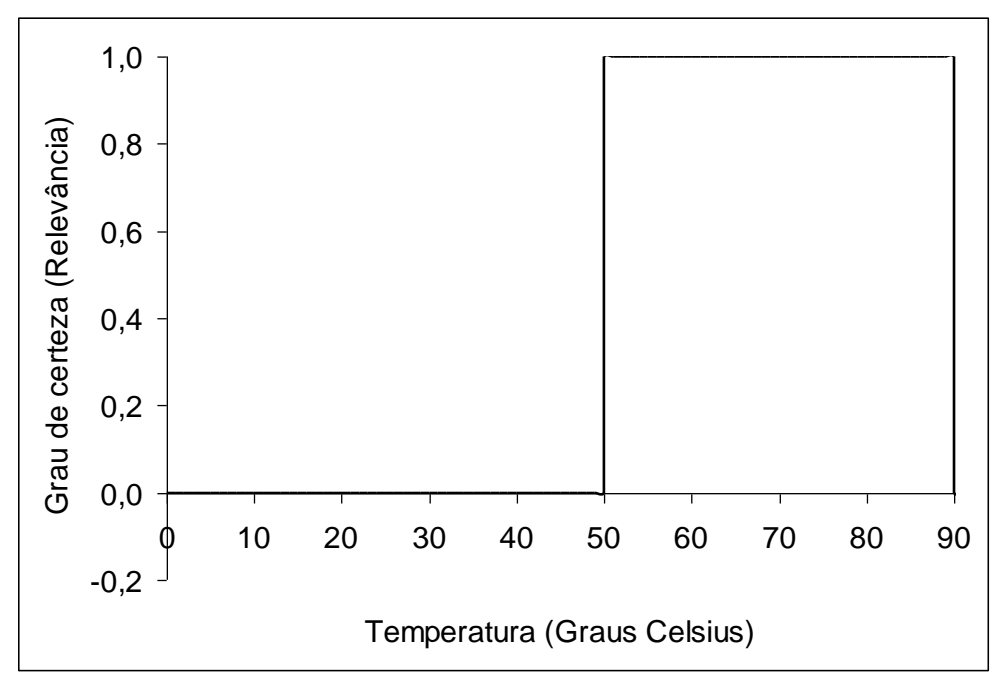

Gráfico 3: Modelagem crisp da definição de Quente

Esta modelagem tem muitas aplicações e utilidades específicas. Contudo em muitos casos, sofre de perda e distorção da informação. Em situações semelhantes, poderíamos afirmar que temperaturas próximas a $50^{\circ} \mathrm{C}$ podem ser considerada quentes, mas não totalmente. Neste ponto, a Lógica Fuzzy desempenha um papel importante. Pela sua abordagem podemos inserir a noção de grau de verdade, de pertinência ou de certeza das afirmações. Tomando o exemplo da temperatura acima, podemos associar a cada medida um grau de certeza de que ela pertence ao subconjunto “Quente” (Gráfico 4).

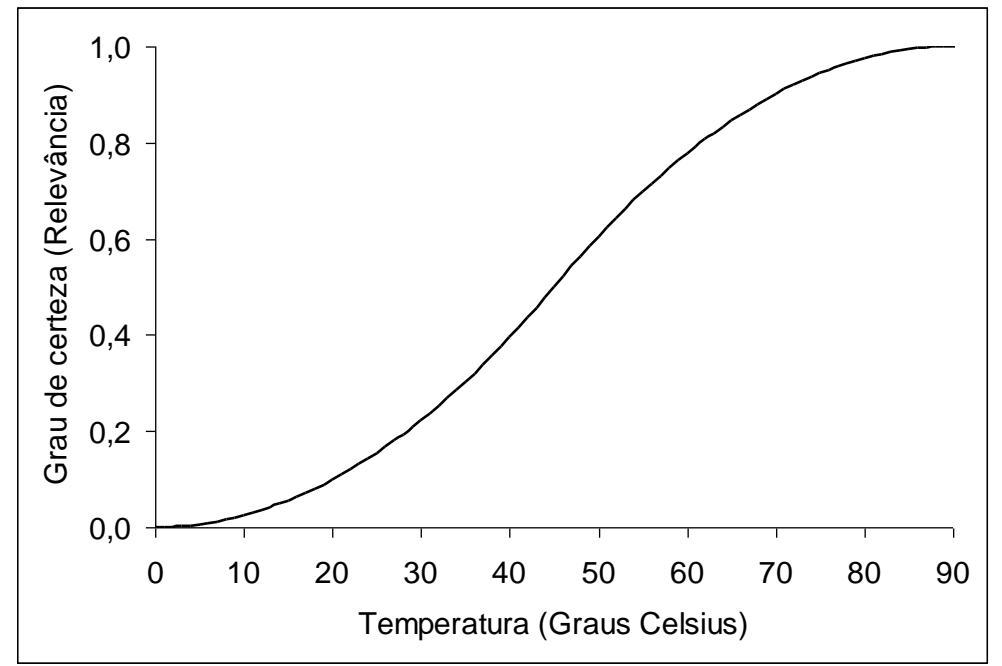

Gráfico 4: Modelagem fuzzy da definição de Quente

Nesta representação, há uma transição gradual entre o "Não-quente" e o "Quente", permitindo que valores próximos aos limites possuam um grau de certeza, ou de pertinência ao 
subconjunto "Quente", que representeará o grau de verdade com que cada valor de temperatura pode ser considerado "Quente".

Por conseguir modelar de uma forma mais adequada estas e outras questões é que a Lógica Fuzzy têm cada vez mais ocupado espaço. Nas últimas décadas tem ocorrido um grande desenvolvimento desta área tanto em questões teóricas como de aplicações (GUPTA, SARIDIS; GAINES, 1977, NAKAMURA; 1995).

Em aplicações relacionadas ao ambiente construído podemos citar os trabalhos de Cheng (1999), Cheng e Harris (2000) mais preocupados com questões ligadas ao conforto e Rheingantz (2002) que foca na construção de um instrumento de avaliação qualitativa de desempenho de edifícios.

Destacamos que a Lógica Fuzzy não exclui a Lógica Clássica, pelo contrário, ela é considerada uma extensão da Teoria Clássica dos Conjuntos.

Para distinguir os conjuntos fuzzy dos conjuntos clássicos (não-fuzzy) utilizaremos o termo conjunto crisp, comumente encontrado na literatura sobre Lógica Fuzzy, ou seja, nítido, claro, conciso, resoluto, decisivo ou incisivo.

A Lógica Fuzzy nos fornece uma série de ferramentas para lidar matematicamente com as incertezas as quais trataremos a seguir. Relembramos, porém, que devemos diferenciar a incerteza devido à aleatoriedade dos eventos, que é tratada pelos métodos estatísticos, da incerteza devido a vagueza, indeterminação ou indefinição de conceitos, que é tratada pela Lógica Fuzzy. Iniciaremos nossa revisão com a formalização da função característica. Destacamos que todos os conceitos e definições descritos a seguir foram traduzidos e resumidos de Klir e Yuan (1995).

\subsection{FUNÇÃO CARACTERÍSTICA OU DE PERTINÊNCIA}

A principal característica que distingue os conjuntos crisp dos conjuntos fuzzy está na relação de pertinência. Enquanto na teoria clássica dos conjuntos, dado um conjunto universo $X$ e um subconjunto $A$ de $X(A \subseteq X)$, para cada elemento $x \in X$ temos duas situações possíveis bem definidas: $x \in A$ ou $x \notin A$. Na Lógica Fuzzy essa condição é relaxada e podemos ter situações onde um elemento x pertence parcialmente ao conjunto. Podemos expressar essa relação de 
pertinência por meio de uma função denominada função característica, a qual é definida a seguir para um subconjunto crisp.

Dado um conjunto universo $X$ e um subconjunto $A$ de $X$, a função característica $A(x)$ do subconjunto $A$ é uma função cujo domínio é o conjunto universo $X$ e a imagem é o conjunto $\operatorname{Im}=\{0 ; 1\}$, a qual associa a cada elemento de $x \in X$ o valor " 1 " caso o elemento $x \in A$ e " 0 " caso contrário. Ou formalmente:

$$
\begin{aligned}
& A: X \quad \rightarrow \quad\{0 ; 1\} \\
& \begin{aligned}
x(x) & \rightarrow\left\{\begin{array}{lll}
1 & \text { se } & x \in A \\
0 & \text { se } & x \notin A
\end{array}\right.
\end{aligned}
\end{aligned}
$$

A notação para a função característica tem assumido várias formas, tais como $\chi_{\mathrm{A}} \mathrm{e} \mu_{\mathrm{A}}$, porém, neste trabalho adotaremos simplesmente a notação $A(x)$.

Definida a função característica, todas as operações matemáticas com conjuntos podem também ser definidas por meio de operações com suas funções características. A função característica também pode ser chamada de função de pertinência e no caso fuzzy como veremos mais adiante, função do grau de verdade ou grau de pertinência. A função característica também é utilizada para o cálculo lógico, associando-se "1" ao valor lógico "Verdade" e "0" ao "Falso".

Como afirmamos, na Lógica Fuzzy a relação de pertinência é relaxada e a função característica pode assumir qualquer valor no intervalo $[0 ; 1]$. Ou seja, um elemento pode pertencer parcialmente ao conjunto.

Ou seja, a função característica para subconjuntos fuzzy é:

$$
\begin{array}{ccc}
A: X & \rightarrow & {[0 ; 1]} \\
x & \rightarrow & A(x)
\end{array}
$$

onde $\mathrm{A}(\mathrm{x})$ representa o grau com que $x$ pertence ao subconjunto $A$.

Este raciocínio é aceitável a partir do ponto em que verificamos em determinadas situações que um dado elemento pode pertencer a mais de um conjunto simultaneamente, ou ainda não pertencer totalmente ao conjunto. Isso ocorre com bastante frequiência em regiões de fronteira. Um exemplo clássico apresentado na literatura está relacionado com a idade. Tomemos os subconjuntos, que representam as idades, apresentados no Gráfico 5 e no Gráfico 6. Dado uma pessoa de 50 anos de idade, pela teoria clássica esse pessoa seria considerada de "Meia- 
idade". Pela teoria fuzzy ele seria de "Meia-idade" (grau de pertinência 0,67) e "Velho" (grau de pertinência 0,33), ou seja, teria mais possibilidade de ser de "Meia-idade", porém com uma possibilidade menor de ser "Velho". O que se aproxima do raciocínio humano, pois não há de fato consenso com relação a estes limites, podendo uma pessoa com 50 anos de idade ser considerada por alguns, já "Velho", enquanto por outros, ainda de "Meia-idade".

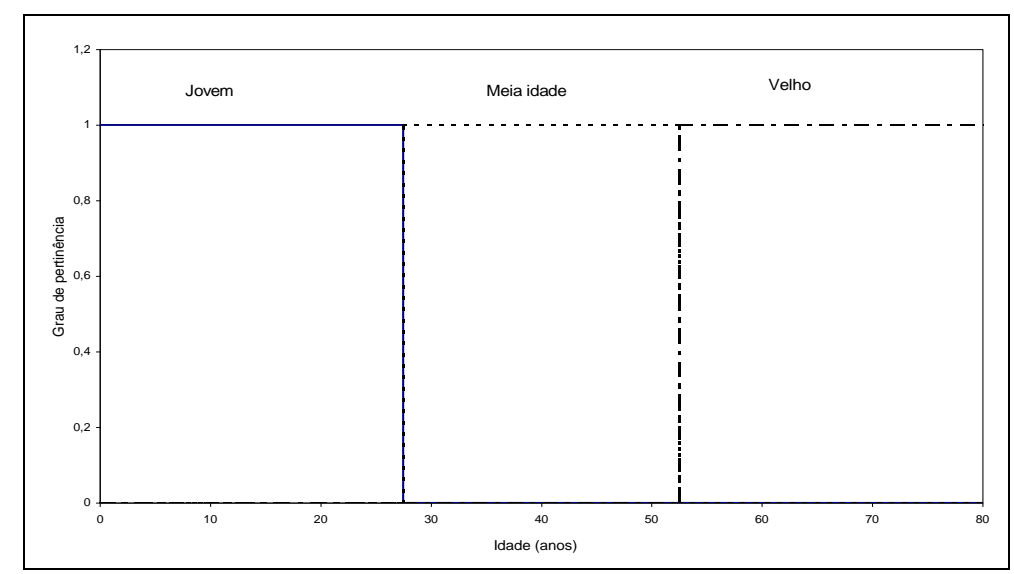

Gráfico 5: Exemplo de representação crisp para os subconjuntos de idades

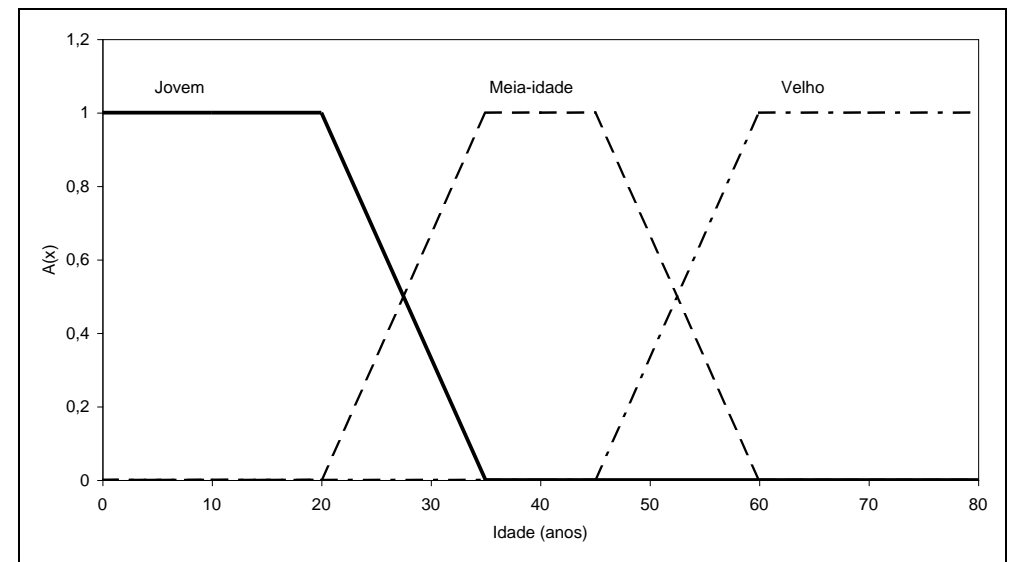

Gráfico 6: Exemplo de representação de subconjuntos fuzzy para idades

O grau de pertinência, introduzido pela Lógica Fuzzy, nos permite modelar matematicamente um dos tipos de incertezas presentes na linguagem humana, que podemos chamar de vagueza ou fuzziness.

Os subconjuntos de idades, apresentados anteriormente, são exemplos de variáveis lingüísticas, as quais serão melhor discutidas mais adiante. Esta tem sido a forma usual de modelagem fuzzy. Contudo, é possível utilizar variáveis qualitativas associadas ao grau de pertinência. Por exemplo, podemos modelar em relação ao subconjunto jovem, o conjunto de pessoas $A=\{$ Ana; Paulo; Pedro,João,José $\}$ atribuindo-lhes os seus respectivos graus de pertinência ao subconjunto: $A(x)=\{0,1 ; 0,7 ; 1,0 ; 0,2 ; 0,0\}$. Isto implica dizer que com 
certeza Pedro é Jovem (grau de pertinência 1,0), e com certeza José não é Jovem (grau de pertinência 0,0 ), os demais pertencem ao conjunto de pessoas jovens com grau de certeza assinalado. De forma simplificada podemos representar o subconjunto A da seguinte forma: $A=\{$ Ana $/ 0,1 ;$ Paulo/0,7; Pedro/1,0; João/0,2;José/0,0 . Esta notação é mais flexível e nos permite trabalhar com variáveis qualitativas.

Diversas notações são utilizadas para representar um subconjunto fuzzy desde o acréscimo do “ ” no nome do subconjunto como, $\tilde{A}$ ou $A$, ou na própria representação do conjunto como:

- $A(x)=\left\{x_{1} ; x_{2} ; \ldots . x_{n}\right\}$

- $A=\left\{\frac{A\left(x_{1}\right)}{x_{1}} ; \frac{A\left(x_{2}\right)}{x_{2}} ; \ldots ; \frac{A\left(x_{n}\right)}{x_{n}}\right\}$

- $A=\left\{\frac{A\left(x_{1}\right)}{x_{1}}+\frac{A\left(x_{2}\right)}{x_{2}}+\ldots+\frac{A\left(x_{n}\right)}{x_{n}}\right\}$

- $A=\sum_{i=1}^{n} \frac{A\left(x_{i}\right)}{x_{i}}$

Note que nas duas últimas notações os sinais de "+" e " $\Sigma$ " não indicam uma soma algébrica, mas sim uma união dos elementos.

Assim como no caso clássico, partindo da definição de função característica, diversas operações podem ser definidas entre os subconjuntos fuzzy. Porém é importante ressaltar que essas operações devem guardar determinadas propriedades, dentre as quais a de serem equivalentes ao caso clássico, quando os subconjuntos forem crisp. A seguir daremos algumas definições específicas à Lógica Fuzzy.

\subsection{CORTES - $\alpha$ OU $\alpha$-CORTES}

Este é um dos conceitos mais importantes dentro da teoria fuzzy. É definido da seguinte forma: dado um subconjunto fuzzy $A$ definido num universo $X$ e um número qualquer $\alpha \in$ [0;1], o corte- $\alpha,{ }^{\alpha} A$, é o conjunto crisp

$$
{ }^{\alpha} A=\{x / A(x) \geq \alpha\}
$$


Uma variação do corte- $\alpha$ também utilizada é o corte- $\alpha$ forte $\left({ }^{\alpha+} A\right)$,

$$
{ }^{\alpha+} A=\{x / A(x)>\alpha\}
$$

\subsection{CONJUNTO NÍVEL}

O conjunto nível da $A(\Lambda(A))$ é o conjunto de todos os níveis $\alpha \in[0 ; 1]$ que representam distintos cortes- $\alpha$ de $A$, ou formalmente:

$$
\Lambda(A)=\{\alpha / A(X)=\alpha, \text { para algum } x \in X\}
$$

\subsection{SUPORTE DE UM SUBCONJUNTO FUZZY}

Dado um conjunto universo $X$ e um subconjunto fuzzy $A$, o suporte de $A, \operatorname{supp}(A)$, é o conjunto crisp que contem todos os elementos de $X$ que tem grau de pertinência não-nulo em $A$. Ou seja, o suporte de $A$ é o corte- $\alpha$ forte de $A\left({ }^{0+} A\right)$, formalmente:

$$
\operatorname{supp}(A)=^{0+} A
$$

Outro corte- $\alpha$ importante é o ${ }^{1} A$, chamado de "core de $A$ ".

\subsection{ALTURA DE UM SUBCONJUNTO FUZZY}

A altura de um subconjunto fuzzy é determinada pelo seu mais alto grau de pertinência, ou seja,

$$
h(A)=\sup _{x \in X}(A(x))
$$

onde "sup" indica o supremo (limite superior). 


\subsection{SUBCONJUNTO FUZZY NORMAL}

Quando a altura de subconjunto fuzzy é igual a um $(h(A)=1)$, chamamos esse subconjunto de fuzzy normal, do contrário se $h(A)<1$, ele é chamado de subnormal.

\subsection{OPERAÇÕES BÁSICAS EM SUBCONJUNTOS FUZZY}

As operações básicas apresentadas a seguir são as mesmas definidas para conjuntos crisp (União, Interseção e Complemento), porém, cabe salientar que, baseadas nas operações com as funções características, a forma de obtê-las não é única, fazendo com que diversas funções sejam propostas e atendam aos requisitos para cada operação. Contudo, existem algumas operações conhecidas como "operações padrão" para cada operação equivalente na teoria clássica.

A seguir apresentaremos os requisitos que cada operação deve satisfazer, com a operação padrão e alguns outros exemplos existentes na literatura.

\subsubsection{Complemento fuzzy}

Seja $A$ um subconjunto fuzzy em $X$. Então, por definição, $A(x)$ é interpretado como o grau no qual $x$ pertence a $A$. Denotamos $c A$ o complemento fuzzy de $A$ do tipo $c$. Então, $c A(x)$ pode ser interpretado não somente como o grau no qual $x$ pertence a $c A$, mas também como o grau no qual $x$ não pertence a $A$. Como convenção, seja um complemento $c A$ definido pela função $c:[0 ; 1] \rightarrow[0 ; 1]$, a qual atribui um valor $c(A(x))$ a cada grau de pertinência $A(x)$ de um dado subconjunto fuzzy $A$. O valor $c(A(x))$ é interpretado como o valor de $c A(x))$. Isto é, $c(A(x))=c A(x)$ para todo $x \in X$ por definição.

A função $c$ tem que possuir certas propriedades para produzir subconjuntos fuzzy que qualificam, num nível intuitivo, como significativo complemento de qualquer subconjunto fuzzy.

Para produzir complementos fuzzy significativos, a função $c$ deve satisfazer ao menos os seguintes dois axiomas: 
- Axioma $1-c(0)=1$ e $c(1)=0$ (condições de contorno)

- Axioma 2 - Para todo $a, b \in[0 ; 1]$, se $a \leq b$, então $c(a) \geq c(b)$ (monotonicidade).

Na prática, é comum considerar alguns axiomas adicionais e geralmente são os seguintes:

- Axioma 3-c é uma função contínua.

- Axioma $4-c$ é involutiva, o que significa que $c(c(a))=a$ para cada $a \in[0 ; 1]$.

Alguns exemplos de complemento fuzzy:

- Complemento padrão: $c(a)=1-a$

- Classe de Sugeno: $c_{\lambda}(a)=\frac{1-a}{1-\lambda a}$ onde $\lambda \in(-1 ; \infty)$

- Classe de Yager: $c_{w}(a)=\left(1-a^{w}\right)^{1 / w}$, onde $w \in(0 ; \infty)$

Note que o complemento padrão é um caso particular das classes de Sugeno e de Yager. Em termos lógicos o complemento pode ser interpretado com uma negação.

\subsubsection{Interseção fuzzy: $t$-norma}

A interseção de dois subconjuntos fuzzy $A$ e $B$ é definida em geral por uma operação binária no intervalo unitário; isto é, uma função da forma: $i=[0 ; 1] \times[0 ; 1] \rightarrow[0 ; 1]$. Para cada elemento $x$ do conjunto universo, esta função toma como argumentos o par de graus de pertinência dos elementos em $A$ e $B$ e atribui o grau de pertinência do elemento no conjunto constituído da interseção de $A$ e $B$. Ou seja, $(A \cap B)(x)=i[A(x), B(x)]$, para todo $x \in X$.

Assim como o complemento fuzzy, uma interseção fuzzy deve satisfazer alguns requerimentos. Dessa forma, uma interseção fuzzy é uma operação binária no intervalo unitário que satisfaz no mínimo os seguintes axiomas para todo $a, b, d \in[0 ; 1]$ :

- Axioma $1-i(a, 1)=a$ (condição de contorno).

- Axioma 2 - $b \leq d$ implica $i(a, b) \leq i(a, d)$ (monotonicidade).

- Axioma $3-i(a, b)=i(b, a)$ (comutatividade).

- Axioma $4-i(a, i(b, d))=i(i(a, b), d)($ associatividade). 
Podemos também, desejar requerimentos adicionais, os mais comuns são:

- Axioma 5 - $i$ é uma função contínua (continuidade).

- Axioma $6-i(a, a)<a$ (subidempotência).

- Axioma $7-a_{1}<a_{2}$ e $b_{1}<b_{2}$ implica $i\left(a_{1}, b_{1}\right)<i\left(a_{2}, b_{2}\right)$ (monotonicidade estrita).

Exemplos de interseção fuzzy:

- Interseção padrão: $i(a, b)=\min (a, b)$.

- Produto algébrico: $i(a, b)=a b$.

- Diferença limitada: $i(a, b)=\max (0, a+b-1)$.

- Interseção drástica: $i(a, b)=\left\{\begin{array}{cc}a & \text { quando } b=1 \\ b & \text { quando } a=1 \\ 0 & \text { caso contrário }\end{array}\right.$

É demonstrado que a maior interseção é dada pela interseção padrão. Assim como o complemento, a $t$-norma pode ser interpretada como um "e" lógico.

\subsubsection{União fuzzy: $t$-conorma}

A união de dois subconjuntos fuzzy $A$ e $B$ também é definida em geral por uma operação binária no intervalo unitário por uma função da forma: $u=[0 ; 1] \times[0 ; 1] \rightarrow[0 ; 1]$. Para cada elemento $x$ do conjunto universo, esta função toma como argumentos o par de graus de pertinência dos elementos em $A$ e $B$ e atribui o grau de pertinência do elemento no conjunto constituído da união de $A$ e $B$. Ou seja, $(A \cup B)(x)=u[A(x), B(x)]$, para todo $x \in X$.

Assim como o complemento fuzzy e a interseção fuzzy, a união fuzzy deve satisfazer alguns requerimentos. A união fuzzy deve satisfazer no mínimo os seguintes axiomas para todo $a, b$, $d \in[0 ; 1]:$

- Axioma $1-u(a, 0)=a$ (condição de contorno).

- Axioma 2 - $b \leq d$ implica $u(a, b) \leq u(a, d)$ (monotonicidade).

- Axioma $3-u(a, b)=u(b, a)$ (comutatividade).

- Axioma $4-u(a, u(b, d))=u(u(a, b), d)$ (associatividade). 
Podemos também, desejar requerimentos adicionais, os mais comuns são:

- Axioma $5-u$ é uma função contínua (continuidade).

- Axioma $6-u(a, a)>a$ (superidempotência).

- Axioma $7-a_{1}<a_{2} e b_{1}<b_{2}$ implica $u\left(a_{1}, b_{1}\right)<u\left(a_{2}, b_{2}\right)$ (monotonicidade estrita).

Exemplos de união fuzzy:

- União padrão: $u(a, b)=\max (a, b)$.

- Soma algébrica: $u(a, b)=a+b-a b$.

- Soma limitada: $u(a, b)=\min (1, a+b)$.

É demonstrado que a menor união é dada pela união padrão. De forma semelhante às operações anteriores, a $t$-conorma pode ser interpretada como um "ou" lógico.

\subsection{NÚMERO FUZZY}

Um subconjunto fuzzy $A$ é chamado número fuzzy quando o conjunto universo no qual está definido é o conjunto dos números reais $\mathfrak{R}$ e satisfaz às seguintes condições:

- todos os $\alpha$-cortes de A são não vazios, com $0 \leq \alpha \leq 1$;

- todos os $\alpha$-cortes de A são intervalos fechados de $\mathfrak{R}$;

- $\quad$ o $\operatorname{supp}(A)=\{x \in \mathfrak{R}: A(x)>0\}$ é limitado.

Algumas funções tem sido utilizadas para representar os números fuzzy, como funções lineares para números triangulares e trapezoidais e funções quadráticas e sua inversa para números L-R (left-right). Alguns exemplos podem ser vistos na Figura 15. 

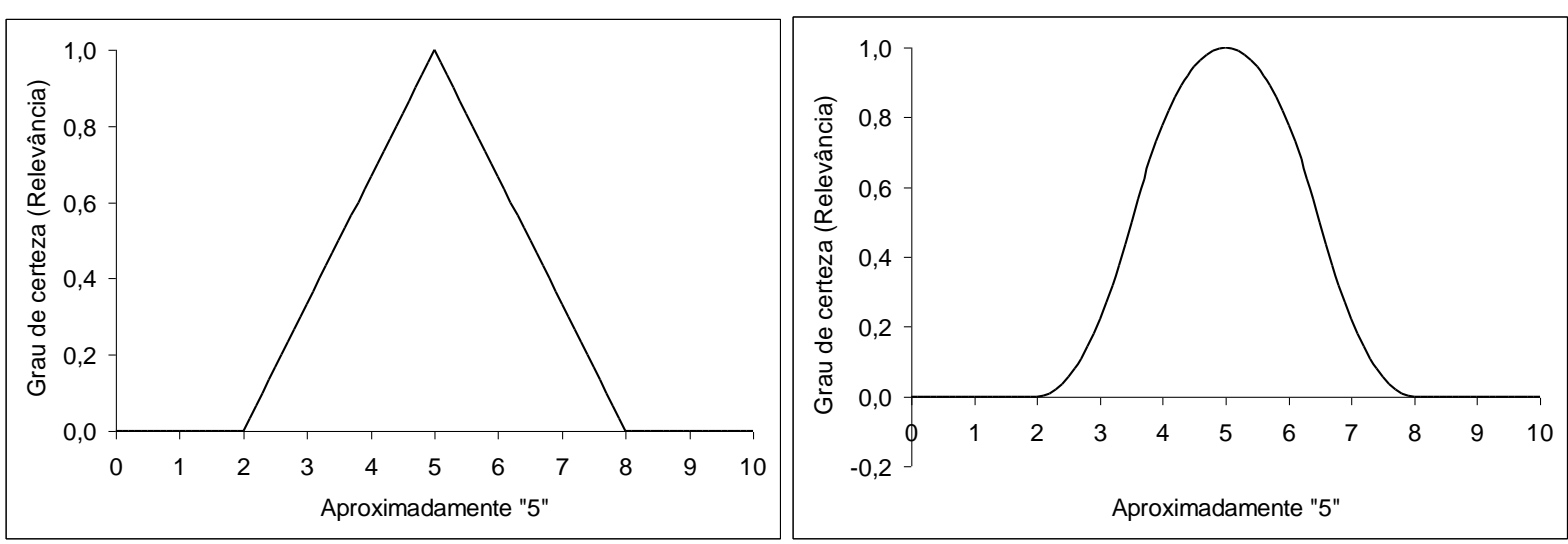

Figura 15: Exemplos de modelagem do número fuzzy "aproximadamente 5"

\subsection{VARIÁVEIS LINGÜÍSTICAS}

O conceito de um número fuzzy leva a uma regra fundamental na formulação de variáveis quantitativas fuzzy. Estas são variáveis cujos estados são números fuzzy e que, além disso, representam conceitos lingüísticos, tais como "muito pequeno", "pequeno", "médio", etc, são geralmente chamadas de variáveis lingüísticas e podem ser interpretadas num determinado contexto como construtos.

As variáveis lingüísticas são expressas por termos lingüísticos, interpretados como números fuzzy específicos, definidos utilizando-se uma variável base, que em termos clássicos pode ser exemplificada por qualquer fenômeno físico (temperatura, pressão, velocidade, umidade, etc) ou qualquer variável numérica (idade, performance, salário, etc). Os termos lingüísticos representam valores aproximados da variável base, relativos a uma aplicação particular, que são capturados por números fuzzy apropriados.

De modo geral, as variáveis lingüísticas são totalmente caracterizadas por:

- o nome da variável (ex.: idade, temperatura, salário, etc.);

- o conjuntos de termos lingüísticos relativos à variável (ex.: muito pequeno, pequeno, médio, grande, muito grande, etc);

- o conjunto universo, intervalo no qual a variável base está definida (ex: idade números Reais positivos)

- regras sintáticas, gramática que gera os termos lingüísticos (muito, não, pouco, etc); 
- regras semânticas, que atribuem a cada termo lingüístico o seu significado (número fuzzy).

São exemplos de variáveis lingüísticas os subconjuntos fuzzy de temperatura e idades representados no Gráfico 4 e no Gráfico 6, respectivamente.

Um exemplo da aplicação de variáveis lingüísticas para avaliação de satisfação pode ser visto em Silva (2004). Este autor buscou por meio da Lógica Fuzzy modelar os termos linguiísticos utilizados na avaliação da satisfação dos usuários de empresas aéreas. Silva (204) elaborou um questionário onde pedia-se ao respondente delimitar o intervalo de valores que ele atribui a um determinado conceito (Figura 16). As freqüências acumuladas de valores dos valores atribuídos podem ser vistas na Tabela 1 .

5 - Marcando com um X, atribua na escala abaixo o intervalo numérico correspondente aos valores
para a Satisfação do Usuário.
Insatisfeito
\begin{tabular}{|c|c|c|c|c|c|c|c|c|c|c|}
\hline & & & & & & & & & & \\
\hline 0 & 1 & 2 & 3 & 4 & 5 & 6 & 7 & 8 & 9 & 10 \\
\hline
\end{tabular}

\section{Pouco Satisfeito}

\begin{tabular}{|l|l|l|l|l|l|l|l|l|l|l|}
\hline & & & & & & & & & & \\
\hline 0 & 1 & 2 & 3 & 4 & 5 & 6 & 7 & 8 & 9 & 10 \\
\hline
\end{tabular}

Satisfeito

\begin{tabular}{|l|l|l|l|l|l|l|l|l|l|l|}
\hline & & & & & & & & & & \\
\hline 0 & 1 & 2 & 3 & 4 & 5 & 6 & 7 & 8 & 9 & 10 \\
\hline
\end{tabular}

Muito Satisfeito

\begin{tabular}{|l|l|l|l|l|l|l|l|l|l|l|}
\hline & & & & & & & & & & \\
\hline 0 & 1 & 2 & 3 & 4 & 5 & 6 & 7 & 8 & 9 & 10 \\
\hline
\end{tabular}

\section{Extremamente Satisfeito}

\begin{tabular}{|l|l|l|l|l|l|l|l|l|l|l|}
\hline & & & & & & & & & & \\
\hline 0 & 1 & 2 & 3 & 4 & 5 & 6 & 7 & 8 & 9 & 10 \\
\hline
\end{tabular}

Figura 16: Trecho de questionário aplicado por Silva (2004)

$\mathrm{Na}$ apuração das freqüências, note que há valores que são atribuídos a mais de um conceito simultaneamente, por exemplo o valor " 1 " por alguns é atribuído ao conceito "Insatisfeito" e por outros ao conceito "Pouco Satisfeito". Isso corrobora para o que discutimos no Capítulo 2, sobre as imprecisões na conversão de escalas qualitativas para quantitativas. Por outro lado, este tipo de imprecisão é justamente um dos tipos de incerteza tratados pela Lógica Fuzzy utilizando graus de verdade. O Gráfico 7 mostra os subconjuntos de avaliação modelados por esta lógica, com base nos resultados da Tabela 1. Enquanto numa abordagem tradicional 
seriam atribuídos valores únicos a cada conceito, ou intervalos bem definidos, na abordagem fuzzy existem zonas de transição e de sobreposição entre os conceitos, as quais são atribuídos graus de verdade que podem ser diferentes de " 1 ".

Tabela 1: Apuração de freqüência para satisfação do usuário

\begin{tabular}{|c|c|c|c|c|c|c|c|c|c|c|c|}
\hline \multirow{3}{*}{ Rótulo de Saída } & \multicolumn{11}{|c|}{ Freqüiência } \\
\hline & \multicolumn{11}{|c|}{ Valor } \\
\hline & $\begin{array}{l}\mathbf{0} \\
\end{array}$ & $\mathbf{1}$ & 2 & 3 & 4 & 5 & 6 & 7 & 8 & 9 & 10 \\
\hline Insatisfeito & 37 & 29 & 17 & 10 & 4 & 1 & 0 & 0 & 0 & 0 & 0 \\
\hline Pouco Satisfeito & 0 & 8 & 19 & 25 & 24 & 15 & 8 & 0 & 0 & 0 & 0 \\
\hline Satisfeito & 0 & 0 & 1 & 2 & 9 & 21 & 26 & 21 & 6 & 0 & 0 \\
\hline Muito Satisfeito & 0 & 0 & 0 & 0 & 0 & 0 & 3 & 16 & 30 & 19 & 0 \\
\hline Extremamente Satisfeito & 0 & 0 & 0 & 0 & 0 & 0 & 0 & 0 & 1 & 18 & 37 \\
\hline
\end{tabular}

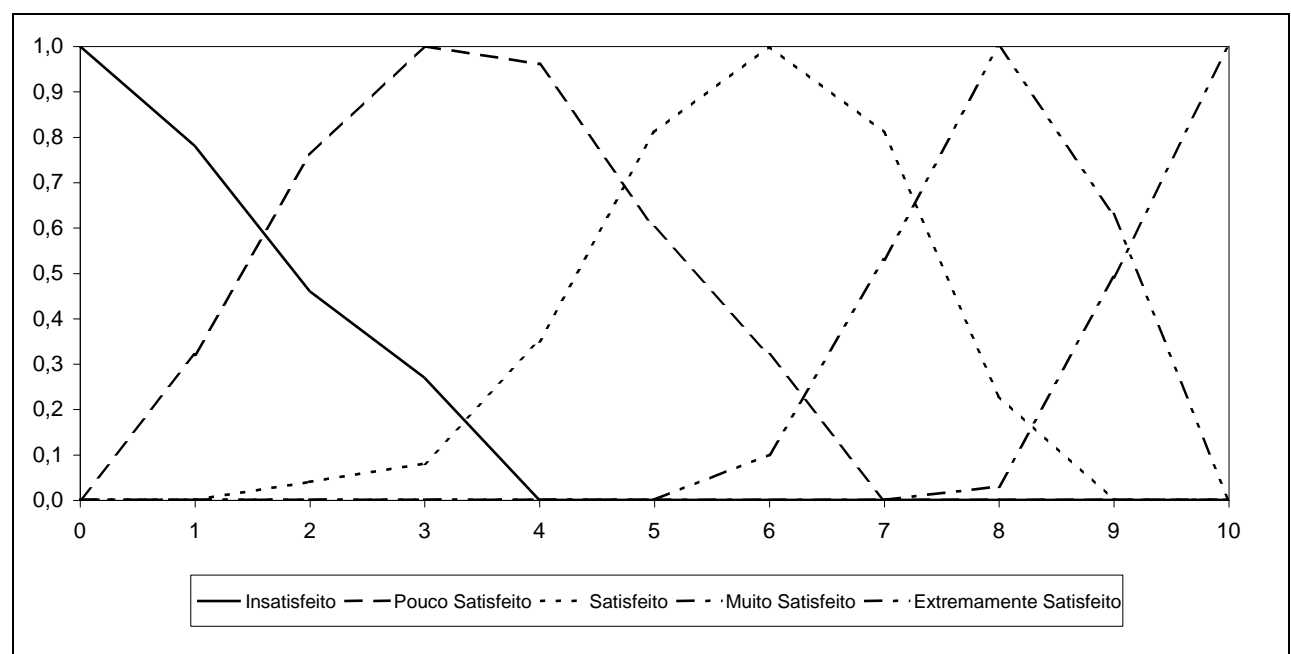

Gráfico 7: Representação dos Conjuntos Fuzzy de Satisfação do Usuário Fonte: Silva (2004)

A partir desta seção a revisão dos termos será direcionada aos objetivos do trabalho, apresentando apenas os temas necessários a compreensão do modelo a ser proposto.

\subsection{MEDIDAS DE INCERTEZA}

A motivação para o estudo das medidas de incerteza surgiu a análise do problema de identificação dos pontos positivos e negativos de um projeto. Esta identificação, em geral, faz parte dos estudos de APO, e os pontos positivos e negativos são obtidos convertendo-se os dados em escalas qualitativas para dados em escalas quantitativas e posterior obtenção de parâmetros numéricos como média e desvio padrão. Com base na média, se um determinado 
item avaliado possui este valor acima do ponto médio da escala de medida, o item é considerado um ponto positivo, caso contrário, um ponto negativo. Porém existem situações claras, onde as frequiências das classes de respostas são muito semelhantes e os parâmetros obtidos não possibilitam a sua identificação, sendo possível apenas por meio da verificação em diagramas de barras. Mesmo assim, permanece ainda a dúvida sobre qual a incerteza apresentada por tal distribuição.

As medidas de incerteza se apresentam como uma alternativa a estes parâmetros, onde podemos, mesmo em uma escala qualitativa, utilizando a notação de graus de verdade, quantificar as incertezas numa dada distribuição.

Segundo Klir e Harmanec (1997) o tratamento matemático da incerteza pode ser visto em basicamente cinco teorias. Os autores afirmam que as incertezas têm sido tratadas nas teorias da probabilidade, da possibilidade, da evidência, dos subconjuntos fuzzy, e na teoria clássica dos conjuntos. Neste leque de teorias podem ser evidenciados três tipos de medida de incerteza: vagueza (fuzziness), não-especificidade e conflito.

Enquanto a vagueza é um tipo de incerteza inerente à linguagem humana, residente na incapacidade, ou inabilidade, de tornar claro ou preciso algumas propriedades de determinados conjuntos (tratada exclusivamente na teoria dos subconjuntos fuzzy), a nãoespecificidade está relacionada a nossa inabilidade para discriminar qual, entre várias alternativas, é a real, ou verdadeira, em uma dada situação e o conflito está presente sempre que estamos diante de algum tipo de discrepância ou inconsistência em nossa informação ou evidência.

Enquanto a vagueza não pode ser reduzida por se tratar de uma deficiência da linguagem humana ou de determinada definição, ambos a não-especificidade e o conflito podem ser reduzidos por observações adicionais, experimentos, ou outras ações relevantes de produção de informação.

\subsubsection{Medida de vagueza}

Como afirmado anteriormente, a vagueza tem sido formalizada somente pela teoria dos subconjuntos fuzzy. Em geral, uma medida de vagueza (measure of fuzziness) é uma função $f: F(X) \rightarrow R^{+}$onde $F(X)$ representa o conjunto de todos os subconjuntos fuzzy do universo 
$X$. Para cada subconjunto fuzzy $A$, o numero real não negativo $f(A)$ expressa o grau de vagueza de $A$.

De Luca e Termine (1972) identificaram três requerimentos básicos que qualquer medida de vagueza razoável deveria satisfazer:

1. $f(A)=0$ se e somente se $A$ é um conjunto clássico (crisp set).

2. $f(A)$ assume o valor máximo se e somente se $A(x)=0,5$ para todo $x \in X$.

3. $f(A) \leq f(B)$ sempre que $A(x) \leq B(x)$ quando $B(x) \leq 0,5$ e $A(x) \geq B(x)$ quando $B(x) \geq 0,5$ para todo $x \in X$.

O requerimento 1 é essencial, pois é o que diferencia a teoria dos subconjuntos fuzzy da teoria clássica, pois afirma que conjuntos clássicos não possuem vagueza.

O requerimento 2 os subconjuntos fuzzy admite que se o grau de verdade máximo é 1 (hum) um elemento que possua grau de verdade 0,5 tem a mesma possibilidade de pertencer ou não ao subconjunto, sendo assim a máxima vagueza atingida.

O requerimento 3 garante que quanto mais crisp for o subconjunto menos fuzzy ele será. De acordo com esse requerimento o subconjunto fuzzy B é menos vago que A na Figura 17.

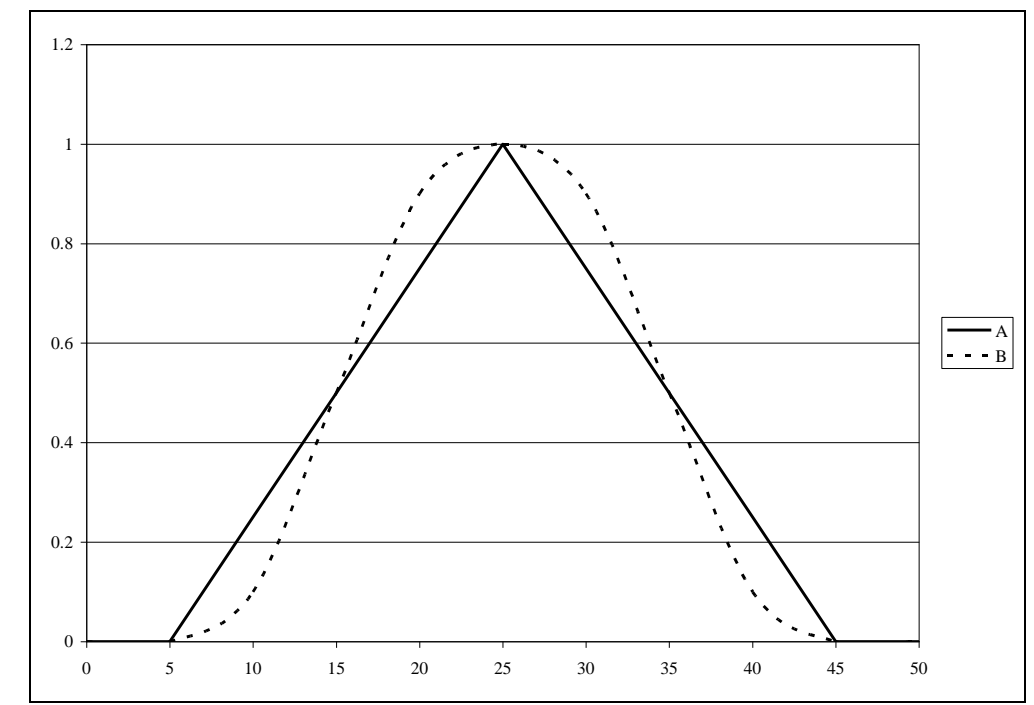

Figura 17: Exemplo de vagueza de subconjuntos fuzzy

Em uma abordagem mais geral os requerimentos 2 e 3 precisariam de uma modificação. É importante salientar que os requerimentos 1 a 3 não determinam uma única medida de vagueza. Segundo Klir e Harmanec (1997) duas amplas abordagens para mensuração da vagueza podem ser encontradas na literatura. A primeira é a mensuração da vagueza de um 
conjunto $A$ pela distância métrica entre a sua função de graus de pertinência e a função do grau de pertinência do conjunto crisp aproximador. A segunda abordagem, a qual parece mais intuitiva e mais geral, é medir a vagueza de um conjunto $A$ pelo grau no qual ele é indistinguível de seu complemento $\bar{A}$. A ausência de distinção entre conjuntos e seus complementos é que separa subconjuntos fuzzy de conjuntos crisp. Quanto menos um conjunto difere de seu complemento mais vago ele é.

5.10.1.1 Cálculo da vagueza de um subconjunto pela comparação com seu complemento

Uma forma adequada de quantificar essa diferença é selecionar uma função de distância métrica para medir a distância entre a função de grau de pertinência de um dado conjunto e a função de grau de pertinência de seu complemento.

Para uma distância métrica $\Delta$, a medida de vagueza baseada no complemento fuzzy padrão tem a forma:

$$
f_{\Delta}(A)=\Delta(X, \varnothing)-\Delta(A, \bar{A})
$$

onde o primeiro termo representa a distância entre o conjunto universo (crisp) e o seu complemento (conjunto vazio) e o segundo termo representa a distância entre o subconjunto fuzzy e o seu complemento.

Essa medida assumirá o valor máximo quando não houver distinção entre o subconjunto e seu complemento, ou seja $\Delta(A, \bar{A})=0$ e o valor mínimo quando o subconjunto $A$ for igual ao conjunto universo, $\operatorname{logo}, \Delta(A, \bar{A})=\Delta(X, \varnothing)$. Então o intervalo de variação da vagueza fica assim determinado com $0 \leq f_{\Delta}(A) \leq \Delta(X, \varnothing)$. Ou, numa versão normalizada:

$$
\hat{f}_{\Delta}(A)=1-\frac{\Delta(A, \bar{A})}{\Delta(X, \varnothing)}
$$

com variação no intervalo $0 \leq \hat{f}_{\Delta}(A) \leq 1$.

Usando a distância de Hamming o complemento fuzzy padrão (Equação 4) nós obtemos a seguinte medida de vagueza.

Distância de Hamming:

$$
d_{H}(A, B)=\sum_{x \in X}|A(x)-B(x)|
$$


Complemento padrão: $\quad \bar{A}(x)=1-A(x)$

Medida de vagueza:

$$
f(A)=|X|-\sum_{x \in X}|2 A(x)-1|
$$

para todo $A \in F(X)$, sendo $|X|$ a cardinalidade de $X$.

A importância desta medida está no fato de que é a única medida que tem bits como sua unidade de medida. Para efeito de comparação a versão normalizada é mais apropriada:

$$
\hat{f}(A)=1-\frac{\sum_{x \in X}|2 A(x)-1|}{|X|}
$$

Por esta fórmula, quanto mais vago é o subconjunto mais próximo de 1 (hum) será esta medida.

5.10.1.2 Cálculo da vagueza de um subconjunto pela comparação com o crisp aproximador

Nesta abordagem precisamos definir um conjunto crisp chamado crisp aproximador e uma função de distância para podermos mensurar o quanto o subconjunto fuzzy distingue-se do seu crisp aproximador. Quanto mais próximo for, menor será sua distância e menor será sua vagueza.

Podemos adotar a seguinte função característica determinar o conjunto crisp aproximador: dado um conjunto universo $X$, o crisp aproximador de um subconjunto fuzzy $A$ de $X$ é:

$$
A^{C A}(x)=\left\{\begin{array}{lll}
1 & \text { se } & A(x) \geq 0,5 \\
0 & \text { se } & A(x)<0,5
\end{array}\right.
$$

Assim, a medida de vagueza para uma determinada distância $\Delta$, pode ser determinada pela seguinte fórmula: $f_{\Delta}(A)=\Delta\left(A, A^{C A}\right)$.

Adotando a distância de Hamming, podemos verificar que esta medida de vagueza varia em $0 \leq f_{\Delta}(A) \leq 0,5|X|$. E de forma análoga podemos normalizá-la para obtermos valores padronizados no intervalo $[0 ; 1]$. 
É importante notar que nesta abordagem o valor 0,5 como de máxima vagueza foi adotado para satisfazer os requerimentos 1 a 3, contudo, este valor pode ser modificado de acordo com a noção de vagueza adotada.

\subsubsection{Medida de não-especificidade}

A incerteza devido a não-especificidade é o tipo mais amplamente reconhecido de incerteza.

É formalizada em quatro das cinco teorias de incerteza citadas por Klir e Harmanec (1997), somente a exceção da teoria da probabilidade.

A não-especificidade pode ser encontrada em situações, nas quais nós expressamos incerteza por meio de conjuntos clássicos (crisp). A incerteza, neste caso não-especificidade, associada com o conhecimento que uma alternativa procurada está entre um conjunto de alternativas foi primeiro quantificada para conjuntos finitos por Hartley, que chegou a seguinte fórmula: $H(A)=c \cdot \log _{b}|A|$, onde $b>1$ e $c>0$. Valores particulares das constantes $b$ e $c$ definem a unidade na qual a não-especificidade é medida.

Para medir a não-especificidade de subconjuntos fuzzy, a medida de Hartley foi generalizada via seus cortes- $\alpha$. A medida resultante, a qual foi nomeada $U$-Uncertainty, e que traduzimos como U-Incerteza, é definida pela fórmula, para subconjuntos fuzzy discretos e finitos:

$$
U(A)=\left.\frac{1}{h(A)} \int_{0}^{h(A)} \log \right|^{\alpha} A \mid d \alpha,
$$

onde $h(A)$ representa a altura de $A$.

Existem outras versões da medida de não-especificidade nas teorias de Dempster-Shafer (Teoria da evidência) e da possibilidade, contudo não serão exploradas neste trabalho.

A medida de não-especificidade será menor quanto maior for predominância de uma determinada alternativa. Observe na Figura 18 que o subconjunto da esquerda possui um intervalo de valores com graus de certeza "1", enquanto o subconjunto da direita possui apenas um ponto. Desta forma a não-especificidade do subconjunto da esquerda será maior que a do subconjunto da direita. Ou seja, o subconjunto da direita apresenta menor incerteza quanto a especificidade. 


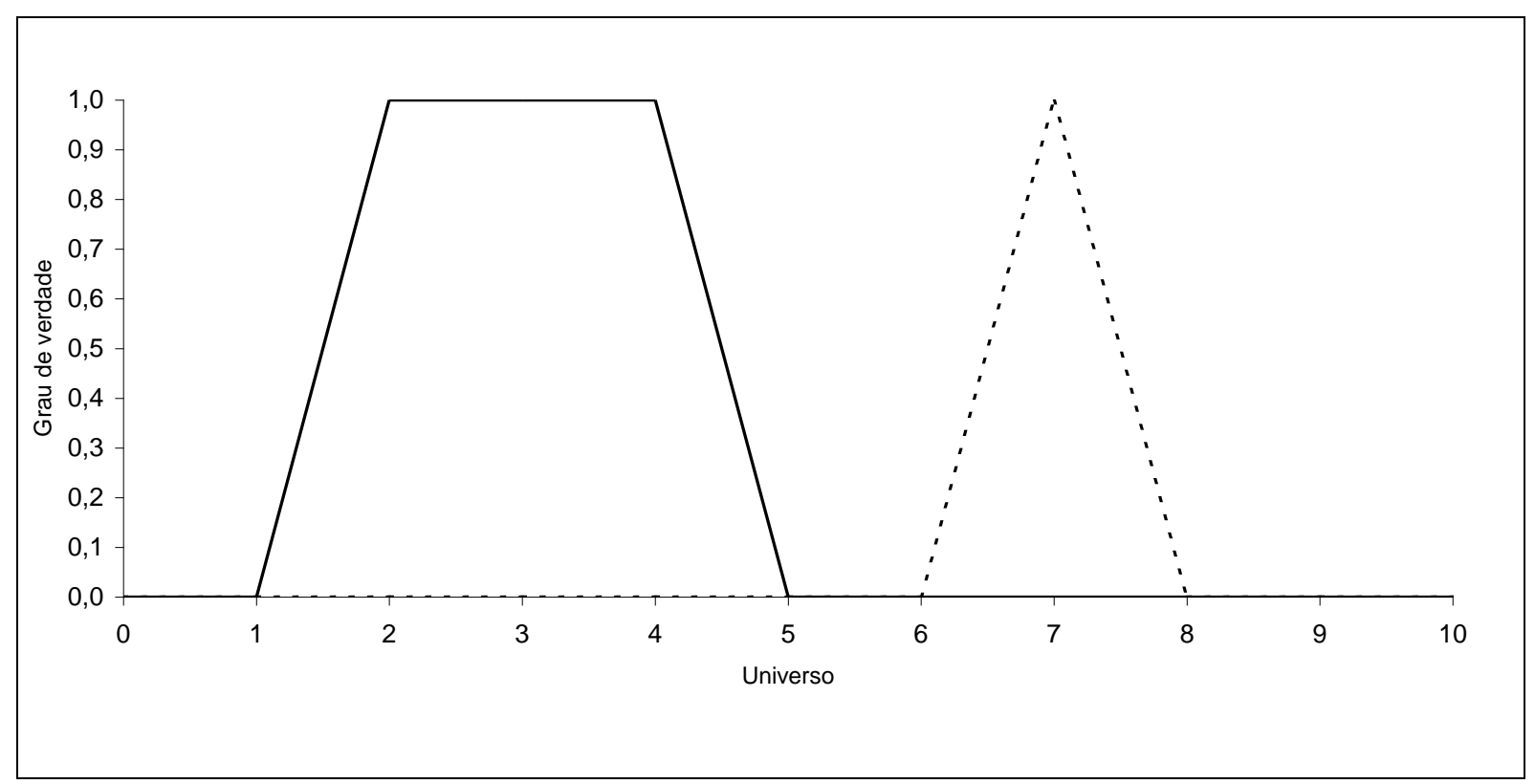

Figura 18: Exemplos de não-especificidade de subconjuntos fuzzy

\subsubsection{Medida de conflito}

A incerteza na forma de conflito está presente na teoria da probabilidade, na teoria de Dempster-Shafer, e em menor grau na teoria da possibilidade. Apesar de existirem muitas propostas de mensuração do conflito na literatura, o assunto ainda é bastante controverso. Segundo Klir e Harmanec (1997) existem muitas propostas para medidas de conflito, mas nenhuma das propostas é totalmente satisfatória e amplamente aceita.

A melhor medida de incerteza estabelecida em geral, e a única amplamente aceita medida de conflito, é a Entropia Shannon definida para uma função de distribuição de probabilidade arbitrária $p$ em $X$ pela fórmula:

$$
S(p)=-\sum_{x \in X} p(x) \log _{2} p(x)
$$

Onde $p(x)$ será a freqüência de cada conceito, como nas outras medidas. Como a maioria das outras medidas de incerteza, a Entropia Shannon mede a incerteza em bits e varia no intervalo $\left[0, \log _{2}|X|\right]$. 


\subsection{INFERÊNCIA FUZZY}

A motivação para o estudo da inferência fuzzy surge com a necessidade de agregar ou sintetizar informações com base em informações parciais. Em nosso caso, a obtenção de indicadores qualitativos finais, não pode ser feita por meio de operações matemáticas convencionais, tais como médias ou somas. A idéia presente na inferência aplicada a obtenção de indicadores de qualidade ambiental urbana é, com base em informações parciais do espaço, como avaliações de itens componentes, poder inferir sobre a avaliação do espaço com um todo, buscando assim, modelar o mecanismo de raciocínio dos moradores.

A inferência pode ser definida como uma operação intelectual por meio da qual se afirma a verdade de uma proposição em decorrência de sua ligação com outras já reconhecidas como verdadeiras ou ainda, deduzir por meio de raciocínio, tirar por conclusão ou consequiência. Pode também, relacionada à estatística, ser considerada uma operação que consiste em, tomando por base amostras estatísticas, efetuar generalizações.

Os processos de inferência fuzzy são compostos basicamente de três elementos: as entradas, ou inputs, ou ainda antecedentes, as saídas, ou outputs, ou ainda conseqüentes, e as regras de inferência.

Um modelo simples pode ser descrito da seguinte forma:

- Se $\{$ entradas $\}$ então $\{$ saída $\}$

As entradas descrevem uma condição (premissas), enquanto a saída descreve uma conclusão ou uma ação que pode ser esboçada quando as premissas se verificam. As regras são determinadas e utilizadas quando as entradas são atendidas. A diferença entre os antecedentes de uma regra fuzzy e uma regra clássica é que os primeiros descrevem uma condição elástica, ou seja, uma condição que pode ser parcialmente satisfeita, enquanto os últimos descrevem uma condição rígida, ou seja, a regra não funciona se os antecedentes não são completamente satisfeitos (ORTEGA, 2001).

Um exemplo simples de inferência utilizada no cotidiano pode ser dada quando desejamos decidir o tipo de roupa a ser utilizado. Se estiver frio devemos escolher roupas quentes, ou pesadas, caso esteja fazendo calor, devemos escolher roupas leves. Assim temos basicamente:

- Entrada:clima: $\{$ frio; calor $\}$ 
- Saída: tipo de roupa:\{pesadas; leves\}

- Regras: 1. Se clima=frio, então roupa=pesadas

2. Se clima=calor, então roupa=leves

Porém, como já vimos, os termos: frio, calor, pesadas e leves, são imprecisos, logo, melhor modelados com a Lógica Fuzzy. Nesta modelagem, freqüentemente são utilizados métodos com variáveis lingüísticas e regras de composição que utilizam as operações de união e interseção, porém há também a possibilidade de obter inferências utilizando-se as relações fuzzy. A ênfase no método das relações fuzzy será dada em função de não exigir a utilização de escalas quantitativas, necessárias à construção das variáveis lingüísticas. Os modelos podem apresentar apenas uma entrada e uma saída, assim como múltiplas entradas e múltiplas saídas. Para maiores detalhes ver Ortega (2001) e Klir e Yuan (1995).

\subsection{RELAÇÕES FUZZY}

O conceito de relação fuzzy, assim como os demais apresentados, também é uma extensão do conceito envolvendo conjuntos crisp. Uma relação clássica indica se há ou não alguma associação entre dois objetos, enquanto que uma relação fuzzy, além de indicar se há ou não associação, indica também o grau desta relação.

Uma relação fuzzy $R$ sobre um produto cartesiano $U_{1} \times U_{2} \times \ldots \times U_{n}$ é qualquer subconjunto fuzzy de $U_{1} \times U_{2} \times \ldots \times U_{n}$. Assim, uma relação fuzzy é definida por uma função de pertinência $R: U_{1} \times U_{2} \times \ldots \times U_{n} \rightarrow[0 ; 1]$.

Se o produto cartesiano for formado apenas por dois conjuntos, a relação é chamada de fuzzy binária. Este tipo de relação é particularmente importante, tanto nos caso de dois conjuntos diferentes como se eles forem iguais, pois determina importantes relações na prática como: semelhança, ordem, etc. 


\subsubsection{Relações fuzzy binárias}

Dada uma relação fuzzy binária $R$ no universo $U_{1} \times U_{2}$ podemos representá-la de diferentes formas, as mais comuns são na forma de tabela ou matriz, onde nas linhas estão os elementos de $U_{1}$ e nas colunas os elementos $U_{2}$ que pertencem a relação em ambos os casos, e os elementos de cada posição representam o grau com que o par ordenado pertencem a relação.

Exemplo: dados os conjuntos de presa e predador, $\mathrm{U}_{1}=\mathrm{U}_{2}=\{$ águias (a); cobras (c); insetos (i); lebres (1); sapos (s) \} podemos estabelecer a seguinte relação: $R: x$ é "presa” de $y$. Onde "presa" representa o grau com o elemento $y$ tem preferência por $x$. Esta relação pode ser representada pela seguinte na Tabela 2 .

Tabela 2: Exemplo de relação fuzzy: presa/predador

\begin{tabular}{|c|c|c|c|c|c|c|}
\hline & \multicolumn{6}{|c|}{ Predador } \\
\hline \multirow{6}{*}{ 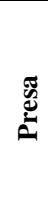 } & $\mathbf{R}$ & $\mathbf{a}$ & $\mathbf{c}$ & $\mathbf{i}$ & 1 & $\mathbf{s}$ \\
\hline & $\mathbf{a}$ & 0 & 0 & 0 & 0 & 0 \\
\hline & c & 1 & 0,2 & 0 & 0 & 0 \\
\hline & I & 0,1 & 0 & 0,3 & 0 & 1 \\
\hline & $\mathbf{L}$ & 1 & 0,8 & 0 & 0 & 0 \\
\hline & $\mathbf{S}$ & 0,2 & 1 & 0 & 0 & 0,1 \\
\hline
\end{tabular}

Ou por meio da matriz abaixo

$$
R=\left[\begin{array}{ccccc}
0 & 0 & 0 & 0 & 0 \\
1 & 0,2 & 0 & 0 & 0 \\
0,1 & 0 & 0,3 & 0 & 1 \\
1 & 0,8 & 0 & 0 & 0 \\
0,2 & 1 & 0 & 0 & 0,1
\end{array}\right]
$$

Isto significa, por exemplo, que a águia não é presa de nenhum dos outros elementos e que a cobra é presa da águia com grau de preferência " 1 " e é presa de outras cobras com grau de preferência " 0,2 ", por exemplo.

Uma definição importante é a de relação inversa ou transposta, se desejarmos obter a relação y é predador de $x$ basta calcularmos $R^{-1}$ que coincide com a transposta de $R$.

Como afirmado anteriormente, existem algumas relações particularmente importantes quando trabalhamos com uma relação fuzzy num mesmo subconjunto.

Seja $R$ uma relação fuzzy binária sobre $U$, cuja função de pertinência é $R(x, y)$. Então, para quaisquer $x$, y e $z$ de $U$, a relação fuzzy $R$ é:

- reflexiva se $R(x, x)=1$, quando todo indivíduo tem relação máxima consigo próprio; 
- simétrica se $R(x, y)=R(y, x)$, quando é caracterizada a reciprocidade com a mesma intensidade entre os indivíduos;

- transitiva se $R(x, z) \geq R(x, y) \wedge R(y, z)$, onde $\wedge$ representa o mínimo, indica que a relação entre dois indivíduos quaisquer não deve ser, simultaneamente, inferior á relação de cada um destes dois com os demais;

- anti-simétrica se $R(x, y)>0$ e $R(y, x)>0$ implica $x=y$, quando não admite qualquer reciprocidade entre indivíduos distintos.

Quando uma relação é reflexiva, simétrica e transitiva, chamamos de relação de equivalência. Essa relação também é conhecida como relação de similaridade ou semelhança. Ela é importante no sentido de que representa o grau de equivalência (similaridade) entre dois elementos de um conjunto, sendo assim fundamental em técnicas de agrupamento.

Quando uma relação é apenas reflexiva e simétrica, geralmente é chamada de relação de compatibilidade, ou ainda de proximidade.

Além das relações de equivalência e de compatibilidade existem várias como a de quaseequivalência, de ordem, etc, porém para efeitos desse trabalho estas duas são suficientes.

\subsubsection{Composições de relações fuzzy}

Sejam dadas duas relações fuzzy binárias $R$ e $S$ em $U \times V$ e $V \times W$, respectivamente. A composição $R \circ S$ é uma relação é uma relação fuzzy binária em $U \times W$ cuja função de pertinência é dada por:

$$
R \circ S(x, z)=\sup _{y \in V}[\min (R(x, y), S(y, z))]
$$

Numa abordagem mais geral o sup pode ser substituído por uma $t$-conorma e o $\min$ por uma $t$ norma. A composição que adota a união e interseção padrão é conhecida como max-min e é amplamente utilizada. 


\subsubsection{Equações relacionais fuzzy}

O problema clássico de uma equação relacional fuzzy pode ser resumido em: considere três relações fuzzy binárias $P(X, Y), Q(Y, Z)$ e $R(X, Z)$, as quais são definidas nos conjuntos $X=\left\{x_{i} / i \in I\right\}, Y=\left\{y_{j} / j \in J\right\}$ e $Z=\left\{z_{k i} / k \in K\right\}$. Seja as matrizes de pertinência P, Q e R denotadas por $\mathrm{P}=\left[p_{i j}\right], \mathrm{Q}=\left[q_{j k}\right]$ e $\mathrm{R}=\left[r_{i k}\right]$.

Considere agora a seguinte equação: $P \circ Q=R$, supondo que a composição seja a padrão (max-min), o problema de dados $P$ e $Q$ determinar $R$ reduz-se a aplicar a regra de composição max-min. Porém, quando desejamos determinar $P$ (ou $Q$ ) conhecendo $Q$ (ou $P$ ) e $R$ o problema passa a ser não trivial. Este é um problema clássico da teoria fuzzy com aplicações onde, conhecendo-se as entradas e as saídas busca-se estabelecer a relação entre estas para poder inferir com base neste conhecimento.

Uma das aplicações conhecidas é a de diagnóstico médico. Suponha que tenhamos a relação entre sintomas e doenças, $Q$, e a relação de sintomas de um determinado paciente $P$, a resposta então (diagnóstico) será $R$. Basta aplicar a composição definida.

Suponha agora, que tenhamos uma base de dados, onde temos para cada paciente os sintomas (graus de pertinência) $Q$ e os respectivos diagnósticos (também em graus de pertinência) $R$. O problema agora é estabelecer qual a relação entre sintomas e doenças $Q$ baseados nos dados existentes para auxiliar em novos diagnósticos (KLIR; YUAN, 1995; PEREIRA et al., 2004; BARROS; BASSANEZI, 2006).

A solução para este problema depende dentre outras questões do tipo de composição utilizada. É provado que para uma composição $P \stackrel{i}{\circ} Q$, onde $\stackrel{i}{\circ}$ representa uma composição sup- $i$ a solução maximal dada pela composição $P^{-1} \stackrel{w_{i}}{\circ} R$, onde $\stackrel{w_{i}}{\circ}$ é a composição inf- $w_{i}$ (KLIR; YUAN, 1995).

A composição inf- $w_{i}$ é definida por meio de uma implicação fuzzy. Dado uma $t$-norma $i$, então $w_{i}(a, b)=\sup \{x \in[0 ; 1] \mid i(a, x) \leq b\}$ é uma implicação fuzzy e a composição inf- $w_{i}$ é dada pelo $\inf \left(w_{i}\right)$. Para a composição max-min, é garantido que se existir solução para a equação, a solução máxima será dada pela implicação de Gödel, definida como: 


$$
w_{g}(a, b)=\left\{\begin{array}{lll}
1 & \text { se } & a \leq b \\
b & \text { se } & a>b
\end{array}\right.
$$

Assim, basta calcular a composição $P^{-1} \stackrel{w_{i}}{\circ} R$, verificar se satisfaz a equação e em caso positivo, adotá-la como a máxima solução, obtendo a relação entre sintomas e doenças. Desta forma, para sabermos os graus de possibilidade para um novo paciente, dados os sintomas, basta aplicar a regra de composição inicial com a nova matriz de relação.

De uma forma geral, se possuirmos uma base de conhecimento, de entradas e respectivas saídas, podemos obter uma matriz que substitui as regras de inferência.

\subsection{RECONHECIMENTO DE PADRÃO E ANÁLISE DE AGRUPAMENTO}

A motivação para o estudo de reconhecimento de padrão e análise de agrupamento reside na possibilidade de, alternativamente ao modelo de inferência por relações fuzzy apresentado, obtermos um método onde a avaliação final do espaço seja feita utilizando a comparação com padrões já existentes de respostas.

Existem dois tipos de problemas aqui envolvidos, o primeiro é dado um conjunto de elementos descritos por determinadas características estabelecer grupos semelhantes, o segundo é dados grupos de elementos semelhantes, definir para um novo elemento em qual grupo classificá-lo.

A análise de agrupamento, ou Clustering, enquadra-se no primeiro tipo de problema. É uma técnica exploratória de análise multivariada, cujo objetivo pode ser definido como, dado um conjunto de elementos caracterizados por um número de variáveis, estabelecer arranjos homogêneos de elementos (grupos de elementos semelhantes), com a maior distinção entre si, baseados em medidas de similaridade, ou dissimilaridade. Como resultado, também podemos obter as características diferenciadoras em cada grupo.

Existem diversas técnicas desenvolvidas na estatística. Na teoria fuzzy também houve bastante desenvolvimento e os métodos encontram aplicações em diferentes áreas. Dentre as técnicas utilizadas na teoria fuzzy temos o Método das $k$-médias fuzzy, que é um método partitivo, cujo número de grupos (partições) é determinado a priori. O objetivo neste caso é determinar a $k$ partição que melhor distingue $k$ grupos. Há outro método, baseado nas relações fuzzy de equivalência. Neste caso não é necessário definir o número de grupos a priori, pois neste caso 
o resultados são baseados numa matriz de compatibilidade para chegar numa matriz de equivalência que nos fornecerá o grau de semelhança entre cada par de elementos da análise. Desta forma podemos obter a estrutura de semelhança do conjunto pelo grau de similaridade. No segundo tipo de problema, o qual aqui chamaremos de reconhecimento de padrão, podemos destacar na análise clássica o método da análise discriminante. $\mathrm{Na}$ teoria fuzzy podemos citar os métodos da lista de pertinência fuzzy e o método sintático fuzzy. Destes, daremos ênfase no método da lista de pertinência fuzzy.

\subsubsection{Agrupamento fuzzy baseado em relações de equivalência}

O método das $k$-médias requer que o número de grupos desejados seja especificado. O que se torna uma desvantagem pois nem sempre isto é claro para o pesquisador a priori. Em tais problemas, o número de grupos reflete, de uma forma natural, a estrutura do conjunto de dados. Os métodos baseados nas relações fuzzy de equivalência trabalham desta forma.

Cada relação de equivalência (reflexiva, simétrica e max-min transitiva) induz uma partição crisp em cada um de seus $\alpha$-cortes. O problema de agrupamento fuzzy pode então ser visualizado como o problema de identificar uma relação fuzzy de equivalência apropriada ao conjunto dado. Embora isto não possa ser feito diretamente, nós podemos facilmente determinar uma relação fuzzy de compatibilidade em termos de uma função de distância apropriada aplicada ao conjunto de dados. Então, uma relação fuzzy de equivalência é definida como a transitiva mais próxima (closure) desta relação fuzzy de compatibilidade.

Klir e Yuan (1995) sugerem determinarmos e relação de compatibilidade pela classe de distâncias de Minkowski, utilizando a fórmula abaixo para cada par de indivíduos $\left\langle x_{i}, x_{k}\right\rangle$ :

$$
R\left(x_{i}, x_{k}\right)=1-\delta\left(\sum_{j=1}^{p}\left|x_{i j}-x_{k j}\right|^{q}\right)^{\frac{1}{q}},
$$

onde $p$ é o número de características dos indivíduos, $q \in \mathfrak{R}^{+}$e $\delta$ é uma constante que assegura que $R\left(x_{i}, x_{k}\right) \in[0 ; 1]$.

Obtida a matriz de compatibilidade é provado que a matriz de relação max-min transitiva mais próxima de $R$ é a relação $R_{T}=R^{(n-1)}$, ou seja $R_{T}$ pode ser obtida compondo $R$ com ela mesma 
até chegar a uma relação max-min transitiva. Os grupos são obtidos por meio da análise da matriz de equivalência e definindo-se cortes- $\alpha$ apropriados.

\subsubsection{Reconhecimento de padrão utilizando o método da lista fuzzy de pertinência}

No método da lista fuzzy de pertinência, é necessário armazenar apenas um exemplo de padrão para cada classe de padrão. Para um dado padrão desconhecido, mede-se de forma apropriada, seu grau de compatibilidade com cada exemplo de padrão e então classificamos o padrão em uma classe particular de acordo com algum critério.

Assumindo que $n$ classes de padrão são reconhecidas, nas quais são rotuladas pelos inteiros

em $\mathrm{N}_{n}$. Dado um padrão relevante $\mathrm{u}=\left\langle u_{1}, u_{2}, \ldots, u_{p}\right\rangle$, onde $u_{i}$ é a medida associada com a $i$ ésima característica do padrão ( $i$ pertence a $\mathrm{N}_{p}$ ), Denotamos $A_{k}(u)$ o grau de compatibilidade de "u" com o exemplo padrão representante da classe $k\left(k \in \mathrm{N}_{n}\right)$. Um dado padrão é geralmente classificado pelo maior valor de $A_{k}(u)$ para todo $k \in \mathrm{N}_{n}$, porém outros critérios de classificação também tem sido sugeridos.

Métodos específicos para seleção de características padrão, determinação do grau $A_{k}(u)$, e classificação de um dado padrão de acordo com estes graus tem sido desenvolvidas para tipos específicos de problemas de reconhecimento de padrão. 


\section{MÉTODO PROPOSTO: CONCEPÇÃO INICIAL}

Como vimos no Capítulo 4, considerar o ponto de vista do usuário/morador tem sido cada vez mais reconhecido como fundamental nas avaliações, partindo da idéia de que o usuário/morador é o principal experimentador do espaço urbano estudado e também responsável por sua manutenção, por tanto por sua sustentabilidade (SALAT, 2006). O método proposto a seguir parte da idéia de utilizar ferramentas de Lógica Fuzzy, menos restritivas em relação a escala de mensuração dos dados, para o tratamento das variáveis qualitativas da avaliação do ambiente urbano, bem como buscar formas de aperfeiçoamento dos métodos de agregação tanto de dados qualitativos quanto quantitativos e por fim, obter uma forma de comparação destes resultados.

\subsection{ETAPAS}

A concepção do método alia algumas ferramentas de APO - pesquisa documental (leitura de projetos e relatórios) e pesquisa de campo (aplicação de formulários) para a coleta de dados e a análise de pontos positivos e negativos de um projeto, com a necessidade de estabelecer indicadores de avaliação da qualidade do projeto. Assim, dividimos este método em 6 etapas conforme a Figura 19, que apresenta também os principais entraves identificados na literatura.

\subsubsection{Definição de variáveis/indicadores}

A definição de QAU que norteia este trabalho é aquela onde a QAU é entendida como a qualidade referente às condições ambientais do meio urbano (natural e cultural), sendo resultante da ação do homem e repercutindo na sua qualidade de vida. A partir da revisão sobre sistemas indicadores foi elaborado um quadro síntese (Quadro 16), buscando avaliar as similaridades e complementaridades entre eles, para subsidiar a definição dos indicadores para a pesquisa piloto. 


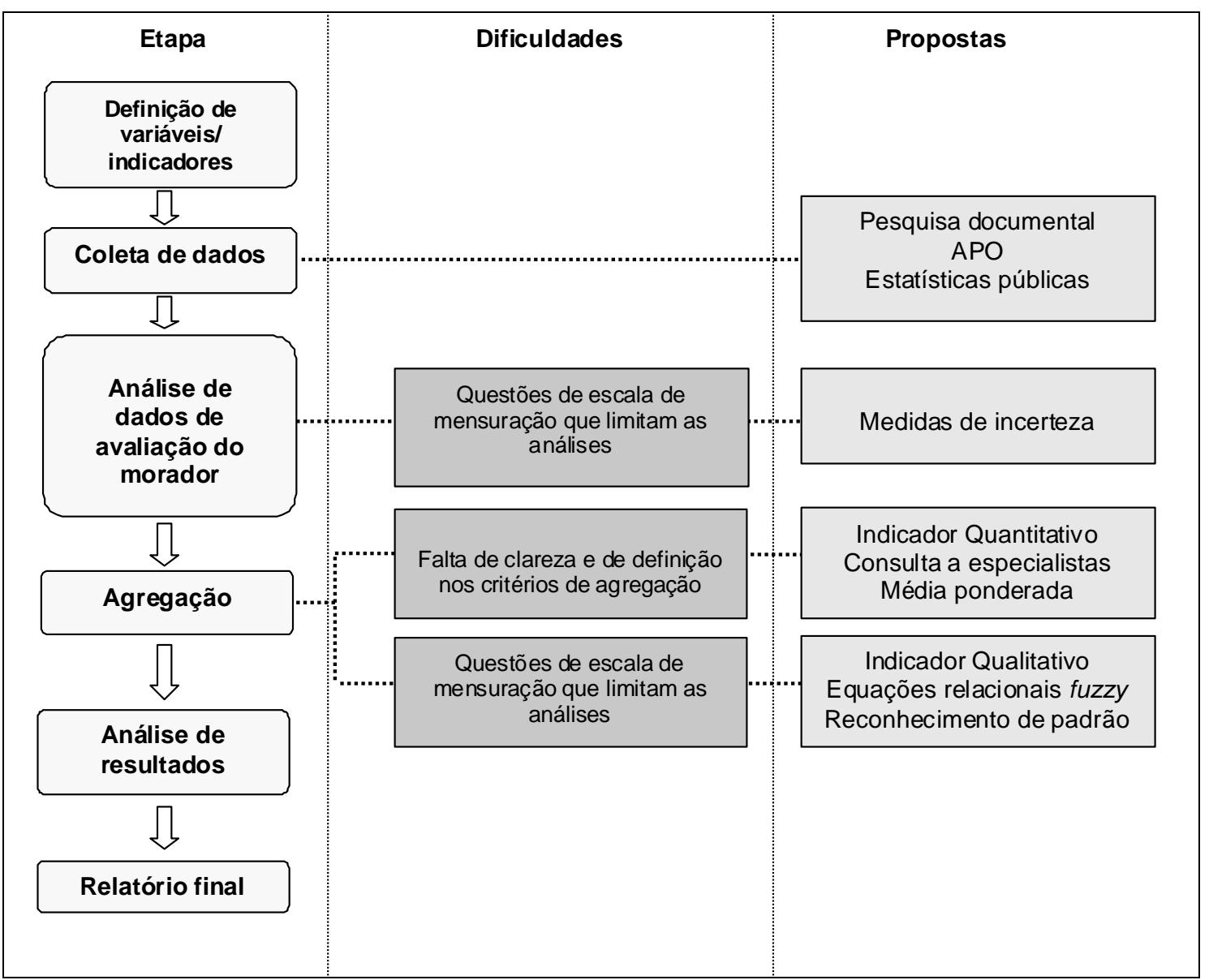

Figura 19: Concepção do método

Quadro 16: Síntese dos indicadores pesquisados

\begin{tabular}{|c|c|c|c|c|c|c|c|c|}
\hline & Variável & $\overbrace{}^{\prime}=$ & 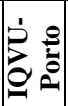 & 党: & $\underset{\mathscr{\Omega}}{\mathbb{\Omega}}$ & $\sum_{\mathscr{\Omega}}^{\mathscr{L}}$ & $\underset{\substack{2 \\
\varrho}}{\stackrel{5}{\varrho}}$ & שِ \\
\hline 1 & Esgoto & $\mathrm{X}$ & $\mathrm{X}$ & $\mathrm{X}$ & $\mathrm{X}$ & $\mathrm{X}$ & $\mathrm{X}$ & $\mathrm{X}$ \\
\hline 2 & Resíduos sólidos & $\mathrm{X}$ & $\mathrm{X}$ & $\mathrm{X}$ & $\mathrm{X}$ & $\mathrm{X}$ & $\mathrm{X}$ & $\mathrm{X}$ \\
\hline 3 & Abastecimento de água & $\mathrm{X}$ & & $\mathrm{X}$ & $\mathrm{X}$ & $\mathrm{X}$ & $\mathrm{X}$ & $\mathrm{X}$ \\
\hline 4 & Drenagem & & & & & $\mathrm{X}$ & $\mathrm{X}$ & $\mathrm{X}$ \\
\hline 5 & Vias de circulação (Condições das vias) & & & & & $\mathrm{X}$ & $\mathrm{X}$ & $\mathrm{X}$ \\
\hline 6 & Transporte e mobilidade (Meios de transporte) & $\mathrm{X}$ & $\mathrm{X}$ & & & & & $\mathrm{X}$ \\
\hline 7 & Energia elétrica & $\mathrm{X}$ & & & & $\mathrm{X}$ & & $\mathrm{X}$ \\
\hline 8 & Serviços urbanos (bancos, postos de gasolina, telefones públicos) & $\mathrm{X}$ & $\mathrm{X}$ & & & & & \\
\hline 9 & Comunicação (Rede de telefonia) & $\mathrm{X}$ & & & & & & $\mathrm{X}$ \\
\hline 10 & Equipamentos comunitários de lazer e cultura & & & & & $\mathrm{X}$ & & $\mathrm{X}$ \\
\hline 11 & Equipamentos comunitários de educação & $\mathrm{X}$ & $\mathrm{X}$ & & & & & \\
\hline 12 & Abastecimento & $\mathrm{X}$ & & & & & & $\mathrm{X}$ \\
\hline 13 & Saúde & $\mathrm{X}$ & $\mathrm{X}$ & $\mathrm{X}$ & & & & \\
\hline 14 & Assistência social & $\mathrm{X}$ & & & & & & \\
\hline 15 & Moradia & $\mathrm{X}$ & & $\mathrm{X}$ & & & $\mathrm{X}$ & $\mathrm{X}$ \\
\hline 16 & Conforto e meio ambiente & $\mathrm{X}$ & $\mathrm{X}$ & & & & & \\
\hline 17 & Controle de vetores/saúde ambiental & & & & $\mathrm{X}$ & & $\mathrm{X}$ & \\
\hline 18 & Educação (Índices de alfabetização) & $\mathrm{X}$ & $\mathrm{X}$ & $\mathrm{X}$ & $\mathrm{X}$ & $\mathrm{X}$ & $\mathrm{X}$ & $\mathrm{X}$ \\
\hline 19 & Cultura & $\mathrm{X}$ & $\mathrm{X}$ & & & & & \\
\hline 20 & Esportes & $\mathrm{X}$ & $\mathrm{X}$ & & & & & \\
\hline 21 & Cidadania e participação cívica & & $\mathrm{X}$ & & & & & $\mathrm{X}$ \\
\hline 22 & População & & $\mathrm{X}$ & & & $\mathrm{X}$ & $\mathrm{X}$ & \\
\hline 23 & Segurança urbana & $\mathrm{X}$ & $\mathrm{X}$ & & & & & \\
\hline 24 & Renda & & $\mathrm{X}$ & & $\mathrm{X}$ & $\mathrm{X}$ & $\mathrm{X}$ & \\
\hline 25 & Mercado de trabalho & & $X$ & & & & & \\
\hline 26 & Mercado de habitação & & $X$ & & & & & \\
\hline
\end{tabular}


$\mathrm{Na}$ revisão bibliográfica dos indicadores é fácil notar que alguns sistemas recorrem ao agrupamento das variáveis em dimensões, ou temas, da realidade estudada. Este agrupamento é bastante útil quando se deseja produzir indicadores "condensados". Contudo, pode levar a simplificações que não reproduzem a realidade de forma satisfatória. Diante disso, optou-se por trabalhar os indicadores em blocos, com base na delimitação espacial e uma subdivisão em temas como veremos mais adiantes (Figura 20).

Dessa forma temos um indicador relacionado às condições individuais (moradia) e dois indicadores relacionados às condições coletivas, sendo um relativo à área urbanizada e o outro relativo aos elementos de integração com as demais áreas (transporte, lazer e serviços).

O Quadro 17 apresenta os componentes para cada indicador, bem como as variáveis necessárias a sua obtenção. Para os indicadores de Moradia e Entorno, os dados são obtidos diretamente como os moradores, já para o Indicador de Salubridade Ambiental os dados podem ser obtidos por meio de pesquisa de campo ou junto aos órgãos de planejamento.

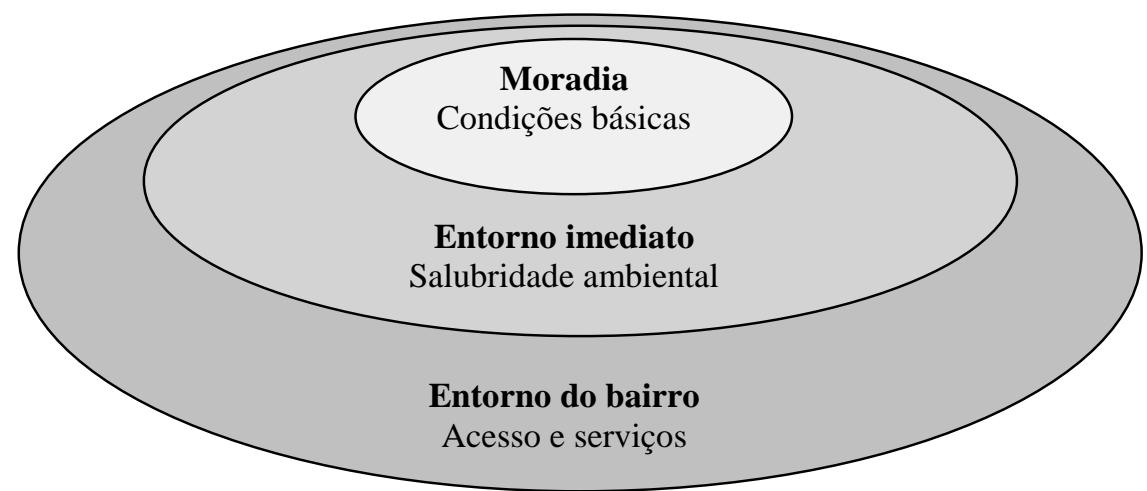

Figura 20: Definição do agrupamento espacial dos indicadores

A coleta dos dados, se por amostragem ou em toda população, será determinada em cada caso. De antemão, sabemos que as informações, da forma como são necessárias aos indicadores, nem sempre estão disponíveis. Assim, nesta análise será dada prioridade aos dados obtidos diretamente com moradores. 
Quadro 17: Indicadores selecionados

\begin{tabular}{|c|c|c|}
\hline Indicador & Componentes & Variáveis relacionadas \\
\hline \multirow[t]{16}{*}{ Moradia } & \multirow[t]{5}{*}{ Composição e adequação } & Número de quartos \\
\hline & & Número de moradores \\
\hline & & Domicúlios com uso de outros cômodos para dormir \\
\hline & & Domicílios sem banheiro \\
\hline & & Domicílios sem cozinha \\
\hline & \multirow{2}{*}{ Cobertura } & Domicílios com material adequado no telhado \\
\hline & & Domicílios sem problemas no telhado quando chove \\
\hline & \multirow[t]{3}{*}{ Paredes } & Domicílios com material adequado nas paredes \\
\hline & & Domicílios com revestimento interno \\
\hline & & Domicílios com revestimento externo \\
\hline & \multirow[t]{2}{*}{ Piso } & Domicílios com material adequado no piso \\
\hline & & Domicílios sem problemas de umidade \\
\hline & Iluminação e ventilação natural & Domicílios com iluminação/ventilação em todos os cômodos \\
\hline & Instalações de água & Domicílios com instalação de água \\
\hline & Instalações de esgoto & Domicílios com instalação de esgoto \\
\hline & Instalações elétricas & Domicílios com instalação elétrica \\
\hline \multirow{31}{*}{$\begin{array}{l}\text { Salubridade } \\
\text { da favela }\end{array}$} & \multirow[t]{2}{*}{ Abastecimento de água } & Domicílios atendidos com abastecimento de água \\
\hline & & Domicílios atendidos que recebem conta \\
\hline & \multirow[t]{2}{*}{ Esgoto } & Domicílios atendidos com rede de esgoto \\
\hline & & Domicílios atendidos que recebem conta \\
\hline & \multirow[t]{2}{*}{ Coleta de lixo } & Domicílios na favela com coleta de lixo \\
\hline & & Domicílios que depositam em locais inadequados \\
\hline & \multirow[t]{2}{*}{ Drenagem } & Habitações com problema de acesso em dias de chuva \\
\hline & & Habitações com problema de inundação em dias de chuva \\
\hline & \multirow[t]{4}{*}{ Vias de circulação } & Domicílios com via de acesso maior ou igual a 6 metros \\
\hline & & Domicílios com via de acesso entre 3,60 e 6,00 metros \\
\hline & & Domicílios com via de acesso entre 1,20 e 3,60 metros \\
\hline & & Domicílios com via de casso menor que 1,20 metros \\
\hline & \multirow[t]{3}{*}{ Segurança geológico-geotécnica } & Área sem risco \\
\hline & & Área com risco baixo \\
\hline & & Área com risco alto ou moderado \\
\hline & \multirow[t]{2}{*}{ Densidade demográfica bruta } & Número de moradores \\
\hline & & Área total da favela \\
\hline & \multirow[t]{2}{*}{ Energia elétrica } & Domicílios atendidos com energia elétrica \\
\hline & & Domicílios atendidos que recebem conta \\
\hline & \multirow[t]{4}{*}{ Regularização fundiária } & Domicílios em área regularizada \\
\hline & & Domicílios em área passível de ser regularizada, com projeto de lei em tramitação \\
\hline & & Domicílios em área passível de ser regularizada, sem projeto de lei em tramitação \\
\hline & & Domicílios em área sem possibilidade de regularização em curto prazo \\
\hline & \multirow[t]{3}{*}{ Varrição } & Domicílios com serviço de varrição \\
\hline & & Domicílios com varrição executada pelo morador \\
\hline & & Domicílios sem varrição \\
\hline & Iluminação Pública & Domicílios com iluminação pública \\
\hline & \multirow[t]{2}{*}{ Espaços públicos } & Existência de área de espaços públicos \\
\hline & & Percentual de população utilizadora destes espaços \\
\hline & Educação & Chefes de família com 8 anos ou mais de estudos \\
\hline & Renda & Índice Gini da área ou subdistrito \\
\hline \multirow[t]{10}{*}{ Entorno } & Transporte e mobilidade & Número de pessoas que utilizam ônibus ou trem para trabalhar \\
\hline & \multirow{4}{*}{$\begin{array}{l}\text { Equipamentos comunitários e de } \\
\text { serviços }\end{array}$} & Domicílios em que se utiliza telefone público \\
\hline & & Domicílios em que se utiliza escola \\
\hline & & Domicílios em que se utiliza posto de saúde \\
\hline & & Domicílios em que se utiliza creche \\
\hline & Associativismo & Domicílios em que algum membro participa de associação \\
\hline & & Domicílios em que algum membro participa de associação de moradores \\
\hline & & Domicílios em que algum membro participa de cooperativa \\
\hline & & Domicílios em que algum membro participa de ONG \\
\hline & Espaços públicos & Domicílios em que os membros utilizam outros locais da cidade para lazer \\
\hline
\end{tabular}




\subsubsection{Coleta de dados}

Os procedimentos de coleta de dados são baseados em alguns métodos utilizados na APO, conforme já afirmado. Primeiro, uma pesquisa documental deverá ser feita sobre o projeto em estudo. Esta pesquisa busca ter o máximo de informações sobre o projeto, bem como, elementos para a pesquisa de campo. A partir desta pesquisa deverá ser planejada a pesquisa de campo que constará de duas etapas: um Walktrough - pesquisa exploratória - e uma pesquisa de campo utilizando formulários em uma amostra da área. Os formulários serão baseados nas variáveis definidas na etapa de "Definição de variáveis/indicadores" e compostos de questões objetivas sobre a presença, ou não, de determinadas características e questões subjetivas, de avaliação do morador, sobre as mesmas variáveis, de forma que as questões objetivas subsidiarão a elaboração dos indicadores quantitativos e as questões subjetivas a elaboração dos qualitativos. Um registro fotográfico também deverá ser realizado com a identificação de elementos notáveis da área em estudo os quais ajudarão entender os resultados obtidos na pesquisa de campo.

Por se tratar de uma área urbana extensa, há também a possibilidade de obtenção de dados censitários ou pesquisas anteriores dos órgãos estaduais e municipais as quais deverão ser buscadas, sempre que possível, para subsidiar a obtenção dos indicadores.

\subsubsection{Análise de dados de avaliação do morador}

Nesta etapa as questões de avaliação dos moradores deverão ser analisadas tanto sob a ótica da abordagem clássica, quanto sob a ótica da abordagem fuzzy de forma a identificar possíveis vantagens e desvantagens. A principal questão a ser avaliada nesta etapa está relacionada à identificação dos pontos positivos e negativos da área em estudo, sob o ponto de vista do morador, e a adequação do uso de escalas quantitativas para representação de conceitos. Para a abordagem fuzzy serão utilizadas nesta etapa as modas associadas a medidas de incerteza no lugar das médias e desvios-padrão freqüentemente utilizados. 


\subsubsection{Agregação}

O objetivo desta etapa é obter um indicador global de avaliação da qualidade ambiental da área. Para isso serão utilizados dois procedimentos diferentes em função das características das medidas utilizadas. Primeiro, buscaremos analisar a possibilidade de elaboração de um indicador qualitativo baseado nas opiniões dos moradores e depois, buscaremos aperfeiçoar o método de agregação de indicadores quantitativos, estabelecendo um sistema de ponderação baseado em opiniões de especialistas. Cabe aqui destacar que há uma série de operadores de agregação definidos na literatura sobre Lógica Fuzzy, tais como os operadores de média, porém, estes somente são aplicáveis a dados em escalas de medida numéricas (KLIR; YUAN, 1995).

\subsubsection{Indicadores qualitativos}

Obter indicadores baseados em pesquisas de opinião consiste numa tarefa complexa visto que cada pessoa avalia um dado objeto, ou espaço, baseada em valores individuais: logo, cada indivíduo pondera as qualidades do referido objeto ou espaço de uma forma diferente. Assim, dificilmente, uma avaliação global corresponderá a uma somatória de avaliações parciais e esta agregação se dará de forma semelhante. Além disso, a avaliação do morador geralmente é dada por meio de conceitos, ou seja, numa escala qualitativa que, de acordo com o exposto anteriormente, impõe limitações ao processo de agregação dos dados, pois as operações aritméticas não são permitidas neste tipo de escala.

As duas ferramentas selecionadas para tentar modelar este processo de avaliação do morador são baseadas em padrões de respostas. Agrupamos as respostas em duas classes: avaliações parciais, que são as avaliações dos sub-indicadores como abastecimento de água, serviço de esgoto, coleta de lixo e avaliações finais que são as avaliações da moradia como um todo, da salubridade ambiental e do entorno.

$\mathrm{Na}$ primeira ferramenta, baseada em relações fuzzy, agrupamos os formulários nos quais foram atribuídos a mesma avaliação final e modelamos o seu comportamento em relação as avaliações parciais, baseados nas freqüências das respostas. Este modelo não oferece limitações com relação a escala de medida utilizada, pois as operações são feitas utilizando-se 
os graus de verdades das proposições, que no caso de dados qualitativos podem ser representados pelas suas freqüências normalizadas. Ele utiliza princípios de inferência para relacionar as entradas e as saídas do modelo simulando o raciocínio humano (Figura 21).

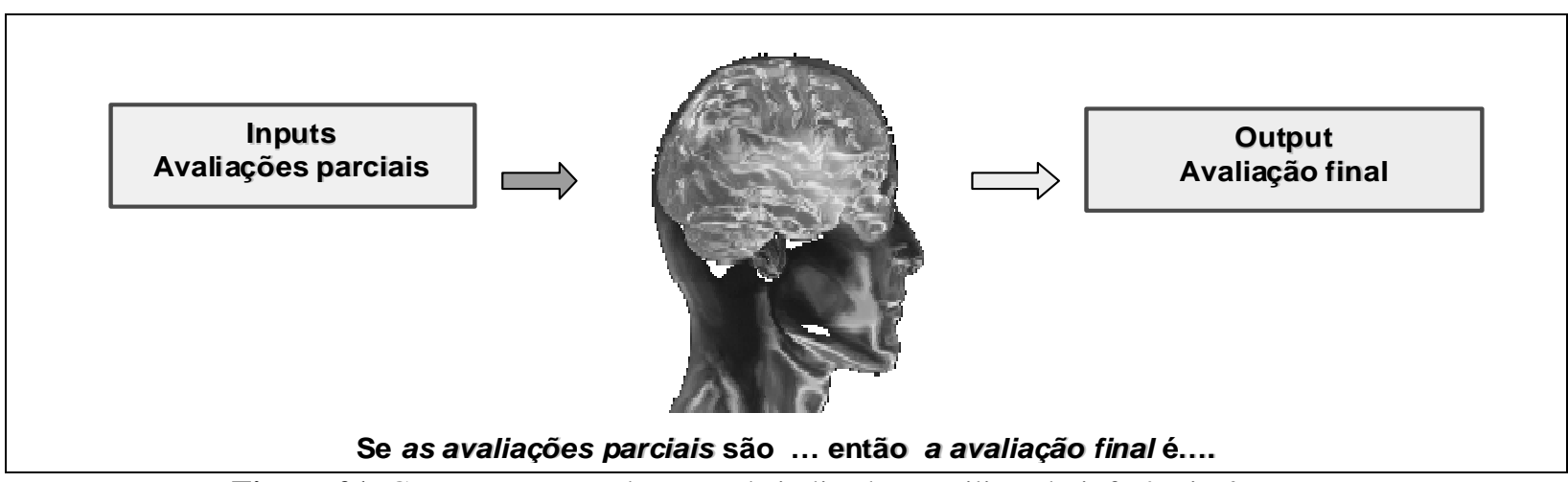

Figura 21: Concepção para obtenção de indicadores utilizando inferência fuzzy

O seu princípio é semelhante ao utilizado em inferência, contudo, no lugar de regras de composição dos resultados, saídas, é utilizada uma matriz de relação entre as avaliações parciais e finais. Este modelo está representado na Figura 22.

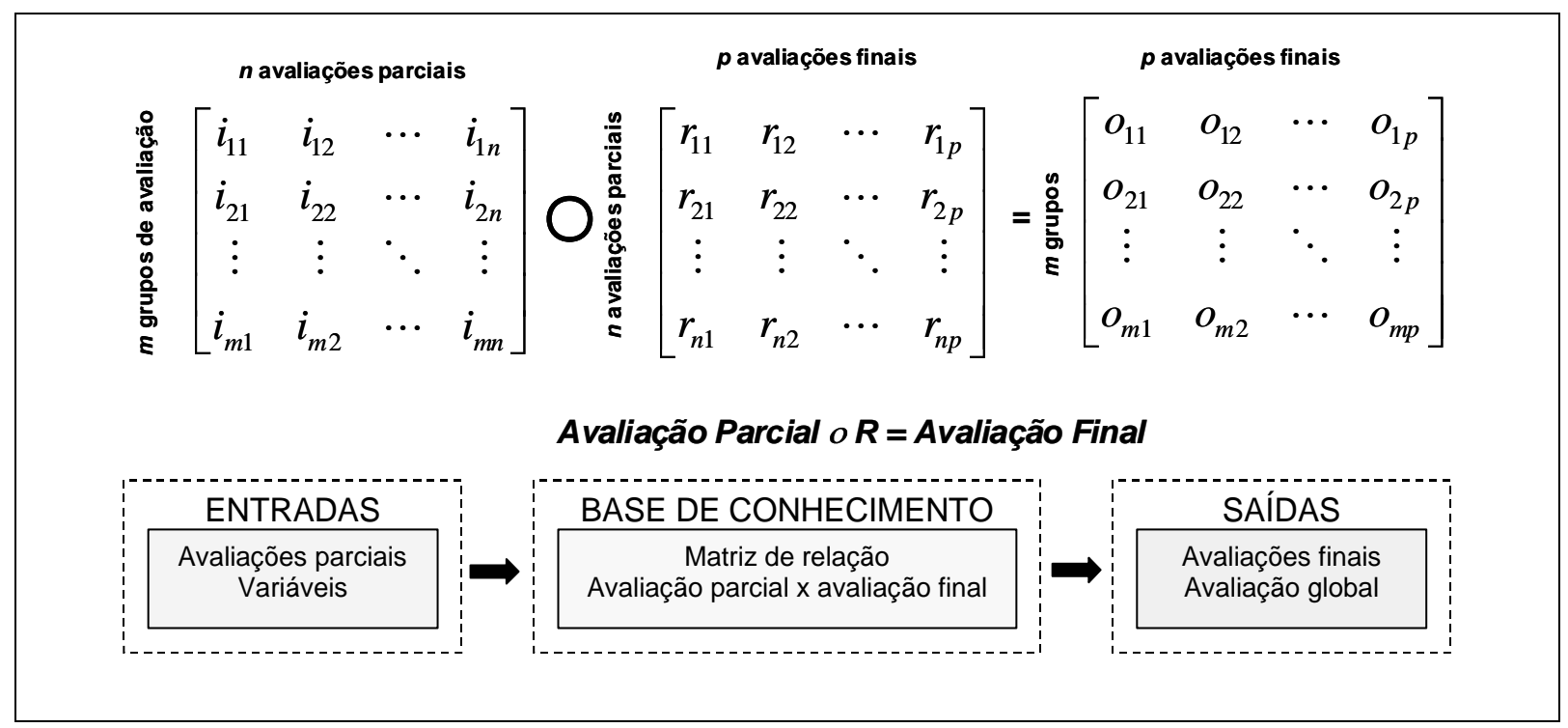

Figura 22: Modelo de inferência baseado nas relações fuzzy

O modelo específico para a avaliação da moradia pode ser visto na Figura 23. 


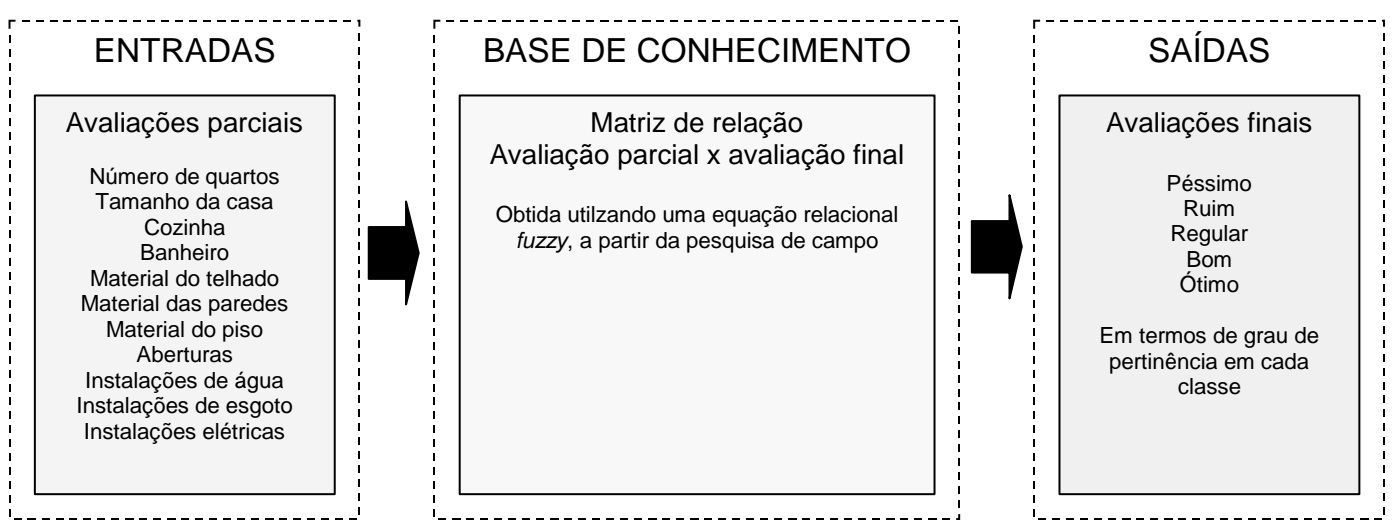

Figura 23: Modelo de inferência baseado nas relações fuzzy para avaliação da Moradia

Uma das grandes vantagens deste método é a obtenção de uma matriz que relaciona avaliações parciais e finais, de forma a identificar as variáveis que têm maior possibilidade de influenciar nas avaliações finais.

O outro modelo a ser testado é o de reconhecimento de padrão fuzzy. Neste modelo, como no anterior, os formulários são agrupados de acordo com as avaliações finais. De posse de suas freqüências são modelados os padrões de resposta para cada grupo de avaliação final. A classificação de um novo indivíduo será dada por comparação em relação a cada padrão preestabelecido (Figura 24).

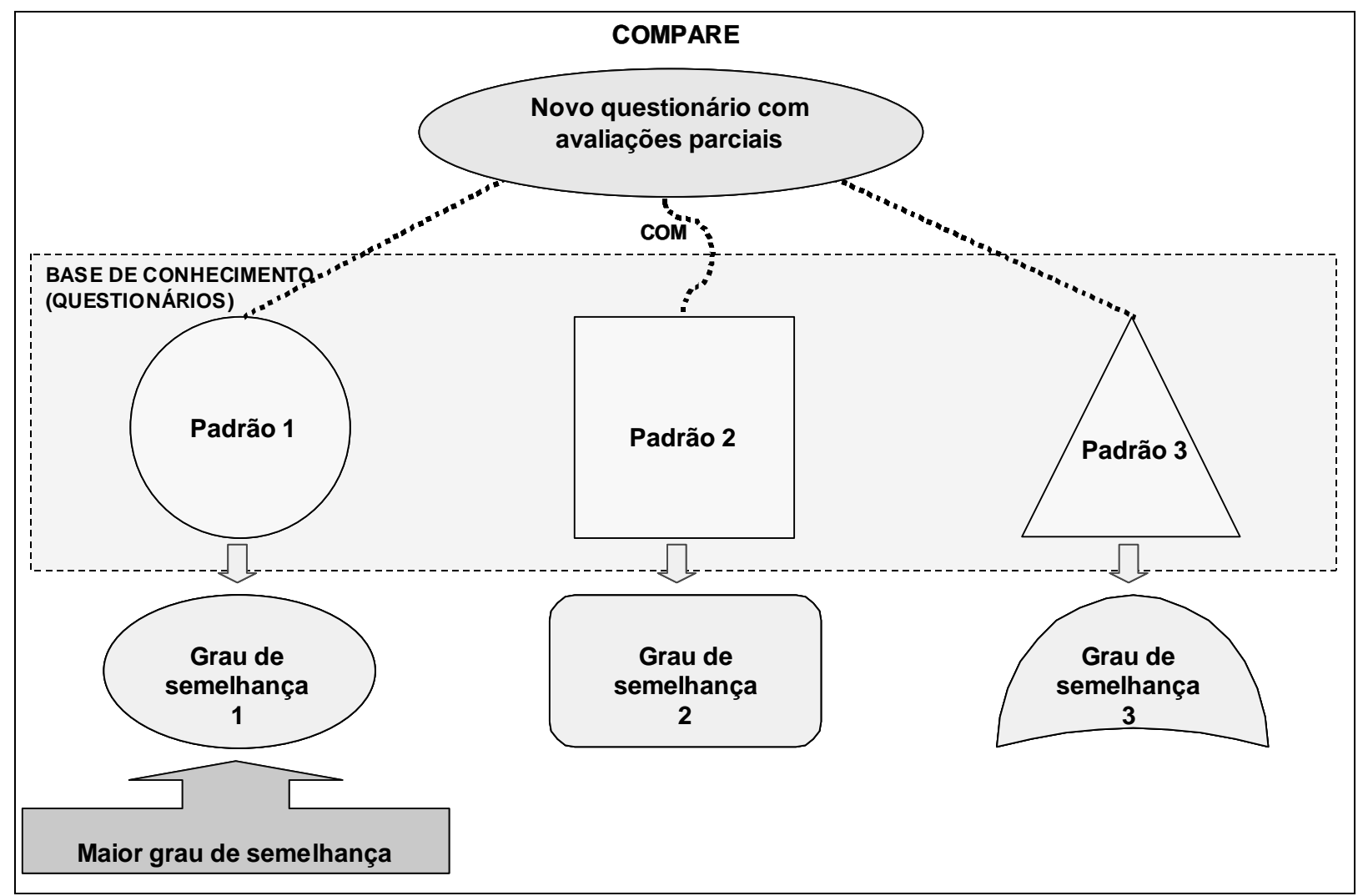

Figura 24: Esquema de classificação pelo reconhecimento de padrão 
Este modelo requer a definição de uma medida semelhança. Em nosso caso utilizaremos uma medida de semelhança conhecida como Índice de conformidade (MATTHÉ et al., 2006), que envolve apenas as operações de interseção e união de conjuntos, já definidas anteriormente, o qual é definido como:

$$
\mathrm{IC}(\mathrm{A}, \mathrm{B})=\frac{|\mathrm{A} \cap \mathrm{B}|}{|\mathrm{A} \cup \mathrm{B}|} .
$$

Definidos os padrões e suas características, dado um novo indivíduo e também suas características, por meio do cálculo da medida de semelhança, este indivíduo deverá ser classificado em um determinado padrão (avaliação final). Neste modelo, diferentemente do modelo das equações fuzzy, não é possível obter diretamente as características que influenciam na avaliação final. Contudo é possível desenvolver outras ferramentas para isto, tais como um teste chi-quadrado ou medidas de similaridade, como o já citado índice de conformidade.

\subsubsection{Indicadores quantitativos}

O objetivo desta etapa é agregar os indicadores parciais de natureza quantitativa de forma a obtermos um indicador sintético que represente a avaliação final da intervenção. Embora já existam diversos indicadores desenvolvidos como os apresentados na revisão bibliográfica, identificamos, que um dos maiores pontos de discussão reside nos sistemas de ponderação destes indicadores. Dentre os métodos disponíveis para definição de sistemas de ponderação optamos pela consulta a especialistas utilizando ferramentas do Processo Analítico Hierárquico (Analytic Hierarchy Process (AHP)).

O AHP é um método utilizado para tomada de decisão em problemas não estruturados, desenvolvido por Saaty (1980), também utilizada para realizar prognósticos. A técnica parte da elaboração de uma hierarquia montada para entender o problema, onde no primeiro nível está o foco, ou objetivo, e nos demais as variáveis intervenientes, que podem ser organizadas em fatores e níveis. A Figura 25 apresenta um exemplo utilizado para determinação da melhor alternativa de transporte interurbano.

A partir desta hierarquia são montadas matrizes de comparação pareada, ou seja, as variáveis, fatores ou componentes, são comparadas entre si, duas a duas, numa escala que vai de 1/9 a 9 
com significados associados, sobre a importância de uma variável em relação a outra. Esta escala resumida pode ser vista no Quadro 18.

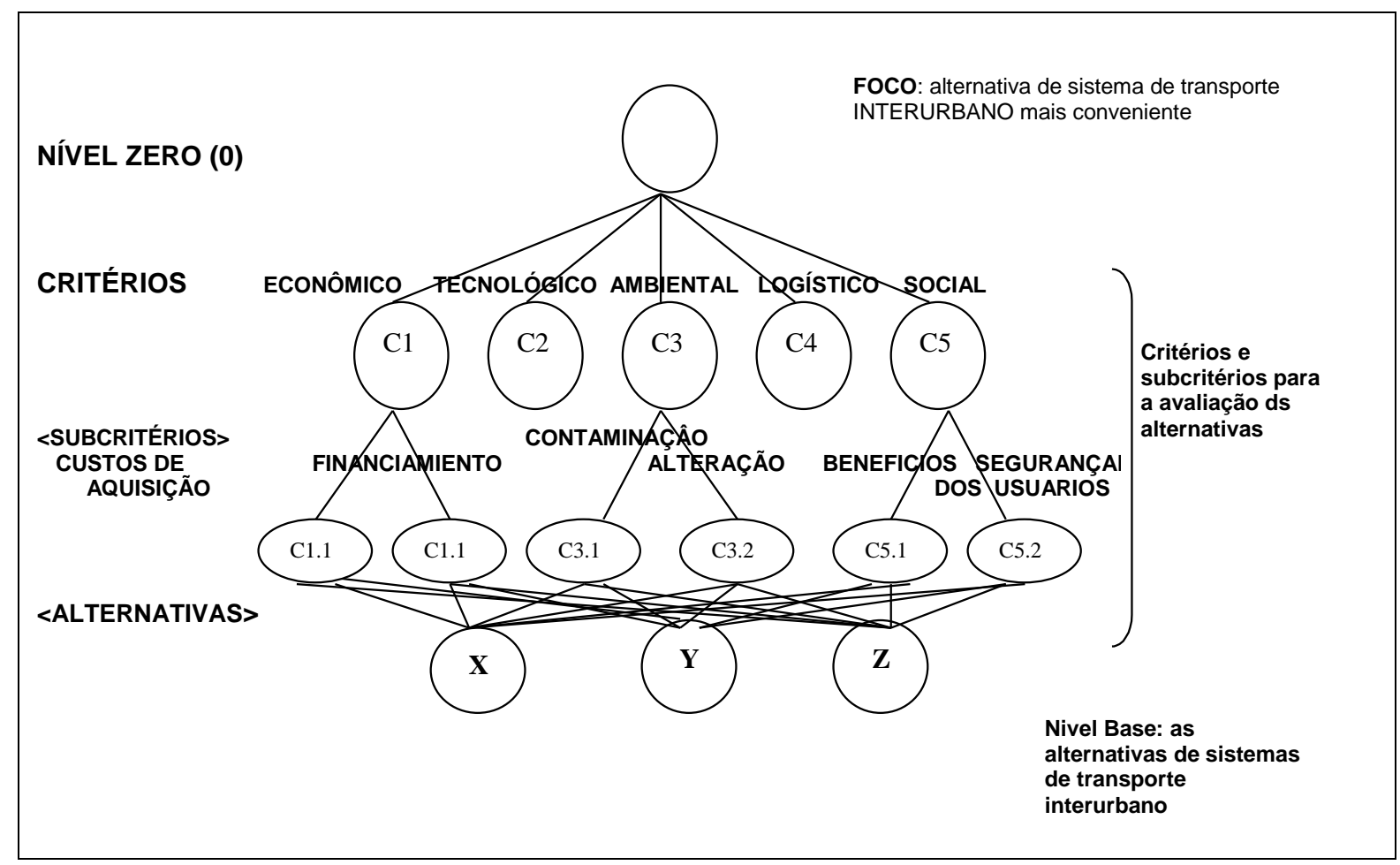

Figura 25: Exemplo de hierarquia para AHP

Fonte: Arapé (2000)

Quadro 18: Escala de importâncias utilizada no AHP

\begin{tabular}{|c|l|l|}
\hline Importância & \multicolumn{1}{|c|}{ Intensidade } & \multicolumn{1}{|c|}{ Significado } \\
\hline 1 & Igual ou indiferente a... & Ao comparar um elemento com outro, não há diferença entre eles \\
\hline 3 & $\begin{array}{l}\text { Um pouco, ou ligeiramente, mais } \\
\text { importante... }\end{array}$ & $\begin{array}{l}\text { Ao comparar um elemento com outro, o primeiro é ligeiramente } \\
\text { mais importante que o segundo }\end{array}$ \\
\hline 5 & Mais importante que... & $\begin{array}{l}\text { Ao comparar um elemento com outro, o primeiro é considerado } \\
\text { mais importante que o segundo }\end{array}$ \\
\hline 7 & Muito mais importante que... & $\begin{array}{l}\text { Ao comparar um elemento com outro, o primeiro é considerado } \\
\text { muito mais importante que o segundo }\end{array}$ \\
\hline 9 & $\begin{array}{l}\text { Absolutamente, ou totalmente, mais } \\
\text { importante que... }\end{array}$ & $\begin{array}{l}\text { Ao comparar um elemento com outro, o primeiro é considerado } \\
\text { absolutamente, ou totalmente mais importante que o segundo }\end{array}$ \\
\hline $\begin{array}{l}\text { Obs.: Quando o primeiro elemento da comparação tiver importância menor que o segundo utilizamos os valores inversos da escala, } \\
\text { podemos também utilizar os valores intermediários da escala }\end{array}$
\end{tabular}

Fonte: Adaptado de Arapé (2000)

Saaty (1980) testou a equivalência e adequação entre a escala numérica e os significados semânticos atribuídos e demonstrou que a importância de cada critério pode ser obtida calculando-se o autovetor normalizado correspondente ao maior autovalor da matriz. Assim, após a consulta aos especialistas sobre as importâncias das variáveis componentes da QAU, poderemos obter os pesos de cada variável para a composição de um indicador final. 


\subsubsection{Análise dos resultados}

De posse dos resultados apresentados nas etapas "Análise de dados de avaliação do morador" e "Agregação" deverá ser feita uma análise, de preferência comparativa com os procedimentos já existentes. É importante salientar que no caso da identificação dos pontos positivos e negativos o procedimento clássico está bem estabelecido, utilizando-se as médias e os desvios-padrão das variáveis, porém, para o cálculo dos indicadores qualitativos seria necessário o desenvolvimento de um modelo comparativo, o que demandaria um novo trabalho de pesquisa. De modo que a avaliação destes modelos se dará pelo percentual de acerto das avaliações já obtidas com os formulários, bem como, pela congruência dos resultados das duas ferramentas analisadas.

\subsubsection{Relatório de qualidade ambiental}

Os resultados apresentados em cada etapa, bem como suas conclusões deverão compor um relatório de qualidade ambiental. O relatório será composto por:

- Histórico e descrição da área de estudo.

- Descrição dos dados coletados.

- Identificação de pontos positivos e negativos da área.

- Indicadores qualitativos e quantitativos da área, com possíveis análises sobre as variáveis mais importantes do ponto de vista do morador e aquelas mais carentes do ponto de vista técnico.

- E por fim, as considerações finais e recomendações.

Em função da disposição do texto nesta tese, este relatório será substituído pelo conteúdo das análises dos estudos de caso. 


\section{DESCRIÇÃo DA ÁREA DE ESTUdO: ÁREA DO PROGRAMA RIBEIRA AZUL}

Conforme já foi descrito no plano de trabalho, as áreas selecionadas para pesquisa piloto e validação do método fazem parte do Programa Ribeira Azul, do Governo do Estado da Bahia.

O Programa Ribeira Azul é um programa integrado, vinculando as intervenções físicas às ações sociais e geradoras de renda. O Programa tem como objetivos gerais promover a redução da pobreza urbana, a recuperação e preservação física/ambiental, elaborar estratégias para implementação de programas de redução da pobreza urbana na Região Metropolitana de Salvador. Seus objetivos específicos são promover a urbanização, a infra-estrutura das áreas consolidadas e a erradicação das palafitas por meio de aterro com reassentamento das famílias; promover o desenvolvimento econômico social, o exercício da cidadania e a participação comunitária por meio da educação ambiental e sanitária e o treinamento e qualificação de mão de obra (Companhia de Desenvolvimento Urbano do Estado da Bahia (CONDER)), 2003).

A área do Programa, compreende um conjunto de bairros situados no Subúrbio Ferroviário, somando $4 \mathrm{Km}^{2}$ que abriga cerca de 40.000 famílias, equivalente a aproximadamente 150.000 habitantes, o que representa 6\% da população atual do município de Salvador (Figura 26). Esta área abriga um conjunto de invasões datado da década de 1940, famoso pela persistência e o avanço ocorrido na direção da Baía de Todos os Santos sobre o mar (CONDER, 2003).

Destacamos que este programa tem sido alvo de estudos, tanto pelo montante de recursos alocados, quanto pelas parcerias firmadas, bem como pelas ações integradas, que mereceram o prêmio de umas das dez melhores práticas de gestão de 2001, dado pela Caixa Econômica Federal (IBAM, 2002).

As primeiras invasões datam do final da década de 1940, quando surge Alagados, formada por migrantes do Recôncavo em busca de emprego. A partir deste período a expansão da área se deu basicamente por meio das invasões (Figura 27). Diversas obras urbanas interferiram no processo de expansão da área, como a construção da Avenida Suburbana nos anos 1970, que potencializou a expansão do processo de ocupação ao longo das enseadas entre Lobato e Plataforma, também na mesma década a implantação do Centro Industrial de Aratu (CIA) e 
do Pólo Petroquímico de Camaçari, influenciaram na redefinição dos espaços da cidade, tornando a periferia mais populosa devido ao grande fluxo de pessoas vindas do interior, atraídas pela industrialização, contudo precarizada, por não ter recebido os benefícios dessa modernização (CARVALHO, 2002; CONDER, [ca. 2000]).

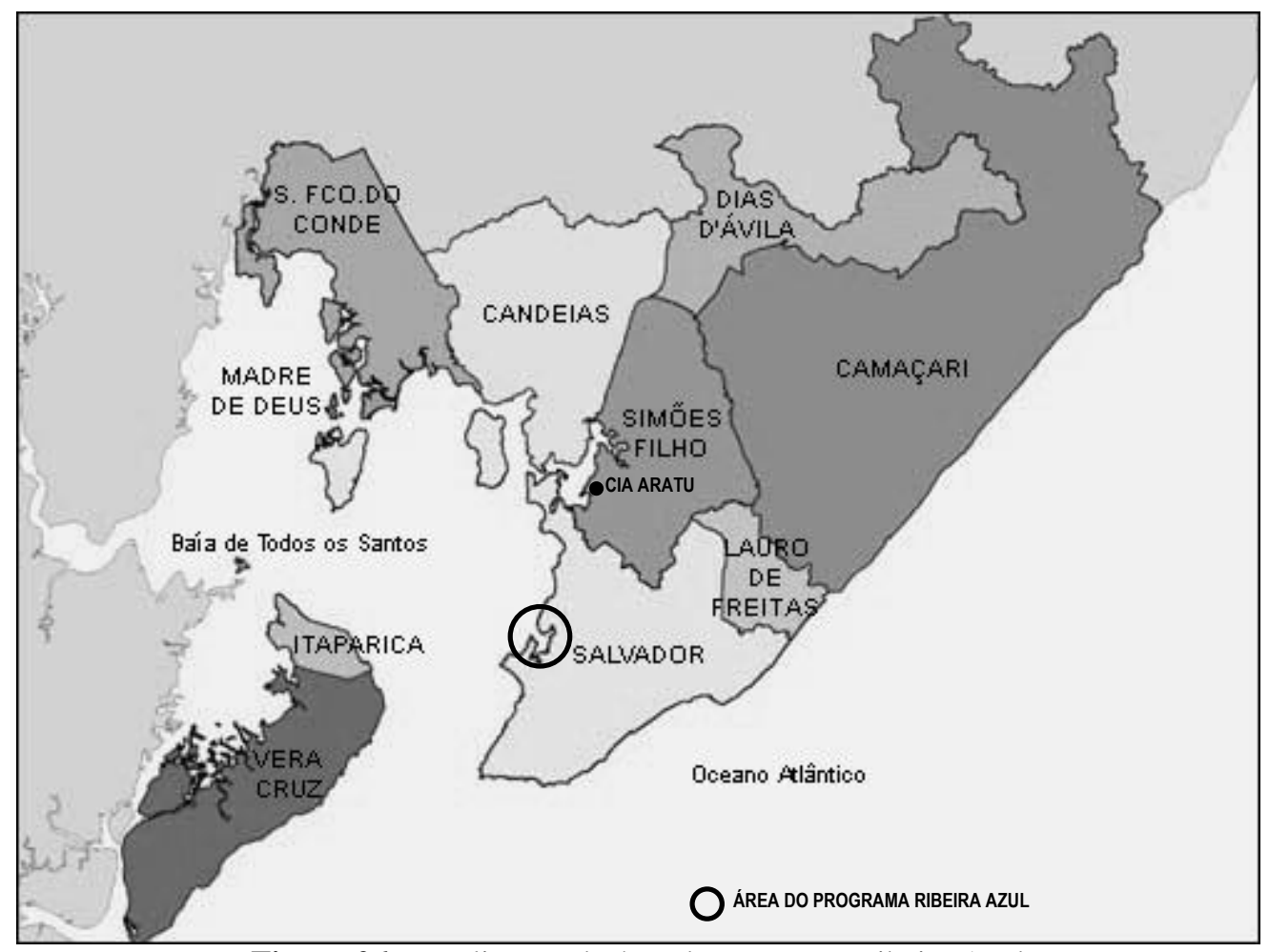

Figura 26: Localização da área do Programa Ribeira Azul

Fonte: Elaborado a partir de mapa disponível em http://www.conder.ba.gov.br

Com o decorrer do tempo os domicílios situados nas invasões evoluíram em relação à sua estrutura, passando a empregar materiais de construções mais resistentes como pedras, cimento e blocos, porém, novas invasões se seguiram e ainda é significativo o número de habitações precárias no local.

Para efeito do Programa, a área foi dividida em duas frentes: Alagados, na Enseada dos Tainheiros e Novos Alagados, na Enseada do Cabrito (Figura 28).

Segundo o diagnóstico elaborado para o Projeto de Apoio Técnico e Social na Área do Ribeira Azul (PATS) a área do Ribeira Azul dispõe de poucos equipamentos sociais e de infra-estrutura de serviços, contribuindo ainda mais para a degradação da área, que possui uma concentração de vulnerabilidades sociais, como o baixo nível de escolaridade, desemprego, informalidade no trabalho, proliferação de doenças infecto-contagiosas, situação epidemiológica de alto risco, e elevados índices de violência (CONDER, [ca. 2000]). 


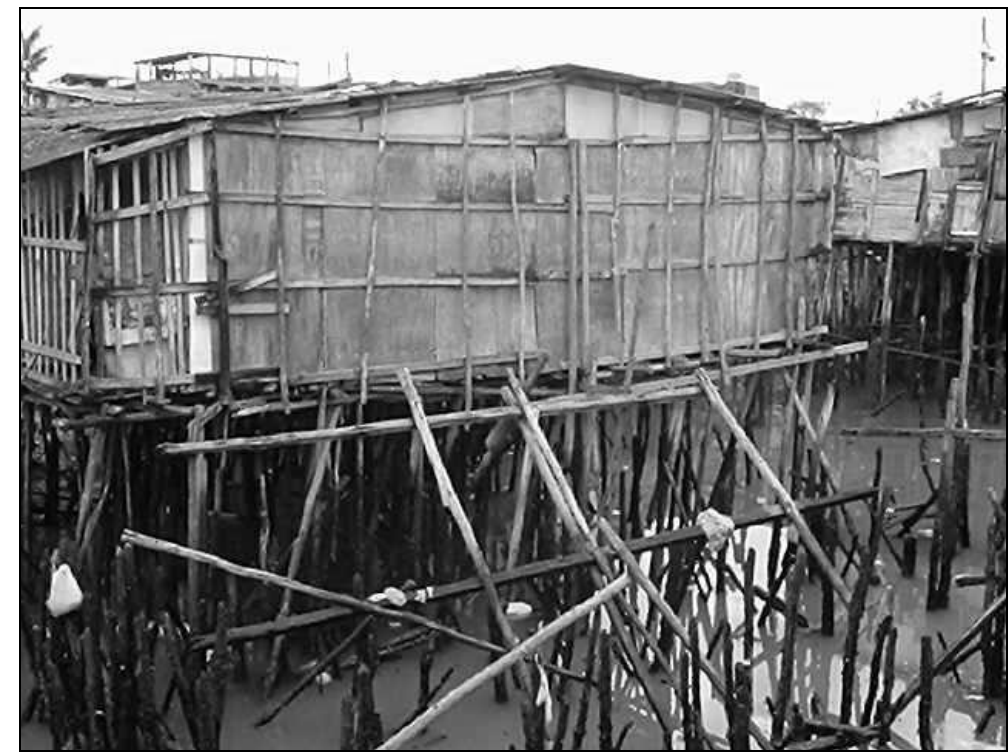

Figura 27: Palafitas - moradia precária típica da área do Programa Ribeira Azul Fonte: arquivo cedido pelo projeto Revafela/USP

A área do programa Ribeira Azul apresenta os piores indicadores sociais da cidade. No começo das intervenções 13.100 pessoas viviam nestes assentamentos em condições subumanas, 3.500 famílias viviam em palafitas, $45 \%$ da população economicamente ativa não possuía nenhuma renda, $59 \%$ das famílias na área viviam com meio salário mínimo por mês, 13\% das moradias em terra não possuíam banheiros, e $64 \%$ das instalações sanitárias não funcionavam adequadamente (BAKER, 2006).

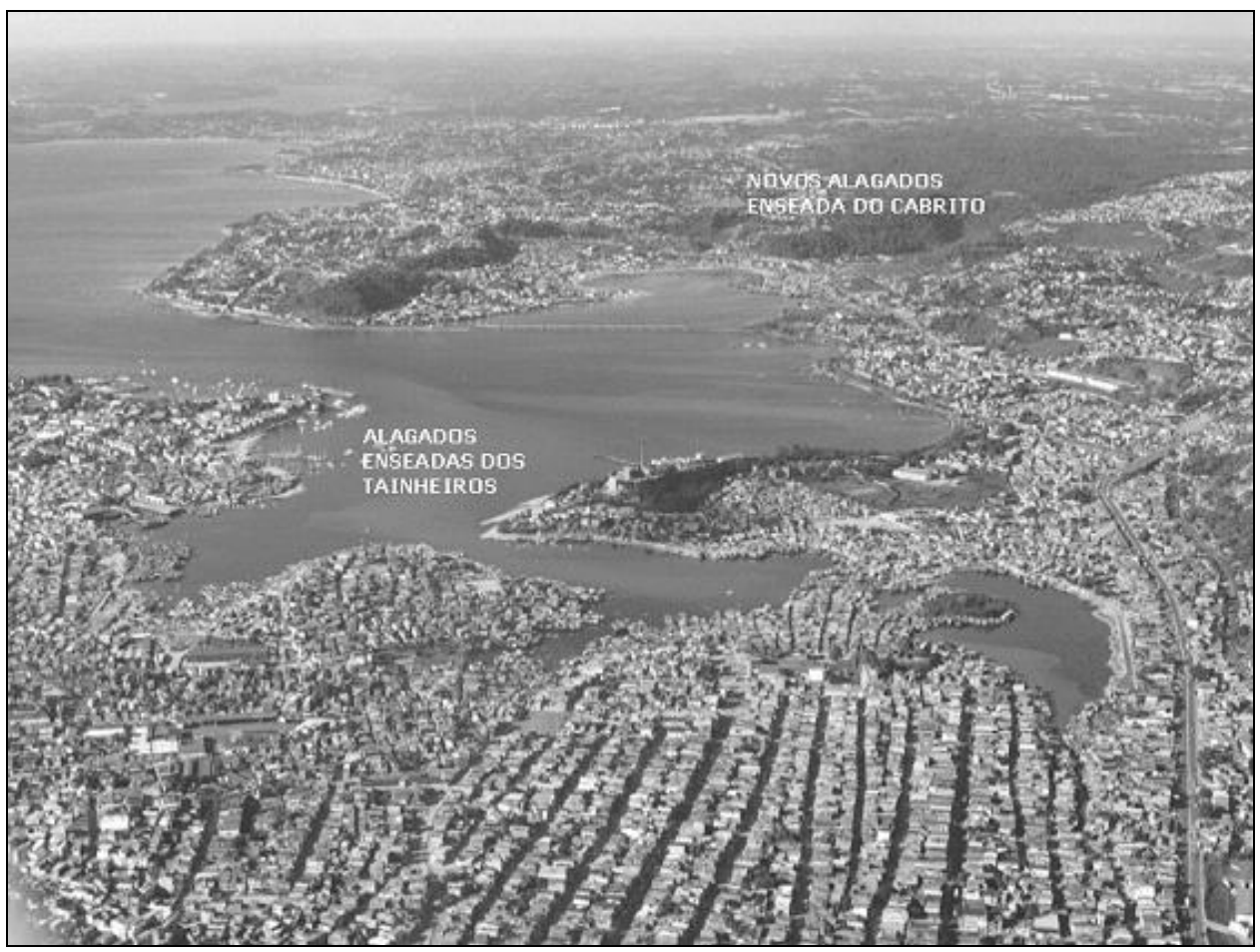

Figura 28: Vista da área do Programa Ribeira Azul Fonte: Carvalho (2002) 
Atualmente, a Enseada dos Tainheiros é considerada a área mais crítica em termos de comprometimento ambiental da Baía de Todos os Santos, em conseqüência do processo de ocupação industrial e populacional, evidentemente acompanhado por uma progressiva degradação ambiental (CONDER, [ca. 2000]).

\subsection{HISTÓRICO DE INTERVENÇÕES E CARACTERIZAÇÃO DA ÁREA}

A área hoje denominada de Programa Ribeira Azul vem sendo alvo de intervenções desde a década de 1970 quando foi criada a Alagados Melhoramentos S. A. (AMESA), empresa de capital misto, com o objetivo de dotar a área de infra-estrutura e erradicar as palafitas ali existentes. Apesar de ter cumprido os seu objetivo, atuando na área no período de 1974 a 1984, a ação da AMESA não foi suficiente para coibir as novas invasões, que voltaram a ocorrer na área poucos anos depois.

Em 1984 o Governo amplia o alcance de atuação da AMESA pra todo o Estado, transformando-a na Habitação Melhoramentos S.A. (HAMESA) que durou quatro anos (1983 a 1987), sendo incorporada à Habitação e Urbanização do Estado da Bahia S.A. (URBIS). Esta, por sua vez, foi liquidada em 1999, passando à CONDER a responsabilidade sobre seus projetos.

Durante este período de mudanças nos órgãos responsáveis pela habitação no estado da Bahia, ocorreram ações simultâneas da CONDER e URBIS na atual área de intervenção. Enquanto a CONDER, a partir de 1994, havia passado a ser responsável pela recuperação da área de Novos Alagados, com um projeto subdividido em duas etapas, a URBIS atuava em Alagados, a partir de 1995, pelo Programa Viver Melhor.

A $1^{\text {a }}$ etapa do projeto de Novos Alagados foi financiada pelo Programa Metropolitano do Governo do Estado da Bahia, Viver Melhor, Banco Mundial, Ministério dos Assuntos Exteriores da Itália (MAE), que implantou suas ações por meio da Associação Voluntários para o Serviço Internacional (AVSI). A $2^{\text {a }}$ etapa foi financiada pelo Governo do Estado da Bahia, Banco Mundial e fundos privados da AVSI.

Já o Programa Viver Melhor contava com financiamentos do Governo do Estado, Caixa Econômica Federal, Orçamento Geral da União, Habitar Brasil. Os objetivos do Viver Melhor foram: erradicar as palafitas, construir novas casas para o assentamento das famílias 
removidas, melhorar as condições habitacionais, e realizar infra-estrutura de base a partir de ações pontuais e localizadas definindo poligonais de intervenção física nas áreas mais carentes.

Considerando o Projeto de Novos Alagados exitoso (Figura 29), o Governo do Estado da Bahia decidiu aplicar a mesma metodologia em novos projetos. Essa decisão permitiu ao Governo ampliar a escala das ações, de projeto a um programa em nível urbano (Programa de redução da pobreza urbana na área do Ribeira Azul), cujo objetivo é integrar todas as intervenções pontuais que vinham ocorrendo na área, captando e fazendo convergir novos recursos para dar continuidade às intervenções em andamento e para favorecer, ao mesmo tempo, o desenvolvimento social da comunidade (CONDER, [ca. 2000]).

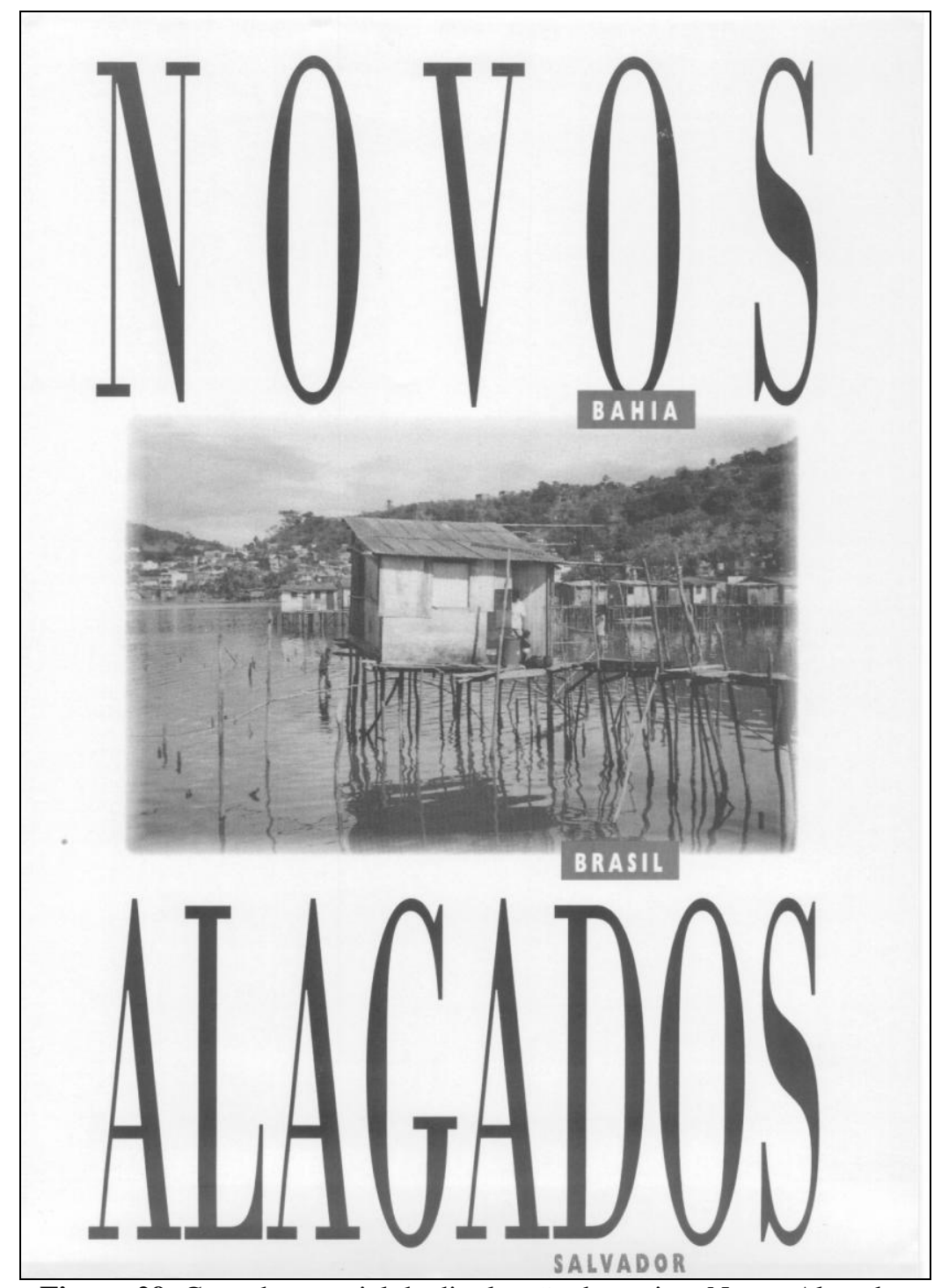

Figura 29: Capa de material de divulgação do projeto Novos Alagados 
Atualmente, os projetos físicos em andamento e executados nesta área compreendem as seguintes comunidades:

- Baixa do Caranguejo (867 famílias - obras realizadas) - Programa Viver Melhor.

- Alagados I (537 famílias - obras realizadas) - Programa Viver Melhor.

- Alagados II (214 famílias - obras realizadas) - Programa Viver Melhor

- Alagados III (422 famílias - Projetos prontos de Arquitetura e Engenharia - em fase de negociação com o Programa de Administração Municipal e Desenvolvimento de InfraEstrutura Urbana (PRODUR)).

- Alagados IV e V (2.195 famílias - obras da $1^{\mathrm{a}}$ etapa em andamento, e recursos em fase de negociação junto à Caixa Econômica Federal (CEF) para a $2^{\mathrm{a}}$ etapa) Financiamento Governo do Estado da Bahia, Caixa Econômica Federal, Habitar Brasil - BID.

- Alagados VI (2.166 famílias - Projetos de Arquitetura e Engenharia - em fase de elaboração, com recursos do PATS).

- Mangueira II (complementação de urbanização - Projetos de Arquitetura e Engenharia - em fase de elaboração, com recursos do PATS).

- Mudança (365 domicílios - obra concluída) - Programa Viver Melhor.

- Joanes Centro-Oeste (987 domicílios - obra concluída) - Programa Viver Melhor.

- São João de Plataforma (será elaborado o projeto).

- Novos Alagados $1^{\text {a }}$ ETAPA (1.697 famílias - obras complementares em execução Financiamento Governo do Estado da Bahia, Banco Mundial, MAE, AVSI).

- Novos Alagados 2a ETAPA (2.021 famílias - Financiamento Governo do Estado da Bahia, PRODUR, AVSI).

- Joanes Azul e pista de borda de Joanes (obras em andamento, com financiamento do PRO-MORADIA e da Caixa Econômica Federal).

Estas áreas podem ser visualizadas na Figura 30. 


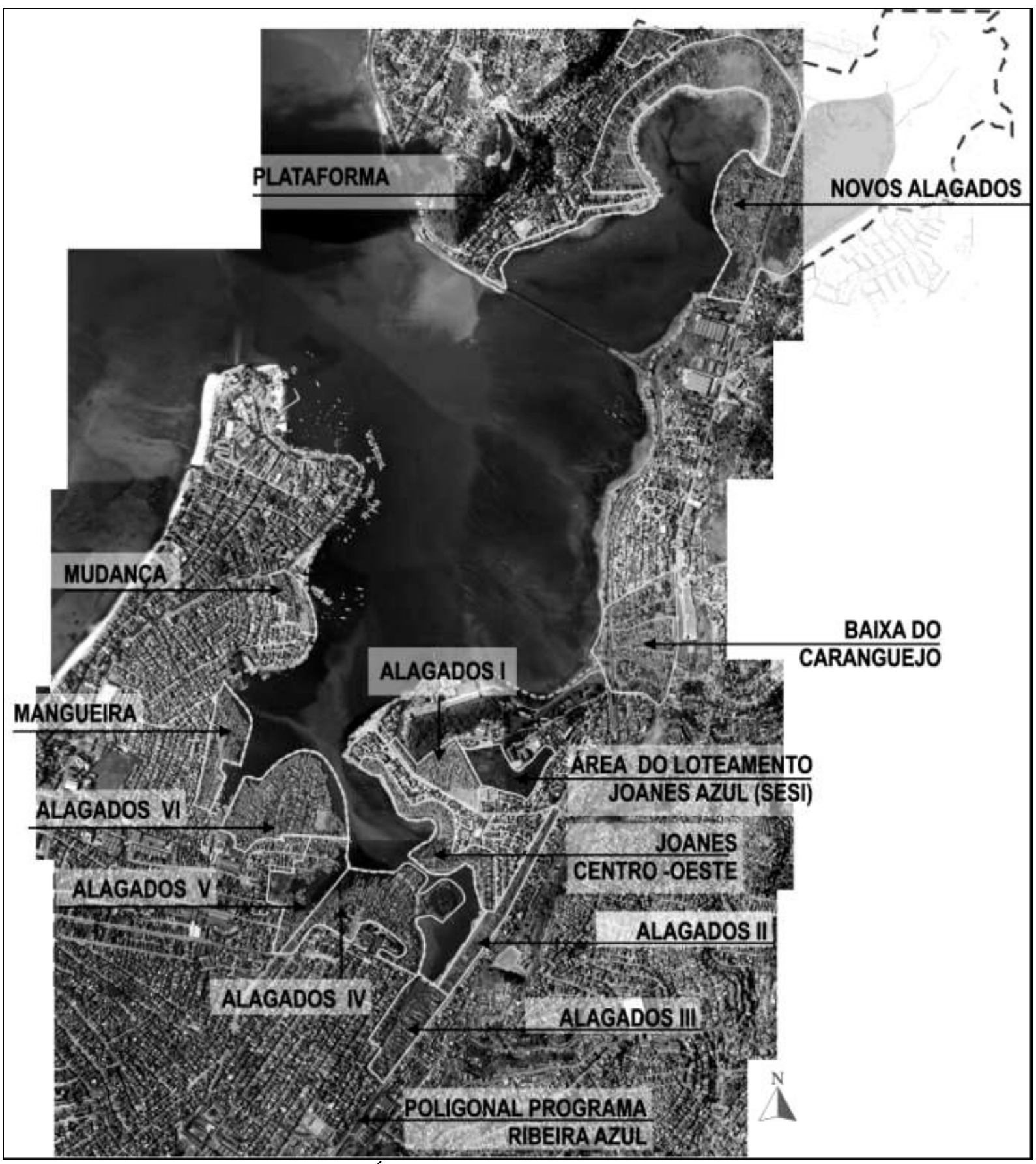

Figura 30: Áreas de atuação do Programa Ribeira Azul

Fonte: Carvalho (2002)

A poligonal do Programa Ribeira Azul inclui áreas demarcadas como poligonais de intervenção física e uma área maior, denominada área de intervenção social. A área de intervenção social, mesmo não recebendo benefícios diretos com ações físicas, será beneficiada com as melhorias da área como um todo. A Tabela 3 apresenta os dados iniciais das áreas pesquisadas neste trabalho apresentados no PATS (CONDER, [ca. 2000]). 
Tabela 3: Dados sobre as áreas pesquisadas utilizando os setores censitários

\begin{tabular}{|c|c|c|c|c|c|}
\hline & $\begin{array}{c}\text { Área de } \\
\text { intervenção social }\end{array}$ & $\begin{array}{c}\text { Novos Alagados } \\
\mathbf{1}^{\mathrm{a}} \text { etapa } \\
\end{array}$ & Alagados I & Alagados II & $\begin{array}{r}\text { Total do } \\
\text { Programa } \\
\end{array}$ \\
\hline Total de residentes & 86.205 & 10.706 & 1.374 & 2.165 & 133.387 \\
\hline Percentual de residentes das áreas no total geral & $64,63 \%$ & $8,03 \%$ & $1,03 \%$ & $1,62 \%$ & $100,00 \%$ \\
\hline Total de domicílios & 22.061 & 2.671 & 362 & 577 & 34.283 \\
\hline Percentual de domicílios das áreas no total geral & $64,35 \%$ & $7,79 \%$ & $1,06 \%$ & $1,68 \%$ & $100,00 \%$ \\
\hline Habitantes por domicilio particular permanente & 3,9 & 4,0 & 3,8 & 3,8 & 3,9 \\
\hline Total de responsáveis dos domicílios & 21.918 & 2.660 & 357 & 575 & 34.088 \\
\hline $\begin{array}{l}\text { Total de pessoas residentes não alfabetizadas - } 5 \\
\text { anos de idades ou mais }\end{array}$ & 7.194 & 1.311 & 285 & 432 & 14.102 \\
\hline
\end{tabular}

Fonte: dados do Censo do IBGE 2000 extraídos do PATS (CONDER, [ca. 2000])

É importante ressaltar que os dados constantes no PATS (CONDER, [ca. 2000]) são baseados no Censo 2000 do IBGE, portanto, referem-se a uma realidade pós-intervenção.

A Tabela 4 apresenta dados sobre as condições de ocupação dos domicílios. Observe que o fato dos moradores declararem "próprio" o domicílio em que residem não significa que exista uma regularização fundiária dos mesmos.

Tabela 4: Percentual de domicílios particulares permanentes (DPP) por condição da ocupação - 2000

\begin{tabular}{l|c|c|c|c|c}
\hline Condição da ocupação & Área de intervenção social & Novos Alagados 1a etapa & Alagados I & Alagados II & Total da área física \\
\hline Próprio - adquirido & $78,7 \%$ & $87,7 \%$ & $71,7 \%$ & $93,2 \%$ & $80,2 \%$ \\
Próprio - em aquisição & $2,3 \%$ & $1,2 \%$ & $7,8 \%$ & $0,5 \%$ & $1,8 \%$ \\
Alugado & $13,7 \%$ & $9,2 \%$ & $4,2 \%$ & $4,3 \%$ \\
Cedido por emprego & $0,2 \%$ & $0,1 \%$ & $0,0 \%$ & $0,0 \%$ \\
Cedido de outra forma & $4,1 \%$ & $1,5 \%$ & $3,9 \%$ & $1,0 \%$ \\
Outra condição & $1,1 \%$ & $0,3 \%$ & $12,3 \%$ & $0,9 \%$ & $0,2 \%$ \\
\hline
\end{tabular}

Fonte: dados do Censo do IBGE 2000 extraídos do PATS (CONDER, [ca. 2000])

A maioria dos domicílios possui entre três e quatro habitantes, com maior freqüência de pessoas entre 25 e 64 anos, não diferindo substancialmente entre as áreas do Programa (Tabela 5 e Tabela 6).

Tabela 5: Percentual de DPP por número de habitantes - 2000

\begin{tabular}{l|c|c|c|c|c}
\hline \multicolumn{1}{c|}{ Número de habitantes } & Área de intervenção social & Novos Alagados 1 etapa $^{\text {a }}$ & Alagados I & Alagados II & Total da área física \\
\hline DPP - 1 habitante & $9,4 \%$ & $9,7 \%$ & $8,7 \%$ & $14,8 \%$ & $10,0 \%$ \\
DPP - 2 habitantes & $16,2 \%$ & $13,4 \%$ & $17,9 \%$ & $16,3 \%$ & $16,0 \%$ \\
DPP - 3 habitantes & $21,8 \%$ & $22,2 \%$ & $21,8 \%$ & $19,0 \%$ & $21,9 \%$ \\
DPP - 4 habitantes & $21,6 \%$ & $20,6 \%$ & $22,1 \%$ & $19,1 \%$ & $21,2 \%$ \\
DPP - 5 habitantes & $13,2 \%$ & $15,1 \%$ & $13,4 \%$ & $12,9 \%$ & $13,2 \%$ \\
DPP - 6 habitantes & $7,4 \%$ & $8,1 \%$ & $7,6 \%$ & $8,5 \%$ & $7,5 \%$ \\
DPP - 7 habitantes & $4,1 \%$ & $4,0 \%$ & $3,4 \%$ & $3,5 \%$ & $4,0 \%$ \\
DPP - 8 habitantes & $2,6 \%$ & $3,2 \%$ & $1,4 \%$ & $2,3 \%$ & $2,5 \%$ \\
DPP - 9 habitantes & $1,4 \%$ & $1,7 \%$ & $2,2 \%$ & $1,7 \%$ & $1,4 \%$ \\
DPP - 10 habitantes ou mais & $2,2 \%$ & $2,0 \%$ & $1,4 \%$ & $1,9 \%$ & $2,1 \%$ \\
\hline
\end{tabular}

Fonte: dados do Censo do IBGE 2000 extraídos do PATS (CONDER, [ca. 2000]) 
Tabela 6: Pessoas residentes por faixa etária - 2000

\begin{tabular}{l|c|c|c|c|c}
\hline \multicolumn{1}{c|}{ Faixas de idade } & $\begin{array}{c}\text { Área de intervenção } \\
\text { social }\end{array}$ & $\begin{array}{c}\text { Novos Alagados 1 } \\
\text { etapa }\end{array}$ & $\begin{array}{c}\text { Alagados I } \\
\text { Alagados II }\end{array}$ & $\begin{array}{c}\text { Total da área } \\
\text { física }\end{array}$ \\
\hline Pessoas residentes - de 0 a 14 anos de idade & $25,1 \%$ & $29,7 \%$ & $36,0 \%$ & $36,2 \%$ \\
Pessoas residentes - de 15 a 24 anos de idade & $22,6 \%$ & $23,6 \%$ & $22,0 \%$ & $24,1 \%$ \\
Pessoas residentes - de 25 a 64 anos de idade & $46,9 \%$ & $42,9 \%$ & $40,7 \%$ & $38,8 \%$ \\
Pessoas com mais de 65 anos de idade & $5,4 \%$ & $3,8 \%$ & $1,3 \%$ & $1,0 \%$ \\
\hline
\end{tabular}

Fonte: dados do Censo do IBGE 2000 extraídos do PATS (CONDER, [ca. 2000])

Podemos notar que Alagados I e II apresentam maiores percentuais de responsáveis por domicílios analfabetos; há um percentual bastante elevado de jovens nesta situação (Tabela 7 e Tabela 8). É um fato preocupante, no sentido de que este valor varia entre quase 1/3 e metade dos jovens entre 5 e 14 anos não-alfabetizados.

Tabela 7: Percentual de responsáveis por domicílios segundo graus de escolaridade - 2000

\begin{tabular}{|c|c|c|c|c|c|}
\hline Graus de escolaridade & \begin{tabular}{|c|}
$\begin{array}{c}\text { Área de intervenção } \\
\text { social }\end{array}$ \\
\end{tabular} & $\begin{array}{c}\text { Novos Alagados } \\
1^{\text {a }} \text { etapa } \\
\end{array}$ & Alagados I & Alagados II & $\begin{array}{c}\text { Total da } \\
\text { área física } \\
\end{array}$ \\
\hline Analfabetos & $8,4 \%$ & $10,1 \%$ & $21,6 \%$ & $17,6 \%$ & $10,2 \%$ \\
\hline Escolaridade médio-baixa (menos de 9 anos de estudo ) & $55,1 \%$ & $69,1 \%$ & $63,0 \%$ & $68,0 \%$ & $59,7 \%$ \\
\hline Escolaridade alta (de 9 a 17 anos de estudo ou mais) & $36,5 \%$ & $20,8 \%$ & $15,4 \%$ & $14,4 \%$ & $30,0 \%$ \\
\hline
\end{tabular}

Fonte: dados do Censo do IBGE 2000 extraídos do PATS (CONDER, [ca. 2000])

Tabela 8: Percentual de pessoas residentes não-alfabetizadas, com 5 anos ou mais, segundo faixas de idade 2000

\begin{tabular}{l|c|c|c|c|c}
\hline \multicolumn{1}{c|}{ Faixas de idade } & $\begin{array}{c}\text { Área de intervenção } \\
\text { social }\end{array}$ & $\begin{array}{c}\text { Novos Alagados 1 } \\
\text { etapa }\end{array}$ & $\begin{array}{c}\text { Alagados I } \\
\text { Alagados II }\end{array}$ & $\begin{array}{c}\text { Total da área } \\
\text { física }\end{array}$ \\
\hline de 5 a 14 anos & $21,8 \%$ & $32,9 \%$ & $41,5 \%$ & $44,7 \%$ \\
de 15 a 64 anos & $4,7 \%$ & $6,6 \%$ & $16,7 \%$ & $13,8 \%$ \\
65 anos e mais & $25,2 \%$ & $32,9 \%$ & $66,7 \%$ & $61,9 \%$ \\
\hline
\end{tabular}

Fonte: dados do Censo do IBGE 2000 extraídos do PATS (CONDER, [ca. 2000])

A Tabela 9 mostra que a maior parte dos responsáveis pelos domicílios possui renda de 1 a 5 Salários Mínimos; notamos também que os responsáveis sem renda atingem um percentual maior em Alagados I e Novos Alagados $1^{\mathrm{a}}$. Etapa, que nas demais áreas do Programa.

Tabela 9: Percentual de responsáveis dos domicílios por classe de renda - 2000

\begin{tabular}{l|c|c|c|c|c}
\hline \multicolumn{1}{c}{ Classes de renda } & Área de intervenção social & Novos Alagados 1 a etapa & Alagados I & Alagados II & Total da área física \\
\hline sem renda & $11,3 \%$ & $26,4 \%$ & $38,4 \%$ & $11,8 \%$ & $15,5 \%$ \\
até 1 salário mínimo & $24,1 \%$ & $25,7 \%$ & $29,1 \%$ & $45,2 \%$ & $27,5 \%$ \\
de 1 a 5 & $50,0 \%$ & $40,2 \%$ & $30,8 \%$ & $41,9 \%$ & $46,2 \%$ \\
de 5 a 20 & $14,6 \%$ & $7,7 \%$ & $1,7 \%$ & $1,0 \%$ & $10,8 \%$ \\
\hline
\end{tabular}

Fonte: dados do Censo do IBGE 2000 extraídos do PATS (CONDER, [ca. 2000])

Com relação aos serviços básicos, observamos na Tabela 10 um percentual relativamente alto de domicílios ligados à rede de esgoto a exceção de Alagados II, provável reflexo da intervenção na área. 
Tabela 10: Percentual de DPP por tipologia do esgotamento sanitário - 2000

\begin{tabular}{l|c|c|c|c|c}
\hline Tipologia do esgotamento sanitário & Área de intervenção social & Novos Alagados 1a etapa & Alagados I & Alagados II & Total da área física \\
\hline DPP - rede geral de esgoto & $93,4 \%$ & $83,6 \%$ & $89,4 \%$ & $59,3 \%$ & $79,3 \%$ \\
DPP - fossa séptica & $2,3 \%$ & $3,8 \%$ & $0,6 \%$ & $2,4 \%$ & $2,7 \%$ \\
DPP - fossa rudimentar (negra) & $1,1 \%$ & $4,8 \%$ & $0,0 \%$ & $3,1 \%$ & $1,8 \%$ \\
DPP - rio, lago ou mar & $1,9 \%$ & $3,2 \%$ & $0,0 \%$ & $25,6 \%$ & $11,8 \%$ \\
DPP - outra forma & $0,4 \%$ & $0,6 \%$ & $4,5 \%$ & $0,3 \%$ & $0,5 \%$ \\
DPP - sem banheiro & $0,8 \%$ & $4,1 \%$ & $5,6 \%$ & $9,2 \%$ & $3,8 \%$ \\
\hline
\end{tabular}

Fonte: dados do Censo do IBGE 2000 extraídos do PATS (CONDER, [ca. 2000])

Com relação à coleta de lixo o percentual também é muito bom, considerando o serviço de coleta e coleta por contêineres (Tabela 11). Salientamos que a predominância da coleta por contêineres em Alagados I também se deve ao fato das larguras das vias, que são muito reduzidas, não permitindo acesso ao caminhão coletor.

Tabela 11: Percentual de DPP por situação da coleta de lixo - 2000

\begin{tabular}{|c|c|c|c|c|c|}
\hline Situação da coleta de lixo & $\begin{array}{c}\text { Área de intervenção } \\
\text { social }\end{array}$ & $\begin{array}{c}\text { Novos Alagados } \\
\mathbf{1}^{\mathrm{a}} \text { etapa } \\
\end{array}$ & Alagados I & Alagados II & $\begin{array}{c}\text { Total da área } \\
\text { física }\end{array}$ \\
\hline DPP - serviço de coleta de lixo urbano & $85,5 \%$ & $75,0 \%$ & $0,6 \%$ & $48,3 \%$ & $74,0 \%$ \\
\hline DPP - em contêineres de lixo & $11,5 \%$ & $20,5 \%$ & $99,2 \%$ & $27,7 \%$ & $17,0 \%$ \\
\hline DPP - lixo queimado & $0,0 \%$ & $0,3 \%$ & $0,0 \%$ & $0,2 \%$ & $0,1 \%$ \\
\hline DPP - enterrado (na propriedade) & $0,0 \%$ & $0,1 \%$ & $0,0 \%$ & $0,0 \%$ & $0,0 \%$ \\
\hline DPP - lançado no rio, lagoa ou mar & $2,6 \%$ & $3,9 \%$ & $0,0 \%$ & $0,2 \%$ & $3,0 \%$ \\
\hline DPP - jogado em terrenos vazios ou públicos & $0,3 \%$ & $0,2 \%$ & $0,0 \%$ & $23,7 \%$ & $5,8 \%$ \\
\hline DPP - outra destinação & $0,0 \%$ & $0,0 \%$ & $0,3 \%$ & $0,0 \%$ & $0,1 \%$ \\
\hline
\end{tabular}

Fonte: dados do Censo do IBGE 2000 extraídos do PATS (CONDER, [ca. 2000])

\subsection{CONSIDERAÇÕES SOBRE AS ÁREAS DE ESTUDO}

As áreas que serão pesquisadas foram alvo de intervenções integradas, que combinaram projetos físicos e ações sociais. Em função disto, espera-se que os indicadores quantitativos atinjam padrões elevados, o que acentuam a importância dos indicadores qualitativos que, com base na opinião dos moradores, nos darão uma visão daqueles que vivem o cotidiano da área. Cabe ressaltar que embora Alagados I e II estejam incluídos na área do Programa Ribeira Azul, estas áreas foram inicialmente alvo de um outro programa, realizado por outro órgão do Estado da Bahia. Logo, deverão ser notadas diferenças entre as áreas. 


\section{PESQUISA PILOTO - NOVOS ALAGADOS $1^{\text {A }}$. ETAPA}

Das áreas do Programa Ribeira Azul, optou-se em realizar a pesquisa piloto em Novos Alagados $-1^{\mathrm{a}}$. Etapa, por ter sido a primeira área onde foram realizadas as intervenções, além de ter sido modelo para o Programa. Existe uma série de dados obtidos para elaboração do Projeto de Apoio Técnico e Social na Área do Ribeira Azul (PATS), porém, estes dados não correspondem exatamente à delimitação do Programa, visto que o PATS foi feito com base nos setores censitários do Instituto Brasileiro de Geografia e Estatística (IBGE), que na maioria das vezes extrapolam os limites da área de intervenção.

A intervenção física em Novos Alagados $-1^{\mathrm{a}}$. Etapa foi composta de projeto urbanístico e de infra-estrutura com novo sistema viário e mobiliário urbano, além de reassentamento de algumas famílias em embriões com 22 e $14 \mathrm{~m}^{2}$.

Segundo o PATS, foram construídos 270 embriões com $22 \mathrm{~m}^{2}$ e 144 embriões com $14 \mathrm{~m}^{2} .144$ novas casas foram resultado de remanejamento interno e 283 de remanejamento externo. Nessa fase do projeto, foram construídos os loteamentos Araçás I e II - situados na meia encosta da localidade conhecida como Plataforma, voltada para a Enseada do Cabrito - para abrigar as 285 famílias, transferidas das palafitas e remanejadas por conta das obras de infraestrutura (CARVALHO, 2002) e por este motivo não fizeram parte da pesquisa piloto.

Além das obras urbanísticas e da construção de novas moradias foram realizadas 150 melhorias nas residências em terra firme com alterações físicas em suas estruturas, para que as mesmas pudessem atender plenamente às necessidades das famílias residentes na área. Estas alterações foram realizadas pela Cooperativa de Habitação, Produção e Serviços dos Moradores de Novos Alagados (COMONAL), fomentada pela AVSI. A obra para execução do projeto urbanístico e de infra-estrutura foi iniciada em 1995 e concluída em 1999. O projeto contou ainda com projetos sociais e equipamentos comunitários construídos e reformados.

Os dados sobre a área não são muito precisos; enquanto o PATS afirma que Novos Alagados $-1^{\text {a }}$. Etapa possui cerca de 1.697 famílias (CONDER, [ca. 2000]), Carvalho (2002), baseado também em dados da CONDER, afirma que a área possui 1.750 domicílios com uma população de total de 6.737 habitantes e cerca de 61,67ha. Já com a delimitação pelos setores 
censitários, a priori superestimada, esse número chega a 2.671 famílias (Tabela 3). É importante ressaltar que os dados constantes no PATS são baseados no Censo 2000 do IBGE, portanto, referem-se a uma realidade pós-intervenção. A Figura 31 mostra a área de Novos Alagados antes e depois da intervenção; é notável após a intervenção a presença da pista de borda e do manguezal que tem sido replantado.

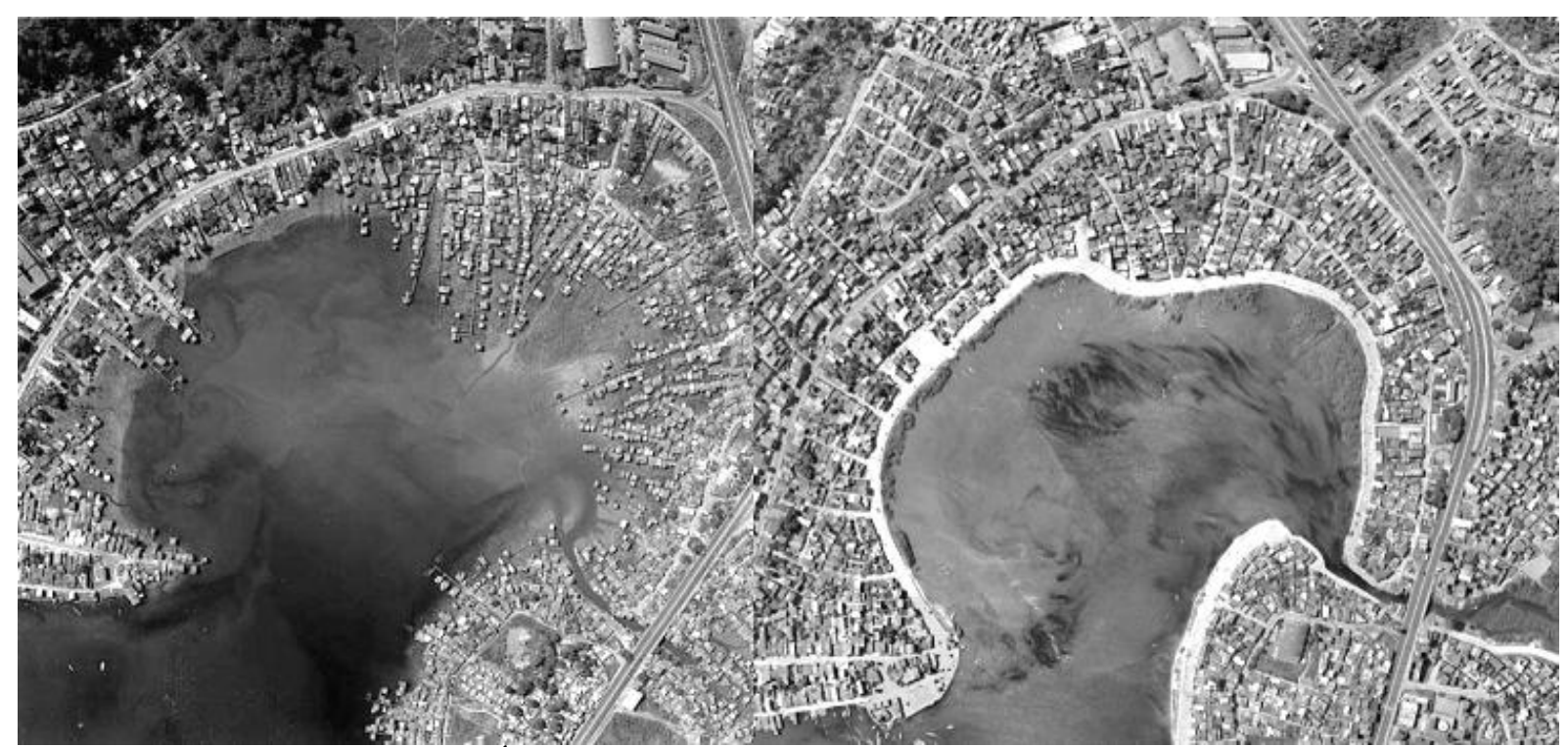

Figura 31: Área de Novos Alagados, antes e depois da intervenção

Fonte: Montagem a partir de Carvalho (2002), à esquerda, e http://www.mapadigital.salvador.ba.gov.br, à direita

\subsection{DESCRIÇÃO DOS DADOS COLETADOS}

Para a pesquisa piloto foi elaborado um formulário com perguntas relacionadas aos indicadores selecionados. Além dos indicadores quantitativos, baseados em questões objetivas, foram elaboradas questões relativas à avaliação do morador para cada componente dos indicadores selecionados. Estas questões compuseram o formulário em formato de múltipla escolha com uma escala qualitativa ordinal de cinco classes (APÊNDICE A).

Foram aplicados, utilizando pesquisadores treinados em domicílios escolhidos aleatoriamente em campo, no mês de fevereiro de 2006, 140 formulários em Novos Alagados - $1^{\text {a }}$. Etapa, dos quais 20 foram descartados pela alta freqüência de questões em branco. A partir destes 120 formulários finais foi feita a tabulação cujos resultados são descritos a seguir. 


\subsubsection{Caracterização dos domicílios pesquisados}

A maioria das moradias pesquisadas foi construída pelo morador, seguidas das que foram construídas pela CONDER e ampliadas pelo morador (Figura 32). Na amostra foi baixa a frequiência de moradias alugadas ou adquiridas de outros (Tabela 12).

Tabela 12: Tipo da moradia - Pesquisa Piloto

\begin{tabular}{l|c}
\hline \multicolumn{1}{c|}{ Tipo } & \% de domicílios \\
\hline Construída pela CONDER & 21,7 \\
Construída pela CONDER e ampliada & 24,2 \\
Construída pelo morador & 41,7 \\
Adquirida de outros & 8,3 \\
Alugada & 4,2 \\
\hline
\end{tabular}

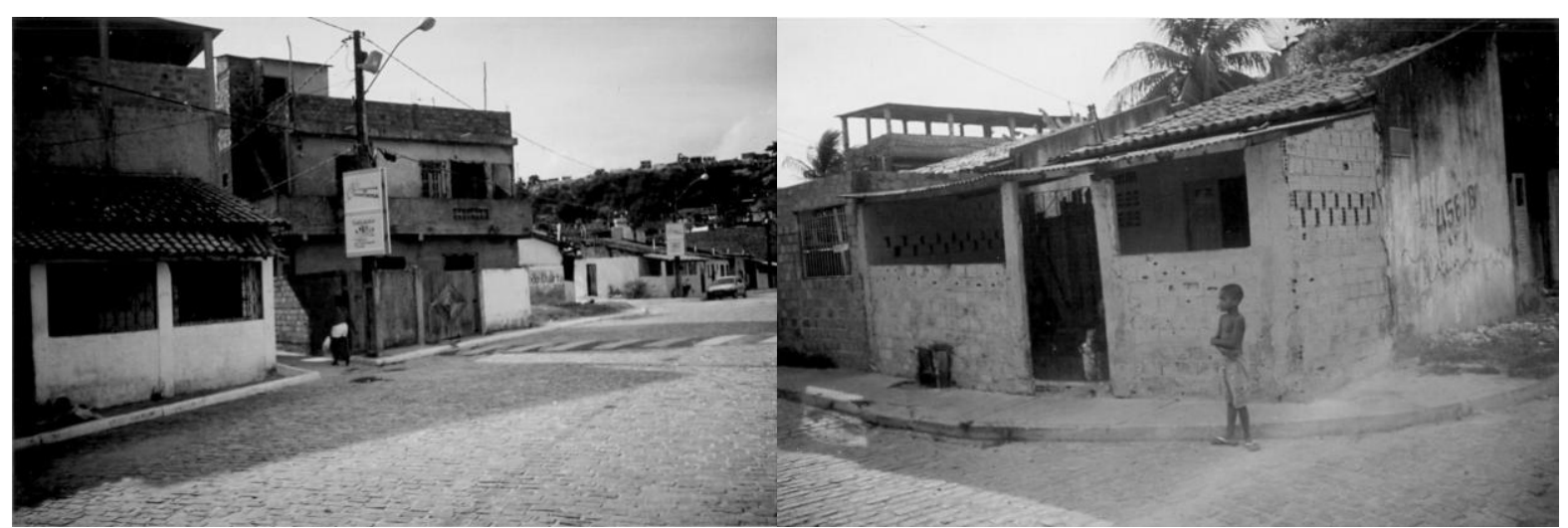

Figura 32: Autoconstrução à esquerda e embrião da Conder com ampliação à direita - - Pesquisa Piloto

A média de pessoas por domicílio foi de 4,65 com uma moda de 3 habitantes por domicílio, conforme mostrado na Tabela 13 e no Gráfico 8, um pouco acima do valor mostrado pelos dados do IBGE na Tabela 3.

Tabela 13: Quantas pessoas moram na casa - Pesquisa Piloto

\begin{tabular}{l|c}
\hline \multicolumn{1}{c|}{ Parâmetro } & Pessoas \\
\hline Média & 4,65 \\
Moda & 3,00 \\
Mediana & 4,00 \\
Desvio padrão & 2,16 \\
Mínimo & 1,00 \\
Máximo & 12,00 \\
\hline
\end{tabular}




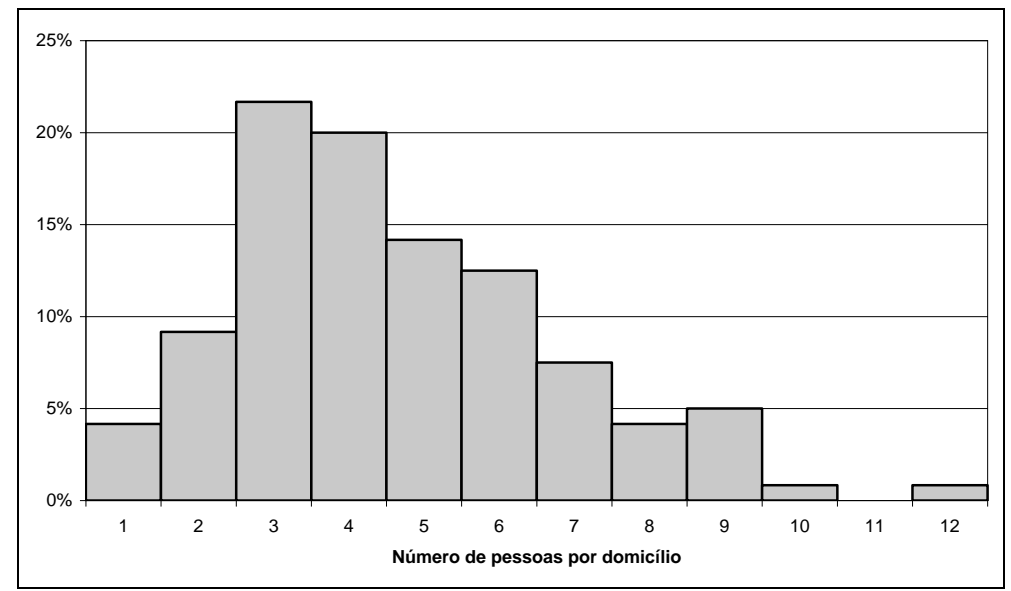

Gráfico 8: Distribuição do número de pessoas por domicílio - Pesquisa Piloto

A renda familiar declarada foi muito baixa com $80 \%$ das famílias com renda entre $1 / 2$ e 1 Salário Mínimo (SM). A renda média está em torno de 1 SM (Tabela 14).

Quando se pergunta apenas quem tem o maior nível de escolaridade na família um percentual expressivo diz ter algum morador com o segundo grau $(35,8 \%)$ e apenas $3,3 \%$ tendo cursado até a $4^{\text {a }}$. série do ensino fundamental (Tabela 15). Essa medida nos mostra apenas um elemento da família em melhor posição no ensino. Propõe-se registrar nas próximas pesquisas, tanto a pessoa com mais quanto a que possui menos anos de estudo, garantindo assim que as demais pessoas da família estarão neste intervalo. Uma alternativa é usar os dados do IBGE, quando disponíveis por setor censitário.

Tabela 14: Renda média da família - Pesquisa Piloto

\begin{tabular}{l|c}
\hline \multicolumn{1}{c|}{ Parâmetro } & Renda (SM) \\
\hline Média & 1,10 \\
Moda & 1,00 \\
Mediana & 1,00 \\
Desvio padrão & 0,46 \\
Mínimo & 0,22 \\
Máximo & 3,33 \\
\hline
\end{tabular}

Tabela 15: Grau de escolaridade máxima - Pesquisa Piloto

\begin{tabular}{l|c}
\hline \multicolumn{1}{c|}{ Escolaridade Máxima } & \% de domicílios \\
\hline Não respondeu & 0,8 \\
Até $4^{\text {a. }}$ Série & 3,3 \\
Da $4^{\text {a }}$ até $8^{\text {a. }}$ Série & 27,5 \\
Da $8^{\text {a }}$. até $3^{\text {a. }}$ do $2^{\text {o. }}$ Grau & 32,5 \\
$2^{\text {o. }}$ Grau completo & 35,8 \\
\hline
\end{tabular}

Quanto ao tempo de residência no local, o tempo médio foi de 13 anos, com uma moda de 10 anos. De acordo com o Gráfico 9 existem dois valores mais freqüentes (entre 5 e 10 anos e entre 1 e 5 anos). Nesta questão existe a possibilidade de alguns terem respondido o tempo de 
residência na moradia e outros no local. A partir da constatação dessa inconsistência, esta questão foi aprimorada nos estudos de validação.

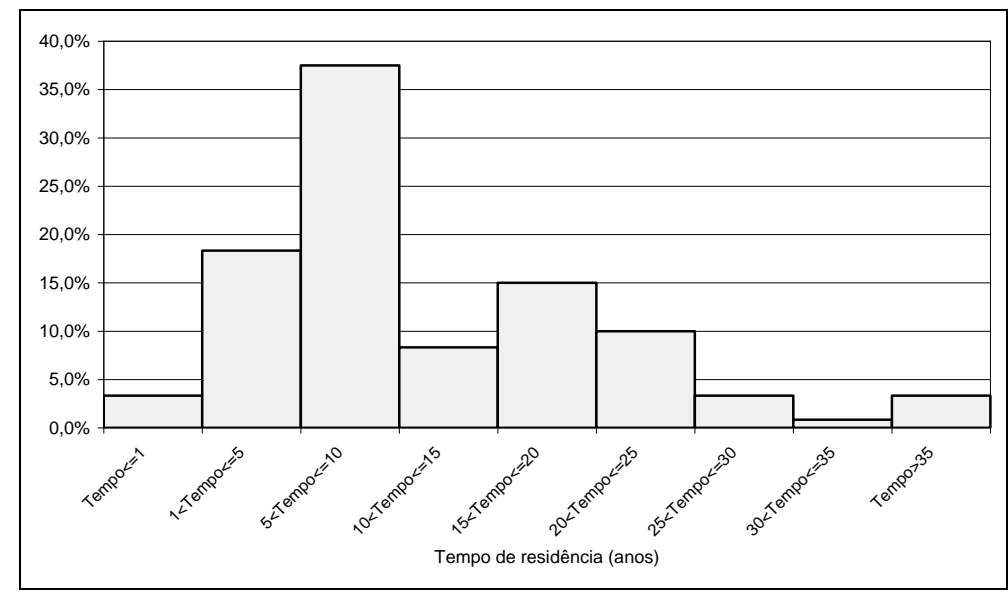

Gráfico 9: Tempo de residência no local - Pesquisa Piloto

\subsubsection{Moradia}

As tipologias predominantes são Sala - Quarto - Cozinha - Banheiro (SQCB) e Sala Cozinha - Banheiro (SCB). Nota-se que apenas 5,0\% das casas não possuem banheiro e 16,5\% não possuem cozinha (Tabela 16). Com relação aos dormitórios, cerca de $26 \%$ das moradias não possuem quartos (Tabela 17); levando em conta que a média de moradores por domicílio é de 4 a 5 moradores, existe um problema de adequação do espaço às famílias residentes.

Tabela 16: Tipologia espacial - Pesquisa Piloto

\begin{tabular}{c|c|c|c|c|c|c|c}
\hline Padrão & $\begin{array}{c}\text { \% de } \\
\text { domícilios }\end{array}$ & Padrão & $\begin{array}{c}\text { \% de } \\
\text { domícilios }\end{array}$ & Padrão & $\begin{array}{c}\text { \% de } \\
\text { domícilios }\end{array}$ & Padrão & $\begin{array}{c}\text { \% de } \\
\text { domícilios }\end{array}$ \\
\hline S & 0,8 & SCB & 19,2 & SQBA & 0,8 & SQCBA & 7,5 \\
SB & 4,2 & SCBAV & 0,8 & SQBV & 2,5 & SQCBAV & 16,7 \\
SBA & 0,8 & SQ & 0,8 & SQC & $1,7 \%$ & SQCBV & 10,0 \\
SBV & 0,8 & SQB & 5,8 & SQCB & 25,8 & SQCV & 1,7 \\
\hline
\end{tabular}

Reforçando a questão da inadequação dos espaços, na Tabela 17 notamos que em quase metade das moradias outros cômodos são utilizados como dormitórios. Essa inadequação reflete-se também na opinião do morador, onde quase metade considera o número de quartos e o tamanho da casa Ruim ou Péssimo. 
Tabela 17: Número de quartos, utilização de outros cômodos para dormir e avaliação do morador - Pesquisa

\begin{tabular}{l|c|l|c|l|c|c}
\multicolumn{1}{c}{$\begin{array}{c}\text { Quantidade de } \\
\text { quartos }\end{array}$} & $\begin{array}{c}\text { \% de } \\
\text { domicílios }\end{array}$ & $\begin{array}{c}\text { Utiliza outros cômodos } \\
\text { para dormir }\end{array}$ & $\begin{array}{c}\text { \% de } \\
\text { domicílios }\end{array}$ & \multicolumn{1}{|c|}{ Avaliação } & $\begin{array}{c}\text { Quanto ao número } \\
\text { de quartos }\end{array}$ & $\begin{array}{c}\text { Quanto ao tamanho da } \\
\text { casa }\end{array}$ \\
\hline Não possui & 26,4 & Não respondeu & 1,7 & Péssimo & $25,9 \%$ & $24,2 \%$ \\
1 Quarto & 37,2 & Sim & 48,8 & Ruim & $24,1 \%$ & $21,7 \%$ \\
2 Quartos & 26,4 & Não & 49,6 & Regular & $15,5 \%$ & $20,0 \%$ \\
3 Quartos & 9,1 & - & - & Bom & $28,4 \%$ & $25,8 \%$ \\
4 Quartos & 0,8 & & - & Ótimo & $6,0 \%$ & $8,3 \%$ \\
\hline
\end{tabular}

Com relação às instalações de água e esgoto em quase todas as moradias foi registrada a presença das mesmas (Tabela 18), o que também foi constatado para as instalações elétricas (Tabela 19). Na maioria dos casos as instalações de água e esgoto foram consideradas pelo menos Regular. O mesmo ocorre com as instalações elétricas.

Tabela 18: Instalações hidrossanitárias e avaliação do morador - Pesquisa Piloto

\begin{tabular}{l|c|c|l|c|c}
\hline & $\begin{array}{c}\text { Possui instalações de } \\
\text { água }\end{array}$ & $\begin{array}{c}\text { Possui instalações } \\
\text { de esgoto }\end{array}$ & Avaliação & Instalações de água & $\begin{array}{c}\text { Instalações de } \\
\text { esgoto }\end{array}$ \\
\hline Não respondeu & $0,0 \%$ & $2,5 \%$ & Péssimo & $5,1 \%$ & $5,7 \%$ \\
Sim & $95,9 \%$ & $88,4 \%$ & Ruim & $6,8 \%$ & $4,7 \%$ \\
Não & $4,1 \%$ & $9,1 \%$ & Regular & $19,7 \%$ & $17,0 \%$ \\
- & - & - & Bom & $65,0 \%$ & $71,7 \%$ \\
- & - & - & Ótimo & $3,4 \%$ & $0,9 \%$ \\
\hline
\end{tabular}

Tabela 19: Instalações elétricas e avaliação do morador - Pesquisa Piloto

\begin{tabular}{l|c|l|c}
\hline \multicolumn{1}{c|}{ Possui instalações elétricas } & \% de domicílios & \multicolumn{1}{|c|}{ Avaliação } & \% de domicílios \\
\hline Não respondeu & 1,7 & Péssimo & 5,1 \\
Embutida & 30,6 & Ruim & 11,9 \\
Aparente & 33,1 & Regular & 33,1 \\
Embutida na parede e aparente no teto & 31,4 & Bom & 44,9 \\
Mista & 3,3 & Ótimo & 5,1 \\
\hline
\end{tabular}

O material predominante na cobertura é a telha de fibrocimento, seguida pela telha cerâmica e as lajes (Tabela 20). A telha de fibrocimento possui as vantagens de baixo custo e instalação rápida, porém ainda é um assunto discutido em relação aos aspectos ambientais e de saúde.

Apesar do uso de materiais duráveis na cobertura, o percentual de moradias que apresentam problemas no período de chuva é relativamente alto, cerca de 56\%. A avaliação do morador fica distribuída em torno do Regular.

Tabela 20: Cobertura: material, problemas no telhado quando chove e avaliação do morador - Pesquisa Piloto

\begin{tabular}{l|c|l|c|l|c}
\hline \multicolumn{1}{c|}{ Telhado } & $\begin{array}{c}\text { \% de } \\
\text { domicílios }\end{array}$ & Problemas quando chove & $\begin{array}{c}\text { \% de } \\
\text { domicílios }\end{array}$ & \multicolumn{1}{|c|}{ Avaliação } & \% de domicílios \\
\hline Não respondeu & 0,8 & Não respondeu & 3,3 & Péssimo & 18,8 \\
Telha cerâmica & 36,4 & Sim & 56,2 & Ruim & 17,9 \\
Telha de fibrocimento & 39,7 & Não & 40,5 & Regular & 31,6 \\
Laje & 19,0 & - & - & Bom & 25,6 \\
Outros & 1,7 & & - & & 6,0 \\
Telha de amianto e laje & 1,7 & & - & & - \\
Telha cerâmica e laje & 0,8 & & & - \\
\hline
\end{tabular}


De acordo com a Tabela 21 a maioria das casas foi construída com tijolos ou blocos de concreto, com revestimento interno e externo (Figura 33). Ressalta-se porém, a existência de um percentual significativo de moradias sem revestimento interno. A avaliação predominante do morador ficou entre Regular e Bom.

Tabela 21: Paredes: material, revestimento e avaliação do morador - Pesquisa Piloto

\begin{tabular}{l|c|l|c|l|c|l|c}
\hline \multicolumn{1}{c|}{ Material } & $\begin{array}{c}\text { \% de } \\
\text { domicílios }\end{array}$ & $\begin{array}{c}\text { Revestimento } \\
\text { Interno }\end{array}$ & $\begin{array}{c}\text { \% de } \\
\text { domicílios }\end{array}$ & $\begin{array}{c}\text { Revestimento } \\
\text { Externo }\end{array}$ & $\begin{array}{c}\text { \% de } \\
\text { domicílios }\end{array}$ & Avaliação & $\begin{array}{c}\text { \% de } \\
\text { domicílios }\end{array}$ \\
\hline Não respondeu & 0,8 & Não respondeu & 1,7 & Não respondeu & 1,7 & Péssimo & 10,9 \\
Tijolos furados & 60,3 & Sim & 48,8 & Sim & 62,0 & Ruim & 17,6 \\
Blocos de concreto & 28,9 & Não & 44,6 & Não & 29,8 & Regular & 20,2 \\
Outros & 9,1 & Em algumas partes & 5,0 & Em algumas partes & 6,6 & Bom & 47,9 \\
Tij. furados e blc. de concreto & 0,8 & & - & & - & Ótimo & 3,4 \\
\hline
\end{tabular}

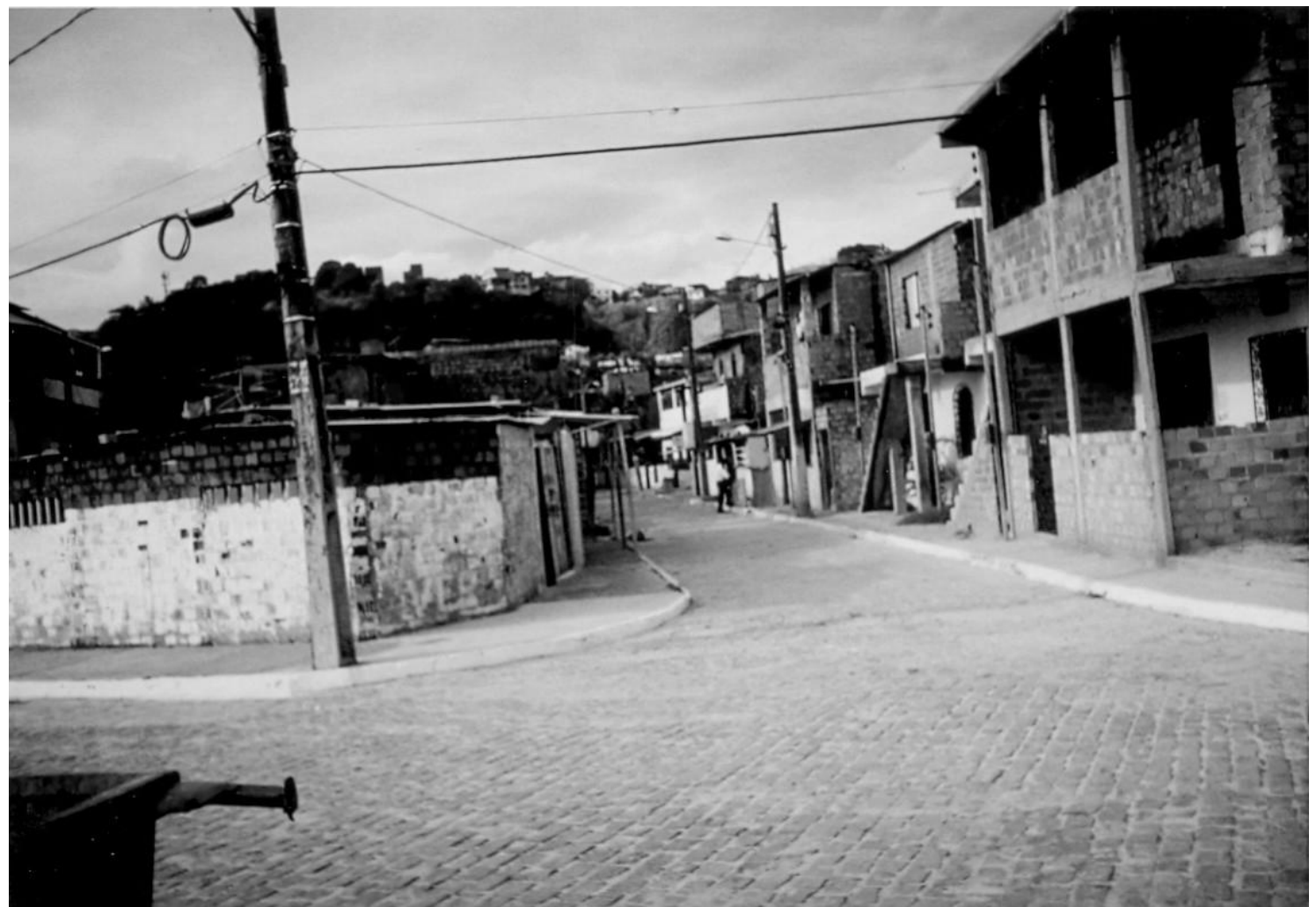

Figura 33: Autoconstrução com tijolos cerâmicos furados - Pesquisa Piloto

Com relação ao piso, constatou-se que enquanto quase metade das moradias possui piso em revestimento cerâmico, a outra metade possui piso em cimento grosso ou outros, como barro ou sem piso. Os problemas de umidade do piso ocorrem em mais de 1/3 das moradias. A avaliação predominante do morador ficou entre Regular e Bom (Tabela 22). 
Tabela 22: Piso: material, problemas de umidade e avaliação do morador - Pesquisa Piloto

\begin{tabular}{l|c|l|c|l|c}
\hline \multicolumn{1}{c|}{ Material } & \% de domicílios & Problemas de umidade & \% de domicílios & Avaliação & \% de domicílios \\
\hline Não respondeu & 0,8 & Não respondeu & 1,7 & Péssimo & 17,5 \\
Sem piso & 0,8 & Sim & 34,7 & Ruim & 14,2 \\
Cimento queimado & 8,3 & Não & 63,6 & Regular & 25,8 \\
Cimento grosso & 37,2 & & - & Bom & 37,5 \\
Cerâmica & 41,3 & - & - & Ótimo & 5,0 \\
Barro & 5,8 & & - & & - \\
Outros & 5,8 & & - & & - \\
\hline
\end{tabular}

A existência de iluminação/ventilação natural em todos os ambientes das casas foi constatada em pouco mais da metade das moradias; as demais apresentam pelo menos um cômodo sem abertura para o ambiente externo. Mesmo assim, a avaliação do morador ficou entre Regular e Bom (Tabela 23).

Tabela 23: Iluminação e ventilação e avaliação do morador - Pesquisa Piloto

\begin{tabular}{l|c|l|c}
\hline $\begin{array}{c}\text { Possui janelas ou combogós em } \\
\text { todos os ambientes }\end{array}$ & \% de domicílios & \multicolumn{1}{|c}{ Avaliação } & \% de domicílios \\
\hline Sim & 50,8 & Péssimo & 12,7 \\
Não & 49,2 & Ruim & 16,9 \\
- & - & Regular & 19,5 \\
- & - & Bom & 45,8 \\
- & - & Ótimo & 5,1 \\
\hline
\end{tabular}

\subsubsection{Salubridade ambiental}

Mais de $90 \%$ das moradias possui água encanada, porém, apenas 74,2\% respondeu que recebe conta (Tabela 24). Aqueles que não possuem água encanada afirmaram que a água é fornecida pelo vizinho utilizando-se ligação irregular (gato). A avaliação do morador pode ser considerada boa, o que não ocorre com o serviço de esgotamento sanitário (Tabela 25).

Tabela 24: Abastecimento, regularização, origem da água e avaliação do abastecimento de água - Pesquisa Piloto

\begin{tabular}{l|c|c|l|l|l|c}
\hline & Possui água encanada & Recebe conta & Origem da água & \% de domicílios & Avaliação & \% de domicílios \\
\hline Não respondeu & $0,0 \%$ & $9,2 \%$ & Água Encanada & 88,4 & Péssimo & 3,4 \\
Sim & $91,7 \%$ & $74,2 \%$ & Chafariz & 0,8 & Ruim & 5,0 \\
Não & $8,3 \%$ & $16,7 \%$ & Fonte & 0,8 & Regular & 26,1 \\
- & - & - & Vizinho & 6,7 & Bom & 60,5 \\
- & - & - & Outros & 3,3 & Ótimo & 5,0 \\
\hline
\end{tabular}

94,2\% das moradias possui esgotamento sanitário, porém quando é perguntado sobre a conta de esgoto 63,3\% responderam que não recebem conta (Tabela 25). Temos que ressaltar que quando regularizada, a conta de esgoto vem junto à conta de água e talvez o respondente não 
tenha esse conhecimento. Essa questão também merece maior cuidado ou aperfeiçoamento na aplicação.

Tabela 25: Esgotamento sanitário e regularização - Pesquisa Piloto

\begin{tabular}{l|c|l|c|l|c}
\hline $\begin{array}{c}\text { Possui ligação com rede de } \\
\text { esgoto ou fossa }\end{array}$ & $\begin{array}{c}\text { \% de } \\
\text { domiícilios }\end{array}$ & Recebe conta de esgoto & $\begin{array}{c}\text { \% de } \\
\text { domicílios }\end{array}$ & Avaliação & $\begin{array}{c}\text { \% de } \\
\text { domicílios }\end{array}$ \\
\hline Não respondeu & 0,8 & Não respondeu & 5,8 & Péssimo & 29,3 \\
Rede de esgoto & 94,2 & Sim & 30,8 & Ruim & 10,3 \\
Fossa & 1,7 & Não & 63,3 & Regular & 25,0 \\
Não possui esgoto & 3,3 & - & - & Bom & 32,8 \\
- & - & - & - & Ótimo & 2,6 \\
\hline
\end{tabular}

A maior parte das casas é atendida pelo serviço de coleta de lixo, por meio de contêineres que são coletados diariamente. Já o serviço de varrição é realizado parcialmente pela prefeitura e pelos próprios moradores (Tabela 26, Figura 34).

Tabela 26: Coleta de lixo e varrição e avaliação dos serviços - Pesquisa Piloto

\begin{tabular}{l|c|l|c|l|c|c|c|c}
\hline \multicolumn{1}{c|}{ Tipo de coleta de lixo } & $\begin{array}{c}\text { \% de } \\
\text { domicílios }\end{array}$ & $\begin{array}{c}\text { Freqüiência da } \\
\text { coleta }\end{array}$ & $\begin{array}{c}\text { \% de } \\
\text { domicílios }\end{array}$ & $\begin{array}{c}\text { Quem varre a } \\
\text { rua }\end{array}$ & $\begin{array}{c}\text { \% de } \\
\text { domicílios }\end{array}$ & $\begin{array}{l}\text { Avaliação } \\
\text { Coleta } \\
\text { de lixo }\end{array}$ & $\begin{array}{c}\text { Serviço de } \\
\text { varrição }\end{array}$ \\
\hline Não respondeu & 1,7 & Não respondeu & 1,7 & Não respondeu & 1,7 & Péssimo & $5,9 \%$ & $24,4 \%$ \\
Caminhão de porta em porta & 7,5 & Todo dia & 90,8 & Gari & 61,7 & Ruim & $5,0 \%$ & $5,0 \%$ \\
Gari de porta em porta & 0,8 & Dia sim, dia não & 7,5 & Morador & 33,3 & Regular & $22,7 \%$ & $18,5 \%$ \\
Contêiner mais próximo & 89,2 & & - & Não é varrida & 3,3 & Bom & $50,4 \%$ & $42,0 \%$ \\
Ponto de lixo mais próximo & 0,8 & & - & - & - & Ótimo & $16,0 \%$ & $10,1 \%$ \\
\hline
\end{tabular}

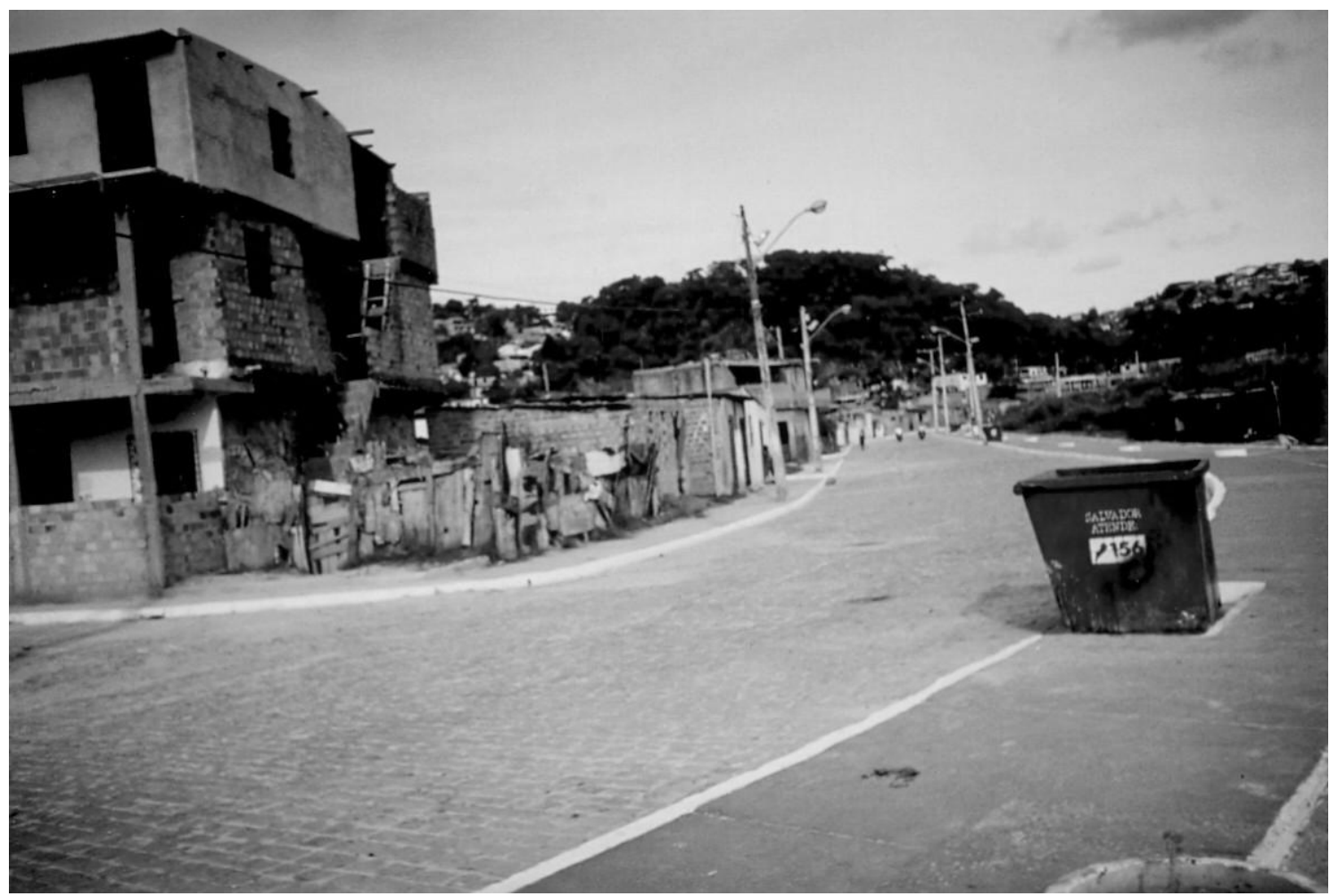

Figura 34: Contêiner utilizado para a coleta de lixo - Pesquisa Piloto 
O serviço de coleta de lixo foi considerado de Regular a Bom, em sua maioria, enquanto a varrição apresenta um percentual considerável de Péssimo.

Com relação à drenagem, em cerca de $40 \%$ dos casos o morador afirmou que não consegue andar na rua quando chove, reduzindo-se este percentual para menos de $25 \%$ nos casos em que ocorre inundação das casas (Tabela 27). Ressalta-se que durante a pesquisa, alguns moradores queixaram-se de inundação das ruas durante a subida da maré.

Tabela 27: Drenagem - Pesquisa Piloto

\begin{tabular}{l|c|l|c}
\hline Quando chove inunda a casa & \% de domicílios & Quando chove consegue andar na rua & \% de domicílios \\
\hline Sim & 24,2 & Sim & 58,3 \\
Não & 75,8 & Não & 41,7 \\
\hline
\end{tabular}

A avaliação das bocas de lobo foi, na maioria, de Ruim/Péssimo a Regular e metade dos entrevistados afirma se sentir inseguro com relação ao risco de inundação (Tabela 28).

Tabela 28: Avaliação do morador quanto ao funcionamento de bocas de lobo e sarjetas e segurança contra inundação - Pesquisa Piloto

\begin{tabular}{l|c|l|c|c}
\hline \multicolumn{1}{c|}{ Avaliação } & Bocas de lobo e sarjetas & \multicolumn{1}{|c|}{ Avaliação } & Segurança contra inundação & Segurança no terreno \\
\hline Péssimo & $43,3 \%$ & Totalmente inseguro & $20,0 \%$ & $3.3 \%$ \\
Ruim & $13,3 \%$ & Um pouco inseguro & $30,0 \%$ & $20.0 \%$ \\
Regular & $24,2 \%$ & Não sabe informar & $7,5 \%$ & $11.7 \%$ \\
Bom & $17,5 \%$ & Um pouco seguro & $17,5 \%$ & $22.5 \%$ \\
Ótimo & $1,7 \%$ & Totalmente seguro & $25,0 \%$ & $42.5 \%$ \\
\hline
\end{tabular}

A situação das vias de circulação (largura, tipo do pavimento e estado de conservação) foi registrada pelo próprio pesquisador de campo; nota-se que quase metade das vias possui entre 1,20 e 3,60 metros, seguida daquelas com largura entre 3,60 e 6,00 metros, sendo pavimentadas, predominantemente, com asfalto ou paralelepípedo (Tabela 29). Quanto a situação do pavimento, pouco mais da metade foi considerado Bom/Ótimo ou Regular, enquanto o restante Ruim ou Péssimo (Figura 35).

Tabela 29: Vias de circulação e condições do pavimento e avaliação do morador - Pesquisa Piloto

\begin{tabular}{l|c|l|c|l|c|l|l|l}
\hline \multicolumn{1}{c|}{ Largura da rua } & $\begin{array}{c}\text { \% de } \\
\text { domicílios }\end{array}$ & $\begin{array}{c}\text { Tipo de } \\
\text { pavimento }\end{array}$ & $\begin{array}{c}\text { \% de } \\
\text { domicílios }\end{array}$ & $\begin{array}{c}\text { Estado da } \\
\text { rua }\end{array}$ & $\begin{array}{c}\text { \% de } \\
\text { domicílios }\end{array}$ & $\begin{array}{c}\text { Avaliação } \\
\text { do morador }\end{array}$ & $\begin{array}{c}\text { Largura } \\
\text { da rua }\end{array}$ & Rua \\
\hline Maior ou igual a 6 metros & 10,2 & Asfalto & 33,1 & Péssimo & 18,6 & Péssimo & $12,6 \%$ & $10,0 \%$ \\
Entre 3,60 e 6 metros & 22,9 & Paralelepípedo & 55,9 & Ruim & 22,9 & Ruim & $21,0 \%$ & $13,3 \%$ \\
Entre 1,20 e 3,60metros & 45,8 & Sem pavimentação & 11,0 & Regular & 39,8 & Regular & $19,3 \%$ & $25,0 \%$ \\
Menor que 1,20 metros & 21,2 & & - & Bom & 17,8 & Bom & $41,2 \%$ & $41,7 \%$ \\
- & - & & - & Ótimo & 0,8 & Ótimo & $5,9 \%$ & $10,0 \%$ \\
\hline
\end{tabular}




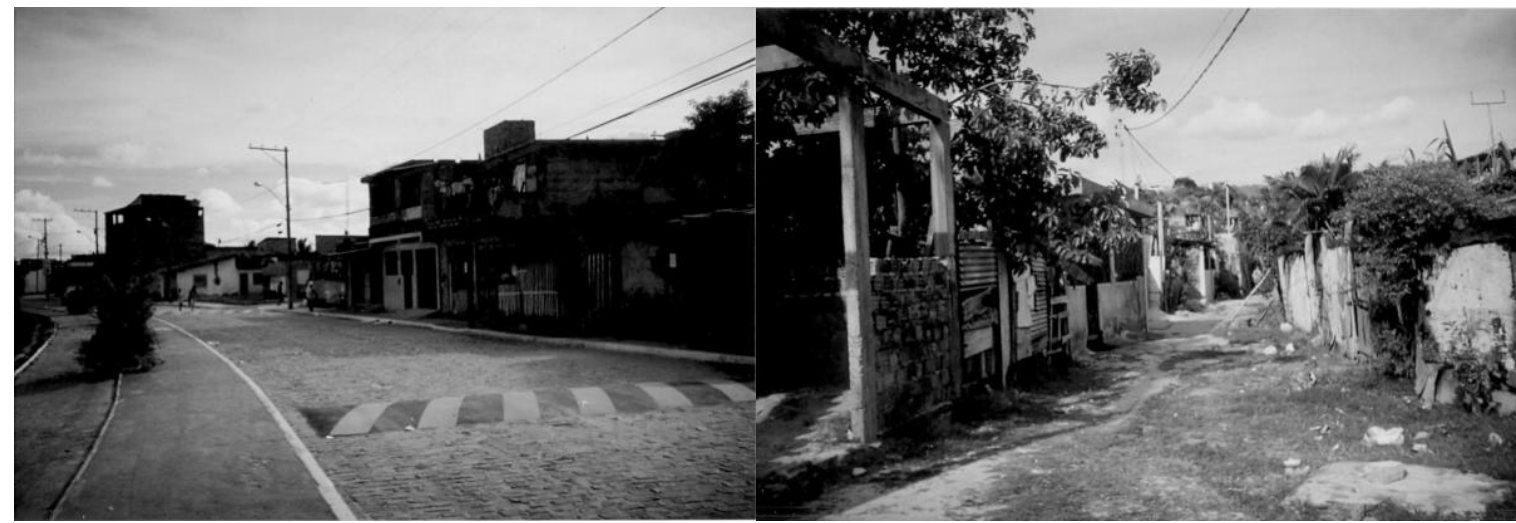

Figura 35: Contrastes entre ruas: pista de borda à esquerda e rua sem pavimento à direita - Pesquisa Piloto

O serviço de energia elétrica foi o que apresentou a maior cobertura, acompanhado da melhor taxa de regularização (Tabela 30). O mesmo ocorre para a iluminação pública, com de fornecimento pela prefeitura. Essas taxas são acompanhadas de freqüências altas de avaliação positiva.

Tabela 30: Energia elétrica, iluminação pública e avaliação do morador - Pesquisa Piloto

\begin{tabular}{l|c|l|c|l|c|l|c|l|c|c}
\hline $\begin{array}{c}\text { Possui energia } \\
\text { elétrica }\end{array}$ & $\begin{array}{c}\text { \% de } \\
\text { domicílios }\end{array}$ & Recebe conta & $\begin{array}{c}\text { \% de } \\
\text { domicílios }\end{array}$ & $\begin{array}{c}\text { Iluminação na } \\
\text { rua }\end{array}$ & $\begin{array}{c}\text { \% de } \\
\text { domicílios }\end{array}$ & Quem fornece & $\begin{array}{c}\text { \% de } \\
\text { domicílios }\end{array}$ & $\begin{array}{l}\text { Avaliação } \\
\text { Energia } \\
\text { elétrica }\end{array}$ & $\begin{array}{c}\text { Iluminação } \\
\text { pública }\end{array}$ \\
\hline Não respondeu & 0,0 & Não respondeu & 1,7 & Não respondeu & 0,0 & Não respondeu & 6,7 & Péssimo & $5,1 \%$ & $14,3 \%$ \\
Sim & 98,3 & Sim & 96,7 & Sim & 93,3 & Prefeitura & 89,2 & Ruim & $2,5 \%$ & $9,2 \%$ \\
Não & 1,7 & Não & 1,7 & Não & 6,7 & Morador & 4,2 & Regular & $8,5 \%$ & $23,5 \%$ \\
- & - & - & - & - & - & & - & Bom & $77,1 \%$ & $46,2 \%$ \\
- & - & - & - & - & - & Ótimo & $6,8 \%$ & $6,7 \%$ \\
\hline
\end{tabular}

A maior parte dos entrevistados respondeu que utiliza os espaços públicos da área, sendo a praça e a quadra os espaços mais utilizados, seguido da pista de caminhada. A avaliação predominante dos moradores com relação aos espaços foi Bom (Tabela 31).

Tabela 31: Espaços públicos de lazer e avaliação do morador - Pesquisa Piloto

\begin{tabular}{l|c|l|c|l|c}
\hline Utiliza espaços públicos na área & \% de domicílios & Equipamento & \% de domicílios & Avaliação & \% de domicílios \\
\hline Não respondeu & 0,8 & Praça & 46,0 & Péssimo & 3,6 \\
Sim & 71,9 & Campo de futebol & 9,2 & Ruim & 5,4 \\
Não & 27,3 & Quadra & 46,0 & Regular & 15,3 \\
- & - & Pista de caminhada & 44,8 & Bom & 69,4 \\
- & - & - & - & Ótimo & 6,3 \\
\hline
\end{tabular}

Dos entrevistados pouco menos de 1/3 afirmou existir orelhão na própria rua, mesmo assim mais de 3/4 deles afirmam que utilizam o telefone público. Mais da metade avalia que os telefones públicos ficam distantes ou muito distantes (Tabela 32). 
Tabela 32: Telefone público e avaliação do morador - Pesquisa Piloto

\begin{tabular}{l|c|c|l|c}
\hline & Tem orelhão na sua rua & Utiliza o orelhão & \multicolumn{1}{|c}{ Avaliação } & \% de domicílios \\
\hline Sim & $30,0 \%$ & $77,5 \%$ & Muito distante & 34,2 \\
Não & $70,0 \%$ & $22,5 \%$ & Distante & 23,1 \\
- & - & - & Numa distância razoável & 18,8 \\
- & - & - & Próximo & 19,7 \\
- & - & - & Muito próximo & 4,3 \\
\hline
\end{tabular}

Em pouco mais de 3/4 dos casos os entrevistados responderam que possuíam algum tipo de documento que comprove a posse da casa e a maioria afirma estar seguro da posse (Tabela $33)$.

Tabela 33: Regularização fundiária e avaliação do morador - Pesquisa Piloto

\begin{tabular}{l|c|l|c}
\hline Possui algum documento da casa & \% de domicílios & \multicolumn{1}{|c|}{ Avaliação } & \% de domicílios \\
\hline Não respondeu & $0,8 \%$ & Totalmente inseguro & $16,7 \%$ \\
Sim & $75,8 \%$ & Um pouco inseguro & $12,5 \%$ \\
Não & $24,2 \%$ & Não sabe informar & $7,5 \%$ \\
- & - & Um pouco seguro & $7,5 \%$ \\
- & - & Totalmente seguro & $55,8 \%$ \\
\hline
\end{tabular}

\subsubsection{Entorno e serviços comunitários}

Dos entrevistados a maioria afirmou que utiliza os serviços do posto de saúde, a escola e a creche. A avaliação desses serviços é considerada de Regular a Bom pela maioria (Tabela 34).

Tabela 34: Serviços comunitários e avaliação do morador - Pesquisa Piloto

\begin{tabular}{l|c|l|c}
\hline \multicolumn{1}{c|}{ Serviços comunitários } & \% de domicílios & \multicolumn{1}{|c|}{ Avaliação } & \% de domicílios \\
\hline Escola & 62,8 & Péssimo & 12,4 \\
Posto de saúde & 74,4 & Ruim & 15,9 \\
Creche & 22,3 & Regular & 22,1 \\
- & - & Bom & 46,0 \\
- & - & Ótimo & 3,5 \\
\hline
\end{tabular}

Com relação ao lazer fora da área urbanizada, cerca de metade das pessoas afirmou utilizar outras áreas, enquanto a outra metade respondeu que não utiliza áreas de lazer fora da área urbanizada. Quanto aos que utilizam, estes consideraram os locais Bom, em sua maioria (Tabela 35).

Tabela 35: Lazer fora da área e avaliação do morador - Pesquisa Piloto

\begin{tabular}{l|c|l|c}
\hline Utilizam locais de lazer fora da área & \% de domicílios & \multicolumn{1}{|c|}{ Avaliação } & \% de domicílios \\
\hline Não respondeu & 1,7 & Péssimo & 0,0 \\
Sim & 48,8 & Ruim & 1,7 \\
Não & 49,6 & Regular & 25,4 \\
- & - & Bom & 62,7 \\
- & - & Ótimo & 10,2 \\
\hline
\end{tabular}


Cerca de $20 \%$ dos entrevistados afirmou que fazia parte de algum tipo de associação, sendo que destes, quase metade participa de cooperativas. Para aqueles que participam de associações a maioria considera a atuação da organização Bom/Ótimo (Tabela 36).

Tabela 36: Associativismo e avaliação do morador - Pesquisa Piloto

\begin{tabular}{l|c|l|c|l|c}
\hline Faz parte de alguma associação & \% de domicílios & \multicolumn{1}{|c|}{ Tipo } & \% de domicílios & Avaliação & \% de domicílios \\
\hline Não respondeu & 0,8 & Nenhuma & 80,2 & Péssimo & 0,0 \\
Sim & 19,8 & Associação de moradores & 5,8 & Ruim & 0,0 \\
Não & 79,3 & Cooperativa & 7,4 & Regular & 16,7 \\
- & - & ONG & 5,8 & Bom & 79,2 \\
- & - & Outra & 0,8 & Ótimo & 4,2 \\
\hline
\end{tabular}

Praticamente todos os entrevistados afirmaram que utilizam ônibus como meio de transporte para o trabalho, seguido daqueles que também utilizam trem. A avaliação da distância do ponto de ônibus dividiu-se entre Pouco distante, Numa distância razoável e Próximo (Tabela $37)$.

Tabela 37: Transporte e avaliação do morador quanto ao ponto de ônibus - Pesquisa Piloto

\begin{tabular}{l|c|l|c}
\hline \multicolumn{1}{c|}{ Transporte } & \% de domicílios & \multicolumn{1}{|c}{ Avaliação } & \% de domicílios \\
\hline Barco & 3,3 & Muito distante & 7,6 \\
Trem & 17,4 & Pouco distante & 26,3 \\
Ônibus & 95,9 & Numa distância razoável & 25,4 \\
- & - & Próximo & 38,1 \\
- & - & Muito próximo & 2,5 \\
\hline
\end{tabular}

\subsubsection{Avaliação final}

Além das questões específicas apresentadas, foram feitas perguntas sobre a casa, a casa depois da urbanização, o bairro e a área após a urbanização.

A avaliação das casas ficou em torno de Bom, decrescendo nos demais conceitos. Da mesma forma mais de $60 \%$ avaliam que a casa Melhorou depois da urbanização (Tabela 38).

Tabela 38: Avaliação da casa - Pesquisa Piloto

\begin{tabular}{l|c|l|c}
\hline $\begin{array}{c}\text { O que você acha da sua casa } \\
\text { como um todo }\end{array}$ & \% de domicílios & $\begin{array}{c}\text { O que você acha da sua casa depois da } \\
\text { urbanização }\end{array}$ & \% de domicílios \\
\hline Péssima & 12,5 & Piorou muito & 0,8 \\
Ruim & 10,0 & Piorou & 3,3 \\
Regular & 26,7 & Não faz diferença & 15,8 \\
Boa & 40,0 & Melhorou & 60,8 \\
Ótima & 10,8 & Melhorou muito & 19,2 \\
\hline
\end{tabular}

Com relação ao bairro, assim como a maioria acha que a área Melhorou, ou Melhorou muito, após a urbanização, temos que quase $80 \%$ dos entrevistados avalia o bairro como sendo Bom ou Ótimo (Tabela 39). 
Tabela 39: Avaliação da área e do bairro - Pesquisa Piloto

\begin{tabular}{l|c|l|c}
\hline $\begin{array}{c}\text { Como você avalia a área que foi urbanizada, antes } \\
\text { e depois }\end{array}$ & \% de domicílios & $\begin{array}{c}\text { O que você acha de morar } \\
\text { neste bairro }\end{array}$ & \% de domicílios \\
\hline Piorou muito & 0,0 & Péssimo & 2,5 \\
Piorou & 1,7 & Ruim & 2,5 \\
Não faz diferença & 14,2 & Regular & 15,8 \\
Melhorou & 54,2 & Bom & 67,5 \\
Melhorou muito & 30,0 & Ótima & 11,7 \\
\hline
\end{tabular}

\subsubsection{Considerações sobre Novos Alagados $-1^{\text {a }}$. Etapa com base nos dados descritos}

Notamos que apesar dos pontos negativos, como o esgotamento sanitário, a população avalia a intervenção positivamente. Além disso, as questões abertas do formulário, mesmo que em baixa freqüência - cerca de $10 \%$ dos entrevistados responderam estas perguntas - revelaram problemas com relação à segurança da área. Alguns moradores apontaram este item com sendo um dos pontos negativos da área. Como ponto positivo, foi citada a saída das palafitas para as casas de alvenaria.

\subsection{QUESTÕES PRELIMINARES À ANÁLISE DE DADOS}

A primeira questão no processo de modelagem dos dados para aplicação das ferramentas de Lógica Fuzzy diz respeito ao processo que chamamos de fuzzificação. A fuzzificação é o processo de transformação de dados na sua forma clássica para a forma fuzzy, ou seja, com suas incertezas (KLIR; YUAN, 1995). Neste trabalho a questão a ser respondida é como entender as frequiências de respostas como graus de verdade. Outra questão importante, relacionada à regra de composição nos processos de inferência será discutida na seção correspondente.

Assim como a questão do método de fuzzificação, uma outra questão geral está relacionada ao número de classes que serão utilizadas nas escalas qualitativas. Por fim o método de defuzzificação, que ao contrário da fuzzificação, converte dados fuzzy em dados crisp, será definido como o processo inverso da fuzzificação. 


\subsubsection{Definição do método de fuzzificação}

Fuzzificar de uma forma geral implica em converter uma dada distribuição de medida em distribuição de possibilidade para, assim, analisá-la como fuzzy. No nosso caso, discutiremos basicamente entre trabalhar com medidas de freqüência relativa como um subconjunto fuzzy, ou seja, sem a exigência de normalidade ou, de alguma forma normalizá-los.

Diversos autores propuseram métodos de fuzzificação e seus equivalentes de defuzzificação. A opção por método específico está relacionada ao conhecimento que o pesquisador tem do fenômeno em análise, pois todos os métodos possuem consistência matemática. Dentre os métodos de conversão das distribuições de probabilidades em distribuições de possibilidades, o método mais simples, e mais freqüentemente utilizado, é a multiplicação das medidas por uma constante. Formalmente temos que, dada uma distribuição de probabilidades $p=\left\{p\left(x_{1}\right) ; p\left(x_{2}\right) ; \ldots ; p\left(x_{n}\right)\right\}, \quad$ ou $\quad$ simplesmente $\quad p=\left\{p_{1} ; p_{2} ; \ldots ; p_{n}\right\} \quad$ com $\quad \sum_{i=1}^{n} p_{i}=1, \quad$ a distribuição de possibilidade equivalente é, onde $\pi_{i}=\alpha p_{i}$. Admitindo $p$ uma distribuição ordenada não-crescente, toma-se $\alpha=\frac{1}{p_{1}}=\frac{1}{p_{\max }}($ KLIR; YUAN, 1995).

Ou seja, para fuzzificar um conjunto de freqüências, basta dividirmos cada freqüência, pelo valor máximo no conjunto.

\subsubsection{Definição do método de defuzzificação}

Existem diversos métodos de defuzzificação na literatura, porém, todos relacionados a escalas quantitativas (KLIR; YUAN, 1995). No caso dos dados de avaliação do morador, já que estamos trabalhando com escalas qualitativas, propomos a adoção da classe associada ao valor máximo de grau de verdade, o que equivale no caso das frequiências a adotar a moda, em lugar da média. 


\subsubsection{Definição do número de classes da escala de avaliação do morador}

A definição do número de classes da escala qualitativa de avaliação do morador tem sido uma questão discutida em estudos de APO; alguns defendem uma escala de cinco classes com uma classe neutra, outros defendem uma escala de quatro classes, sem a classe neutra. Com base na teoria apresentada por Galster (1987) para satisfação residencial, devemos sim, considerar uma classe neutra, intermediária, entre as situações de satisfação e insatisfação. Esta classe representaria, tanto situações transitórias de satisfação, como talvez alguns casos de alienação quanto à satisfação avaliada.

Já com relação ao número de classes, utilizaremos como exemplo os dados de avaliação da moradia, para fazer uma comparação dos resultados da aplicação da medida de incerteza e seus impactos nas conclusões.

Estes dados foram obtidos para avaliação da moradia utilizando-se uma escala de cinco classes, original da coleta de dados. Agruparemos as classes com mesmo sentido semântico para obter uma escala reduzida de três classes. Assim a escala que originalmente possuía as classe Péssimo, Ruim, Regular, Bom e Ótimo para a uma escala de Péssim/Ruim, Regular e Bom/Ótimo a partir da agregação simples dos valores em cada classe. Esse tipo de operação é comum em testes não-paramétricos, quando algumas células nas tabelas de contingência não atendem às quantidades mínimas.

A Tabela 40 e a Tabela 41 apresentam as distribuições de freqüência relativa e correspondente distribuições de possibilidade para estas variáveis com cinco e três classes, respectivamente, ou seja, distribuições fuzzificadas. Estas distribuições de possibilidades são obtidas apenas dividindo-se cada freqüência pelo valor máximo da distribuição em cada variável. As variáveis serão apresentadas com seus códigos de análise, cujos significados são apresentados no APÊNDICE B.

Tabela 40: Dados de moradia: freqüência relativa e distribuição de possibilidade - escala com cinco classes Pesquisa Piloto

\begin{tabular}{l|c|c|c|c|c|c|c|c|c|c}
\hline \multirow{2}{*}{\multicolumn{1}{c}{ Item }} & \multicolumn{4}{c|}{ Conceito /Freqüência relativa } & \multicolumn{4}{c}{ Conceito/Possibilidade } \\
\cline { 2 - 10 } & Péssimo & Ruim & Regular & Bom & Ótimo & Péssimo & Ruim & Regular & Bom & Ótimo \\
\hline Av_Inst_Agua & $5 \%$ & $7 \%$ & $19 \%$ & $66 \%$ & $3 \%$ & 0,08 & 0,11 & 0,29 & 1,00 & 0,05 \\
Av_Inst_Esgoto & $6 \%$ & $5 \%$ & $17 \%$ & $71 \%$ & $1 \%$ & 0,08 & 0,07 & 0,24 & 1,00 & 0,01 \\
Av_Inst_Eletrica & $5 \%$ & $12 \%$ & $33 \%$ & $45 \%$ & $5 \%$ & 0,11 & 0,27 & 0,73 & 1,00 & 0,11 \\
Av_Quartos & $26 \%$ & $24 \%$ & $16 \%$ & $28 \%$ & $6 \%$ & 0,93 & 0,86 & 0,57 & 1,00 & 0,21 \\
Av_Tam_Casa & $24 \%$ & $22 \%$ & $20 \%$ & $26 \%$ & $8 \%$ & 0,92 & 0,85 & 0,77 & 1,00 & 0,31 \\
Av_Telhado & $19 \%$ & $18 \%$ & $32 \%$ & $26 \%$ & $6 \%$ & 0,59 & 0,56 & 1,00 & 0,81 & 0,19 \\
Av_Paredes & $11 \%$ & $18 \%$ & $20 \%$ & $48 \%$ & $3 \%$ & 0,23 & 0,38 & 0,42 & 1,00 & 0,06 \\
Av_Piso & $18 \%$ & $14 \%$ & $26 \%$ & $38 \%$ & $5 \%$ & 0,47 & 0,37 & 0,68 & 1,00 & 0,13 \\
Av_Ventila & $13 \%$ & $17 \%$ & $19 \%$ & $46 \%$ & $5 \%$ & 0,28 & 0,37 & 0,41 & 1,00 & 0,11 \\
\hline
\end{tabular}


Tabela 41: Dados de moradia: frequêencia relativa e distribuição de possibilidade - escala com três classes Pesquisa Piloto

\begin{tabular}{l|c|c|c|c|c|c}
\hline \multirow{2}{*}{\multicolumn{1}{c|}{ Item }} & \multicolumn{3}{|c|}{ Conceito/Freqüência relativa } & \multicolumn{3}{c}{ Conceito/Possibilidade } \\
\cline { 2 - 7 } & Péssimo/Ruim & Regular & Bom/Ótimo & Péssimo/Ruim & Regular & Bom/Ótimo \\
\hline Av_Inst_Agua & $12 \%$ & $19 \%$ & $69 \%$ & 0,17 & 0,28 & 1,00 \\
Av_Inst_Esgoto & $10 \%$ & $17 \%$ & $72 \%$ & 0,14 & 0,24 & 1,00 \\
Av_Inst_Eletrica & $17 \%$ & $33 \%$ & $50 \%$ & 0,34 & 0,66 & 1,00 \\
Av_Quartos & $50 \%$ & $16 \%$ & $34 \%$ & 1,00 & 0,32 & 0,68 \\
Av_Tam_Casa & $46 \%$ & $20 \%$ & $34 \%$ & 1,00 & 0,43 & 0,74 \\
Av_Telhado & $37 \%$ & $32 \%$ & $32 \%$ & 1,00 & 0,86 & 0,86 \\
Av_Paredes & $29 \%$ & $20 \%$ & $51 \%$ & 0,57 & 0,39 & 1,00 \\
Av_Piso & $32 \%$ & $26 \%$ & $43 \%$ & 0,74 & 0,60 & 1,00 \\
Av_Ventila & $30 \%$ & $19 \%$ & $51 \%$ & 0,59 & 0,37 & 1,00 \\
\hline
\end{tabular}

A Tabela 42 apresenta os valores obtidos para a medida de não especificidade com as duas escalas. Adotaremos, para efeito de classificação, três faixas de incerteza: baixa - menores ou iguais a 0,33, média - maiores que 0,33 e menores ou iguais a 0,66 e alta - maiores que 0,66. Note na Tabela 42 que a maior variação com relação à escala ocorre nos pontos de incerteza média ou alta ou nos que estão nas fronteiras das faixas. Isto acontece por que existem variáveis que, na escala de cinco classes apresentavam dois conceitos positivos (ou negativos) predominantes o que implica numa medida de não-especificidade média, porém, quando agrupadas numa escala de três pontos, estes dois conceitos se transformaram em um único com predominância ainda maior, o que fez com que a não-especificidade diminuísse. Por outro lado se, no agrupamento, esses conceitos passam a se equilibrar (positivos e negativos), a medida de não-especificidade tende a aumentar.

Tabela 42: Moradia: freqüências relativas e medidas de incerteza com escalas de cinco e três classes - Pesquisa

\begin{tabular}{|c|c|c|c|c|c|c|c|c|c|c|c|}
\hline \multicolumn{12}{|c|}{ Piloto } \\
\hline \multirow{2}{*}{ Item } & \multicolumn{6}{|c|}{ Escala de 5 pontos } & \multicolumn{4}{|c|}{ Escala de 3 pontos } & \multirow{2}{*}{ Diferenç: } \\
\hline & Péssimo & Ruim & Regular & Bom & Ótimo & U-Incerteza & Péssimo/Ruim & Regular & Bom/Ótimo & U-Incerteza & \\
\hline$\overline{\mathrm{Av} \text { _Inst_Agua }}$ & 0,08 & 0,11 & 0,29 & 1,00 & 0,05 & 0,17 & 0,17 & 0,28 & 1,00 & 0,24 & 0,07 \\
\hline Av_Inst_Esgoto & 0,08 & 0,07 & 0,24 & 1,00 & 0,01 & 0,14 & 0,14 & 0,24 & 1,00 & 0,20 & 0,06 \\
\hline Av_Inst_Eletrica & 0,11 & 0,27 & 0,73 & 1,00 & 0,11 & 0,42 & 0,34 & 0,66 & 1,00 & 0,54 & 0,12 \\
\hline Av_Quartos & 0,93 & 0,86 & 0,57 & 1,00 & 0,21 & 0,73 & 1,00 & 0,32 & 0,68 & 0,55 & $-0,18$ \\
\hline Av_Tam_Casa & 0,92 & 0,85 & 0,77 & 1,00 & 0,31 & 0,80 & 1,00 & 0,43 & 0,74 & 0,63 & $-0,17$ \\
\hline Av_Telhado & 0,59 & 0,56 & 1,00 & 0,81 & 0,19 & 0,63 & 1,00 & 0,86 & 0,86 & 0,86 & 0,23 \\
\hline Av_Paredes & 0,23 & 0,38 & 0,42 & 1,00 & 0,06 & 0,32 & 0,57 & 0,39 & 1,00 & 0,50 & 0,18 \\
\hline Av_Piso & 0,47 & 0,37 & 0,68 & 1,00 & 0,13 & 0,50 & 0,74 & 0,60 & 1,00 & 0,69 & 0,19 \\
\hline$A v_{-}$Ventila & 0,28 & 0,37 & 0,41 & 1,00 & 0,11 & 0,34 & 0,59 & 0,37 & 1,00 & 0,51 & 0,17 \\
\hline
\end{tabular}

Para uma melhor visualização, os resultados são apresentados no Gráfico 10 e no Gráfico 11. 


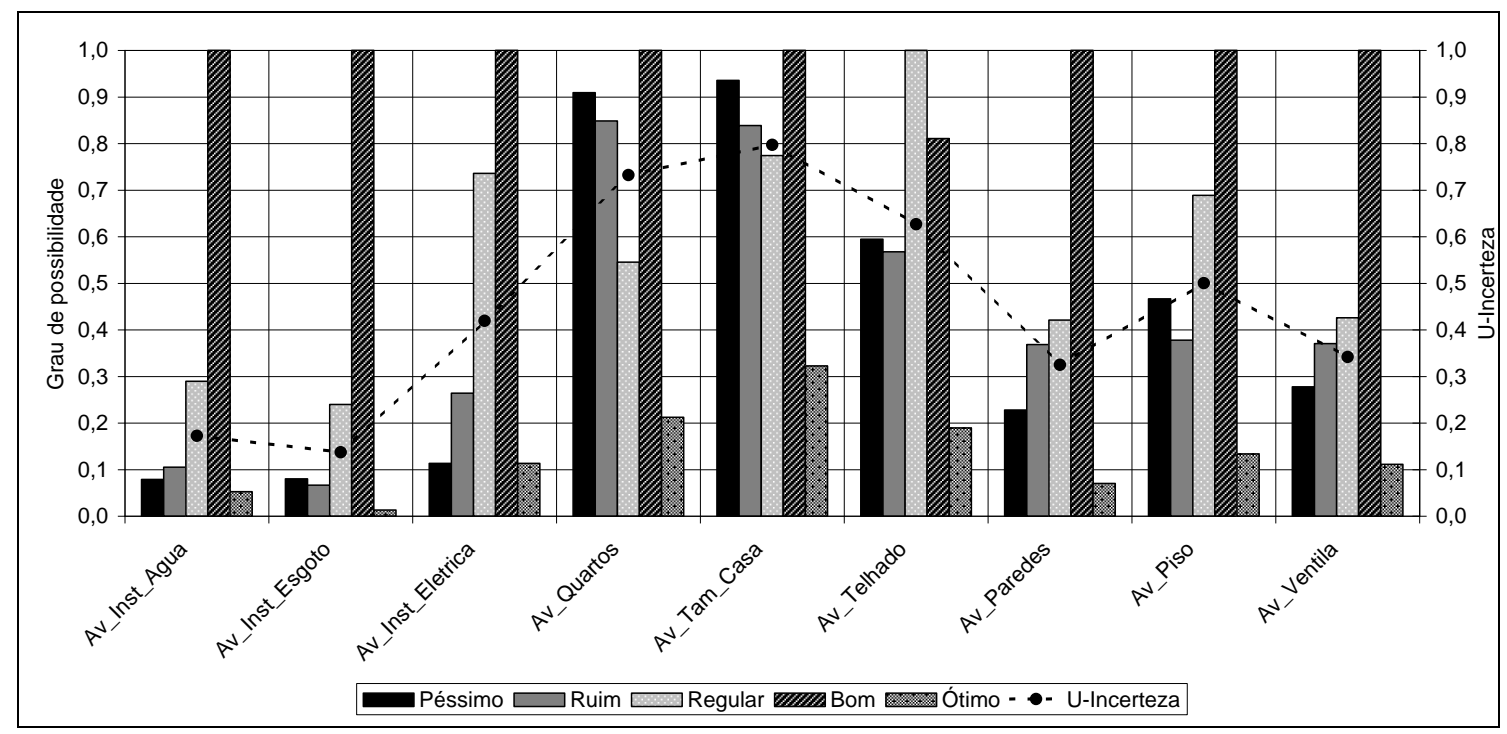

Gráfico 10: Frequiências relativas e U-Incerteza para uma escala com cinco classes - Pesquisa Piloto

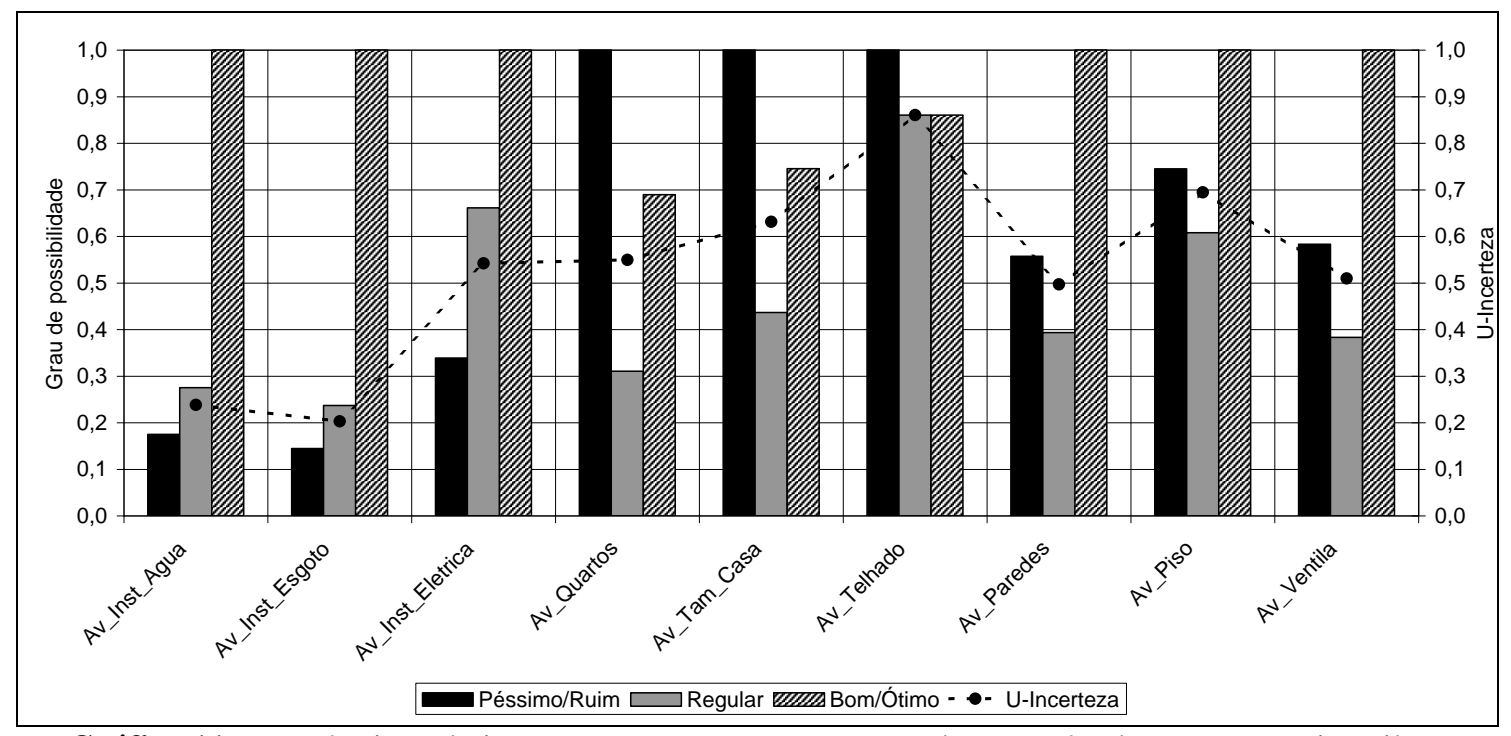

Gráfico 11: Frequiências relativas e U-Incerteza para uma escala com três classes - Pesquisa Piloto

Apesar da maioria das variáveis manter uma tendência de aumento no valor da incerteza ao mudarmos a escala de avaliação, aquelas relacionadas à quantidade de quartos e tamanho da casa sofrem variações negativas, passando de uma situação de alta incerteza para média incerteza. Essa diminuição da incerteza se dá pelo fato de que os conceitos negativos antes (escala de cinco pontos) mais equilibrados com os positivos e regulares, na agregação na escala de três classes passam a ter destaque.

Percebemos, na comparação com as duas escalas que, para a medida de não especificidade a escala de três classes torna-se mais segura, visto que considera apenas três possibilidades (negativo, neutro e positivo), sendo reforçada quando os pontos positivos ou negativos são predominantes, independente de qual positivo ou negativo. Reafirmamos que essa agregação 
só foi possível pelo fato das classes agrupadas da escala terem o mesmo sentido para identificar os pontos positivos (ou negativos).

\subsection{ANÁLISE DE DADOS DE AVALIAÇÃO DO MORADOR}

Esta primeira etapa de análise tem por objetivo verificar a confiabilidade das afirmações feitas em relação aos pontos positivos e negativos da intervenção com base nas respostas de avaliação do morador, e para isso utilizaremos as medidas de incerteza apresentadas. As análises serão feitas por grupos de variáveis (indicadores), ou seja, Moradia, Salubridade ambiental e Entorno. Em paralelo, serão mostrados os resultados de análises tradicionais feitas com base em médias e desvio padrão.

Antes, dado que foram apresentadas três formas de incerteza: vagueza, não-especificidade e conflito, precisamos definir qual tipo de incerteza é mais adequada para a nossa análise.

Das medidas apresentadas foi feito um estudo prévio que pode ser visto em Moraes e Abiko (2006) sobre a adequação dessas medidas à análise de dados de avaliação do morador. Com base neste estudo constatamos que tanto conceitualmente quanto na prática, a medida mais adequada para os nossos propósitos é a medida de não-especificidade, uma vez que identifica a presença de um conceito predominante na avaliação. A medida de conflito, na forma como é proposta não apresentou sensibilidade suficiente para os dados. Já a vagueza, além de possuir um significado diferente e mesmo com adequações necessita cautela no seu uso, visto que não diferencia conjuntos predominantemente unitários dos não-unitários. A vagueza pode ser útil para mensurar a incerteza presente em variáveis lingüísticas, como as que foram obtidas por Silva (2004) e apresentadas no Gráfico 7.

Destacamos que a medida de não-especificidade independe da fuzzificação e da medida de distância. Cabe destacar também, que a escolha da medida incerteza, bem como dos outros métodos para mensuração da incerteza dependem dos objetivos da análise. Em nosso caso, o objetivo é verificar o quanto uma afirmação sobre os aspectos positivos e negativos é verdadeira, com base na predominância dos conceitos. Adotando a medida de nãoespecificidade e escala reduzida de três classes obtivemos os resultados que são descritos a seguir. 


\subsubsection{Moradia}

Os resultados das variáveis relacionadas à moradia encontram-se na Tabela 43 e podem ser melhor visualizados no Gráfico 12 e no Gráfico 13, onde as medidas de U-Incerteza estão ordenadas do menor para o maior valor. Adotando as faixas de incerteza já definidas na seção anterior temos como aspectos positivos com grau baixo de incerteza (ou alto grau de certeza, complemento da incerteza): instalações de esgoto e instalações de água; aspectos positivos com grau médio de incerteza: paredes, ventilação e iluminação natural e instalações elétricas; aspectos negativos com grau médio de incerteza: quartos e tamanho da casa. As avaliações do piso e do telhado possuem um grau de incerteza alto e qualquer afirmação seria pouco acertada.

Numa análise tradicional procederíamos a transformação da escala ordinal, numa escala intervalar, onde os conceitos Péssimo/Ruim, Regular, Bom/Ótimo passariam a valer 1, 2 e 3 respectivamente e posteriormente o cálculo de médias e desvio padrão, os resultados encontram-se também na Tabela 43. Ressaltamos que essa abordagem não é a mais adequada, porém é bastante utilizada e a tomaremos como comparação.

Tabela 43: Moradia: Graus de possibilidade, incerteza, avaliação média e desvio padrão - Pesquisa Piloto

\begin{tabular}{|c|c|c|c|c|c|c|}
\hline \multirow{2}{*}{ Item } & \multicolumn{3}{|c|}{ Conceitos/Graus de possibilidade } & \multirow{2}{*}{ U-Incerteza } & \multirow{2}{*}{ Avaliação média } & \multirow{2}{*}{ Desvio padrão } \\
\hline & Péssimo/Ruim & Regular & Ótimo/Bom & & & \\
\hline$\overline{\text { Av_Inst_Agua }}$ & 0,17 & 0,28 & 1,00 & 0,24 & 2,57 & 0,70 \\
\hline Av_Inst_Esgoto & 0,14 & 0,24 & 1,00 & 0,20 & 2,62 & 0,67 \\
\hline Av_Inst_Eletrica & 0,34 & 0,66 & 1,00 & 0,54 & 2,33 & 0,75 \\
\hline Av_Quartos & 1,00 & 0,32 & 0,68 & 0,55 & 1,84 & 0,91 \\
\hline Av_Tam_Casa & 1,00 & 0,43 & 0,74 & 0,63 & 1,88 & 0,89 \\
\hline Av_Telhado & 1,00 & 0,86 & 0,86 & 0,86 & 1,95 & 0,83 \\
\hline Av_Paredes & 0,57 & 0,39 & 1,00 & 0,50 & 2,23 & 0,87 \\
\hline Av_Piso & 0,74 & 0,60 & 1,00 & 0,69 & 2,11 & 0,86 \\
\hline Av_Ventila & 0,59 & 0,37 & 1,00 & 0,51 & 2,21 & 0,88 \\
\hline
\end{tabular}

Observamos no Gráfico 12, que apenas os itens telhado, tamanho da casa e quartos podem ser considerados negativos nesta análise, e observando a distribuição de freqüência da Tabela 43, percebemos que a ligeira predominância dos conceitos negativos conduz a média para abaixo do valor regular. 


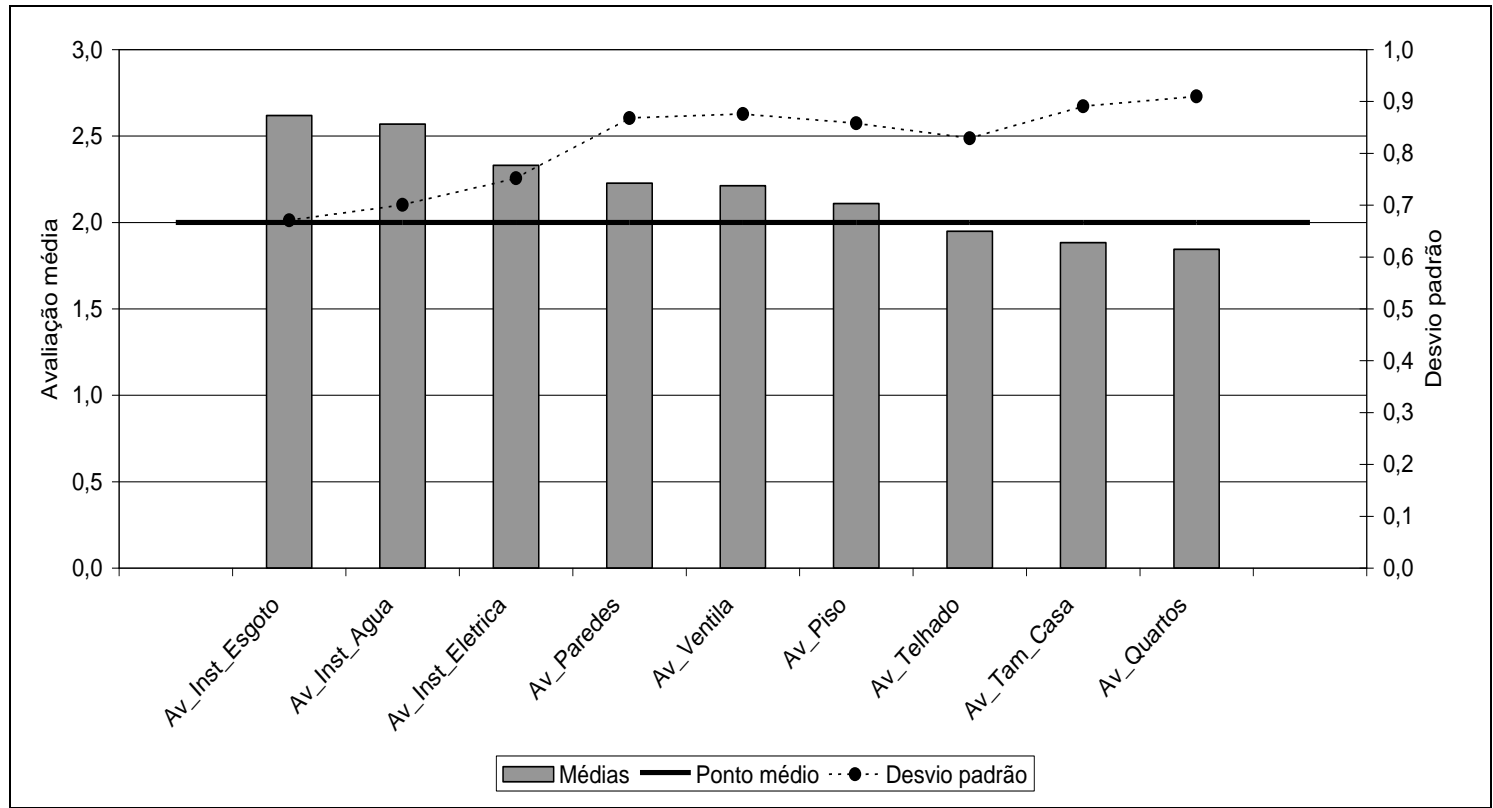

Gráfico 12: Moradia: médias e desvios-padrão - Pesquisa Piloto

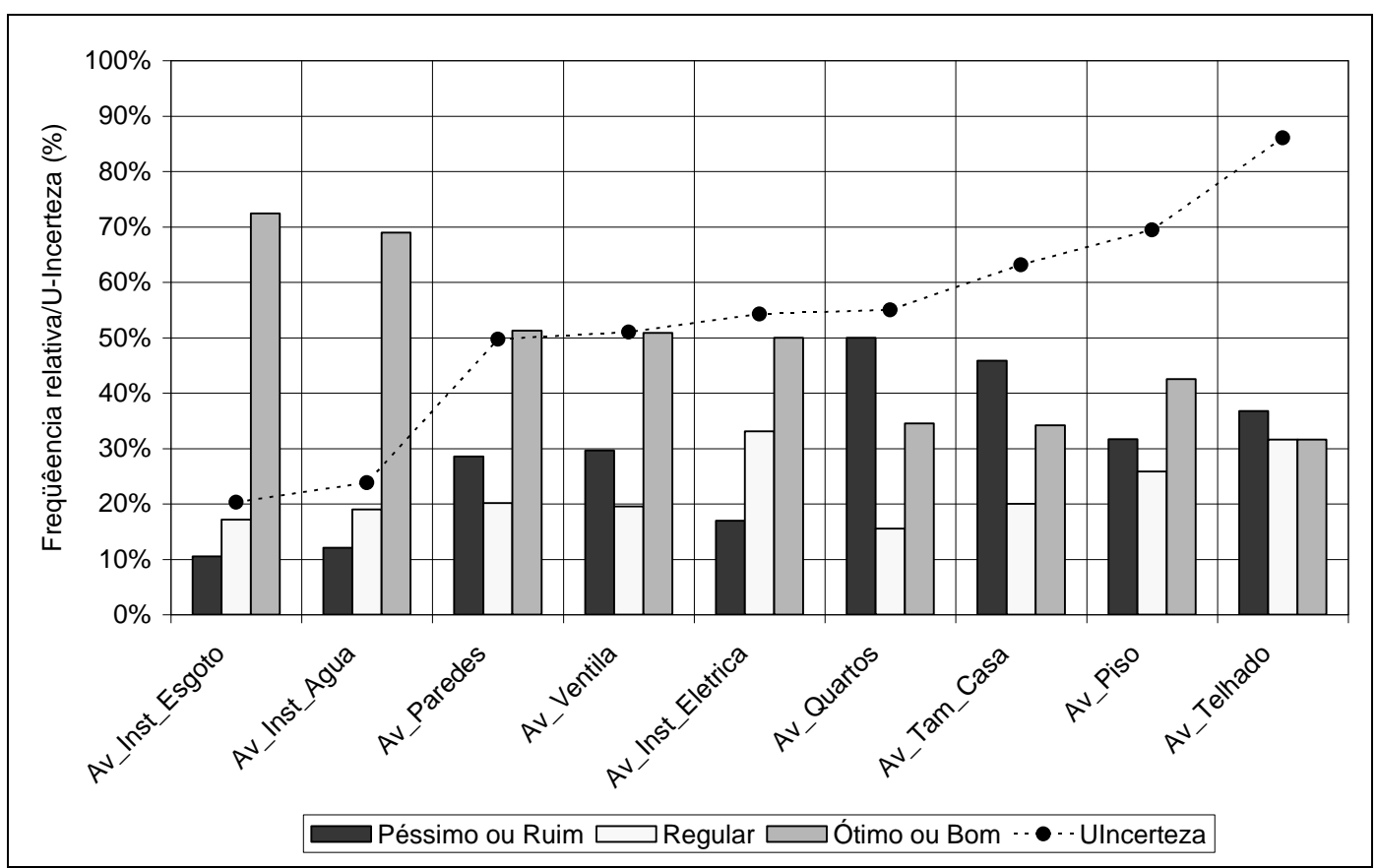

Gráfico 13: Moradia: frequiências relativas e U-Incerteza - Pesquisa Piloto

Comparando os resultados das medidas de incerteza com a análise do diagrama de barras temos que, tomando apenas as incertezas altas, existem dois pontos, piso e telhado, que seriam, equivocamente, considerados positivo e negativo, respectivamente. $\mathrm{O}$ resumo da comparação está apresentado na Tabela 44. Ou seja, calculando o grau de verdade (certeza) como o complemento da incerteza tem-se que: a afirmação "O telhado é um ponto negativo" 
possui um grau de verdade de 0,14 da mesma forma a afirmação "O piso é um ponto positivo" tem grau de verdade 0,31 .

Por outro lado, quando se afirma "As instalações de água são um ponto positivo" tem-se um grau de verdade de 0,76. Assim, a medida de incerteza agrega informação a afirmação obtida, quer seja pelo valor predominante, quer seja pela média.

Tabela 44: Moradia: síntese dos pontos positivos e negativos - Pesquisa Piloto

\begin{tabular}{l|c|c|c|c}
\hline \multirow{2}{*}{\multicolumn{1}{c|}{ Item }} & Abordagem clássica & \multicolumn{3}{c}{ Abordagem fuzzy } \\
\cline { 2 - 5 } & Aspecto & Aspecto & Incerteza & Grau de verdade \\
\hline Av_Inst_Agua & + & + & Baixa & 0,76 \\
Av_Inst_Esgoto & + & + & Baixa & 0,80 \\
Av_Inst_Eletrica & + & + & Média & 0,46 \\
Av_Quartos & - & - & Média & 0,45 \\
Av_Tam_Casa & - & - & Média & 0,37 \\
Av_Telhado & - & - & Alta & 0,14 \\
Av_Paredes & + & + & Média & 0,50 \\
Av_Piso & + & + & Alta & 0,31 \\
Av_Ventila & + & + & Média & 0,49 \\
\hline
\end{tabular}

\subsubsection{Salubridade ambiental}

Para as variáveis de Salubridade ambiental, procedemos de forma semelhante e os resultados são apresentados na Tabela 45 e no Gráfico 14 e Gráfico 15.

Tabela 45: Salubridade ambiental: Graus de possibilidade, incerteza, avaliação média e desvio padrão -

\begin{tabular}{|c|c|c|c|c|c|c|}
\hline \multirow{2}{*}{ Item } & \multicolumn{3}{|c|}{ Conceitos/Graus de possibilidade } & \multirow{2}{*}{ U-Incerteza } & \multirow{2}{*}{ Avaliação média } & \multirow{2}{*}{$\begin{array}{l}\text { Desvio } \\
\text { padrão }\end{array}$} \\
\hline & Péssimo/Ruim & Regular & Bom/Ótimo & & & \\
\hline Av_Abast_Agua & 0,12 & 0,40 & 1,00 & 0,30 & 2,57 & 0,65 \\
\hline Av_Esgoto & 1,00 & 0,60 & 0,90 & 0,79 & 1,96 & 0,87 \\
\hline Av_Coleta_Lixo & 0,17 & 0,35 & 1,00 & 0,28 & 2,55 & 0,69 \\
\hline Av_Varrição & 0,58 & 0,37 & 1,00 & 0,50 & 2,22 & 0,88 \\
\hline Av_Boc_Sarj & 1,00 & 0,42 & 0,33 & 0,39 & 1,63 & 0,79 \\
\hline Seg_Inund & 1,00 & 0,16 & 0,86 & 0,59 & 1,93 & 0,96 \\
\hline Av_larg_rua & 0,72 & 0,40 & 1,00 & 0,60 & 2,13 & 0,89 \\
\hline Av_Rua & 0,44 & 0,48 & 1,00 & 0,47 & 2,28 & 0,82 \\
\hline Seg_Terreno & 0,35 & 0,18 & 1,00 & 0,29 & 2,42 & 0,85 \\
\hline Av_Esp_Pub & 0,12 & 0,20 & 1,00 & 0,17 & 2,67 & 0,64 \\
\hline Av_Energia & 0,10 & 0,10 & 1,00 & 0,10 & 2,76 & 0,58 \\
\hline Av_Ilumina & 0,45 & 0,45 & 1,00 & 0,44 & 2,29 & 0,83 \\
\hline Dist_Tel & 1,00 & 0,33 & 0,42 & 0,38 & 1,67 & 0,84 \\
\hline Seg_Posse & 0,46 & 0,13 & 1,00 & 0,33 & 2,34 & 0,90 \\
\hline
\end{tabular}




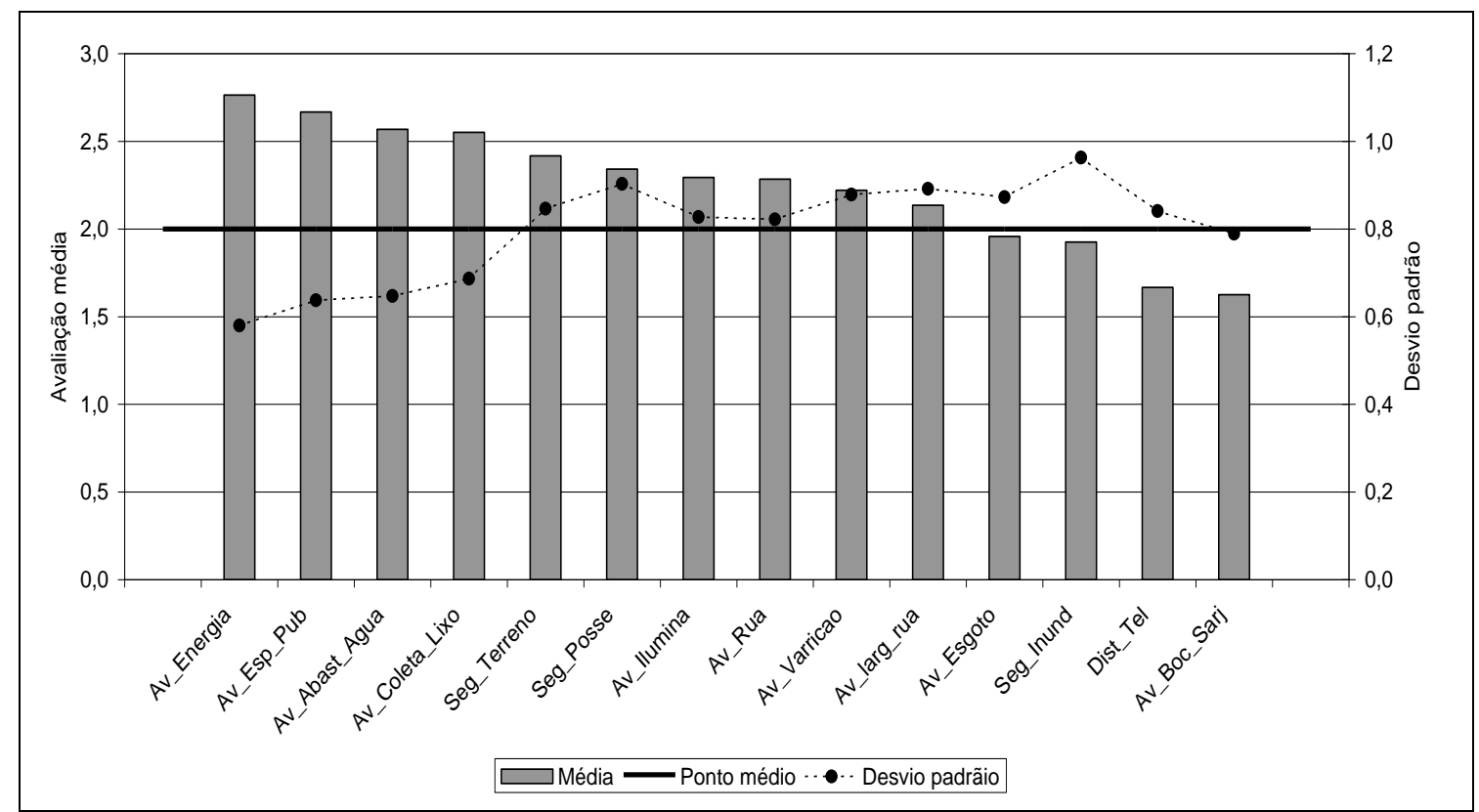

Gráfico 14 : Salubridade ambiental: médias e desvios-padrão - Pesquisa Piloto

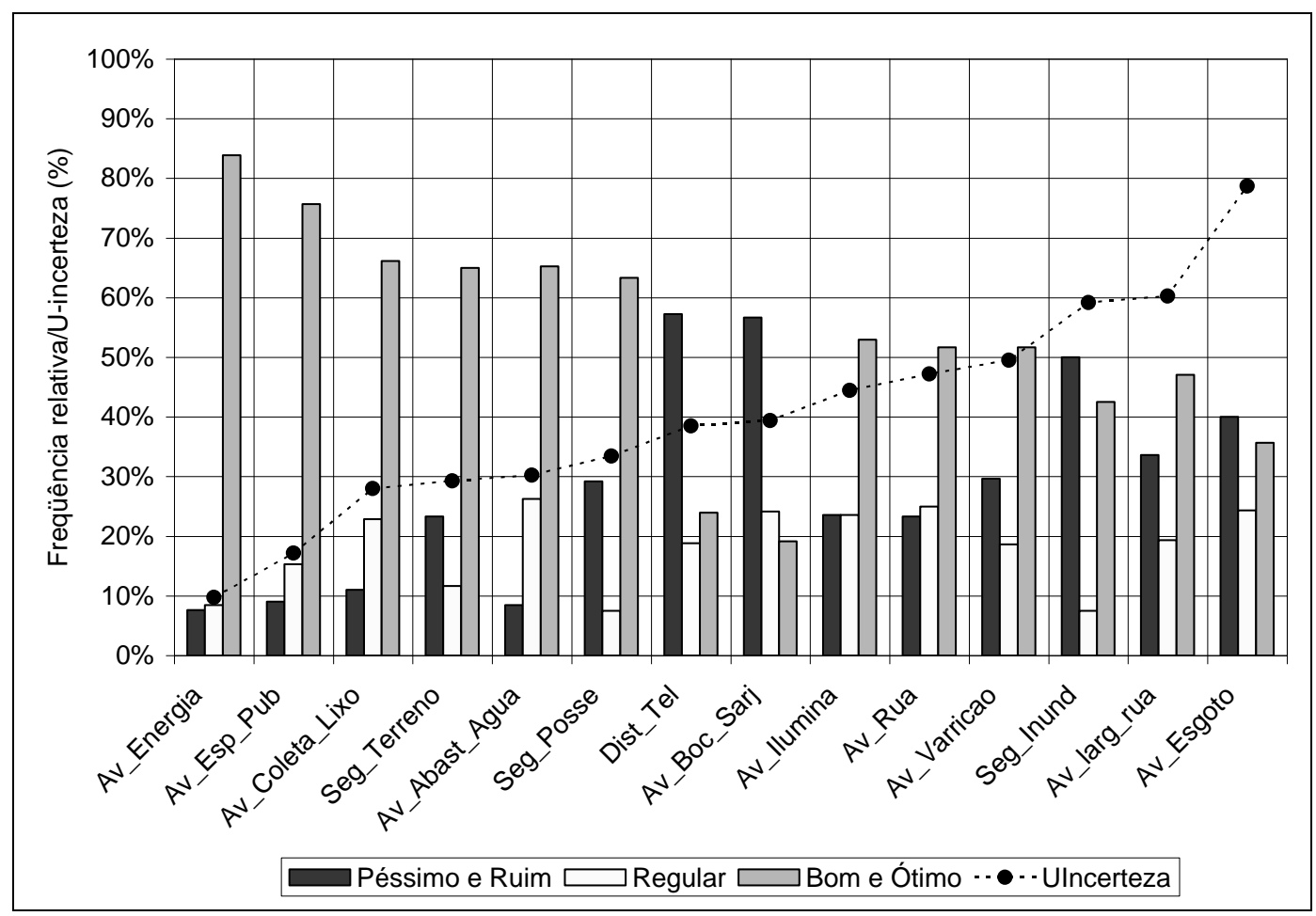

Gráfico 15: Salubridade ambiental: Freqüências relativas e U-Incerteza - Pesquisa Piloto

Adotando o mesmo critério utilizado nas variáveis de moradia, apenas o item esgoto apresentou uma incerteza alta, os demais apresentaram incerteza média ou baixa (Tabela 46). 
Tabela 46: Salubridade ambiental: síntese dos pontos positivos e negativos - Pesquisa Piloto

\begin{tabular}{l|c|c|c|c}
\hline \multirow{2}{*}{ Item } & Abordagem clássica & \multicolumn{3}{c}{ Abordagem fuzzy } \\
\cline { 2 - 5 } & Aspecto & Aspecto & Incerteza & Grau de verdade \\
\hline Av_Abast_Agua & + & + & Baixa & 0,70 \\
Av_Esgoto & - & - & Alta & 0,21 \\
Av_Coleta_Lixo & + & + & Baixa & 0,72 \\
Av_Varricao & + & + & Média & 0,50 \\
Av_Boc_Sarj & - & - & Média & 0,61 \\
Seg_Inund & - & Média & 0,41 \\
Av_larg_rua & + & + & Média & 0,40 \\
Av_Rua & + & + & Média & 0,53 \\
Seg_Terreno & + & Baixa & 0,71 \\
Av_Esp_Pub & + & + & Baixa & 0,83 \\
Av_Energia & + & + & Baixa & 0,90 \\
Av_Ilumina & + & Média & 0,56 \\
Dist_Tel & - & - & Média & 0,62 \\
Seg_Posse & + & + & Baixa & 0,67 \\
\hline
\end{tabular}

\subsubsection{Entorno}

Para as variáveis do Entorno, os resultados são apresentados na Tabela 47 e no Gráfico 16 e Gráfico 17.

Tabela 47: Entorno: Graus de possibilidade, incerteza, avaliação média e desvio padrão - Pesquisa Piloto

\begin{tabular}{|c|c|c|c|c|c|c|}
\hline \multirow{2}{*}{ Item } & \multicolumn{3}{|c|}{ Conceitos/Graus de possibilidade } & \multirow{2}{*}{ U-Incerteza } & \multirow{2}{*}{ Avaliação média } & \multirow{2}{*}{ Desvio padrão } \\
\hline & Péssimo/Ruim & Regular & Bom/Ótimo & & & \\
\hline Av_Lazer_Fora & 0,03 & 0,34 & 1,00 & 0,23 & 2,71 & 0,49 \\
\hline Dist_Ponto_Onibus & 0,83 & 0,61 & 1,00 & 0,76 & 2,07 & 0,86 \\
\hline
\end{tabular}

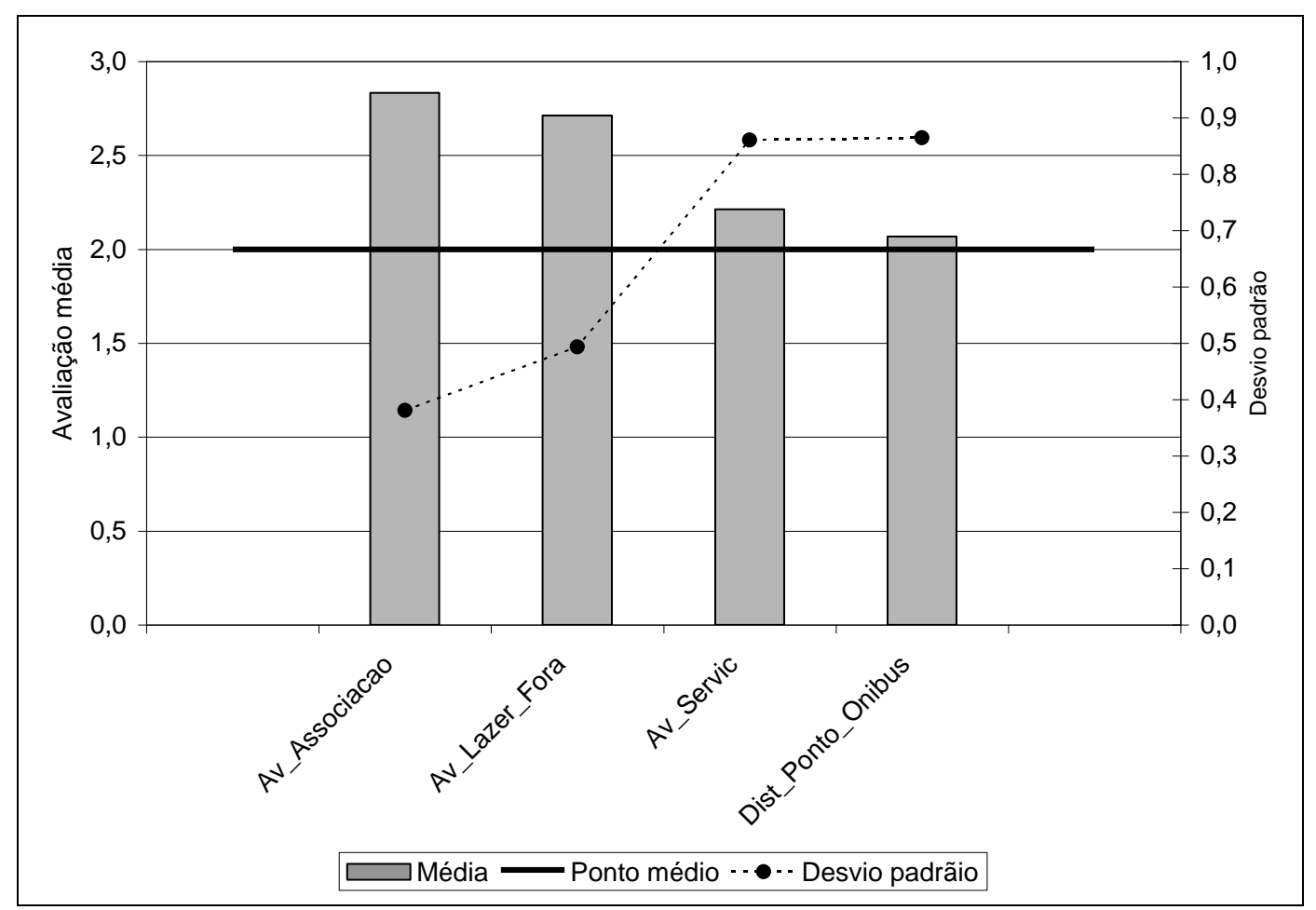

Gráfico 16: Entorno: médias e desvios-padrão - Pesquisa Piloto 


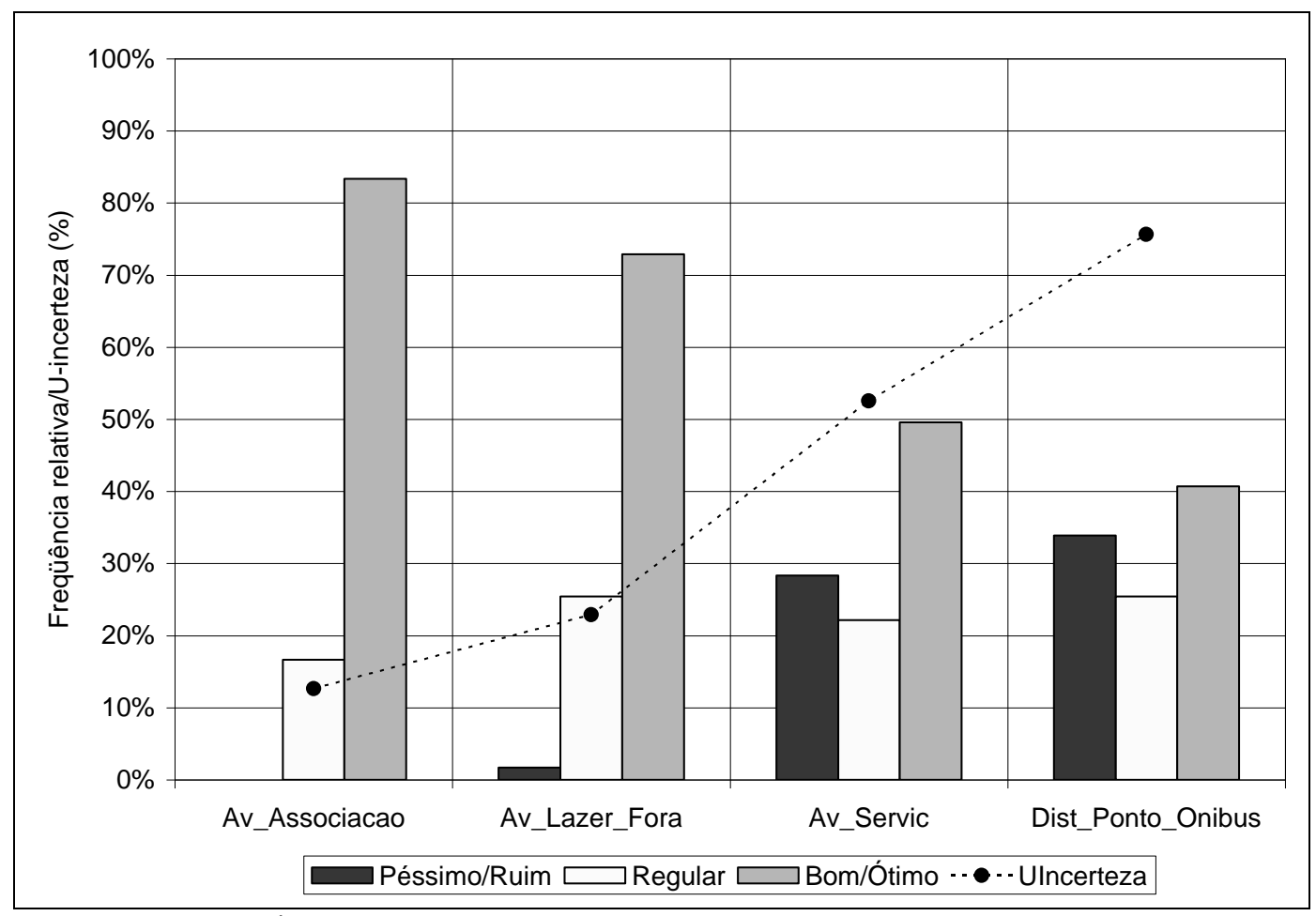

Gráfico 17: Entorno: Freqüências e U-Incerteza - Pesquisa Piloto

Neste caso, apenas o item distância do ponto de ônibus apresentou uma incerteza alta, cabe destacar que, como este item depende da localização da moradia do entrevistado, pode ser interessante uma análise georreferenciada (Tabela 48).

Tabela 48: Entorno: síntese dos pontos positivos e negativos - Pesquisa Piloto

\begin{tabular}{l|c|c|c|c}
\hline \multirow{2}{*}{\multicolumn{1}{c|}{ Item }} & Abordagem clássica & \multicolumn{3}{c}{ Abordagem fuzzy } \\
\cline { 2 - 5 } & Aspecto & Aspecto & Incerteza & Grau de verdade \\
\hline Av_Servic & + & + & Média & 0,47 \\
Av_Lazer_Fora & + & + & Baixa & 0,77 \\
Av_Associacao & + & + & Baixa & 0,87 \\
Dist_Ponto_Onibus & + & + & Alta & 0,24 \\
\hline
\end{tabular}

\subsubsection{Desdobramentos}

É notável que algumas variáveis apresentam uma medida de incerteza alta, o que significa que estas variáveis não possuem consenso e não podem ser consideradas como pontos positivos ou negativos verdadeiros. Esta falta de consenso pode estar relacionada a outras variáveis, por exemplo, as variáveis "Bocas de lobo e sarjetas" e "segurança contra inundação" indicam uma avaliação não consensual talvez relacionado a problemas locais de inundação.

Para reduzir as incertezas apresentadas por algumas variáveis uma análise complementar é necessária. Uma primeira análise foi realizada, separando os dados em categorias por tipo de 
moradia ( 1 - Construída pela Conder, 2 - Construída pela Conder e ampliada pelo morador, 3 - Autoconstruída e 4 - Comprada ou alugada de outros).

A Tabela 49 mostra que a separação em categorias não é suficiente para reduzir ou manter baixas as incertezas em cada categoria. Por exemplo, a avaliação das instalações de água permanece baixa em todas as categorias, exceto a categoria 1, que aumenta. Esta tabela mostra que, embora as incertezas não sejam reduzidas pela categorização, alguns grupos respondem diferentemente de outros.

Tabela 49: Abordagem fuzzy por categorias de moradia - Pesquisa Piloto

\begin{tabular}{|c|c|c|c|c|c|c|c|c|c|c|}
\hline \multirow{2}{*}{ Item } & \multicolumn{2}{|c|}{ Todos as categorias } & \multicolumn{2}{|c|}{ Categoria 1} & \multicolumn{2}{|c|}{ Categoria 2} & \multicolumn{2}{|c|}{ Categoria 3} & \multicolumn{2}{|c|}{ Categoria 4} \\
\hline & Aspecto & U-Incerteza (U) & Aspecto & $\mathbf{U}$ & Aspecto & $\mathbf{U}$ & Aspecto & $\mathbf{U}$ & Aspecto & $\mathbf{U}$ \\
\hline \multicolumn{11}{|c|}{ Moradia } \\
\hline$\overline{\text { Av_Inst_Agua }}$ & + & 0,24 & + & 0,55 & + & 0,19 & + & 0,21 & + & 0,08 \\
\hline Av_Inst_Esgoto & + & 0,20 & + & 0,39 & + & 0,15 & + & 0,17 & + & 0,18 \\
\hline Av_Inst_Eletrica & + & 0,54 & + & 0,68 & + & 0,38 & + & 0,57 & + & 0,33 \\
\hline Av_Quartos & - & 0,55 & - & 0,14 & - & 0,60 & + & 0,70 & - & 0,61 \\
\hline Av_Tam_Casa & - & 0,63 & - & 0,16 & + & 0,68 & + & 0,72 & - & 0,61 \\
\hline Av_Telhado & - & 0,86 & - & 0,43 & + & 0,72 & + & 0,81 & - & 0,52 \\
\hline Av_Paredes & + & 0,50 & - & 0,69 & + & 0,17 & + & 0,55 & + & 0,45 \\
\hline Av_Piso & + & 0,69 & - & 0,65 & + & 0,37 & + & 0,78 & + & 0,26 \\
\hline Av_Ventila & + & 0,51 & + & 0,24 & + & 0,37 & $+/-$ & 0,74 & - & 0,77 \\
\hline \multicolumn{11}{|c|}{ Salubridade ambiental } \\
\hline Av_Abast_Agua & + & 0,30 & + & 0,17 & + & 0,26 & + & 0,44 & + & 0,26 \\
\hline Av_Esgoto & - & 0,79 & + & 0,65 & + & 0,55 & - & 0,68 & - & 0,05 \\
\hline Av_Coleta_Lixo & + & 0,28 & + & 0,50 & + & 0,10 & + & 0,25 & $+/-$ & 0,82 \\
\hline Av_Varrição & + & 0,50 & + & 0,36 & + & 0,31 & + & 0,51 & - & 0,14 \\
\hline Av_Boc_Sarj & - & 0,39 & - & 0,61 & - & 0,64 & - & 0,38 & - & 0,05 \\
\hline Seg_Inund & - & 0,59 & + & 0,50 & + & 0,55 & - & 0,50 & - & 0,21 \\
\hline Av_larg_rua & + & 0,60 & + & 0,47 & + & 0,37 & + & 0,60 & - & 0,15 \\
\hline Av_Rua & + & 0,47 & + & 0,27 & + & 0,43 & + & 0,44 & - & 0,14 \\
\hline Seg_Terreno & + & 0,29 & + & 0,39 & + & 0,19 & + & 0,23 & - & 0,52 \\
\hline Av_Esp_Pub & + & 0,17 & + & 0,10 & + & 0,24 & + & 0,21 & + & 0,10 \\
\hline Av_Energia & + & 0,10 & + & 0,05 & + & 0,17 & + & 0,10 & + & 0,08 \\
\hline Av_Ilumina & + & 0,44 & + & 0,30 & + & 0,37 & + & 0,54 & - & 0,61 \\
\hline Dist_Tel & - & 0,38 & - & 0,74 & - & 0,47 & - & 0,33 & - & 0,14 \\
\hline Seg_Posse & + & 0,33 & - & 0,35 & + & 0,26 & + & 0,23 & + & 0,10 \\
\hline \multicolumn{11}{|c|}{ Entorno } \\
\hline$\overline{A v \_S e r v i c}$ & + & 0,53 & + & 0,16 & + & 0,69 & + & 0,59 & - & 0,82 \\
\hline Av_Lazer_Fora & + & 0,23 & + & 0,16 & + & 0,08 & + & 0,46 & + & 0,00 \\
\hline Av_Associacao & + & 0,13 & + & 0,00 & + & 0,11 & + & 0,21 & + & 0,21 \\
\hline Dist_Ponto_Onibus & + & 0,76 & + & 0,72 & + & 0,46 & + & 0,59 & - & 0,21 \\
\hline
\end{tabular}

É possível observar que em termos de moradia: (i) todas categorias avaliam as instalações de água, esgoto e elétricas como pontos positivos, embora as instalações apresentem níveis diferentes de incertezas; as categorias 2 e 3 são similares nas avaliações das condições de moradia; (iii) a ventilação é um ponto positivo no tipo 1 com baixa incerteza, diferentemente dos outros; em temos de Salubridade ambiental: (iv) abastecimento de água, energia elétrica e espaços públicos são pontos positivos em todas as categorias; (v) bocas de lobo e sarjetas e distância do telefone público são pontos negativos em todas as categorias; (vi) moradias nas categorias 1 e 2 exibem os mesmos pontos positivos e negativos exceto pela segurança na posse do terreno; (vii) a categoria 4 apresenta as piores avaliações - com exceção da 
abastecimento de água, espaços públicos, energia elétrica e segurança na posse do terreno, as demais variáveis são consideradas pontos negativos e; em termos de Entorno (viii) a categoria 4 é a única que apresenta pontos negativos - serviços públicos e distância do ponto de ônibus. Após esta análise, uma outra análise exaustiva foi realizada procurando entender as altas medidas de incerteza mantidas por algumas variáveis.

Quadro 19: Abordagem fuzzy: resultados finais - Pesquisa Piloto

\begin{tabular}{|c|c|c|c|c|}
\hline Item & $\begin{array}{c}\text { Avaliação } \\
\text { geral }\end{array}$ & \begin{tabular}{|c|} 
U-Incerteza \\
geral
\end{tabular} & $\begin{array}{l}\text { Nível de } \\
\text { incerteza }\end{array}$ & Principais conclusões \\
\hline \multicolumn{5}{|r|}{ Moradia } \\
\hline Av_Inst_Agua & + & 0,24 & Baixa & $t$ \\
\hline Av_Inst_Esgoto & + & 0,20 & Baixa & + \\
\hline $\mathrm{Av} \_$Inst_Eletrica & + & 0,54 & Média & $\begin{array}{l}\text { Somente o grupo de instalações elétricas embutidas apresenta baixa incerteza (+, } \\
\mathrm{U}=0,08)\end{array}$ \\
\hline Av_Quartos & - & 0,55 & Média & $\begin{array}{l}\text { Existem dois grupos distintos: moradia que não utilizam outro cômodo como quarto } \\
(+, \mathrm{U}=0,43) \text { e aquelas que utilizam outros cômodos como quarto }(-, \mathrm{U}=0,11)\end{array}$ \\
\hline Av_Tam_Casa & - & 0,63 & Média & $\begin{array}{l}\text { Existem dois grupos distintos: moradia que não utilizam outro cômodo como quarto } \\
(+, \mathrm{U}=0,41) \text { e aquelas que utilizam outros cômodos como quarto }(-, \mathrm{U}=0,21)\end{array}$ \\
\hline Av_Telhado & - & 0,86 & Alta & $\begin{array}{l}\text { Existem dois grupos distintos: moradias sem problemas no telhado durante o } \\
\text { período de chuva }(+, U=0,26) \text { e aquelas com problemas no telhado durante o } \\
\text { período de chuva }(-, U=0,40)\end{array}$ \\
\hline Av_Paredes & + & 0,50 & Média & $\begin{array}{l}\text { Existem grupos de material: Tijolos furados }(+, \mathrm{U}=0,46) \text {, Tijolos de concreto }(+, \\
\mathrm{U}=0,35) \text {. Outros materiais }(-, \mathrm{U}=0,07) \\
\text { Existem também grupos de revestimentos interno: com revestimento }(+, \mathrm{U}=0,14) \text { e } \\
\text { sem revestimento }(-, \mathrm{U}=0,36)\end{array}$ \\
\hline Av_Piso & + & 0,69 & Alta & Somente o grupo com piso cerâmico apresenta baixa incerteza $(+, \mathrm{U}=0,14)$ \\
\hline Av_Ventila & + & 0,51 & Média & $\begin{array}{l}\text { O grupo de moradia com aberturas em todos os cômodos apresenta baixa incerteza } \\
(+, \mathrm{U}=0,16) \text { e o grupo com aberturas em apenas alguns cômodos apresenta incerteza } \\
\text { intermediária }(-, \mathrm{U}=0,64) \text {. }\end{array}$ \\
\hline \multicolumn{5}{|r|}{ Salubridade ambiental } \\
\hline Av_Abast_Agua & + & 0,30 & Baixa & - \\
\hline Av_Esgoto & - & 0,79 & Alta & Com as informações disponíveis não foi possível reduzir as incertezas. \\
\hline Av_Coleta_Lixo & + & 0,28 & Baixa & - \\
\hline Av_Varricao & + & 0,50 & Média & $\begin{array}{l}\text { Existem dois grupos distintos: ruas com serviço público de varrição }(+, \mathrm{U}=0,28) \text { e } \\
\text { ruas varridas pelo próprio morador }(-, \mathrm{U}=0,31)\end{array}$ \\
\hline Av_Boc_Sarj & - & 0,39 & Média & $\begin{array}{l}\text { Os tipos } 1 \text { e } 2 \text { exibem altos valores de incerteza e os tipos } 3 \text { e } 4 \text { baixo. } \\
\text { Onde ocorre inundação na casa (-, U=0,06) e onde ocorre inundação na rua (- } \\
\text { U=0,11). As outras situações apresentam alta incerteza. }\end{array}$ \\
\hline Seg_Inund & - & 0,59 & Média & $\begin{array}{l}\text { Os tipos } 1 \text { e } 2 \text { exibem altos valores de incerteza e os tipos } 3 \text { e } 4 \text { baixo. } \\
\text { Onde ocorre inundação na casa (-, U=0,14) e onde ocorre inundação na rua (-, } \\
\text { U=0,26). AS outras situações apresentam alta incerteza. }\end{array}$ \\
\hline Av_larg_rua & + & 0,60 & Média & $\begin{array}{l}\text { Ruas com largura acima de } 6,00 \mathrm{~m}(+, \mathrm{U}=0,13) \\
\text { Com largura entre } 3,60 \mathrm{~m} \text { e } 6,00 \mathrm{~m}(+, \mathrm{U}=0,16) \\
\text { Com largura entre } 1,20 \mathrm{~m} \text { e } 3,60 \mathrm{~m} \text { (Não há consenso, } \mathrm{U}=0,89) \\
\text { Com largura abaixo de } 1,20 \mathrm{~m}(-\mathrm{U}=0,29)\end{array}$ \\
\hline Av_Rua & + & 0,47 & Média & $\begin{array}{l}\text { Ruas com largura acima de } 6,00 \mathrm{~m}(+, \mathrm{U}=0,06) \\
\text { Com largura entre } 3,60 \mathrm{~m} \text { e } 6,00 \mathrm{~m}(+, \mathrm{U}=0,32) \\
\text { Com largura entre } 1,20 \mathrm{~m} \text { e } 3,60 \mathrm{~m}(+, \mathrm{U}=0,57) \\
\text { Com largura abaixo de } 1,20 \mathrm{~m}(-, \mathrm{U}=0,50)\end{array}$ \\
\hline Seg_Terreno & + & 0,29 & Baixa & - \\
\hline Av_Esp_Pub & + & 0,17 & Baixa & - \\
\hline $\mathrm{Av} \_$Energia & + & 0,10 & Baixa & - \\
\hline $\mathrm{Av} \_$Ilumina & + & 0,44 & Média & $\begin{array}{l}\text { Existem dois grupos: com serviço público }(+, \mathrm{U}=0,38) \text { e sem serviço público (-, } \\
\mathrm{U}=0,11)\end{array}$ \\
\hline Dist_Tel & - & 0,38 & Média & Com as informações disponíveis não foi possível reduzir as incertezas. \\
\hline Seg_Posse & + & 0,33 & Baixa & Somente o tipo 1 considera como ponto fraco \\
\hline \multicolumn{5}{|r|}{ Entorno } \\
\hline Av_Servic & + & 0,53 & Média & $\begin{array}{l}\text { Agrupando por serviço temos: escola }(+, \mathrm{U}=0,38) \text {, posto de saúde }(+, \mathrm{U}=0,44) \text { e } \\
\text { creche }(+, \mathrm{U}=0,18)\end{array}$ \\
\hline Av_Lazer_Fora & + & 0,23 & Baixa & - \\
\hline Av_Associacao & + & 0,13 & Baixa & - \\
\hline Dist_Ponto_Onibus & + & 0,76 & Alta & Com as informações disponíveis não foi possível reduzir as incertezas. \\
\hline
\end{tabular}


Esta análise foi realizada separando por grupos baseados em alguma característica objetiva. Por exemplo, além do tipo de moradia, a avaliação do telhado pode ser categorizada pelos materiais utilizados, ou se as moradias exibem problemas ou não de infiltração durante os períodos de chuva. O Quadro 19 resume os resultados finais encontrados.

\subsubsection{Considerações finais sobre a utilização de medidas de incerteza}

As medidas de incerteza possuem algumas vantagens em relação às medidas clássicas utilizadas. Podemos destacar: a independência da escala utilizada, onde podemos trabalhar desde a escala nominal até a escala de razões, sem necessidade de suposições ou adequações; a medida resultante pode ser normalizada facilmente, pois os intervalos de variação são bem definidos, proporcionando assim uma leitura uniforme e de fácil comparação. Por fim, estas medidas contribuem no sentido de agregar mais informação nas conclusões obtidas a partir de uma APO, uma vez que se obtém, além do conceito predominante, o seu grau de verdade.

\subsection{AGREGAÇÃO}

\subsubsection{Indicadores qualitativos}

\subsubsection{Utilizando o método das equações relacionais fuzzy}

Neste método o objetivo é estabelecer uma matriz de relação fuzzy entre as avaliações parciais (por exemplo: instalações, tamanho, materiais, conforto da casa) e a avaliação final de forma que, dada uma nova avaliação parcial possamos pré-dizer qual a distribuição de possibilidades das avaliações finais, por meio da composição da nova avaliação parcial com a matriz de relações obtida.

Para dados qualitativos, este método é interessante, uma vez que estabelece um mecanismo que se aproxima da opinião do morador. Com a obtenção matriz de relação entre avaliações parciais e finais podemos, para uma avaliação parcial coletiva (freqüências relativas totais em cada avaliação parcial), obter a avaliação final coletiva mais próxima da opinião do morador. 
Neste método a regra de composição das matrizes desempenha um papel muito importante. Como visto na Seção 5.12.2, há uma variedade de composições possíveis. Adotaremos as duas mais comuns utilizadas na literatura para esta primeira análise, são a max-min e a maxproduto.

O procedimento de cálculo então segue como descrito. Primeiro agrupamos os formulários por avaliação final desejada e calculamos as frequiências de cada avaliação parcial por grupo de avaliação e procedemos a normalização. Por exemplo, na Tabela 50 o elemento na linha Péssimo/Ruim e coluna Regular, 19\%, resulta do fato de que, entre aqueles que afirmaram que a avaliação final da casa era Regular, 19\% consideram as instalações de água Péssimo/Ruim. O agrupamento em três classes segue o mesmo raciocínio da seção anterior.

Tabela 50: Agrupamento da variável instalações de água por avaliação final da casa - Pesquisa Piloto

\begin{tabular}{l|ccc|c|c|c}
\hline \multirow{2}{*}{ Conceitos } & \multicolumn{3}{|c|}{ Grupos (Avaliação final) } & \multicolumn{3}{c}{ Grupos (Avaliação final) - fuzzificados } \\
\cline { 2 - 7 } & Péssimo/Ruim & Regular & Ótimo/Bom & Péssimo/Ruim & Regular & Ótimo/Bom \\
\hline Péssimo/Ruim & $12 \%$ & $19 \%$ & $8 \%$ & 0,63 & 1,00 & 0,42 \\
Regular & $23 \%$ & $38 \%$ & $8 \%$ & 0,61 & 1,00 & 0,21 \\
Ótimo/Bom & $65 \%$ & $44 \%$ & $83 \%$ & 0,78 & 0,53 & 1,00 \\
\hline
\end{tabular}

Calculada a matriz de avaliações parciais, a equação relacional a ser resolvida fica então determinada da seguinte forma: $A v_{-}$Parcial $\circ R=A v_{-}$Final, ou seja: "Se Avaliação parcial é ... então Avaliação final é...”. A questão que resta definir é qual é a matriz de avaliação final, ou de saída.

Em um modelo clássico a matriz de saída para esses grupos poderia ser dada por uma matriz cuja diagonal seria igual a " 1 " e os demais elementos seriam " 0 ", porém, estaríamos diante de uma solução muito exigente, de forma que podemos supor que a avaliação final possui uma vagueza e que existe uma possibilidade menor da avaliação ser outra que não aquela definida pelo morador. Poderíamos então definir essas saídas como na Tabela 51.

Tabela 51: Moradia: exemplo avaliações finais para o modelo de equações relacionais fuzzy

\begin{tabular}{|c|c|c|c|c|}
\hline & \multicolumn{3}{|c|}{ Avaliação final } \\
\hline & & Péssimo/Ruim & Regular & Bom/Ótimo \\
\hline \multirow{3}{*}{ Grupos } & Péssimo/Ruim & 1,00 & 0,50 & 0,00 \\
\hline & Regular & 0,00 & 1,00 & 0,00 \\
\hline & Bom/Ótimo & 0,00 & 0,50 & 1,00 \\
\hline
\end{tabular}


Então para resolvermos a equação relacional, utilizando a composição max-min, os teoremas existentes na literatura sobre Lógica Fuzzy garantem que haverá solução, se e somente se, a composição dada pela implicação Gödel for solução da equação (KLIR; YUAN, 1995). Portanto, devemos calcular a composição e verificar se ela recupera os dados originais; caso isto ocorra, existe solução e a máxima será a calculada pela composição com a implicação de Gödel.

Porém, nem sempre haverá solução para o nosso problema, mas, com pequenas adaptações nos conjuntos de avaliação final, podemos obter uma solução; é o que chamamos de solução aproximada. O problema consiste então em construir os conjuntos de avaliação final, de tal forma que nos forneça uma solução aceitável.

Notamos que teremos uma solução, construindo os subconjuntos de avaliação final fuzzy selecionando na matriz transposta de entrada um subconjunto em cada avaliação parcial que mais se aproxime de um subconjunto fuzzy idealizado para a avaliação final e transpondo-o na avaliação final. Com isso basta definirmos o que é um subconjunto fuzzy de avaliação final idealizado. Para o nosso caso adotaremos como ideais, subconjuntos fuzzy triangulares como os mostrados na Tabela 51.

Elaboramos, então, dois critérios para construção da avaliação final: um pela menor soma das pertinências (MSP) e o outro, pela menor distância ao fuzzy ideal (MDI). A adoção destes procedimentos busca interferir o mínimo possível nos resultados obtidos.

No método MSP por exemplo, para a avaliação final "Péssimo/Ruim" selecionamos o subconjunto fuzzy da matriz de avaliação parcial (coluna) dentre aqueles que possuem grau de pertinência "1" no grupo "Péssimo/Ruim" aquele cuja soma das pertinências seja a menor, de forma semelhante selecionamos os subconjuntos para as avaliações "Regular" e "Bom/Ótimo". Já no método MDI, no lugar de minimizarmos a soma das pertinências, minimizamos a distância ao subjconjunto fuzzy considerado ideal (Tabela 51).

Para verificar a adequação destes procedimentos utilizaremos as avaliações parciais do formulários de cada domicílio e a matriz de relação avaliação parcial x avaliação final para obter a avaliação final calculada pelo método e a compararemos com a avaliação final atribuída pelo morador. Calcularemos então percentual de acertos como um indicador de desempenho do método. Os resultados obtidos são analisados e discutidos a seguir. 


\subsection{Moradia}

Para as variáveis de moradia já descritas anteriormente temos as seguintes matrizes de avaliações parciais e finais apresentadas na Tabela 52 e na Tabela 53. Ressaltamos que a matriz de saída ideal não forneceu solução para a equação; daí optamos pelas matrizes apresentadas. A matriz de relação obtida é apresentada na Tabela 54.

Atenção especial deve ser dada às variáveis cujo valor na matriz de relação sejam próximo de “1,0”, pois são eles que mais interferem na avaliação final.

Podemos destacar nas matrizes de relação para MDI que os elementos: instalações de água, instalações de esgoto e material das paredes Péssimo/Ruim possuem total relação com a avaliação final Péssimo/Ruim. Já a avaliação da ventilação Regular tem total relação com a avaliação final Regular e o telhado da casa Bom/Ótimo tem total relação com a avaliação final Bom/Ótimo. Estes seriam os fatores determinantes para cada avaliação final. De forma semelhante também podemos analisar os dados com MSP.

Cabe salientar que esta é a solução maximal, ou seja, existem outras possíveis soluções para a equação dada, porém admitimos que a solução com as maiores possibilidades (relações) é a que nos interessa neste momento.

Tabela 52: Moradia: matriz de avaliações parciais para equações relacionais fuzzy - Pesquisa Piloto

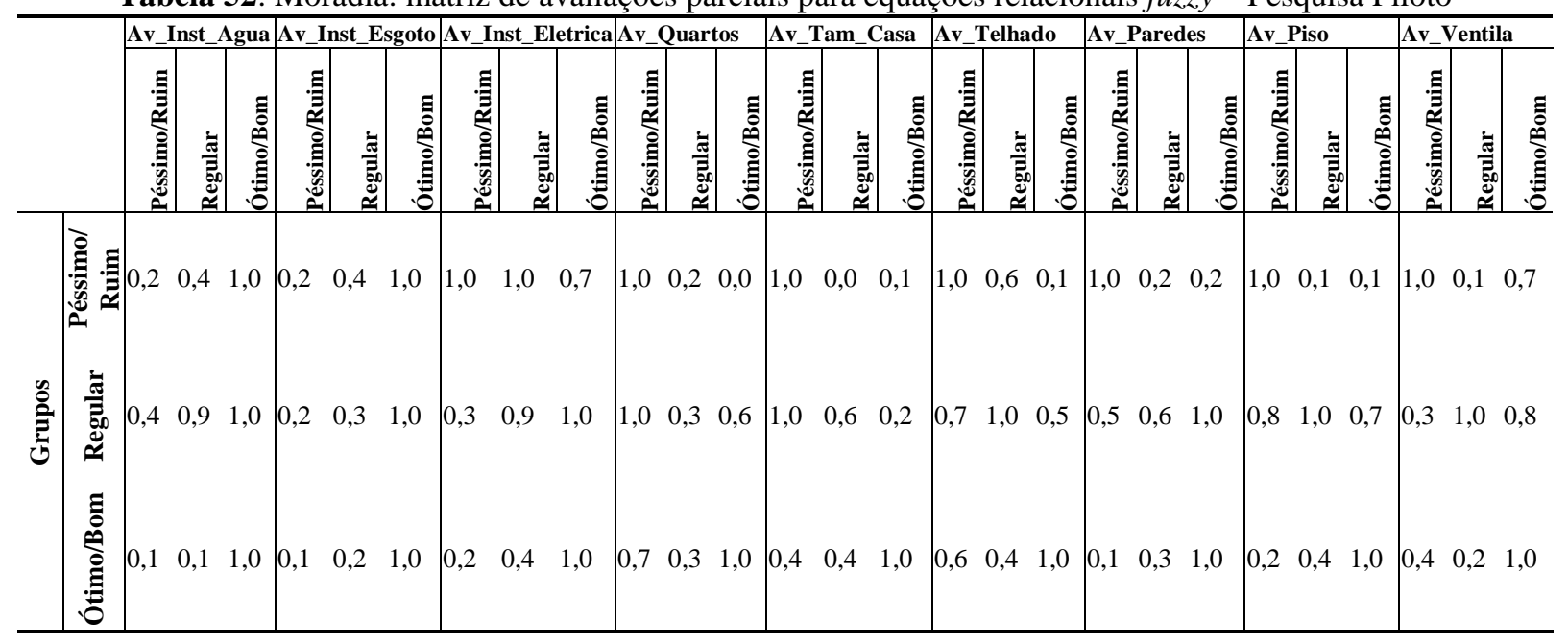


Tabela 53: Moradia: matrizes de avaliação final - menor distância ao ideal (MDI) e menor soma das pertinências (MSP) - Pesquisa Piloto

\begin{tabular}{|c|c|c|c|c|c|c|c|}
\hline & & \multicolumn{3}{|c|}{ Avaliação final - MDI } & \multicolumn{3}{|c|}{ Avaliação final - MSP } \\
\hline & & Péssimo/Ruim & Regular & Ótimo/Bom & Péssimo/Ruim & Regular & Ótimo/Bom \\
\hline \multirow{3}{*}{$\stackrel{\mathscr{E}}{Z}$} & Péssimo/Ruim & 1,0 & 0,1 & 0,1 & 1,0 & 0,1 & 0,1 \\
\hline & Regular & 0,5 & 1,0 & 0,5 & 0,3 & 1,0 & 0,2 \\
\hline & Ótimo/Bom & 0,1 & 0,2 & 1,0 & 0,2 & 0,2 & 1,0 \\
\hline
\end{tabular}

Tabela 54: Moradia: matrizes de relação com MDI e MSP e composição max-min - Pesquisa Piloto

\begin{tabular}{|c|c|c|c|c|c|c|c|}
\hline \multirow{2}{*}{\multicolumn{2}{|c|}{ Avaliação parcial }} & \multicolumn{3}{|c|}{ Avaliação final - MDI } & \multicolumn{3}{|c|}{ Avaliação final - MSP } \\
\hline & & \multirow{2}{*}{$\begin{array}{c}\text { Péssimo/Ruim } \\
1,0\end{array}$} & \multirow{2}{*}{\begin{tabular}{|c|} 
Regular \\
0,1
\end{tabular}} & \multirow{2}{*}{$\begin{array}{c}\text { Bom/Ótimo } \\
0,1\end{array}$} & \multirow{2}{*}{$\frac{\text { Péssimo/Ruim }}{0,3}$} & \multirow{2}{*}{$\frac{\text { Regular }}{0,1}$} & \multirow{2}{*}{$\begin{array}{c}\text { Bom/Ótimo } \\
0,1\end{array}$} \\
\hline \multirow{3}{*}{ Av_Inst_Agua } & Péssimo/Ruim & & & & & & \\
\hline & Regular & 0,5 & 0,1 & 0,1 & 0,3 & 0,1 & 0,1 \\
\hline & Bom/Ótimo & 0,1 & 0,1 & 0,1 & 0,2 & 0,1 & 0,1 \\
\hline \multirow{3}{*}{ Av_Inst_Esgoto } & Péssimo/Ruim & 1,0 & 0,1 & 0,1 & 1,0 & 0,1 & 0,1 \\
\hline & Regular & 0,1 & 0,1 & 0,1 & 0,2 & 0,1 & 0,1 \\
\hline & Bom/Ótimo & 0,1 & 0,1 & 0,1 & 0,2 & 0,1 & 0,1 \\
\hline \multirow{3}{*}{ Av_Inst_Eletrica } & Péssimo/Ruim & 0,1 & 0,1 & 0,1 & 1,0 & 0,1 & 0,1 \\
\hline & Regular & 0,1 & 0,1 & 0,1 & 0,2 & 0,1 & 0,1 \\
\hline & Bom/Ótimo & 0,1 & 0,1 & 0,1 & 0,2 & 0,1 & 0,1 \\
\hline \multirow{3}{*}{ Av_Quartos } & Péssimo/Ruim & 0,1 & 0,1 & 0,1 & 0,2 & 0,1 & 0,1 \\
\hline & Regular & 0,1 & 0,1 & 0,1 & 0,2 & 0,1 & 0,1 \\
\hline & Bom/Ótimo & 0,1 & 0,2 & 0,5 & 0,2 & 0,2 & 0,2 \\
\hline \multirow{3}{*}{ Av_Tam_Casa } & Péssimo/Ruim & 0,1 & 0,1 & 0,1 & 0,2 & 0,1 & 0,1 \\
\hline & Regular & 0,1 & 0,2 & 0,5 & 0,2 & 0,2 & 0,2 \\
\hline & Bom/Ótimo & 0,1 & 0,1 & 0,1 & 0,2 & 0,1 & 1,0 \\
\hline \multirow{3}{*}{ Av_Telhado } & Péssimo/Ruim & 0,1 & 0,1 & 0,1 & 0,2 & 0,1 & 0,1 \\
\hline & Regular & 0,1 & 0,1 & 0,1 & 0,2 & 0,1 & 0,1 \\
\hline & Bom/Ótimo & 0,1 & 0,2 & 1,0 & 0,2 & 0,2 & 0,2 \\
\hline \multirow{3}{*}{ Av_Paredes } & Péssimo/Ruim & 1,0 & 0,1 & 0,1 & 0,3 & 0,1 & 0,1 \\
\hline & Regular & 0,1 & 0,1 & 0,1 & 0,2 & 0,1 & 0,1 \\
\hline & Bom/Ótimo & 0,1 & 0,1 & 0,1 & 0,2 & 0,1 & 0,1 \\
\hline \multirow{3}{*}{ Av_Piso } & Péssimo/Ruim & 0,1 & 0,1 & 0,1 & 0,2 & 0,1 & 0,1 \\
\hline & Regular & 0,1 & 0,1 & 0,1 & 0,2 & 0,1 & 0,1 \\
\hline & Bom/Ótimo & 0,1 & 0,1 & 0,1 & 0,2 & 0,1 & 0,1 \\
\hline \multirow{3}{*}{ Av_Ventila } & Péssimo/Ruim & 0,1 & 0,1 & 0,1 & 0,2 & 0,1 & 0,1 \\
\hline & Regular & 0,1 & 1,0 & 0,1 & 0,2 & 1,0 & 0,2 \\
\hline & Bom/Ótimo & 0,1 & 0,1 & 0,1 & 0,2 & 0,1 & 0,1 \\
\hline
\end{tabular}

Como afirmamos anteriormente, pode ser feita uma variação nas regras de composição; então, realizamos testes com algumas delas e verificamos a porcentagem de acerto nas avaliações finais. Os resultados são mostrados na Tabela 55. Verificamos que para as variáveis de moradia o melhor resultado em relação ao erros foi obtido com o MSP e a composição maxmin, já apresentada anteriormente. Já tomando-se como referência os acertos absolutos, a composição max-produto com a construção pelo MSP obteve melhores resultados.

Tabela 55: Moradia: percentual de acertos por construção da avaliação final e regra de composição - Pesquisa Piloto

\begin{tabular}{l|c|c|c|c}
\hline Construção da avaliação final & Acertos & Empates & Empates com possibilidade de acerto & Erros \\
\hline \multicolumn{7}{|c}{ max-min } \\
\hline MDI & $54 \%$ & $11 \%$ & $10 \%$ & $36 \%$ \\
MSP & $56 \%$ & $13 \%$ & $13 \%$ & $31 \%$ \\
\hline \multicolumn{7}{|c|}{$\max$-produto } \\
MSP & $58 \%$ & $11 \%$ & $10 \%$ & $33 \%$ \\
\hline
\end{tabular}




\subsection{Salubridade ambiental}

Admitimos aqui que a avaliação do bairro pode ser utilizada como avaliação final da salubridade ambiental. Esta suposição foi feita pela ausência da variável relacionada às condições ambientais da área recuperada que se deu devido ao fato de não termos, na época da coleta de dados, definido todo o método de análise. Neste caso, na fase de validação deverão ser inseridas novas questões no formulário relativas à salubridade e ao entorno.

Na Tabela 56 apresentamos a matriz de relação das avaliações parciais com a avaliação do bairro como uma aproximação da salubridade ambiental da área. A partir deste trecho do relatório, dado os tamanhos das matrizes de relação, elas serão apresentadas sempre que necessário em sua forma transposta.

Tabela 56: Salubridade ambiental: matriz de avaliações parciais transposta - Pesquisa Piloto

\begin{tabular}{|c|c|c|c|c|}
\hline \multirow{2}{*}{\multicolumn{2}{|c|}{ Avaliação parcial }} & \multicolumn{3}{|c|}{ Grupos } \\
\hline & & \multirow{2}{*}{$\begin{array}{c}\text { Péssimo/Ruim } \\
0,0\end{array}$} & \multirow{2}{*}{$\begin{array}{c}\text { Regular } \\
0,3\end{array}$} & \multirow{2}{*}{$\frac{\text { Ótimo/Bom }}{0,1}$} \\
\hline \multirow{3}{*}{ Av_Abast_Agua } & Péssimo/Ruim & & & \\
\hline & Regular & 0,5 & 0,8 & 0,3 \\
\hline & ótimo/Bom & 1,0 & 1,0 & 1,0 \\
\hline \multirow{3}{*}{ Av_Esgoto } & Péssimo/Ruim & 1,0 & 1,0 & 0,8 \\
\hline & Regular & 0,0 & 0,2 & 0,7 \\
\hline & Ótimo/Bom & 1,0 & 0,1 & 1,0 \\
\hline \multirow{3}{*}{ Av_Coleta_Lixo } & Péssimo/Ruim & 0,5 & 0,5 & 0,1 \\
\hline & Regular & 0,0 & 0,3 & 0,4 \\
\hline & Ótimo/Bom & 1,0 & 1,0 & 1,0 \\
\hline \multirow{3}{*}{ Av_Varricao } & Péssimo/Ruim & 1,0 & 1,0 & 0,5 \\
\hline & Regular & 0,0 & 0,5 & 0,3 \\
\hline & Ótimo/Bom & 1,0 & 0,8 & 1,0 \\
\hline \multirow{3}{*}{ Av_Boc_Sarj } & Péssimo/Ruim & 1,0 & 1,0 & 1,0 \\
\hline & Regular & 0,0 & 0,3 & 0,5 \\
\hline & Ótimo/Bom & 0,5 & 0,2 & 0,4 \\
\hline \multirow{3}{*}{ Seg_Inund } & Péssimo/Ruim & 1,0 & 1,0 & 0,9 \\
\hline & Regular & 0,3 & 0,1 & 0,1 \\
\hline & Ótimo/Bom & 0,7 & 0,2 & 1,0 \\
\hline \multirow{3}{*}{ Av_larg_rua } & Péssimo/Ruim & 1,0 & 1,0 & 0,5 \\
\hline & Regular & 0,0 & 0,1 & 0,4 \\
\hline & Ótimo/Bom & 0,2 & 0,4 & 1,0 \\
\hline \multirow{3}{*}{ Av_Rua } & Péssimo/Ruim & 1,0 & 1,0 & 0,2 \\
\hline & Regular & 0,0 & 0,7 & 0,4 \\
\hline & Ótimo/Bom & 0,2 & 0,4 & 1,0 \\
\hline \multirow{3}{*}{ Seg_Terreno } & Péssimo/Ruim & 0,3 & 0,5 & 0,3 \\
\hline & Regular & 0,3 & 0,1 & 0,2 \\
\hline & Ótimo/Bom & 1,0 & 1,0 & 1,0 \\
\hline \multirow{3}{*}{ Av_Esp_Pub } & Péssimo/Ruim & 0,3 & 0,2 & 0,1 \\
\hline & Regular & 0,7 & 0,3 & 0,2 \\
\hline & Ótimo/Bom & 1,0 & 1,0 & 1,0 \\
\hline \multirow{3}{*}{ Av_Energia } & Péssimo/Ruim & 0,0 & 0,2 & 0,1 \\
\hline & Regular & 0,2 & 0,1 & 0,1 \\
\hline & Ótimo/Bom & 1,0 & 1,0 & 1,0 \\
\hline \multirow{3}{*}{ Av_Ilumina } & Péssimo/Ruim & 1,0 & 0,9 & 0,3 \\
\hline & Regular & 0,0 & 1,0 & 0,4 \\
\hline & Ótimo/Bom & 0,2 & 0,9 & 1,0 \\
\hline \multirow{3}{*}{ Dist_Tel } & Péssimo/Ruim & 1,0 & 1,0 & 1,0 \\
\hline & Regular & 0,2 & 0,0 & 0,4 \\
\hline & Ótimo/Bom & 0,0 & 0,4 & 0,5 \\
\hline \multirow{3}{*}{ Seg_Posse } & Péssimo/Ruim & 0,3 & 0,1 & 0,6 \\
\hline & Regular & 0,3 & 0,2 & 0,1 \\
\hline & Ótimo/Bom & 1,0 & 1,0 & 1,0 \\
\hline
\end{tabular}


Note na Tabela 57 que as matrizes são iguais, logo os resultados produzidos também serão os mesmos.

Tabela 57: Salubridade ambiental: matrizes de avaliação final - Pesquisa Piloto

\begin{tabular}{c|l|ccc|cc|c}
\hline \multicolumn{2}{c|}{} & \multicolumn{3}{c|}{ Avaliação final - MDI } & \multicolumn{3}{c}{ Avaliação final - MSP } \\
\cline { 3 - 8 } \multicolumn{2}{c|}{} & Péssimo/Ruim & Regular & Ótimo/Bom & Péssimo/Ruim & Regular & Ótimo/Bom \\
\hline \multirow{3}{*}{} & Péssimo/Ruim & 1,0 & 0,0 & 0,2 & 1,0 & 0,0 & 0,2 \\
\cline { 2 - 7 } & Regular & 0,9 & 1,0 & 0,4 & 0,9 & 1,0 & 0,4 \\
\cline { 3 - 7 } & Ótimo/Bom & 0,3 & 0,4 & 1,0 & 0,3 & 0,4 & 1,0 \\
\hline
\end{tabular}

Na Tabela 58 estão os resultados das matrizes de relação entre as avaliações parciais e finais com os diferentes métodos de construção de avaliação final.

Tabela 58: Salubridade ambiental: matriz de relação com MDI e MSP e composição max-min - Pesquisa Piloto

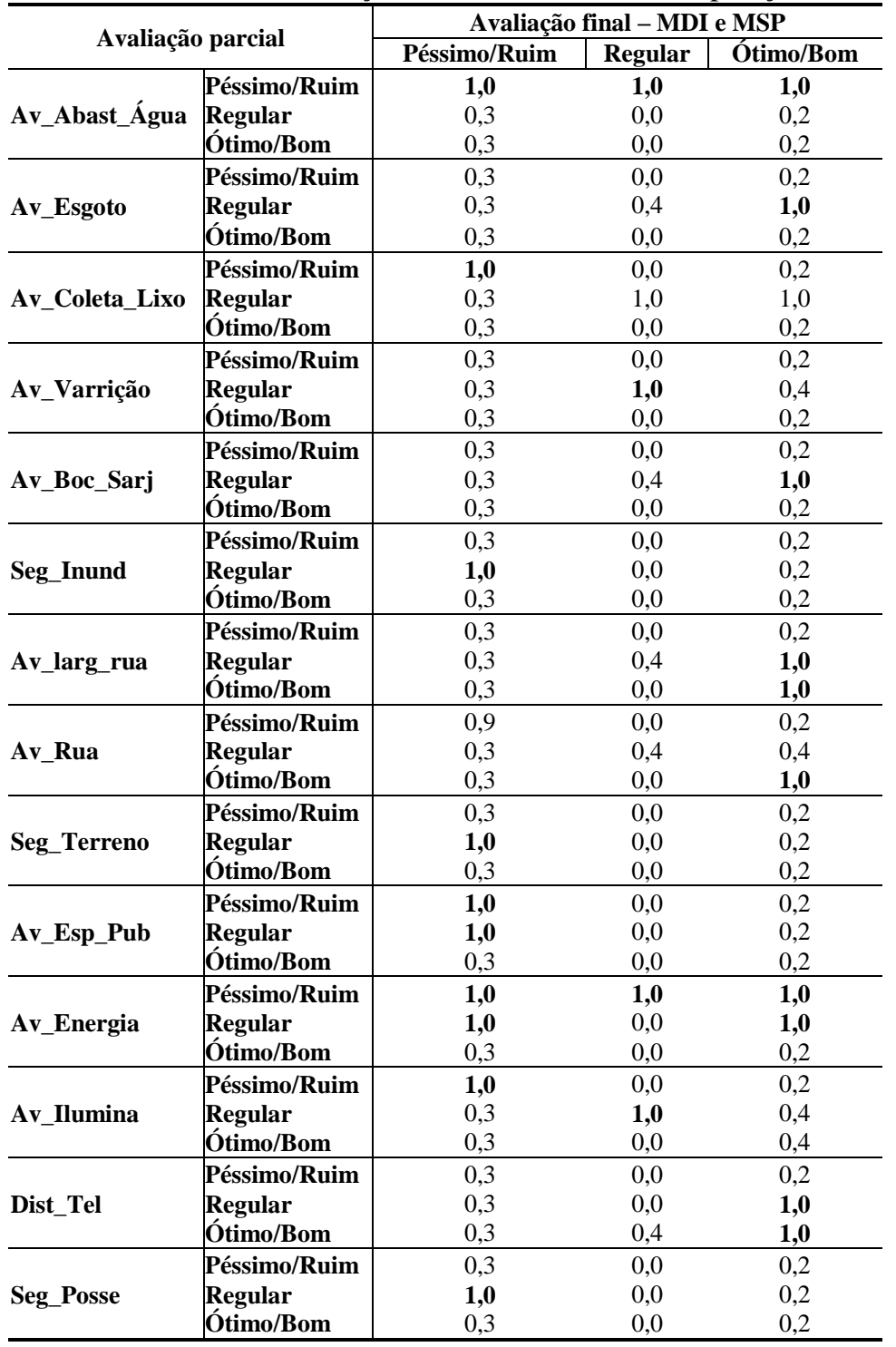


A análise do desempenho, variando as composições, apresentou resultados semelhantes para as duas formas de obtenção dos subconjuntos fuzzy de avaliação final, com apenas $28 \%$ de acertos absolutos; mesmo assim há que se ressaltar o grande número de empates com possibilidades de acerto (Tabela 59).

Tabela 59: Salubridade : percentual de acertos por construção da avaliação final e regra de composição Pesquisa Piloto

\begin{tabular}{l|c|c|c|c}
\hline Construção da avaliação final & Acertos & Empates & Empates com possibilidade de acerto & Erros \\
\hline \multicolumn{7}{|c}{$\max$-min } \\
\hline MDI e MSP & $28 \%$ & $64 \%$ & $63 \%$ & $9 \%$ \\
\hline MDI e MSP & $28 \%$ & $64 \%$ & max-produto & $9 \%$ \\
\hline
\end{tabular}

\subsection{Entorno}

Utilizamos para o entorno a mesma variável de avaliação final que utilizamos para Salubridade. A Tabela 60 apresenta a matriz de avaliações parciais.

Tabela 60: Entorno: matriz de avaliações parciais transposta - Pesquisa Piloto

\begin{tabular}{|c|c|c|c|c|}
\hline \multirow{2}{*}{\multicolumn{2}{|c|}{ Avaliação parcial }} & \multicolumn{3}{|c|}{ Avaliação final - MDI e MSP } \\
\hline & & \multirow{2}{*}{$\begin{array}{c}\text { Péssimo/Ruim } \\
0,7\end{array}$} & \multirow{2}{*}{$\begin{array}{c}\text { Regular } \\
1,0\end{array}$} & \multirow{2}{*}{$\frac{\text { Ótimo/Bom }}{0,5}$} \\
\hline Ay Servic & Péssimo/Ruim & & & \\
\hline Av_Servic & Regular & 1,0 & 0,6 & 0,4 \\
\hline & Ótimo/Bom & 0,3 & 1,0 & 1,0 \\
\hline \multirow{3}{*}{ Av_Lazer_Fora } & Péssimo/Ruim & 0,5 & 0,0 & 0,0 \\
\hline & Regular & 0,0 & 0,8 & 0,3 \\
\hline & Ótimo/Bom & 1,0 & 1,0 & 1,0 \\
\hline \multirow{3}{*}{ Av_Associacao } & Péssimo/Ruim & 0,0 & 0,0 & 0,0 \\
\hline & Regular & 0,5 & 1,0 & 0,1 \\
\hline & Ótimo/Bom & 1,0 & 1,0 & 1,0 \\
\hline \multirow{3}{*}{ Dist_Ponto_Onibus } & Péssimo/Ruim & 1,0 & 0,6 & 0,8 \\
\hline & Regular & 0,0 & 0,6 & 0,6 \\
\hline & Ótimo/Bom & 0,2 & 1,0 & 1,0 \\
\hline
\end{tabular}

Mais uma vez as matrizes de avaliação final são iguais nos dois métodos (Tabela 61).

Tabela 61: Entorno: matrizes de avaliação final - Pesquisa Piloto

\begin{tabular}{|c|c|c|c|c|c|c|c|}
\hline & & \multicolumn{3}{|c|}{ Avaliação final - MDI } & \multicolumn{3}{|c|}{ Avaliação final - MSP } \\
\hline & & Péssimo/Ruim & Regular & Ótimo/Bom & Péssimo/Ruim & Regular & Ótimo/Bom \\
\hline \multirow{3}{*}{ 豙 } & Péssimo/Ruim & 1,0 & 0,5 & 0,2 & 1,0 & 0,5 & 0,2 \\
\hline & Regular & 0,6 & 1,0 & 1,0 & 0,6 & 1,0 & 1,0 \\
\hline & Ótimo/Bom & 0,4 & 0,1 & 1,0 & 0,4 & 0,1 & 1,0 \\
\hline
\end{tabular}

A matriz de relação é apresentada na Tabela 62. Como os conjuntos de avaliação final com os dois métodos foram iguais os resultados entre eles não diferem. 
Tabela 62: Entorno: matriz de relação com MDI e MSP e composição max-min - Pesquisa Piloto

\begin{tabular}{|c|c|c|c|c|}
\hline \multirow{2}{*}{\multicolumn{2}{|c|}{ Avaliação parcial }} & \multicolumn{3}{|c|}{ Avaliação final - MDI e MSP } \\
\hline & & Péssimo/Ruim & Regular & Ótimo/Bom \\
\hline \multirow{3}{*}{ Av_Servic } & Péssimo/Ruim & 0,4 & 0,1 & 0,2 \\
\hline & Regular & 1,0 & 0,1 & 0,2 \\
\hline & Ótimo/Bom & 0,4 & 0,1 & 0,2 \\
\hline \multirow{3}{*}{ Av_Lazer_Fora } & Péssimo/Ruim & 1,0 & 1,0 & 0,2 \\
\hline & Regular & 0,6 & 0,1 & 1,0 \\
\hline & Ótimo/Bom & 0,4 & 0,1 & 0,2 \\
\hline \multirow{3}{*}{ Av_Associacao } & Péssimo/Ruim & 1,0 & 1,0 & 1,0 \\
\hline & Regular & 0,6 & 1,0 & 0,2 \\
\hline & Ótimo/Bom & 0,4 & 0,1 & 0,2 \\
\hline \multirow{3}{*}{ Dist_Ponto_Onibus } & Péssimo/Ruim & 0,4 & 0,1 & 0,2 \\
\hline & Regular & 0,4 & 0,1 & 1,0 \\
\hline & Ótimo/Bom & 0,4 & 0,1 & 1,0 \\
\hline
\end{tabular}

$\mathrm{Na}$ avaliação de desempenho pelos acertos, a composição max-min obteve $58 \%$ de acertos e a max-produto $68 \%$. Porém ressaltamos que assim como na Salubridade, trabalhamos aqui com uma aproximação do entorno pela ausência de uma variável final para este item.

Tabela 63: Entorno: percentual de acertos por construção da avaliação final e regra de composição - Pesquisa Piloto

\begin{tabular}{l|c|c|c|c}
\hline Construção da avaliação final & Acertos & Empates & Empates com possibilidade de acerto & Erros \\
\hline \multicolumn{7}{|c}{$\max$-min } & $13 \%$ & $38 \%$ \\
\hline MDI e MSP & $49 \%$ & $13 \%$ & & $28 \%$ \\
\hline MDI e MSP & $59 \%$ & $13 \%$ & $13 \%$ & max-produto \\
\hline
\end{tabular}

\subsection{Indicadores segundo o modelo das equações relacionais fuzzy}

Para o cálculo dos indicadores finais pelo método das equações relacionais fuzzy basta agora definir qual composição utilizar e inserir os dados globais na equação. Os dados para cada grupo de variáveis são apresentados na Tabela 64.

Como os resultados não diferiram substancialmente entre os critérios e composições adotaremos o critério MDI com a composição max-min para obter os indicadores finais que são apresentados na Tabela 65. 
Tabela 64: Dados para o cálculo dos indicadores finais qualitativos - Pesquisa Piloto

\begin{tabular}{|c|c|c|c|c|c|c|}
\hline Conceito & Moradia & $\begin{array}{c}\text { Grau de } \\
\text { pertinência } \\
(\text { GP) }\end{array}$ & Salubridade ambiental & GP & Entorno & GP \\
\hline $\begin{array}{l}\text { Péssimo/Ruim } \\
\text { Regular } \\
\text { Bom/Ótimo } \\
\end{array}$ & Av_Inst_Agua & $\begin{array}{l}0,18 \\
0,28 \\
1,00 \\
\end{array}$ & Av_Abast_Agua & $\begin{array}{l}0,13 \\
0,40 \\
1,00 \\
\end{array}$ & Av_Servic & $\begin{array}{l}0,57 \\
0,45 \\
1,00 \\
\end{array}$ \\
\hline $\begin{array}{l}\text { Péssimo/Ruim } \\
\text { Regular } \\
\text { Bom/Ótimo }\end{array}$ & Av_Inst_Esgoto & $\begin{array}{l}0,14 \\
0,24 \\
1,00\end{array}$ & Av_Esgoto & $\begin{array}{l}1,00 \\
0,61 \\
0,89\end{array}$ & Av_Lazer_Fora & $\begin{array}{l}0,02 \\
0,35 \\
1,00 \\
\end{array}$ \\
\hline $\begin{array}{l}\text { Péssimo/Ruim } \\
\text { Regular } \\
\text { Bom/Ótimo } \\
\end{array}$ & Av_Inst_Eletrica & $\begin{array}{l}0,34 \\
0,66 \\
1,00 \\
\end{array}$ & Av_Coleta_Lixo & $\begin{array}{l}0,17 \\
0,35 \\
1,00\end{array}$ & Av_Associacao & $\begin{array}{l}0,00 \\
0,20 \\
1,00\end{array}$ \\
\hline $\begin{array}{l}\text { Péssimo/Ruim } \\
\text { Regular } \\
\text { Bom/Ótimo }\end{array}$ & Av_Quartos & $\begin{array}{l}1,00 \\
0,31 \\
0,69 \\
\end{array}$ & Av_Varricao & $\begin{array}{l}0,57 \\
0,36 \\
1,00 \\
\end{array}$ & Dist_Ponto_Onibus & $\begin{array}{l}0,83 \\
0,63 \\
1,00 \\
\end{array}$ \\
\hline $\begin{array}{l}\text { Péssimo/Ruim } \\
\text { Regular } \\
\text { Bom/Ótimo } \\
\end{array}$ & Av_Tam_Casa & $\begin{array}{l}1,00 \\
0,44 \\
0,75 \\
\end{array}$ & Av_Boc_Sarj & $\begin{array}{l}1,00 \\
0,43 \\
0,34 \\
\end{array}$ & - & - \\
\hline $\begin{array}{l}\text { Péssimo/Ruim } \\
\text { Regular } \\
\text { Bom/Ótimo }\end{array}$ & Av_Telhado & $\begin{array}{l}1,00 \\
0,86 \\
0,86\end{array}$ & Seg_Inund & $\begin{array}{l}1,00 \\
0,15 \\
0,85\end{array}$ & 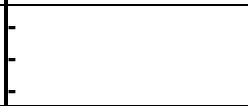 & $\begin{array}{l}- \\
- \\
-\end{array}$ \\
\hline $\begin{array}{l}\text { Péssimo/Ruim } \\
\text { Regular } \\
\text { Bom/Ótimo } \\
\end{array}$ & Av_Paredes & $\begin{array}{l}0,56 \\
0,39 \\
1,00 \\
\end{array}$ & Av_larg_rua & $\begin{array}{l}0,71 \\
0,41 \\
1,00 \\
\end{array}$ & - & $\begin{array}{l}- \\
- \\
-\end{array}$ \\
\hline $\begin{array}{l}\text { Péssimo/Ruim } \\
\text { Regular } \\
\text { Bom/Ótimo } \\
\end{array}$ & Av_Piso & $\begin{array}{l}0,75 \\
0,61 \\
1,00 \\
\end{array}$ & Av_Rua & $\begin{array}{l}0,45 \\
0,48 \\
1,00 \\
\end{array}$ & - & $\begin{array}{l}- \\
- \\
-\end{array}$ \\
\hline $\begin{array}{l}\text { Péssimo/Ruim } \\
\text { Regular } \\
\text { Bom/Ótimo }\end{array}$ & Av_Ventila & $\begin{array}{l}0,58 \\
0,38 \\
1,00\end{array}$ & Seg_Terreno & $\begin{array}{l}0,36 \\
0,18 \\
1,00\end{array}$ & - & $\begin{array}{l}- \\
- \\
-\end{array}$ \\
\hline $\begin{array}{l}\text { Péssimo/Ruim } \\
\text { Regular } \\
\text { Bom/Ótimo } \\
\end{array}$ & - & $\begin{array}{l}- \\
- \\
-\end{array}$ & Av_Esp_Pub & $\begin{array}{l}0,12 \\
0,20 \\
1,00 \\
\end{array}$ & - & $\begin{array}{l}- \\
- \\
-\end{array}$ \\
\hline $\begin{array}{l}\text { Péssimo/Ruim } \\
\text { Regular } \\
\text { Bom/Ótimo }\end{array}$ & - & $\begin{array}{l}- \\
- \\
-\end{array}$ & Av_Energia & $\begin{array}{l}0,09 \\
0,10 \\
1,00\end{array}$ & 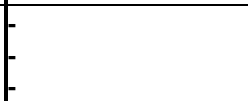 & $\begin{array}{l}- \\
- \\
-\end{array}$ \\
\hline $\begin{array}{l}\text { Péssimo/Ruim } \\
\text { Regular } \\
\text { Bom/Ótimo } \\
\end{array}$ & - & $\begin{array}{l}- \\
- \\
-\end{array}$ & Av_Ilumina & $\begin{array}{l}0,44 \\
0,44 \\
1,00\end{array}$ & - & $\begin{array}{l}- \\
- \\
-\end{array}$ \\
\hline $\begin{array}{l}\text { Péssimo/Ruim } \\
\text { Regular } \\
\text { Bom/Ótimo }\end{array}$ & - & $\begin{array}{l}- \\
- \\
-\end{array}$ & Dist_Tel & $\begin{array}{l}1,00 \\
0,33 \\
0,42\end{array}$ & - & $\begin{array}{l}- \\
- \\
-\end{array}$ \\
\hline $\begin{array}{l}\text { Péssimo/Ruim } \\
\text { Regular } \\
\text { Bom/Ótimo }\end{array}$ & - & $\begin{array}{l}- \\
-\end{array}$ & Seg_Posse & $\begin{array}{l}0,46 \\
0,12 \\
1,00 \\
\end{array}$ & - & $\begin{array}{l}- \\
- \\
-\end{array}$ \\
\hline
\end{tabular}

Tabela 65: Indicadores qualitativos da intervenção obtidos utilizando equações relacionais fuzzy - Pesquisa Piloto

\begin{tabular}{l|c|c|c}
\hline \multicolumn{1}{c|}{ Avaliação } & Moradia & Salubridade ambiental & Entorno \\
\hline Péssimo/Ruim & 0,56 & 0,45 & 0,45 \\
Regular & 0,38 & 0,44 & 0,20 \\
Bom/Ótimo & 0,86 & 1,00 & 1,00 \\
\hline
\end{tabular}

Se compararmos estes resultados com a avaliação direta da moradia e do bairro, veremos que estes indicadores são confirmados. 
8.4.1.2 Reconhecimento de padrão fuzzy - Método da lista fuzzy de pertinência

Como afirmamos anteriormente, para o método da lista fuzzy de pertinência, precisamos definir os exemplos de padrão e um critério de classificação. Neste método, assim como no método das equações relacionais fuzzy, os padrões serão definidos pelas avaliações parciais de cada grupo de avaliação final. Estes grupos são formados por todos aqueles formulários cuja resposta a avaliação final tenha sido a mesma. Como critério de conformidade, utilizaremos o índice de conformidade já referido. Utilizamos também medidas de distância, porém, a interpretação final dessa medida para um grau de certeza ainda precisa ser mais bem trabalhada.

O índice de conformidade é dado pela razão entre a interseção e a união de dois subconjuntos, ou seja, quanto maior a interseção, elementos comuns, maior será o índice de conformidade. A utilização deste índice também é interessante, pois o seu intervalo de variação é [0;1].

Assim como na equação relacional fuzzy após definirmos os padrões, também estaremos habilitados a verificar em qual padrão os nossos resultados coletivos se classificam. A seguir, apresentaremos os resultados da aplicação deste método.

Neste método também testamos manter a quantidade de padrões, mas refinando as características numa escala de cinco classes, além da possibilidade de utilizar os dados normalizados ou não, ou seja, adotamos as freqüências relativas como graus de possibilidade (conjuntos fuzzy subnormais). Como critério para decisão de qual procedimento adotar, utilizamos mais uma vez, o número de acertos no reconhecimento das respostas obtidas.

\subsection{Moradia}

A Tabela 66 apresenta os padrões de respostas para avaliação da moradia. É importante notar que as instalações de água e esgoto receberam avaliação semelhante nos padrões Péssimo/Ruim e Bom/Ótimo com uma ligeira diferença no padrão Regular. Isto sugere que estes elementos não foram decisivos na avaliação global do morador. 
Tabela 66: Moradia: Padrões de respostas - Pesquisa Piloto

\begin{tabular}{|c|c|c|c|c|c|c|c|c|c|}
\hline & \multicolumn{3}{|c|}{ Péssimo/Ruim } & \multicolumn{3}{|c|}{ Regular } & \multicolumn{3}{|c|}{ Bom/Ótimo } \\
\hline & \multicolumn{3}{|c|}{\begin{tabular}{|l|l|} 
Péssimo/Ruim|Regular|Bom/Ótimo \\
\end{tabular}} & \multirow{2}{*}{$\begin{array}{l}\text { Péssimo/Ruim } \\
\text { Padrões fuzzy n }\end{array}$} & \multirow{2}{*}{$\begin{array}{l}\text { Regular } \\
\text { rmais }\end{array}$} & \multirow[t]{2}{*}{ Bom/Ótimo } & \multicolumn{3}{|c|}{ 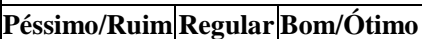 } \\
\hline & & & & & & & & & \\
\hline$\overline{\text { Av_Inst_Agua }}$ & 0,18 & 0,35 & 1,00 & 0,43 & 0,86 & 1,00 & 0,10 & 0,08 & 1,00 \\
\hline Av_Inst_Esgoto & 0,19 & 0,38 & 1,00 & 0,21 & 0,26 & 1,00 & 0,10 & 0,17 & 1,00 \\
\hline Av_Inst_Eletrica & 1,00 & 1,00 & 0,70 & 0,29 & 0,93 & 1,00 & 0,16 & 0,42 & 1,00 \\
\hline Av_Quartos & 1,00 & 0,18 & 0,05 & 1,00 & 0,25 & 0,56 & 0,67 & 0,33 & 1,00 \\
\hline Av_Tam_Casa & 1,00 & 0,04 & 0,08 & 1,00 & 0,56 & 0,22 & 0,37 & 0,37 & 1,00 \\
\hline Av_Telhado & 1,00 & 0,56 & 0,06 & 0,67 & 1,00 & 0,47 & 0,59 & 0,45 & 1,00 \\
\hline Av_Paredes & 1,00 & 0,15 & 0,20 & 0,53 & 0,60 & 1,00 & 0,14 & 0,29 & 1,00 \\
\hline Av_Piso & 1,00 & 0,14 & 0,14 & 0,77 & 1,00 & 0,69 & 0,18 & 0,38 & 1,00 \\
\hline Av_Ventila & 1,00 & 0,07 & 0,73 & 0,33 & 1,00 & 0,80 & 0,41 & 0,19 & 1,00 \\
\hline \multicolumn{10}{|c|}{ Padrões fuzzy subnormais } \\
\hline$\overline{\text { Av_Inst_Agua }}$ & 0,12 & 0,23 & 0,65 & 0,19 & 0,38 & 0,44 & 0,09 & 0,07 & 0,84 \\
\hline Av_Inst_Esgoto & 0,12 & 0,24 & 0,64 & 0,14 & 0,18 & 0,68 & 0,08 & 0,13 & 0,79 \\
\hline Av_Inst_Eletrica & 0,37 & 0,37 & 0,26 & 0,13 & 0,42 & 0,45 & 0,10 & 0,27 & 0,63 \\
\hline Av_Quartos & 0,81 & 0,15 & 0,04 & 0,55 & 0,14 & 0,31 & 0,33 & 0,17 & 0,50 \\
\hline Av_Tam_Casa & 0,89 & 0,04 & 0,07 & 0,56 & 0,31 & 0,13 & 0,21 & 0,21 & 0,57 \\
\hline Av_Telhado & 0,62 & 0,35 & 0,04 & 0,31 & 0,47 & 0,22 & 0,29 & 0,22 & 0,49 \\
\hline Av_Paredes & 0,74 & 0,11 & 0,15 & 0,25 & 0,28 & 0,47 & 0,10 & 0,20 & 0,70 \\
\hline Av_Piso & 0,78 & 0,11 & 0,11 & 0,31 & 0,41 & 0,28 & 0,11 & 0,25 & 0,64 \\
\hline Av_Ventila & 0,56 & 0,04 & 0,41 & 0,16 & 0,47 & 0,38 & 0,25 & 0,12 & 0,63 \\
\hline
\end{tabular}

Os resultados dos percentuais de acerto são apresentados na Tabela 67. Embora tenhamos testado o refinamento das classes com cinco divisões, os resultados não diferiram muito dos resultados com três classes.

Tabela 67: Moradia: percentual de acertos com reconhecimento de padrão - Pesquisa Piloto

\begin{tabular}{l|c|c|c}
\hline & Número de acertos & Número total & $\%$ de acertos \\
\hline Índice de conformidade padrões fuzzy & 78 & 120 & $65,0 \%$ \\
Índice de conformidade padrões fuzzy subnormais & 83 & 120 & $69,2 \%$ \\
\hline
\end{tabular}

\subsection{Salubridade ambiental}

Repetimos o procedimento para os dados de salubridade ambiental, tomando como resposta final a avaliação do bairro, como já explicado, pela falta dessa variável no formulário. Os padrões são apresentados na Tabela 68. 
Tabela 68: Salubridade: Padrões de respostas - Pesquisa Piloto

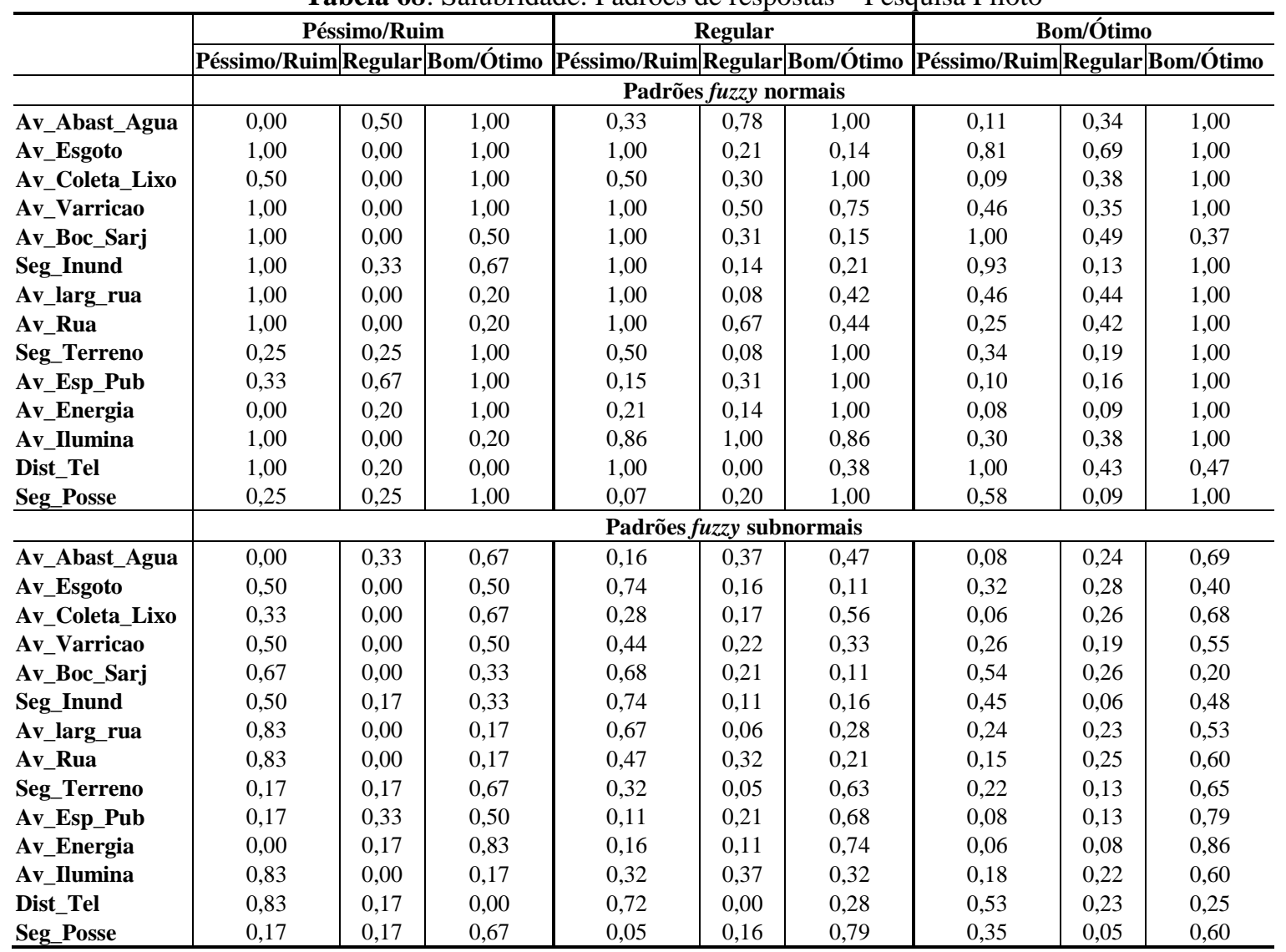

Os resultados dos percentuais de acerto são apresentados na Tabela 69. Embora tenhamos testado o refinamento das classes com cinco divisões, os resultados não diferiram significativamente.

Tabela 69: Salubridade: percentual de acertos com reconhecimento de padrão - Pesquisa Piloto

\begin{tabular}{l|c|c|c}
\hline & Número de acertos & Número total & \% de acertos \\
\hline Índice de conformidade padrões fuzzy & 83 & 120 & 69 \\
Índice de conformidade padrões fuzzy subnormais & 79 & 120 & 66 \\
\hline
\end{tabular}

\subsection{Entorno}

De forma semelhante apresentamos os resultados para os dados do entorno na Tabela 70. 
Tabela 70: Entorno: Padrões de respostas - Pesquisa Piloto

\begin{tabular}{|c|c|c|c|c|c|c|c|c|c|}
\hline & \multicolumn{3}{|c|}{ Péssimo/Ruim } & \multicolumn{3}{|c|}{ Regular } & \multicolumn{3}{|c|}{ Bom/Ótimo } \\
\hline & Péssimo/Ruim| & \multicolumn{2}{|c|}{\begin{tabular}{|l|l|} 
Regular & Bom/Ótimo \\
\end{tabular}} & \multicolumn{3}{|c|}{\begin{tabular}{|l|l|} 
Péssimo/Ruim & Regular \\
\end{tabular}} & \multicolumn{3}{|c|}{ Péssimo/Ruim|Regular Bom/Ótimo } \\
\hline & \multicolumn{9}{|c|}{ Padrões fuzzy normais } \\
\hline Av_Servic & 0,67 & 1,00 & 0,33 & 1,00 & 0,57 & 1,00 & 0,48 & 0,38 & 1,00 \\
\hline Av_Lazer_Fora & 0,50 & 0,00 & 1,00 & 0,00 & 0,80 & 1,00 & 0,00 & 0,31 & 1,00 \\
\hline Av_Associacao & 0,00 & 0,50 & 1,00 & 0,00 & 1,00 & 1,00 & 0,00 & 0,06 & 1,00 \\
\hline \multirow[t]{2}{*}{ Dist_Ponto_Onibus } & 1,00 & 0,00 & 0,20 & 0,63 & 0,63 & 1,00 & 0,77 & 0,64 & 1,00 \\
\hline & \multicolumn{9}{|c|}{ Padrões fuzzy subnormais } \\
\hline Av_Servic & 0,33 & 0,50 & 0,17 & 0,39 & 0,22 & 0,39 & 0,26 & 0,20 & 0,54 \\
\hline Av_Lazer_Fora & 0,33 & 0,00 & 0,67 & 0,00 & 0,44 & 0,56 & 0,00 & 0,23 & 0,77 \\
\hline Av_Associacao & 0,00 & 0,33 & 0,67 & 0,00 & 0,50 & 0,50 & 0,00 & 0,06 & 0,94 \\
\hline Dist_Ponto_Onibus & 0,83 & 0,00 & 0,17 & 0,28 & 0,28 & 0,44 & 0,32 & 0,27 & 0,41 \\
\hline
\end{tabular}

Tabela 71: Salubridade: percentual de acertos com reconhecimento de padrão - Pesquisa Piloto

\begin{tabular}{l|c|c|c}
\hline & Número de acertos & Número total & \% de acertos \\
\hline Índice de conformidade padrões fuzzy & 61 & 120 & 51 \\
Índice de conformidade padrões fuzzy subnormais & 59 & 120 & 49 \\
\hline
\end{tabular}

\subsection{Indicadores finais utilizando o método de reconhecimento de padrão}

Visto que não houve mudanças significativas na utilização de padrões fuzzy normais ou subnormais, utilizaremos os valores fuzzy normais para o cálculo dos indicadores finais (Tabela 72).

Tabela 72: Padrões globais de respostas - Pesquisa Piloto

\begin{tabular}{|c|c|c|c|}
\hline & Péssimo/Ruim & Regular & Bom/Ótimo \\
\hline \multicolumn{4}{|c|}{ Moradia } \\
\hline$\overline{\text { Av_Inst_Agua }}$ & 0,18 & 0,28 & 1,00 \\
\hline Av_Inst_Esgoto & 0,14 & 0,24 & 1,00 \\
\hline Av_Inst_Eletrica & 0,34 & 0,66 & 1,00 \\
\hline Av_Quartos & 1,00 & 0,31 & 0,69 \\
\hline Av_Tam_Casa & 1,00 & 0,44 & 0,75 \\
\hline Av_Telhado & 1,00 & 0,86 & 0,86 \\
\hline Av_Paredes & 0,56 & 0,39 & 1,00 \\
\hline Av_Piso & 0,75 & 0,61 & 1,00 \\
\hline Av_Ventila & 0,58 & 0,38 & 1,00 \\
\hline \multicolumn{4}{|c|}{ Salubridade } \\
\hline$\overline{\text { Av_Abast_Agua }}$ & 0,00 & 0,50 & 1,00 \\
\hline Av_Esgoto & 1,00 & 0,00 & 1,00 \\
\hline Av_Coleta_Lixo & 0,50 & 0,00 & 1,00 \\
\hline Av_Varricao & 1,00 & 0,00 & 1,00 \\
\hline Av_Boc_Sarj & 1,00 & 0,00 & 0,50 \\
\hline Seg_Inund & 1,00 & 0,33 & 0,67 \\
\hline Av_larg_rua & 1,00 & 0,00 & 0,20 \\
\hline Av_Rua & 1,00 & 0,00 & 0,20 \\
\hline Seg_Terreno & 0,25 & 0,25 & 1,00 \\
\hline Av_Esp_Pub & 0,33 & 0,67 & 1,00 \\
\hline Av_Energia & 0,00 & 0,20 & 1,00 \\
\hline Av_Ilumina & 1,00 & 0,00 & 0,20 \\
\hline Dist_Tel & 1,00 & 0,20 & 0,00 \\
\hline Seg_Posse & 0,25 & 0,25 & 1,00 \\
\hline \multicolumn{4}{|c|}{ Entorno } \\
\hline$\overline{\text { Av_Servic }}$ & 0,57 & 0,45 & 1,00 \\
\hline Av_Lazer_Fora & 0,02 & 0,35 & 1,00 \\
\hline Av_Associacao & 0,00 & 0,20 & 1,00 \\
\hline Dist_Ponto_Onibus & 0,83 & 0,63 & 1,00 \\
\hline
\end{tabular}


Dessa forma calculamos para os três grupos de variáveis os padrões correspondentes para uma avaliação final. Os valores nas tabelas de padrões são os mesmos apresentados para o método das equações relacionais fuzzy, apenas o procedimento é diferente. Logo, apresentaremos apenas os resultados finais na Tabela 73. Note que os resultados não contradizem o método anterior.

Tabela 73: Indicadores qualitativos da intervenção obtidos utilizando o reconhecimento de padrão fuzzy -

\begin{tabular}{l|c|c|c}
\multicolumn{4}{c}{ Pesquisa Piloto } \\
\hline \multicolumn{1}{c|}{ Avaliação } & Moradia & Salubridade ambiental & Entorno \\
\hline Péssimo/Ruim & 0,58 & 0,63 & 0,53 \\
Regular & 0,76 & 0,69 & 0,64 \\
Bom/Ótimo & 0,73 & 0,91 & 0,90 \\
\hline
\end{tabular}

\subsubsection{Considerações finais}

Os dois métodos apresentados, equações relacionais fuzzy e reconhecimento de padrão fuzzy, buscam trabalhar as informações obtidas nas pesquisas de campo para compor um indicador final de avaliação com base na opinião do morador. A opção por estes métodos foi feita por dois motivos: (1) a construção dos métodos pode ser baseada apenas nos dados disponíveis, logo não há qualquer interferência do pesquisador sobre os dados coletados, o que implica também numa avaliação mais próxima da opinião dos pesquisados; (2) não há necessidade de conversão das escalas, como afirmado anteriormente, já que as operações são realizadas apenas nas pertinências dos elementos, ou seja, os dados são tratados de acordo como foram coletados.

O método das equações relacionais fuzzy apresenta vantagens sobre o reconhecimento padrão, uma vez que identifica as relações entre as avaliações parciais e as avaliações finais; por outro lado exige um maior número de tomadas de decisões do pesquisador, uma vez que o número de parâmetros envolvidos é maior. Contudo, ambos demonstraram serem úteis no cálculo de um indicador final. 


\subsubsection{Indicadores quantitativos}

Nesta etapa descreveremos os resultados obtidos com a consulta aos especialistas para composição do sistema de ponderação dos indicadores quantitativos, bem como os resultados obtidos para a pesquisa piloto.

\subsubsection{Definição dos pesos relativos dos indicadores}

Para definição dos pesos foi aplicado o método AHP com consulta a um grupo de especialistas. Foram definidos os agrupamentos e as hierarquias dos indicadores, de forma a construir matrizes de comparação pareada. As variáveis foram agrupadas em indicadores e sub-indicadores de acordo com as hierarquias da Figura 36, Figura 37 e Figura 38.

Determinadas estas hierarquias, foram construídas as matrizes de comparação (exemplo no Quadro 20); as células da matriz são preenchidas comparando-se os elementos das linhas com os elementos das colunas, segundo a escala apresentada no Quadro 18, já apresentado. A partir destas matrizes foi elaborado um questionário para facilitar a obtenção dos pesos (APÊNDICE C).

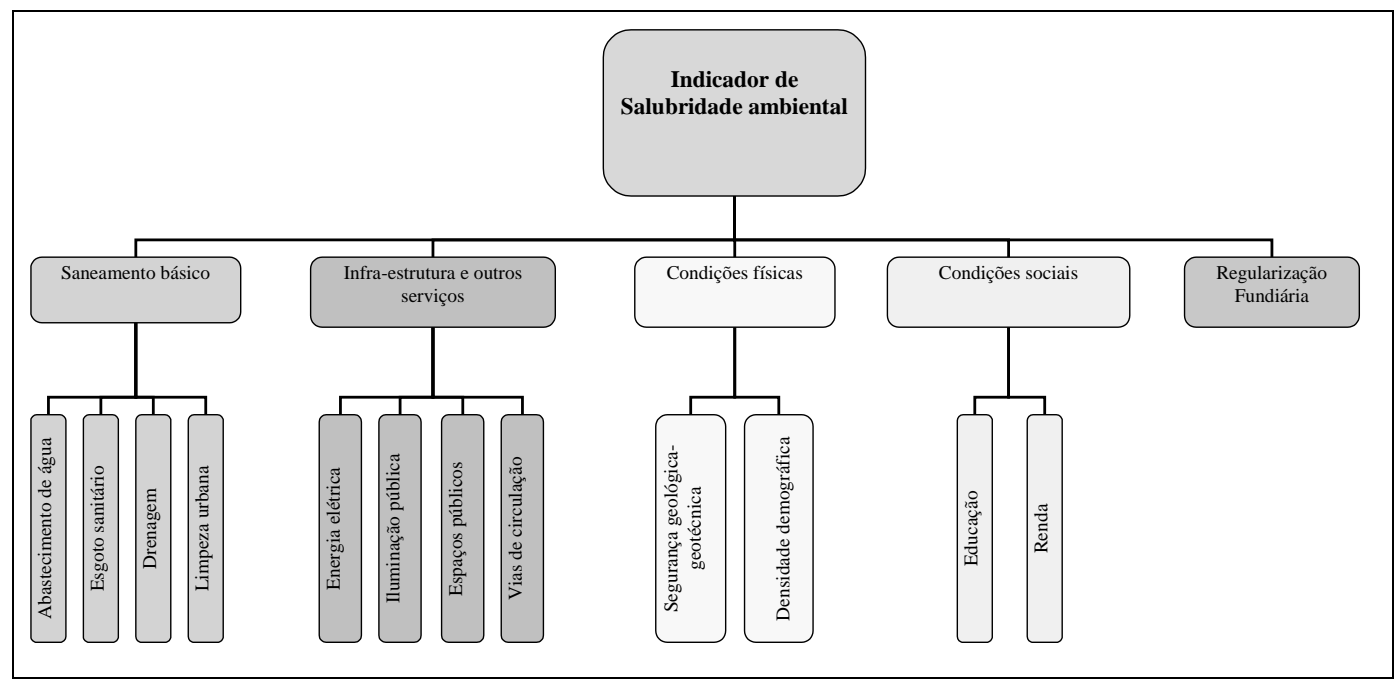

Figura 36: Hierarquia para o Indicador de Salubridade ambiental 


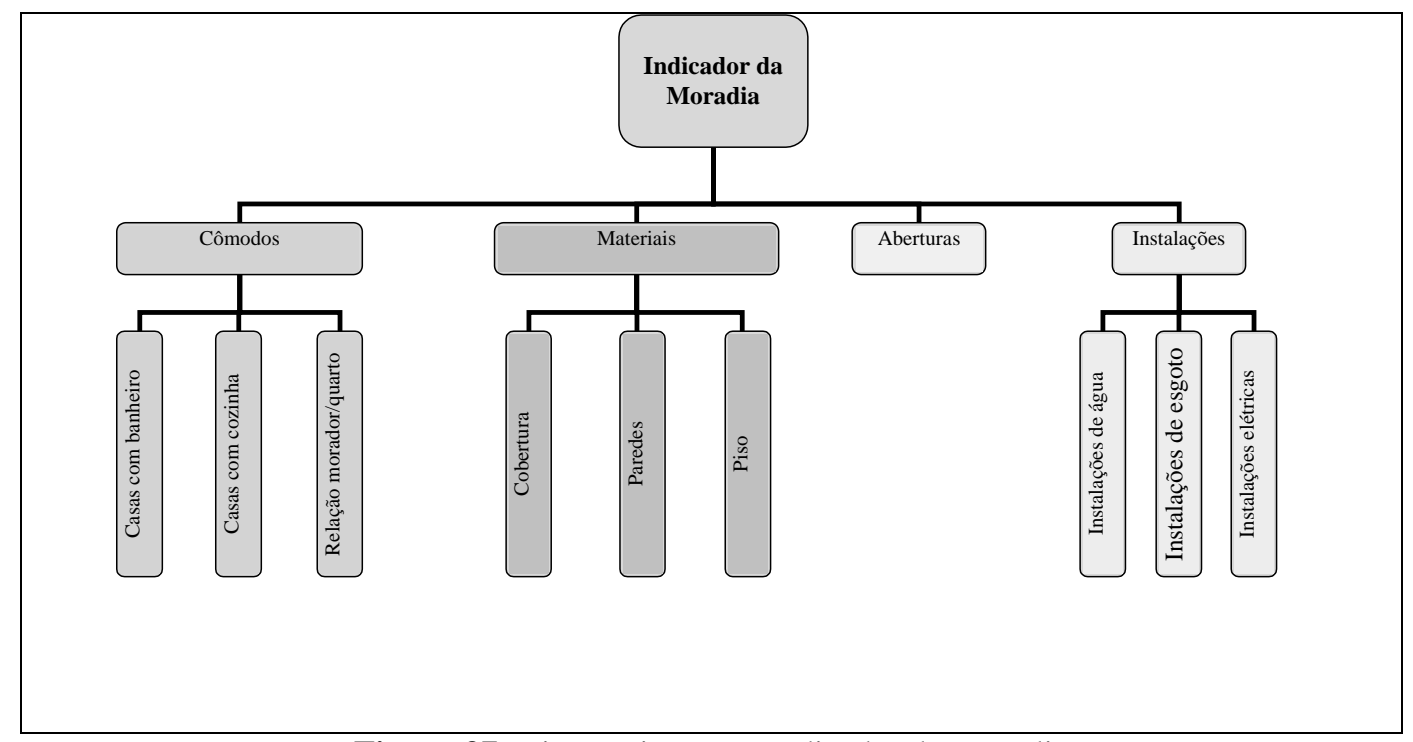

Figura 37: Hierarquia para o Indicador de Moradia

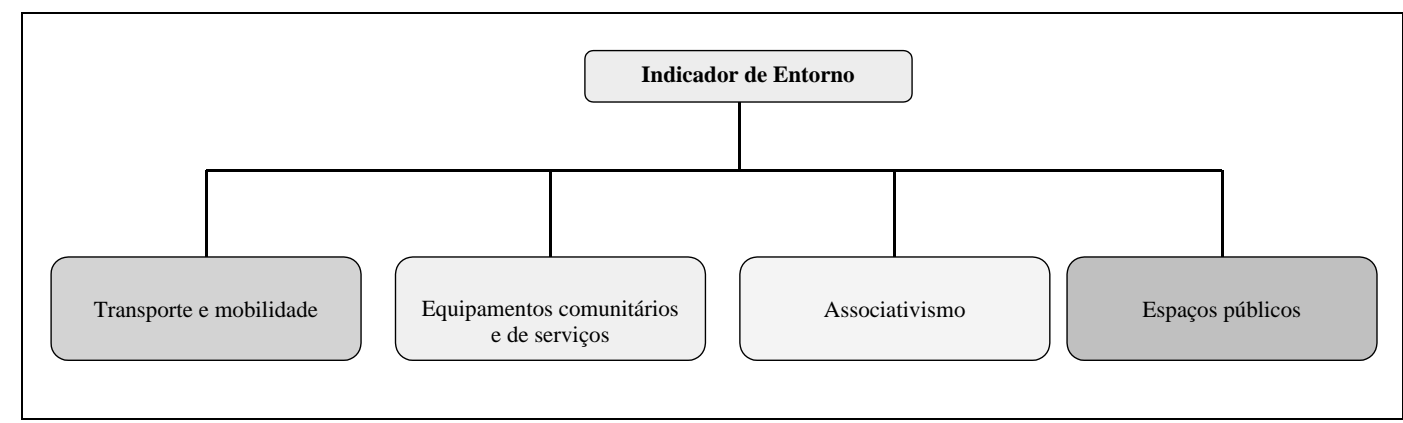

Figura 38: Hierarquia para o Indicador de Entorno

Quadro 20: Exemplo de matriz de comparação utilizada no AHP

\begin{tabular}{|l|l|l|l|l|}
\hline Variável/fator & Cômodos & Materiais & Aberturas & Instalações \\
\hline Cômodos & & & & \\
\hline Materiais & & & & \\
\hline Aberturas & & & & \\
\hline Instalações & & & & \\
\hline
\end{tabular}

Foram enviados 17 questionários dos quais 11 retornaram com as respostas. Os questionários foram tabulados e os julgamentos agrupados por média geométrica conforme sugerem Forman e Peniwati (1998). Os resultados podem ser vistos na Tabela 74. É importante também avaliar os pesos do ponto de vista da importância das variáveis para os especialistas; note que os maiores pesos são atribuídos ao saneamento básico e ao Indicador de Salubridade. 
Tabela 74: Pesos dos indicadores obtidos utilizando o AHP

\begin{tabular}{|c|c|c|c|c|}
\hline \multirow{2}{*}{$\begin{array}{r}\text { Indicador } \\
\text { INDICADOR DE MORADIA }\end{array}$} & \multicolumn{4}{|c|}{ Pesos } \\
\hline & & & & $34,4 \%$ \\
\hline Cômodos & & & $21,3 \%$ & \\
\hline Cozinha & & $29,2 \%$ & & \\
\hline Banheiros & & $52,5 \%$ & & \\
\hline Quartos & & $18,3 \%$ & & \\
\hline Materiais & & & $20,1 \%$ & \\
\hline Material da cobertura & & $49,8 \%$ & & \\
\hline Material das paredes & & $33,7 \%$ & & \\
\hline Material do piso & & $16,5 \%$ & & \\
\hline Instalações & & & $32,7 \%$ & \\
\hline Instalações de água & & $37,9 \%$ & & \\
\hline Instalações de esgoto & & $39,5 \%$ & & \\
\hline Instalações elétricas & & $22,6 \%$ & & \\
\hline Aberturas & & & $25,9 \%$ & \\
\hline INDICADOR DE SALUBRIDADE AMBIENTAL & & & & $48,9 \%$ \\
\hline Saneamento básico & & & $40,9 \%$ & \\
\hline Abastecimento de água & & $32,8 \%$ & & \\
\hline Abastecimento de água regularizado & $82,2 \%$ & & & \\
\hline Abastecimento de água irregular & $17,8 \%$ & & & \\
\hline Esgotamento sanitário & & $35,2 \%$ & & \\
\hline Esgotamento sanitário regularizado & $78,7 \%$ & & & \\
\hline Esgotamento sanitário irregular & $21,3 \%$ & & & \\
\hline Drenagem & & $18,8 \%$ & & \\
\hline Limpeza urbana & & $13,2 \%$ & & \\
\hline Coleta de lixo & $84,3 \%$ & & & \\
\hline Serviço de varrição & $15,7 \%$ & & & \\
\hline Infra-estrutura e outros serviços & & & $21,9 \%$ & \\
\hline Energia elétrica & & $40,8 \%$ & & \\
\hline Energia elétrica regularizada & $79,8 \%$ & & & \\
\hline Energia elétrica irregular & $20,2 \%$ & & & \\
\hline Iluminação pública & & $14,5 \%$ & & \\
\hline Espaços públicos & & $12,6 \%$ & & \\
\hline Vias de circulação & & $32,1 \%$ & & \\
\hline Condições físicas & & & $18,6 \%$ & \\
\hline Segurança geológico-geotécnica & & $84,2 \%$ & & \\
\hline Densidade demográfica & & $15,8 \%$ & & \\
\hline Condições sociais & & & $13,3 \%$ & \\
\hline Educação & & $69,6 \%$ & & \\
\hline Renda & & $30,4 \%$ & & \\
\hline Regularização fundiária & & & $5,2 \%$ & \\
\hline INDICADOR DE ENTORNO & & & & $16,7 \%$ \\
\hline Transporte e mobilidade & & & $45,2 \%$ & \\
\hline Equipamentos comunitários e de serviços & & & $21,4 \%$ & \\
\hline Associativismo & & & $15,1 \%$ & \\
\hline Espaços públicos fora da área & & & $18,3 \%$ & \\
\hline
\end{tabular}

\subsubsection{Indicadores parciais}

Os quadros (Quadro 21, Quadro 22, Quadro 23) a seguir descrevem como foram calculados os indicadores parciais, quais as variáveis envolvidas e quais as fórmulas utilizadas. 
Quadro 21: Composição do Indicador de Salubridade ambiental

\begin{tabular}{|c|c|c|}
\hline Indicador & Fórmula & Variáveis \\
\hline $\begin{array}{l}\text { Indicador de abastecimento } \\
\text { de água }\end{array}$ & $I_{A G}=A_{R}+A_{I} \times \frac{p_{A I}}{p_{A R}}$ & $\begin{array}{l}A_{R}: \text { Percentual de domicílios com abastecimento de água } \\
\text { regularizado } \\
A_{I}: \text { Percentual de domicílios com abastecimento de água sem } \\
\text { regularização } \\
P_{A R}: \text { peso dos domicílios com abastecimento de água } \\
\text { regularizado } \\
P_{A I}: \text { peso dos domicílios com abastecimento de água sem } \\
\text { regularização } \\
\text { A relação } \frac{p_{A I}}{p_{A R}} \text { representa o quanto os domicilio com } \\
\text { abastecimento sem regularização equivalem aos } \\
\text { regularizados. }\end{array}$ \\
\hline $\begin{array}{l}\text { Indicador de esgotamento } \\
\text { sanitário }\end{array}$ & $I_{E S}=E_{R}+E_{I} \times \frac{p_{E I}}{p_{E R}}$ & $\begin{array}{l}E_{R}: \text { Percentual de domicílios com esgotamento sanitário } \\
\text { regularizado } \\
E_{I}: \text { Percentual de domicílios com esgotamento sanitário sem } \\
\text { regularização } \\
P_{E R}: \text { peso dos domicílios com esgotamento sanitário } \\
\text { regularizado } \\
P_{E I}: \text { peso dos domicílios com esgotamento sanitário sem } \\
\text { regularização } \\
\text { A relação } \frac{p_{E I}}{p_{E R}} \text { representa o quanto os domicilio com } \\
\text { esgotamento sem regularização equivalem aos regularizados. }\end{array}$ \\
\hline Indicador de drenagem & $I_{D}=\frac{\left(D_{n i}+D_{R n i}\right)}{2}$ & $\begin{array}{l}D_{n i}: \text { percentual de domicílios que não inundam quando chove } \\
D_{R n i}: \text { percentual de domicílios que não inundam quando } \\
\text { chove }\end{array}$ \\
\hline $\begin{array}{l}\text { Indicador de limpeza } \\
\text { urbana }\end{array}$ & $I_{L U}=C \times p_{c}+V \times p_{v}$ & $\begin{array}{l}C: \text { percentual de domicílios atendidos com coleta regular ou } \\
\text { contêiner } \\
V: \text { percentual de domicílios onde há serviço de varrição } \\
p_{c}: \text { peso atribuído ao serviço de coleta } \\
p_{v}: \text { peso atribuído ao serviço de varrição }\end{array}$ \\
\hline $\begin{array}{l}\text { Indicador de energia } \\
\text { elétrica }\end{array}$ & $I_{E L}=E L_{R}+E L_{I} \times \frac{p_{E L I}}{p_{E L R}}$ & $\begin{array}{l}E L_{R}: \text { Percentual de domicílios com energia elétrica } \\
\text { regularizada } \\
E L_{I}: \text { Percentual de domicílios com energia elétrica sem } \\
\text { regularização } \\
P_{E L R}: \text { peso dos domicílios com energia elétrica regularizada } \\
P_{E L I}: \text { peso dos domicílios com energia elétrica sem } \\
\text { regularização } \\
\text { A relação } \frac{p_{E L I}}{p_{E L R}} \text { representa o quanto os domicilio com energia } \\
\text { elétrica sem regularização equivalem aos regularizados. }\end{array}$ \\
\hline $\begin{array}{l}\text { Indicador de iluminação } \\
\text { pública }\end{array}$ & $I_{I L}=D_{I L}$ & $D_{I L}:$ percentual de domicílios com iluminação pública na rua \\
\hline $\begin{array}{l}\text { Indicador de espaços } \\
\text { públicos }\end{array}$ & $I_{E P}=D_{E P}$ & $\begin{array}{l}D_{E P}: \text { percentual de domicílios que utilizam os espaços } \\
\text { públicos }\end{array}$ \\
\hline Indicador de vias públicas & $I_{\text {Vias }}=\sum D_{n} \times p_{n}$ & $\begin{array}{l}D_{n}: \text { percentual de domicílios na faixa } n \text { de largura } \\
p_{n}: \text { peso atribuído a faixa } n \text { de largura } \\
\text { largura acima de } 6 \mathrm{~m} p_{1}=1 \\
\text { largura entre } 3,6 \text { e } 6 \mathrm{~m} p_{2}=0,7 \\
\text { largura entre } 1,2 \text { e } 3,6 \mathrm{~m} p_{3}=0,35 \\
\text { largura abaixo de } 1,2 \mathrm{~m} p_{4}=0\end{array}$ \\
\hline $\begin{array}{l}\text { Indicador de segurança } \\
\text { geológico-geotécnica }\end{array}$ & - & $\begin{array}{l}\text { Por se tratar de uma área de aterro, realizado por equipe } \\
\text { técnica especializada, consideramos o risco geológico- } \\
\text { geotécnico baixo, ou seja, segurança plena. }\end{array}$ \\
\hline Indicador de densidade & $I_{D}=\left\{\begin{array}{c}100 \text { se } d \leq 225 h a b / h a \\
110-\frac{2}{45} \times d \text { se } 225<d \leq 2.475 h a b / h a \\
0 \text { se } d>2.475 h a b / h a\end{array}\right.$ & $\begin{array}{l}d: \text { densidade demográfica } \\
\text { Esse indicador foi ajustado de Almeida (1999), pois estava em } \\
\text { classes de densidade e optamos por distribuí-lo } \\
\text { continuamente. }\end{array}$ \\
\hline Indicador de educação & \multicolumn{2}{|c|}{$\begin{array}{l}I_{E} \text { : Na ausência de dados, foram obtidas no site do IBGE as distribuições de anos de estudos dos chefes dos domicílios } \\
\text { nos subdistritos. Foi estabelecida uma medida } m_{e d}=100-\sum p_{i}+\sum p_{s} \text {, onde } p_{i} \text { é a diferença entre o valor } \\
\text { percentual do domicílio na faixa de estudo do município e do subdistrito quando o valor do subdistrito está abaixo do } \\
\text { município e } p_{s} \text { é a diferença entre o valor percentual do domicílio na faixa de estudo, do município e do subdistrito } \\
\text { quando o subdistrito supera o município. Os valores foram então normalizados com relação ao melhor subdistrito. Foi } \\
\text { adotado o valor do subdistrito no qual a área está inserida. }\end{array}$} \\
\hline Indicador de renda & \multicolumn{2}{|c|}{$\begin{array}{l}I_{R} \text { : De forma semelhante aos dados de educação, obtivemos as distribuições de renda do chefe dos domicílios por } \\
\text { subdistrito e calculamos o índice de Gini. Com o índice de Gini igual a zero representa melhor distribuição de renda e } \\
\text { igual a um a pior. Par manter o sentido positivo da avaliação calculamos o complemento de cada subdistrito. Os valores } \\
\text { foram então normalizados com relação ao melhor subdistrito e adotamos o valor do subdistrito no qual a área está } \\
\text { inserida. }\end{array}$} \\
\hline
\end{tabular}


Quadro 22: Composição do Indicador de Moradia

\begin{tabular}{|l|l|}
\hline \multicolumn{1}{|c|}{ Indicador } & \multicolumn{1}{c|}{ Variáveis } \\
\hline Indicador de cozinha & Percentual de domicílios que possuem cozinha \\
\hline Indicador de banheiro & Percentual de domicílios que possuem banheiro \\
\hline Indicador de quartos & Percentual de domicílios que possuem pelo menos 1 quarto para cada duas pessoas \\
\hline Indicador de cobertura & $\begin{array}{l}\text { Média entre o percentual de domicílios que possuem material durável na cobertura } \\
\text { e não apresentam problemas nos período de chuva }\end{array}$ \\
\hline Indicador de material das paredes & $\begin{array}{l}\text { Média entre o percentual de domicílios que possuem material durável nas paredes, } \\
\text { possuem revestimento interno e possuem revestimento externo }\end{array}$ \\
\hline Indicador de instalações de água & Percentual dos domicílios que possuem instalações de água \\
\hline Indicador de instalações de esgoto & Percentual de domicílios que possuem instalações de esgoto \\
\hline Indicador de instalações elétricas & Percentual de domicílios que possuem instalações elétricas \\
\hline
\end{tabular}

Quadro 23: Composição do Indicador de Entorno

\begin{tabular}{|c|c|}
\hline Indicador & Variáveis \\
\hline Transporte e mobilidade & $\begin{array}{l}\text { Percentual de domicílios nos quais se utiliza ônibus para } \\
\text { trabalho }\end{array}$ \\
\hline Equipamentos comunitários e de serviços & $\begin{array}{l}\text { Percentual médio dos domicílios que utilizam creche, escola } \\
\text { e posto de saúde. }\end{array}$ \\
\hline Associativismo & $\begin{array}{l}\text { Percentual de domicílios nos quais se faz parte de algum } \\
\text { tipo de associação do bairro. }\end{array}$ \\
\hline $\begin{array}{l}\text { Espaços públicos fora da área de } \\
\text { intervenção }\end{array}$ & $\begin{array}{l}\text { Percentual de domicílios nos quais se utilizam outros } \\
\text { espaços públicos fora da área para lazer. }\end{array}$ \\
\hline
\end{tabular}

\subsubsection{Cálculo do indicador quantitativo final}

Para o cálculo dos indicadores finais utilizamos a média ponderada com os pesos obtidos na Tabela 74. Os resultados parciais e finais estão descritos na Tabela 75.

Note que a maioria dos indicadores e sub-indicadores situam-se em faixas superiores a 70\%, o que indica uma boa situação física, porém merecem atenção as seguintes variáveis: quartos, materiais de cobertura e paredes e as aberturas, no item moradia; esgotamento sanitário, drenagem e vias de circulação, no item salubridade ambiental e no item de entorno e serviços comunitários, a baixa utilização dos equipamentos comunitários e de serviços e a participação em associações. 
Tabela 75: Indicadores quantitativos - Pesquisa Piloto

\begin{tabular}{|c|c|c|c|c|}
\hline INDICADOR DE QUALIDADE AMBIENTAL & & & & $\mathbf{7 5 , 0 \%}$ \\
\hline INDICADOR DE MORADIA & & & & $\mathbf{7 5 , 7 \%}$ \\
\hline Cômodos & & & $84,6 \%$ & \\
\hline Cozinha & & $83,5 \%$ & & \\
\hline Banheiros & & $95,0 \%$ & & \\
\hline Quartos & & $56,7 \%$ & & \\
\hline Materiais & & & $69,3 \%$ & \\
\hline Material da cobertura & & $69,0 \%$ & & \\
\hline Material das paredes & & $67,0 \%$ & & \\
\hline Material do piso & & $75,2 \%$ & & \\
\hline Instalações & & & $93,5 \%$ & \\
\hline Instalações de água & & $95,9 \%$ & & \\
\hline Instalações de esgoto & & $88,4 \%$ & & \\
\hline Instalações elétricas & & $98,3 \%$ & & \\
\hline Aberturas & & & $50,8 \%$ & \\
\hline INDICADOR DE SALUBRIDADE AMBIENTAL & & & & $\mathbf{7 7 , 5 \%}$ \\
\hline Saneamento básico & & & $67,7 \%$ & \\
\hline Abastecimento de água & & $77,8 \%$ & & \\
\hline Abastecimento de água regularizado & $74,2 \%$ & & & \\
\hline Abastecimento de água irregular & $16,7 \%$ & & & \\
\hline Esgotamento sanitário & & $49,6 \%$ & & \\
\hline Esgotamento sanitário regularizado & $32,5 \%$ & & & \\
\hline Esgotamento sanitário irregular & $63,3 \%$ & & & \\
\hline Drenagem & & $67,1 \%$ & & \\
\hline Limpeza urbana & & $91,9 \%$ & & \\
\hline Coleta de lixo & $97,53 \%$ & & & \\
\hline Serviço de varrição & $61,7 \%$ & & & \\
\hline Infra-estrutura e outros serviços & & & $75,8 \%$ & \\
\hline Energia elétrica & & $97,1 \%$ & & \\
\hline Energia elétrica regularizada & $96,7 \%$ & & & \\
\hline Energia elétrica irregular & $1,7 \%$ & & & \\
\hline Iluminação pública & & $93,3 \% \%$ & & \\
\hline Espaços públicos & & $71,9 \%$ & & \\
\hline Vias de circulação & & $42,3 \%$ & & \\
\hline Condições físicas & & & $100,0 \%$ & \\
\hline Segurança geológico-geotécnica & & $100,0 \%$ & & \\
\hline Densidade demográfica & & $100,0 \%$ & & \\
\hline Condições sociais & & & $79,3 \%$ & \\
\hline Educação & & $76,1 \%$ & & \\
\hline Renda & & $86,7 \%$ & & \\
\hline Regularização fundiária & & & $75,8 \%$ & \\
\hline INDICADOR DE ENTORNO & & & & $66,5 \%$ \\
\hline Transporte e mobilidade & & & $95,6 \%$ & \\
\hline Equipamentos comunitários e de serviços & & & $53,2 \%$ & \\
\hline Associativismo & & & $19,8 \%$ & \\
\hline Espaços públicos fora da área & & & $48,8 \%$ & \\
\hline
\end{tabular}

\subsubsection{Considerações finais}

\subsubsection{Sobre a moradia}

$\mathrm{Na}$ análise dos pontos positivos e negativos os itens de quantidade de quartos, tamanho da casa e telhado foram identificados como pontos negativos. A incerteza em alguns casos pode ser reduzida por meio da separação em grupos distintos que melhor expliquem a falta de consenso. 
Já nas matrizes de relações identificamos algumas variáveis com maior relação com a avaliação final:

- para uma avaliação Péssimo/Ruim: instalações de água, instalações de esgoto e material das paredes Péssimo/Ruim pelo MDI e instalações de esgoto e elétricas Péssimo/Ruim pelo MSP;

- para uma avaliação Regular: ventilação Regular tanto no MDI como no MSP;

- para uma avaliação Bom/Ótimo: telhado Bom/Ótimo pelo MDI e tamanho da casa pelo MSP.

Já nos indicadores quantitativos destacamos os itens com maior peso dado pelos especialistas: banheiros, cobertura e instalações de água e esgoto. Note que um item considerado importante pelos moradores, tamanho da casa, que está relacionado ao número de quartos, não tem peso elevado na opinião dos especialistas. Como resultado, este indicador tem pouco impacto na avaliação do especialista e é um dos que apresenta pior desempenho, tanto qualitativo quanto quantitativo.

\subsubsection{Sobre a salubridade ambiental e o entorno}

Para estes dois grupos de variáveis teceremos comentários apenas sobre os pontos positivos e negativos e os indicadores quantitativos, visto que a matriz de relação foi obtida com uma variável aproximada, a avaliação do bairro. Porém, destacamos nesta aproximação que os serviços de abastecimento de água e energia elétrica Péssimo/Ruim estão relacionados a todas as avaliações finais, ou seja, se o serviço de abastecimento de água ou energia elétrica for Péssimo/Ruim a avaliação final pode ser qualquer uma. Por outro lado, são bem relacionados com uma avaliação final positiva Bom/Ótimo os seguintes itens positivos: largura da rua, rua como um todo e distância com telefone, além de outros itens regulares: esgotamento sanitário, coleta de lixo e funcionamento de bocas de lobo e sarjetas.

Sobre os pontos positivos e negativos da Salubridade ambiental:

- positivos: abastecimento de água, coleta de lixo, serviço de varrição, largura da rua e a rua como um todo, segurança do terreno, espaços públicos, energia elétrica, 
iluminação e segurança de posse. Em geral, estes indicadores também, apresentam melhor desempenho quantitativo;

- negativos: esgoto sanitário, bocas e sarjetas, segurança contra inundação e distância do telefone público. O indicador quantitativo de esgotamento sanitário é um dos que apresentam pior desempenho;

Sobre os pontos positivos e negativos do Entorno:

- positivos: todos os elementos analisados foram considerados positivos, apesar de alguns deles apresentarem uma incerteza alta. Destacamos também o fato de que um percentual muito baixo de pessoas participa de algum tipo de associação.

Observamos em alguns itens que nem sempre há concordância entre a opinião do morador e a opinião do especialista (aqui representada pela importância das variáveis, pesos) com relação à importância dada aos itens. Contudo, temos que ressaltar que, no caso da opinião do morador, esta mantém um processo de retroalimentação constante, de forma que as informações aqui apresentadas referem-se exclusivamente à comunidade pesquisada em um determinado momento. Porém, o método de obtenção pode ser replicado em outros momentos ou contextos. Já a opinião do especialista, mesmo podendo sofrer mudanças em relação ao contexto, tende a manter-se constante com relação às importâncias atribuídas. 


\section{MÉTODO PROPOSTO: CONSOLIDAÇÕES}

Após a pesquisa piloto alguns procedimentos foram consolidados e novas questões foram levantadas. A Figura 39 apresenta o método consolidado. O procedimento amostral para coleta de dados não foi considerado na pesquisa piloto, porém, uma discussão sobre o tema se fez necessária e será descrita a seguir. É importante também destacar que o formulário de campo também sofreu algumas mudanças, principalmente para incluir questões de avaliação geral (APÊNDICE D).

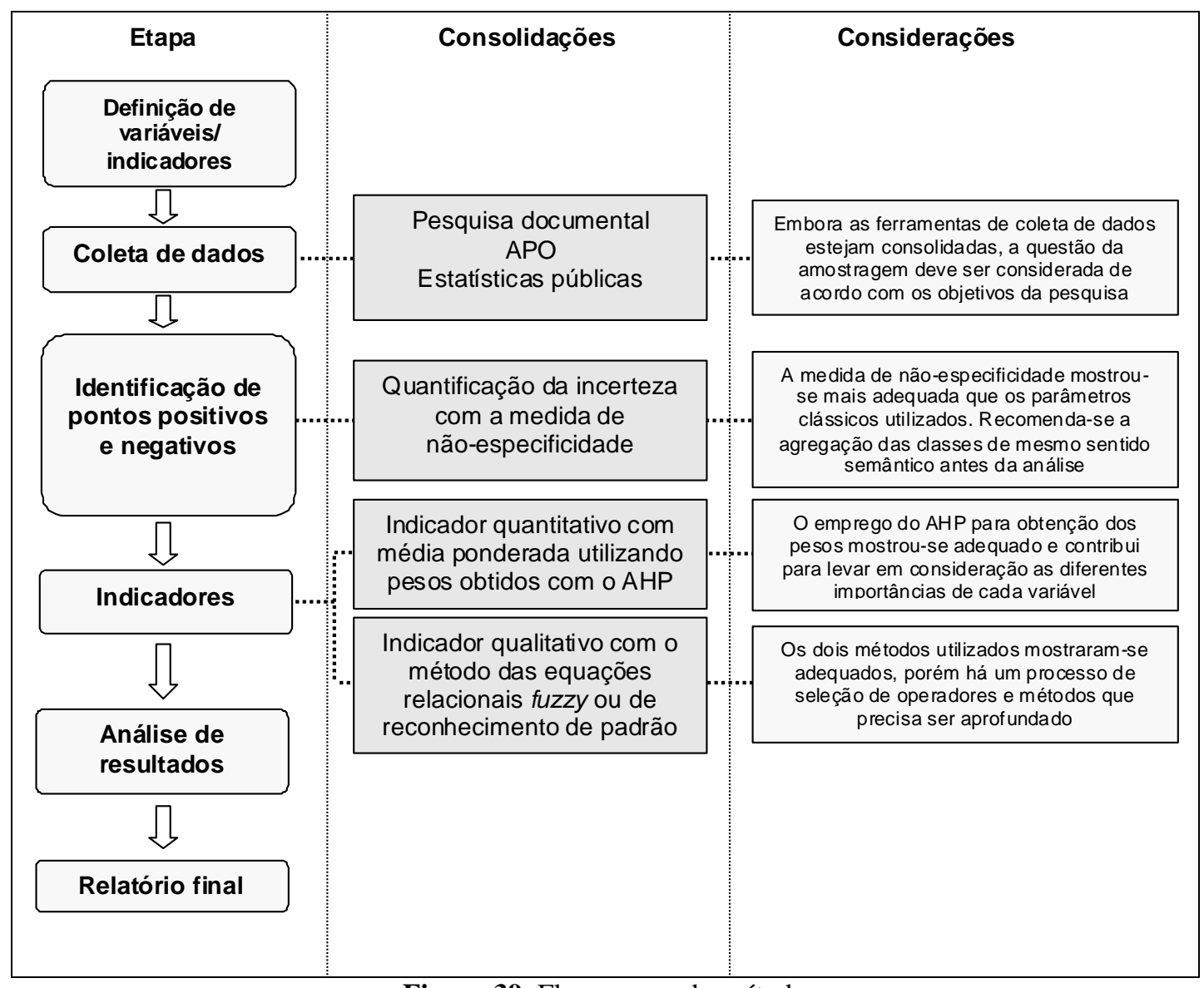

Figura 39: Fluxograma do método

\subsection{DEFINIÇÃO DE VARIÁVEIS/INDICADORES}

A definição das variáveis estará intimamente ligada ao objetivo da pesquisa, bem como a habilidade destas variáveis de representar o fenômeno em estudo. A pesquisa bibliográfica 
torna-se essencial nesta etapa. Os indicadores selecionados para este trabalho são descritos no

Quadro 24. Ressaltamos que, assim como nos estudos de APO, estes indicadores podem ser reduzidos ou ampliados de acordo com a pesquisa.

Quadro 24: Indicadores selecionados: consolidação

\begin{tabular}{|c|c|c|}
\hline Indicador & Componentes & Variáveis relacionadas \\
\hline \multirow[t]{16}{*}{ Moradia } & \multirow{5}{*}{ Composição e adequação } & Número de quartos \\
\hline & & Número de moradores \\
\hline & & Domicílios com uso de outros cômodos para dormir \\
\hline & & Domicílios sem banheiro \\
\hline & & Domicílios sem cozinha \\
\hline & \multirow[t]{2}{*}{ Cobertura } & Domicílios com material adequado no telhado \\
\hline & & Domicílios sem problemas no telhado quando chove \\
\hline & \multirow[t]{3}{*}{ Paredes } & Domicílios com material adequado nas paredes \\
\hline & & Domicílios com revestimento interno \\
\hline & & Domicílios com revestimento externo \\
\hline & \multirow[t]{2}{*}{ Piso } & Domicílios com material adequado no piso \\
\hline & & Domicílios sem problemas de umidade \\
\hline & Iluminação e ventilação natural & Domicílios com iluminação/ventilação em todos os cômodos \\
\hline & Instalações de água & Domicílios com instalação de água \\
\hline & Instalações de esgoto & Domicílios com instalação de esgoto \\
\hline & Instalações elétricas & Domicílios com instalação elétrica \\
\hline \multirow{31}{*}{$\begin{array}{l}\text { Salubridade } \\
\text { ambiental }\end{array}$} & \multirow[t]{2}{*}{ Abastecimento de água } & Domicílios atendidos com abastecimento de água \\
\hline & & Domicílios atendidos que recebem conta \\
\hline & \multirow[t]{2}{*}{ Esgoto } & Domicílios atendidos com rede de esgoto \\
\hline & & Domicílios atendidos que recebem conta \\
\hline & \multirow[t]{2}{*}{ Coleta de lixo } & Domicílios na favela com coleta de lixo \\
\hline & & Domicílios que depositam em locais inadequados \\
\hline & \multirow[t]{2}{*}{ Drenagem } & Habitações com problema de acesso em dias de chuva \\
\hline & & Habitações com problema de inundação em dias de chuva \\
\hline & \multirow[t]{4}{*}{ Vias de circulação } & Domicílios com via de acesso maior ou igual a 6 metros \\
\hline & & Domicílios com via de acesso entre 3,60 e 6,00 metros \\
\hline & & Domicílios com via de acesso entre 1,20 e 3,60 metros \\
\hline & & Domicílios com via de casso menor que 1,20 metros \\
\hline & \multirow[t]{3}{*}{ Segurança geológico-geotécnica } & Área sem risco \\
\hline & & Área com risco baixo \\
\hline & & Área com risco alto ou moderado \\
\hline & \multirow[t]{2}{*}{ Densidade demográfica bruta } & Número de moradores \\
\hline & & Área total da favela \\
\hline & \multirow[t]{2}{*}{ Energia elétrica } & Domicílios atendidos com energia elétrica \\
\hline & & Domicílios atendidos que recebem conta \\
\hline & \multirow[t]{4}{*}{ Regularização fundiária } & Domicílios em área regularizada \\
\hline & & Domicílios em área passível de ser regularizada, com projeto de lei em tramitação \\
\hline & & Domicílios em área passível de ser regularizada, sem projeto de lei em tramitação \\
\hline & & Domicílios em área sem possibilidade de regularização em curto prazo \\
\hline & \multirow[t]{3}{*}{ Varrição } & Domicílios com serviço de varrição \\
\hline & & Domicílios com varrição executada pelo morador \\
\hline & & Domicílios sem varrição \\
\hline & Iluminação Pública & Domicílios com iluminação pública \\
\hline & \multirow[t]{2}{*}{ Espaços públicos } & Existência de área de espaços públicos \\
\hline & & Percentual de população utilizadora destes espaços \\
\hline & Educação & População alfabetizada \\
\hline & Renda & Renda média dos responsáveis pelos domicílios \\
\hline \multirow[t]{10}{*}{ Entorno } & Transporte e mobilidade & Distâncias até o ponto de ônibus \\
\hline & \multirow{4}{*}{$\begin{array}{l}\text { Equipamentos comunitários e de } \\
\text { serviços }\end{array}$} & Domicílios em que se utiliza telefone público \\
\hline & & Domicílios em que se utiliza escola \\
\hline & & Domicílios em que se utiliza posto de saúde \\
\hline & & Domicílios em que se utiliza creche \\
\hline & Associativismo & Domicílios em que algum membro participa de associação \\
\hline & & Domicílios em que algum membro participa de associação de moradores \\
\hline & & Domicílios em que algum membro participa de cooperativa \\
\hline & & Domicílios em que algum membro participa de ONG \\
\hline & Espaços públicos & Domicílios em que os membros utilizam outros locais da cidade para lazer \\
\hline
\end{tabular}




\subsection{COLETA DE DADOS}

Os procedimentos de coleta de dados serão selecionados de acordo com a disponibilidade de recursos e dados sendo dividido em três grupos:

- Pesquisa documental: levantamento de material produzido sobre a área de estudo, como projetos e relatórios que também subsidiarão o planejamento da pesquisa de campo.

- Estatísticas públicas: bases de dados como do IBGE e outros órgãos de informações, estaduais e municipais, sempre que possível, também deverão ser levantadas.

- Avaliação pós-ocupação: o nível de APO dependerá dos objetivos da pesquisa, contudo, recomenda-se pelo menos a realização de walkthroughs e pesquisa de campo utilizando formulários com questões de múltipla escolha para avaliação dos moradores e questões técnicas a serem preenchidas pelo pesquisador. A aplicação de formulários levanta a questão da seleção dos entrevistados. No caso específico deste trabalho, como também objetivamos a obtenção de indicadores que valerão para toda a área utilizaremos alguns procedimentos amostrais que discutiremos a seguir.

\subsubsection{Amostragem}

A definição do processo de amostragem está intimamente ligada aos objetivos da pesquisa e das informações disponíveis. Destacamos que a primeira decisão a ser tomada está relacionada ao processo de seleção, que pode ser probabilístico ou não probabilístico. Existem inúmeras vantagens do processo probabilístico em relação ao não probabilístico, em sua maioria refletindo na precisão e nas possibilidades de generalização dos resultados para a população (OLIVEIRA, 2001). Por outro lado, neste processo exige-se um conjunto mínimo de informações sobre a população pesquisada, nem sempre disponíveis. Do lado do procedimento de seleção não probabilístico, pesa de forma negativa, a impossibilidade de generalização dos resultados por métodos estatísticos, mas sendo recomendada nos casos onde essa generalização não é necessária. 
Em nosso estudo, visto que os resultados devem ser considerados como representativos da população, ou seja, deverão retratar a realidade de toda a área pesquisada, o uso da amostragem probabilística torna-se imprescindível.

Neste caso devemos decidir ainda quanto ao critério do amostrista, que segundo Bolfarine e Bussab (2005) pode ser objetivo ou subjetivo. No primeiro caso adotado neste estudo, este critério garantirá que quando o procedimento for utilizado por pessoas distintas, produzirá a mesma amostra, ou uma com as mesmas propriedades.

Ainda no caso de uma amostra probabilística objetiva podemos ter outras subdivisões; contudo, como o nosso objetivo não é a discussão dos tipos de amostras, nos restringiremos a descrever o critério adotado para a seleção da amostra.

Em função das informações que dispomos sobre as áreas pesquisadas optamos por uma amostra aleatória simples sem reposição. Destacamos que obtivemos junto à Conder dados sobre o número de domicílios existentes na época da intervenção bem como alguns mapas cuja fidedignidade à realidade apresentada atualmente já não é total. Porém, dada a velocidade da dinâmica dos processos de ocupação, dificilmente será possível obter uma base atualizada. Neste sentido, Bolfarine e Bussab (2005) definem as populações possíveis de serem encontradas e que vale a pena descrever aqui, além de outros conceitos necessários ao entendimento da tomada de decisão, que são:

- Unidade elementar: ou simplesmente elemento de uma população, o objeto ou entidade portadora das informações que pretende-se coletar.

- População: ou universo, é a reunião de todas as unidades elementares, ou conjunto de elementos, cujas propriedades se investigam por meio de subconjuntos que lhes pertencem.

- População objetivo: ou população alvo, é a população que se pretende atingir, usualmente estabelecida nos objetivos da pesquisa.

- Sistema de referência: lista ou descrição das unidades amostrais da população, por meio da qual é possível selecionar a amostra.

- População referida: população previamente disponível e descrita pelo sistema de referência e para a qual podem ser construídas e selecionadas as amostras.

- População amostrada: população da qual foi retirada a amostra. 
Com base nestas definições ressaltamos que a população amostrada (de campo) não será a mesma população referida (mapas e listas), pois de fato sempre haverá uma defasagem de informações sobre a área nos registros. A população amostrada só poderá ser descrita, após a realização do levantamento, onde procuraremos verificar as possíveis diferenças entre a população referida e a amostrada.

\subsubsection{Definição dos parâmetros para seleção da amostra}

Em nosso estudo estaremos tratando na maioria das variáveis da determinação de proporções, ou seja, estaremos buscando determinar qual o percentual de domicílios que apresentam determinada característica.

Para determinação do tamanho da amostra é necessário definir alguns parâmetros, são eles:

- Intervalo de confiança: intervalo aleatório que contém a quantidade de interesse com probabilidade fixada.

- Coeficiente de confiança (1- $\alpha)$ : de modo prático, é o parâmetro para o qual garantese que se forem observadas 100 amostras e construídos 100 intervalos de confiança baseados nestas amostras, então, aproximadamente 100(1- $\alpha) \%$ dos intervalos devem conter o parâmetro estudado.

- Erro máximo de estimação (B): é a máxima diferença entre o valor "real" e o valor estimado com um determinado grau de confiança. Ou seja, definido o grau de confiança $(1-\alpha)$ e o erro máximo de estimação $B$, dizemos que o parâmetro $x$ está no intervalo $[x-B ; x+B]$ com um grau de confiança $100(1-\alpha) \%$.

De um modo geral, a definição destes parâmetros dependerá do conhecimento prévio sobre a população alvo e a da precisão que se deseja das generalizações. Ressaltamos que altos níveis de confiança e/ou baixos erros de estimação, geralmente implicam em tamanhos de amostras muito grandes. Logo, deveremos analisar o equilíbrio entre níveis de confiança e erros de estimação aceitáveis e custos de levantamento.

Para amostras aleatórias simples sem reposição o tamanho da amostra, definidos o coeficiente de confiança e o erro máximo de estimação, é dado pela fórmula: 


$$
n=\frac{N}{\frac{(N-1) D}{P Q}+1}
$$

onde $\mathrm{N}$ é o tamanho da população alvo, D é função do erro máximo de estimação e do coeficiente de confiança e é dado pela fórmula $D=\frac{B^{2}}{z_{\alpha}^{2}}$ e $z_{\alpha}$ é obtido da curva normal. P é a proporção do parâmetro em análise e $\mathrm{Q}=1$-P. Para uma dada população $\mathrm{N}$ e um coeficiente de confiança estabelecido, quando trabalhamos com proporções, em nosso caso freqüências, é possível demonstrar que o tamanho máximo da amostra $n$ é dado quando $\mathrm{P}=\mathrm{Q}=0,5$.

$\mathrm{Na}$ análise da fórmula acima percebemos que quanto menor for a população alvo, maior será o tamanho da amostra em relação ao tamanho da população alvo. Logo, para populações pequenas teremos que amostrar uma parcela maior da população para obtermos a mesma precisão obtida em uma população maior (Gráfico 18).

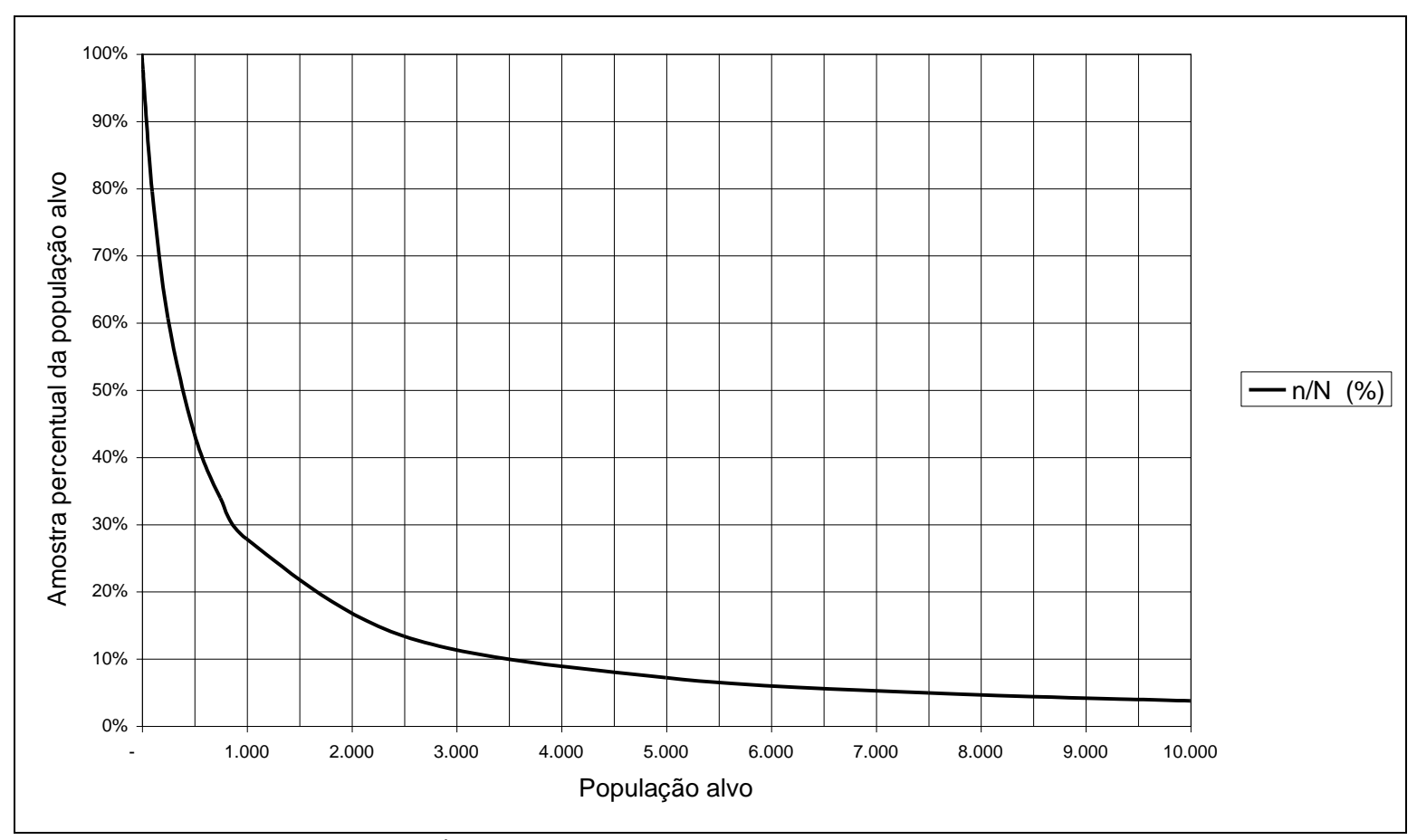

Gráfico 18: Percentual da população x população

Por fim, a definição dos parâmetros para o cálculo do tamanho de uma amostra é um juízo do pesquisador e depende tanto dos recursos disponíveis, quanto dos níveis de confiança desejados. 


\subsection{IDENTIFICAÇÃO DOS PONTOS POSITIVOS E NEGATIVOS}

A abordagem proposta, e consolidada, adota a medida de não-especificidade para quantificar as incertezas das informações sobre os pontos positivos e negativos. O procedimento de cálculo segue os seguintes passos:

- Calcular as frequiências de respostas por item avaliado.

- Normalizar as distribuições, dividindo cada valor pelo valor máximo da distribuição na resposta.

- Calcular a moda para cada distribuição de respostas, caso a moda seja Bom/Ótimo o item será considerado um ponto positivo, caso seja Péssimo/Ruim, será considerado um ponto negativo, caso seja Regular, verificar o segundo valor mais freqüente.

- Calcular a medida de não-especificidade, U-Incerteza, para cada distribuição. Alternativamente, pode-se calcular o grau de verdade como complemento da UIncerteza.

- Avaliar se os níveis de incerteza obtidos são aceitáveis. Caso contrário pode-se recorrer à análise por estratos.

Caso seja necessário, pode-se efetuar a abordagem clássica com o cálculo das médias e desvios-padrão para comparação dos resultados.

\subsection{INDICADORES}

\subsubsection{Indicadores qualitativos}

Os indicadores qualitativo poderão ser calculados por dois métodos: o método das equações relacionais fuzzy e o método de reconhecimento de padrão fuzzy.

No método das equações relacionais fuzzy deve ser seguido o procedimento:

- Agrupar os formulários por classe de avaliação final.

- Calcular as freqüências de avaliações parciais para cada grupo. 
- Normalizar as distribuições, dividindo-se cada valor pelo valor máximo da distribuição em cada item de avaliação parcial.

- Montar a matriz de avaliações parciais dispondo as avaliações parciais de cada grupo em uma única linha.

- Montar a matriz de avaliações parciais selecionando os valores a partir da matriz de avaliações parciais que mais se aproximem da matriz de avaliações finais ideais; podese utilizar os critérios propostos neste trabalho que são, pela menor distância ao subconjunto fuzzy ideal e a menor soma das pertinências.

- Definir a regra de composição: max-min, max-produto ou outra.

- Calcular a matriz de relação, avaliações parciais $x$ avaliações finais.

- Para avaliar o desempenho da matriz, pode-se fazer o teste com formulários, comparando-se as avaliações finais obtidas com o modelo e aquelas dadas pelos próprios moradores, e ao final calculando-se o percentual de acertos.

- Notar na matriz de avaliações parciais x avaliações finais aquelas variáveis com valores próximos a unidade, pois são aquelas que têm maior possibilidade de interferência nas avaliações finais.

No método de reconhecimento de padrão fuzzy o procedimento é similar, porém a avaliação final é obtida pela comparação do padrão de entrada com os padrões preestabelecidos. O procedimento é o seguinte:

- Agrupar os formulários por classe de avaliação final.

- Calcular as freqüências de avaliações parciais para cada grupo.

- Normalizar as distribuições, dividindo-se cada valor pelo valor máximo da distribuição em cada item de avaliação parcial.

- Os conjuntos de distribuições por grupo formam os padrões de respostas.

- Para obter o indicador final, comparar, utilizando o índice de conformidade, o conjunto de respostas a ser classificado com cada padrão de resposta já estabelecida.

- A classificação final será aquele grupo cujo índice de conformidade for máximo.

- Assim como no método das equações relacionais fuzzy, podemos calcular o nível de acertos como medida de desempenho do modelo. 


\subsubsection{Indicadores quantitativos}

Os indicadores quantitativos serão calculados de acordo com o Quadro 25, Quadro 26 e Quadro 27. Para o nosso objetivo, alguns indicadores selecionados, foram revisados e substituídos ou adequados. A maioria dos indicadores se manteve, a exceção dos indicadores de espaços públicos, renda, educação e transportes que foram remodelados conforme os quadros a seguir. A alteração nestes indicadores busca dar um maior sentido aos indicadores condensados de forma que quanto maiores são seus valores, melhores serão as condições ambientais da área.

Quadro 25: Composição do Indicador de Moradia: consolidação

\begin{tabular}{|l|l|}
\hline \multicolumn{1}{|c|}{ Indicador } & \multicolumn{1}{c|}{ Variáveis } \\
\hline Indicador de cozinha & Percentual de domicílios que possuem cozinha \\
\hline Indicador de banheiro & Percentual de domicílios que possuem banheiro \\
\hline Indicador de quartos & $\begin{array}{l}\text { Percentual de domicílios que possuem pelo menos 1 quarto para } \\
\text { cada duas pessoas }\end{array}$ \\
\hline Indicador de material da cobertura & $\begin{array}{l}\text { Média entre o percentual de domicílios que possuem material } \\
\text { durável na cobertura e não apresentam problemas nos período de } \\
\text { chuva }\end{array}$ \\
\hline Indicador de material das paredes & $\begin{array}{l}\text { Média entre o percentual de domicílios que possuem material } \\
\text { durável nas paredes, possuem revestimento interno e possuem } \\
\text { revestimento externo }\end{array}$ \\
\hline Indicador de material do piso & $\begin{array}{l}\text { Média entre o percentual de casas com piso e os que não } \\
\text { apresentam problemas de umidade. }\end{array}$ \\
\hline Indicador de instalações de água & Percentual dos domicílios que possuem instalações de água \\
\hline Indicador de instalações de esgoto & Percentual de domicílios que possuem instalações de esgoto \\
\hline Indicador de instalações elétricas & Percentual de domicílios que possuem instalações elétricas \\
\hline
\end{tabular}

Quadro 26: Composição do Indicador de Entorno

\begin{tabular}{|l|l|}
\hline \multicolumn{1}{|c|}{ Indicador } & \multicolumn{1}{c|}{ Variáveis } \\
\hline \multicolumn{1}{|c|}{} & $\begin{array}{l}\text { Média entre o I calculado para a maior didt6ancia percorrida } \\
\text { até o ponto de ônibus e o I calculado para a menor distância, } \\
\text { segundo a função: Se D <500m I=1, caso contrário, I= (D- } \\
500) / 500.500 \mathrm{~m} \text { é a distância percorrida máxima recomendada } \\
\text { para se chegar ao ponto de ônibus. }\end{array}$ \\
\hline Transporte e mobilidade & $\begin{array}{l}\text { Percentual médio dos domicílios que utilizam creche, escola e } \\
\text { posto de saúde. }\end{array}$ \\
\hline Assuipamentos comunitários e de serviços & $\begin{array}{l}\text { Percentual de domićlios nos quais se faz parte de algum tipo } \\
\text { de associação do bairro. }\end{array}$ \\
\hline $\begin{array}{l}\text { Espaços públicos fora da área de } \\
\text { intervenção }\end{array}$ & $\begin{array}{l}\text { Percentual de domićlios nos quais se utilizam outros espaços } \\
\text { públicos fora da área para lazer. }\end{array}$ \\
\hline
\end{tabular}


Quadro 27: Composição do Indicador de Salubridade Ambiental

\begin{tabular}{|c|c|c|}
\hline Indicador & Fórmula & Variáveis \\
\hline $\begin{array}{l}\text { Indicador de } \\
\text { abastecimento de } \\
\text { água }\end{array}$ & $I_{A G}=A_{R}+A_{I} \times \frac{p_{A I}}{p_{A R}}$ & $\begin{array}{l}A_{R}: \text { Percentual de domicílios com abastecimento de água } \\
\text { regularizado } \\
A_{I}: \text { Percentual de domicílios com abastecimento de água sem } \\
\text { regularização } \\
P_{A R}: \text { peso dos domicílios com abastecimento de água regularizado } \\
P_{A I}: \text { peso dos domicílios com abastecimento de água sem } \\
\text { regularização } \\
\text { A relação } \frac{p_{A I}}{p_{A R}} \text { representa o quanto os domicilio com abastecimento } \\
\text { sem regularização equivalem aos regularizados. }\end{array}$ \\
\hline $\begin{array}{l}\text { Indicador de } \\
\text { esgotamento } \\
\text { sanitário }\end{array}$ & $I_{E S}=E_{R}+E_{I} \times \frac{p_{E I}}{p_{E R}}$ & $\begin{array}{l}E_{R}: \text { Percentual de domicílios com esgotamento sanitário } \\
\text { regularizado } \\
E_{I}: \text { Percentual de domicílios com esgotamento sanitário sem } \\
\text { regularização } \\
P_{E R}: \text { peso dos domicílios com esgotamento sanitário regularizado } \\
P_{E I} \text { : peso dos domicílios com esgotamento sanitário sem } \\
\text { regularização } \\
\text { A relação } \frac{p_{E I}}{p_{E R}} \text { representa o quanto os domicilio com esgotamento } \\
\text { sem regularização equivalem aos regularizados. }\end{array}$ \\
\hline $\begin{array}{l}\text { Indicador de } \\
\text { drenagem }\end{array}$ & $I_{D}=\frac{\left(D_{n i}+D_{R n i}\right)}{2}$ & $\begin{array}{l}D_{n i}: \text { percentual de domicílios que não inundam quando chove } \\
D_{R n i}: \text { percentual de domicílios que não inundam quando chove }\end{array}$ \\
\hline $\begin{array}{l}\text { Indicador de } \\
\text { limpeza urbana }\end{array}$ & $I_{L U}=C \times p_{c}+V \times p_{v}$ & $\begin{array}{l}C: \text { percentual de domicílios atendidos com coleta regular ou } \\
\text { contêiner } \\
V: \text { percentual de domicílios onde há serviço de varrição } \\
p_{c}: \text { peso atribuído ao serviço de coleta } \\
p_{v}: \text { peso atribuído ao serviço de varrição }\end{array}$ \\
\hline $\begin{array}{l}\text { Indicador de } \\
\text { energia elétrica }\end{array}$ & $I_{E L}=E L_{R}+E L_{I} \times \frac{p_{E L I}}{p_{E L R}}$ & $\begin{array}{l}E L_{R}: \text { Percentual de domicílios com energia elétrica regularizada } \\
E L_{I}: \text { Percentual de domicílios com energia elétrica sem } \\
\text { regularização } \\
P_{E L R}: \text { peso dos domicílios com energia elétrica regularizada } \\
P_{E L I}: \text { peso dos domicílios com energia elétrica sem regularização } \\
\text { A relação } \frac{p_{E L I}}{p_{E L R}} \text { representa o quanto os domicilio com energia } \\
\text { elétrica sem regularização equivalem aos regularizados. }\end{array}$ \\
\hline $\begin{array}{l}\text { Indicador de } \\
\text { iluminação } \\
\text { pública }\end{array}$ & $I_{I L}=D_{I L}$ & $D_{I L}:$ percentual de domicílios com iluminação pública na rua \\
\hline $\begin{array}{l}\text { Indicador de } \\
\text { espaços públicos }\end{array}$ & $I_{E P}=D_{E P} \times \frac{A_{E P}}{0,35 \times A_{T}}$ & $\begin{array}{l}D_{E P}: \text { percentual de domicílios cujos entrevistados que utilizam os } \\
\text { espaços públicos } \\
A_{E P}: \text { área de espaços públicos } \\
A_{T}: \text { área total }\end{array}$ \\
\hline $\begin{array}{l}\text { Indicador de vias } \\
\text { públicas }\end{array}$ & $I_{\text {Vias }}=\sum D_{n} \times p_{n}$ & $\begin{array}{l}D_{n}: \text { percentual de domicílios na faixa } n \text { de largura } \\
p_{n}: \text { peso atribuído a faixa } n \text { de largura } \\
\text { largura acima de } 6 \mathrm{~m} p_{1}=1 \\
\text { largura entre } 3,6 \text { e } 6 \mathrm{~m} p_{2}=0,7 \\
\text { largura entre } 1,2 \text { e } 3,6 \mathrm{~m} p_{3}=0,35 \\
\text { largura abaixo de } 1,2 \mathrm{~m} p_{4}=0\end{array}$ \\
\hline $\begin{array}{l}\text { Indicador de } \\
\text { segurança } \\
\text { geológico- } \\
\text { geotécnica }\end{array}$ & $I_{S G}=\frac{A_{S}}{A_{T}}$ & $\begin{array}{l}A_{S}: \text { área com segurança geológico-geotécnica } \\
A_{T}: \text { área total }\end{array}$ \\
\hline $\begin{array}{l}\text { Indicador de } \\
\text { densidade }\end{array}$ & $I_{D D}=\left\{\begin{array}{c}d \text { se } 0<d \leq 100 \mathrm{hab} / \mathrm{ha} \\
100 \text { se } 100<d \leq 300 \mathrm{hab} / \mathrm{ha} \\
\frac{(500-d)}{200} \text { se } 300<d<500 \mathrm{hab} / \mathrm{ha} \\
0 \text { se } d \geq 500 \mathrm{hab} / \mathrm{ha}\end{array}\right.$ & $d:$ densidade demográfica \\
\hline $\begin{array}{l}\text { Indicador de } \\
\text { educação }\end{array}$ & $I_{E}=\frac{P_{A l f}}{P_{T}}$ & $\begin{array}{l}P_{a l f}: \text { população com } 5 \text { anos ou mais alfabetizada } \\
P_{T}: \text { população com } 5 \text { anos ou mais }\end{array}$ \\
\hline $\begin{array}{l}\text { Indicador de } \\
\text { renda }\end{array}$ & $I_{E}=\frac{R_{m A}}{R_{m M}}$ & $\begin{array}{l}R_{m A}: \text { renda média dos responsáveis pelos domicílios na área } \\
R_{m M}: \text { : renda média dos responsáveis pelos domicílios no município }\end{array}$ \\
\hline $\begin{array}{l}\text { Indicador de } \\
\text { regularização } \\
\text { fundiária }\end{array}$ & $I_{R F}$ & $\begin{array}{l}\text { Percentual da população que afirma ter algum tipo de documento de } \\
\text { posse }\end{array}$ \\
\hline
\end{tabular}




\subsection{ANÁLISE DOS RESULTADOS}

Os resultados serão analisados de acordo com os procedimentos já definidos e os resultados farão parte do relatório de qualidade ambiental.

\subsection{RELATÓRIO DE QUALIDADE AMBIENTAL}

O relatório de qualidade ambiental deverá ser composto das seguintes seções:

- Histórico e descrição da área de estudos.

- Descrição dos dados coletados.

- Identificação de pontos positivos e negativos da área.

- Indicadores qualitativos e quantitativos da área, com possíveis análises sobre as variáveis mais importantes do ponto de vista do morador e aquelas mais carentes do ponto de vista técnico.

- E por fim, as considerações finais e recomendações. 


\section{VALIDAÇÃO DO MÉTODO: ALAGADOS I E II}

\section{1 ÁREAS DE ESTUDO}

Os estudos de validação foram desenvolvidos em outras duas áreas do Programa Ribeira Azul, cujas obras já haviam sido concluídas há cerca de sete anos. Embora sejam áreas vizinhas, apresentam diferenças no relevo que justificam a avaliação separada das áreas. Aspectos como os sistemas viário e de drenagem diferem consideravelmente entre as áreas e devem refletir também nos pontos positivos e negativos das áreas. As pesquisas de campo foram realizadas no período de março a junho de 2007 (março e abril em Alagados II e maio e junho em Alagados I) e seguiram os mesmos procedimentos da pesuisa piloto, exceto pela seleção dos domicílios, que desta vez foi feita utilizando amostra aleatória simples sem reposição. A seguir faremos uma breve descrição das áreas seguidas dos resultados obtidos.

\subsubsection{Alagados I}

A área de Alagados I apresentava sérios problemas de insalubridade pelas precárias condições de infra-estrutura urbana (Figura 40). Com aproximadamente 3,87ha, em determinadas áreas eram improvisadas redes de esgotamento sanitário por iniciativa da própria população atingindo $10 \%$ da comunidade. Quanto à limpeza urbana, havia uma certa regularidade na coleta de lixo, mas não atingia toda área. As casas eram servidas de água e energia elétrica, utilizando-se de ligações clandestinas, embora algumas possuíssem medidores de energia mas, sem funcionamento. As vias internas se encontravam em péssimo estado, sem pavimentação, com esgoto a céu aberto, contribuindo para a proliferação de vetores de doenças, expondo a população, principalmente as crianças, a tais riscos.

As intervenções na área integraram o Programa "Viver Melhor" desenvolvido pelo Estado por meio da Secretaria de Recursos Hídricos, Saneamento e Habitação - SRHSH e URBIS, com recursos do FGTS/Pró-Moradia 97 e do Governo Estadual. O resumo, a seguir, do projeto de Alagados I foi feito baseado no PATS, já mencionado na pesquisa piloto e em documentos 
disponibilizados pela Conder. Como já afirmamos para Novos Alagados $-1^{\text {a }}$. Etapa, os dados não são muito precisos.

O projeto urbanístico e de infra-estrutura beneficiou as 537 famílias da comunidade com novo sistema viário e mobiliário urbano. As tipologias utilizadas para o reassentamento foram:

- Embrião com $16,40 \mathrm{~m}^{2}$ composto por 1 sala, 1 cozinha e 1 banheiro;

- Embrião com 40,00m², modelo BA-70 dúplex composto por 2 quartos, 1 sala, 1 cozinha e área de serviço;

- Embrião com 29,00 m², modelo BA-70 GD2 composto por 1 quarto, 1 sala, 1 cozinha e área de serviço.

Foram construídas 53 unidades sanitárias, 30 embriões, 60 unidades tipo BA-70 dúplex, 108 unidades tipo BA 70 GD2, totalizando 198 novas unidades habitacionais. Foi feito também o remanejamento de 18 famílias para o loteamento Jardim Valéria II - Coutos, Vale das Cambonas e Baixinho de Santo Antonio e reassentamento de 99 famílias para as novas unidades construídas na própria comunidade.

O projeto contemplou a execução de $900 \mathrm{~m}^{2}$ de pavimentação em asfalto, $5.188 \mathrm{~m}^{2}$ de caminho em concreto, $4.151 \mathrm{~m}$ de rede de água, $4.536 \mathrm{~m}$ de rede de esgoto, $2.360 \mathrm{~m}$ de drenagem. Os dados socioeconômicos já foram apresentados no Capítulo 7. 


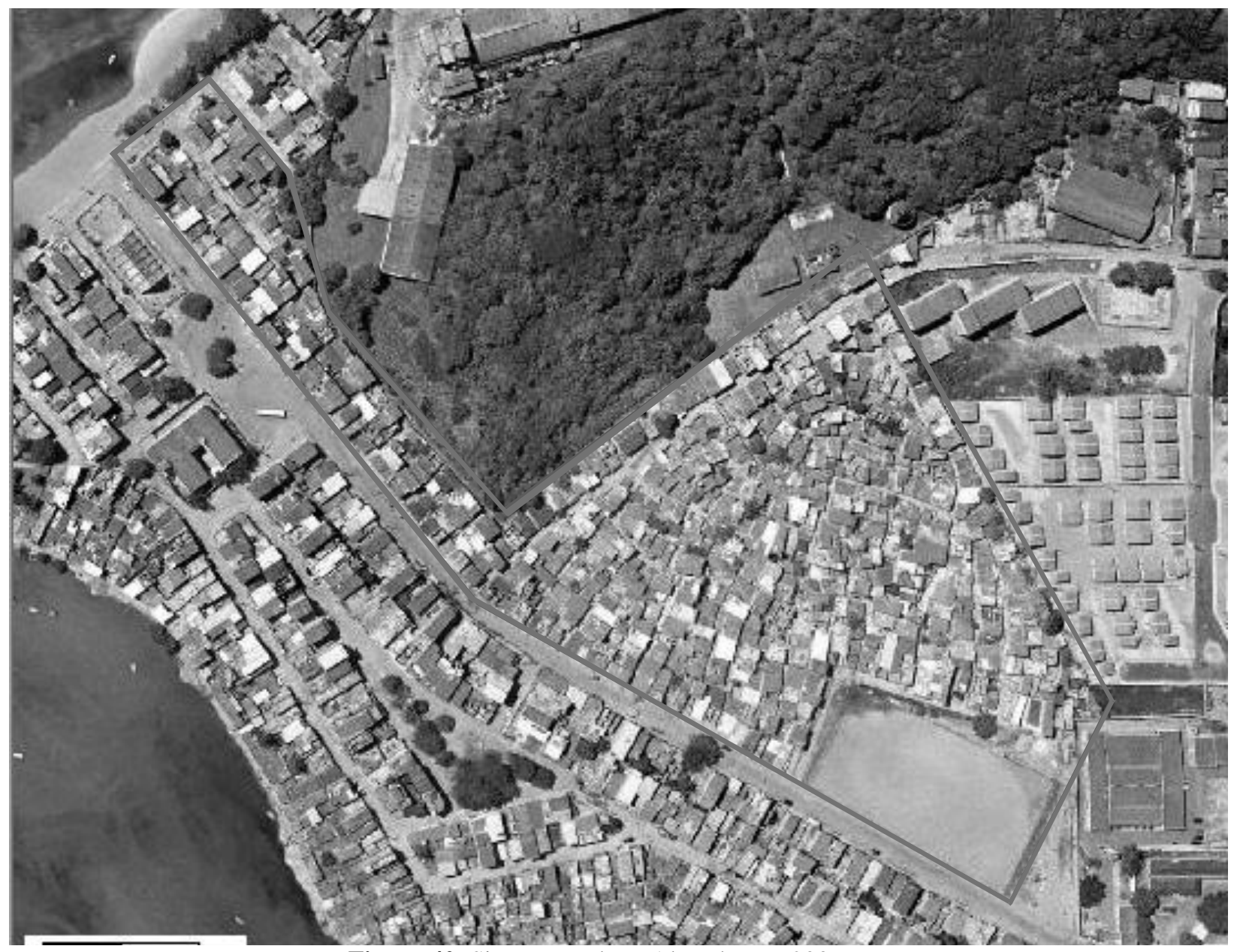

Figura 40: Situação real em Alagados I - 2006

Fonte: www.mapadigital.salvador.ba.gov.br

\subsubsection{Alagados II}

O assentamento denominado Alagados II faz parte de um conjunto de ocupações irregulares, nas proximidades do bairro de Massaranduba e da Península de Itapagipe (Figura 41). Na época do cadastramento do projeto havia $90 \%$ de casas em alvenaria de bloco de até 2 pavimentos. As demais eram em madeira e/ou chapas em palafitas. Não existiam unidades sanitárias em 94\% das habitações. A área, com aproximadamente 3,93ha, apresentava situação de risco, com possibilidade de alagamentos e desabamentos. Não havia área pavimentada, os serviços em geral possuíam cobertura parcial ou irregular. 


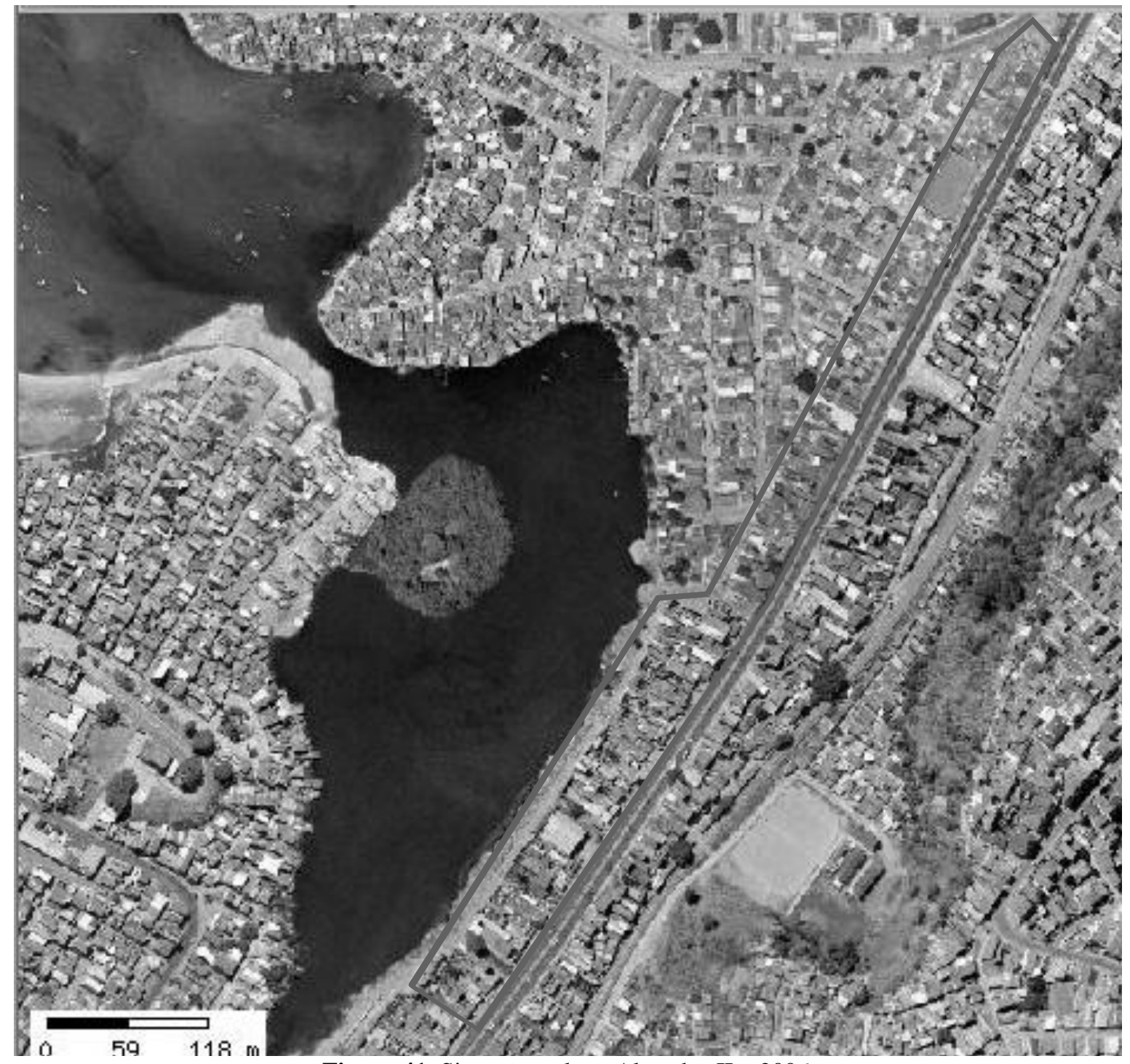

Figura 41: Situação real em Alagados II - 2006

Fonte: www.mapadigital.salvador.ba.gov.br

As intervenções na área também integraram o Programa "Viver Melhor" desenvolvido pelo Estado por meio da SRHSH e URBIS, com recursos do FGTS/Pró-Moradia 97 e do Governo Estadual.

Assim como em Alagados I, neste item, o resumo é baseado no PATS, já referido. O projeto urbanístico e de infra-estrutura beneficiou as 214 famílias da comunidade com novo sistema viário e mobiliário urbano. As tipologias utilizadas para o reassentamento foram:

- Embrião com 16,40 m² composto por 1 sala, 1 cozinha e 1 banheiro;

- Embrião com $40,00 \mathrm{~m}^{2}$, modelo BA-70 dúplex composto por 2 quartos, 1 sala, 1 cozinha e área de serviço; 
- Embrião com 29,00m² , modelo BA-70 GD2 composto por 1 quarto, 1 sala, 1 cozinha e área de serviço.

Foram construídos 27 embriões, 06 unidades tipo BA-70, 88 unidades tipo BA-70 GD2, 06 unidades sanitárias, totalizando 121 unidades habitacionais. 38 famílias foram remanejadas para o loteamento Jardim Valéria II e reassentamento de 37 famílias para novas unidades habitacionais construídas na comunidade.

A obra para execução do projeto urbanístico e de infra-estrutura está concluída. O projeto contemplou a execução de $6.700 \mathrm{~m}^{3}$ de corte de solo, $86.873 \mathrm{~m}^{3}$ de aterro em solo, $243 \mathrm{~m}^{2}$ de caminho em concreto, $2.389 \mathrm{~m}$ de rede de água, $2.557 \mathrm{~m}$ de rede de esgoto, $1.259 \mathrm{~m}$ de drenagem. Assim como Alagados I, os dados sócio-econômicos de Alagados II já foram apresentados no Capítulo 7.

\subsubsection{Amostragem}

Adotamos o procedimento de amostragem aleatória simples. Para definirmos o tamanho da amostra, calculamos diversos tamanhos para a maior população alvo (801 domicílios - Tabela 76) e verificamos quais os erros máximos e coeficientes de confiança poderiam ser tolerados em função dos custos e tempos necessários para o levantamento dos dados (Gráfico 19). Visto que o número de famílias beneficiadas difere em alguns documentos consultados, foram adotados os maiores valores encontrados nos documentos (Tabela 76).

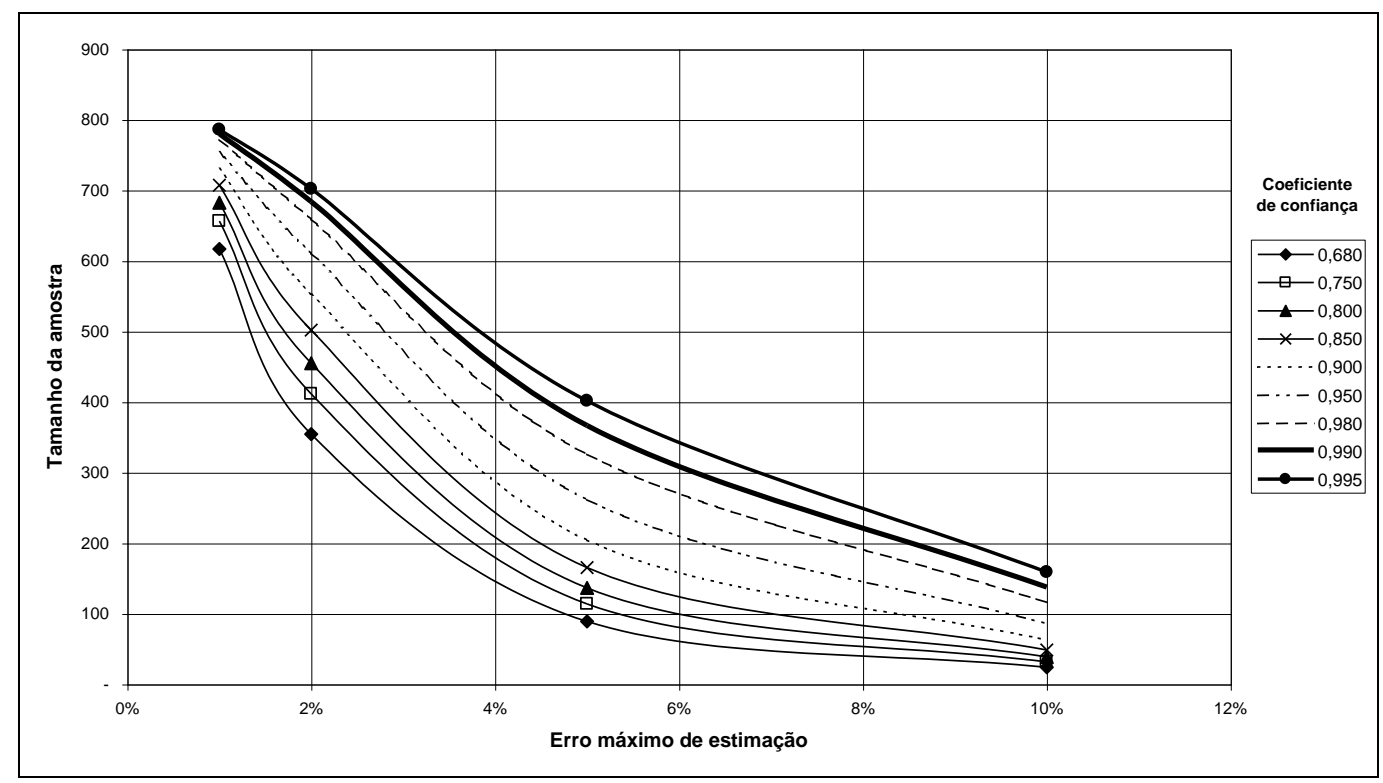

Gráfico 19: Tamanhos das amostras para diferentes erros de estimação e coeficientes de confiança 
Optamos por uma amostra com erro máximo de estimação de 5\% com um coeficiente de confiança mínimo de $80 \%$. Vale destacar que esses valores foram obtidos para um produto máximo PQ (igual a 0,25), o qual produzirá o maior tamanho de amostra para os parâmetros selecionados.

Adotando estes parâmetros para a outra área encontramos os seguintes tamanhos de amostra da Tabela 76.

Tabela 76: População e tamanho da amostra nas áreas de estudo

\begin{tabular}{l|c|c|c|c|c}
\hline Área de intervenção & $\begin{array}{c}\text { População } \\
\text { beneficiada } \\
\text { (Domicílios) }\end{array}$ & $\begin{array}{c}\text { Tamanho da } \\
\text { amostra }\end{array}$ & Reserva (10\%) & Total de formulários & \% da população alvo \\
\hline Alagados I & 801 & 137 & 14 & 151 & $17,1 \%$ \\
Alagados II & 362 & 114 & 11 & 125 & $31,5 \%$ \\
\hline
\end{tabular}

A partir desta análise e com as bases cadastrais disponibilizadas pela Conder, associamos a cada lote no mapa um número e utilizando um programa desenvolvido para geração de números aleatórios sorteamos o total de domicílios no tamanho das amostras (Figura $42 \mathrm{e}$ Figura 43). Algumas moradias amostradas estavam fechadas ou eram utilizadas exclusivamente para comércio, nestas situações, a moradia mais próxima (à direita ou à esquerda) substituiu a selecionada. Note que em Alagados I o número de casas onde não foi possível aplicar o formulário foi bem menor que em Alagados II, cuja poligonal engloba um trecho lateral da Avenida Suburbana, com intenso comércio. O total de formulários foi mantido nas duas áreas e não houve descarte de nenhum deles na tabulação dos dados. 


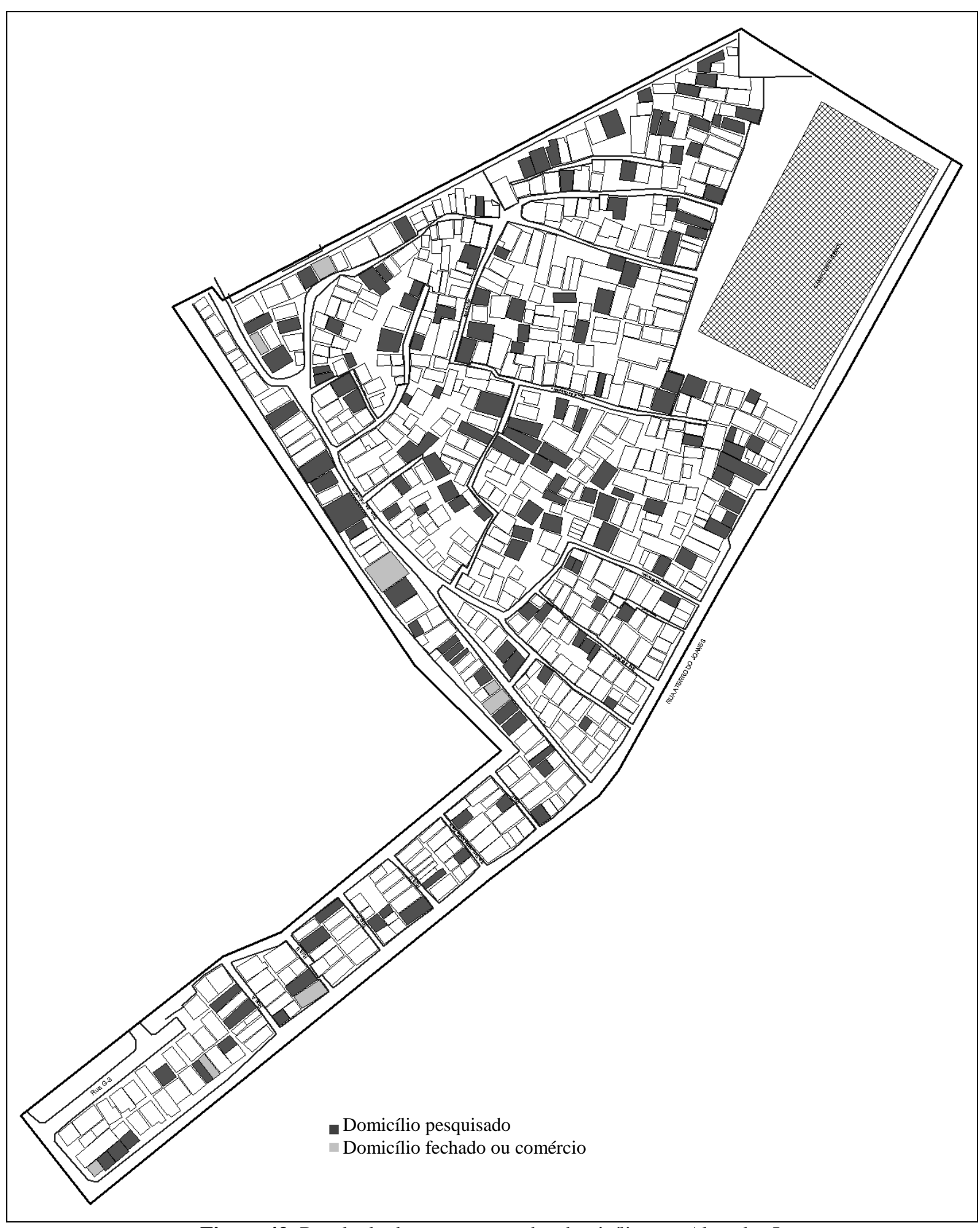

Figura 42: Resultado da amostragem dos domicílios em Alagados I 


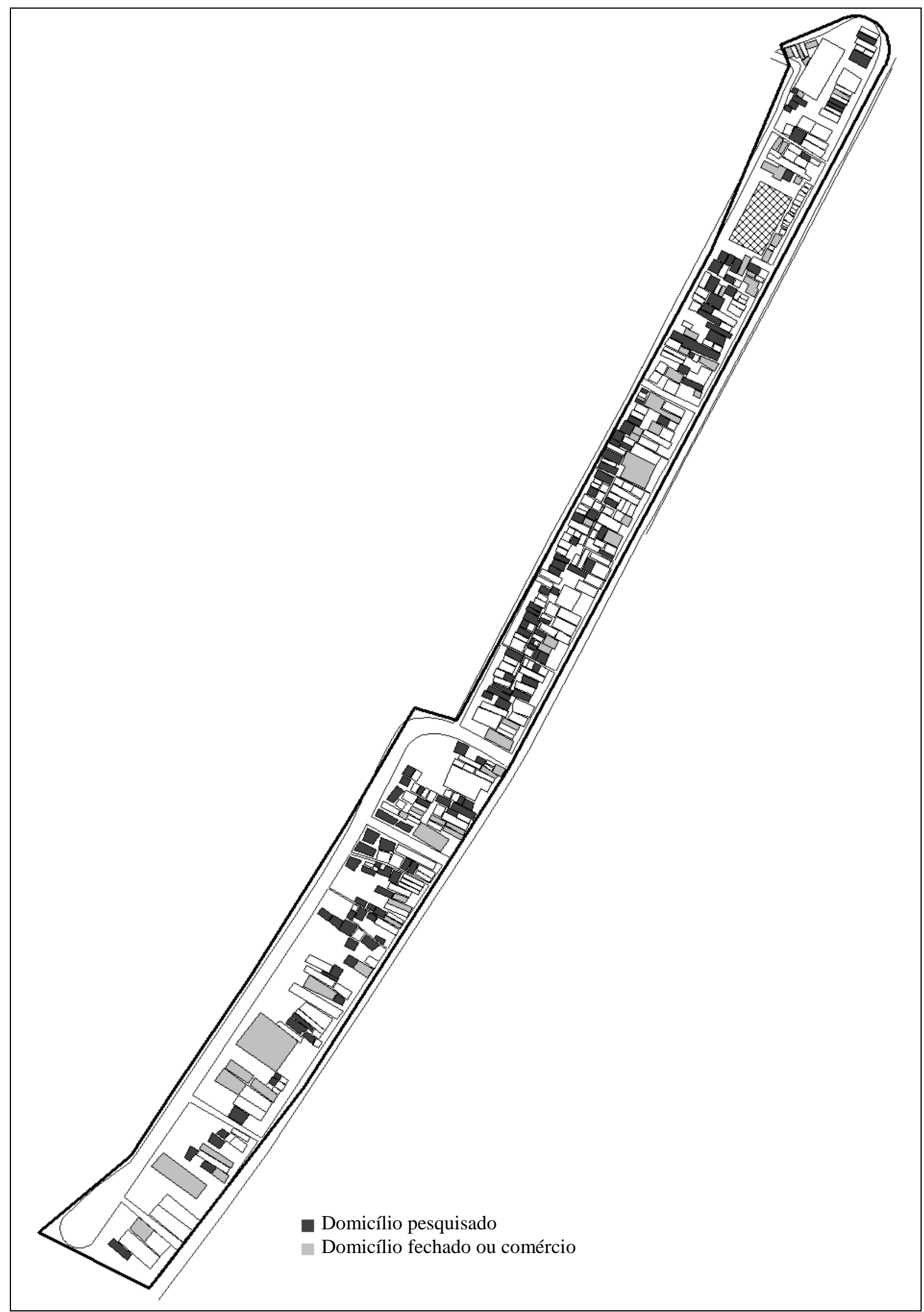

Figura 43: Resultado da amostragem de domicílios em Alagados II 


\subsection{DESCRIÇÃO DOS DADOS COLETADOS}

\subsubsection{Caracterização}

Tanto em Alagados I como em Alagados II a maioria das casas pesquisadas foi construída pelo morador (Figura 44 e Figura 45), com uma média de quatro pessoas por domicílio e renda mensal média em torno de 1,5 SM. O grau de escolaridade dos chefes de família não alfabetizados é relativamente baixo e o tempo de residência na área é em média 22,5 anos em Alagados I e 16,4 anos em Alagados II (Tabela 77).

Tabela 77: Caracterização dos domicílios pesquisados - Alagados I e II

\begin{tabular}{|c|c|c|c|}
\hline & & Alagados I & Alagados II \\
\hline Tipo de moradia & $\begin{array}{l}\text { Construída pela CONDER } \\
\text { Construída pela CONDER e ampliada } \\
\text { Construída pelo morador } \\
\text { Adquirida de outros } \\
\text { Alugada } \\
\text { Outros } \\
\end{array}$ & $\begin{array}{c}14,4 \% \\
24,2 \% \\
46,4 \% \\
15,0 \% \\
0,0 \% \\
0,0 \% \\
\end{array}$ & $\begin{array}{c}7,2 \% \\
9,6 \% \\
74,4 \% \\
4,0 \% \\
2,4 \% \\
2,4 \% \\
\end{array}$ \\
\hline Quantas pessoas moram na casa & $\begin{array}{l}\text { Média } \\
\text { Moda } \\
\text { Mediana } \\
\text { Desvio padrão } \\
\text { Mínimo } \\
\text { Máximo } \\
\end{array}$ & $\begin{array}{l}4,10 \\
5,00 \\
4,00 \\
1,49 \\
1,00 \\
7,00 \\
\end{array}$ & $\begin{array}{c}4,14 \\
4,00 \\
4,00 \\
1,75 \\
1,00 \\
10,00 \\
\end{array}$ \\
\hline Renda média da família & $\begin{array}{l}\text { Média } \\
\text { Moda } \\
\text { Mediana } \\
\text { Desvio padrão } \\
\text { Mínimo } \\
\text { Máximo }\end{array}$ & $\begin{array}{l}1,71 \\
2,00 \\
2,00 \\
0,67 \\
0,50 \\
3,50 \\
\end{array}$ & $\begin{array}{l}1,54 \\
1,00 \\
1,50 \\
0,73 \\
0,30 \\
6,00 \\
\end{array}$ \\
\hline Grau de escolaridade do chefe da família & $\begin{array}{l}\text { Não alfabetizado } \\
1^{\circ} \text {. Grau } \\
2^{\circ} \text {. Grau }\end{array}$ & $\begin{array}{r}3,9 \% \\
46,4 \% \\
49,7 \% \\
\end{array}$ & $\begin{array}{l}8,0 \% \\
68,0 \% \\
24,0 \% \\
\end{array}$ \\
\hline Grau de escolaridade máximo no domicílio & $\begin{array}{l}\text { Não alfabetizado } \\
1^{\circ} \text {. Grau } \\
2^{\circ} \text {. Grau }\end{array}$ & $\begin{array}{c}0,0 \% \\
25,5 \% \\
74,5 \% \\
\end{array}$ & $\begin{array}{l}0,0 \% \\
29,6 \% \\
70,4 \% \\
\end{array}$ \\
\hline Tempo de residência na área & $\begin{array}{l}\text { Média } \\
\text { Moda } \\
\text { Mediana } \\
\text { Desvio padrão } \\
\text { Mínimo } \\
\text { Máximo }\end{array}$ & $\begin{array}{c}22,48 \\
24,00 \\
23,00 \\
2,84 \\
6,00 \\
30,00 \\
\end{array}$ & $\begin{array}{c}16,42 \\
18,00 \\
16,00 \\
5,29 \\
2,00 \\
41,00 \\
\end{array}$ \\
\hline Tempo de residência na casa & $\begin{array}{l}\text { Média } \\
\text { Moda } \\
\text { Mediana } \\
\text { Desvio padrão } \\
\text { Mínimo } \\
\text { Máximo }\end{array}$ & $\begin{array}{c}21,33 \\
24,00 \\
22,00 \\
4,23 \\
5,00 \\
26,00\end{array}$ & $\begin{array}{c}11,77 \\
15,00 \\
13,00 \\
4,46 \\
0,40 \\
20,00\end{array}$ \\
\hline
\end{tabular}




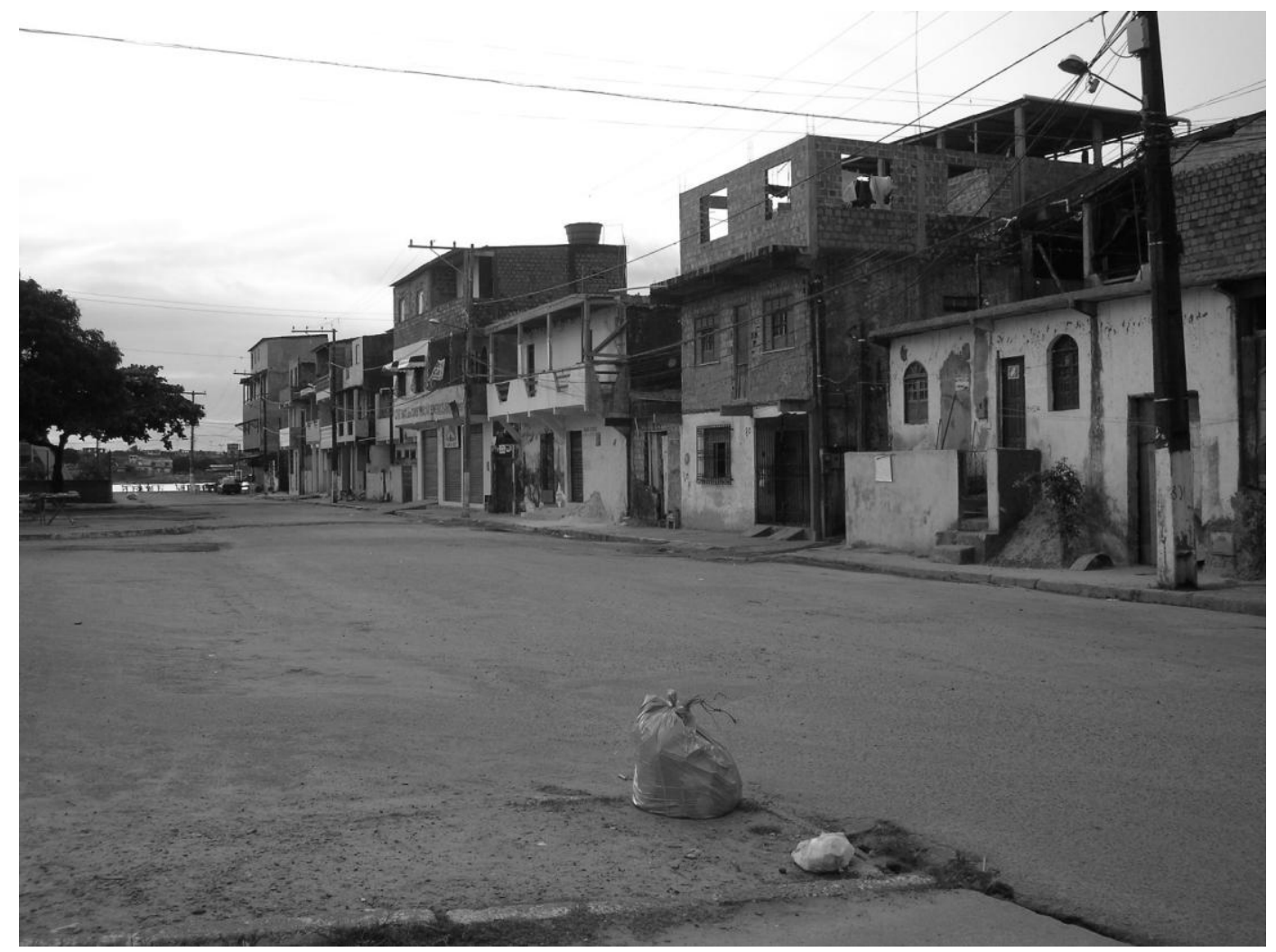

Figura 44: Autoconstrução na via principal de Alagados I

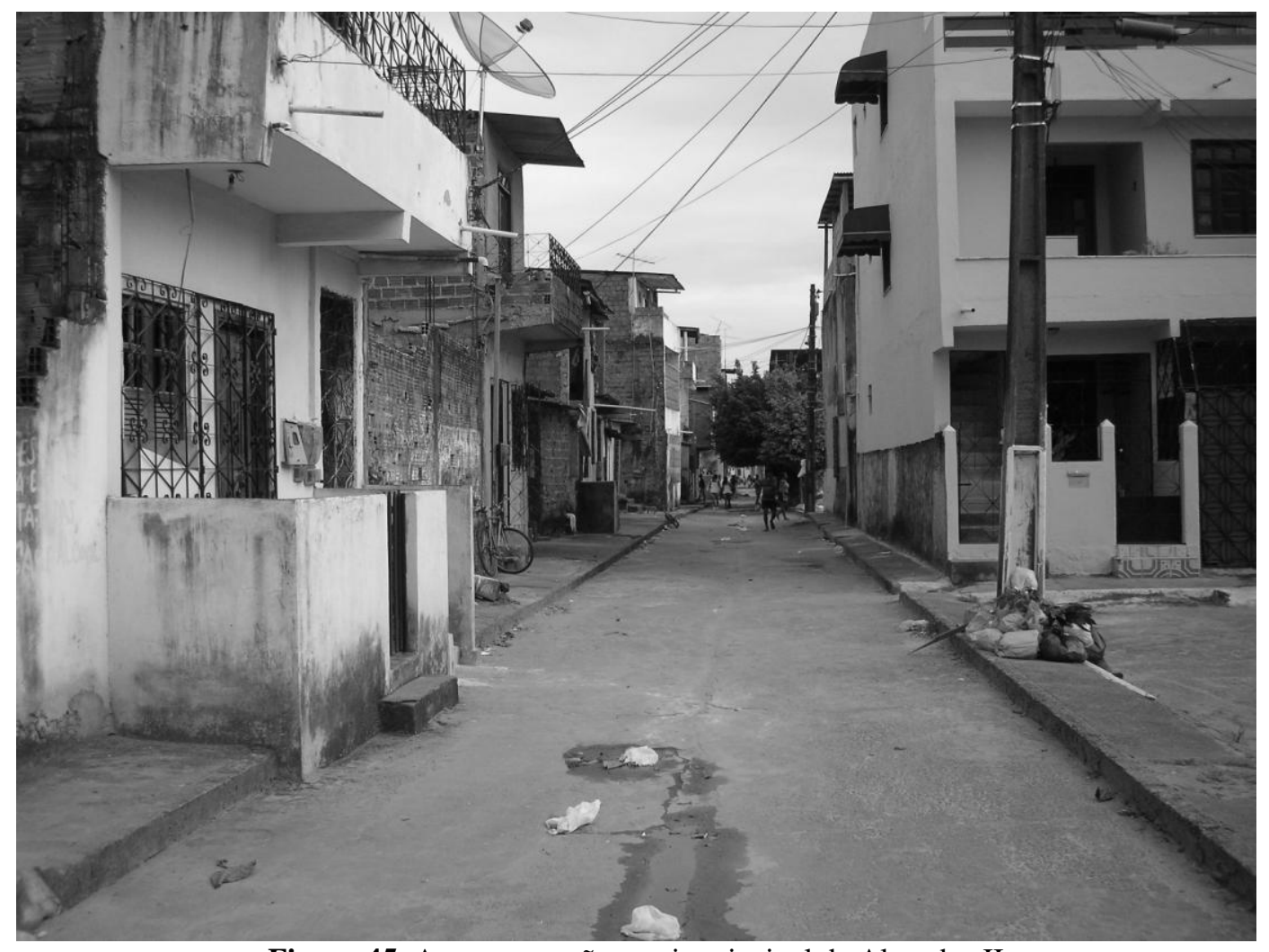

Figura 45: Autoconstrução na via principal de Alagados II 


\subsubsection{Moradia}

\subsubsection{Composição e adequação}

Em Alagados I as casas são em sua maioria compostas por sala, quarto, cozinha e banheiro, sendo que $15 \%$ não possuem quartos. Mesmo que esse percentual pareça baixo, a situação de inadequação agrava-se pelo percentual de domicílios onde outros cômodos são utilizados para dormir que é de 37,9\%. Já em Alagados II as moradias também são compostas, em sua maioria, por sala, quarto, cozinha e banheiro, sendo que 9,6\% dos domicílios não possuem quartos e quase $1 / 3$ utiliza outros cômodos para dormir (Tabela 78).

Tabela 78: Composição e adequação dos domicílios - Alagados I e II

\begin{tabular}{l|l|c|c}
\hline \multicolumn{2}{l|}{} & Alagados I & Alagados II \\
\hline & Sala & $100,0 \%$ & $99,2 \%$ \\
& Quarto & $85,0 \%$ & $90,4 \%$ \\
& Cozinha & $100,0 \%$ & $87,2 \%$ \\
& Banheiro & $100,0 \%$ & $100,0 \%$ \\
& Área de serviço & $48,4 \%$ & $30,4 \%$ \\
& Varanda & $28,1 \%$ & $22,4 \%$ \\
\hline \multirow{5}{*}{ Quantidade de quartos } & Não possui & $15,0 \%$ & $9,6 \%$ \\
& 1 Quarto & $30,7 \%$ & $31,2 \%$ \\
& 2 Quartos & $46,4 \%$ & $49,6 \%$ \\
& 3 Quartos & $7,2 \%$ & $9,6 \%$ \\
& 4 Quartos & $0,7 \%$ & $0,0 \%$ \\
\hline \multirow{3}{*}{ Utiliza outros cômodos para dormir } & Não respondeu & $0,0 \%$ & $4,8 \%$ \\
& Sim & $37,9 \%$ & $31,2 \%$ \\
& Não & $62,1 \%$ & $64,0 \%$ \\
\hline
\end{tabular}

A inadequação espacial reflete-se na avaliação do número de quartos onde há um percentual significativo de avaliações negativas comparadas com os outros itens (Tabela 79).

Tabela 79: Ambientes: avaliação do morador - Alagados I e II

\begin{tabular}{|c|c|c|c|c|c|c|c|c|}
\hline \multirow[t]{2}{*}{ Avaliação } & \multicolumn{2}{|c|}{$\begin{array}{c}\text { Avaliação do número de } \\
\text { quartos }\end{array}$} & \multicolumn{2}{|c|}{ Avaliação do banheiro } & \multicolumn{2}{|c|}{ Avaliação do cozinha } & \multicolumn{2}{|c|}{$\begin{array}{c}\text { Avaliação do tamanho da } \\
\text { casa }\end{array}$} \\
\hline & Alagados I & Alagados II & Alagados I & Alagados II & Alagados I & Alagados II & Alagados I & Alagados II \\
\hline Não respondeu & $14,4 \%$ & $8,8 \%$ & $0,0 \%$ & $0,8 \%$ & $0,0 \%$ & $8,0 \%$ & $0,0 \%$ & $0,8 \%$ \\
\hline Péssimo & $3,9 \%$ & $6,4 \%$ & $0,7 \%$ & $2,4 \%$ & $0,0 \%$ & $0,0 \%$ & $2,6 \%$ & $12,8 \%$ \\
\hline Ruim & $19,6 \%$ & $20,0 \%$ & $11,1 \%$ & $12,8 \%$ & $1,3 \%$ & $12,8 \%$ & $13,7 \%$ & $12,8 \%$ \\
\hline Regular & $28,8 \%$ & $33,6 \%$ & $36,6 \%$ & $40,8 \%$ & $34,6 \%$ & $36,8 \%$ & $30,1 \%$ & $32,8 \%$ \\
\hline Bom & $30,7 \%$ & $25,6 \%$ & $50,3 \%$ & $36,0 \%$ & $62,1 \%$ & $35,2 \%$ & $51,6 \%$ & $29,6 \%$ \\
\hline Ótimo & $2,6 \%$ & $5,6 \%$ & $1,3 \%$ & $7,2 \%$ & $2,0 \%$ & $7,2 \%$ & $2,0 \%$ & $11,2 \%$ \\
\hline
\end{tabular}


10.2.2.2 Instalações

Em Alagados I todos os moradores entrevistados afirmam ter instalações de água, esgoto e elétricas em suas residências; a avaliação quanto ao funcionamento das mesmas é bastante positiva. Em Alagados II há um pequeno percentual sem estas instalações e as avaliações são predominantemente positivas (Tabela 80 e Tabela 81 ).

Tabela 80: Instalações de água, esgoto e elétricas - Alagados I e II

\begin{tabular}{l|l|c|c}
\hline \multicolumn{2}{l}{} & Alagados I & Alagados II \\
\hline \multirow{3}{*}{ Instalações de água } & Não respondeu & $0,0 \%$ & $0,8 \%$ \\
& Sim & $100,0 \%$ & $97,6 \%$ \\
& Não & $0,0 \%$ & $1,6 \%$ \\
\hline \multirow{3}{*}{ Instalações de esgoto } & Não respondeu & $0,0 \%$ & $0,0 \%$ \\
& Sim & $100,0 \%$ & $100,0 \%$ \\
& Não & $0,0 \%$ & $0,0 \%$ \\
\hline \multirow{5}{*}{ Instalações elétricas } & Não respondeu & $0,0 \%$ & $0,0 \%$ \\
& Embutida & $7,2 \%$ & $37,6 \%$ \\
& Aparente & $0,0 \%$ & $7,2 \%$ \\
& Embutida na parede e aparente no teto & $87,6 \%$ & $51,2 \%$ \\
& Mista & $5,2 \%$ & $4,0 \%$ \\
\hline
\end{tabular}

Tabela 81: Instalações: avaliação do morador - Alagados I e II

\begin{tabular}{|c|c|c|c|c|c|c|}
\hline \multirow{2}{*}{ Avaliação } & \multicolumn{2}{|c|}{ Instalações de água } & \multicolumn{2}{|c|}{ Instalações de esgoto } & \multicolumn{2}{|c|}{ Instalações elétricas } \\
\hline & Alagados I & Alagados II & Alagados I & Alagados II & Alagados I & Alagados II \\
\hline Não respondeu & $0,0 \%$ & $1,6 \%$ & $0,0 \%$ & $0,0 \%$ & $0,0 \%$ & $0,0 \%$ \\
\hline Péssimo & $0,0 \%$ & $1,6 \%$ & $0,0 \%$ & $1,6 \%$ & $0,0 \%$ & $1,6 \%$ \\
\hline Ruim & $0,0 \%$ & $1,6 \%$ & $0,0 \%$ & $1,6 \%$ & $0,0 \%$ & $4,0 \%$ \\
\hline Regular & $14,4 \%$ & $33,6 \%$ & $14,4 \%$ & $34,4 \%$ & $12,4 \%$ & $27,2 \%$ \\
\hline Bom & $85,0 \%$ & $56,8 \%$ & $85,0 \%$ & $55,2 \%$ & $87,6 \%$ & $64,8 \%$ \\
\hline Ótimo & $0,7 \%$ & $4,8 \%$ & $0,7 \%$ & $7,2 \%$ & $0,0 \%$ & $2,4 \%$ \\
\hline
\end{tabular}

10.2.2.3 Materiais do teto, parede e piso

Em ambos, Alagados I e II, o material predominante da cobertura é a telha de fibrocimento e nas paredes o tijolo furado, com a maioria das casas possuindo revestimento interno e externo. Já o revestimento do piso é em sua maioria de cimento queimado ou grosso em Alagados I e em Alagados II há uma proporção similar de cimento queimado e cerâmico (Tabela 82). 
Tabela 82: Materiais e acabamento do telhado, paredes e piso - Alagados I e II

\begin{tabular}{ll|c|c}
\hline & & Alagados I & Alagados II \\
\hline \multirow{4}{*}{ Telhado } & Não respondeu & $0,0 \%$ & $0,0 \%$ \\
& Telha cerâmica & $28,1 \%$ & $12,8 \%$ \\
& Telha de amianto & $60,8 \%$ & $52,0 \%$ \\
& Laje & $11,1 \%$ & $31,2 \%$ \\
& Misto & $0,0 \%$ & $4,0 \%$ \\
\hline \multirow{5}{*}{ Paredes } & Não respondeu & $0,0 \%$ & $0,0 \%$ \\
& Tijolos furados & $100,0 \%$ & $97,6 \%$ \\
& Blocos de cimento & $0,0 \%$ & $1,6 \%$ \\
& Outros & $0,0 \%$ & $0,8 \%$ \\
\hline \multirow{5}{*}{ Revestimento Interno } & Não respondeu & $0,0 \%$ & $0,0 \%$ \\
& Sim & $79,7 \%$ & $77,6 \%$ \\
& Não & $0,0 \%$ & $10,4 \%$ \\
& Em algumas partes & $20,3 \%$ & $12,0 \%$ \\
\hline \multirow{5}{*}{ Piso } & Não respondeu & $0,0 \%$ & $0,0 \%$ \\
& Sim & $79,7 \%$ & $60,0 \%$ \\
& Não & $0,0 \%$ & $8,8 \%$ \\
& Em algumas partes & $20,3 \%$ & $31,2 \%$ \\
\hline & Não respondeu & $0,0 \%$ & $0,0 \%$ \\
& Sem piso & $0,0 \%$ & $4,0 \%$ \\
& Cimento queimado & $57,5 \%$ & $47,2 \%$ \\
& Cimento grosso & $32,0 \%$ & $3,2 \%$ \\
& Cerâmica & $10,5 \%$ & $45,6 \%$ \\
& Barro & $0,0 \%$ & $0,0 \%$ \\
& Outros & $0,0 \%$ & $0,0 \%$ \\
\hline
\end{tabular}

Em Alagados I, um percentual baixo afirma que existem problemas no telhado e no piso, estes indicadores são acompanhados de uma boa avaliação destes componentes, a exceção do piso que apresenta alto percentual de avaliação Regular. Em Alagados II estes percentuais são um pouco maiores, mas a avaliação, em todo caso, é positiva (Tabela 83 e Tabela 84).

Tabela 83: Problemas do telhado, paredes e piso - Alagados I e II

\begin{tabular}{l|c|c|c|c}
\hline \multirow{2}{*}{ Problemas } & \multicolumn{2}{|c|}{ Telhado quando chove } & \multicolumn{2}{c}{ Umidade } \\
\cline { 2 - 5 } & Alagados I & Alagados II & Alagados I & Alagados II \\
\hline Não respondeu & $0,0 \%$ & $1,6 \%$ & $0,0 \%$ & $1,6 \%$ \\
Sim & $11,8 \%$ & $17,6 \%$ & $14,4 \%$ & $25,6 \%$ \\
Não & $88,2 \%$ & $80,8 \%$ & $85,6 \%$ & $72,8 \%$ \\
\hline
\end{tabular}

Tabela 84: Telhado, paredes e piso: avaliação do morador - Alagados I e II

\begin{tabular}{|c|c|c|c|c|c|c|}
\hline \multirow{2}{*}{ Avaliação } & \multicolumn{2}{|c|}{ Telhado } & \multicolumn{2}{|c|}{ Paredes } & \multicolumn{2}{|c|}{ Piso } \\
\hline & Alagados I & Alagados II & Alagados I & Alagados II & Alagados I & Alagados II \\
\hline Não respondeu & $0,0 \%$ & $0,8 \%$ & $0,0 \%$ & $1,6 \%$ & $0,0 \%$ & $4,0 \%$ \\
\hline Péssimo & $0,0 \%$ & $4,0 \%$ & $0,0 \%$ & $1,6 \%$ & $0,0 \%$ & $7,2 \%$ \\
\hline Ruim & $7,8 \%$ & $9,6 \%$ & $2,6 \%$ & $8,0 \%$ & $3,9 \%$ & $16,0 \%$ \\
\hline Regular & $19,6 \%$ & $27,2 \%$ & $35,9 \%$ & $35,2 \%$ & $53,6 \%$ & $37,6 \%$ \\
\hline Bom & $72,5 \%$ & $55,2 \%$ & $61,4 \%$ & $50,4 \%$ & $42,5 \%$ & $32,8 \%$ \\
\hline Ótimo & $0,0 \%$ & $3,2 \%$ & $0,0 \%$ & $3,2 \%$ & $0,0 \%$ & $2,4 \%$ \\
\hline
\end{tabular}




\subsubsection{Aberturas}

Em Alagados I, nenhum domicílio possui aberturas em todos os cômodos, o que se reflete numa avaliação predominantemente Regular. Apenas 13,6\% dos domicílios possuem aberturas em todos os cômodos e a avaliação deste item é considerada em torno do Regular. Em Alagados II a situação é um pouco melhor, porém a avaliação também é predominantemente Regular (Tabela 85 e Tabela 86)

Tabela 85: Janelas ou aberturas - Alagados I e II

\begin{tabular}{l|c|c}
\hline Possui janelas ou cobogós em todos os ambientes & Alagados I & Alagados II \\
\hline Sim & $0,0 \%$ & $13,6 \%$ \\
Não & $100,0 \%$ & $86,4 \%$ \\
\hline
\end{tabular}

\begin{tabular}{l|c|c}
\multicolumn{2}{c}{ Tabela 86: Ventilação: avaliação do morador - Alagados I e II } \\
\hline \multicolumn{1}{c}{ Avaliação } & Alagados I & Alagados II \\
\hline Não respondeu & $0,0 \%$ & $0,8 \%$ \\
Péssimo & $0,0 \%$ & $8,0 \%$ \\
Ruim & $3,3 \%$ & $17,6 \%$ \\
Regular & $88,9 \%$ & $56,8 \%$ \\
Bom & $7,8 \%$ & $16,8 \%$ \\
Ótimo & $0,0 \%$ & $0,0 \%$ \\
\hline
\end{tabular}

\subsubsection{Salubridade ambiental}

\subsubsection{Saneamento básico}

Em Alagados I as taxas de cobertura dos serviços nesta área são bastante altas: nenhum morador afirmou não possuir qualquer tipo de serviço de saneamento. Apesar de não existir um sistema de bocas de lobo devido à situação do terreno com grande declive, não há relato de problemas de inundação. O único serviço com um percentual significativo de avaliação negativa foi o serviço de varrição. Porém o serviço de coleta de lixo foi considerado apenas Regular, talvez associado ao tipo de coleta, que em função da largura das vias não pode ser feito pelo caminhão coletor. Em Alagados II os serviços de abastecimento de água e esgoto também atingem taxas muito altas, porém a coleta de lixo apresenta um grande percentual de disposição inadequada, em pontos de lixo. O serviço de varrição, em grande parte, é realizado pelos moradores e um número considerável de domicílios está sujeito a inundação da rua 
quando chove. Em relação a inundação das casas é possível identificar no registro fotográfico muitas moradias com barreiras contra inundação, o que pode explicar a baixa frequiência de respostas afirmando a ocorrência de inundação das casas (Tabela 87).

Tabela 87: Saneamento básico - Alagados I e II

\begin{tabular}{|c|c|c|c|c|}
\hline & & & Alagados I & Alagados II \\
\hline \multirow[t]{2}{*}{$\begin{array}{l}\text { Abastecimento de } \\
\text { água }\end{array}$} & Origem da água & \begin{tabular}{|l|} 
Não respondeu \\
Água Encanada \\
Chafariz \\
Fonte \\
Vizinho \\
Outros: Gato \\
\end{tabular} & $\begin{array}{c}0,0 \% \\
100,0 \% \\
0,0 \% \\
0,0 \% \\
0,0 \% \\
0,0 \% \\
\end{array}$ & $\begin{array}{c}0,0 \% \\
98,4 \% \\
0,0 \% \\
0,0 \% \\
1,6 \% \\
0,0 \%\end{array}$ \\
\hline & Recebe conta & $\begin{array}{l}\text { Não respondeu } \\
\text { Sim } \\
\text { Não }\end{array}$ & $\begin{array}{c}0,0 \% \\
100,0 \% \\
0,0 \% \\
\end{array}$ & $\begin{array}{c}0,0 \% \\
85,6 \% \\
14,4 \% \\
\end{array}$ \\
\hline \multirow{2}{*}{$\begin{array}{l}\text { Esgotamento } \\
\text { sanitário }\end{array}$} & $\begin{array}{l}\text { Possui ligação com rede de } \\
\text { esgoto ou fossa }\end{array}$ & $\begin{array}{l}\text { Não respondeu } \\
\text { Rede de esgoto } \\
\text { Fossa } \\
\text { Não possui esgoto } \\
\end{array}$ & $\begin{array}{c}0,0 \% \\
100,0 \% \\
0,0 \% \\
0,0 \% \\
\end{array}$ & $\begin{array}{c}0,8 \% \\
94,4 \% \\
3,2 \% \\
1,6 \% \\
\end{array}$ \\
\hline & Recebe conta de esgoto & $\begin{array}{l}\text { Não respondeu } \\
\text { Sim } \\
\text { Não }\end{array}$ & $\begin{array}{c}0,0 \% \\
100,0 \% \\
0,0 \%\end{array}$ & $\begin{array}{c}4,8 \% \\
75,8 \% \\
19,4 \% \\
\end{array}$ \\
\hline \multirow{2}{*}{ Coleta de lixo } & Tipo de coleta de lixo & $\begin{array}{l}\text { Não respondeu } \\
\text { Caminhão de porta em porta } \\
\text { Gari de porta em porta } \\
\text { Contêiner mais próximo } \\
\text { Ponto de lixo mais próximo }\end{array}$ & $\begin{array}{c}0,0 \% \\
7,2 \% \\
0,0 \% \\
92,8 \% \\
0,0 \%\end{array}$ & $\begin{array}{c}0,0 \% \\
22,4 \% \\
6,4 \% \\
1,6 \% \\
69,6 \%\end{array}$ \\
\hline & Freqüência da coleta & $\begin{array}{l}\text { Não respondeu } \\
\text { Todo dia } \\
\text { Dia sim, dia não } \\
\text { Uma vez por semana }\end{array}$ & $\begin{array}{c}0,0 \% \\
99,3 \% \\
0,7 \% \\
0,0 \%\end{array}$ & $\begin{array}{c}33,6 \% \\
37,6 \% \\
2,4 \% \\
26,4 \%\end{array}$ \\
\hline $\begin{array}{l}\text { Serviço de } \\
\text { varrição }\end{array}$ & Quem varre a rua & $\begin{array}{l}\text { Não respondeu } \\
\text { Gari } \\
\text { Morador } \\
\text { Não é varrida }\end{array}$ & $\begin{array}{c}0,0 \% \\
41,2 \% \\
58,8 \% \\
0,0 \%\end{array}$ & $\begin{array}{c}0,0 \% \\
19,2 \% \\
80,0 \% \\
0,8 \%\end{array}$ \\
\hline \multirow{2}{*}{ Drenagem } & Quando chove inunda a rua & $\begin{array}{l}\text { Sim } \\
\text { Não }\end{array}$ & $\begin{array}{c}0,0 \% \\
100,0 \%\end{array}$ & $\begin{array}{l}36,8 \% \\
63,2 \%\end{array}$ \\
\hline & Quando chove inunda a casa & $\begin{array}{l}\text { Sim } \\
\text { Não }\end{array}$ & $\begin{array}{c}0,0 \% \\
100,0 \%\end{array}$ & $\begin{array}{c}3,2 \% \\
96,8 \%\end{array}$ \\
\hline
\end{tabular}

A avaliação dos moradores na Tabela 88 reflete as taxas de coberturas dos serviços avaliados, sendo de Regular a Boa para a maioria. Contudo, atenção especial deve ser dada a questão dos alagamentos em Alagados II (Tabela 89 e Figura 48) e a coleta de lixo em ambas as áreas (Figura 46 e Figura 47).

Tabela 88: Saneamento básico: avaliação do morador - Alagados I e II

\begin{tabular}{l|c|c|c|c|c|c|c|c|c|c}
\hline \multirow{2}{*}{ Avaliação } & \multicolumn{2}{|c|}{ Abastecimento de água } & \multicolumn{2}{c|}{ Esgotamento sanitário } & \multicolumn{2}{c|}{ Coleta de lixo } & \multicolumn{2}{c}{ Serviço de varrição } & \multicolumn{2}{c}{ Bocas de lobo e sarjetas } \\
\cline { 2 - 9 } & Alagados I & Alagados II & Alagados I & Alagados II & Alagados I & Alagados II & Alagados I & Alagados II & Alagados I & Alagados II \\
\hline Não respondeu & $0,0 \%$ & $0,8 \%$ & $0,0 \%$ & $5,6 \%$ & $0,0 \%$ & $0,0 \%$ & $0,0 \%$ & $0,0 \%$ & $8,5 \%$ & $58,9 \%$ \\
Péssimo & $0,0 \%$ & $1,6 \%$ & $0,7 \%$ & $5,6 \%$ & $0,0 \%$ & $8,8 \%$ & $1,3 \%$ & $7,3 \%$ & $0,0 \%$ & $5,6 \%$ \\
Ruim & $0,0 \%$ & $0,8 \%$ & $1,3 \%$ & $10,5 \%$ & $1,3 \%$ & $16,8 \%$ & $33,3 \%$ & $18,7 \%$ & $0,0 \%$ & $14,5 \%$ \\
Regular & $34,6 \%$ & $9,6 \%$ & $76,5 \%$ & $50,0 \%$ & $81,7 \%$ & $11,2 \%$ & $47,7 \%$ & $49,6 \%$ & $2,0 \%$ & $8,1 \%$ \\
Bom & $65,4 \%$ & $84,0 \%$ & $21,6 \%$ & $27,4 \%$ & $17,0 \%$ & $59,2 \%$ & $17,6 \%$ & $21,1 \%$ & $89,5 \%$ & $12,1 \%$ \\
Ótimo & $0,0 \%$ & $3,2 \%$ & $0,0 \%$ & $0,8 \%$ & $0,0 \%$ & $4,0 \%$ & $0,0 \%$ & $3,3 \%$ & $0,0 \%$ & $0,8 \%$ \\
\hline
\end{tabular}




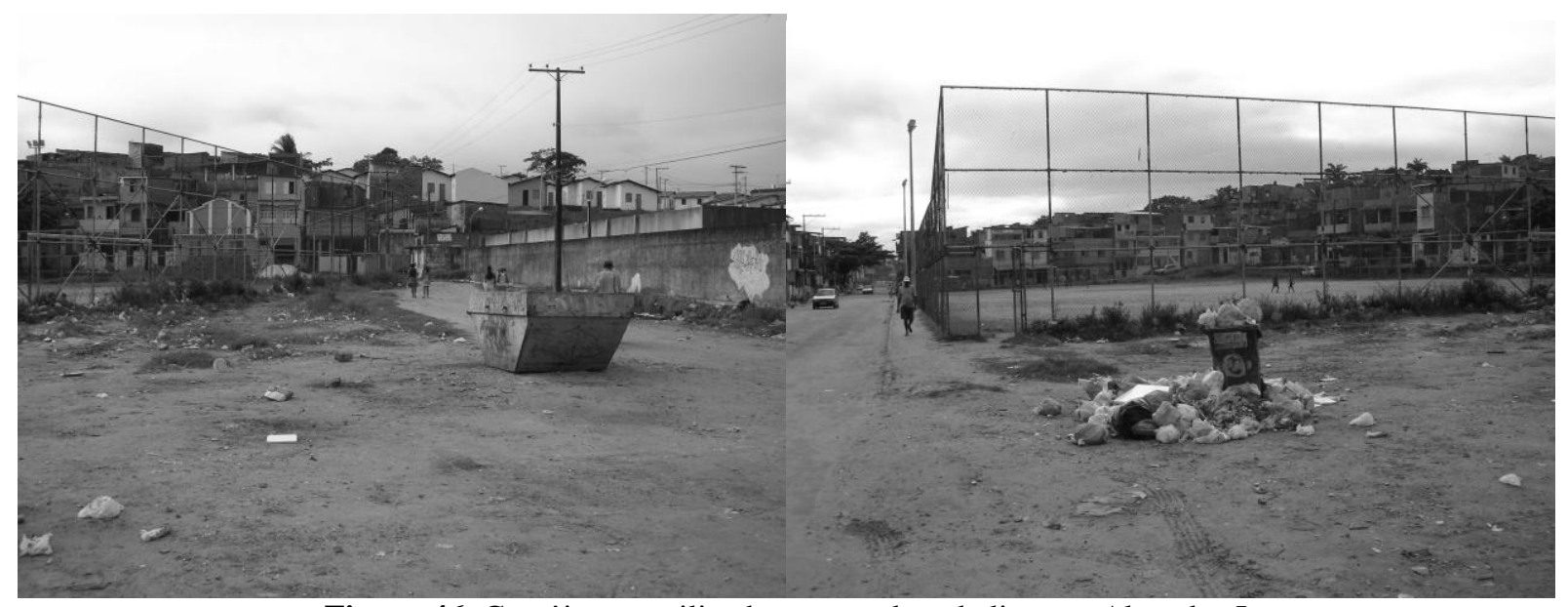

Figura 46: Contêineres utilizados para coleta de lixo em Alagados I

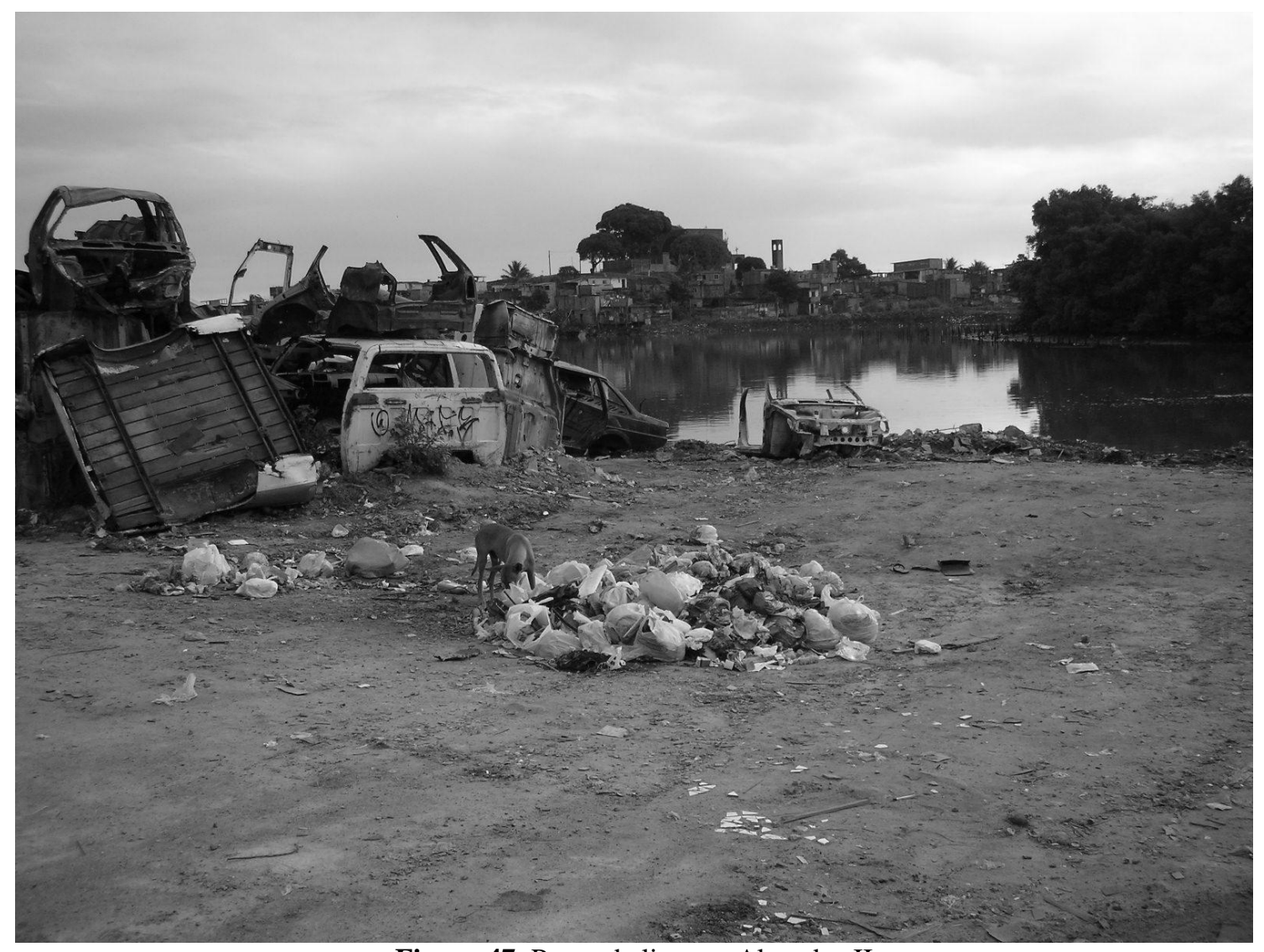

Figura 47: Ponto de lixo em Alagados II

Tabela 89: Segurança contra inundação: avaliação do morador - Alagados I e II

\begin{tabular}{l|c|c}
\hline \multicolumn{1}{c|}{ Avaliação } & Alagados I & Alagados II \\
\hline Não respondeu & $0,0 \%$ & $1,6 \%$ \\
Totalmente inseguro & $0,0 \%$ & $4,0 \%$ \\
Um pouco inseguro & $0,0 \%$ & $16,0 \%$ \\
Não sabe informar & $1,3 \%$ & $13,6 \%$ \\
Um pouco seguro & $81,7 \%$ & $56,0 \%$ \\
Totalmente seguro & $17,0 \%$ & $8,8 \%$ \\
\hline
\end{tabular}




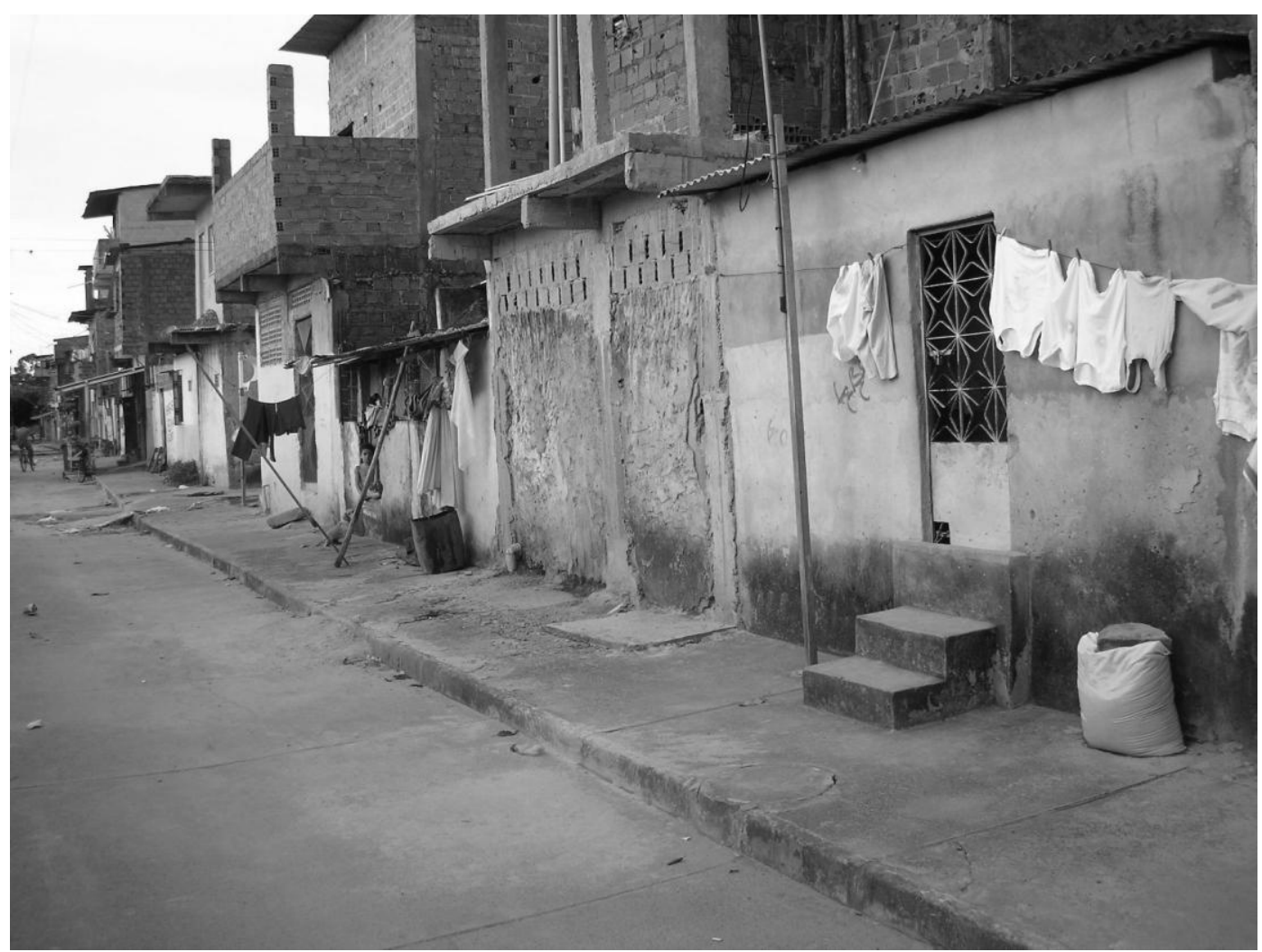

Figura 48: Proteção construída pela própria população contra alagamentos em Alagados II

10.2.3.2 Infra-estrutura e outros serviços

Também neste item, em Alagados I os resultados são satisfatórios, e acompanhados de uma boa avaliação dos moradores. Note que a maioria das ruas tem largura entre 1,20 e 3,60 metros e embora sejam estreitas, estão em bom estado de conservação e receberam uma avaliação positiva. Em Alagados II todas as moradias possuem energia elétrica, porém apenas parte, próximo a $80 \%$, recebe conta de energia. A iluminação pública, em sua maioria, é fornecida pelos próprios moradores, a utilização de espaços públicos é relativamente baixa e a proporção de vias é bem distribuída quanto a largura e estado de preservação (Tabela 90, Figura 49 e Figura 50). Destacamos que ambas as áreas são servidas de quadra de esportes, existe também uma praça que, embora situada fora das poligonais, serve às duas áreas e às margens de Alagados I existe uma faixa de praia com campo de futebol. 
Tabela 90: Infra-estrutura e outros serviços - Alagados I e II

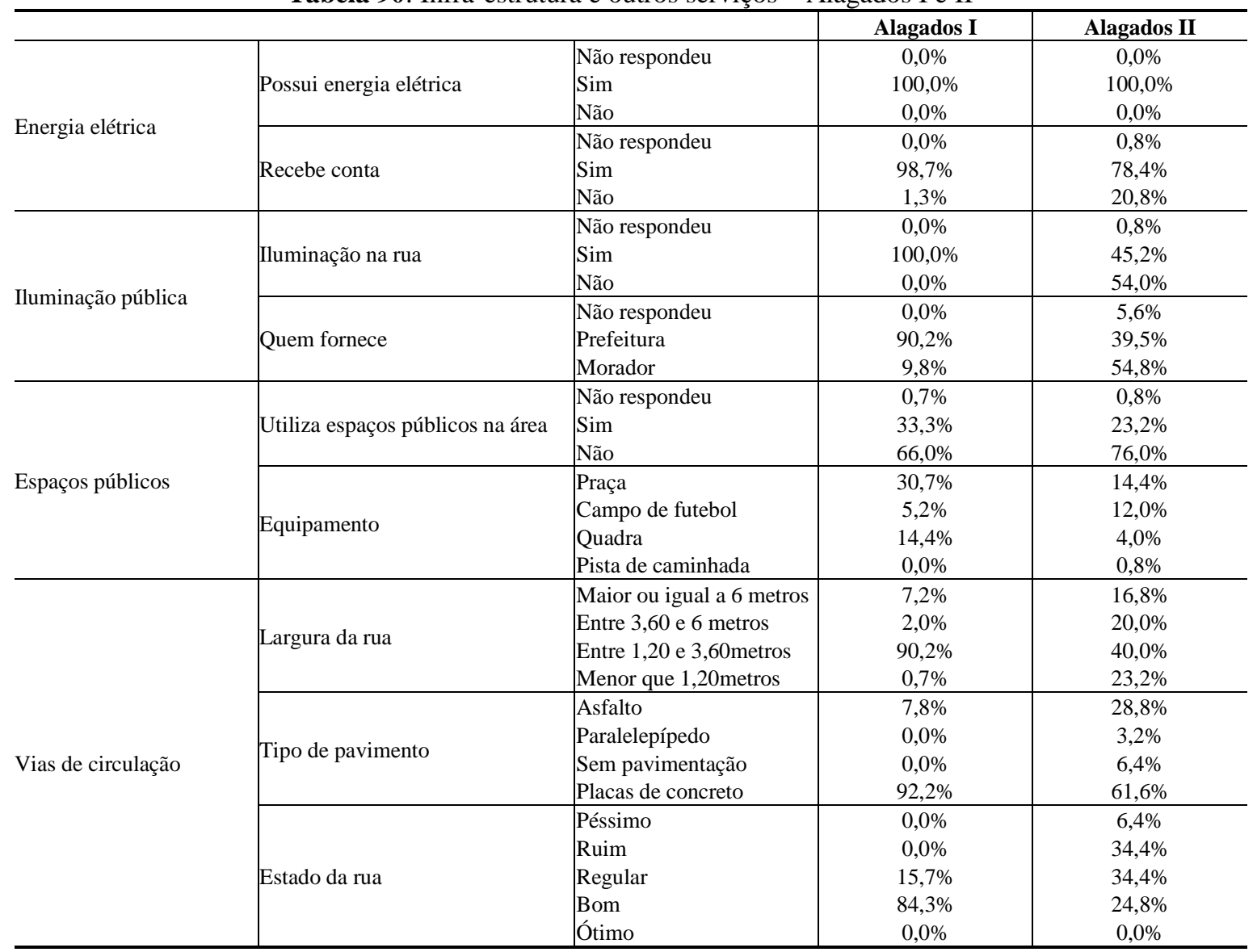

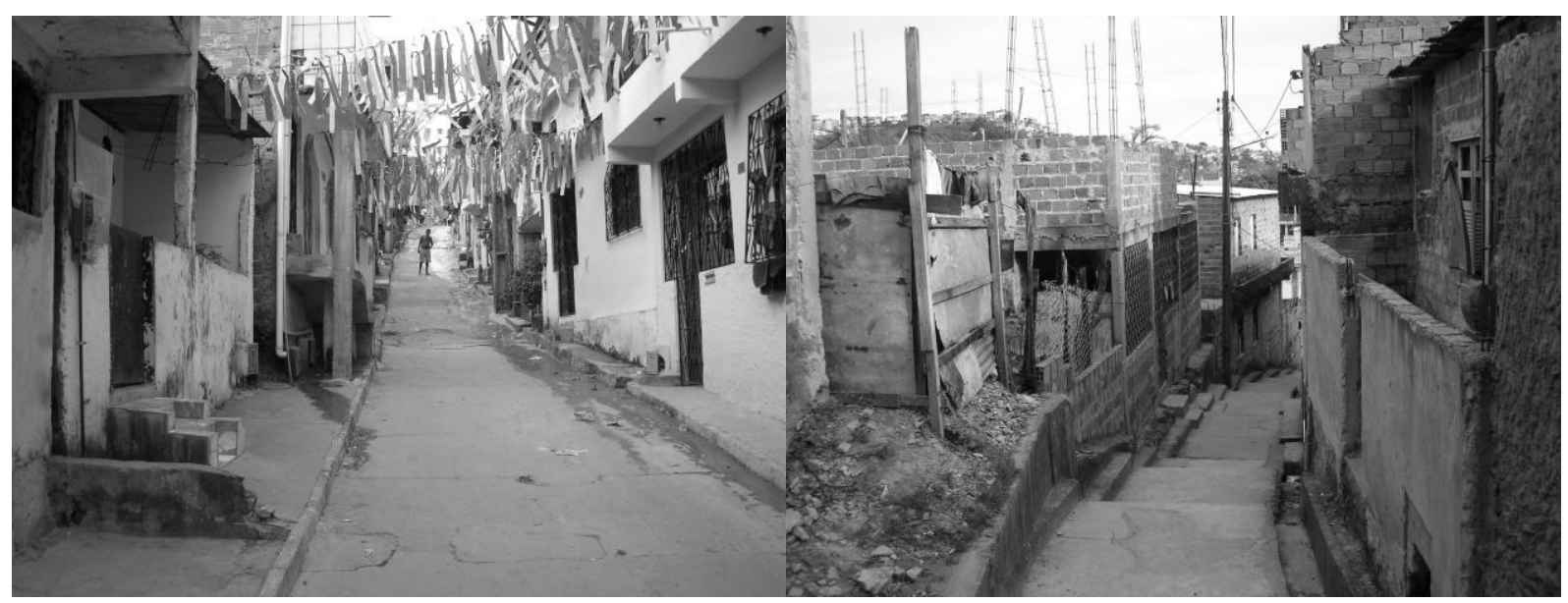

Figura 49: Vias típicas em Alagados I 


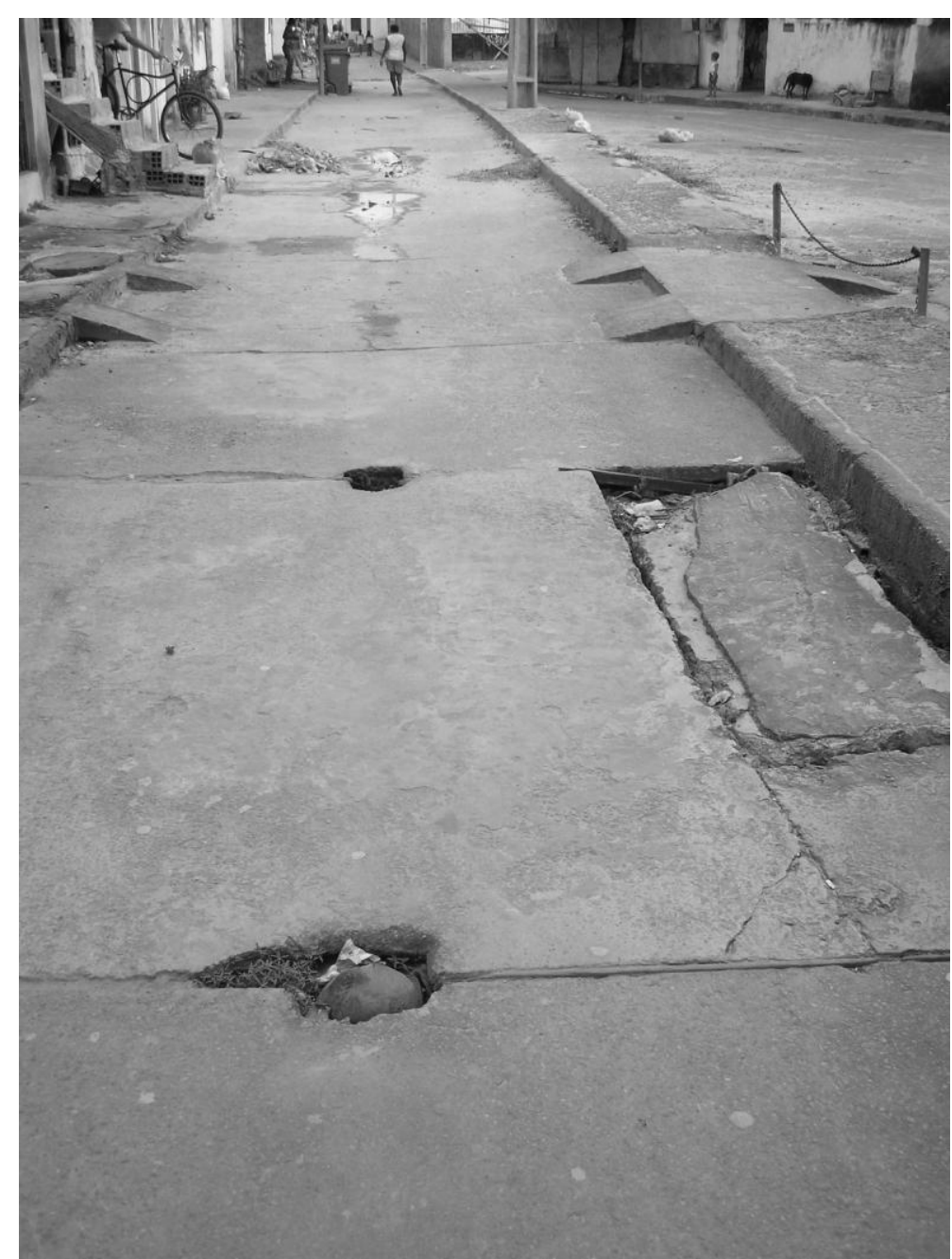

Figura 50: Situação precária de trechos de via em Alagados II

Em Alagados I e II a energia elétrica é o item com melhor avaliação, os demais apresentam distribuições em torno do Regular (Tabela 91).

Tabela 91: Infra-estrutura e outros serviços: avaliação do morador - Alagados I e II

\begin{tabular}{l|c|c|c|c|c|c|c|c|c|c}
\hline \multirow{2}{*}{ Avaliação } & \multicolumn{2}{|c|}{ Energia elétrica } & \multicolumn{2}{|c|}{ Iluminação pública } & \multicolumn{2}{c|}{ Espaços públicos } & \multicolumn{2}{c|}{ Largura da rua } & \multicolumn{2}{c}{ Rua } \\
\cline { 2 - 10 } & Alagados I I Alagados II & Alagados I & Alagados II & Alagados I & Alagados II & Alagados I & Alagados II & Alagados I & Alagados II \\
\hline Não respondeu & $0,0 \%$ & $0,0 \%$ & $0,0 \%$ & $6,5 \%$ & $66,0 \%$ & $71,2 \%$ & $0,0 \%$ & $0,0 \%$ & $0,0 \%$ & $0,0 \%$ \\
Péssimo & $0,7 \%$ & $1,6 \%$ & $0,0 \%$ & $4,8 \%$ & $0,7 \%$ & $3,2 \%$ & $0,0 \%$ & $8,0 \%$ & $0,0 \%$ & $7,2 \%$ \\
Ruim & $0,0 \%$ & $0,8 \%$ & $2,0 \%$ & $22,6 \%$ & $7,2 \%$ & $2,4 \%$ & $2,6 \%$ & $22,4 \%$ & $1,3 \%$ & $14,4 \%$ \\
Regular & $0,7 \%$ & $14,4 \%$ & $1,3 \%$ & $34,7 \%$ & $15,0 \%$ & $10,4 \%$ & $3,3 \%$ & $35,2 \%$ & $20,9 \%$ & $45,6 \%$ \\
Bom & $98,0 \%$ & $77,6 \%$ & $96,7 \%$ & $28,2 \%$ & $11,1 \%$ & $12,8 \%$ & $88,2 \%$ & $24,0 \%$ & $77,1 \%$ & $28,0 \%$ \\
Ótimo & $0,7 \%$ & $5,6 \%$ & $0,0 \%$ & $3,2 \%$ & $0,0 \%$ & $0,0 \%$ & $5,9 \%$ & $10,4 \%$ & $0,7 \%$ & $4,8 \%$ \\
\hline
\end{tabular}

A proporção de respondentes que afirmaram ter orelhão em sua rua foi semelhante em ambas as áreas, contudo, em Alagados I o percentual que utiliza é maior. A avaliação de sua distância ficou em torno do Regular (Tabela 92 e Tabela 93). 
Tabela 92: Telefone público - Alagados I e II

\begin{tabular}{|c|c|c|c|c|}
\hline & \multicolumn{2}{|c|}{ Tem orelhão na sua rua } & \multicolumn{2}{|c|}{ Utiliza o orelhão } \\
\hline & Alagados I & Alagados II & Alagados I & Alagados II \\
\hline Não respondeu & $0,0 \%$ & $1,6 \%$ & $0,0 \%$ & $58,5 \%$ \\
\hline Sim & $32,0 \%$ & $31,2 \%$ & $42,5 \%$ & $24,4 \%$ \\
\hline Não & $68,0 \%$ & $67,2 \%$ & $57,5 \%$ & $17,1 \%$ \\
\hline
\end{tabular}

Tabela 93: Telefone público: avaliação do morador - Alagados I e II

\begin{tabular}{l|c|c}
\hline \multicolumn{1}{c|}{ Avaliação } & Alagados I & Alagados II \\
\hline Não respondeu & $0,0 \%$ & $65,9 \%$ \\
Muito distante & $2,6 \%$ & $4,1 \%$ \\
Distante & $6,5 \%$ & $7,3 \%$ \\
Numa distância razoável & $81,0 \%$ & $12,2 \%$ \\
Próximo & $9,2 \%$ & $9,8 \%$ \\
Muito próximo & $0,7 \%$ & $0,8 \%$ \\
\hline
\end{tabular}

\subsubsection{Condições físicas}

Em Alagados I, com relação à segurança geológico-geotécnica na opinião dos moradores, embora não afirmem estar totalmente seguro, nenhum deles afirma estar inseguro. Já em Alagados II, os moradores sentem-se um pouco seguros quanto aos riscos geológicogeotécnicos e quase 1/4 deles não sabe informar a sua avaliação (Tabela 94).

Tabela 94: Segurança no terreno: Alagados I e II

\begin{tabular}{l|c|c}
\hline \multicolumn{1}{c|}{ Avaliação } & Alagados I & Alagados II \\
\hline Não respondeu & $0,0 \%$ & $0,0 \%$ \\
Totalmente inseguro & $0,0 \%$ & $0,8 \%$ \\
Um pouco inseguro & $0,7 \%$ & $5,6 \%$ \\
Não sabe informar & $2,6 \%$ & $24,0 \%$ \\
Um pouco seguro & $82,4 \%$ & $64,0 \%$ \\
Totalmente seguro & $14,4 \%$ & $5,6 \%$ \\
\hline
\end{tabular}

\subsubsection{Regularização fundiária}

Na questão fundiária, em Alagados I todos afirmaram ter algum tipo de documento que comprove a posse da casa; este percentual reflete-se também na sua avaliação da segurança de posse - de um pouco seguro a totalmente seguro. Já em Alagados II apenas pouco mais de 1/3 dos moradores afirma possuir algum tipo de documento de posse da moradia, o que se reflete no percentual de moradores que não sabe informar sobre a segurança de posse (Tabela 95 e Tabela 96) 
Tabela 95: Regularização Fundiária - Alagados I e II

\begin{tabular}{l|c|c}
\hline \multicolumn{1}{c|}{ Possui algum documento da casa } & Alagados I & Alagados II \\
\hline Não respondeu & $0,0 \%$ & $6,4 \%$ \\
Sim & $100,0 \%$ & $34,4 \%$ \\
Não & $0,0 \%$ & $59,2 \%$ \\
\hline
\end{tabular}

Tabela 96: Segurança de posse: avaliação do morador - Alagados I e II

\begin{tabular}{l|c|c}
\hline \multicolumn{1}{c|}{ Avaliação } & Alagados I & Alagados II \\
\hline Não respondeu & $0,0 \%$ & $2,4 \%$ \\
Totalmente inseguro & $0,7 \%$ & $1,6 \%$ \\
Um pouco inseguro & $0,0 \%$ & $8,0 \%$ \\
Não sabe informar & $0,0 \%$ & $30,4 \%$ \\
Um pouco seguro & $82,4 \%$ & $46,4 \%$ \\
Totalmente seguro & $17,0 \%$ & $11,2 \%$ \\
\hline
\end{tabular}

\subsubsection{Entorno e serviços comunitários}

Em Alagados I o posto de saúde é utilizado por todos os entrevistados e avaliação dos serviços é predominantemente Boa. Poucos entrevistados afirmam utilizar outros locais de lazer fora da área e nenhum participa de qualquer tipo de associação, ressaltamos que a participação em associação não se restringe à área física do projeto, podendo a mesma situarse em bairros vizinhos ou outras áreas da cidade. O meio de transporte predominante é o ônibus. Em Alagados II a maior parte dos moradores também utiliza o posto de saúde e a escola. Grande parte não utiliza outros locais de lazer fora da área, assim como não participa de qualquer tipo de associação e o meio de transporte predominante também é o ônibus (Tabela 97).

Tabela 97: Entorno e serviços comunitários - Alagados I e II

\begin{tabular}{l|l|c|c}
\hline \multicolumn{2}{c}{} & Alagados I & Alagados II \\
\hline \multirow{3}{*}{ Serviços comunitários } & Escola & $49,7 \%$ & $71,2 \%$ \\
& Posto de saúde & $100,0 \%$ & $99,2 \%$ \\
& Creche & $17,0 \%$ & $8,0 \%$ \\
\hline \multirow{3}{*}{ Utilizam locais de lazer fora da área } & Não respondeu & $0,0 \%$ & $0,8 \%$ \\
& Sim & $5,2 \%$ & $8,0 \%$ \\
& Não & $94,8 \%$ & $91,2 \%$ \\
\hline \multirow{5}{*}{ Faz parte de alguma associação } & Não respondeu & $0,0 \%$ & $2,4 \%$ \\
& Sim & $0,0 \%$ & $0,8 \%$ \\
& Não & $100,0 \%$ & $96,8 \%$ \\
\hline \multirow{5}{*}{ Tipo de associação } & Nenhuma & $100,0 \%$ & $98,4 \%$ \\
& Associação de moradores & $0,0 \%$ & $0,8 \%$ \\
& Cooperativa & $0,0 \%$ & $0,0 \%$ \\
& ONG & $0,0 \%$ & $0,8 \%$ \\
Transporte & Outra & $0,0 \%$ & $0,0 \%$ \\
\hline & Barco & $24,8 \%$ & $1,6 \%$ \\
& Trem & $38,6 \%$ & $16,0 \%$ \\
& Onnibus & $100,0 \%$ & $98,4 \%$ \\
\hline
\end{tabular}


Na avaliação dos serviços temos uma avaliação de Regular a Bom e o meio transporte é avaliado positivamente (Tabela 98).

Tabela 98: Entorno e serviços comunitários: avaliação do morador - Alagados I e II

\begin{tabular}{l|c|c|c|c|c|c|c|c}
\hline \multirow{2}{*}{\multicolumn{1}{c|}{ Avaliação }} & \multicolumn{2}{c|}{ Serviços } & \multicolumn{2}{c|}{ Locais de lazer } & \multicolumn{2}{c|}{ Associações } & \multicolumn{2}{c}{ Transporte } \\
\cline { 2 - 9 } & Alagados I & Alagados II & Alagados I & Alagados II & Alagados I & Alagados II & Alagados I & Alagados II \\
\hline Não respondeu & $0,0 \%$ & $1,6 \%$ & $94,8 \%$ & $88,0 \%$ & $100,0 \%$ & $98,4 \%$ & $0,0 \%$ & $1,6 \%$ \\
Péssimo & $0,0 \%$ & $3,2 \%$ & $0,0 \%$ & $0,0 \%$ & $0,0 \%$ & $0,0 \%$ & $0,0 \%$ & $5,6 \%$ \\
Ruim & $0,7 \%$ & $3,2 \%$ & $0,0 \%$ & $0,8 \%$ & $0,0 \%$ & $0,0 \%$ & $0,0 \%$ & $7,2 \%$ \\
Regular & $27,5 \%$ & $36,0 \%$ & $3,9 \%$ & $4,0 \%$ & $0,0 \%$ & $0,8 \%$ & $69,9 \%$ & $20,8 \%$ \\
Bom & $71,9 \%$ & $54,4 \%$ & $1,3 \%$ & $6,4 \%$ & $0,0 \%$ & $0,8 \%$ & $30,1 \%$ & $62,4 \%$ \\
Ótimo & $0,0 \%$ & $1,6 \%$ & $0,0 \%$ & $0,8 \%$ & $0,0 \%$ & $0,0 \%$ & $0,0 \%$ & $2,4 \%$ \\
\hline
\end{tabular}

\subsubsection{Avaliação geral}

Tanto em Alagados I como em Alagados II, na avaliação geral da casa há uma predominância do Regular, demonstrando que a moradia não satisfaz totalmente as aspirações dos moradores, porém, a avaliação do antes e do depois é predominantemente positiva, mas destaca-se o grande percentual de pessoas que dizem que não fez diferença em Alagados I (Tabela 99).

Tabela 99: Avaliação geral da casa e comparação do antes e depois: avaliação do morador - Alagados I e II

\begin{tabular}{l|c|c|l|c|c}
\hline \multirow{2}{*}{ Avaliação } & O que você acha da sua casa como um todo & \multirow{2}{*}{ Avaliação } & \multicolumn{2}{|c}{ O que você acha antes e depois } \\
\cline { 2 - 3 } \cline { 5 - 6 } & Alagados I & Alagados II & & Alagados I & Alagados II \\
\hline Não respondeu & $0,0 \%$ & $0,0 \%$ & Não respondeu & $0,0 \%$ & $0,0 \%$ \\
Péssima & $3,9 \%$ & $2,4 \%$ & Piorou muito & $0,0 \%$ & $0,0 \%$ \\
Ruim & $14,4 \%$ & $4,8 \%$ & Piorou & $5,9 \%$ & $0,0 \%$ \\
Regular & $56,9 \%$ & $48,0 \%$ & Não faz diferença & $56,9 \%$ & $16,0 \%$ \\
Boa & $24,2 \%$ & $40,0 \%$ & Melhorou & $32,7 \%$ & $68,0 \%$ \\
Ótima & $0,7 \%$ & $4,8 \%$ & Melhorou muito & $4,6 \%$ & $16,0 \%$ \\
\hline
\end{tabular}

Quanto à área urbanizada as conclusões são semelhantes à moradia (Tabela 100).

Tabela 100: Avaliação geral da área e comparação do antes e depois: avaliação do morador - Alagados I e II

\begin{tabular}{l|c|c|c|c}
\hline \multirow{2}{*}{\multicolumn{1}{c}{ Avaliação }} & O que você acha da área urbanizada & Como você avalia a área que foi urbanizada, antes e depois \\
\cline { 2 - 5 } & Alagados I & Alagados II & Alagados I & Alagados II \\
\hline Não respondeu & $0,0 \%$ & $1,6 \%$ & $0,0 \%$ & $0,0 \%$ \\
Piorou muito & $0,0 \%$ & $0,8 \%$ & $0,0 \%$ & $0,0 \%$ \\
Piorou & $0,0 \%$ & $1,6 \%$ & $0,0 \%$ & $0,0 \%$ \\
Não faz diferença & $26,1 \%$ & $29,6 \%$ & $24,8 \%$ & $5,6 \%$ \\
Melhorou & $71,9 \%$ & $60,0 \%$ & $69,9 \%$ & $72,0 \%$ \\
Melhorou muito & $2,0 \%$ & $6,4 \%$ & $5,2 \%$ & $22,4 \%$ \\
\hline
\end{tabular}


Tanto os serviços, como o bairro, também são avaliados como Bom pela maioria (Tabela 101).

Tabela 101: Avaliação geral dos serviços e do bairro: avaliação do morador - Alagados I e II

\begin{tabular}{l|c|c|c|c}
\hline \multirow{2}{*}{ Avaliação } & \multicolumn{2}{|c|}{ O que você acha dos serviços } & \multicolumn{2}{c}{ Como você avalia o bairro } \\
\cline { 2 - 5 } & Alagados I & Alagados II & Alagados I & Alagados II \\
\hline Não respondeu & $0,0 \%$ & $0,0 \%$ & $0,0 \%$ & $0,0 \%$ \\
Péssimo & $0,0 \%$ & $5,6 \%$ & $0,0 \%$ & $0,0 \%$ \\
Ruim & $1,3 \%$ & $2,4 \%$ & $0,0 \%$ & $0,8 \%$ \\
Regular & $83,7 \%$ & $31,2 \%$ & $37,9 \%$ & $19,2 \%$ \\
Bom & $15,0 \%$ & $60,8 \%$ & $60,1 \%$ & $73,6 \%$ \\
Ótimo & $0,0 \%$ & $0,0 \%$ & $2,0 \%$ & $6,4 \%$ \\
\hline
\end{tabular}

\subsubsection{Considerações sobre Alagados I e II com base nos dados descritos}

A área de Alagados I apresenta indicadores positivos, acompanhados também de uma avaliação do morador positiva. Destaca-se, contudo, alguns itens com um alto percentual de avaliação Regular, o que demonstra talvez um estágio intermediário das construções da área, onde os moradores avaliam que a situação atual não está totalmente congruente com suas aspirações.

Como já afirmamos, Alagados II embora em área vizinha a Alagados I possui características bem diferentes, a começar pelo terreno, plano. A área é também visivelmente sujeita a inundações, fato refletido nos batentes construídos nas portas das casas e no aumento dos níveis dos pisos. Esta área encontra-se entre a via principal (Avenida Suburbana) e uma via paralela, secundária, donde apresenta um traçado bastante regular e simples.

\subsection{IDENTIFICAÇÃO DOS PONTOS POSITIVOS E NEGATIVOS}

\subsubsection{Moradia}

Em Alagados I como afirmado anteriormente, a avaliação dos moradores é positiva; de fato, nenhum item é considerado negativo. Porém os itens relacionados ao número de quartos e ao banheiro merecem uma análise mais detalhada em função do alto valor de incerteza associado. No caso do número de quartos um fator que deve influenciar é a diversidade de 
tipologias espaciais. Já em Alagados II apenas a ventilação é considerada um ponto negativo. Porém, nota-se também altos graus de incerteza associados as variáveis de composição das moradias: número de quartos, banheiro, cozinha e tamanho da casa. A avaliação do piso e da casa como um todo também apresentam valores altos de incerteza (Tabela 102). Adotaremos a notação “+” para um ponto positivo, “-” e "R" para um ponto regular, acrescido da notação da segunda maior freqüência.

Tabela 102: Moradia: pontos positivos e negativos - Alagados I e II

\begin{tabular}{|c|c|c|c|c|c|c|c|c|}
\hline \multirow[b]{2}{*}{ Item } & \multicolumn{3}{|c|}{ Conceitos/Freqüência relativa } & \multicolumn{2}{|c|}{ Abordagem Clássica } & \multirow[b]{2}{*}{ Aspecto } & \multicolumn{2}{|c|}{ Abordagem Fuzzy } \\
\hline & Péssimo/Ruim & Regular & Ótimo/Bom & $\begin{array}{c}\text { Avaliação } \\
\text { média }\end{array}$ & Desvio padrão & & U-Incerteza & $\begin{array}{l}\text { Grau de } \\
\text { verdade }\end{array}$ \\
\hline \multicolumn{9}{|c|}{ Alagados I } \\
\hline$\overline{\text { Av_Quartos }}$ & $27 \%$ & $34 \%$ & $39 \%$ & 2,11 & 0,81 & + & 0,80 & 0,20 \\
\hline Av_Banheiro & $12 \%$ & $37 \%$ & $52 \%$ & 2,40 & 0,69 & + & 0,53 & 0,47 \\
\hline Av_Cozinha & $1 \%$ & $35 \%$ & $64 \%$ & 2,63 & 0,51 & + & 0,35 & 0,65 \\
\hline Av_Inst_Esgoto & $0 \%$ & $14 \%$ & $86 \%$ & 2,86 & 0,35 & + & 0,11 & 0,89 \\
\hline Av_Inst_Elétrica & $0 \%$ & $12 \%$ & $88 \%$ & 2,88 & 0,33 & + & 0,09 & 0,91 \\
\hline Av_Telhado & $8 \%$ & $20 \%$ & $73 \%$ & 2,65 & 0,62 & + & 0,21 & 0,79 \\
\hline Av_Paredes & $3 \%$ & $36 \%$ & $61 \%$ & 2,59 & 0,54 & + & 0,38 & 0,62 \\
\hline Av_Piso & $4 \%$ & $54 \%$ & $42 \%$ & 2,39 & 0,56 & $\mathrm{R}+$ & 0,53 & 0,47 \\
\hline Av_Quartos & $29 \%$ & $37 \%$ & $34 \%$ & 2,79 & 0,43 & $\mathrm{R}+$ & 0,88 & 0,12 \\
\hline Av_Banheiro & $15 \%$ & $41 \%$ & $44 \%$ & 2,05 & 0,80 & + & 0,73 & 0,27 \\
\hline Av_Cozinha & $14 \%$ & $40 \%$ & $46 \%$ & 2,28 & 0,72 & + & 0,66 & 0,34 \\
\hline Av_Tam_Casa & $26 \%$ & $33 \%$ & $41 \%$ & 2,32 & 0,71 & + & 0,74 & 0,26 \\
\hline Av_Inst_Água & $3 \%$ & $34 \%$ & $63 \%$ & 2,15 & 0,81 & + & 0,36 & 0,64 \\
\hline Av_Inst_Esgoto & $3 \%$ & $34 \%$ & $62 \%$ & 2,59 & 0,56 & + & 0,37 & 0,63 \\
\hline Av_Inst_Elétrica & $6 \%$ & $27 \%$ & $67 \%$ & 2,59 & 0,55 & + & 0,29 & 0,71 \\
\hline Av_Telhado & $14 \%$ & $27 \%$ & $59 \%$ & 2,62 & 0,59 & + & 0,38 & 0,62 \\
\hline Av_Paredes & $10 \%$ & $36 \%$ & $54 \%$ & 2,45 & 0,73 & + & 0,48 & 0,52 \\
\hline Av_Piso & $24 \%$ & $39 \%$ & $37 \%$ & 2,45 & 0,67 & $\mathrm{R}+$ & 0,82 & 0,18 \\
\hline
\end{tabular}

Também foi realizada uma análise por categorias de moradias como na pesquisa piloto: Categoria 1 - Casas construídas pela Conder, Categoria 2 - Casas construídas pela Conder e ampliadas pelo morador, Categoria 3 - Casas autoconstruídas e Categoria 4 - Casas adquiridas de outros ou alugadas. Observamos uma clara transição, no sentido positivo, das categorias 1 para a 4, a Categoria 1 apresenta a situação mais desfavorável enquanto a Categoria 4 apresenta a situação mais favorável. Já em Alagados II, a exceção das casas na Categoria 4, o sentido de aumento na satisfação do morador é o mesmo, embora apresentem muitas avaliações na classe Regular. Nota-se também em Alagados II que a diminuição das incertezas não ocorre uniformemente. Em alguns casos, ocorre o aumento do grau de incerteza (Tabela 103). 
Tabela 103: Moradia: pontos positivos e negativos por categorias de moradia - Alagados I e II

\begin{tabular}{|c|c|c|c|c|c|c|c|c|}
\hline \multirow{2}{*}{ Item } & \multicolumn{2}{|c|}{ Categoria 1} & \multicolumn{2}{|c|}{ Categoria 2} & \multicolumn{2}{|c|}{ Categoria 3} & \multicolumn{2}{|c|}{ Categoria 4} \\
\hline & Aspecto & U-Incerteza (U) & Aspecto & $\mathbf{U}$ & Aspecto & $\mathbf{U}$ & Aspecto & $\mathbf{U}$ \\
\hline \multicolumn{9}{|c|}{ Alagados I } \\
\hline$\overline{\text { Av_Quartos }}$ & - & 0,00 & - & 0,35 & + & 0,52 & + & 0,56 \\
\hline Av_Banheiro & $R+$ & 0,46 & + & 0,44 & + & 0,47 & + & 0,47 \\
\hline Av_Cozinha & + & 0,32 & + & 0,30 & + & 0,39 & + & 0,34 \\
\hline Av_Tam_Casa & + & 0,68 & + & 0,53 & + & 0,37 & + & 0,72 \\
\hline Av_Inst_Água & + & 0,24 & + & 0,06 & + & 0,12 & + & 0,06 \\
\hline Av_Inst_Esgoto & + & 0,36 & + & 0,06 & + & 0,08 & + & 0,09 \\
\hline Av_Inst_Elétrica & + & 0,14 & + & 0,06 & + & 0,10 & + & 0,06 \\
\hline Av_Telhado & + & 0,63 & + & 0,34 & + & 0,12 & + & 0,13 \\
\hline Av_Paredes & $\mathrm{R}-$ & 0,06 & $\mathrm{R}+$ & 0,09 & + & 0,01 & + & 0,08 \\
\hline Av_Piso & $\mathrm{R}-$ & 0,09 & $\mathrm{R}+$ & 0,07 & + & 0,31 & + & 0,39 \\
\hline Av_Ventila & $\mathrm{R}-$ & 0,03 & $\mathrm{R}+$ & 0,02 & $\mathrm{R}+$ & 0,08 & $\mathrm{R}$ & 0,19 \\
\hline Av_Casa & $\mathrm{R}-$ & 0,36 & $\mathrm{R}+$ & 0,09 & + & 0,58 & + & 0,28 \\
\hline Av_Casa_Antes_Depois & - & 0,19 & $\mathrm{R}-$ & 0,52 & $\mathrm{R}+$ & 0,21 & $\mathrm{R}+$ & 0,58 \\
\hline \multicolumn{9}{|c|}{ Alagados II } \\
\hline$\overline{\text { Av_Quartos }}$ & $\mathrm{R}-$ & 0,63 & - & 0,73 & + & 0,88 & $\mathrm{R}$ & 0,40 \\
\hline Av_Banheiro & - & 0,45 & $\mathrm{R}$ & 1,00 & + & 0,55 & $\mathrm{R}+$ & 0,14 \\
\hline Av_Cozinha & - & 0,21 & $\mathrm{R}-$ & 0,91 & + & 0,55 & $\mathrm{R}+$ & 0,44 \\
\hline Av_Tam_Casa & - & 0,32 & - & 0,41 & + & 0,54 & $\mathrm{R}-$ & 0,32 \\
\hline Av_Inst_Água & $\mathrm{R}$ & 0,17 & + & 0,45 & + & 0,28 & + & 0,53 \\
\hline Av_Inst_Esgoto & R- & 0,66 & + & 0,45 & + & 0,30 & + & 0,53 \\
\hline Av_Inst_Elétrica & + & 0,45 & + & 0,32 & + & 0,26 & + & 0,44 \\
\hline Av_Telhado & $\mathrm{R}+$ & 0,72 & + & 0,45 & + & 0,32 & $\mathrm{R}+$ & 0,70 \\
\hline Av_Paredes & + & 0,66 & + & 0,28 & + & 0,46 & $\mathrm{R}+$ & 0,65 \\
\hline Av_Piso & + & 0,66 & $\mathrm{R}+$ & 0,54 & $\mathrm{R}+$ & 0,83 & $\mathrm{R}+$ & 0,91 \\
\hline Av_Ventila & - & 0,57 & $\mathrm{R}-$ & 0,41 & $\mathrm{R}$ - & 0,32 & $\mathrm{R}-$ & 0,91 \\
\hline Av_Casa & + & 0,08 & + & 0,13 & + & 0,12 & + & 0,14 \\
\hline Av_Casa_Antes_Depois & $\mathrm{R}$ & 0,40 & $R+$ & 0,28 & + & 0,59 & $R+$ & 0,48 \\
\hline
\end{tabular}

\subsubsection{Salubridade ambiental}

Com relação à salubridade ambiental, em Alagados I apenas o serviço de varrição é considerado um ponto negativo, os demais itens são considerados pontos positivos com baixo grau de incerteza. Uma análise mais detalhada das questões relacionadas a varrição deverá ser feita, no intuito de reduzir esta incerteza. Em Alagados II os serviços de varrição, bocas de lobo e sarjeta e distância do telefone público são considerados pontos negativos. As altas incertezas, porém, aparecem nas avaliações da largura das ruas, dos espaços públicos, da iluminação pública e da distância do telefone público ( Tabela 104). 
Tabela 104: Salubridade ambiental: pontos positivos e negativos - Alagados I e II

\begin{tabular}{|c|c|c|c|c|c|c|c|c|}
\hline \multirow[b]{2}{*}{ Item } & \multicolumn{3}{|c|}{ Conceitos/Freqüência relativa } & \multicolumn{2}{|c|}{ Abordagem Clássica } & \multirow[b]{2}{*}{ Aspecto } & \multicolumn{2}{|c|}{ Abordagem Fuzzy } \\
\hline & Péssimo/Ruim & Regular & Ótimo/Bom & $\begin{array}{c}\text { Avaliação } \\
\text { média }\end{array}$ & Desvio padrão & & U-Incerteza & $\begin{array}{l}\text { Grau de } \\
\text { verdade }\end{array}$ \\
\hline \multicolumn{9}{|c|}{ Alagados I } \\
\hline$\overline{\text { Av_Abast_Agua }}$ & $0 \%$ & $35 \%$ & $65 \%$ & 2,65 & 0,48 & + & 0,33 & 0,67 \\
\hline Av_Esgoto & $2 \%$ & $76 \%$ & $22 \%$ & 2,20 & 0,45 & $\mathrm{R}+$ & 0,19 & 0,81 \\
\hline Av_Coleta_Lixo & $1 \%$ & $82 \%$ & $17 \%$ & 2,16 & 0,40 & $\mathrm{R}+$ & 0,14 & 0,86 \\
\hline Av_Varrição & $35 \%$ & $48 \%$ & $18 \%$ & 1,83 & 0,71 & R- & 0,59 & 0,41 \\
\hline Av_Boc_Sarj & $0 \%$ & $2 \%$ & $98 \%$ & 2,98 & 0,15 & + & 0,01 & 0,99 \\
\hline Seg_Inund & $0 \%$ & $1 \%$ & $99 \%$ & 2,99 & 0,11 & + & 0,01 & 0,99 \\
\hline Av_larg_rua & $3 \%$ & $3 \%$ & $94 \%$ & 2,92 & 0,36 & + & 0,03 & 0,97 \\
\hline Av_Rua & $1 \%$ & $21 \%$ & $78 \%$ & 2,76 & 0,46 & + & 0,18 & 0,82 \\
\hline Seg_Terreno & $1 \%$ & $3 \%$ & $97 \%$ & 2,96 & 0,23 & + & 0,02 & 0,98 \\
\hline Av_Esp_Pub & $23 \%$ & $44 \%$ & $33 \%$ & 2,10 & 0,75 & $\mathrm{R}+$ & 0,66 & 0,34 \\
\hline Av_Energia & $1 \%$ & $1 \%$ & $99 \%$ & 2,98 & 0,18 & + & 0,01 & 0,99 \\
\hline Av_Ilumina & $2 \%$ & $1 \%$ & $97 \%$ & 2,95 & 0,30 & + & 0,02 & 0,98 \\
\hline Dist_Tel & $9 \%$ & $81 \%$ & $10 \%$ & 2,01 & 0,44 & $\mathrm{R}+$ & 0,12 & 0,88 \\
\hline Seg_Posse & $1 \%$ & $0 \%$ & $99 \%$ & 2,99 & 0,16 & + & 0,00 & 1,00 \\
\hline Av_Area & $0 \%$ & $26 \%$ & $74 \%$ & 2,74 & 0,44 & + & 0,22 & 0,78 \\
\hline Av_Antes_Depois & $0 \%$ & $25 \%$ & $75 \%$ & 2,75 & 0,43 & + & 0,21 & 0,79 \\
\hline \multicolumn{9}{|c|}{ Alagados II } \\
\hline$\overline{\text { Av_Abast_Agua }}$ & $2 \%$ & $10 \%$ & $88 \%$ & 2,85 & 0,42 & + & 0,08 & 0,92 \\
\hline Av_Esgoto & $17 \%$ & $53 \%$ & $30 \%$ & 2,13 & 0,68 & $\mathrm{R}+$ & 0,48 & 0,52 \\
\hline Av_Coleta_Lixo & $26 \%$ & $11 \%$ & $63 \%$ & 2,38 & 0,87 & + & 0,32 & 0,68 \\
\hline Av_Varricao & $26 \%$ & $50 \%$ & $24 \%$ & 1,98 & 0,71 & R- & 0,51 & 0,49 \\
\hline Av_Boc_Sarj & $49 \%$ & $20 \%$ & $31 \%$ & 1,82 & 0,89 & - & 0,55 & 0,45 \\
\hline Seg_Inund & $20 \%$ & $14 \%$ & $66 \%$ & 2,46 & 0,81 & + & 0,27 & 0,73 \\
\hline Av_larg_rua & $30 \%$ & $35 \%$ & $34 \%$ & 2,04 & 0,81 & $\mathrm{R}+$ & 0,94 & 0,06 \\
\hline Av_Rua & $22 \%$ & $46 \%$ & $33 \%$ & 2,11 & 0,73 & $\mathrm{R}+$ & 0,63 & 0,37 \\
\hline Seg_Terreno & $6 \%$ & $24 \%$ & $70 \%$ & 2,63 & 0,60 & + & 0,25 & 0,75 \\
\hline Av_Esp_Pub & $19 \%$ & $36 \%$ & $44 \%$ & 2,25 & 0,77 & + & 0,67 & 0,33 \\
\hline Av_Energia & $2 \%$ & $14 \%$ & $83 \%$ & 2,81 & 0,45 & + & 0,12 & 0,88 \\
\hline Av_Ilumina & $29 \%$ & $37 \%$ & $34 \%$ & 2,04 & 0,80 & $\mathrm{R}+$ & 0,86 & 0,14 \\
\hline Dist_Tel & $33 \%$ & $36 \%$ & $31 \%$ & 1,98 & 0,81 & - & 0,91 & 0,09 \\
\hline Seg_Posse & $10 \%$ & $31 \%$ & $59 \%$ & 2,49 & 0,67 & + & 0,39 & 0,61 \\
\hline Av_Area & $2 \%$ & $30 \%$ & $67 \%$ & 2,65 & 0,53 & + & 0,29 & 0,71 \\
\hline Av_Antes_Depois & $0 \%$ & $6 \%$ & $94 \%$ & 2,94 & 0,23 & + & 0,04 & 0,96 \\
\hline
\end{tabular}

Notamos em Alagados I uma tendência à mesma avaliação nas diferentes categorias, o que demonstra que as baixas incertezas apresentadas para a população geral são mantidas na análise por categorias. Com exceção do serviço de varrição e dos espaços públicos, as demais variáveis mantêm um valor baixo de incerteza (Tabela 105). Apenas para exemplificar outras possibilidades de análises, elaboramos o mapa da Figura 51, que mostra a distribuição espacial das respostas dadas pelos moradores para a avaliação do serviço de varrição. Note que há indícios de uma tendência de concentração das avaliações negativas em pontos do miolo da área, enquanto as avaliações regulares e positivas situam-se próximas às vias principais e de contorno. Este fato, não captado pelas variáveis do formulário, nos ajuda a mostrar que a incerteza na avaliação deste item, assim como de outros, pode ser reduzida por uma análise da distribuição espacial das avaliações que pode ser obtida utilizando aplicativos de sistemas de informações geográficas (SIG). 


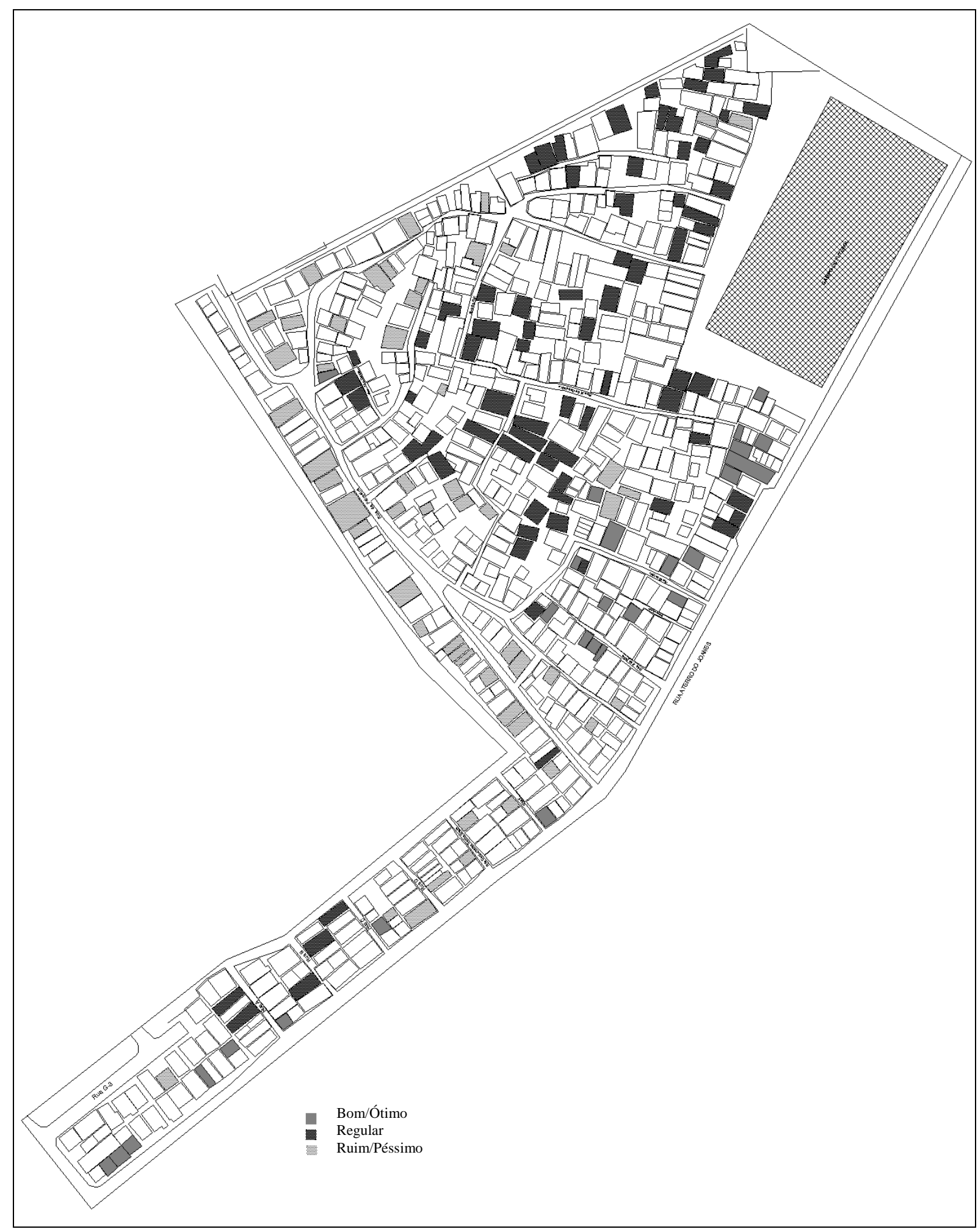

Figura 51: Distribuição espacial das avaliações do serviço de varrição pelo morador - Alagados I 
Tabela 105: Moradia: pontos positivos e negativos por categorias de moradia - Alagados I e II

\begin{tabular}{|c|c|c|c|c|c|c|c|c|}
\hline \multirow{2}{*}{ Item } & \multicolumn{2}{|c|}{ Categoria 1} & \multicolumn{2}{|c|}{ Categoria 2} & \multicolumn{2}{|c|}{ Categoria 3} & \multicolumn{2}{|c|}{ Categoria 4} \\
\hline & Aspecto & U-Incerteza (U) & Aspecto & $\mathbf{U}$ & Aspecto & $\mathbf{U}$ & Aspecto & $\mathbf{U}$ \\
\hline \multicolumn{9}{|c|}{ Alagados I } \\
\hline Av_Abast_Água & + & 0,53 & + & 0,30 & + & 0,36 & + & 0,18 \\
\hline Av_Esgoto & $\mathrm{R}+$ & 0,22 & $\mathrm{R}+$ & 0,23 & $\mathrm{R}+$ & 0,16 & $\mathrm{R}+$ & 0,16 \\
\hline Av_Coleta_Lixo & $\mathrm{R}+$ & 0,06 & $\mathrm{R}+$ & 0,12 & $\mathrm{R}+$ & 0,14 & $\mathrm{R}+$ & 0,26 \\
\hline Av_Varrição & $\mathrm{R}-$ & 0,53 & - & 0,67 & $\mathrm{R}-$ & 0,44 & $\mathrm{R}-$ & 0,95 \\
\hline Av_Boc_Sarj & + & 0,00 & + & 0,00 & + & 0,02 & + & 0,04 \\
\hline Seg_Inund & + & 0,00 & + & 0,00 & + & 0,01 & + & 0,03 \\
\hline Av_larg_rua & + & 0,03 & + & 0,00 & + & 0,03 & + & 0,12 \\
\hline Av_Rua & + & 0,09 & + & 0,12 & + & 0,21 & + & 0,28 \\
\hline Seg_Terreno & + & 0,06 & + & 0,02 & + & 0,01 & + & 0,03 \\
\hline Av_Esp_Pub & + & 0,66 & $\mathrm{R}$ & 0,33 & $\mathrm{R}+$ & 0,57 & $\mathrm{R}+$ & 0,88 \\
\hline Av_Energia & + & 0,00 & + & 0,00 & + & 0,01 & + & 0,03 \\
\hline Av_Ilumina & + & 0,03 & + & 0,00 & + & 0,01 & + & 0,08 \\
\hline Dist_Tel & $\mathrm{R}+$ & 0,13 & $\mathrm{R}-$ & 0,08 & $\mathrm{R}+$ & 0,11 & $\mathrm{R}-$ & 0,28 \\
\hline Seg_Posse & + & 0,03 & + & 0,00 & + & 0,00 & + & 0,00 \\
\hline Av_Antes_Depois & + & 0,29 & + & 0,20 & + & 0,21 & + & 0,13 \\
\hline Av_Área & + & 0,36 & + & 0,17 & + & 0,23 & + & 0,18 \\
\hline \multicolumn{9}{|c|}{ Alagados II } \\
\hline Av_Abast_Agua & + & 0,00 & + & 0,06 & + & 0,08 & + & 0,14 \\
\hline Av_Esgoto & $\mathrm{R}$ & 0,50 & $\mathrm{R}+$ & 0,53 & $\mathrm{R}+$ & 0,46 & R- & 0,66 \\
\hline Av_Coleta_Lixo & - & 0,18 & - & 0,28 & + & 0,19 & + & 0,32 \\
\hline Av_Varricao & - & 0,14 & $\mathrm{R}-$ & 0,41 & $\mathrm{R}+$ & 0,44 & + & 0,65 \\
\hline Av_Boc_Sarj & + & 0,32 & + & 0,13 & - & 0,39 & - & 0,32 \\
\hline Seg_Inund & + & 0,18 & + & 0,13 & + & 0,30 & + & 0,44 \\
\hline Av_larg_rua & - & 0,45 & + & 0,41 & $\mathrm{R}+$ & 0,76 & $\mathrm{R}+$ & 0,65 \\
\hline Av_Rua & - & 0,66 & + & 0,73 & $\mathrm{R}+$ & 0,54 & $\mathrm{R}+$ & 0,48 \\
\hline Seg_Terreno & + & 0,08 & + & 0,32 & + & 0,24 & + & 0,53 \\
\hline Av_Esp_Pub & $\mathrm{R}$ & 0,00 & $\mathrm{R}-$ & 0,63 & + & 0,59 & $+/-$ & 0,63 \\
\hline Av_Energia & + & 0,00 & + & 0,13 & + & 0,13 & + & 0,14 \\
\hline Av_Ilumina & - & 0,17 & - & 0,41 & $\mathrm{R}+$ & 0,82 & $\mathrm{R}+$ & 0,82 \\
\hline Dist_Tel & $\mathrm{R}$ & 0,00 & $*$ & 0,00 & $\mathrm{R}-$ & 0,89 & $+/-$ & 0,82 \\
\hline Seg_Posse & + & 0,08 & + & 0,10 & + & 0,52 & + & 0,32 \\
\hline Av_Antes_Depois & + & 0,08 & + & 0,00 & + & 0,04 & + & 0,00 \\
\hline Av_Area & + & 0,21 & + & 0,21 & + & 0,31 & + & 0,36 \\
\hline
\end{tabular}

\subsubsection{Entorno}

Em ambas as áreas a situação do entorno é semelhante, com todos os itens sendo considerados positivos e com baixa incerteza, porém o transporte apresenta um grau de incerteza acima das demais (Tabela 106). 
Tabela 106: Entorno: pontos positivos e negativos - Alagados I e II

\begin{tabular}{|c|c|c|c|c|c|c|c|c|}
\hline \multirow[b]{2}{*}{ Item } & \multicolumn{3}{|c|}{ Conceitos/Freqüiência relativa } & \multicolumn{2}{|c|}{ Abordagem Clássica } & \multirow[b]{2}{*}{ Aspecto } & \multicolumn{2}{|c|}{ Abordagem Fuzzy } \\
\hline & Péssimo/ Ruim & Regular & Ótimo/Bom & $\begin{array}{c}\text { Avaliação } \\
\text { média }\end{array}$ & Desvio padrão & & U-Incerteza & $\begin{array}{l}\text { Grau de } \\
\text { verdade }\end{array}$ \\
\hline \multicolumn{9}{|c|}{ Alagados I } \\
\hline Av_Servic & $1 \%$ & $27 \%$ & $72 \%$ & 2,71 & 0,47 & + & 0,24 & 0,76 \\
\hline Av_Lazer_Fora & $0 \%$ & $75 \%$ & $25 \%$ & 2,25 & 0,46 & + & 0,21 & 0,79 \\
\hline Av_Transp & $0 \%$ & $70 \%$ & $30 \%$ & 2,30 & 0,46 & + & 0,27 & 0,73 \\
\hline Av_ServiçosEntorno & $1 \%$ & $84 \%$ & $15 \%$ & 2,14 & 0,38 & + & 0,12 & 0,88 \\
\hline Av_Bairro & $0 \%$ & $38 \%$ & $62 \%$ & 2,62 & 0,49 & + & 0,39 & 0,61 \\
\hline \multicolumn{9}{|c|}{ Alagados II } \\
\hline$\overline{\text { Av_Servic }}$ & $7 \%$ & $37 \%$ & $57 \%$ & 2,50 & 0,62 & + & 0,45 & 0,55 \\
\hline Av_Lazer_Fora & $7 \%$ & $33 \%$ & $60 \%$ & 2,53 & 0,64 & + & 0,39 & 0,61 \\
\hline Av_Transp & $0 \%$ & $50 \%$ & $50 \%$ & 2,50 & 0,71 & + & 0,63 & 0,37 \\
\hline Av_ServiçosEntorno & $13 \%$ & $21 \%$ & $66 \%$ & 2,53 & 0,72 & + & 0,28 & 0,72 \\
\hline Av_Bairro & $8 \%$ & $31 \%$ & $61 \%$ & 2,53 & 0,64 & + & 0,37 & 0,63 \\
\hline
\end{tabular}

Para o entorno, algumas incertezas são reduzidas na análise por categorias, contudo, as respostas são basicamente as mesmas em cada uma delas (Tabela 107).

Tabela 107: Entorno: pontos positivos e negativos - Alagados I e II

\begin{tabular}{|c|c|c|c|c|c|c|c|c|}
\hline \multirow{2}{*}{ Item } & \multicolumn{2}{|c|}{ Categoria 1} & \multicolumn{2}{|c|}{ Categoria 2} & \multicolumn{2}{|c|}{ Categoria 3} & \multicolumn{2}{|c|}{ Categoria 4} \\
\hline & Aspecto & U-Incerteza (U) & Aspecto & $\mathbf{U}$ & Aspecto & $\mathbf{U}$ & Aspecto & $\mathbf{U}$ \\
\hline \multicolumn{9}{|c|}{ Alagados I } \\
\hline Av_Servic & + & 0,29 & + & 0,23 & + & 0,23 & + & 0,26 \\
\hline Av_Transp & $\mathrm{R}+$ & 0,24 & $\mathrm{R}+$ & 0,10 & $\mathrm{R}+$ & 0,36 & $\mathrm{R}+$ & 0,41 \\
\hline Av_Bairro & + & 0,36 & + & 0,30 & + & 0,46 & + & 0,34 \\
\hline Av_ServiçosEntorno & + & 0,06 & $\mathrm{R}+$ & 0,04 & $\mathrm{R}+$ & 0,15 & $\mathrm{R}+$ & 0,26 \\
\hline \multicolumn{9}{|c|}{ Alagados II } \\
\hline$\overline{\text { Av_Servic }}$ & $\mathrm{R}+$ & 0,27 & + & 0,21 & + & 0,41 & $\mathrm{R}+$ & 0,63 \\
\hline Av_Transp & Sem resposta & 0,00 & $*$ & 0,00 & + & 0,41 & + & 0,32 \\
\hline Av_Bairro & + & 0,08 & + & 0,24 & + & 0,26 & $\mathrm{R}+$ & 0,65 \\
\hline Av_ServiçosEntorno & + & 0,00 & + & 0,13 & + & 0,18 & + & 0,14 \\
\hline
\end{tabular}

\subsection{OBTENÇÃO DE INDICADORES}

\subsubsection{Indicadores qualitativos}

Assim como na pesquisa piloto, utilizaremos os dois métodos definidos anteriormente. $\mathrm{O}$ método utilizando equações relacionais fuzzy e o método de reconhecimento de padrão, de forma a podermos comparar os dois resultados obtidos.

10.4.1.1 Método das equações relacionais fuzzy

Seguindo os procedimentos já determinados obtivemos os resultados descritos a seguir. 


\subsection{Moradia}

A Tabela 108 apresenta as avaliações parciais e suas respectivas avaliações finais estão na Tabela 109 sob a forma de matrizes para a avaliação da moradia. Para fazermos uma comparação, utilizamos dois critérios para geração da matriz de avaliação final (MDI e MSP).

Tabela 108: Moradia: matrizes de avaliações parciais transpostas - Alagados I e II

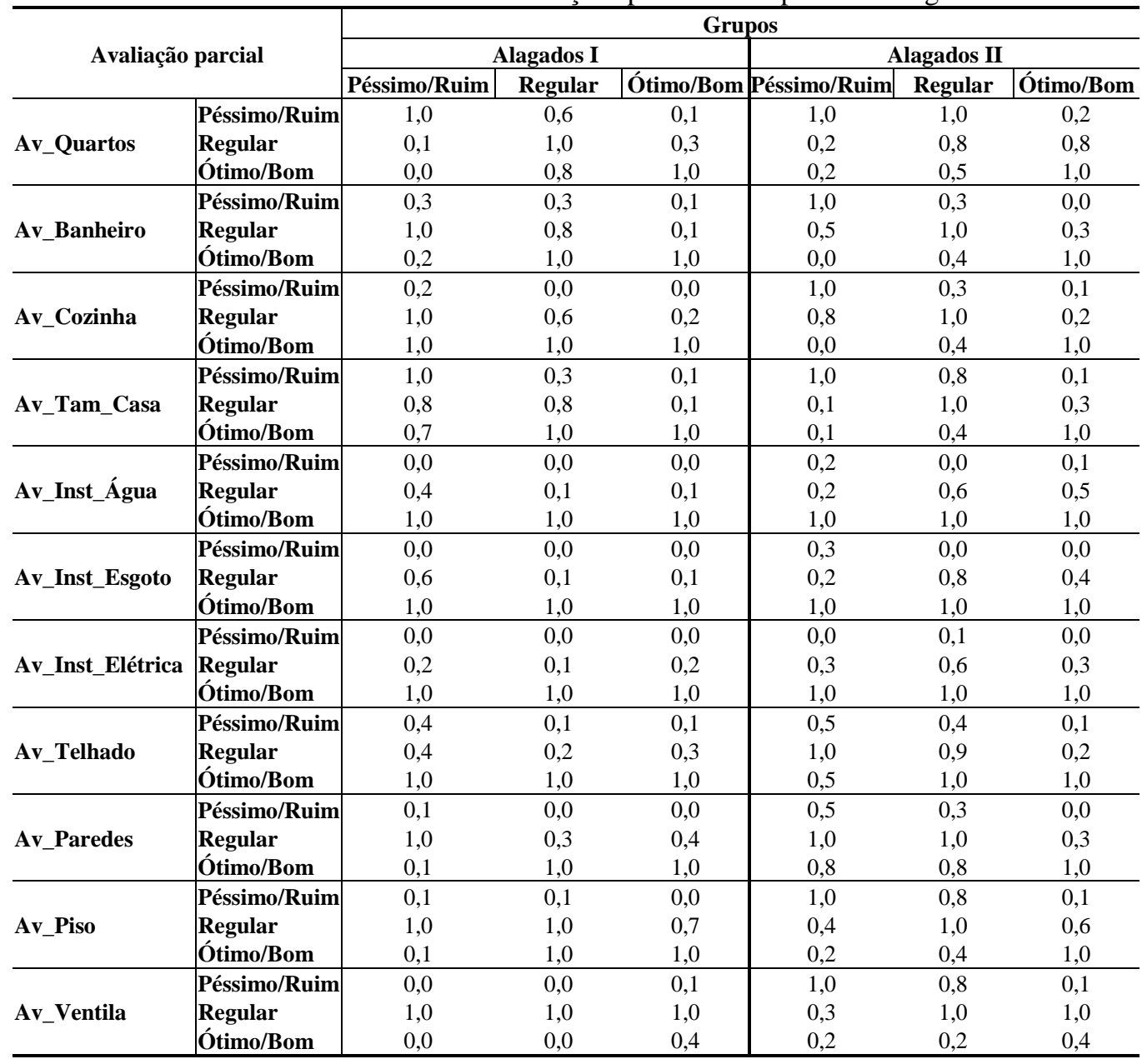

Tabela 109: Moradia: matrizes de avaliação final - Alagados I e II

\begin{tabular}{|c|c|c|c|c|c|c|c|c|c|c|c|c|}
\hline \multirow[b]{3}{*}{ Grupos } & \multicolumn{6}{|c|}{ Alagados I } & \multicolumn{6}{|c|}{ Alagados II } \\
\hline & \multicolumn{3}{|c|}{ Avaliação final - MDI } & \multicolumn{3}{|c|}{ Avaliacão final - MSP } & \multicolumn{3}{|c|}{ Avaliação final - MDI } & \multicolumn{3}{|c|}{ Avaliação final - MSP } \\
\hline & 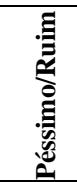 & 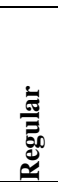 & 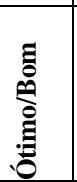 & 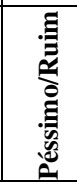 & 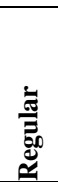 & ڤ્ڤ & 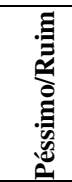 & 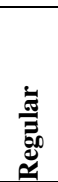 & 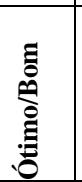 & 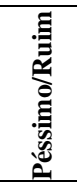 & 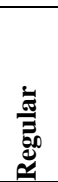 & ڤ્ڤ \\
\hline 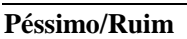 & 1,0 & 0,1 & 0,0 & 1,0 & 0,1 & 0,0 & 1,0 & 0,1 & 0,0 & 1,0 & 0,1 & 0,0 \\
\hline Regular & 0,6 & 1,0 & 0,8 & 0,3 & 1,0 & 0,8 & 0,3 & 1,0 & 0,4 & 0,3 & 1,0 & 0,4 \\
\hline Ótimo/Bom & 0,1 & 0,3 & 1,0 & 0,1 & 0,3 & 1,0 & 0,0 & 0,3 & 1,0 & 0,1 & 0,3 & 1,0 \\
\hline
\end{tabular}


Podemos observar na Tabela 110 que os itens destacados são aqueles que têm maior grau de possibilidade de interferência na avaliação final, ou seja, neste caso, temos por exemplo em Alagados I, o número de quartos, o banheiro, o tamanho da casa e o telhado. Os demais itens, embora possuam graus de possibilidade altos, apresentam possibilidade com mais de uma avaliação final, logo não são definidores. Note que em Alagados I as variáveis com maiores graus de possibilidade são em número maior que em Alagados II, o que denota também que, os moradores desta área apresentam, carências maiores, ou mal definidas, em relação a suas moradias. Em Alagados I a matriz de relação conseguiu recuperar quase metade das respostas sendo que em $20 \%$ de empates, $14 \%$ teriam possibilidade de acertos. Já em Alagados II o número de acertos foi ligeiramente maior (Tabela 111).

Tabela 110: Moradia: matrizes de relação com MDI e MSP - Alagados I e II

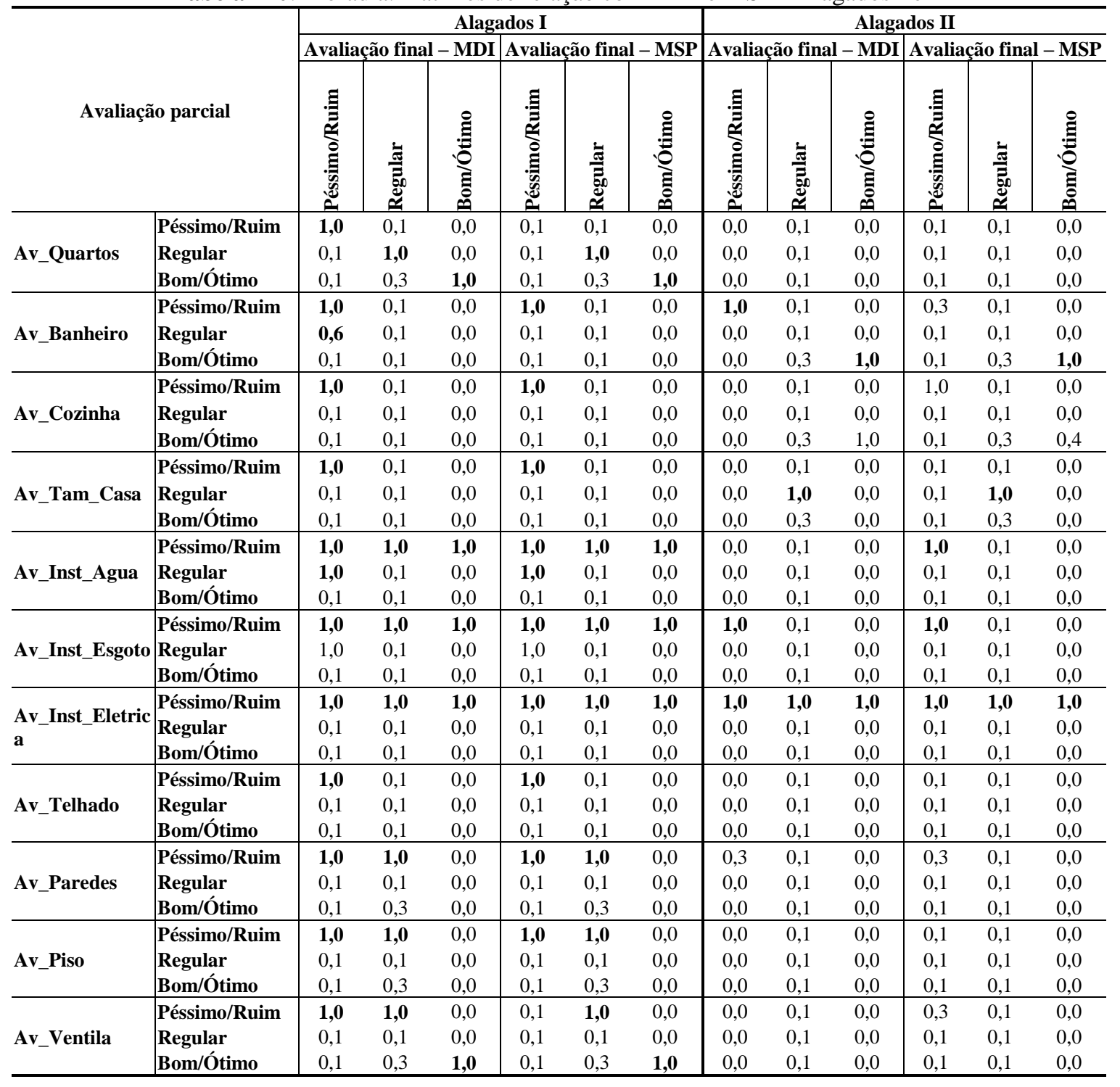


Tabela 111: Moradia: percentual de acertos por construção da avaliação final - Alagados I e II

\begin{tabular}{lc|c|c|c|c}
\hline & Alagados I & Acertos & Empates & Empates com possibilidade de acerto & Erros \\
\hline MDI & $47 \%$ & $20 \%$ & $14 \%$ & $39 \%$ \\
MSP & $50 \%$ & $19 \%$ & $13 \%$ & $37 \%$ \\
\hline \multicolumn{2}{c|}{ Alagados II } & & & & \\
\hline MDI & $54 \%$ & $17 \%$ & $17 \%$ & $29 \%$ \\
MSP & $52 \%$ & $16 \%$ & $16 \%$ & $32 \%$ \\
\hline
\end{tabular}

\subsection{Salubridade ambiental}

Na Tabela 112 e Tabela 113 estão os resultados obtidos para a avaliação da salubridade ambiental.

Tabela 112: Salubridade ambiental: matrizes de avaliações parciais transpostas - Alagados I e II

\begin{tabular}{|c|c|c|c|c|c|c|c|}
\hline \multirow{3}{*}{\multicolumn{2}{|c|}{ Avaliação Parcial }} & \multicolumn{6}{|c|}{ Grupos } \\
\hline & & \multicolumn{3}{|c|}{ Alagados I } & \multicolumn{3}{|c|}{ Alagados II } \\
\hline & & Péssimo/Ruim & Regular & Bom/Ótimo & Péssimo/R & gular & Bom/Ótimo \\
\hline \multirow{3}{*}{ Av_Abast_Agua } & Péssimo/Ruim & 0,0 & 0,0 & 0,0 & 0,0 & 0,0 & 0,0 \\
\hline & Regular & 0,0 & 1,0 & 0,3 & 1,0 & 0,1 & 0,1 \\
\hline & Bom/Ótimo & 0,0 & 0,4 & 1,0 & 0,5 & 1,0 & 1,0 \\
\hline \multirow{3}{*}{ Av_Esgoto } & Péssimo/Ruim & 0,0 & 0,0 & 0,0 & 0,0 & 0,1 & 0,5 \\
\hline & Regular & 0,0 & 1,0 & 1,0 & 0,0 & 1,0 & 1,0 \\
\hline & Bom/Ótimo & 0,0 & 0,0 & 0,4 & 1,0 & 0,3 & 0,8 \\
\hline \multirow{3}{*}{ Av_Coleta_Lixo } & Péssimo/Ruim & 0,0 & 0,1 & 0,0 & 0,0 & 0,7 & 0,3 \\
\hline & Regular & 0,0 & 1,0 & 1,0 & 0,0 & 0,3 & 0,1 \\
\hline & Bom/Ótimo & 0,0 & 0,0 & 0,3 & 1,0 & 1,0 & 1,0 \\
\hline \multirow{3}{*}{ Av_Varricao } & Péssimo/Ruim & 0,0 & 0,7 & 0,8 & 1,0 & 0,3 & 0,5 \\
\hline & Regular & 0,0 & 1,0 & 1,0 & 0,0 & 1,0 & 1,0 \\
\hline & Bom/Ótimo & 0,0 & 0,4 & 0,4 & 0,0 & 0,2 & 0,7 \\
\hline \multirow{3}{*}{ Av_Boc_Sarj } & Péssimo/Ruim & 0,0 & 0,0 & 0,0 & 1,0 & 1,0 & 1,0 \\
\hline & Regular & 0,0 & 0,0 & 0,0 & 0,0 & 0,3 & 0,5 \\
\hline & Bom/Ótimo & 0,0 & 1,0 & 1,0 & 0,0 & 0,7 & 0,7 \\
\hline \multirow{3}{*}{ Seg_Inund } & Péssimo/Ruim & 0,0 & 0,0 & 0,0 & 1,0 & 0,3 & 0,3 \\
\hline & Regular & 0,0 & 0,0 & 0,0 & 0,0 & 0,3 & 0,2 \\
\hline & Bom/Ótimo & 0,0 & 1,0 & 1,0 & 0,0 & 1,0 & 1,0 \\
\hline \multirow{3}{*}{ Av_larg_rua } & Péssimo/Ruim & 0,0 & 0,1 & 0,0 & 0,0 & 0,5 & 0,9 \\
\hline & Regular & 0,0 & 0,0 & 0,0 & 0,0 & 1,0 & 0,7 \\
\hline & Bom/Ótimo & 0,0 & 1,0 & 1,0 & 1,0 & 0,4 & 1,0 \\
\hline \multirow{3}{*}{ Av_Rua } & Péssimo/Ruim & 0,0 & 0,1 & 0,0 & 1,0 & 0,3 & 0,6 \\
\hline & Regular & 0,0 & 0,3 & 0,3 & 1,0 & 1,0 & 1,0 \\
\hline & Bom/Ótimo & 0,0 & 1,0 & 1,0 & 1,0 & 0,4 & 0,9 \\
\hline \multirow{3}{*}{ Seg_Terreno } & Péssimo/Ruim & 0,0 & 0,0 & 0,0 & 1,0 & 0,0 & 0,1 \\
\hline & Regular & 0,0 & 0,1 & 0,0 & 1,0 & 0,5 & 0,3 \\
\hline & Bom/Ótimo & 0,0 & 1,0 & 1,0 & 1,0 & 1,0 & 1,0 \\
\hline \multirow{3}{*}{ Av_Esp_Pub } & Péssimo/Ruim & 0,0 & 0,8 & 0,2 & 0,0 & 0,5 & 0,3 \\
\hline & Regular & 0,0 & 1,0 & 1,0 & 0,0 & 1,0 & 0,6 \\
\hline & Bom/Ótimo & 0,0 & 0,5 & 1,0 & 0,0 & 0,7 & 1,0 \\
\hline \multirow{3}{*}{ Av_Energia } & Péssimo/Ruim & 0,0 & 0,0 & 0,0 & 0,0 & 0,0 & 0,0 \\
\hline & Regular & 0,0 & 0,0 & 0,0 & 0,0 & 0,4 & 0,1 \\
\hline & Bom/Ótimo & 0,0 & 1,0 & 1,0 & 1,0 & 1,0 & 1,0 \\
\hline \multirow{3}{*}{ Av_Ilumina } & Péssimo/Ruim & 0,0 & 0,1 & 0,0 & 0,0 & 0,8 & 0,7 \\
\hline & Regular & 0,0 & 0,0 & 0,0 & 1,0 & 1,0 & 1,0 \\
\hline & Bom/Ótimo & 0,0 & 1,0 & 1,0 & 0,0 & 0,8 & 1,0 \\
\hline \multirow{3}{*}{ Dist_Tel } & Péssimo/Ruim & 0,0 & 0,1 & 0,1 & 0,0 & 0,5 & 1,0 \\
\hline & Regular & 0,0 & 1,0 & 1,0 & 1,0 & 1,0 & 0,7 \\
\hline & Bom/Ótimo & 0,0 & 0,2 & 0,1 & 1,0 & 0,8 & 0,6 \\
\hline \multirow{3}{*}{ Seg_Posse } & Péssimo/Ruim & 0,0 & 0,0 & 0,0 & 0,5 & 0,1 & 0,2 \\
\hline & Regular & 0,0 & 0,0 & 0,0 & 0,0 & 0,9 & 0,4 \\
\hline & Bom/Ótimo & 0,0 & 1,0 & 1,0 & 1,0 & 1,0 & 1,0 \\
\hline
\end{tabular}


Neste caso é importante salientar que não foi possível definir as características associadas ao padrão de avaliação final Ruim em Alagados I, visto que este não foi detectado na amostra. De fato, podemos crer que na avaliação do morador está avaliação foi descartada.

Tabela 113: Salubridade ambiental: matrizes de avaliações final - Alagados I e II

\begin{tabular}{|c|c|c|c|c|c|c|c|c|c|c|c|c|}
\hline \multirow[b]{3}{*}{ Grupos } & \multicolumn{6}{|c|}{ Alagados I } & \multicolumn{6}{|c|}{ Alagados II } \\
\hline & \multicolumn{3}{|c|}{ Avaliação final - MDI } & \multicolumn{3}{|c|}{ Avaliação final - MSP } & \multicolumn{3}{|c|}{ Avaliação final - MDI } & \multicolumn{3}{|c|}{ Avaliação final - MSF } \\
\hline & 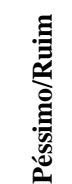 & 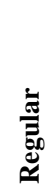 & 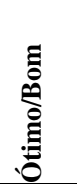 & 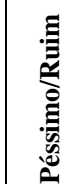 & 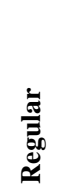 & 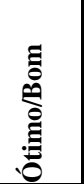 & 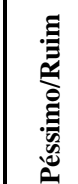 & 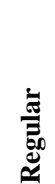 & 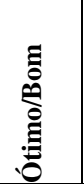 & 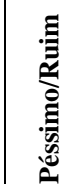 & 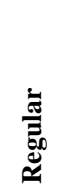 & 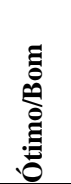 \\
\hline Péssimo/Ruim & 0,0 & 0,0 & 0,0 & 0,0 & 0,0 & 0,0 & 1,0 & $\overline{0,0}$ & 0,0 & 1,0 & 0,0 & 0,0 \\
\hline Regular & 0,0 & 1,0 & 0,5 & 0,0 & 1,0 & 0,3 & 0,5 & 1,0 & 0,5 & 0,0 & 1,0 & 0,5 \\
\hline Ótimo/Bom & 0,0 & 0,3 & 1,0 & 0,0 & 0,3 & 1,0 & 0,3 & 0,6 & 1,0 & 0,1 & 0,6 & 1,0 \\
\hline
\end{tabular}

Notamos na matriz da Tabela 114 que há uma grande quantidade de variáveis com graus de possibilidade altos, de forma que, neste caso, seria interessante analisar quais as variáveis não interferem na avaliação final, ou seja, aquelas com graus de possibilidade muito baixos.

Em Alagados I, praticamente todas as variáveis podem ser definidoras da avaliação final. Já em Alagados II, algumas variáveis podem ser selecionadas para as avaliações finais, mas a matriz também não é muito nítida, com a mesma avaliação parcial podendo resultar em avaliações finais diferentes. Esta falta de nitidez nas matrizes, pode se refletir na sua capacidade de modelar o raciocínio dos moradores, provocando altos índices de empates nas respostas. De fato, os percentuais de empates foram bem maiores que na avaliação da moradia (Tabela 115). 
Tabela 114: Salubridade ambiental: matrizes de relação com MDI e MSP- Alagados I e II

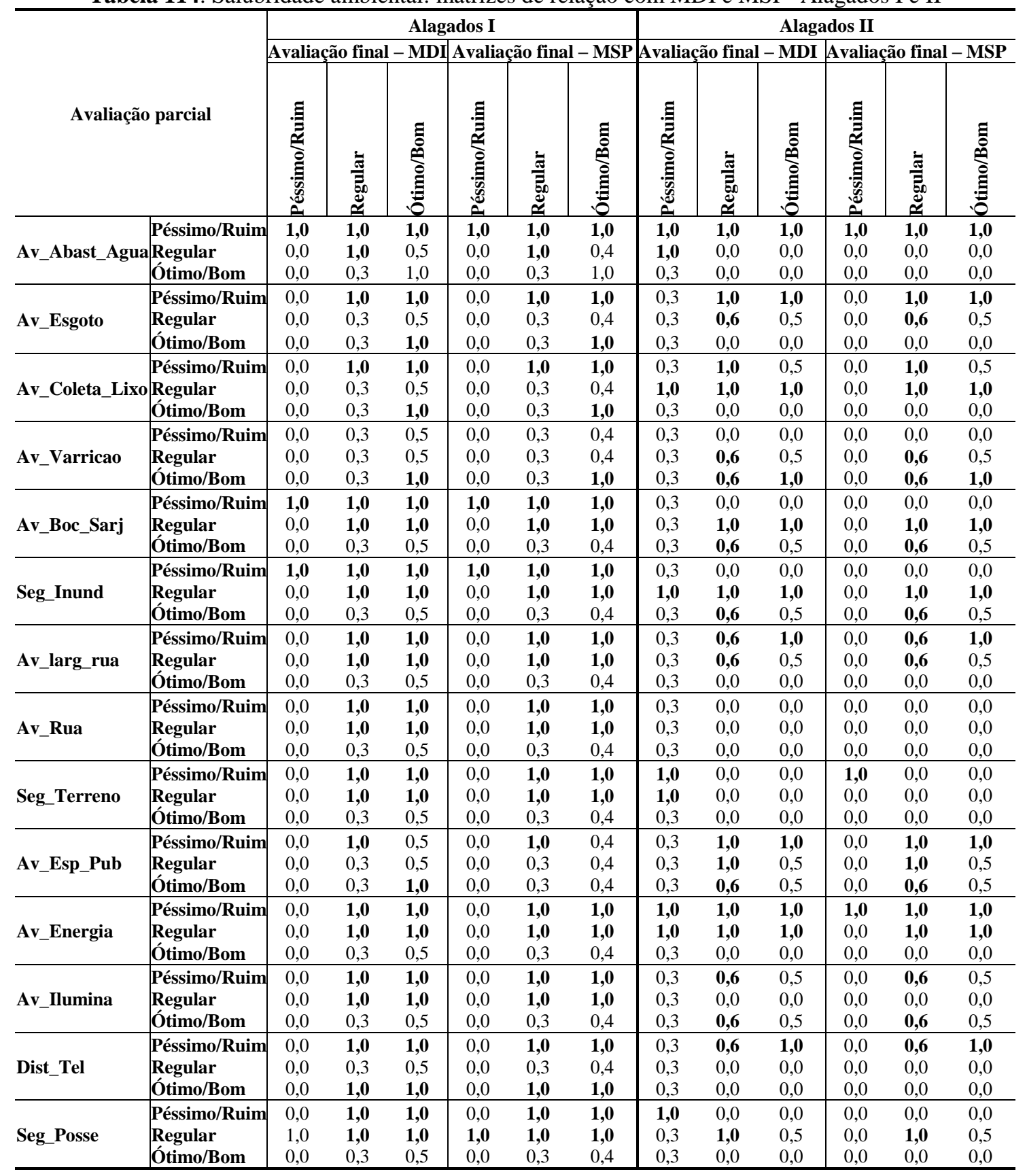

Tabela 115: Salubridade ambiental: percentual de acertos por construção da avaliação final - Alagados I e II

\begin{tabular}{lc|c|c|c|c}
\hline & Alagados I & Acertos & Empates & Empates com possibilidade de acerto & Erros \\
\hline MDI & $42 \%$ & $47 \%$ & $47 \%$ & $10 \%$ \\
MSP & & $44 \%$ & $44 \%$ & $44 \%$ & $11 \%$ \\
\hline \multicolumn{2}{r|}{ Alagados II } & & & & \\
\hline MDI & $12 \%$ & $70 \%$ & $67 \%$ & $21 \%$ \\
MSP & $18 \%$ & $62 \%$ & $62 \%$ & $21 \%$ \\
\hline
\end{tabular}


Segue a mesma análise para o entorno. Em função do baixo percentual de pessoas que utilizam outros lugares fora da área para lazer em Alagados I e que participam de algum tipo de associação em Alagados I e II, optamos por excluir estas variáveis da análise (Tabela 116).

Tabela 116: Entorno: matrizes de avaliações parciais transpostas - Alagados I e II

\begin{tabular}{|c|c|c|c|c|c|c|c|}
\hline \multirow{3}{*}{\multicolumn{2}{|c|}{ Avaliação parcial }} & \multicolumn{6}{|c|}{ Grupos } \\
\hline & & \multirow{2}{*}{\multicolumn{3}{|c|}{\begin{tabular}{|c|}
\multicolumn{2}{|c|}{ Alagados I } \\
Péssimo/Ruim|Regular|Ótimo/Bom
\end{tabular}}} & \multirow{2}{*}{\multicolumn{3}{|c|}{\begin{tabular}{|c|}
\multicolumn{2}{|c|}{ Alagados II } \\
Péssimo/Ruim|Regular|Ótimo/Bon \\
\end{tabular}}} \\
\hline & & & & & & & \\
\hline \multirow{3}{*}{ Av_Servic } & Péssimo/Ruim & 1,0 & 0,0 & 0,0 & 1,0 & 0,0 & 0,0 \\
\hline & Regular & 0,0 & 0,4 & 0,4 & 0,2 & 1,0 & 0,4 \\
\hline & Ótimo/Bom & 1,0 & 1,0 & 1,0 & 0,6 & 0,7 & 1,0 \\
\hline \multirow{3}{*}{ A_Lazer_Fora } & Péssimo/Ruim & - & - & - & 0,0 & 0,0 & 0,3 \\
\hline & Regular & - & - & - & 0,5 & 0,3 & 1,0 \\
\hline & Ótimo/Bom & - & - & - & 1,0 & 1,0 & 1,0 \\
\hline \multirow{3}{*}{ Av_Transporte } & Péssimo/Ruim & 0,0 & 0,0 & 0,0 & 1,0 & 0,4 & 0,1 \\
\hline & Regular & 1,0 & 1,0 & 0,5 & 0,4 & 0,6 & 0,2 \\
\hline & Ótimo/Bom & 0,0 & 0,3 & 1,0 & 0,4 & 1,0 & 1,0 \\
\hline
\end{tabular}

A Tabela 117 apresenta as matrizes de avaliação final para o entorno.

Tabela 117: Entorno: matrizes de avaliação final com MDI e MSP-Alagados I e II

\begin{tabular}{|c|c|c|c|c|c|c|c|c|c|c|c|c|}
\hline \multirow[b]{3}{*}{ Grupos } & \multicolumn{6}{|c|}{ Alagados I } & \multicolumn{6}{|c|}{ Alagados II } \\
\hline & \multicolumn{3}{|c|}{ Avaliação final - MDI } & \multicolumn{3}{|c|}{ Avaliação final - MSP } & \multicolumn{3}{|c|}{ Avaliação final - MDI } & \multicolumn{3}{|c|}{ Avaliação final - MSP } \\
\hline & 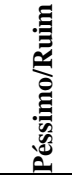 & 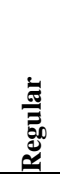 & 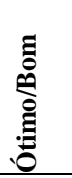 & 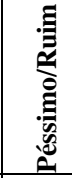 & 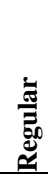 & 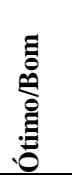 & 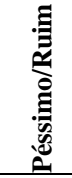 & 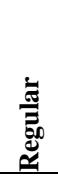 & 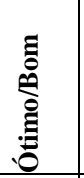 & 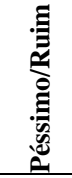 & 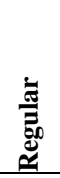 & 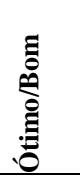 \\
\hline Péssimo/Ruim & 1,0 & 1,0 & 0,0 & 1,0 & 1,0 & 0,0 & 1,0 & 0,2 & 0,5 & 1,0 & 0,2 & 0,5 \\
\hline Regular & 0,0 & 1,0 & 0,3 & 0,0 & 1,0 & 0,3 & 0,4 & 1,0 & 0,3 & 0,0 & 1,0 & 0,3 \\
\hline Ótimo/Bom & 0,0 & 0,5 & 1,0 & 0,0 & 0,5 & 1,0 & 0,1 & 0,4 & 1,0 & 0,0 & 0,4 & 1,0 \\
\hline
\end{tabular}

Notamos na Tabela 118 que em Alagados I e II que basicamente os serviços são os definidores da avaliação final. 
Tabela 118: Entorno: matrizes de relação com MDI e MSP-Alagados I e II

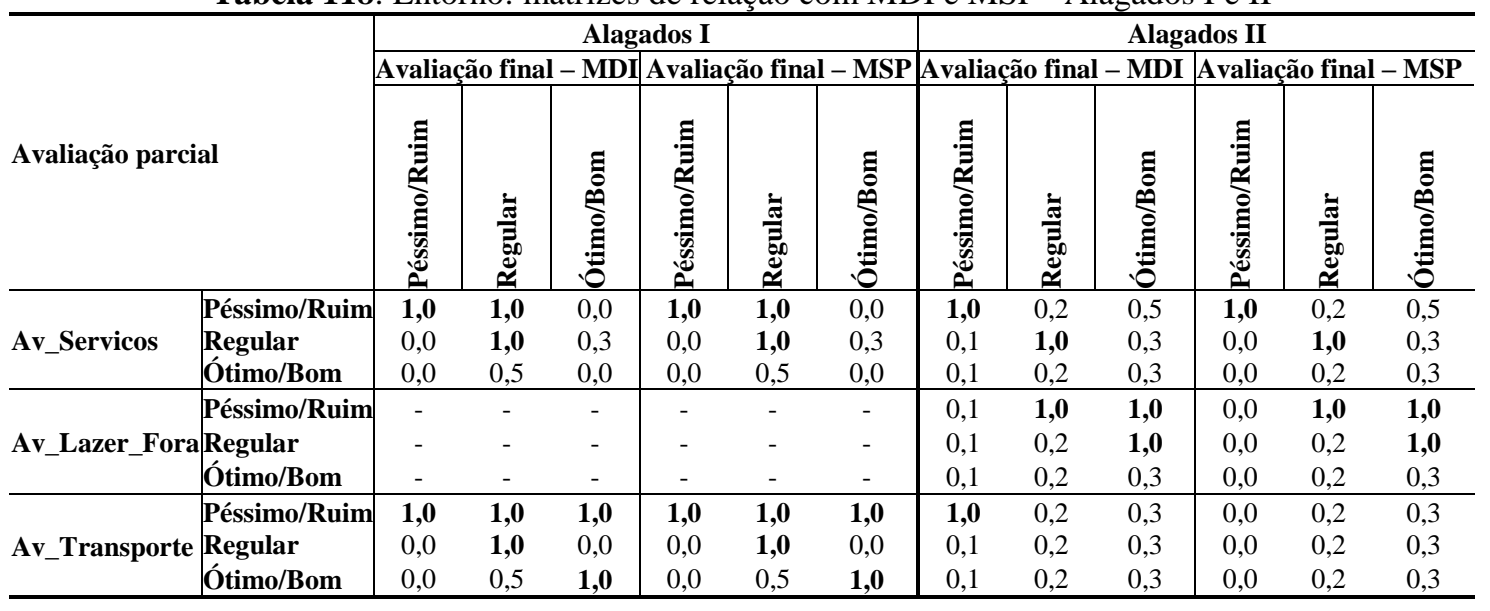

Em Alagados I obtivemos um percentual de acertos elevado (71\%), enquanto em Alagados II esse percentual ficou em torno de 60\% (Tabela 119).

Tabela 119: Entorno: percentual de acertos por construção da avaliação final - Alagados I e II

\begin{tabular}{lc|c|c|c|c}
\hline \multicolumn{1}{c|}{ Alagados I } & Acertos & Empates & Empates com possibilidade de acerto & Erros \\
\hline MDI & $71 \%$ & $10 \%$ & $10 \%$ & $19 \%$ \\
MSP & $71 \%$ & $10 \%$ & $10 \%$ & $19 \%$ \\
\hline \multicolumn{2}{c|}{ Alagados II } & & & & \\
\hline MDI & $59 \%$ & $8 \%$ & $8 \%$ & $33 \%$ \\
MSP & $64 \%$ & $4 \%$ & $4 \%$ & $32 \%$ \\
\hline
\end{tabular}

10.4.1.1.4 Indicadores segundo o modelo das equações relacionais fuzzy

De posse das matrizes anteriores e das freqüências de avaliação dos moradores (Tabela 120), podemos obter os indicadores finais segundo a avaliação dos moradores; os percentuais de acerto acima podem ser visto como os graus de verdade das matrizes e de seus resultados. 
Tabela 120: Dados para o cálculo dos indicadores finais qualitativos - Alagados I e II

\begin{tabular}{|c|c|c|c|c|c|c|c|c|c|}
\hline Conceito & Moradia & Alagados I & Alagados II & $\begin{array}{c}\text { Salubridade } \\
\text { ambiental }\end{array}$ & Alagados I & Alagados II & Entorno & Alagados I & Alagados II \\
\hline $\begin{array}{l}\text { Péssimo/Ruim } \\
\text { Regular } \\
\text { Bom/Ótimo }\end{array}$ & Av_Quartos & $\begin{array}{l}0,7 \\
0,9 \\
1,0\end{array}$ & $\begin{array}{l}0,8 \\
1,0 \\
0,9 \\
\end{array}$ & Av_Abast_Agua & $\begin{array}{l}0,0 \\
0,5 \\
1,0\end{array}$ & $\begin{array}{l}0,0 \\
0,1 \\
1,0\end{array}$ & Av_Servic & $\begin{array}{l}0,0 \\
0,4 \\
1,0 \\
\end{array}$ & $\begin{array}{l}0,1 \\
0,6 \\
1,0 \\
\end{array}$ \\
\hline $\begin{array}{l}\text { Péssimo/Ruim } \\
\text { Regular } \\
\text { Bom/Ótimo }\end{array}$ & Av_Banheiro & $\begin{array}{l}0,2 \\
0,7 \\
1,0\end{array}$ & $\begin{array}{l}0,4 \\
0,9 \\
1,0\end{array}$ & Av_Esgoto & $\begin{array}{l}0,0 \\
1,0 \\
0,3 \\
\end{array}$ & $\begin{array}{l}0,3 \\
1,0 \\
0,6 \\
\end{array}$ & Av_Lazer_Fora & $\begin{array}{l}- \\
- \\
-\end{array}$ & $\begin{array}{l}0,1 \\
0,6 \\
1,0\end{array}$ \\
\hline $\begin{array}{l}\text { Péssimo/Ruim } \\
\text { Regular } \\
\text { Bom/Ótimo } \\
\end{array}$ & Av_Cozinha & $\begin{array}{l}0,0 \\
0,5 \\
1,0 \\
\end{array}$ & $\begin{array}{l}0,3 \\
0,9 \\
1,0 \\
\end{array}$ & Av_Coleta_Lixo & $\begin{array}{l}0,0 \\
1,0 \\
0,2 \\
\end{array}$ & $\begin{array}{l}0,4 \\
0,2 \\
1,0 \\
\end{array}$ & Av_Associação & $\begin{array}{l}- \\
- \\
-\end{array}$ & $\begin{array}{l}- \\
- \\
-\end{array}$ \\
\hline $\begin{array}{l}\text { Péssimo/Ruim } \\
\text { Regular } \\
\text { Bom/Ótimo } \\
\end{array}$ & Av_Tam_Casa & $\begin{array}{l}0,3 \\
0,6 \\
1,0 \\
\end{array}$ & $\begin{array}{l}0,6 \\
0,8 \\
1,0 \\
\end{array}$ & Av_Varricao & $\begin{array}{l}0,7 \\
1,0 \\
0,4 \\
\end{array}$ & $\begin{array}{l}0,5 \\
1,0 \\
0,5 \\
\end{array}$ & Av_Transporte & $\begin{array}{l}0,0 \\
1,0 \\
0,4 \\
\end{array}$ & $\begin{array}{l}0,2 \\
0,3 \\
1,0 \\
\end{array}$ \\
\hline $\begin{array}{l}\text { Péssimo/Ruim } \\
\text { Regular } \\
\text { Bom/Ótimo } \\
\end{array}$ & Av_Inst_Agua & $\begin{array}{l}0,0 \\
0,2 \\
1,0 \\
\end{array}$ & $\begin{array}{l}0,1 \\
0,5 \\
1,0 \\
\end{array}$ & Av_Boc_Sarj & $\begin{array}{l}0,0 \\
0,0 \\
1,0 \\
\end{array}$ & $\begin{array}{l}1,0 \\
0,4 \\
0,6 \\
\end{array}$ & - & $\begin{array}{l}- \\
- \\
-\end{array}$ & $\begin{array}{l}- \\
- \\
-\end{array}$ \\
\hline $\begin{array}{l}\text { Péssimo/Ruim } \\
\text { Regular } \\
\text { Bom/Ótimo }\end{array}$ & Av_Inst_Esgoto & $\begin{array}{l}0,0 \\
0,2 \\
1,0 \\
\end{array}$ & $\begin{array}{l}0,1 \\
0,6 \\
1,0 \\
\end{array}$ & Seg_Inund & $\begin{array}{l}0,0 \\
0,0 \\
1,0\end{array}$ & $\begin{array}{l}0,3 \\
0,2 \\
1,0 \\
\end{array}$ & - & $\begin{array}{l}- \\
- \\
-\end{array}$ & $\begin{array}{l}- \\
- \\
-\end{array}$ \\
\hline $\begin{array}{l}\text { Péssimo/Ruim } \\
\text { Regular } \\
\text { Bom/Ótimo }\end{array}$ & Av_Inst_Eletrica & $\begin{array}{l}0,0 \\
0,1 \\
1,0\end{array}$ & $\begin{array}{l}0,1 \\
0,4 \\
1,0\end{array}$ & Av_larg_rua & $\begin{array}{l}0,0 \\
0,0 \\
1,0\end{array}$ & $\begin{array}{l}0,9 \\
1,0 \\
1,0\end{array}$ & - & $\begin{array}{l}- \\
- \\
-\end{array}$ & $\begin{array}{l}- \\
- \\
-\end{array}$ \\
\hline $\begin{array}{l}\text { Péssimo/Ruim } \\
\text { Regular } \\
\text { Bom/Ótimo } \\
\end{array}$ & Av_Telhado & $\begin{array}{l}0,1 \\
0,3 \\
1,0 \\
\end{array}$ & $\begin{array}{l}0,2 \\
0,5 \\
1,0 \\
\end{array}$ & Av_Rua & $\begin{array}{l}0,0 \\
0,3 \\
1,0 \\
\end{array}$ & $\begin{array}{l}0,5 \\
1,0 \\
0,7 \\
\end{array}$ & - & $\begin{array}{l}- \\
- \\
-\end{array}$ & $\begin{array}{l}- \\
- \\
-\end{array}$ \\
\hline $\begin{array}{l}\text { Péssimo/Ruim } \\
\text { Regular } \\
\text { Bom/Ótimo }\end{array}$ & Av_Paredes & $\begin{array}{l}0,0 \\
0,6 \\
1,0\end{array}$ & $\begin{array}{l}0,2 \\
0,7 \\
1,0 \\
\end{array}$ & Seg_Terreno & $\begin{array}{l}0,0 \\
0,0 \\
1,0\end{array}$ & $\begin{array}{l}0,1 \\
0,4 \\
1,0 \\
\end{array}$ & - & $\begin{array}{l}- \\
- \\
-\end{array}$ & $\begin{array}{l}- \\
- \\
-\end{array}$ \\
\hline $\begin{array}{l}\text { Péssimo/Ruim } \\
\text { Regular } \\
\text { Bom/Ótimo }\end{array}$ & Av_Piso & $\begin{array}{l}0,1 \\
1,0 \\
0,8 \\
\end{array}$ & $\begin{array}{l}0,6 \\
1,0 \\
0,9\end{array}$ & Av_Esp_Pub & $\begin{array}{l}0,5 \\
1,0 \\
0,7 \\
\end{array}$ & $\begin{array}{l}0,4 \\
0,8 \\
1,0 \\
\end{array}$ & - & $\begin{array}{l}- \\
- \\
-\end{array}$ & $\begin{array}{l}- \\
- \\
-\end{array}$ \\
\hline $\begin{array}{l}\text { Péssimo/Ruim } \\
\text { Regular } \\
\text { Bom/Ótimo } \\
\end{array}$ & Av_Ventila & $\begin{array}{l}0,0 \\
1,0 \\
0,1 \\
\end{array}$ & $\begin{array}{l}0,5 \\
1,0 \\
0,3 \\
\end{array}$ & Av_Energia & $\begin{array}{l}0,0 \\
0,0 \\
1,0 \\
\end{array}$ & $\begin{array}{l}0,0 \\
0,2 \\
1,0 \\
\end{array}$ & - & $\begin{array}{l}- \\
- \\
-\end{array}$ & $\begin{array}{l}- \\
- \\
-\end{array}$ \\
\hline $\begin{array}{l}\text { Péssimo/Ruim } \\
\text { Regular } \\
\text { Bom/Ótimo } \\
\end{array}$ & - & - & $\begin{array}{l}- \\
- \\
-\end{array}$ & Av_Ilumina & $\begin{array}{l}0,0 \\
0,0 \\
1,0 \\
\end{array}$ & $\begin{array}{l}0,7 \\
1,0 \\
0,9 \\
\end{array}$ & - & $\begin{array}{l}- \\
- \\
-\end{array}$ & $\begin{array}{l}- \\
- \\
-\end{array}$ \\
\hline $\begin{array}{l}\text { Péssimo/Ruim } \\
\text { Regular } \\
\text { Bom/Ótimo }\end{array}$ & - & $\begin{array}{l}- \\
- \\
-\end{array}$ & $\begin{array}{l}- \\
- \\
-\end{array}$ & Dist_Tel & $\begin{array}{l}0,1 \\
1,0 \\
0,1\end{array}$ & $\begin{array}{l}0,9 \\
1,0 \\
0,9\end{array}$ & - & $\begin{array}{l}- \\
- \\
-\end{array}$ & $\begin{array}{l}- \\
- \\
-\end{array}$ \\
\hline $\begin{array}{l}\text { Péssimo/Ruim } \\
\text { Regular } \\
\text { Bom/Ótimo }\end{array}$ & - & $\begin{array}{l}- \\
- \\
-\end{array}$ & $\begin{array}{l}- \\
- \\
-\end{array}$ & Seg_Posse & $\begin{array}{l}0,0 \\
0,0 \\
1,0\end{array}$ & $\begin{array}{l}0,2 \\
0,5 \\
1,0\end{array}$ & - & $\begin{array}{l}- \\
- \\
-\end{array}$ & $\begin{array}{l}- \\
-\end{array}$ \\
\hline
\end{tabular}

$\mathrm{Na}$ avaliação final em Alagados I, a Moradia e a Salubridade Ambiental podem ser consideradas Bom/Ótimo e o Entorno Regular. Podemos ver que, de forma semelhante a Alagados I, em Alagados II a Moradia e Salubridade Ambiental são considerados Bons e o Entorno de Regular a Bom (Tabela 121). 
Tabela 121: Indicadores qualitativos obtidos utilizando equações relacionais fuzzy - Alagados I e II

\begin{tabular}{|c|c|c|c|c|c|c|}
\hline \multirow{2}{*}{ Alagados I } & \multicolumn{2}{|c|}{ Moradia } & \multicolumn{2}{|c|}{ Salubridade ambiental } & \multicolumn{2}{|c|}{ Entorno } \\
\hline & MDI & MSP & MDI & MSP & MDI & MSP \\
\hline Péssimo/Ruim & 0,7 & 0,3 & 0,0 & 0,0 & 0,0 & 0,0 \\
\hline Regular & 0,9 & 0,9 & 0,5 & 0,5 & 1,0 & 1,0 \\
\hline Bom/Ótimo & 1,0 & 1,0 & 1,0 & 1,0 & 0,4 & 0,4 \\
\hline \multirow{2}{*}{ Alagados II } & \multicolumn{2}{|c|}{ Moradia } & \multicolumn{2}{|c|}{ Salubridade ambiental } & \multicolumn{2}{|c|}{ Entorno } \\
\hline & MDI & MSP & MDI & MSP & MDI & MSP \\
\hline Péssimo/Ruim & 0,4 & 0,3 & 0,4 & 0,1 & 0,2 & 0,1 \\
\hline Regular & 0,8 & 0,8 & 0,8 & 0,8 & 0,6 & 0,6 \\
\hline Bom/Ótimo & 1,0 & 1,0 & 0,9 & 0,9 & 0,6 & 0,6 \\
\hline
\end{tabular}

10.4.1.2 Método do reconhecimento de padrão fuzzy

A análise utilizando o reconhecimento de padrão é similar na forma de agrupamento das respostas para obter os padrões, porém, parte apenas de uma medida de comparação com cada padrão para alocar um novo indivíduo. De modo que, definidos os padrões apenas verificamos o seu percentual de acertos. As análises para os dados de Alagados I e II são apresentadas abaixo.

\subsection{Moradia}

As tabelas a seguir apresentam os padrões para avaliação da moradia fuzzy normais e subnormais (Tabela 122).

O percentual de acertos deste método foi superior ao método anterior, sendo que neste caso não identificamos nenhum empate. Em Alagados II o percentual de acertos chegou a 70\% (Tabela 123). 
Tabela 122: Moradia: Padrões de satisfação fuzzy - Alagados I e II

\begin{tabular}{|c|c|c|c|c|c|c|c|c|c|c|c|c|c|c|c|c|c|c|}
\hline \multirow{3}{*}{ 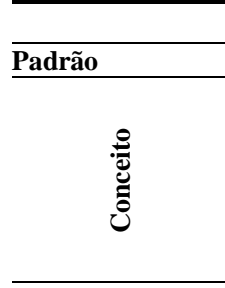 } & \multicolumn{9}{|c|}{ Alagados I } & \multicolumn{9}{|c|}{ Alagados II } \\
\hline & \multicolumn{3}{|c|}{ Péssimo/Ruim } & \multicolumn{3}{|c|}{ Regular } & \multicolumn{3}{|c|}{ Bom/Ótimo } & \multicolumn{3}{|c|}{ Péssimo/Ruim } & \multicolumn{3}{|c|}{ Regular } & \multicolumn{3}{|c|}{ Bom/Ótimo } \\
\hline & 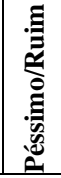 & 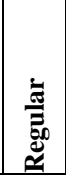 & 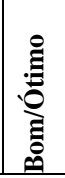 & 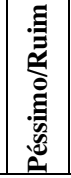 & 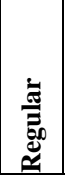 & 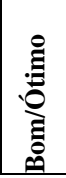 & 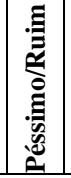 & 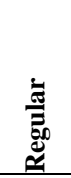 & 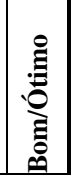 & 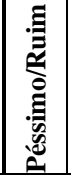 & 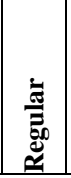 & 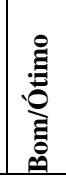 & 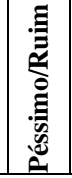 & & 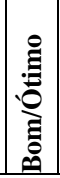 & 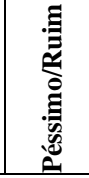 & 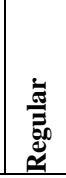 & 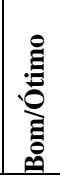 \\
\hline \multicolumn{19}{|c|}{ Fuzzy normais } \\
\hline Av_Quar & 1,00 & 0,08 & 0,00 & 0,58 & 1,00 & 0,75 & 0,13 & 0,29 & 1,00 & $1,00 \mid$ & 0,20 & 0,20 & 1,00 & 0,83 & $0,52 \mid$ & 0,19 & 0,85 & 1,00 \\
\hline Av_B & 0,26 & 1,00 & 0,21 & 0,26 & 0,77 & 1,00 & 06 & 0,13 & 1,00 & $1,00 \mid$ & 0,50 & 0,00 & 0,31 & 1 & $0,36 \mid$ &, 05 &, 29 & 00 \\
\hline Av_C & 0,15 & 1,00 & 1,00 & 0,00 & 0,64 & 1,00 & 00 & 0,19 & 1,00 & $1,00 \mid$ & 0,75 & 0,00 & 0,27 & 1 & $0,36 \mid$ & 0,07 & 0,24 & 00 \\
\hline asa & 1, & 0,82 & 0,73 & 0,26 & 0,77 & 1,00 & $|0,10|$ & 0,13 & 1,00 & $1,00 \mid$ & 0,14 & 0,14 & 0,81 & 1,00 & $0,41 \mid$ & 0,08 & 0,33 & 1,00 \\
\hline Av_Ins & 0,00 & 0,40 & 1,00 & 0,00 & 0,14 & 1,00 & 0,00 & 0,09 & 1,0 & 0,17 & 0,17 & 1,00 & 0,03 & 0,61 & 1,00 & 0,06 & 0,54 & 1,00 \\
\hline $\mathbf{v}_{-}$ & 0,00 & 0,56 & 1,00 & 0,00 & 0,12 & 1,00 & $|0,00|$ & 0,09 & 1,00 & 0,33 & 0,17 & 1,00 & 0,03 & 0,79 & $1,00 \mid$ & 0,03 & 0,41 & 1,00 \\
\hline ica & 0,00 & 0,22 & 1,00 & $0,00 \mid$ & 0,12 & 1,00 & $|0,00|$ & 0,15 & 1,00 & $0,00 \mid$ & 0,29 & 1,00 & 0,15 & 0,62 & $1,00 \mid$ & 0,05 & 0,26 & 1,00 \\
\hline $\mathbf{a v}_{-}$? & 0,38 & 0,38 & 1,00 & 0,06 & 0,22 & 1,00 & $|0,07|$ & 0,33 & 1,00 & $0,50 \mid$ & 1,00 & 0,50 & 0,42 & 0,88 & $1,00 \mid$ & 0,09 & 0,16 & 1,00 \\
\hline wes & 0,08 & 1,00 & 0,08 & 0,03 & 0,31 & 1,00 & $|0,00|$ & 0,41 & 1,00 & $0,50 \mid$ & 1,00 & 0,75 & 0,32 & 1 & 0,7 & 0,02 & 0,29 & 1,00 \\
\hline & 0,08 & 1,00 & 0,08 & 0,07 & 1,00 & 0,95 & 0,05 & 0,68 & 1,00 & $1,00 \mid$ & 0,40 & 0,20 & 0,77 & 1 & 0,38 & 0,12 & 0,58 & 1,00 \\
\hline- & 0,04 & 1,00 & 0,00 & 0,01 & 1,00 & 0,02 & 0,12 & 1,00 & 0,40 & 1,00 & 0,33 & 0,17 & 0,80 & 1,00 & 0,17 & 0,05 & 1,00 & 0,38 \\
\hline \multicolumn{19}{|c|}{ Fuzzy subnormais } \\
\hline Av_Q & 0,92 & 0,08 & 0,00 & 0,25 & 0,43 & 0,32 & 0,09 & 0,21 & 0,71 & 0,71 & 0,14 & 0,14 & 0,43 & 0,35 & 0,22 & 0,09 & 0,42 & 0,49 \\
\hline & 0,18 & 0,68 & 0,14 & 0,13 & 0,38 & 0,49 & 0,05 & 0,11 & 0,84 & 0,67 & 0,33 & 0,00 & 0,18 & 0,60 & 0,22 & 0,04 & 0,22 & 0,75 \\
\hline & 0,07 & 0,46 & 0,46 & 0,00 & 0,39 & 0,61 & $|0,00|$ & 0,16 & 0,84 & 0,57 & 0,43 & 0,00 & 0,17 & 1 & 0,22 & 0,06 & 0,19 & 0,76 \\
\hline & & 0,32 & 0,29 & 0,13 & 0,38 & 0,49 & 0,08 & 0,11 & 0,82 & 0,78 & 0,11 & 0,11 & 0,37 & 0 & 0,18 & 0,05 &, 24 & 0,71 \\
\hline & 0 & 0,29 & 0,71 & $0,00 \mid$ & 0,13 & 0,87 & 0,0 & 0,08 & 0,92 & 0,13 & 0,13 & 0,75 & 0,02 & 0 & 0,6 & 0,04 & 0,34 & 0,63 \\
\hline & 0,00 & 0,36 & 0,64 & 0,00 & 0,10 & 0,90 & $0,00 \mid$ & 0,08 & 0,92 & 0,22 & 0,11 & 0,67 & 0,02 & 0 & 0,5 & 0,02 & 0,29 & 0,70 \\
\hline ca & 0,00 & 0,18 & 0,82 & 0,00 & 0,10 & 0,90 & $|0,00|$ & 0,13 & 0,87 & 0,00 & 0,22 & 0,78 & 0,08 & 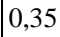 & 0,5 & 0,04 & 0,20 & 0,77 \\
\hline & 0,21 & 0,21 & 0,57 & 0,05 & 0,17 & 0,78 & 0,05 & 0,24 & 0,71 & 0,25 & 0,50 & 0,25 & 0,18 & ( & 0,4 & 0,07 & 0,13 & 0,80 \\
\hline des & 0,07 & 0,86 & 0,07 & 0,02 & 0,23 & 0,75 & $|0,00|$ & 0,29 & 0,71 & 0,22 & 0,44 & 0,33 & 0,15 & 0 & $0,37 \mid$ & 0,02 & 0,22 & 0,76 \\
\hline & 0,07 & 0,86 & 0,07 & 0,03 & 0,49 & 0,47 & $0,03 \mid$ & 0,39 & 0,58 & 0.63 & 0,25 & 0,13 & 0,36 & 0,46 & 0,18 & 0,07 & 0,34 & 0,59 \\
\hline Av_Ventila & 0,04 & 0,96 & 0,00 & 0,01 & 0,97 & 0,02 & 0,08 & 0,66 & 0,2 & 0,67 & 0,22 & 0,11 & 0,41 & 0,51 & 0,08 & 0,04 & 0,70 & 0,27 \\
\hline
\end{tabular}

Tabela 123: Moradia: percentual de acertos com o reconhecimento de padrão - Alagados I e II

\begin{tabular}{l|c|c}
\hline \multicolumn{1}{c|}{ Padrão } & Alagados I & Alagados II \\
\hline Fuzzy normal & $55 \%$ & $70 \%$ \\
\hline Fuzzy Subnormal & $57 \%$ & $63 \%$ \\
\hline
\end{tabular}

\subsection{Salubridade ambiental}

De forma semelhante, apresentamos os resultados para a Salubridade Ambiental (Tabela 124). 
Tabela 124: Salubridade ambiental - padrões de satisfação - Alagados I e II

\begin{tabular}{|c|c|c|c|c|c|c|c|c|c|c|c|c|c|c|c|c|c|c|}
\hline \multirow{3}{*}{ 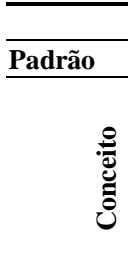 } & \multicolumn{9}{|c|}{ Alagados I } & \multicolumn{9}{|c|}{ Alagados II } \\
\hline & \multicolumn{3}{|c|}{ Péssimo/Ruim } & \multicolumn{3}{|c|}{ Regular } & \multicolumn{3}{|c|}{ Bom/Ótimo } & \multicolumn{3}{|c|}{ Péssimo/Ruim } & \multicolumn{3}{|c|}{ Regular } & \multicolumn{3}{|c|}{ Bom/Ótimo } \\
\hline & 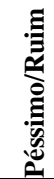 & 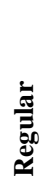 & 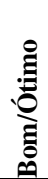 & 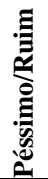 & 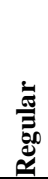 & ڤ્. & 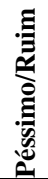 & 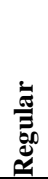 & 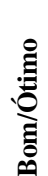 & 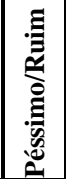 & 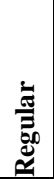 & 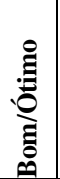 & 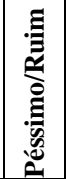 & 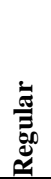 & 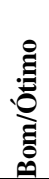 & 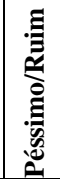 & 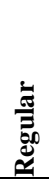 & 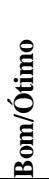 \\
\hline
\end{tabular}

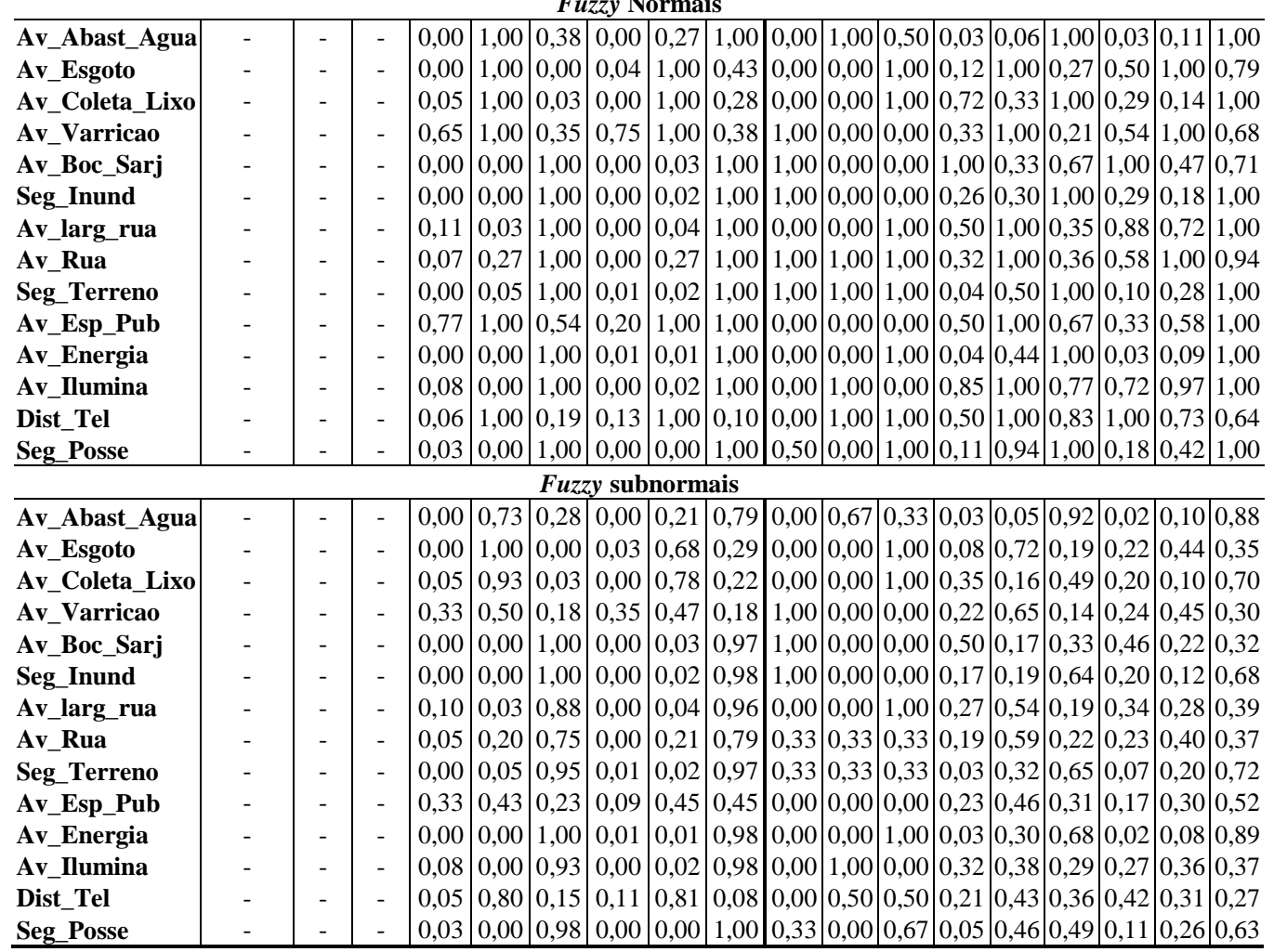

Para a Salubridade ambiental, os percentuais de acertos se inverteram, enquanto que em Alagados I este percentual quase atingiu 80\%, em Alagados II o percentual de acerto ficou em torno de 50\% (Tabela 125). Lembrando o baixo desempenho do método das equações relacionais fuzzy para os mesmos dados, parece que a amostra apresenta uma baixa capacidade de modelagem dos dados, ou a população apresenta um grau de subjetividade não captado pelo formulário.

Tabela 125: Salubridade ambiental: percentual de acertos com o reconhecimento de padrão - Alagados I e II

\begin{tabular}{l|c|c}
\hline \multicolumn{1}{c|}{ Padrão } & Alagados I & Alagados II \\
\hline Fuzzy normal & $78 \%$ & $53 \%$ \\
\hline Fuzzy subnormal & $78 \%$ & $47 \%$ \\
\hline
\end{tabular}


Para o entorno, fizemos as mesmas considerações do método anterior e excluímos dos locais de lazer fora da área para Alagados I e a participação em associações para Alagados I e II (Tabela 126).

Tabela 126: Entorno: padrões de satisfação - Alagados I e II

\begin{tabular}{|c|c|c|c|c|c|c|c|c|c|c|c|c|c|c|c|c|c|c|}
\hline \multirow{3}{*}{ 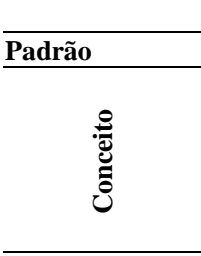 } & \multicolumn{9}{|c|}{ Alagados I } & \multicolumn{9}{|c|}{ Alagados II } \\
\hline & \multicolumn{3}{|c|}{ Péssimo/Ruim } & \multicolumn{3}{|c|}{ Regular } & \multicolumn{3}{|c|}{ Bom/Ótimo } & \multicolumn{3}{|c|}{ Péssimo/Ruim } & \multicolumn{3}{|c|}{ Regular } & \multicolumn{3}{|c|}{ Bom/Ótimo } \\
\hline & 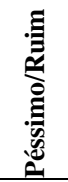 & 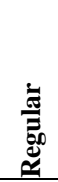 & 兽 & 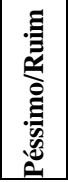 & 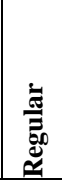 & 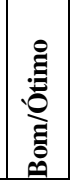 & 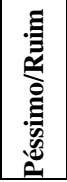 & 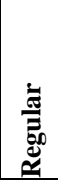 & 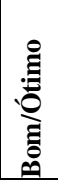 & 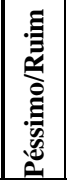 & 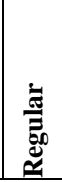 & 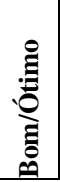 & 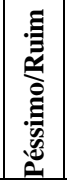 & 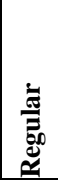 & 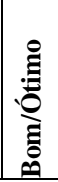 & 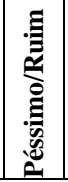 & 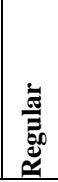 & @ٍ \\
\hline \multicolumn{19}{|c|}{ Fuzzy Normais } \\
\hline$\overline{\text { Av_Servic }}$ & 1,00 & 0,00 & 1,00 & 0,00 & 0,39 & 1,00 & 0,00 & 0,35 & 1,00 & 1,00 & 0,20 & 0,60 & 0,04 & 1,00 & 0,65 & 0,04 & 0,40 & 1,00 \\
\hline Av_Lazer_Fora & - & - & - & - & - & - & - & - & - & 0,00 & 0,50 & 1,00 & 0,00 & 0,25 & 1,00 & 0,33 & 1,00 & 1,00 \\
\hline Av_Transp & 0,00 & 1,00 & 0,00 & 0,00 & 1,00 & 0,32 & 0,00 & 0,53 & 1,00 & 1,00 & 0,40 & 0,40 & 0,42 & 0,63 & 1,00 & 0,05 & 0,20 & 1,00 \\
\hline \multicolumn{19}{|c|}{ Fuzzy subnormais } \\
\hline Av_Servic & 0,50 & 0,00 & 0,50 & 0,00 & 0,28 & 0,72 & 0,00 & 0,26 & 0,74 & 0,56 & 0,11 & 0,33 & 0,03 & 0,59 & 0,38 & 0,03 & 0,28 & 0,69 \\
\hline Av_Lazer_Fora & - & - & - & - & - & - & - & - & - & 0,00 & 0,33 & 0,67 & 0,00 & 0,20 & 0,80 & 0,14 & 0,43 & 0,43 \\
\hline Av_Transp & 0,00 & 1,00 & 0,00 & 0,00 & 0,76 & 0,24 & 0,00 & 0,35 & 0,65 & 0,56 & 0,22 & 0,22 & 0,21 & 0,31 & 0,49 & 0,04 & 0,16 & 0,80 \\
\hline
\end{tabular}

O percentual de acertos foi em torno de $70 \%$ para ambas as áreas. O que denota que este modelo apresenta uma maior estabilidade que o das equações relacionais fuzzy.

Tabela 127: Entorno: percentual de acertos com o reconhecimento de padrão - Alagados I e II

\begin{tabular}{l|c|c}
\hline \multicolumn{1}{|c|}{ Padrão } & Alagados I & Alagados II \\
\hline Fuzzy normal & $74 \%$ & $66 \%$ \\
\hline Fuzzy subnormal & $27 \%$ & $70 \%$ \\
\hline
\end{tabular}

10.4.1.2.4 Indicadores segundo o modelo de reconhecimento de padrão

A Tabela 128 mostra os dados para o cálculo dos indicadores finais de Moradia, Salubridade Ambiental e Entorno. 
Tabela 128: Padrão de satisfação geral - Alagados I e II

\begin{tabular}{|c|c|c|c|c|c|c|c|c|c|c|c|c|}
\hline \multirow[b]{3}{*}{ 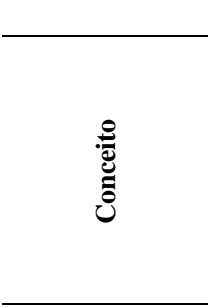 } & \multicolumn{6}{|c|}{ Alagados I } & \multicolumn{6}{|c|}{ Alagados II } \\
\hline & \multicolumn{3}{|c|}{ Fuzzy normal } & \multicolumn{3}{|c|}{ Fuzzy subnormal } & \multicolumn{3}{|c|}{ Fuzzy normal } & \multicolumn{3}{|c|}{ Fuzzy subnormal } \\
\hline & 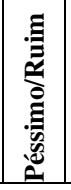 & 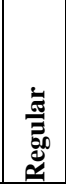 & 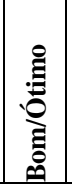 & 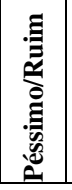 & 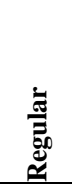 & 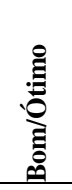 & 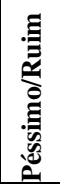 & 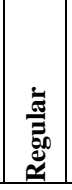 & 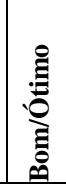 & 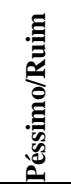 & 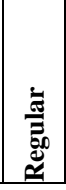 & 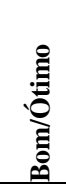 \\
\hline \multicolumn{13}{|c|}{ Moradia } \\
\hline Av_Quartos & 0,71 & 0,86 & $|1,00|$ & $0,27 \mid$ & 0,34 & 0,39 & 0,79 & $|1,00|$ & 0,93 & 0,29 & 0,37 & 0,34 \\
\hline Av_Banheiro & 0,23 & 0,71 & 1,00 & 0,12 & 0,37 & 0,52 & 0,35 & 0,94 & 1,00 & 0,15 & 0,41 & 0,44 \\
\hline Av_Cozinha & 0,02 & 0,54 & 1,00 & 0,01 & 0,35 & 0,64 & 0,30 & 0,87 & 1,00 & 0,14 & 0,40 & 0,46 \\
\hline Av_Tam_Casa & 0,30 & 0,56 & 1,00 & 0,16 & 0,30 & 0,54 & 0,63 & 0,80 & 1,00 & 0,26 & 0,33 & 0,41 \\
\hline Av_Inst_Agua & $0,00 \mid$ & 0,17 & 1,00 & 0,00 & 0,14 & 0,86 & 0,05 & 0,55 & 1,00 & 0,03 & 0,34 & 0,63 \\
\hline Av_Inst_Esgoto & 0,00 & 0,17 & 1,00 & 0,00 & 0,14 & 0,86 & 0,05 & 0,55 & 1,00 & 0,03 & 0,34 & 0,62 \\
\hline Av_Inst_Eletrica & 0,00 & 0,14 & 1,00 & 0,00 & 0,12 & 0,88 & 0,08 & 0,40 & 1,00 & 0,06 & 0,27 & 0,67 \\
\hline Av_Telhado & 0,11 & 0,27 & 1,00 & 0,08 & 0,20 & 0,73 & 0,23 & 0,47 & 1,00 & 0,14 & 0,27 & 0,59 \\
\hline Av_Paredes & 0,04 & 0,59 & 1,00 & 0,03 & 0,36 & 0,61 & 0,18 & $|0,66|$ & 1,00 & 0,10 & 0,36 & 0,54 \\
\hline Av_Piso & 0,07 & 1,00 & 0,79 & 0,04 & 0,54 & 0,42 & 0,62 & 1,00 & 0,94 & 0,24 & 0,39 & 0,37 \\
\hline Av_Ventila & 0,04 & 1,00 & 0,09 & 0,03 & 0,89 & 0,08 & 0,45 & 1,00 & 0,30 & 0,26 & 0,57 & 0,17 \\
\hline \multicolumn{13}{|c|}{ Salubridade ambiental } \\
\hline Av_Abast_Agua & 0,00 & 0,53 & 1,00 & 0,00 & 0,35 & 0,65 & 0,03 & 0,11 & 1,00 & 0,02 & 0,10 & 0,88 \\
\hline Av_Esgoto & 0,03 & 1,00 & 0,28 & 0,02 & 0,76 & 0,22 & 0,33 & 1,00 & 0,58 & 0,17 & 0,52 & 0,30 \\
\hline Av_Coleta_Lixo & 0,02 & 1,00 & 0,21 & 0,01 & 0,82 & 0,17 & 0,38 & 0,18 & 1,00 & 0,24 & 0,11 & 0,64 \\
\hline $\mathbf{A}$ & 0,73 & 1,00 & $0,37 \mid$ & 0,35 & 0,48 & 0,18 & 0,49 & $\mid 1,00$ & 0,49 & 0,25 & 0,50 & 0,25 \\
\hline Av_Bo & 0,00 & 0,02 & 1,00 & 0,00 & 0,02 & 0,98 & 1,00 & $0,40 \mid$ & 0,64 & 0,49 & 0,20 & 0,31 \\
\hline Seg_Inund & $0,00 \mid$ & 0,01 & $1,00 \mid$ & $0,00 \mid$ & 0,01 & 0,99 & 0,32 & $0,22 \mid$ & 1,00 & 0,21 & 0,14 & 0,65 \\
\hline Av_larg_rua & 0,03 & 0,03 & 1,00 & 0,03 & 0,03 & 0,94 & 0,88 & 1,00 & 0,98 & 0,31 & 0,35 & 0,34 \\
\hline Av_Rua & 0,02 & 0,27 & 1,00 & 0,01 & 0,21 & 0,78 & 0,48 & 1,00 & 0,71 & 0,22 & 0,46 & 0,33 \\
\hline Seg_Terreno & 0,01 & 0,03 & 1,00 & 0,01 & 0,03 & 0,97 & 0,09 & 0,35 & 1,00 & 0,07 & 0,24 & 0,69 \\
\hline Av_Esp_Pub & $0,52 \mid$ & 1,00 & 0,74 & 0,23 & 0,44 & 0,33 & 0,44 & 0,81 & 1,00 & 0,19 & 0,36 & 0,44 \\
\hline Av_Energia & 0,01 & 0,01 & 1,00 & 0,01 & 0,01 & 0,99 & 0,03 & 0,18 & 1,00 & 0,02 & 0,15 & 0,83 \\
\hline Av_Ilumina & 0,02 & 0,01 & 1,00 & 0,02 & 0,01 & 0,97 & 0,74 & 1,00 & 0,91 & 0,28 & 0,38 & 0,34 \\
\hline Dist_Tel & 0,11 & 1,00 & $0,12 \mid$ & 0,09 & 0,81 & 0,10 & 0,93 & $|1,00|$ & 0,87 & 0,33 & 0,36 & 0,31 \\
\hline Seg_Posse & 0,01 & 0,00 & $1,00 \mid$ & 0,01 & 0,00 & 0,99 & 0,17 & 0,54 & 1,00 & 0,10 & 0,32 & 0,58 \\
\hline \multicolumn{13}{|c|}{ Entorno } \\
\hline Av_Servic & 0,01 & 0,38 & 1,00 & 0,01 & 0,27 & 0,72 & 0,11 & 0,64 & 1,00 & 0,07 & 0,37 & 0,57 \\
\hline Av_Lazer_Fora & & - & - & - & -- & - & 0,11 & $0,56 \mid$ & 1,00 & 0,07 & 0,33 & 0,60 \\
\hline Av_Transp & 0,00 & 1,00 & 0,43 & 0,00 & 0,70 & 0,30 & 0,20 & 0,32 & 1,00 & 0,13 & 0,21 & 0,66 \\
\hline
\end{tabular}

De acordo com a Tabela 129, a Moradia tem maior possibilidade de ser avaliada como Regular e a Salubridade Ambiental com Boa/Ótima em Alagados I e II, e o Entorno como Regular em Alagados I e Bom/Ótima em Alagados II. A exceção da Moradia, os resultados dos demais itens convergem para os resultados modelo das equações relacionais fuzzy.

Tabela 129: Indicadores qualitativos obtidos utilizando reconhecimento de padrão fuzzy - Alagados I e II

\begin{tabular}{|c|c|c|c|c|c|c|}
\hline & \multicolumn{3}{|c|}{ Alagados I } & \multicolumn{3}{|c|}{ Alagados II } \\
\hline Avaliação & Moradia & $\begin{array}{c}\text { Salubridade } \\
\text { ambiental }\end{array}$ & Entorno & Moradia & $\begin{array}{c}\text { Salubridade } \\
\text { ambiental }\end{array}$ & Entorno \\
\hline \multicolumn{7}{|c|}{ Fuzzy normal } \\
\hline Péssimo/Ruim & 0,61 & - & 0,53 & 0,47 & 0,42 & 0,50 \\
\hline Regular & 0,91 & 0,86 & 0,95 & 0,74 & 0,81 & 0,70 \\
\hline Bom/Ótimo & 0,76 & 0,93 & 0,68 & 0,71 & 0,90 & 0,78 \\
\hline \multicolumn{7}{|c|}{ Fuzzy subnormal } \\
\hline Péssimo/Ruim & 0,57 & - & 0,43 & 0,48 & 0,33 & 0,50 \\
\hline Regular & 0,89 & 0,84 & 0,94 & 0,73 & 0,79 & 0,67 \\
\hline Bom/Ótimo & 0,72 & 0,93 & 0,69 & 0,67 & 0,90 & 0,75 \\
\hline
\end{tabular}




\subsubsection{Indicadores quantitativos}

A Tabela 130 apresenta os indicadores quantitativos calculados para as duas áreas pesquisadas. Nota-se um desempenho ligeiramente melhor da área de Alagados I, que se deve provavelmente às condições favoráveis do sítio desta área.

Tabela 130: Indicadores quantitativos - Alagados I e II

\begin{tabular}{|c|c|c|c|c|c|c|c|c|}
\hline Indicador & & Alagados I & & $74,46 \%$ & & Alagados II & & $68,74 \%$ \\
\hline Indicador de Moradia & Variável & Subindicador & Indicador & $70,09 \%$ & Variável & Subindicador & Indicador & $71,21 \%$ \\
\hline Cômodos & & & $\mathbf{8 9 , 3 5 \%}$ & & & & $\mathbf{8 5 , 8 7 \%}$ & \\
\hline Cozinha & & $100,00 \%$ & & & & $87,20 \%$ & & \\
\hline Banheiros & & $100,00 \%$ & & & & $100,00 \%$ & & \\
\hline Quartos & & $41,80 \%$ & & & & $43,20 \%$ & & \\
\hline Materiais & & & $91,31 \%$ & & & & $84,56 \%$ & \\
\hline Material da cobertura & & $94,10 \%$ & & & & $90,45 \%$ & & \\
\hline Material das paredes & & $86,47 \%$ & & & & $75,93 \%$ & & \\
\hline Material do piso & & $92,80 \%$ & & & & $84,40 \%$ & & \\
\hline Instalações & & & $100,00 \%$ & & & & $99,09 \%$ & \\
\hline Instalações de água & & $100,00 \%$ & & & & $97,60 \%$ & & \\
\hline Instalações de esgoto & & $100,00 \%$ & & & & $100,00 \%$ & & \\
\hline Instalações elétricas & & $100,00 \%$ & & & & $100,00 \%$ & & \\
\hline Aberturas & & $0,00 \%$ & $0,00 \%$ & & & $13,60 \%$ & $13,60 \%$ & \\
\hline Indicador de Salubridade Ambiental & & & & $84,43 \%$ & & & & $72,05 \%$ \\
\hline Saneamento básico & & & $\mathbf{9 8 , 7 8 \%}$ & & & & $76,45 \%$ & \\
\hline Abastecimento de água & & $100,00 \%$ & & & & $88,72 \%$ & & \\
\hline Abastecimento de água & & & & & & & & \\
\hline regularizado & $82,20 \%$ & & & & $100,00 \%$ & & & \\
\hline Abastecimento de água irregular & $17,80 \%$ & & & & $0,00 \%$ & & & \\
\hline Esgotamento sanitário & & $100,00 \%$ & & & & $81,05 \%$ & & \\
\hline Esgotamento sanitário & & & & & & & & \\
\hline regularizado & $78,70 \%$ & & & & $100,00 \%$ & & & \\
\hline Esgotamento sanitário irregular & $21,30 \%$ & & & & $0,00 \%$ & & & \\
\hline Drenagem & & $100,00 \%$ & & & & $80,00 \%$ & & \\
\hline Limpeza urbana & & $90,77 \%$ & & & & $28,64 \%$ & & \\
\hline Coleta de lixo & $84,30 \%$ & & & & $100,00 \%$ & & & \\
\hline Serviço de varrição & $15,70 \%$ & & & & $41,20 \%$ & & & \\
\hline Infra-estrutura e outros serviços & & & $69,67 \%$ & & & & $56,16 \%$ & \\
\hline Energia elétrica & & $99,03 \%$ & & & & $83,67 \%$ & & \\
\hline Energia elétrica regularizada & $79,80 \%$ & & & & $98,70 \%$ & & & \\
\hline Energia elétrica irregular & $20,20 \%$ & & & & $1,30 \%$ & & & \\
\hline Iluminação pública & & $90,20 \%$ & & & & $39,50 \%$ & & \\
\hline Espaços públicos & & $26,16 \%$ & & & & $15,25 \%$ & & \\
\hline Vias de circulação & & $40,17 \%$ & & & & $44,80 \%$ & & \\
\hline Condições físicas & & & $84,20 \%$ & & & & $100,00 \%$ & \\
\hline Segurança geológico-geotécnica & & $100,00 \%$ & & & & $100,00 \%$ & & \\
\hline Densidade demográfica & & $0,00 \%$ & & & & $100,00 \%$ & & \\
\hline Condições sociais & & & $\mathbf{5 9 , 4 3} \%$ & & & & $60,85 \%$ & \\
\hline Educação & & $76,05 \%$ & & & & $75,46 \%$ & & \\
\hline Renda & & $21,37 \%$ & & & & $27,39 \%$ & & \\
\hline Regularização fundiária & & & $100,00 \%$ & & & & $\mathbf{3 4 , 4 0 \%}$ & \\
\hline Indicador de Entorno & & & & $54,29 \%$ & & & & $53,95 \%$ \\
\hline Transporte e mobilidade & & $91,70 \%$ & & & & $87,70 \%$ & & \\
\hline Equipamentos comunitários e de & & & & & & & & \\
\hline serviços & & $55,57 \%$ & & & & $59,47 \%$ & & \\
\hline Associativismo & & $0,00 \%$ & & & & $0,80 \%$ & & \\
\hline Espaços públicos fora da área & & $5,20 \%$ & & & & $8,00 \%$ & & \\
\hline
\end{tabular}




\subsection{CONSIDERAÇÕES FINAIS}

\subsubsection{Sobre as intervenções}

10.5.1.1 Moradia

Em Alagados I todos os itens foram considerados positivos ou regulares positivos, porém as questões relacionadas ao tamanho e composição apresentaram alta incerteza que puderam ser reduzidas com a categorização por tipo de construção. Atenção também deve ser dada às variáveis cuja moda foi regular, pois nestes casos, há duas situações possíveis: alienação em relação ao item avaliado ou de fato uma situação transitória entre uma avaliação negativa e positiva. Já em Alagados II apenas o item ventilação foi considerado regular negativo, os demais itens foram considerados positivos ou regulares positivos, porém, também as variáveis relacionadas ao tamanho e composição das moradias apresentaram altas incertezas que em alguns casos também foram reduzidas com a categorização. Esta categorização mostrou que em Alagados I a tendência de que as avaliações melhorem da categoria 1 - casas construídas pela Conder para categoria 4,- adquiridas de outros ou alugadas ou seja, enquanto a categoria 1 apresenta as piores avaliações a categoria 4 apresenta as melhores. Em Alagados II a categoria 1 também apresenta as piores avaliações, porém a melhor avaliação é apresentada pela categoria 3 - autoconstruídas.

Em relação aos indicadores qualitativos em Alagados I, notou-se que para uma avaliação final Péssimo/Ruim praticamente todas as variáveis analisadas são importantes, enquanto que apenas os quartos e os materiais das paredes e piso e ventilação são importantes para uma avaliação Regular e para uma avaliação Bom/Ótimo apenas a ventilação. As instalações, apesar de apresentarem graus de possibilidade elevados, podem levar a qualquer avaliação final. Em Alagados II, as variáveis intervenientes são em menor número. Para uma avaliação final Péssimo/Ruim, o banheiro e as instalações de esgoto são importantes, para a avaliação final Regular o tamanho da casa e para uma avaliação final Bom/Ótimo apenas o banheiro. Em Alagados I e II os indicadores qualitativos finais são Bom/Ótimo utilizando o método das equações relacionais fuzzy e Regular com o método de reconhecimento de padrão. Os indicadores quantitativos também são altos, em torno de 70\%, mas deve-se atentar para os indicadores de número de quartos e de aberturas. 
10.5.1.2 Salubridade ambiental

Em Alagados I apenas o serviço de varrição foi considerado ponto regular negativo, os demais foram considerados positivos ou regulares positivos, porém destaca-se a alta incerteza apresentada por este item assim como a avaliação dos espaços públicos. Com análise por categorias estas incertezas não foram reduzidas, mas pode-se notar que as melhores avaliações foram dadas pela categoria 1, ao contrário da moradia. Em Alagados II, alem do serviço de varrição, também são considerados negativos ou regulares negativos as bocas de lobo e sarjetas e a distância ao telefone público. Porém, em geral, as incertezas nas afirmações são mais altas que em Alagados II. A categorização em Alagados II reduziu as incertezas em algumas variáveis, porém, não há uma leitura uniforme desta redução, nota-se somente que as melhores avaliações são dadas na categoria 2 - casas construídas pela Conder e ampliadas pelo morador.

Os indicadores qualitativos de Alagados I e II apresentaram matrizes pouco claras, que se refletiram num baixo percentual de acertos em ambas as áreas, logo, a interpretação das variáveis mais importantes do ponto de vista do morador fica prejudicada. Os indicadores qualitativos das duas áreas em ambos os métodos é Bom/Ótimo e os quantitativos também apresentam resultados elevados, $84 \%$ em Alagados I e 72\% em Alagados II, com atenção para as variáveis de infra-estrutura e de condições sociais que apresentaram valores abaixo das demais.

\subsubsection{Entorno}

Sobre o entorno, em ambos os casos as variáveis foram avaliadas como pontos positivos ou regulares positivos, em geral com baixas incertezas, que se mantiveram com a categorização.

Sobre as variáveis mais importantes na composição dos indicadores qualitativos, nota-se que a exceção da avaliação final Bom/Ótimo, todas as variáveis são consideradas pelos moradores em Alagados I, no caso da avaliação Bom/Ótimo, apenas o transporte é importante. Já em Alagados II, apenas os serviços definem uma avaliação final Péssimo/Ruim ou Regular.

Os indicadores qualitativos e entorno foram Regular em Alagados I em ambos os métodos e em Alagados II, Regular-Bom/Ótimo pelo método das equações relacionais fuzzy e 
Bom/Ótimo pelo método de reconhecimento de padrão. Embora, em ambas as áreas os indicadores quantitativos foram os mais baixos dos três avaliados, em torno de $50 \%$.

\subsubsection{Sobre os métodos}

O procedimento desenvolvido para identificação dos pontos positivos e negativos mostrou-se adequado e confiável, uma vez que não prescinde de processos de conversão nas escalas de avaliação e apresenta uma leitura fácil da distribuição.

Já os procedimentos para obtenção de indicadores qualitativos, apesar de apresentarem resultados satisfatórios, no caso das matrizes de relação, obtivemos alguns casos onde a leitura mostrou-se difícil, o que se refletiu também no baixo desempenho da matriz. O método de reconhecimento de padrão apresenta-se mais estável, porém carece do desenvolvimento de ferramentas auxiliares para identificação das variáveis intervenientes.

O processo de agregação de indicadores quantitativos também apresentou vantagens, visto que, leva em consideração as diferentes importâncias de cada indicador, que foram obtidas utilizando-se consulta a especialistas. Ressalta-se, porém, que verificou-se a necessidade de qualificação destes indicadores,o que deve ser feita em trabalhos futuros, para que se possa comparar de forma mais simples os resultados qualitativos e quantitativos. 


\section{CONCLUSÕES E RECOMENDAÇÕES}

\subsection{MEIO AMBIENTE URBANO: AVALIAÇÕES E INCERTEZAS}

O século $\mathrm{XX}$ foi um século onde as incertezas, em suas variadas formas, se fizeram presentes de forma intensa. As discussões sobre os impactos das ações do homem no meio ambiente nos conduziram a conclusões incertas sobre o futuro da Terra. Novos modelos de desenvolvimento estão sendo debatidos na tentativa de contornar os resultados negativos dessas ações que, durante um longo período consideraram que o homem mantinha um controle unilateral sobre a natureza.

Nas cidades, os impactos ambientais têm se tornado cada vez mais evidentes. Enchentes, poluição do ar, da água e do solo, são cada vez mais freqüentes nas grandes cidades. Em países em desenvolvimento, soma-se a estes impactos, um quadro de desigualdades sociais, refletido num ambiente segregado, onde as condições de saneamento e de infra-estrutura propiciam o agravamento dos impactos negativos no meio ambiente e na própria saúde do homem.

Com base nas diferenças entre os conceitos de desenvolvimento e crescimento, apresentadas por Veiga (2005), onde o autor destaca que enquanto o crescimento está relacionado aos aspectos quantitativos, o desenvolvimento está mais relacionado aos aspectos qualitativos, podemos afirmar que o "desenvolvimento" urbano no Brasil pode ser mais associado ao crescimento urbano que ao desenvolvimento em si. Esta constatação é decorrência de um crescimento da população urbana sem o crescimento da infra-estrutura e dos serviços necessários, o que tem afetado as condições de habitabilidade das grandes cidades brasileiras, logo também tem afetado as suas condições de qualidade vida.

Embora, a questão habitacional não seja recente no Brasil, com ações que vêm desde o início do século XX, de eliminação de cortiços e habitações precárias com uma visão mais higienista, até os dias atuais, com as obras de urbanização de favelas, recuperações de cortiços e requalificações de centros urbanos degradados, o desafio mostra-se cada vez mais complexo, exigindo ações físicas de recuperação do habitat aliado a ações sociais que 
contribuam para a manutenção e sustentabilidade das melhores condições de habitabilidade obtidas.

Estas ações, justificadas pela busca da melhoria da qualidade de vida e do desenvolvimento sustentável, no entanto, carecem de uma avaliação sistemática que busquem o aperfeiçoamento dos métodos empregados bem como, avaliem o desempenho de tais ações.

Estas avaliações devem ser feitas considerando tanto o ponto de vista técnico quanto do morador/usuário, para que se possa obter uma visão global do ambiente em questão e para verificar de fato o impacto destas ações no atendimento de suas expectativas e necessidades. Assim, ações percebidas pela população como positivas possuirão maiores chances de preservação de suas condições, contribuindo também para a sua sustentabilidade.

Embora os métodos de avaliação do ambiente urbano reconheçam a importância desse tipo de avaliação, na sua análise têm-se encontrado dificuldades para representar e analisar adequadamente os conceitos presentes na linguagem humana e que fazem parte desse tipo de avaliação.

Estas dificuldades estão relacionadas à subjetividade e à vagueza que estes conceitos apresentam e que por muito tempo foram considerados inadequados ao tratamento científico. Porém, como já afirmado, houve uma mudança no pensamento científico recente, passando de uma postura onde se considerava apenas o certo, específico e exato, para uma postura de reconhecimento da importância dos aspectos incertos e não-específicos, admitindo assim, a modelagem e incorporação de aspectos das incertezas nos processos de análises.

Inicialmente, a incerteza foi admitida sob a forma de aleatoriedade, com grande desenvolvimento das técnicas estatísticas. Mais recentemente, a Lógica Fuzzy apresenta-se como uma alternativa para o tratamento das incertezas sob a forma de vagueza, mal-definição e subjetividade de conceitos presentes na linguagem humana. A principal diferença entre a Lógica Clássica, bivaluada, e a Lógica Fuzzy, multivaluada, consiste no fato de que, enquanto na Lógica Clássica, existem apenas duas situações claras de pertinência aos conjuntos, pertence e não pertence, mutuamente excludentes, na Lógica Fuzzy, há um continuum de situações, não necessariamente excludentes, que tendem a uma aproximação mais consistente da realidade.

No contexto apresentado, onde os principais conceitos, qualidade de vida e desenvolvimento sustentável, mostram-se ambíguos, vagos e altamente complexos, tende-se a admitir uma abordagem que reconheça estas características, para que se possa obter uma representação 
mais fiel da realidade. Assim, o meio ambiente urbano e as relações do homem com esse meio formam um sistema demasiadamente complexo e incerto para ser entendido por teorias e modelos que não considerem tais aspectos.

Da revisão da literatura, constatamos que a alternativa da abordagem fuzzy, bastante explorada em áreas como automação e controle, em simulações do raciocínio humano, é ainda pouco explorada em áreas relacionadas ao ambiente urbano e apresenta um grande potencial para melhorar a compreensão dos processos de avaliação principalmente, aqueles que envolvem a avaliação dos moradores, cuja informação é tipicamente carregada de incertezas devido a sua subjetividade.

\subsection{MÉTODOS PROPOSTOS: PRINCIPAIS CONCLUSÕES}

A modelagem utilizando a Lógica Fuzzy não pode, e não deve, ser vista como uma forma de obter resultados que se contrapõem a Lógica Clássica. Dado que a primeira é uma extensão da segunda, os resultados obtidos pela Lógica Fuzzy deverão ser os mesmos obtidos pela Lógica Clássica nos casos em que se utilizam conjuntos clássicos em modelos fuzzy. Isto demonstra, que não há contradição entre os resultados nem entre as abordagens. Há sim, uma ampliação da informação obtida, bem como da capacidade de representação de fenômenos tipicamente incertos ou vagos. Como vimos no Capítulo 3, as abordagens dadas aos fenômenos são complementares: tratam as suas diferentes facetas e devem ser analisadas pela sua capacidade de representação.

\subsubsection{A agregação de informações pelos métodos propostos utilizando a Lógica Fuzzy}

Da revisão da literatura em Lógica Fuzzy notamos que há um grande desenvolvimento de aplicações nas mais variadas áreas, cujos problemas são similares aos problemas de avaliação do ambiente urbano. Destas ferramentas, selecionamos apenas algumas com foco em nossos objetivos iniciais, porém, ressaltamos que há um vasto campo de possibilidades de desenvolvimento de ferramentas nesta área. Destacaremos a seguir, os ganhos obtidos com a aplicação das ferramentas selecionadas ao problema de avaliação de áreas urbanas recuperadas. Ressaltamos, porém que, embora as técnicas empregadas foram utilizadas numa 
seqüência formando um método específico para avaliação de áreas urbanas recuperadas do tipo favela urbanizada, estas ferramentas podem ser facilmente adaptadas para outros problemas de avaliação do ambiente urbano, pela revisão das variáveis e dos indicadores selecionados, bem como pela seleção das técnicas de acordo com os objetivos da avaliação.

\subsubsection{Medidas de incerteza}

$\mathrm{O}$ uso da medida de não-especificidade associada à moda da distribuição mostrou-se muito mais eficiente e segura que a abordagem tradicional, que utiliza médias e desvios-padrão, para a identificação de pontos positivos e negativos no projeto com base na avaliação do morador. As vantagens identificadas foram:

- a moda é a medida de posição central mais adequada para escalas qualitativas;

- a medida de não-especificidade pode ser utilizada em diferentes escalas, desde as escalas qualitativas às quantitativas;

- a medida de não especificidade apresenta intervalo de variação bem definido, podendo ser normalizada e facilmente interpretada;

- a medida de não-especificidade apresenta melhor sensibilidade que o desvio-padrão, normalmente utilizado em abordagens tradicionais e;

- no caso da análise de um grande número de variáveis, a medida de não-especificidade indica aquelas que precisam de aprofundamento na análise.

Constatou-se também que para o uso da medida de não-especificidade em escalas qualitativas, com classes de mesmo sentido, ou seja, positivo ou negativo, o agrupamento destas classes semelhantes fornece melhores resultados. Ou seja, suponha que numa distribuição com cinco classes, Péssimo, Ruim, Regular, Bom e Ótimo, apresentam freqüências apenas nas classes Bom e Ótimo. Nesta situação o cálculo da medida de não-especificidade resultará em valor diferente de zero; porém sabemos que nesta distribuição, a variável analisada pode ser considerada um aspecto positivo sem nenhuma incerteza. De outra forma, ao agruparmos as classes Bom e Ótimo, obtemos um resultado para a medida de não-especificidade igual a zero, de fato, nesta situação o aspecto é considerado positivo sem nenhuma incerteza. Isto sugere que neste caso, o agrupamento de classes de mesmo sentido semântico produz melhores resultados. Ressaltamos, porém, que este agrupamento está relacionado ao objetivo da análise. 
Outra questão importante na utilização da medida de não-especificidade está relacionada ao processo de redução das incertezas. Este processo mostrou-se eficiente quando se dispõe de variáveis de controle para categorização e averiguação de hipóteses. Na maioria dos casos a redução da incerteza foi possível utilizando-se o agrupamento das respostas por categorias semelhantes. Em outros podemos notar que, uma análise espacial utilizando as informações georreferenciadas, pode ajudar a explicar os resultados.

Por fim, a análise dos pontos positivos e negativos de um projeto pela abordagem fuzzy proposta, embora não contradiga os resultados da abordagem clássica, nem poderia como já afirmamos, nos fornece resultados mais consistentes e agrega informações sobre o grau de certeza nas afirmações.

\subsubsection{Equações relacionais fuzzy}

A utilização das equações relacionais fuzzy para a modelagem do raciocínio do morador e posterior obtenção de indicadores de qualidade ambiental urbana sob este ponto de vista mostrou-se válida uma vez que é obtida com base nas avaliações dos próprios moradores e não utiliza pesos atribuídos por especialistas. A base de conhecimento utilizada neste método é reconhecidamente a avaliação do morador.

Este método apresenta como vantagens:

- mais uma vez, a possibilidade de uso de escalas qualitativas de mensuração;

- a utilização das avaliações dos moradores como base de conhecimento;

- a obtenção de matrizes que evidenciam as variáveis mais importantes na avaliação do morador e;

- a possibilidade de obtenção de indicadores qualitativos baseados nas avaliações dos moradores, com mínima interferência da visão dos especialista.

Como desvantagens e limitações identificamos:

- a necessidade de produzir matrizes de avaliação final, neste caso critérios precisam ser definidos e; 
- avaliações em áreas onde há muitas carências, ou seja muitas variáveis podem interferir na avaliação final, podem produzir matrizes de difícil interpretação ou baixa capacidade de representação.

Mesmo com estas limitações o método proposto apresenta um grande potencial de desenvolvimento, com possibilidades de uso de diferentes regras de composição e operadores, que podem nos fornecer diferentes interpretações sobre o fenômeno estudado.

\subsubsection{Reconhecimento de padrão fuzzy}

O método de reconhecimento de padrão fuzzy foi utilizado como uma alternativa ao método das equações relacionais fuzzy. É um método simples e fácil de ser aplicado e apresenta como vantagens:

- a possibilidade de uso com dados em escalas qualitativas;

- a construção dos padrões é feita unicamente com base nas avaliações dos moradores, ou seja, mais uma vez a base de conhecimento é a avaliação do morador e;

- a interpretação do resultado é direta e intuitiva.

A principal desvantagem deste método reside no fato dele não identificar as variáveis mais importantes sob a ótica do morador; porém é possível desenvolver métodos auxiliares, como o teste do chi-quadrado ou utilização de medidas de conformidade para identificar estas variáveis.

\subsubsection{A utilização do AHP para definição de pesos em indicadores quantitativos}

A utilização do AHP mostrou-se adequada, uma vez que estabelece, com base na opinião de especialistas, os pesos de cada variável/indicador na composição final de um indicador de qualidade ambiental de áreas urbanas recuperadas. Nota-se nestes pesos a importância dada pelos especialistas às questões de salubridade ambiental e principalmente, aquelas relacionadas ao saneamento básico, água e esgoto. 
É importante destacar esse fato, uma vez que, durante muito tempo, no Brasil, a política habitacional estava direcionada à construção de novas moradias, enquanto no momento atual, há de fato, uma convergência para questões mais relacionadas aos serviços básicos.

\subsection{AS AÇÕES DO PROGRAMA RIBEIRA AZUL: PRINCIPAIS CONCLUSÕES BASEADAS NA PESQUISA PILOTO E NOS ESTUDOS DE VALIDAÇÃO}

As ações do Programa Ribeira Azul, tiveram um impacto positivo nas áreas de intervenção física e social. A avaliação dos moradores, bem como os indicadores quantitativos, podem ser considerados positivos. A pesquisa piloto, embora não tenha seguido um plano amostral probabilístico, revelou que embora a provisão de certos serviços básicos permaneça não resolvida, o método empregado para urbanização da favela em Novos Alagados $1^{\text {a }}$. Etapa tem chances substanciais de sucesso. A maioria das variáveis analisadas foi avaliada positivamente e a pesquisa piloto mostrou que alguns dos seguintes itens ainda merecem atenção: (i) o planejamento do tamanho das casas e de numero de quartos; (ii) melhorias nos telhados que apresentam problemas durante o período de chuvas; (iii) melhorias nas aberturas das moradias, principalmente em moradias autoconstruídas, onde foram identificadas as maiores deficiências; (iv) os serviços de esgoto, com muitas ligações clandestinas em algumas áreas e; (v) o sistema de drenagem, que se mostrou ainda deficiente, devendo-se ser dada maior atenção, visto se tratar de uma área com possibilidades de alagamento.

Os estudos de validação, em Alagados I e II apresentaram problemas semelhantes relacionados à moradia no que diz respeito ao seu tamanho e número de quartos. Ressalta-se, porém, que nestas áreas há uma freqüência alta da avaliação Regular pelos moradores. As hipóteses que podem ser levantadas, de acordo com as teorias apresentadas são de um pouco de satisfação, que pode decorrer de um ajustamento entre ambiente existente e o aspirado, ou de alienação dos respondentes em relação às questões levantadas. Ressalta-se como principal problema em Alagados I o serviço de varrição e em Alagados II, além do serviço de varrição, o funcionamento de bocas de lobo e sarjetas. Notamos que de fato, não existem bocas de lobo na área, sendo a coleta das águas de drenagem feitas pelas frestas das placas que compõem o pavimento das ruas, o que é insuficiente na maioria das vezes. Outra questão a ser destacada nestas duas áreas é o baixo nível de participação comunitária, declarada nos formulários. A quantidade de pessoas que afirmaram fazer parte de algum tipo de associação foi praticamente 
desprezível, o que nos levou a obtenção de indicadores muito baixos sobre o entorno. Por fim, destacamos ainda que, embora estas áreas façam parte do Programa Ribeira Azul, as suas ações foram feitas no âmbito de outro programa o Programa Viver Melhor ainda sob a responsabilidade da extinta URBIS.

Concluímos ainda que, os estudos de avaliação nestas áreas revelaram problemas comuns que poderiam ser evitados com uma avaliação sistemática dos projetos visando a retroalimentação do processo de planejamento das ações.

\subsection{RECOMENDAÇÕES PARA FUTUROS TRABALHOS}

A aplicação de algumas ferramentas da Lógica Fuzzy mostrou um grande potencial para a modelagem de problemas de avaliação do ambiente urbano. A revisão da literatura nesta área revelou também um vasto campo de pesquisa que se abre para o desenvolvimento de novas ferramentas de análise de dados. Dentre as diversas demandas que se apresentaram durante este trabalho, destacamos:

- a implementação de ferramentas sob a forma de aplicativos para facilitar o processo de análise dos dados;

- estudos de avaliação do significado e importância de outras medidas de incerteza encontradas na literatura;

- estudos de avaliação de outras regras de composição e de outros operadores no método das equações relacionais fuzzy;

- desenvolvimento de ferramentas para identificação das variáveis mais importantes do ponto de vista do morador, bem como, de ferramentas de avaliação do seu desempenho para o método de reconhecimento de padrão fuzzy;

- desenvolvimento de ferramentas computacionais de agregação fuzzy dos dados quantitativos e de uma possível, se necessária, agregação dos dados qualitativos e quantitativos e, por fim;

- utilização de ferramentas de georrefenciamento de informações para análise de dados, visto que muitas variáveis possuem influência da localização; 
- aplicação do método em outros empreendimentos e em outras áreas, tanto em urbanização de favelas como em outros projetos urbanos ou de edificações.

Finalmente, ressaltamos que, embora as operações utilizadas na modelagem fuzzy sejam simples, dada a quantidade de variáveis a ser levada em consideração, bem como a repetição das operações, o desenvolvimento de ferramentas que auxiliem neste processo é de fundamental importância, sob pena de dificultar a divulgação e disseminação das ferramentas propostas. 


\section{REFERÊNCIAS}

ABIKO, Alex Kenya. Quanto custaria urbanizar uma favela no Brasil?. In: ABRAMO, Pedro (org.). Cidade da Informalidade: o desafio das cidades latino-americanas. Rio de Janeiro: Sete Letras, 2003. p. 225-236.

ABRAMO, Pedro. Eu já tenho onde morar... a Cidade da informalidade. In: ABRAMO, Pedro (org.). Cidade da Informalidade: o desafio das cidades latino-americanas. Rio de Janeiro: Sete Letras, 2003. p. 7-12.

ACSELRAD, Henri (org). A duração das cidades: sustentabilidade e risco nas políticas urbanas. Rio de Janeiro: DP\&A editora, 2001. 240p.

AJA, Agustín Hernández. Informe sobre los indicadores locales de sostenibilidad utilizados por los municipios españoles firmantes de la Carta de Aalborg. Madrid: UPM, 2004. Disponível em: <http://habitat.aq.upm.es/indloc/aindloc.html.>. Acesso em: 26 abr. 2004.

ALDRICH B. C.; SANDHU R. S. The Global Context of Housing Poverty. In: ALDRICH B. C.; SANDHU R. S.(ed.). Housing the Urban Poor. London: Zed Books, 1995. p. 17-33.

ALMEIDA, Marco Antonio Plácido de. Indicadores de salubridade ambiental em favelas urbanizadas: o caso das favelas em áreas de proteção ambiental. 1999. 226p. Tese (Doutorado) - Escola Politécnica, Universidade de São Paulo, São Paulo, 1999.

ALVA, Eduardo N. Qualidade Ambiental Urbana. Notas de aula. Salvador: Faculdade de Arquitetura e Urbanismo da UFBA, 1994.

AMÉRIGO, Maria; ARAGONÉS, Juan Ignacio. Residential satisfaction in council housing. Journal of Environmental Psychology, [S.1.]: Academic Press, v 10, n. 4, pp 313-325, dec. 1990.

AMOLE, Dolapo. Residentil satsfaction in students' housing. Journal of Environmental Psychology, [S.1.], Elsevier, pp. 1-10, 2008.

ARAPÉ, Jesús E. Manual de metodologias: Tomo V - A técnica AHP. Trieste: Programa de Prospectiva Tecnológica para Latinoamérica y el Caribe: UNIDO, 2000. Disponível em: <http://www.ics.trieste.it/Foresight/Library/default.asp>. Acesso em: 20 mar. 2005.

AJZEMBERG, Marcos Gorelik et al. Utilização de indicadores de caráter social na definição de prioridades de obras de saneamento. Revista DAE. São Paulo, vol. 46, nº 147, 1986.

BAKER J.. Integrated urban upgrading for the poor: the experience of Ribeira Azul, Brazil. Policy Research Working Paper. Washington D.C.:The World Bank, 2006. Disponível em: 〈http://go.worldbank.org/U0R6LSL9D0>. 2006. Acesso em: 20 jan. 2007.

BARBETTA, Pedro Alberto. Estatística aplicada às Ciências Sociais. $3^{\mathrm{a}}$. ed.. Florianópolis: Ed. da UFSC, 1999, 284p.

BARROS, Laécio Carvalho de. BASSANEZI, Rodney Carlos. Tópicos de lógica fuzzy e biomatemática. Campinas: UNICAMP/IMECC, 2006. 
BASSO, Admir. Avaliação pós-ocupação das características de habitabilidade da Vila Tecnológica de Ribeirão Preto COHAB-RP/PROTEC. In: Encontro Nacional de Tecnologia do Ambiente Construído, $7^{\circ}$, Florianópolis, 1998. Artigo técnico. Florianópolis, SC. 1998. v.1 p. 569-572.

BATESON Gregory. Number is Different from Quantity. CoEvolution Quarterly., S.l.: Spring, pp. 44-46, 1978.

BATESON, Gregory. Steps to an ecology of mind: collected essays in anthropology, psychiatry, evolution, and epistemology. Northvale: Jason Aronson, 1987. 545p.

BECHTEL, Robert B.. Environment \& behavior: an introduction. Thousand Oaks, California: Sage Publications, 1997. 679p.

BECHTEL, Robert; CHURCHMAN, Arza (ed). Handbook of environmental psychology. New York: John Wiley \& Sons, [ca. 2002], 722p.

BELL, Paul A. et al. Environmental psychology. Fort Worth: Harcourt Brace College Publishers, [ca. 1996], 645p.

BELLEN, Hans Michael van. Indicadores de sustentabilidade: uma análise comparativa. Rio de Janeiro: FGV, 2005. 253p.

BOLFARINE, Heleno, BUSSAB, Wilton O. Elementos de amostragem. São Paulo: Edgard Blücher, 2005. 269p.

BONAIUTO, Marino, et al. Multidimensional perception of residential environment quality and neighbourhood attachment in the urban environment. Journal of Environmental Psychology, [S.1.]: Academic Press, v 19, n. 4, pp 331-352, dec. 1999.

BONDUKI, Nabil. Autogestão na Produção de Habitação: um Programa de Qualidade e Baixo Custo. In: GORDILHO-SOUZA, Ângela Maria. (org). Habitar Contemporâneo: Novas Questões no Brasil dos Anos 90. Salvador: Ed. Ultragraph, 1997, p. 89-107.

Origens da habitação social no Brasil: arquitetura moderna, lei do inquilinato e difusão da casa própria. São Paulo: Estação Liberdade, 1998. 343p.

BORJA, Patrícia C. Avaliação da Qualidade Ambiental Urbana: Uma contribuição metodológica. 1997. 188p. Dissertação (Mestrado) - Faculdade de Arquitetura e Urbanismo, Universidade Federal da Bahia. Salvador, 1997

CARVALHO, Eduardo Teixeira de. Os Alagados da Bahia: Intervenções Públicas e Apropriação Informal do Espaço Urbano. 2002. 307p. Dissertação (Mestrado) - Faculdade de Arquitetura e Urbanismo, Universidade Federal da Bahia. Salvador, 2002.

CHANG, Hsin-li; CHANG, Hsin-wen. Comparison between the differences of recreational cyclists in national scenic bikeway and local bike lane. Journal of the Eastern Asia Society for Transportation Studies, v. 6, pp. 2178-2193, 2005.

CHENG, Liang Yee. A teoria de sistema nebuloso e as informações subjetivas de conforto ambiental. In: ENCONTRO LATINO AMERICANO DE CONFORTO NO AMBIENTE CONSTRUÍDO, 2, 1999, Fortaleza. Anais.... Fortaleza: ANTAC, 1999, Não paginado.

CHENG, Liang-Yee. HARRIS, Ana Lúcia N.C.. A teoria de sistemas nebulosos na análise da qualidade do espaço interior. In: ENCONTRO NACIONAL DE TECNOLOGIA DO 
AMBIENTE CONSTRUÍDO, 8, 2000, Salvador. Anais.... Salvador: ANTAC, 2000, v.1 p.797-804.

CHENG, Liang-Yee. Informações subjetivas no estudo do conforto ambiental: Uma Introdução às Abordagens Baseadas na Teoria dos Sistemas Nebulosos. IN: ENCONTRO NACIONAL DE CONFORTO NO AMBIENTE CONSTRUÍDO, 6, 2001, Campinas. Apostila do mini-curso. Campinas: ANTAC, 2001.

COMPANHIA DE DESENVOLVIMENTO URBANO DO ESTADO DA BAHIA (CONDER). Plano de Desenvolvimento Social e Ambiental do Programa Ribeira Azul. CONDER: Salvador, [ca.2000].

Programa Ribeira Azul. Salvador: CONDER: Salvador, 2003. Disponível em: <http://www.conder.ba.gov.br/ribeira.htm>. Acesso em: 10 nov. 2003.

COMUNE, Antônio E., CAHPINO, Antônio C. C., RIZZIERI, Juarez A. B. Indicadores de qualidade de vida. In: LONGO, Carlos Alberto, RIZZIERI, Juarez, A. B. (org.). Economia urbana; custos de urbanização e finanças públicas. São Paulo: IPE da USP, 1982.

CORNELISSEN A. M. G. et al. Assessment of the contribution of sustainability indicators to sustainable development: a novel approach using fuzzy set theory. Agriculture, Ecosystem and Environment. S.1.: Elsevier, v. 86, n. 2, p. 173-185 , 2001.

COSTA NETO. Pedro Luiz de Oliveira. Estatística. São Paulo: Edgard Blücher, 2002. 266p.

COSTA, Marcela da Silva. Mobilidade urbana sustentável: um estudo comparativo e as bases de um sistema de gestão para Brasil e Portugal. 2003. 196p. Dissertação (Mestrado) - Escola de Engenharia de São Carlos, Universidade de São Paulo. São Carlos, 2003.

DANTAS, Edmundo Brandão. Satisfação do cliente: um confronto entre a teoria, o discurso e a prática. 2001. 175p. Dissertação (Mestrado) - Centro Tecnológico, Departamento de Engenharia de Produção, Universidade Federal de Santa Catarina. Florianópolis, 2001.

DE LUCA A.; TERMINI S. Entropy of L-fuzzy sets. Information and Control. New York: Academic Press, v. 24, n. 1, p. 55-73, 1974

DEPONT, Cidonea Machado. ECKERT, Córdula. AZAMBUJA, José Luiz Bortoli de. Estratégia para construção de indicadores para avaliação da sustentabilidade e monitoramento de sistemas. Agroecologia e Desenvolvimento Rural Sustentável. Porto Alegre: EMATER/RS, v.3, n.4, p. 44-52, out/dez 2002.

DIAS, Marion Cunha. BORJA, Patrícia Campos. MORAES, Luiz Roberto Santos. Índice de Salubridade Ambiental em Áreas de Ocupação Espontâneas: Um Estudo em Salvador Bahia. Engenharia Sanitária e Ambiental. Rio de Janeiro: ABES, v. 9, n. 1, p. 82-92, jan/mar 2004.

DVORAK, Antonin et al.. The concept of LFLC 2000 - its specificity, realization and power of applications. Computers in Industry. S.1.: Elsevier, v. 51, n. 3, p 269-280, 2003.

ESPÍRITO SANTO, Maria Teresa Gomes do. O arquiteto e a produção da habitação social em Salvador 1965/1998. In: NUNES, Débora (org.). Salvador: o arquiteto e a cidade informal. Salvador: Ed. Ultragraph, 2000. 244p. 
FFC - FEDERAL FACILITIES COUNCIL. Learning from our Buildings: A State-of-thePractice Summary of Post-Occupancy Evaluation. Washington D.C.: National Academy Press, 2002, Disponível em: <https://www.nap.edu/catalog/10288.html>. Acesso em: 25 nov. 2006.

FERNANDES. Ana Cristina; NEGREIROS. Rovena. Economic developmentism and change within the Brazilian urban system. Geoforum. S.l: Elsevier. v. 32, n. 4, p. 415-435, nov. 2001.

FLEURY-BAHI, Ghozlane; FÉLONNEAU, Marie-Line; MARCHAND, Dorothée. Processes of place identification and residential satisfaction. Environment and behavior. Beverly Hills: Sage, v. 40, n. 5, p. 669-682, set. 2008.

FORMAN. Ernest; PENIWATI. Kirti. Aggregating individual judgments and priorities with the Analytic Hierarchy Process. European Journal of Operational Research. S.1.: Elsevier, v. 108, p. 165-169, 1998.

GALSTER, George C.. Identifying the correlates of dwelling satisfaction: an empirical critique. Environment and behavior. Beverly Hills: Sage, v. 19, n. 5, p. 539-568, set. 1987.

GALSTER, George C.; HESSER, Garry H.. Residential satisfaction: composition and contextual correlates. Environment and behavior. Beverly Hills: Sage, v. 13, n. 6, p. 735758, nov. 1981.

GARCIAS, Carlos Mello. Indicadores de qualidade dos serviços e infra-estrutura urbana de saneamento. 1991. 206p. Tese (Doutorado) - Escola Politécnica, Universidade de São Paulo. São Paulo, 1991.

GIFFORD, Robert. Environmental psychology: principles and practices. Boston: Allyn \& Bacon, 1996. 504p.

GILL. J. An entropy measure of uncertainty in vote choice. Electoral Studies. [S.1.]: Elsevier, v. 24, n.3, p. 371-392, 2005.

GOLDBARG, Marco César; LUNA, Henrique Pacca L.. Otimização combinatória e programação linear: modelos e algoritmos. Rio de Janeiro: Campus, 2000. 649p.

GÓMEZ, Julio Alguacil. Calidad de vida y modelo de ciudad. Madrid: UPM, 2001. Disponível em: <http://habitat.aq.upm.es/boletin/n15/ajalg.html >. Acesso em: 30 mar. 2005.

GORDILHO-SOUZA, Ângela Maria. Invasões e intervenções públicas: uma política de atribuição espacial em Salvador 1946-1989. 1990. 315p. Dissertação (Mestrado) - Instituto de Pesquisa e Planejamento Urbano e Regional, Universidade Federal do Rio de Janeiro. Rio de Janeiro, 1990.

Faculdade de Arquitetura e Urbanismo, Universidade de São Paulo. São Paulo, 1999.

GRAÇA, Valeria Azzi Collet da; CHENG, Liang-Yee; PETRECHE, João Roberto Diego. Qualificação subjetiva de imagens arquitetônicas utilizando a teoria de sistema nebuloso. Ouro Preto/MG. 2000. 9p.. GRAPHICA 2000, Ouro Preto, 2000. 
GRIGOLETTI, Giane de Campos; SATTLER, Miguel Aloysio. Estratégias ambientais para indústrias de cerâmica vermelha do Estado do Rio Grande do Sul. Ambiente Construído. Porto Alegre: ANTAC, v3, n3, p. 19-32, 2003.

GUEDES, Suzana Zeni; ARAÚJO, Sergey Alex de. Análise da qualidade de vida do bairro Praia Brava - Itajaí (SC), a partir de indicadores sociais. Geografia. Londrina: Departamento de Geociências da UEL, v. 13, n. 2, p. 65-89, jul./dez. 2004.

GUPTA M. M., SARIDIS G. N. and GAINES B. R. Fuzzy automata and decision processes. New York: North-Holland, 1977.

HAIR, J.F.Jr.; ANDERSON, R.E.; TATHAM, R.L. e BLACK, W.C. Multivariate Data Analysis with readings. $4^{\text {a. }}$ ed. Englewood Cliffs, N. J.: Prentice Hall, 1995, 745p.

HANSEN, Henning Sten. A fuzzy logic approach to urban land-use mapping. The ScanGIS Conference Series. Espoo, Finlândia: [S.n.] jun. 2003. Disponível em: <http://www.scangis.org/scangis2003/papers/25.pdf>. Acesso em: 08 mar. 2004.

HASS J. L., BRUNVOLL F. and HOIE H. Overview of sustainable development indicators used by national and international agencies. OECD Statistics working papers. Paris: OECD Publishing, 2002. Disponível em: <http://www.oecd.org/std/research> Acesso em 18/05/2006.

HOUAISS on-line. Dicionário Houaiss da Língua Portuguesa. Disponível em: <http://www.uol.com.br/bibliot>. Acesso em mar. 2005.

HUR, Misun; MORROW-JONES, Hazel. Factors that influence residents' satisfaction with neighborhoods. Environment and behavior. Beverly Hills: Sage, v. 40, n. 5, p. 619-635, set. 2008.

IBAM - INSTITUTO BRASILEIRO DE ADMINISTRAÇÃO MUNICIPAL. Estudo de avaliação da experiência brasileira sobre urbanização de favelas e regularização fundiária. Relatório Final. v 2. Rio de Janeiro: IBAM, 2002. Disponível em:<http://www.ibam.org.br>. Acesso em: 25 out. 2003.

ICLEI - INTERNATIONAL COUNCIL FOR LOCAL ENVIRONMENTAL INITIATIVES. European Local Agenda 21 Planning Guide. How to engage in long - term environmental action planning towards sustainability. Friburgo: ICLEI, 1995, $101 \mathrm{pp}$.

JANUZZI, Paulo de Martino. Indicadores Sociais no Brasil. Campinas, São Paulo: Ed. Alínea, $2^{\text {a }}$. ed., 2003, 141p.

JOBIM, Margaret S. S.; FORMOSO, Carlos T.. Método de avaliação do nível de satisfação dos clientes de imóveis residenciais. Encontro Nacional de Tecnologia do Ambiente Construído, 7º , Florianópolis, 1998. Artigo técnico. Florianópolis, 1998. v.2 p. 499-506.

JOHNSON, Richard Arnold. WICHERN, Dean W., Applied multivariate statistical analysis. $5^{\text {a. }}$ ed. Upper Saddle River, N.J: Prentice Hall. [c2002]. 767p.

KEIVANI, Ramin, WERNA, Edmundo. Refocusing the housing debate in developing countries from a pluralist perspective. Habitat International. Great Britain: Elsevier Science Ltd., n. 25, p. 191-208, 2001. 
KLIR, George J.; HARMANEC, David.; Types and measures of uncertainty. In: KACPRZYK, Janusz; NURMI, Hannu; FEDRIZZI, Mario (ed.). Consensus under fuzziness. Norwell, Massachusetts: Kluwer Academic Publishers, p. 29-51, 1997.

KLIR, George J.; YUAN, Bo; Fuzzy sets and fuzzy logic: theory and applications. Upper Saddle River: Prentice-Hall, 1995. 574p.

LABOVITZ S,. The Assignment of Numbers to Rank Order Categories. American Sociological Review. S.1.: S.n., v. 35, n. 3, p. 515-524, 1970

LAY, Maria Cristina Dias; REIS, Antonio Tarcisio da Luz. O papel dos espaços abertos comunais na avaliação de desempenho de conjuntos habitacionais. Ambiente Construído. Porto Alegre: ANTAC, v. 2, n. 3, p. 25-39, 2002.

LAY, Maria Cristina Dias; REIS, Antônio Tarcísio da Luz. Análise quantitativa na área de estudos ambiente-comportamento. Ambiente Construído: Metodologia de Pesquisa, Porto Alegre, v. 5 n.2, p. 21-36, 2005.

MALHEIROS, Tadeu Fabricio, PHLIPPI JR., Arlindo and COUTINHO, Sonia Maria Viggiani. Agenda 21 nacional e indicadores de desenvolvimento sustentável: contexto brasileiro. Revista Saúde e Sociedade. São Paulo: FSP, vol.17, no.1, p.7-20. Jan./Mar. 2008.

MARCONI, Marina de Andrade; LAKATOS, Eva Maria. Técnicas de pesquisa. $4^{a}$. ed. São Paulo: Atlas, 1999, 260p.

MARGARIDO, Aluízio F. Um enfoque dos materiais das Estruturas. Anais do Seminário “Avaliação Pós-Uso-APU”. São Paulo, FAU-USP, FUPAM, 7-9 jun. 1989, p. 17-27.

MARICATO, Ermínia. Metrópole, legislação e desigualdade. Estudos Avançados. São Paulo: IEA/USP. v. 17, n. 48, p. 151-167, mai/ago 2003.

MARICATO, Ermínia. Urbanismo na periferia do mundo globalizado metrópoles brasileiras. São Paulo em perspectiva. São Paulo: Fundação SEADE, v. 14, n. 4, p. 21-33, out. 2000.

MATTHÉ T., et al. Similarity Between Multi-valued Thesaurus Attributes: Theory and Application in Multimedia Systems. Lecture notes in computer science: International Conference on Flexible Query Answering Systems (FQAS). S.1: Springer, v. 4027, p.331342,2006

MONTEIRO, Circe Maria Gama. Métodos e técnicas para levantamento de campo e análise de dados: avaliação de lugares-o enfoque da Teoria das Facetas. WORKSHOP AVALIAÇÃO PÓS-OCUPAÇÃ̃. Anais.... São Paulo: FAUUSP, 1994, p. 53-74.

MORAES Luiz Roberto Santos et al. Avaliação de ações integradas de saneamento ambiental e de moradia em área periurbana de Salvador (BA) - Projeto AISAM III. In: Abiko, Alex Kenya e Ornstein Sheila Walbe (ed.). Inserção Urbana e Avaliação Pós-Ocupação (APO) da Habitação de Interesse Social. São Paulo: FAUUSP, 2002. (Coletânea Habitare/FINEP,1), 373p. p 94-129.

MORAES, Odair Barbosa de; ABIKO, Alex Kenya. Considerações sobre a utilização de medidas de incerteza em dados de percepção do morador. ENCONTRO NACIONAL DE TECNOLOGIA DO AMBIENTE CONSTRUÍDO, 11, 2006, Florianópolis. Anais.... Florianópolis: ANTAC, 2006, p. 1243-1252. 
MORIN, Edgard. Reformar o pensamento: repensar a reforma, a cabeça bem feita. Lisboa: Instituto Piaget. 2002. 137p.

MUOGHALU L. N. Subjective indices of housing satisfaction as social indicators for planning public housing in Nigeria. Social Indicators Research. Netherlands: Springer, v. 15 n. 2, p. 145-164, aug. 1984.

NAHAS. Maria Inês Pedrosa et al..O índice de qualidade de vida urbana de Belo Horizonte ( IQVU/BH): Um instrumento de avaliação do lugar urbano. Anais do X Encontro Nacional de Estudos Populacionais, 1996. Disponível em: <http://www.abep.org.br/>. Acesso em: 25 out. 2005.

NAKAMURA K. Applications of fuzzy logical thinking in Japan: current and future. Proceedings of 1995 IEEE International Conference on Fuzzy Systems. IEEE, 1995, 3, pp. 1077-1082.

NAREDO, José Manuel. Sobre el origen, el uso y el contenido del término sostenible. Madrid: UPM, jun. 1997. Disponível em: <http://habitat.aq.upm.es/cs/p2/a004.html>. Acesso em: 24 fev. 1999.

OECD - ORGANIZATION FOR ECONOMIC CO-OPERATION AND DEVELOPMENT. The interim Report on the OECD three-year project on sustainable development. Paris: OECD, 1999, 118p.

OLIVEIRA NETO, Humberto Chiani de; AMORIM, Sérgio Roberto Leusin de. A satisfação do cliente um enfoque mercadológico para empresas de construção civil. Congresso de Engenharia Civil, 3º Juiz de Fora, 1998. Artigo Técnico. Juiz de Fora, MG. 1998. 11p.

OLIVEIRA, Maria Carolina Gomes; HEINECK, Luiz Fernando M.. Habitabilidade - Um estudo sobre os fatores que influenciam a satisfação de usuários de ambientes construídos. Encontro Nacional de Tecnologia do Ambiente Construído, $7^{\circ}$, Florianópolis, 1998. Artigo técnico. Florianópolis, 1998. v.2 p. 747-756.

OLIVEIRA, Tânia Modesto Veludo de. Amostragem não Probabilística: Adequação de Situações para uso e Limitações de amostras por Conveniência, Julgamento e Quotas. Revista Administração On Line. São Paulo: FECAP. v. 2, n. 3, 2001. Disponível em: <http://www.fecap.br/adm_online/>. Acesso em: 12 mar. 2007.

ORNSTEIN, Sheila Walbe, BRUNA, Gilda Collet, ROMÉRO, Marcelo de Andrade. Ambiente construído e comportamento: a avaliação pós-ocupação e a qualidade ambiental. São Paulo: Studio Nobel/FAUUSP/FUPAM, 1995. 216p.

ORNSTEIN, Sheila Walbe, BRUNA, Gilda Collet; TASCHNER, Suzana P. Procedimentos e técnicas estatísticas aplicadas à APO. WORKSHOP AVALIAÇÃO PÓS-OCUPAÇÃO. Anais.... São Paulo: FAUUSP, 1994, p. 77-92.

ORNSTEIN, Sheila, ROMERO, Marcelo (colab.). Avaliação pós-ocupação (APO) do ambiente construído. São Paulo: Studio Nobel: EDUSP, 1992, 223p.

ORTEGA, Neli Regina Siqueira. Aplicação da teoria de conjuntos fuzzy a problemas da biomedicina. 2001. 198p. Tese (Doutorado) - Instituto de Física, Universidade de São Paulo. São Paulo, 2001. 
PASTERNAK, S. Squatter Settlements and Slums in Brazil: twenty years of research and policy. In: ALDRICH B. C.; SANDHU R. S. (ed.). Housing the Urban Poor. London: Zed Books, 1995, p. 185-223.

PEREIRA, Júlio César Rodrigues. Análise de dados qualitativos: estratégias metodológicas para as ciências da saúde, humanas e sociais. São Paulo: EDUSP: FAPESP, 3. ed. 2001.

PEREIRA, Júlio César Rodrigues. et al. Clinical signs of pneumonia in children: association with and prediction of diagnosis by fuzzy sets theory. Brazilian Journal of Medical and Biological Research. Ribeirão Preto: Associação Brasileira de Divulgação Científica, v. 37 , n. 5, p. 701-709, 2004. Disponível em: 〈http://www.scielo.br/>. Access on: 10 maio de 2006.

PICCHIAI, Djair. Dimensionamento quantitativo de recursos humanos em hospitais privados e públicos no Estado de São Paulo. São Paulo: EAESP/FGV/NPP - NÚCLEO DE PESQUISAS E PUBLICAÇÕES, 2000.

PIZA. Francisco José de Toledo, GREGORI. Lucio. Indicador De Salubridade Ambiental ISA. 20 . CONGRESSO BRASILEIRO DE ENGENHARIA SANITÁRIA E AMBIENTAL. Rio de Janeiro: ABES, 1999, p. 2913-2922.

PREISER, Wolfgang. The evolution of Post-Occupancy Evaluation: toward building performance and universal design evaluation. In: FFC. Learning from our Buildings: A State-of-the-Practice Summary of Post-Occupancy Evaluation. Washington D.C: National Academic Press, 2002, p. 9-22. Disponível em: <https://www.nap.edu/catalog/10288.html>. Acesso em: 25 nov. 2006.

RABINOWITZ, Harvey Z. Avaliação de pós-ocupação. In: SNYDER, James C. Introdução à Arquitetura. Rio de Janeiro: Campus. 1984. p. 395-411.

RHEINGANTZ, Paulo Afonso. Lógica "fuzzy" e variáveis lingüísticas aplicadas na avaliação de desempenho de edifícios de escritório. Ambiente Construído, Porto Alegre, v.2 n.3, p. 41$56,2002$.

REIS, Antonio Tarcisio; LAY, Maria Cristina Dias. Avaliação da qualidade de projetos - uma abordagem perceptiva e cognitiva. Ambiente Construído, Porto Alegre, v. 6 n. 3, p. 21-34, 2006.

REIS, Antonio Tarcisio; LAY, Maria Cristina Dias. Métodos e técnicas para levantamento de campo e análise de dados: questões gerais. WORKSHOP AVALIAÇÃO PÓS-OCUPAÇÃO. Anais.... São Paulo: FAUUSP, 1994, p. 28-49.

RODRIGUES, Maria Cecília P. O desenvolvimento social nas cidades brasileiras. Ciência Hoje - SBPC, Rio de Janeiro: Instituto Ciência Hoje, v. 13, n. 76. 1991.

ROLNIK, Raquel. Brasil e o Habitat, In: GORDILHO-SOUZA, Angela Maria. (org). Habitar Contemporâneo: Novas Questões no Brasil dos Anos 90. Salvador: Ed. Ultragraph, 1997, p. 51-58.

ROMÉRO, Marcelo de Andrade, ORNSTEIN, Sheila Walbe. Avaliação Pós-Ocupação: métodos de técnicas aplicados à habitação social. Porto Alegre: ANTAC, 2003. 294p.

ROMÉRO, Marcelo de Andrade. (coord.). Procedimentos metodológicos para aplicação da avaliação pós-ocupação em conjuntos habitacionais: do desenho urbano à unidade habitacional. São Paulo: FUPAM/NUTAU-FAUUSP, 1999, 7v. 
RUEDA, Salvador. Habitabilidad y calidad de vida. Madrid: UPM, jun. 1997. Disponível em: <http://habitat.aq.upm.es/cs/p2/a005.html>. Acesso em: 24 fev. 1999.

SAATY, Thomas Lorie. The analytic hierarchy process. [S.1.]: McGraw - Hill. 1980. 286p.

SACHS, Ignacy. Rumo à ecossocioeconomia: teoria e prática do desenvolvimento. São Paulo: Cortez, 2007. 472p.

SALAT, Serge (ed.). The sustainable design handbook - China. France: CSTB, 2006.

SANTANA, Marcos Jorge Almeida. Transferência de tecnologia para a população de baixa renda visando a autoconstrução. 1987. 206p. Dissertação (Mestrado) - Escola de Engenharia de São Carlos, Universidade de São Paulo. São Carlos, 1987.

SANTOS L. D.; MARTINS I. Monitoring urban quality of life: the Porto experience. Social Indicators Research, [S.1.]: Springer, v.80, n. 2, p. 411-425, 2007.

SANTOS, Luís Delfim; MARTINS, Isabel. A qualidade de vida urbana. O caso da cidade do Porto. Porto: Faculdade de Economia do Porto, Working Papers da FEP, 2002. Disponível em: 〈http://www.fep.up.pt>. Acesso em: 20 ago. 2003.

SECRETARIA NACIONAL DE HABITAÇÃO DO MINISTÉRIO DAS CIDADES, CENTRO DE ESTUDOS DA METRÓPOLE. Assentamentos precários no Brasil urbano. Brasília: Ministério das Cidades, [2007?], 390p.

SHANNON C. E. The mathematical theory of communication. In: The Bell Technical Journal, [S.1.]: [S.n.], n. 27, p. 378-423, 623-656, 1948.

SIEGEL, Sidney. Estatística não-paramétrica para as ciências do comportamento. São Paulo: Mcgraw-Hill do Brasil, 1977, 350p.

SILVA, Jane de Souza. Urbanização de favela em áreas de proteção de mananciais: o caso da Comunidade Sete de Setembro. 2003. 113p. Dissertação (Mestrado) - Escola Politécnica, Universidade de São Paulo. São Paulo, 2003.

SILVA, Vladimir Lima da. Modelo de Avaliação de Desempenho de Empresas Aéreas de Transporte Regular de Passageiros - O Caso Brasileiro. 2004. 150p. Dissertação (Mestrado) - Instituto Militar de Engenharia. Rio de Janeiro, 2004.

TASCHNER, Suzana Pasternak. O Brasil e suas favelas. In: ABRAMO, Pedro (org.). Cidade da Informalidade. Rio de Janeiro: Sete Letras, 2003, p. 13-42.

TASCHNER, Suzana Pasternak. Política habitacional no Brasil: Retrospectivas e perspectivas. Cadernos de pesquisa do LAP. São Paulo: FAUUSP, n. 21, set/out 1997. 71p.

TRZESNIAK, Piotr. Indicadores quantitativos: reflexões que antecedem seu estabelecimento. Ci. Inf., Brasília: S.n., v. 27, n. 2, p. 159-164, maio/ago. 1998.

TURNER, John F. C., Vivienda todo el poder para los usuários. Madri: H Blume, 1968.

UNCHS - UNITED NATIONS CENTRE FOR HUMAN SETTLEMENTS. Sustainable Urbanisation. Nairobi: UNCHS, 2002. Disponível em: <http://www.unhabitat.org/>. Acesso em 28 mar. 2007.

UN - UNITED NATIONS. Indicators of Sustainable Development: Guidelines and Methodologies. New York: United Nations Publications. 2007. 
VALLADARES, Lícia do Prado. A invenção da favela: do mito de origem a favela.com. Rio de Janeiro: Editora FGV, 2005. 204p.

VEIGA, José Eli da. Desenvolvimento sustentável: o desafio do século XXI. Rio de Janeiro: Garamond, 2005. 226p.

WALIZER, Michael H.; WIENIR, Paul L.. Research methods and analysis. New York: Harper \& Row, 1978, 516p.

WILHEIM, Jorge. Cidades: O substantivo e o adjetivo. São Paulo: Perspectiva, 2003, 3. ed. $245 p$.

WILLS, J.; BRIGGS, D.. Developing Indicators for Environment and Health. World Health Statistics Quarterly. Geneva: World Health Organization, v. 48, n. 2, p. 155-163, 1995.

WORLD COMMISSION ON ENVIRONMENT AND DEVELOPMENT. Our common future. Oxford: Oxford University Press, 1987, [320]p.

YANNIS A. P.; ANDRIANTIATSAHOLINIAINA L. A.. Sustainability: an ill-define concept and its assessment using Fuzzy Logic. Ecological Economics, [S.1.]: Elsevier, v. 37, n. 3, p. 435-456, 2001.

ZADEH, L, A.. Fuzzy Sets. Information and Control. New York: Academic Press: Elsevier, n. 8, p. 338-353, 1965. 
APÊNDICE A : FORMULÁRIO DE CAMPO - PESQUISA PILOTO 


\section{UNIVERSIDADE DE SÃO PAULO \\ ESCOLA POLITÉCNICA \\ DEPARTAMENTO DE ENGENHARIA DE CONSTRUÇÃO CIVIL FORMULÁRIO PARA AVALIAÇÃO DE ÁREAS URBANAS RECUPERADAS}

Data da entrevista:
Endereço:
Entrevistado:
Quantas pessoas moram na casa?
Quem tem o maior grau de escolaridade?
Tempo de residência no local:
A casa foi: $\square$ Construída pela Conder
$\square$ Conder e ampliada pelo morador
$\square$ Construída pelo próprio morador
$\square$ Adquirida de outros
$\square$ Alugada

ÁGUA

1. A casa possui água encanada?

\section{$\square \operatorname{Sim} \square$ Não}

2. Se a casa possui água, recebe conta de água? $\square \operatorname{Sim} \square$ Não

3. Se não, de onde vem a água?

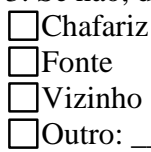

4. Em relação ao serviço de abastecimento de água você acha:

$\square$ Péssimo
$\square$ Ruim
$\square$ Regular
$\square$ Bom
$\square$ Ótimo

5. A casa possui instalações de água (torneiras, chuveiro, descarga)?

$\square \operatorname{Sim} \square$ Não

6. Se sim na pergunta anterior, o que você acha dessas instalações?

$\square$ Péssimas
$\square$ Ruins
$\square$ Regulares
$\square$ Boas
$\square$ Ótimas

\section{ESGOTO}

1. A casa possui ligação com a rede de esgoto ou fossa? $\square$ Rede de esgoto $\square$ Fossa $\square$ Não possui esgoto

2. Se é ligada a rede, recebe conta de esgoto?

\section{$\square$ Sim $\square$ Não}

3. Se possui esgoto, o que você acha do serviço:

$\square$ Péssimo
$\square$ Ruim
$\square$ Regular
$\square$ Bom
$\square$ Ótimo

4. A casa possui instalações de esgoto (ralo no banheiro, saídas das pias e vaso sanitário)?

\section{$\square \operatorname{Sim} \square$ Não}

6. Se sim na pergunta anterior, o que você acha dessas instalações?

$$
\begin{aligned}
& \square \text { Péssimas } \\
& \square \text { Ruins } \\
& \square \text { Regulares } \\
& \square \text { Boas } \\
& \square \text { Ótimas }
\end{aligned}
$$

\section{COLETA DE LIXO}

1. Qual o tipo de coleta de lixo?

$\square$ Caminhão coletor de porta em porta

$\square$ Gari de porta em porta

Contêiner mais próximo

Ponto de lixo mais próximo

$\square$ Outro:

2. Se coleta na própria porta ou conteiner, com que frequiência?

$\square$ Todo dia

$\square$ Dia sim, dia não

$\square$ Uma vez por semana

$\square$ Outra:

3. Em relação a coleta de lixo você acha:

$\square$ Péssimo
$\square$ Ruim
$\square$ Regular
$\square$ Bom
$\square$ Ótimo

VARRIÇÃO DA RUA

1. Quem varre?

$\square$ Gari $\square$ Morador $\square$ Não é varrida

2. Em relação a limpeza da rua você acha:

$\square$ Péssima

$\square$ Ruim

$\square$ Regular

$\square$ Boa

$\square$ Ótima 
DRENAGEM - SARJETAS E BOCAS DE LOBO

1. Quando chove inunda a casa?

$\square \operatorname{Sim} \square$ Não

2. E Quando chove consegue andar nas ruas?

$\square \operatorname{Sim} \square$ Não

3. Com relação ao funcionamento das bocas de lobo e sarjetas durante as chuvas você acha:

$\square$ Péssimo

$\square$ Ruim

$\square$ Regular

$\square$ Bom

$\square$ Ótimo

4. Como você se sente em relação ao risco de inundação:

$\square$ Totalmente inseguro

$\square$ Um pouco inseguro

$\square$ Não sabe informar

$\square$ Um pouco seguro

$\square$ Totalmente seguro

\section{RUAS}

Entrevistador:

1. Largura média da via em frente a casa:

$\square$ Maior ou igual a 6 metros

$\square$ Entre 3,60 e 6 metros

$\square$ Entre 1,20 e 3,60 metros

$\square$ Menor que 1,20 metros

2. Tipo de pavimentação:

$\square$ Asfalto

$\square$ Paralelepípedo

$\square$ Sem pavimentação

3. Estado da rua:

$\square$ Péssimo

$\square$ Ruim

$\square$ Regular

$\square$ Bom

$\square$ Ótimo

5.O que você acha da largura da sua rua?

$\square$ Péssima
$\square$ Ruim
$\square$ Regular
$\square$ Boa
$\square$ Ótima

6. Você acha sua rua:

$\square$ Péssima

$\square$ Ruim

$\square$ Regular

$\square$ Boa

$\square$ ótimo

SEGURANÇA GEOLÓGICA-GEOTÉCNICA

1. Você acha o terreno onde sua casa foi construído seguro?

$\square$ Não, totalmente inseguro

$\square$ Não, um pouco inseguro

$\square$ Não sabe dizer

$\square$ Sim, um pouco seguro

$\square$ Sim, totalmente seguro

\section{ESPAÇOS PÚBLICOS}

1. Você utiliza algum lugar público na área urbanizada (praças, campo de futebol, quadras, pista para caminhada)?

$\square \operatorname{Sim} \square$ Não

2. Quais?

$\square$ Praça

$\square$ Campo de futebol

$\square$ Quadra

$\square$ Pista de caminhada

$\square$ Outro:

3. O que você acha destes lugares:

$\square$ Péssimos
$\square$ Ruins
$\square$ Regulares
$\square$ Bons
$\square$ Ótimos

ENERGIA ELÉTRICA E ILUMINAÇÃO

1. Sua casa possui energia elétrica?

$\square \operatorname{Sim} \square$ Não

2. Se sim, recebe conta de energia?

$\square \operatorname{Sim} \square$ Não

3. Se possui energia o que você acha do serviço de energia elétrica?

$\square$ Péssimo
$\square$ Ruim
$\square$ Regular
$\square$ Bom
$\square$ Ótimo

4. Se possui energia elétrica, qual o tipo de instalações da casa?

$\square$ Embutida

$\square$ Aparente

$\square$ Embutida na parede e aparente no teto

Mista

5. O que você acha das instalações elétricas de sua casa?

$\square$ Péssimas

$\square$ Ruins

$\square$ Regulares

$\square$ Boas

$\square$ Ótimas

6. Possui iluminação na sua rua?

$\square \operatorname{Sim} \square$ Não

7. Quem fornece?

$\square$ Prefeitura $\square$ Morador

8. O que você acha da iluminação de sua rua?

$\square$ Péssima

$\square$ Ruim

$\square$ Regular

$\square$ Boa

$\square$ ótima 
TELEFONES PÚBLICOS

1. Tem orelhão na sua rua?

$\square \operatorname{Sim} \square$ Não

2. Utiliza o orelhão?

$\square \operatorname{Sim} \square$ Não

3. O que você acha da distância do orelhão?

$\square$ Muito distante

$\square$ Distante

$\square$ Razoável

$\square$ Próxima

$\square$ Muito próxima

REGULARIZAÇÃO E POSSE

1. Você possui algum documento da casa?

$\square \operatorname{Sim} \square$ Não

2. Está seguro da posse de sua casa?

$\square$ Não, totalmente inseguro

$\square$ Não, um pouco inseguro

$\square$ Não sabe dizer

$\square$ Sim, um pouco seguro

$\square$ Sim, totalmente seguro

\section{SERVIÇOS EM GERAL}

1. Como você avalia a área que foi urbanizada, antes e depois?
$\square$ Piorou muito
$\square$ Piorou
$\square$ Não faz diferença
$\square$ Melhorou
$\square$ Melhorou muito

2. Você pode dizer os pontos positivos e/ou negativos?

\section{ENTORNO E EQUIPAMENTOS}

1. Serviços comunitários utilizados (Local: fora ou dentro da área):

$\begin{array}{ll}\square \text { Escola } & \text { Local: } \\ \square \text { Posto de saúde } & \text { Local: } \\ \square \text { Creche } & \text { Local: } \\ \square \text { Outro: } & \text { Local: }\end{array}$

2. O que você acha dos serviços oferecidos nesses locais:

$\square$ Péssimos
$\square$ Ruins
$\square$ Regulares
$\square$ Bons
$\square$ Ótimos

3. Observações:

4. Você utiliza outros locais para lazer fora dessa área que foi urbanizada, nas proximidades:

$\square \operatorname{Sim} \square$ Não

5. Se sim, Quais?
6. Se sim, O que você acha desses locais:

$\square$ Péssimos

$\square$ Ruins

$\square$ Regulares

$\square$ Bons

$\square$ Ótimos

7. Faz parte de algum tipo de associação da região? $\square \operatorname{Sim} \square$ Não

8 Se sim, quais:

$\square$ Associação de moradores

$\square$ Cooperativa

$\square$ Organização não governamental

$\square$ Outra:

9 Se sim, o que você acha da atuação dessas organizações:

$\square$ Péssima

$\square$ Ruins

$\square$ Regulares

$\square$ Boa

$\square$ Ótima

10. Meios de transporte utilizados para trabalhar:

$\square$ Barco

$\square$ Trem

$\square$ Ônibus

पOutro:

11. Se utiliza ônibus, o ponto de ônibus é:

$\square$ Muito distante

$\square$ Pouco distante

Numa distância razoável

$\square$ Próximo

$\square$ Muito próximo

12. O que você acha de morar neste bairro?

$\square$ Péssimo

$\square$ Ruim

$\square$ Regular

$\square$ Bom

$\square$ Ótimo 
CASA

COMPOSIÇÃO E ADEQUAÇÃO DO ESPAÇO

1. Composição:

$\square$ Sala

$\square$ Quartos

$\square$ Cozinha

$\square$ Banheiro

$\square$ Área de serviço

$\square$ Varanda

2. Quantidade de quartos:

3. Além dos quartos outros cômodos são usados para dormir?

$\square \operatorname{Sim} \square$ Não

4. Se sim, Quais?

$\square$ Sala

$\square$ Cozinha

$\square$ Banheiro

$\square$ Área de serviço

$\square$ Varanda

5. Como você avalia a quantidade de quartos de sua casa em relação ao número de pessoas?

$\square$ Péssimo

$\square$ Ruim

$\square$ Regular

$\square$ Bom

$\square$ Ótimo

6. Como você avalia o tamanho da sua casa para sua família?

$\square$ Péssimo

$\square$ Ruim

$\square$ Regular

$\square$ Bom

$\square$ Ótimo

\section{COBERTURA}

1. Qual o material do telhado?

$\square$ Telha cerâmica

$\square$ Telha de amianto

$\square$ Laje

$\square$ Outros:

2. Quando chove entra água pelo telhado?

$\square \operatorname{Sim} \square$ Não

3. O que você acha do telhado de sua casa?

$\square$ Péssimo

$\square$ Ruim

$\square$ Regular

$\square$ Bom

$\square$ Ótimo

\section{PAREDES}

1. Qual o material das paredes?

$\square$ Tijolos furados

$\square$ Blocos de concreto

$\square$ Outros:

2. Possui revestimento (reboco) nas paredes de dentro de casa?

$\square \operatorname{Sim} \square$ Não $\square$ Em algumas partes

3 Possui revestimento (reboco) nas parte de fora da casa? $\square$ Sim $\square$ Não $\square$ Em algumas partes

4. O que você acha das paredes:

$\square$ Péssimas

$\square$ Ruins

$\square$ Regulares

$\square$ Boas

$\square$ Ótimas
PISO

1. Qual o material do piso?

$\square$ Sem piso

$\square$ Cimento queimado

$\square$ Cimento grosso

Cerâmica

$\square$ Barro

$\square$ Outros:

2. Existem problemas de umidade nos pés das paredes? $\square \operatorname{Sim} \square$ Não

3. O que você acha do piso de sua casa?

$\square$ Péssimo

$\square$ Ruim

$\square$ Regular

$\square$ Bom

$\square$ Ótimo

ILUMINAÇÃO E VENTILAÇÃO NATURAL

1. A casa possui janelas ou combogós em todos os cômodos?

$\square \operatorname{Sim} \square$ Não

2. Em caso negativo, quais não possuem?

$\square$ Sala

$\square$ Quartos

$\square$ Cozinha

Banheiro

3. O que você acha da ventilação da sua casa?

$\square$ Péssimo

$\square$ Ruim

$\square$ Regular

$\square$ Bom

$\square$ Ótimo

AVALIAÇÃO GERAL

1. O que você acha da sua casa como um todo:

$\square$ Péssimo

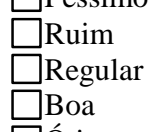

$\square$ Boa

$\square$ Ótima

2. O que você acha da sua casa depois da urbanização?

$\square$ Piorou muito

$\square$ Piorou

$\square$ Não faz diferença

$\square$ Melhorou

$\square$ Melhorou muito

3. Você pode dizer os pontos positivos e/ou negativos? 
APÊNDICE B : CÓDIGOS DA VARIÁVEIS UTILIZADAS 
Códigos das variáveis

\begin{tabular}{|c|c|}
\hline Código & Variável \\
\hline \multicolumn{2}{|l|}{ MORADIA } \\
\hline Av_Inst_Agua & Avaliação das instalações de água \\
\hline Av_Inst_Esgoto & Avaliação das instalações de esgoto \\
\hline Av_Inst_Eletrica & Avaliação das instalações elétricas \\
\hline Av_Quartos & Avaliação da quantidade de quartos \\
\hline Av_Banheiro & Avaliação do banheiro \\
\hline Av_Cozinha & Avaliação da cozinha \\
\hline Av_Tam_Casa & Avaliação do tamanho da casa \\
\hline Av_Telhado & Avaliação do material do telhado \\
\hline Av_Paredes & Avaliação do material das paredes \\
\hline Av_Piso & Avaliação do material do piso \\
\hline Av_Ventila & Avaliação da ventilação e iluminação natural \\
\hline Av_Casa & Avaliação da casa \\
\hline Av_Casa_Antes_Depois & Avaliação da casa antes e depois da intervenção \\
\hline \multicolumn{2}{|l|}{ SALUBRIDADE AMBIENTAL } \\
\hline Av_Abast_Agua & Avaliação do abastecimento de água \\
\hline Av_Esgoto & Avaliação do esgotamento sanitário \\
\hline Av_Coleta_Lixo & Avaliação da coleta de lixo \\
\hline Av_Varricao & Avaliação do serviço de varrição \\
\hline Av_Boc_Sarj & Avaliação do funcionamento de bocas de lobo e sarjetas \\
\hline Seg_Inund & Avaliação da segurança contra inundação \\
\hline Av_larg_rua & Avaliação da largura da rua \\
\hline Av_Rua & Avaliação da rua como um todo \\
\hline Seg_Terreno & Avaliação da segurança no terreno \\
\hline Av_Esp_Pub & Avaliação dos espaços públicos \\
\hline Av_Energia & Avaliação do serviço de energia elétrica \\
\hline Av_Ilumina & Avaliação da iluminação pública \\
\hline Dist_Tel & Avaliação da distância do orelhão \\
\hline Seg_Posse & Avaliação da segurança de posse da casa \\
\hline Av_Area & Avaliação da área urbanizada \\
\hline Av_Antes_Depois & Avaliação da área urbanizada antes e depois da intervenção \\
\hline \multicolumn{2}{|l|}{ ENTORNO } \\
\hline Av_Servic & Avaliação dos serviços comunitários \\
\hline Av_Lazer_Fora & Avaliação das áreas de lazer fora da área \\
\hline Av_Associacao & Avaliação das associações comunitárias que participa \\
\hline Av_Dist_Ponto_Onibus & Avaliação da distância do ponto de ônibus \\
\hline Av_Transp & Avaliação do transporte coletivo \\
\hline Av_ServiçosEntorno & Avaliação dos serviços comunitários do entorno \\
\hline Av_Bairro & Avaliação do bairro \\
\hline
\end{tabular}


APÊNDICE C : QUESTIONÁRIO DE CONSULTA AOS ESPECIALISTAS 


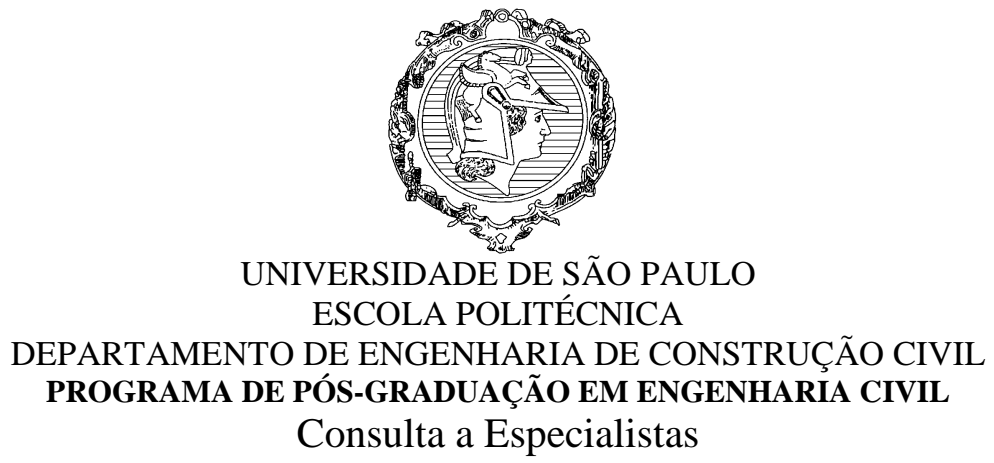

Caro(a) Senhor(a),

Estamos realizando uma pesquisa cujo objetivo é desenvolver um método de análise de dados para avaliação de áreas urbanas recuperadas. O estudo está sendo desenvolvido utilizando como objeto de análise favelas urbanizadas. Foram selecionadas algumas variáveis para compor um sistema de indicadores, estas variáveis foram agrupadas em três componentes que formarão três indicadores (Salubridade ambiental da favela, Moradia e Entorno). Pedimos o seu apoio para a realização deste trabalho, o(a) senhor(a) levará 10 minutos no máximo, neste sentido estamos lhe enviando um questionário com a seguinte orientação de preenchimento:

\section{Exemplo:}

Suponha que estejamos avaliando o abastecimento de água em relação ao esgotamento sanitário e na nossa opinião as variáveis sejam igualmente importantes, então devemos marcar apenas o campo Igualmente, como segue abaixo:

\begin{tabular}{|l|l|l|l|l|}
\hline Abastecimento de água & $\begin{array}{l}\square \text { Totalmente } \\
\square \text { Muito } \\
\square \text { Pouco }\end{array}$ & $\begin{array}{l}\square \text { Mais } \\
\square \text { Menos } \\
\text { Igualmente }\end{array}$ & importante que & Esgotamento sanitário \\
\hline
\end{tabular}

Caso acreditemos que o abastecimento de água seja um pouco mais importante que o esgotamento sanitário, devemos marcar na coluna da esquerda Pouco e na da direta Mais

\begin{tabular}{|l|l|l|l|l}
\hline Abastecimento de água & $\begin{array}{l}\square \text { Totalmente } \\
\square \text { Muito } \\
\square \text { Pouco }\end{array}$ & $\begin{array}{l}\square \text { Mais } \\
\square \text { Igualmente }\end{array}$ & importante que & Esgotamento sanitário \\
\hline
\end{tabular}

A escala pode então variar em nove pontos da seguinte forma

- Igualmente - as duas variáveis tem a mesma importância;

- Pouco mais - a primeira variável é ligeiramente mais importante que a segunda;

- Mais - a primeira variável é mais importante que a segunda;

- Muito mais - a primeira variável é comprovadamente mais importante que a segunda;

- Totalmente mais - a primeira variável é no mais alto nível, mais importante que a segunda;

- E os seus correspondentes com menos.

Contamos com o seu apoio e compreensão e nos colocamos a disposição para dirimir qualquer dúvida (odair.moraes@poli.usp.br).

Atenciosamente,

Odair Barbosa de Moraes

odair.moraes@poli.usp.br

Doutorando

\author{
Alex Kenya Abiko \\ alex.abiko@poli.usp.br \\ Orientador
}


Indicador de Salubridade Ambiental- I

\begin{tabular}{|c|c|c|c|c|}
\hline \multicolumn{5}{|l|}{ Saneamento básico } \\
\hline Abastecimento de água & $\begin{array}{l}\square \text { Totalmente } \\
\square \text { Muito } \\
\square \text { Pouco } \\
\end{array}$ & $\begin{array}{l}\square \text { Mais } \\
\square \text { Menos } \\
\square \text { Igualmente }\end{array}$ & importante que & Esgotamento sanitário \\
\hline Abastecimento de água & $\begin{array}{l}\square \text { Totalmente } \\
\square \text { Muito } \\
\square \text { Pouco }\end{array}$ & $\begin{array}{l}\square \text { Mais } \\
\square \text { Menos } \\
\square \text { Igualmente }\end{array}$ & importante que & Drenagem \\
\hline Abastecimento de água & $\begin{array}{l}\square \text { Totalmente } \\
\square \text { Muito } \\
\square \text { Pouco } \\
\end{array}$ & $\begin{array}{l}\square \text { Mais } \\
\square \text { Menos } \\
\square \text { Igualmente }\end{array}$ & importante que & Limpeza urbana \\
\hline Esgotamento sanitário & $\begin{array}{l}\square \text { Totalmente } \\
\square \text { Muito } \\
\square \text { Pouco }\end{array}$ & $\begin{array}{l}\square \text { Mais } \\
\square \text { Menos } \\
\square \text { Igualmente }\end{array}$ & importante que & Drenagem \\
\hline Esgotamento sanitário & $\begin{array}{l}\text { Totalmente } \\
\square \text { Muito } \\
\square \text { Pouco } \\
\end{array}$ & $\begin{array}{l}\square \text { Mais } \\
\square \text { Menos } \\
\square \text { Igualmente }\end{array}$ & importante que & Limpeza urbana \\
\hline Drenagem & $\begin{array}{l}\square \text { Totalmente } \\
\square \text { Muito } \\
\square \text { Pouco }\end{array}$ & $\begin{array}{l}\square \text { Mais } \\
\square \text { Menos } \\
\square \text { Igualmente }\end{array}$ & importante que & Limpeza urbana \\
\hline Coleta de lixo & $\begin{array}{l}\square \text { Totalmente } \\
\square \text { Muito } \\
\square \text { Pouco }\end{array}$ & $\begin{array}{l}\square \text { Mais } \\
\square \text { Menos } \\
\square \text { Igualmente }\end{array}$ & importante que & Serviço de varrição das vias \\
\hline $\begin{array}{l}\text { Ter abastecimento de água regularizado (com } \\
\text { conta) }\end{array}$ & $\begin{array}{l}\square \text { Totalmente } \\
\square \text { Muito } \\
\square \text { Pouco }\end{array}$ & $\begin{array}{l}\square \text { Mais } \\
\square \text { Menos } \\
\square \text { Igualmente }\end{array}$ & importante que & $\begin{array}{l}\text { Ter abastecimento de água } \\
\text { irregular (sem conta) }\end{array}$ \\
\hline $\begin{array}{l}\text { Ter esgotamento sanitário regularizado (com } \\
\text { conta) }\end{array}$ & $\begin{array}{l}\square \text { Totalmente } \\
\square \text { Muito } \\
\square \text { Pouco }\end{array}$ & $\begin{array}{l}\square \text { Mais } \\
\square \text { Menos } \\
\square \text { Igualmente }\end{array}$ & importante que & $\begin{array}{l}\text { Ter esgotamento sanitário } \\
\text { irregular (sem conta) }\end{array}$ \\
\hline \multicolumn{5}{|l|}{ Infra-estrutura e serviços } \\
\hline Energia elétrica & $\begin{array}{l}\square \text { Totalmente } \\
\square \text { Muito } \\
\square \text { Pouco }\end{array}$ & $\begin{array}{l}\square \text { Mais } \\
\square \text { Menos } \\
\square \text { Igualmente }\end{array}$ & importante que & Iluminação pública \\
\hline Energia elétrica & $\begin{array}{l}\square \text { Totalmente } \\
\square \text { Muito } \\
\square \text { Pouco }\end{array}$ & $\begin{array}{l}\square \text { Mais } \\
\square \text { Menos } \\
\square \text { Igualmente }\end{array}$ & importante que & Espaços públicos \\
\hline Energia elétrica & $\begin{array}{l}\square \text { Totalmente } \\
\square \text { Muito } \\
\square \text { Pouco }\end{array}$ & $\begin{array}{l}\square \text { Mais } \\
\square \text { Menos } \\
\square \text { Igualmente }\end{array}$ & importante que & Vias de circulação \\
\hline Iluminação pública & $\begin{array}{l}\square \text { Totalmente } \\
\square \text { Muito } \\
\square \text { Pouco }\end{array}$ & $\begin{array}{l}\square \text { Mais } \\
\square \text { Menos } \\
\square \text { Igualmente }\end{array}$ & importante que & Espaços públicos \\
\hline Iluminação pública & $\begin{array}{l}\square \text { Totalmente } \\
\square \text { Muito } \\
\square \text { Pouco }\end{array}$ & $\begin{array}{l}\square \text { Mais } \\
\square \text { Menos } \\
\square \text { Igualmente }\end{array}$ & importante que & Vias de circulação \\
\hline Espaços públicos & $\begin{array}{l}\square \text { Totalmente } \\
\square \text { Muito } \\
\square \text { Pouco }\end{array}$ & $\begin{array}{l}\square \text { Mais } \\
\square \text { Menos } \\
\square \text { Igualmente }\end{array}$ & importante que & Vias de circulação \\
\hline Ter energia elétrica regularizada (com conta) & $\begin{array}{l}\square \text { Totalmente } \\
\square \text { Muito } \\
\square \text { Pouco }\end{array}$ & $\begin{array}{l}\square \text { Mais } \\
\square \text { Menos } \\
\square \text { Igualmente }\end{array}$ & importante que & $\begin{array}{l}\text { Ter energia elétrica irregular } \\
\text { (sem conta) }\end{array}$ \\
\hline \multicolumn{5}{|l|}{ Condições físicas } \\
\hline Segurança geológica-geotécnica & $\begin{array}{l}\square \text { Totalmente } \\
\square \text { Muito } \\
\square \text { Pouco }\end{array}$ & $\begin{array}{l}\square \text { Mais } \\
\square \text { Menos } \\
\square \text { Igualmente }\end{array}$ & importante que & Densidade demográfica \\
\hline \multicolumn{5}{|l|}{ Condições sociais } \\
\hline Educação & $\begin{array}{l}\square \text { Totalmente } \\
\square \text { Muito } \\
\square \text { Pouco } \\
\end{array}$ & $\begin{array}{l}\square \text { Mais } \\
\square \text { Menos } \\
\square \text { Igualmente }\end{array}$ & importante que & Renda \\
\hline
\end{tabular}


Indicador de Salubridade Ambiental -II

\begin{tabular}{|c|c|c|c|c|}
\hline Saneamento básico & $\begin{array}{l}\square \text { Totalmente } \\
\square \text { Muito } \\
\square \text { Pouco }\end{array}$ & $\begin{array}{l}\square \text { Mais } \\
\square \text { Menos } \\
\square \text { Igualmente }\end{array}$ & importante que & Infra-estrutura e outros serviços \\
\hline Saneamento básico & $\begin{array}{l}\square \text { Totalmente } \\
\square \text { Muito } \\
\square \text { Pouco }\end{array}$ & $\begin{array}{l}\square \text { Mais } \\
\square \text { Menos } \\
\square \text { Igualmente }\end{array}$ & importante que & Condições físicas \\
\hline Saneamento básico & $\begin{array}{l}\square \text { Totalmente } \\
\square \text { Muito } \\
\square \text { Pouco }\end{array}$ & $\begin{array}{l}\square \text { Mais } \\
\square \text { Menos } \\
\square \text { Igualmente }\end{array}$ & importante que & Condições sociais \\
\hline Saneamento básico & $\begin{array}{l}\square \text { Totalmente } \\
\square \text { Muito } \\
\square \text { Pouco }\end{array}$ & $\begin{array}{l}\text { Mais } \\
\square \text { Menos } \\
\square \text { Igualmente }\end{array}$ & importante que & Regularização fundiária \\
\hline Infra-estrutura e outros serviços & $\begin{array}{l}\square \text { Totalmente } \\
\square \text { Muito } \\
\square \text { Pouco }\end{array}$ & $\begin{array}{l}\square \text { Mais } \\
\square \text { Menos } \\
\square \text { Igualmente }\end{array}$ & Importante que & Condições físicas \\
\hline Infra-estrutura e outros serviços & $\begin{array}{l}\square \text { Totalmente } \\
\square \text { Muito } \\
\square \text { Pouco }\end{array}$ & $\begin{array}{l}\square \text { Mais } \\
\square \text { Menos } \\
\square \text { Igualmente }\end{array}$ & Importante que & Condições sociais \\
\hline Infra-estrutura e outros serviços & $\begin{array}{l}\square \text { Totalmente } \\
\square \text { Muito } \\
\square \text { Pouco }\end{array}$ & $\begin{array}{l}\text { Mais } \\
\square \text { Menos } \\
\square \text { Igualmente }\end{array}$ & Importante que & Regularização fundiária \\
\hline Condições físicas & $\begin{array}{l}\square \text { Totalmente } \\
\square \text { Muito } \\
\square \text { Pouco }\end{array}$ & $\begin{array}{l}\square \text { Mais } \\
\square \text { Menos } \\
\square \text { Igualmente }\end{array}$ & importante que & Condições sociais \\
\hline Condições físicas & $\begin{array}{l}\square \text { Totalmente } \\
\square \text { Muito } \\
\square \text { Pouco }\end{array}$ & $\begin{array}{l}\square \text { Mais } \\
\square \text { Menos } \\
\square \text { Igualmente }\end{array}$ & importante que & Regularização fundiária \\
\hline Condições sociais & $\begin{array}{l}\square \text { Totalmente } \\
\square \text { Muito } \\
\square \text { Pouco }\end{array}$ & $\begin{array}{l}\square \text { Mais } \\
\square \text { Menos } \\
\square \text { Igualmente }\end{array}$ & importante que & Regularização fundiária \\
\hline
\end{tabular}
Indicador de Moradia - I

\begin{tabular}{|c|c|c|c|c|}
\hline \multirow{2}{*}{\multicolumn{5}{|c|}{ Cômodos }} \\
\hline & & & & \\
\hline Ter cozinha & $\begin{array}{l}\square \text { Totalmente } \\
\square \text { Muito } \\
\square \text { Pouco }\end{array}$ & $\begin{array}{l}\square \text { Mais } \\
\square \text { Menos } \\
\square \text { Igualmente }\end{array}$ & importante que & Ter banheiro \\
\hline Ter cozinha & $\begin{array}{l}\square \text { Totalmente } \\
\square \text { Muito } \\
\square \text { Pouco }\end{array}$ & $\begin{array}{l}\square \text { Mais } \\
\square \text { Menos } \\
\square \text { Igualmente }\end{array}$ & importante que & $\begin{array}{l}\text { Ter quartos suficientes ( } 2 \\
\text { pessoas por quarto } \\
\text { aproximadamente) }\end{array}$ \\
\hline Ter banheiro & $\begin{array}{l}\square \text { Totalmente } \\
\square \text { Muito } \\
\square \text { Pouco } \\
\end{array}$ & $\begin{array}{l}\text { Mais } \\
\square \text { Menos } \\
\square \text { Igualmente }\end{array}$ & importante que & $\begin{array}{l}\text { Ter quartos suficientes (2 } \\
\text { pessoas por quarto } \\
\text { aproximadamente) }\end{array}$ \\
\hline \multicolumn{5}{|l|}{ Materiais } \\
\hline Material da cobertura & $\begin{array}{l}\square \text { Totalmente } \\
\square \text { Muito } \\
\square \text { Pouco }\end{array}$ & $\begin{array}{l}\square \text { Mais } \\
\square \text { Menos } \\
\square \text { Igualmente }\end{array}$ & importante que & Material das paredes \\
\hline Material da cobertura & $\begin{array}{l}\square \text { Totalmente } \\
\square \text { Muito } \\
\square \text { Pouco }\end{array}$ & $\begin{array}{l}\square \text { Mais } \\
\square \text { Menos } \\
\square \text { Igualmente }\end{array}$ & importante que & Material do piso \\
\hline Material das paredes & $\begin{array}{l}\square \text { Totalmente } \\
\square \text { Muito } \\
\square \text { Pouco }\end{array}$ & $\begin{array}{l}\square \text { Mais } \\
\square \text { Menos } \\
\square \text { Igualmente }\end{array}$ & importante que & Material do piso \\
\hline \multicolumn{5}{|l|}{ Instalações } \\
\hline Instalações de água & $\begin{array}{l}\square \text { Totalmente } \\
\square \text { Muito } \\
\square \text { Pouco } \\
\end{array}$ & $\begin{array}{l}\square \text { Mais } \\
\square \text { Menos } \\
\square \text { Igualmente }\end{array}$ & importante que & Instalações de esgoto \\
\hline Instalações de água & $\begin{array}{l}\square \text { Totalmente } \\
\square \text { Muito } \\
\square \text { Pouco } \\
\end{array}$ & $\begin{array}{l}\square \text { Mais } \\
\square \text { Menos } \\
\square \text { Igualmente }\end{array}$ & importante que & Instalações elétricas \\
\hline Instalações de esgoto & $\begin{array}{l}\square \text { Totalmente } \\
\square \text { Muito } \\
\square \text { Pouco }\end{array}$ & $\begin{array}{l}\square \text { Mais } \\
\square \text { Menos } \\
\square \text { Igualmente }\end{array}$ & importante que & Instalações elétricas \\
\hline
\end{tabular}


Indicador de Moradia - II

\begin{tabular}{|c|c|c|c|c|}
\hline Cômodos & $\begin{array}{l}\text { Totalmente } \\
\square \text { Muito } \\
\square \text { Pouco }\end{array}$ & $\begin{array}{l}\square \text { Mais } \\
\square \text { Menos } \\
\square \text { Igualmente }\end{array}$ & importante que & Materiais (teto, paredes e piso) \\
\hline Cômodos & $\begin{array}{l}\square \text { Totalmente } \\
\square \text { Muito } \\
\square \text { Pouco }\end{array}$ & $\begin{array}{l}\square \text { Mais } \\
\square \text { Menos } \\
\square \text { Igualmente }\end{array}$ & importante que & Aberturas \\
\hline Cômodos & $\begin{array}{l}\square \text { Totalmente } \\
\square \text { Muito } \\
\square \text { Pouco }\end{array}$ & $\begin{array}{l}\square \text { Mais } \\
\square \text { Menos } \\
\square \text { Igualmente }\end{array}$ & importante que & Instalações \\
\hline Materiais (teto, paredes e piso) & $\begin{array}{l}\square \text { Totalmente } \\
\square \text { Muito } \\
\square \text { Pouco }\end{array}$ & $\begin{array}{l}\square \text { Mais } \\
\square \text { Menos } \\
\square \text { Igualmente }\end{array}$ & importante que & Aberturas \\
\hline Materiais (teto, paredes e piso) & $\begin{array}{l}\square \text { Totalmente } \\
\square \text { Muito } \\
\square \text { Pouco }\end{array}$ & $\begin{array}{l}\square \text { Mais } \\
\square \text { Menos } \\
\square \text { Igualmente }\end{array}$ & importante que & Instalações \\
\hline Aberturas & $\begin{array}{l}\square \text { Totalmente } \\
\square \text { Muito } \\
\square \text { Pouco }\end{array}$ & $\begin{array}{l}\square \text { Mais } \\
\square \text { Menos } \\
\square \text { Igualmente }\end{array}$ & importante que & Instalações \\
\hline
\end{tabular}

\section{Indicador de Entorno}

\begin{tabular}{|c|c|c|c|c|}
\hline Transporte e mobilidade & $\begin{array}{l}\square \text { Totalmente } \\
\square \text { Muito } \\
\square \text { Pouco }\end{array}$ & $\begin{array}{l}\square \text { Mais } \\
\square \text { Menos } \\
\square \text { Igualmente }\end{array}$ & importante que & $\begin{array}{l}\text { Equipamentos comunitários e de } \\
\text { serviços }\end{array}$ \\
\hline Transporte e mobilidade & $\begin{array}{l}\square \text { Totalmente } \\
\square \text { Muito } \\
\square \text { Pouco }\end{array}$ & $\begin{array}{l}\square \text { Mais } \\
\square \text { Menos } \\
\square \text { Igualmente }\end{array}$ & importante que & Associativismo \\
\hline Transporte e mobilidade & $\begin{array}{l}\square \text { Totalmente } \\
\square \text { Muito } \\
\square \text { Pouco } \\
\end{array}$ & $\begin{array}{l}\square \text { Mais } \\
\square \text { Menos } \\
\square \text { Igualmente }\end{array}$ & importante que & Espaços públicos \\
\hline Equipamentos comunitários e de serviços & $\begin{array}{l}\text { Totalmente } \\
\square \text { Muito } \\
\square \text { Pouco }\end{array}$ & $\begin{array}{l}\square \text { Mais } \\
\square \text { Menos } \\
\square \text { Igualmente }\end{array}$ & importante que & Associativismo \\
\hline Equipamentos comunitários e de serviços & $\begin{array}{l}\square \text { Totalmente } \\
\square \text { Muito } \\
\square \text { Pouco } \\
\end{array}$ & $\begin{array}{l}\square \text { Mais } \\
\square \text { Menos } \\
\square \text { Igualmente }\end{array}$ & importante que & Espaços públicos \\
\hline Associativismo & $\begin{array}{l}\square \text { Totalmente } \\
\square \text { Muito } \\
\square \text { Pouco }\end{array}$ & $\begin{array}{l}\square \text { Mais } \\
\square \text { Menos } \\
\square \text { Igualmente }\end{array}$ & importante que & Espaços públicos \\
\hline
\end{tabular}

\section{Indicador Final}

\begin{tabular}{|c|c|c|c|c|}
\hline Indicador de salubridade ambiental da favela & $\begin{array}{l}\text { Totalmente } \\
\text { Muito } \\
\square \text { Pouco }\end{array}$ & $\begin{array}{l}\text { Mais } \\
\square \text { Menos } \\
\square \text { Igualmente }\end{array}$ & importante que & Indicador de moradia \\
\hline Indicador de salubridade ambiental da favela & $\begin{array}{l}\square \text { Totalmente } \\
\square \text { Muito } \\
\square \text { Pouco } \\
\end{array}$ & $\begin{array}{l}\square \text { Mais } \\
\square \text { Menos } \\
\square \text { Igualmente }\end{array}$ & importante que & Indicador de entorno \\
\hline Indicador de moradia & $\begin{array}{l}\square \text { Totalmente } \\
\square \text { Muito } \\
\square \text { Pouco } \\
\end{array}$ & $\begin{array}{l}\square \text { Mais } \\
\square \text { Menos } \\
\square \text { Igualmente }\end{array}$ & importante que & Indicador de entorno \\
\hline
\end{tabular}


APÊNDICE D : FORMULÁRIO DE CAMPO - VALIDAÇÃO 
UNIVERSIDADE DE SÃO PAULO

ESCOLA POLITÉCNICA

DEPARTAMENTO DE ENGENHARIA DE CONSTRUÇÃO CIVIL FORMULÁRIO PARA AVALIAÇÃO DE ÁREAS URBANAS RECUPERADAS

Data da entrevista: I__ Área:

Endereço:

Entrevistado:

Quantas pessoas moram na casa?

Posição na família:

Pai $\square$ Mãe $\square$ Filho $\square$ Outro: No._ ID no mapa

Tempo de residência nesta casa: Qual a renda média da família por mês?

Qual o grau de escolaridade do chefe do domicílio?

Qual o maior grau de escolaridade dos moradores do domicílio?

A casa foi: $\square$ Construída pela Conder

$$
\begin{aligned}
& \square \text { Conder e ampliada pelo morador } \\
& \square \text { Construída pelo próprio morador } \\
& \square \text { Adquirida de outros } \\
& \square \text { Alugada } \\
& \square \text { Outros (especificar): }
\end{aligned}
$$

ÁGUA

1. $\square$ De onde vem a água que abastece a casa?

$1 \square$ Encanada da Embasa

$$
\begin{aligned}
& 2 \square \text { Chafariz } \\
& 3 \square \text { Fonte } \\
& 4 \square \text { Vizinho } \\
& 5 \square \text { Outro: } \\
& \text { 0 } \square \text { N.R. }
\end{aligned}
$$

2. $\square$ Se possui água encanada, recebe conta de água? $1 \square \operatorname{Sim} 2 \square$ Não $0 \square$ N.R.

3. $\square$ O que você acha do serviço de abastecimento de água? $1 \square$ Péssimo $2 \square$ Ruim $3 \square$ Regular $4 \square$ Bom $5 \square$ Ótimo $0 \square$ N.R.

5. $\square$ A casa possui instalações de água (torneiras, chuveiro descarga)?

$$
1 \square \operatorname{Sim} 2 \square \text { Não 0 } \square \text { N.R. }
$$

6. $\square$ Se sim na pergunta anterior, o que você acha dessas instalações?

$$
\begin{aligned}
& 1 \square \text { Péssimas } \\
& 2 \square \text { Ruins } \\
& 3 \square \text { Regulares } \\
& 4 \square \text { Boas } \\
& 5 \square \text { Ótimas } \\
& 0 \square \text { N.R. }
\end{aligned}
$$

\section{ESGOTO}

1. $\square$ A casa possui ligação com a rede de esgoto ou fossa? $1 \square$ Rede de esgoto $2 \square$ Fossa $0 \square$ Não possui esgoto

2. $\square$ Se é ligada a rede, recebe conta de esgoto? $1 \square \operatorname{Sim} 2 \square$ Não $0 \square$ N.R.

3. $\square$ Se possui esgoto, o que você acha do serviço:

$1 \square$ Péssimo

$2 \square$ Ruim

$3 \square$ Regular

$4 \square$ Bom

$5 \square$ Ótimo $0 \square$ N.R.

4. $\square$ A casa possui instalações de esgoto (ralo no banheiro, saídas das pias e vaso sanitário)?
$1 \square \operatorname{Sim} 2 \square$ Não $0 \square$ N.R.

5. $\square$ Se sim na pergunta anterior, o que você acha dessas instalações?

$$
1 \square \text { Péssimas }
$$

$2 \square$ Ruins

$3 \square$ Regulares

$4 \square$ Boas

$5 \square$ Ótimas

$0 \square$ N.R.

\section{COLETA DE LIXO}

1. $\square$ Qual o tipo de coleta de lixo?

$1 \square$ Caminhão coletor de porta em porta

$2 \square$ Gari de porta em porta

$3 \square$ Contêiner mais próximo

$4 \square$ Ponto de lixo mais próximo

$5 \square$ Outro:

2. $\square$ Se coleta na própria porta ou conteiner, com que frequiência?
$1 \square$ Todo dia
$2 \square$ Dia sim, dia não
$3 \square$ Uma vez por semana
$4 \square$ Outra:

3. $\square$ Em relação a coleta de lixo você acha:

$1 \square$ Péssimo

$2 \square$ Ruim

3ロ Regular

$4 \square$ Bom

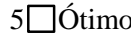

$0 \square$ N.R.

VARRIÇÃO DA RUA

1. $\square$ Quem varre?

$1 \square$ Gari $2 \square$ Morador $3 \square$ Não é varrida $0 \square$ N.R.

2. $\square$ Em relação a limpeza da rua você acha: $1 \square$ Péssima

$2 \square$ Ruim

3पRegular

$4 \square$ Boa

$5 \square$ Ótima

$0 \square$ N.R. 
DRENAGEM - SARJETAS E BOCAS DE LOBO

1. $\square$ Quando chove inunda a rua?

$1 \square \operatorname{Sim} 2 \square$ Não $0 \square$ N.R.

2. $\square$ E quando chove inunda a casa?

$1 \square \operatorname{Sim} 2 \square$ Não $0 \square$ N.R.

3. $\square$ O que você acha do funcionamento das bocas de lobo e sarjetas durante as chuvas:

$1 \square$ Péssimo
$2 \square$ Ruim
$3 \square$ Regular
$4 \square$ Bom
$5 \square$ Ótimo
0 $\square$ N.R.

4. $\square$ Como você se sente em relação ao risco de inundação? $1 \square$ Muito inseguro

$2 \square$ Inseguro

$3 \square$ Nem inseguro, nem seguro

$4 \square$ Seguro

$5 \square$ Muito seguro

$0 \square$ N.R.

RUAS (Entrevistador)

1. $\square$ Largura média da via em frente a casa:

$1 \square$ Maior ou igual a 6 metros

$2 \square$ Entre 3,60 e 6 metros

$3 \square$ Entre 1,20 e 3,60 metros

$4 \square$ Menor que 1,20 metros

2. $\square$ Tipo de pavimentação:

$1 \square$ Asfalto

$2 \square$ Paralelepípedo

$3 \square$ Sem pavimentação

3. $\square$ Estado da rua:

$1 \square$ Péssimo

$2 \square$ Ruim

$3 \square$ Regular

$4 \square$ Bom

$5 \square$ Ótimo

1. $\square$ O que você acha da largura da sua rua?

$1 \square$ Péssima

$2 \square$ Ruim

$3 \square$ Regular

$4 \square$ Boa

$5 \square$ Ótima

$0 \square$ N.R.

2. $\square$ O que você acha da sua rua:

$1 \square$ Péssima

$2 \square$ Ruim

$3 \square$ Regular

$4 \square$ Boa

$5 \square$ Ótimo

$0 \square$ N.R.

SEGURANÇA GEOLÓGICA-GEOTÉCNICA

1. $\square$ O que você acha da segurança do terreno onde sua casa

foi construída em relação a rachaduras, risco de

desmoronamento?

$1 \square$ Muito inseguro

$2 \square$ Inseguro

$3 \square$ Nem inseguro, nem seguro

$4 \square$ Seguro

$5 \square$ Muito seguro

$0 \square$ N.R.

\section{ESPAÇOS PÚBLICOS}

$1 \square$. Você utiliza algum lugar público na área urbanizada

(praças, campo de futebol, quadras, pista para caminhada)? $1 \square \operatorname{Sim} 2 \square$ Não $0 \square$ N.R.

2. Quais?

$1 \square$ Praça

$2 \square$ Campo de futebol

3पQuadra

$4 \square$ Pista de caminhada

$5 \square$ Outro:

3. $\square$ O que você acha destes lugares:

$1 \square$ Péssimos

$2 \square$ Ruins

$3 \square$ Regulares

$4 \square$ Bons

$5 \square$ Ótimos

$0 \square$ N.R.

ENERGIA ELÉTRICA E ILUMINAÇÃO

1. $\square$ Sua casa possui energia elétrica? $1 \square \operatorname{Sim} 2 \square$ Não $0 \square$ N.R.

2. $\square$ Se sim, recebe conta de energia? $1 \square \operatorname{Sim} 2 \square$ Não $0 \square$ N.R.

3. $\square$ Se possui energia o que você acha do serviço de energia elétrica?

$1 \square$ Péssimo

$2 \square$ Ruim

$3 \square$ Regular

$4 \square$ Bom

$5 \square$ Ótimo

$0 \square$ N.R.

4. $\square$ Se possui energia elétrica, qual o tipo de instalações da casa?

$1 \square$ Embutida

$2 \square$ Aparente

$3 \square$ Embutida na parede e aparente no teto

$4 \square$ Mista

5. $\square$ O que você acha das instalações elétricas de sua casa? $1 \square$ Péssimas

$2 \square$ Ruins

$3 \square$ Regulares

$4 \square$ Boas

$5 \square$ Ótimas

$0 \square$ N.R.

6. $\square$ Possui iluminação na sua rua? $1 \square \operatorname{Sim} 2 \square$ Não $0 \square$ N.R.

7. $\square$ Quem fornece? $1 \square$ Prefeitura $2 \square$ Morador $0 \square$ N.R.

8. $\square$ O que você acha da iluminação de sua rua? $1 \square$ Péssima $2 \square$ Ruim

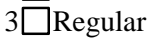
$4 \square$ Boa $5 \square$ Ótima $0 \square$ N.R.

TELEFONES PÚBLICOS

1. $\square$ Tem orelhão na sua rua?

$1 \square \operatorname{Sim} 2 \square$ Não 0 $\square$ N.R. 
2. $\square$ Utiliza orelhão?

$1 \square \operatorname{Sim} 2 \square$ Não $0 \square$ N.R.

3. $\square$ O que você acha da distância do orelhão?

$1 \square$ Péssima - muito longe

$2 \square$ Ruim - um pouco longe

$3 \square$ Regular - razoável

$4 \square$ Boa - próxima

$5 \square$ Ótima - muito próxima

$0 \square$ N.R.

REGULARIZAÇÃO E POSSE

1. $\square$ Você possui algum documento da casa? $1 \square \operatorname{Sim} 2 \square$ Não $0 \square$ N.R.

2. $\square$ Está seguro da posse de sua casa?

$1 \square$ Não, muito inseguro

$2 \square$ Não, inseguro

$3 \square$ Nem inseguro, nem seguro

$4 \square$ Sim, seguro

$5 \square$ Sim, muito seguro

$0 \square$ N.R.

ÁREA URBANIZADA

1. $\square \mathrm{O}$ que você acha da a área que foi urbanizada?

$1 \square$ Péssima

$2 \square$ Ruim

$3 \square$ Regular

$4 \square$ Boa

$5 \square$ Ótima

$0 \square$ N.R.

2. $\square$ Como você avalia o antes e depois da área urbanizada? $1 \square$ Piorou muito

$2 \square$ Piorou

$3 \square$ Não fez diferença

$4 \square$ Melhorou

$5 \square$ Melhorou muito

$0 \square$ N.R.

3. Você pode dizer os pontos positivos e/ou negativos?

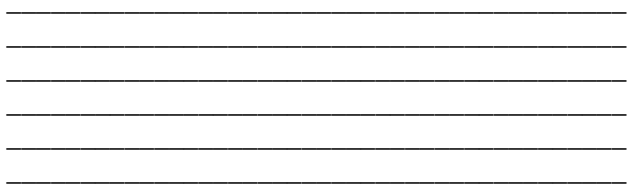

\section{ENTORNO E EQUIPAMENTOS}

1. Serviços comunitários utilizados (Local: fora ou dentro da área de intervenção):

$\begin{array}{ll}1 \square \text { Escola } & \text { Local: } \\ 2 \square \text { Posto de saúde } & \text { Local: } \\ 3 \square \text { Creche } & \text { Local: } \\ 4 \square \text { Outro: } & \text { Local: }\end{array}$

2. $\square$ O que você acha dos serviços oferecidos nesses locais:

$1 \square$ Péssimos

$2 \square$ Ruins

$3 \square$ Regulares

$4 \square$ Bons

$5 \square$ Ótimos

$0 \square$ N.R.
3. Observações:

4. $\square$ Você utiliza outros locais para lazer fora dessa área que foi urbanizada, nas proximidades:

$1 \square \operatorname{Sim} 2 \square$ Não $0 \square$ N.R.

5. Se sim, Quais?

6. $\square$ Se sim, O que você acha desses locais:

$1 \square$ Péssimos

$2 \square$ Ruins

$3 \square$ Regulares

$4 \square$ Bons

$5 \square$ Ótimos

$0 \square$ N.R.

7. $\square$ Faz parte de algum tipo de associação da região? $\square$ Sim $\square$ Não $0 \square$ N.R

$8 \square$ Se sim, quais:

$1 \square$ Associação de moradores

$2 \square$ Cooperativa

$3 \square$ Organização não governamental

$4 \square$ Outra:

9. $\square$ Se sim, o que você acha da atuação dessas

organizações:

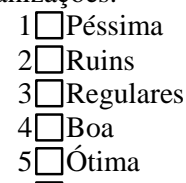

10. Meios de transporte utilizados para trabalhar: $1 \square$ Barco

$2 \square$ Trem

$3 \square$ Ônibus

$4 \square$ Outro:

11. $\square$ Se utiliza transporte coletivo (ônibus ou trem) o que você acha do serviço?
$1 \square$ Péssimo
$2 \square$ Ruim
3ロ Regular
$4 \square$ Bom
5 Ótimo
$0 \square$ N.R.

12. O que você acha dos serviços que têm aqui próximo (transporte, lazer, educação, associações)?
$1 \square$ Péssimo
$2 \square$ Ruim
$3 \square$ Regular
$4 \square$ Bom
$5 \square$ Ótimo
$0 \square$ N.R.

13. O que você acha de morar neste bairro?

$1 \square$ Péssimo

$2 \square$ Ruim

$3 \square$ Regular

$4 \square$ Bom

5ロ Ótimo

$0 \square$ N.R. 
CASA - COMPOSIÇÃO E ADEQUAÇÃO DO ESPAÇO

1. Composição:

$1 \square$ Sala

$2 \square$ Quartos

3पCozinha

$4 \square$ Banheiro

$5 \square$ Área de serviço

$6 \square$ Varanda

2. $\square$ Quantidade de quartos:

3. $\square$ Além dos quartos outros cômodos são usados para dormir?

$1 \square \operatorname{Sim} 2 \square$ Não $0 \square$ N.R.

4. $\square$ Como você avalia a quantidade de quartos de sua casa em relação ao número de pessoas?

$1 \square$ Péssimo

$2 \square$ Ruim

$3 \square$ Regular

$4 \square$ Bom

$5 \square$ Ótimo

$0 \square$ N.R.

5. $\square$ O que você acha do seu banheiro?

$1 \square$ Péssimo

2पRuim

$3 \square$ Regular

$4 \square$ Bom

$5 \square$ Ótimo

$0 \square$ N.R.

6. $\square$ O que você acha da sua cozinha?

$1 \square$ Pésima

$2 \square$ Ruim

$3 \square$ Regular

$4 \square$ Boa

$5 \square$ Ótima

$0 \square$ N.R.

7. $\square$ Como você avalia o tamanho da casa? $1 \square$ Péssimo

2पRuim

$3 \square$ Regular

$4 \square$ Bom

$5 \square$ Ótimo

$0 \square$ N.R.

\section{COBERTURA}

1. Qual o material do telhado?

$1 \square$ Telha cerâmica

2पTelha de amianto

$3 \square$ Laje

$4 \square$ Outros:

2. $\square$ Quando chove entra água pelo telhado? $1 \square \operatorname{Sim} 2 \square$ Não $0 \square$ N.R.

3. $\square$ O que você acha do telhado de sua casa? $1 \square$ Péssimo

$2 \square$ Ruim

3पRegular

$4 \square$ Bom

$5 \square$ Ótimo

$0 \square$ N.R.

\section{PAREDES}

1. Qual o material das paredes?

$1 \square$ Tijolos furados

$2 \square$ Blocos de concreto

$3 \square$ Outros:
2. $\square$ Possui revestimento (reboco) nas paredes de dentro de casa?

$1 \square \operatorname{Sim} 2 \square$ Não $3 \square$ Em algumas partes

3. $\square$ Possui revestimento (reboco) nas parte de fora da casa? $1 \square \operatorname{Sim} 2 \square$ Não $3 \square$ Em algumas partes

4. $\square$ O que você acha das paredes:

$1 \square$ Péssimas

$2 \square$ Ruins

$3 \square$ Regulares

$4 \square$ Boas

5口Ótimas

$0 \square$ N.R.

PISO

1. $\square$ Qual o material do piso?

$1 \square$ Sem piso

$2 \square$ Cimento queimado

$3 \square$ Cimento grosso

$4 \square$ Cerâmica

$5 \square$ Barro

$6 \square$ Outros:

2. $\square$ Existem problemas de umidade nos pés das paredes? $1 \square \operatorname{Sim} 2 \square$ Não $0 \square$ N.R.

3. $\square$ O que você acha do piso de sua casa?

$1 \square$ Péssimo

$2 \square$ Ruim

3पRegular

$4 \square$ Bom

$5 \square$ Ótimo

$0 \square$ N.R.

ILUMINAÇÃO E VENTILAÇÃO NATURAL

1. $\square$ A casa possui janelas ou combogós em todos os cômodos?

$1 \square \operatorname{Sim} 2 \square$ Não $0 \square$ N.R.

2. $\square$ O que você acha da ventilação da sua casa?

$1 \square$ Péssimo

$2 \square$ Ruim

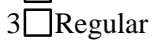

$4 \square$ Bom

$5 \square$ Ótimo

$0 \square$ N.R.

AVALIAÇÃO GERAL

1. $\square$ O que você acha da sua casa como um todo:

$1 \square$ Péssimo

$2 \square$ Ruim

$3 \square$ Regular

$4 \square$ Boa

$5 \square$ Ótima

$0 \square$ N.R.

2. O que você acha da sua casa depois da urbanização?

$1 \square$ Piorou muito

$2 \square$ Piorou

$3 \square$ Não faz diferença

$4 \square$ Melhorou

$5 \square$ Melhorou muito

$0 \square$ N.R.

3. Você pode dizer os pontos positivos e/ou negativos? 